\title{
Projeto de Sinais de Excitação para Identificação Multivariável de Plantas Industriais
}

Tese apresentada à Escola Politécnica da Universidade de São Paulo para obtenção do Título de Doutor em Engenharia Elétrica. 


\section{Projeto de Sinais de Excitação para Identificação Multivariável de Plantas Industriais}

Tese apresentada à Escola Politécnica da Universidade de São Paulo para obtenção do Título de Doutor em Engenharia Elétrica.

Área de concentração:

Engenharia de Sistemas

Orientador:

Prof. Dr. Claudio Garcia 
Este exemplar foi revisado e alterado em relação à versão original, sob responsabilidade única do autor e com a anuência de seu orientador.

São Paulo, 10 de dezembro de 2012.

Assinatura do autor

Assinatura do orientador

Kuramoto, André Seichi Ribeiro

Projeto de sinais de excitação para identificação multivariá vel de plantas industriais / A.S.R. Kuramoto. -- ed.rev. -- São Paulo, 2012. $370 \mathrm{p}$.

Tese (Doutorado) - Escola Politécnica da Universidade de São Paulo. Departamento de Engenharia de Telecomunicações e Controle.

1. Identificação de sistemas 2. Modelos matemáticos 3. Controle de processos 4. Sinais de excitação I. Universidade de São Paulo. Escola Politécnica. Departamento de Engenharia de Telecomunicações e Controle II. t. 
"The essential point in science is not a complicated mathematical formalism or a ritualized experimentation. Rather the heart of science is a kind of shrewd honesty that springs from really wanting to know what the hell is going on!"

\section{Saul-Paul Sirag}

"Mathematics is the queen of the sciences and number theory is the queen of mathematics." frase atribuída a Carl Friedrich Gauss G. H. Hardy, A Mathematician's Apology, 1940. "...it is a redeeming feature of life that we are able to use many things without understanding every detail of them."

Lennart Ljung

Prefácio da primeira edição de seu livro: System Identification: Theory for the User, 
Aos meus pais. 


\section{Agradecimentos}

Meus sinceros agradecimentos ao professor Dr. Claudio Garcia pelo trabalho de orientação e apoio constante para a realização desta tese. Ao Dr. Antonio Carlos Zanin pela confiança depositada. Ao Dr. Osmel Reyes Vaillant pelas discussões sobre temas relacionados à tese. Aos colegas do grupo de pesquisa em identificação de sistemas pelo conhecimento compartilhado. Ao professor Dr. Paul Jean Etienne Jeszenszky por indicar o caminho e pelo incentivo. Ao professor Dr. Taufik Abrão pelas suas palavras de motivação.

Agradeço aos meus pais Satoru e Regina por muito me influenciar com seus exemplos de dedicação, perseverança e otimismo. À Priscilla Alexandre pela paciência principalmente nos momentos de redação solitária da tese. Aos meus amigos por compreender minha ausência do convívio durante algumas etapas do programa de doutorado. 


\section{Resumo}

Neste trabalho são discutidos e avaliados métodos de construção de conjuntos de sinais de excitação para identificação de sistemas. Esse estudo é realizado tendo como objetivo aplicações na indústria de processos, particularmente no refino de petróleo.

As restrições operacionais da indústria de refino de petróleo estão cada vez mais severas em virtude do aumento da demanda energética, qualidade de derivados, variações de preço de petróleo, concorrência no mercado de derivados e outros fatores econômicos, ambientais e de eficiência energética. Nesse cenário, é crescente o uso de técnicas de controle preditivo por modelos e, consequentemente, a demanda por identificação de plantas de processamento.

As características particulares das plantas de processamento e de sua operação impõem restrições ao projeto e à aplicação de sinais de excitação. Vários métodos de construção de sinais encontrados na literatura e outros três propostos neste trabalho são avaliados e comparados com referência ao atendimento a essas restrições.

Uma das principais restrições para a aplicação de sinais de excitação para identificação é relativa ao tempo disponível para excitação da planta. Assim, para o bom uso desse período, faz-se necessário garantir o sucesso de um experimento previamente à sua realização. Na literatura, encontram-se várias medidas de desempenho de sinais de excitação possíveis de serem obtidas previamente ao experimento de identificação. Neste trabalho, são propostas duas novas medidas que complementam essas na avaliação dos conjuntos de sinais previamente ao experimento.

A eficácia dos métodos de construção e das medidas de desempenho de sinais de excitação é avaliada por meio de simulação de identificação multivariável de duas plantas típicas de refinarias. As conclusões deste trabalho apresentam em síntese essas avaliações, como também sugestões de trabalhos futuros que visam à continuidade da pesquisa desenvolvida aqui. 


\section{Abstract}

In this work methods for generating sets of excitation signals for system identification are discussed and evaluated. This study is focused on applications in the process industries, particularly in oil refining.

The operational constraints of the oil refining industry are becoming increasingly severe due to increased energy demand, quality of products, oil price variations, market competition and other economic, environmental and energy efficiency factors. In this scenario the use of model predictive control techniques is increasing, thus the demand for plant identification as well.

The particular characteristics of the processing plants impose restrictions to the project and application of excitation signals. Various methods for generating signals accessible in the literature and three new others proposed in this work are compared with reference to these restrictions.

One of the main constraints for applying excitation signals for identification is relative to the period available for excitation of the plant. Thus, for the proper use of this time interval, it is necessary to ensure the success of an experiment prior to its implementation. In the literature there are several performance measurements for evaluation of sets of excitation signals prior to the experiment. This work proposes two new measures to complement the evaluation.

The effectiveness of the generating methods and performance measurements for excitation signals is evaluated by simulation of multivariable identification of two typical oil refining plants. The conclusions of this work briefly present these evaluations, as well as some suggestions of future work for the continuity of the current research. 


\section{Sumário}

\section{Lista de Figuras}

\section{Lista de Tabelas}

\section{Lista de Abreviaturas e Siglas}

\section{Lista de Símbolos}

1 Introdução 1

1.1 Modelagem na indústria de processos . . . . . . . . . . . . . 1

1.2 Controle na indústria de processos . . . . . . . . . . . . 7

1.3 Modelagem para as técnicas atuais de controle . . . . . . . . . . . 13

1.4 Motivação e objetivos do trabalho . . . . . . . . . . . . . . . 15

1.5 Estrutura do trabalho . . . . . . . . . . . . . . . 17

2 Projeto de sinais de excitação $\quad 20$

2.1 Projeto ótimo de sinais de excitação $\ldots$. . . . . . . . . . . . . . 20

2.1.1 Caso particular FIR SISO . . . . . . . . . . . . . 24

2.1.2 Critério para projeto ótimo de sinais de excitação . . . . . . 26

2.2 Projeto de sinais para identificação MIMO . . . . . . . . . . . . . 28

2.2.1 Caso particular FIR MISO . . . . . . . . . . . . . 29

3 Critérios de projeto de sinais de excitação 35

3.1 Experimento de identificação . . . . . . . . . . . . . . . . 35

3.2 Conhecimentos a priori . . . . . . . . . . . . . . . 38

3.3 Critérios de projeto de sinais de excitação para identificação MIMO 41 
3.4 Considerações sobre a duração do experimento . . . . . . . . . . . 42

3.5 Funções de correlação dos sinais de excitação . . . . . . . . . . . . . 44

3.6 Limites para as funções de correlação . . . . . . . . . . . . . . . 49

3.7 Propriedades desejáveis para os sinais de excitação . . . . . . . . . 54

4 Avaliação de sinais de excitação $\quad 57$

4.1 Índice de desempenho para sinais de excitação (PIPS) . . . . . . . . . 59

4.2 Índice de desempenho efetivo para sinais de excitação (PIPSE) . . . . 60

4.3 Índice EMINE . . . . . . . . . . . . . . . . . . 60

4.4 Fator de crista $(\mathrm{CF}) \ldots \ldots \ldots \ldots 2$

4.5 Fator de tempo $(\mathrm{TF}) \ldots \ldots \ldots \ldots 2$

4.6 Considerações sobre medidas de qualidade . . . . . . . . . . . . . . 64

4.7 Proposta de avaliação de conjuntos de sinais de excitação . . . . . . . . 64

5 Sinais de excitação $\quad 68$

5.1 Sinais aleatórios . . . . . . . . . . . . . . . . 69

5.1 .1 Sinal ruído binário . . . . . . . . . . . . 70

5.1.2 Sinal ruído binário generalizado . . . . . . . . . . 77

5.2 Sinais otimizados por computador . . . . . . . . . . . . . 84

5.2.1 Sinais soma de harmônicos . . . . . . . . . . . . 85

5.2.2 Sinal binário e ternário de intervalo discreto . . . . . . . . . . 100

5.2.3 Sinal multi harmônico multinível . . . . . . . . . . 101

5.2.4 Supressão de harmônicos . . . . . . . . . . . . . . 105

5.2.5 Parametrização de sinais otimizados por computador . . . . . 108

5.3 Sinais de espectro fixo . . . . . . . . . . . . 116

5.3.1 Sinal binário de resíduo quadrático . . . . . . . . . . . . . 117

5.3.2 Sinal ternário de resíduo quadrático . . . . . . . . . . . 118

5.3 .3 Sinal binário Hall . . . . . . . . . . . . . . . . . 121

5.3.4 Sinal binário de primos gêmeos . . . . . . . . . . 122 
5.3.5 Sinal pseudo-aleatório binário . . . . . . . . . . . . . 124

5.3.6 Sinal pseudo-aleatório multinível . . . . . . . . . 126

5.3.7 Conjunto de sinais pseudo-aleatórios binários . . . . . . . . 132

5.3.8 Conjunto de sinais pseudo-aleatórios ternários . . . . . . . . . 137

5.3.9 Período do sinal de excitação e de chaveamento . . . . . . . . 141

5.3.10 Influência das funções de correlação dos sinais na duração do experimento . . . . . . . . . . . . . 145

5.3.11 Parametrização de sinais de espectro fixo . . . . . . . . . 148

5.4 Sinais híbridos e outros sinais . . . . . . . . . . . . . . . . 157

6 Propostas de projeto de conjuntos de sinais de excitação 159

6.1 Conjunto de sinais pseudo-aleatórios multinível ortogonais . . . . . . 160

6.2 Conjunto de sinais não lineares multinível . . . . . . . . . . . . . 166

6.2.1 Funções de correlação de sequências não lineares . . . . . . . . 167

6.2.2 Construção do conjunto de sinais MLNL . . . . . . . . . . 175

6.2.3 Resumo das características do conjunto de sinais MLNL . . . 177

7 Comparação dos sinais de excitação 180

7.1 Quadro comparativo dos sinais de excitação . . . . . . . . . . . . 181

8 Direcionalidade de ganho e plantas mal condicionadas 188

8.1 Coluna de destilação de alta pureza . . . . . . . . . . . . . . . . . 190

8.2 Métodos de projeto de sinais de excitação para plantas mal condicionadas 196

8.2.1 Sinais rotacionados . . . . . . . . . . . . . 197

8.2.2 Métodos de dois passos . . . . . . . . . . . . . . . 199

8.2.3 Sinais com espectros intercalados modificados . . . . . . . 201

8.2.4 Sinais ternários com harmônicas correlacionadas . . . . . . 203

8.2.5 Parametrização dos sinais de excitação . . . . . . . . . . 205

8.3 Proposta de avaliação de sinais para identificação de plantas mal condicionadas . . . . . . . . . . . . . . . . . 211 
8.4 Resultados de simulações . . . . . . . . . . . . . . . . . . . . 212

8.4.1 Resultados de simulações da planta de primeira ordem . . . . 214

8.4.2 Resultados de simulações da planta de segunda ordem . . . . 217

8.4.3 Considerações sobre excitações de plantas mal condicionadas 222

8.5 Proposta de rotação de sinais com restrição . . . . . . . . . . . . . 222

8.5.1 Exemplos de rotação de sinais de excitação com restrições . . 227

8.5.2 Simulações de identificação com sinais de excitação rotacionados com restrições . . . . . . . . . . . . . . 230

9 Procedimento para seleção de sinais de excitação 234

9.1 Informações a priori da planta . . . . . . . . . . . . . 236

9.2 Identificação em malha aberta de planta mal condicionada . . . . . 236

9.3 Característica de amplitude dos sinais . . . . . . . . . . . . 237

9.4 Frequências máximas e mínimas de interesse . . . . . . . . . . . 237

9.5 Duração mínima do experimento . . . . . . . . . . . . . . 238

9.6 Período de amostragem para a identificação . . . . . . . . . . . . 238

9.7 Envoltória do espectro de potência . . . . . . . . . . . . . 239

9.8 Amplitudes das entradas . . . . . . . . . . . . . . . . 239

9.9 Selecionar os conjuntos de sinais candidatos . . . . . . . . . . . . 240

9.9 .1 Sinais aleatórios . . . . . . . . . . . . . 240

9.9 .2 Sinais $\mathrm{SOH} \ldots \ldots \ldots \ldots . \ldots . \ldots . \ldots 240$

9.9.3 Sinais de espectro fixo e sinais híbridos . . . . . . . . . . 241

9.10 Escolher os conjuntos de sinais mais adequados . . . . . . . . . . . 241

9.10.1 Caso particular de plantas mal condicionadas . . . . . . . . 242

9.10.2 Menor variância dos parâmetros estimados . . . . . . . . 243

9.11 Ferramenta desenvolvida para selecionar conjuntos de sinais de excitação244

10 Estudo de caso: identificação de uma planta de processamento

10.1 Características da planta . . . . . . . . . . . . . . . 249 
10.2 Parametrização das simulações . . . . . . . . . . . . . . 251

10.3 Parametrização dos sinais . . . . . . . . . . . . . . . . 254

10.3.1 Sinais aleatórios . . . . . . . . . . . . 257

10.3.2 Sinais $\mathrm{SOH} \ldots \ldots \ldots \ldots . \ldots \ldots$

10.3.3 Sinais de espectro fixo . . . . . . . . . . . 259

10.3.4 Sinais híbridos . . . . . . . . . . . . . . 259

10.3.5 Medidas de desempenho dos sinais . . . . . . . . . 263

10.4 Método de validação . . . . . . . . . . . . . . . . . . . . . 274

10.5 Resultados . . . . . . . . . . . . . . . . 275

10.6 Resumo do capítulo . . . . . . . . . . . . . . . . . . . 306

11 Conclusões $\quad 309$

11.1 Principais conclusões . . . . . . . . . . . . . . . . . . . 309

11.2 Trabalhos futuros . . . . . . . . . . . . . . . . 312

Apêndice A - Identificação em malha fechada e em malha aberta 314

Apêndice B - Identificação de plantas com distorções não lineares 316

Apêndice C - Período de amostragem 319

C.1 Determinação da frequência de amostragem empiricamente . . . . . . 320

Apêndice D - Reforço de frequências baixas ou médias 322

Apêndice E - Teorema de Woodward 326

Apêndice F - Convergência do algoritmo clipping de reconstrução de sinais 328

Apêndice G - Sequência de máximo comprimento sobre $G F(q)$, com $q>2332$

Anexo A - Teoria básica de corpos finitos 335

A.1 Corpos finitos . . . . . . . . . . . . . . 335

A.2 Domínio Euclidiano . . . . . . . . . . . . . . . . 336 
A.3 Construção de um corpo finito . . . . . . . . . . . . . . . . 337

A.4 Raiz primitiva . . . . . . . . . . . . . . . . . . . 342

A.5 Polinômio mínimo e polinômio primitivo . . . . . . . . . . . . . 343

A.6 Coconjuntos ciclotômicos . . . . . . . . . . . . . . . . . . . . 349

A.7 Elemento primitivo . . . . . . . . . . . . . . 351

A.8 Função traço . . . . . . . . . . . . . . . . . . . . . . . 351

A.9 Recorrência linear e polinômio característico . . . . . . . . . . . . 352

Anexo B - Sequência de máximo comprimento 355

B.1 Principais propriedades da SMC . . . . . . . . . . . . 355

Referências 


\section{Lista de Figuras}

1.1 Fluxograma do procedimento de identificação de sistemas (LJUNG, 1999). 3

1.2 Representação das hierarquias de controle: a estrutura convencional e a estrutura baseada em MPC (RICHALET et al., 1978) (QIN; BADGWELL, 2002). . . . . . . . . . . . . . . . . 10

3.1 Esboço dos limites de Welch e Sarwate. . . . . . . . . . . . . . 53

3.2 Esboço dos limites de Sarwate generalizado e Tang-Fan. . . . . . . . 54

5.1 Sinal ruído colorido e ruído colorido binário de comprimento $N_{s}=200.71$

5.2 Espectros de amplitudes de sinais ruído colorido. . . . . . . . . . 71

5.3 Sinais BN branco de comprimento $N_{s}=100 \ldots \ldots 73$

5.4 Módulo da DFT dos sinais BN branco de comprimento $N_{s}=100 . \quad$. 73

5.5 Função de autocorrelação periódica dos sinais BN branco de compri-

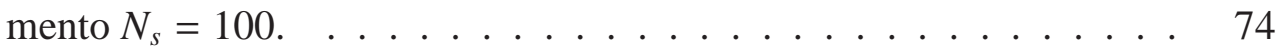

5.6 Função de correlação cruzada periódica entre os sinais BN branco de

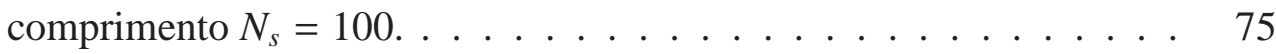

5.7 Sinal ruído colorido e ruído colorido binário de comprimento $N_{s}=700.76$

5.8 Espectros de amplitude de sinais ruído colorido. . . . . . . . . . . . 77

5.9 Espectros de potência de sinais GBN. . . . . . . . . . . . . . . 79

5.10 Sinal GBN de comprimento $N_{s}=50$ e $p=0,7 \ldots \ldots 80$

5.11 Módulo da DFT do sinal GBN de comprimento $N_{s}=50$ e $p=0,7 \ldots \quad .80$

5.12 Função de autocorrelação periódica do sinal GBN de comprimento $N_{s}=50$ e $p=0,7$.

5.13 Espectro de potência do sinal GBN de comprimento $N_{s}=50$ e $p=0,7.81$

5.14 Sinal GBN com $p=0,6869$ e comprimento $N_{s}=700 \ldots \ldots 2$

5.15 Espectros de potência do sinal GBN com $p=0,6869$ e comprimento $N_{s}=700$. 
5.16 Função de autocorrelação periódica dos sinais GBN com $p=0,6869$ e comprimento $N_{s}=700 \ldots \ldots \ldots \ldots \ldots$

5.17 Função de correlação cruzada periódica entre os sinais GBN com $p=$ 0,6869 e comprimento $N_{s}=700 \ldots \ldots \ldots \ldots$

5.18 Sinal Schroeder-SOH de comprimento $N_{s}=50$ e espectro com as 20 primeiras harmônicas com amplitudes iguais e as demais nulas. . . . .

5.19 Módulo da DFT do sinal Schroeder-SOH de comprimento $N_{s}=50$ e espectro com as 20 primeiras harmônicas com amplitudes iguais e as demais nulas. . . . . . . . . . . . . . .

5.20 Função de autocorrelação periódica do sinal SOH de comprimento $N_{s}=50$ e espectro plano. . . . . . . . . . . .

5.21 Sinal Schroeder-SOH de comprimento $N_{s}=50$ e espectro com as 10 primeiras harmônicas com amplitudes iguais, as próximas 10 com metade da amplitude das anteriores e as demais nulas. . . . . . . . .

5.22 Módulo da DFT do sinal Schroeder-SOH de comprimento $N_{s}=50 \mathrm{e}$ espectro não plano. . . . . . . . . . . . . . . . .

5.23 Função de autocorrelação periódica do sinal Schroeder-SOH de comprimento $N_{s}=50$ e espectro não plano. . . . . . . . . . . . 94

5.24 Algoritmo clipping. . . . . . . . . . . . . . . . . . . 95

5.25 Sinal clipping-SOH de comprimento $N_{s}=50$ e espectro não plano obtido com o algoritmo clipping. . . . . . . . . . . . . . 96

5.26 Módulo da DFT do sinal clipping-SOH de comprimento $N_{s}=50 \mathrm{e}$ espectro não plano obtido com o algoritmo clipping. . . . . . . . . . .

5.27 Função de autocorrelação periódica do sinal clipping-SOH de comprimento $N_{s}=50$ e espectro não plano obtido com o algoritmo clipping.

5.28 Evolução dos limites de amplitudes em função das iterações do algoritmo clipping do sinal SOH de comprimento $N_{s}=50$. . . . . . . 98

5.29 Algoritmo clipping com minimização conjunta do CF do sinal de entrada e saída.

5.30 Quantizador de $n$ níveis, com $n$ ímpar, do algoritmo clipping para gerar sinais MLMH. . . . . . . . . . . . . . . . . 102

5.31 Exemplo de um quantizador de $n=5$ níveis $\operatorname{com} q=2 \ldots \ldots 102$ 
5.32 Exemplo de um quantizador de $n=5$ níveis $\operatorname{com} q=2$ aplicado a uma função $\sin (\omega)$, com $0 \leq \omega \leq 2 \pi \ldots \ldots$. . . . . . . . . 103

5.33 Exemplo de um quantizador de $n=6$ níveis $\operatorname{com} q=2 \ldots \ldots 3$

5.34 Exemplo de um quantizador de $n=6$ níveis $\operatorname{com} q=2$ aplicado a uma função $\sin (\omega)$, com $0 \leq \omega \leq 2 \pi \ldots \ldots$. . . . . . . . . . 104

5.35 Sinal MLMH de comprimento $N_{s}=50 \ldots \ldots \ldots$

5.36 Módulo da DFT do sinal MLMH de comprimento $N_{s}=50 \ldots \ldots 105$

5.37 Função de autocorrelação periódica do sinal MLMH de comprimento $N_{s}=50$.

5.38 Evolução do EMINE em função das iterações do algoritmo de otimização do sinal MLMH de comprimento $N_{s}=50 \ldots \ldots$. . . . . . 106

5.39 Sinal Schroeder-SOH parametrizado $\operatorname{com} T=60$ segundos, $N_{s}=700$ e $n_{s}=44$.

5.40 Módulo da DFT do sinal Schroeder-SOH parametrizado com $T=60$ segundos, $N_{s}=700$ e $n_{s}=44$.

5.41 Função de autocorrelação periódica do sinal Schroeder-SOH parametrizado com $T=60$ segundos, $N_{s}=700$ e $n_{s}=44$.

5.42 Módulo da DFT de sinais SOH com espectros intercalados parametrizados com $T=60$ segundos e $N_{s}=700 \ldots \ldots \ldots \ldots$. . . . . 113

5.43 Sinais Schroeder-SOH com espectros intercalados parametrizados com $T=60$ segundos, $N_{s}=700, n_{s}^{(1)}=n_{s}^{(2)}=n_{s}^{(3)}=14$ e $n_{s}=n_{s}^{(1)}+n_{s}^{(2)}+$ $n_{s}^{(3)}=42 \ldots \ldots \ldots \ldots \ldots \ldots \ldots$

5.44 Módulo da DFT dos sinais Schroeder-SOH com espectros intercalados parametrizados com $T=60$ segundos, $N_{s}=700, n_{s}^{(1)}=n_{s}^{(2)}=n_{s}^{(3)}=$ 14 e $n_{s}=n_{s}^{(1)}+n_{s}^{(2)}+n_{s}^{(3)}=42 \ldots \ldots \ldots \ldots \ldots$

5.45 Funções de autocorrelação periódica dos sinais Schroeder-SOH com espectros intercalados parametrizados com $T=60$ segundos, $N_{s}=$ $700, n_{s}^{(1)}=n_{s}^{(2)}=n_{s}^{(3)}=14$ e $n_{s}=n_{s}^{(1)}+n_{s}^{(2)}+n_{s}^{(3)}=42 \ldots \ldots \ldots$

5.46 Funções de correlação cruzada periódica dos sinais Schroeder-SOH com espectros intercalados parametrizados com $T=60$ segundos, $N_{s}=700, n_{s}^{(1)}=n_{s}^{(2)}=n_{s}^{(3)}=14$ e $n_{s}=n_{s}^{(1)}+n_{s}^{(2)}+n_{s}^{(3)}=42 \ldots \ldots 115$

5.47 Sinal QRB de comprimento $N=47$ e $u(N)=-1 \ldots \ldots . \ldots 118$ 
5.48 Módulo da DFT do sinal QRB de comprimento $N=47$ e $u(N)=-1 . \quad 119$

5.49 Função de autocorrelação periódica do sinal QRB de comprimento $N=47$ e $u(N)=-1 . \ldots \ldots \ldots \ldots$

5.50 Sinal QRT de comprimento $N=59 \ldots \ldots \ldots$

5.51 Módulo da DFT do sinal QRT de comprimento $N=59 \ldots \ldots 120$

5.52 Função de autocorrelação periódica do sinal QRT de comprimento $N=$ 59. . . . . . . . . . . . . . . . . . 121

5.53 Sinal HAB de comprimento $N=43 \ldots \ldots \ldots$

5.54 Módulo da DFT do sinal HAB de comprimento $N=43$. . . . . . 122

5.55 Função de autocorrelação periódica do sinal HAB de comprimento

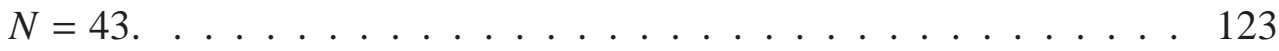

5.56 Sinal TPB de comprimento $N=35 \ldots \ldots \ldots$

5.57 Módulo da DFT do sinal TPB de comprimento $N=35 \ldots$. . . . . . 124

5.58 Função de autocorrelação periódica do sinal TPB de comprimento $N=$

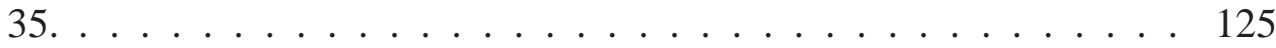

5.59 Sinal PRML de $l=7$ níveis e comprimento $N=48 \ldots \ldots \ldots$

5.60 Módulo da DFT do Sinal PRML de $l=7$ níveis e comprimento $N=48.133$

5.61 Função de autocorrelação periódica do sinal PRML de comprimento $N=48 \ldots \ldots \ldots \ldots \ldots \ldots \ldots \ldots \ldots$

5.62 Conjunto de sequências Rademacher-PRB de comprimento $N=124$. . 136

5.63 Módulo da DFT das sequências Rademacher-PRB de comprimento $N=124$.

5.64 Função de autocorrelação periódica das sequências Rademacher-PRB de comprimento $N=124$.

5.65 Função de correlação cruzada periódica das sequências RademacherPRB de comprimento $N=124 \ldots \ldots \ldots \ldots \ldots$

5.66 Conjunto de sinais PRT de comprimento $N=48$. . . . . . . . . . 140

5.67 Módulo da DFT dos sinais PRT de comprimento $N=48$. . . . . . . 140

5.68 Função de autocorrelação periódica dos sinais PRT de comprimento $N=48$. 
5.69 Função de correlação cruzada periódica entre os sinais PRT de comprimento $N=48 \ldots \ldots \ldots \ldots \ldots$. . . . . . . . . . . . 14

5.70 Conjunto de sinais PRT de comprimento $N_{s}=2.394$, período de chaveamento $T_{c l k}=420$ segundos, com período de amostragem de $T=60$ segundos. . . . . . . . . . . . . . . .

5.71 Módulo da DFT em escala logarítmica dos sinais PRT de comprimento $N_{s}=2.394$, período de chaveamento $T_{c l k}=420$ segundos, com período de amostragem de $T=60$ segundos. . . . . . . . . . . .

5.72 Módulo da DFT dos sinais PRT de comprimento $N_{s}=2.394$, período de chaveamento $T_{c l k}=420$ segundos, com período de amostragem de $T=60$ segundos.

5.73 Detalhe do módulo da DFT dos sinais PRT: harmônicos múltiplos de 6 são suprimidos nos 3 sinais. . . . . . . . . . . . . . . . .

5.74 Função de autocorrelação periódica dos sinais PRT de comprimento $N_{s}=2.394$, período de chaveamento $T_{c l k}=420$ segundos, com período de amostragem de $T=60$ segundos.

5.75 Função de correlação cruzada periódica entre os sinais PRT de comprimento $N_{s}=2.394$, período de chaveamento $T_{c l k}=420$ segundos, com período de amostragem de $T=60$ segundos

5.76 Conjunto de sinais PRML de comprimento $N_{s}=2.394$, com período de chaveamento $T_{c l k}=420$ segundos e período de amostragem de $T=60$ segundos.

5.77 Módulo da DFT em escala logarítmica dos sinais PRML de comprimento $N_{s}=2.394$, com período de chaveamento $T_{c l k}=420$ segundos e período de amostragem de $T=60$ segundos.

5.78 Módulo da DFT dos sinais PRML de comprimento $N_{s}=2.394$, com período de chaveamento $T_{c l k}=420$ segundos e período de amostragem de $T=60$ segundos.

5.79 Detalhe do módulo da DFT dos sinais PRM: harmônicos múltiplos de 2 são suprimidos e os 3 sinais possuem exatamente o mesmo espectro.

5.80 Função de autocorrelação periódica dos sinais PRML de comprimento $N_{s}=2.394$, com período de chaveamento $T_{c l k}=420$ segundos e período de amostragem de $T=60$ segundos. . . . . . . . . . . . . 
5.81 Função de correlação cruzada periódica entre os sinais PRML de comprimento $N_{s}=2.394$, com período de chaveamento $T_{c l k}=420$ segundos e período de amostragem de $T=60$ segundos. . . . . . . . 156

6.1 Conjunto de sequências PRMO de 5 níveis e de comprimento $N=684.164$

6.2 Módulo da DFT das sequências PRMO de 5 níveis e de comprimento $N=684$ do conjunto. . . . . . . . . . . . . . 165

6.3 Função de autocorrelação periódica das sequências PRMO de comprimento $N=684 \ldots \ldots \ldots \ldots \ldots$

6.4 Função de correlação cruzada periódica entre as sequências PRMO de comprimento $N=684$. . . . . . . . . . . . . . . . . 166

6.5 Conjunto de sequências MLNL de comprimento $N=80$. . . . . . 176

6.6 Módulo da DFT das sequências MLNL de comprimento $N=80$. . . 177

6.7 Função de autocorrelação periódica das sequências MLNL de comprimento $N=80 \ldots \ldots \ldots \ldots$. . . . . . . . . 177

6.8 Função de correlação cruzada periódica entre as sequências MLNL de comprimento $N=80 \ldots \ldots \ldots \ldots \ldots$

8.1 Coluna de alta pureza operando na configuração L-V (SKOGESTAD, 1997)

8.2 Plano de saídas $\left\{y_{1} ; y_{2}\right\}$ resultado de um teste com sinal PRB no modelo $G_{2}(s)$ da coluna de destilação de alta pureza. . . . . . . . . . . . . . . 194

8.3 Valores singulares do modelo $G_{2}(s)$ da coluna de destilação de alta pureza. . . . . . . . . . . . . . . .

8.4 Valores singulares do modelo $G_{1}(s)$ da coluna de destilação de alta pureza. . . . . . . . . . . . . . . . .

8.5 Exemplo de sinais rotacionados resultantes da rotação de sinais binários. 199

8.6 Exemplo de sinais utilizados no método de dois passos. . . . . . . . . 200

8.7 Espectros de sinais utilizados no método 2 de dois passos. . . . . . . 201

8.8 Exemplo de sinais SOH com espectros intercalados modificados. . . . 202

8.9 Espectros de sinais SOH com espectros intercalados modificados. . . 203

8.10 Exemplo de sinais PRT com harmônicas correlacionadas. . . . . . . . 204

8.11 Espectros de sinais PRT com harmônicas correlacionadas. . . . . . . 204 
8.12 Segmentos dos sinais rotacionados parametrizados para identificação do modelo de segunda ordem da coluna de alta pureza. . . . . . . . . 207

8.13 Segmentos dos sinais gerados pelo método 1 de dois passos para identificação do modelo de segunda ordem da coluna de alta pureza. . . . . . . . 208

8.14 Segmentos dos sinais gerados pelo método 2 de dois passos para identificação do modelo de segunda ordem da coluna de alta pureza. . . . . . . . 208

8.15 Segmentos dos sinais $\mathrm{SOH}$ com espectros intercalados modificados para identificação do modelo de segunda ordem da coluna de alta pureza.209

8.16 Espectros dos sinais $\mathrm{SOH}$ com espectros intercalados modificados para identificação do modelo de segunda ordem da coluna de alta pureza. As marcas "o" e "x" identificam as entradas $u_{1}$ e $u_{2}$ da planta, respectivamente. . . . . . . . . . . . . . . . . 210

8.17 Segmentos dos sinais PRT com harmônicas correlacionadas para identificação do modelo de segunda ordem da coluna de alta pureza. . . . . . . . 210

8.18 Plano de saídas $\left\{y_{1} ; y_{2}\right\}$ do modelo de primeira ordem da coluna de alta pureza excitada com sinais rotacionados. . . . . . . . . . . 215

8.19 Plano de saídas $\left\{y_{1} ; y_{2}\right\}$ do modelo de primeira ordem da coluna de alta pureza excitada com sinais gerados pelo método 1 de dois passos. . . 216

8.20 Plano de saídas $\left\{y_{1} ; y_{2}\right\}$ do modelo de primeira ordem da coluna de alta pureza excitada com sinais gerados pelo método 2 de dois passos. . . 216

8.21 Plano de saídas $\left\{y_{1} ; y_{2}\right\}$ do modelo de primeira ordem da coluna de alta pureza excitada com sinais SOH com espectros intercalados modificados. 217

8.22 Plano de saídas $\left\{y_{1} ; y_{2}\right\}$ do modelo de primeira ordem da coluna de alta pureza excitada com sinais PRT com harmônicas correlacionadas. . 217

8.23 Plano de saídas $\left\{y_{1} ; y_{2}\right\}$ do modelo de segunda ordem da coluna de alta pureza excitada com sinais rotacionados. . . . . . . . . . . . 218

8.24 Plano de saídas $\left\{y_{1} ; y_{2}\right\}$ do modelo de segunda ordem da coluna de alta pureza excitada com sinais gerados pelo método 1 de dois passos. . .

8.25 Plano de saídas $\left\{y_{1} ; y_{2}\right\}$ do modelo de segunda ordem da coluna de alta pureza excitada com sinais gerados pelo método 2 de dois passos. . .

8.26 Plano de saídas $\left\{y_{1} ; y_{2}\right\}$ do modelo de segunda ordem da coluna de alta pureza excitada com sinais SOH com espectros intercalados modificados. 220 
8.27 Plano de saídas $\left\{y_{1} ; y_{2}\right\}$ do modelo de segunda ordem da coluna de alta pureza excitada com sinais PRT com harmônicas correlacionadas. . .

8.28 Valores singulares do modelo de segunda ordem da coluna de alta pureza e dos modelos ARMAX estimados com $\sigma_{e}^{2}=0,1 \ldots$. . . . .

8.29 Valores singulares do modelo de segunda ordem da coluna de alta pureza e dos modelos ARMAX estimados com $\sigma_{e}^{2}=0,5 \ldots \ldots$

8.30 Plano das combinações dos sinais de excitação $\mathbf{u}_{1}$ e $\mathbf{u}_{2}$ definidos no intervalo $\left|u_{1}(i)\right|,\left|u_{2}(i)\right| \leq 0,003$ e plano das respectivas saídas $\mathbf{y}_{1}$ e $\mathbf{y}_{2}$ em estado estático da coluna de destilação de alta pureza. . . . . . . .

8.31 Plano das combinações dos sinais de excitação rotacionados $\mathbf{u}_{1}^{\prime}$ e $\mathbf{u}_{2}^{\prime}$ e plano das respectivas saídas $\mathbf{y}_{1}$ e $\mathbf{y}_{2}$ em estado estático para a coluna de destilação de alta pureza. . . . . . . . . . . . . . . . .

8.32 Plano das combinações dos sinais de excitação rotacionados com restrições $\tilde{\mathbf{u}}_{1}$ e $\tilde{\mathbf{u}}_{2}$ e plano das respectivas saídas $\mathbf{y}_{1}$ e $\mathbf{y}_{2}$ com restrições $\left(\left|y_{1}(i)\right| \leq\right.$ 0,05 e $\left.\left|y_{2}(i)\right| \leq 0,10\right)$ em estado estático para a coluna de destilação de alta pureza.

8.33 Plano das combinações dos sinais de excitação rotacionados com restrições $\mathbf{u}_{1}$ e $\mathbf{u}_{2}$ e plano das respectivas saídas $\mathbf{y}_{1}$ e $\mathbf{y}_{2}$ com restrições $\left(\left|y_{1}(i)\right| \leq\right.$ 0,15 e $\left.\left|y_{2}(i)\right| \leq 0,40\right)$ em estado estático para a coluna de destilação de alta pureza.

8.34 Segmentos dos sinais rotacionados com restrições parametrizados para identificação da coluna de alta pureza.

8.35 Plano de saídas $\left\{y_{1} ; y_{2}\right\}$ do modelo de primeira ordem $G_{1}(s)$ da coluna de alta pureza excitada com sinais rotacionados com restrições e com $\sigma_{e}^{2}=0,1$

8.36 Plano de saídas $\left\{y_{1} ; y_{2}\right\}$ do modelo de primeira ordem $G_{1}(s)$ da coluna de alta pureza excitada com sinais rotacionados com restrições e com $\sigma_{e}^{2}=0$

8.37 Plano de saídas $\left\{y_{1} ; y_{2}\right\}$ do modelo de segunda ordem $G_{2}(s)$ da coluna de alta pureza excitada com sinais rotacionados com restrições e com $\sigma_{e}^{2}=0,1$.

8.38 Plano de saídas $\left\{y_{1} ; y_{2}\right\}$ do modelo de segunda ordem $G_{2}(s)$, $\operatorname{com} \tau_{1}=$ 90 e $\tau_{2}=50$, da coluna de alta pureza excitada com sinais rotacionados com restrições e com $\sigma_{e}^{2}=0,1 \ldots \ldots \ldots \ldots \ldots$ 
9.1 Fluxograma para seleção de conjuntos de sinais de excitação. . . . . . 235

9.2 Tela de entradas de informações a priori e de resultados da ferramenta desenvolvida para a construção de conjuntos de sinais de excitação. 246

9.3 Exemplos de sinais gerados pela ferramenta desenvolvida. . . . . . . 246

9.4 Espectro de amplitudes dos exemplos de sinais gerados pela ferramenta desenvolvida. . . . . . . . . . . . . . . . . 247

9.5 Autocorrelações dos exemplos de sinais gerados pela ferramenta desenvolvida. . . . . . . . . . . . . . . . 247

9.6 Correlação cruzada dos exemplos de sinais gerados pela ferramenta desenvolvida. . . . . . . . . . . . . . . . . 248

10.1 Diagrama da planta FCC simulada (GROSDIDIER et al., 1993). . . . . . 250

10.2 Diagrama de blocos relacionando as entradas $\left(u_{s r}\right)$ com saídas $\left(y_{p}\right)$ da planta FCC . . . . . . . . . . . . . . . . . . . . 252

10.3 Excitações em degrau utilizadas para identificação da planta. . . . . . 255

10.4 Índice CISS calculado com $d_{r}=\left\lceil\frac{\tau_{\max , r}}{T} \frac{k}{100}\right\rceil$ para os sinais de excitação dos conjuntos de experimentos A e B. . . . . . . . . . . 273

10.5 Índice CISS calculado com $d_{r}=\left\lceil\frac{\tau_{\max , r}}{T} \frac{k}{100}\right\rceil$ para os sinais de excitação do conjunto de experimentos C . . . . . . . . . . . . . . 274

10.6 Sinais GBN utilizados na validação dos modelos. . . . . . . . . . . . 275

10.7 Respostas da planta FCC a excitações em degrau. . . . . . . . . . . . 276

10.8 Perturbações adicionadas às saídas da planta. . . . . . . . . . . . . 277

10.9 Respostas da planta FCC a excitações shift-QRB. . . . . . . . . . . 278

10.10Medidas A-optimality para os modelos FIR ajustados a partir dos dados do experimento A e os correspondentes valores de CISS. . . . . . . . 279

10.11 Medidas A-optimality para os modelos FIR ajustados a partir dos dados do experimento B e os correspondentes valores de CISS. . . . . . . . 280

10.12Medidas A-optimality para os modelos FIR ajustados a partir dos dados do experimento $\mathrm{C}$ e os correspondentes valores de CISS. . . . . . . . 281

10.13Dispersão dos valores da medida A-optimality versus CISS para os modelos FIR ajustados a partir dos dados do experimento A. . . . . . . . 282 
10.14Dispersão dos valores da medida A-optimality versus CISS para os modelos FIR ajustados a partir dos dados do experimento B. . . . . . . . 283

10.15Dispersão dos valores da medida A-optimality versus CISS para os modelos FIR ajustados a partir dos dados do experimento C. . . . . . . . 284

10.16 Validação $\overline{F I T}$ dos modelos ARX de alta ordem, ARX, FIR e ARMAX ajustados a partir dos dados do experimento A quando excitados com o sinal de validação GBN. . . . . . . . . . . . . . . .

10.17Validação $\overline{F I T}$ dos modelos ARX de alta ordem, ARX, FIR e ARMAX ajustados a partir de dados do experimento A quando excitados com o sinal de validação do tipo onda quadrada. . . . . . . . . . . . . . .

10.18Melhor $\overline{F I T}$ obtido com os modelos ARX de alta ordem, ARX, FIR e ARMAX ajustados a partir de dados do experimento A quando excitados com o sinal de validação GBN. . . . . . . . . . . . . . . . . .

10.19Melhor $\overline{F I T}$ obtido com os modelos ARX de alta ordem, ARX, FIR e ARMAX ajustados a partir de dados do experimento A quando excitados com o sinal de validação do tipo onda quadrada. . . . . . . . . . .

10.20 Validação $\overline{F I T}$ dos modelos ARX de alta ordem, ARX, FIR e ARMAX ajustados a partir de dados do experimento B quando excitados com o sinal de validação GBN. . . . . . . . . . . . . . . . . . . .

10.21 Validação $\overline{F I T}$ dos modelos ARX de alta ordem, ARX, FIR e ARMAX ajustados a partir de dados do experimento B quando excitados com o sinal de validação do tipo onda quadrada. . . . . . . . . . . . . . .

10.22Melhor $\overline{F I T}$ obtido com os modelos ARX de alta ordem, ARX, FIR e ARMAX ajustados a partir de dados do experimento B quando excitados com o sinal de validação GBN. . . . . . . . . . . . . . . . .

10.23 Melhor $\overline{F I T}$ obtido com os modelos ARX de alta ordem, ARX, FIR e ARMAX ajustados a partir de dados dos experimentos B quando excitados com o sinal de validação do tipo onda quadrada. . . . . . . .

10.24 Validação $\overline{F I T}$ dos modelos ARX de alta ordem, ARX, FIR e ARMAX ajustados a partir de dados do experimento $\mathrm{C}$ quando excitados com o sinal de validação GBN. . . . . . . . . . . . . . . . . . . . .

10.25 Validação $\overline{F I T}$ dos modelos ARX de alta ordem, ARX, FIR e ARMAX ajustados a partir de dados do experimento $\mathrm{C}$ quando excitados com o sinal de validação do tipo onda quadrada. . . . . . . . . . . . . . . . . 
10.26Melhor $\overline{F I T}$ obtido com os modelos ARX de alta ordem, ARX, FIR e ARMAX ajustados a partir de dados do experimento $\mathrm{C}$ quando excitados com o sinal de validação GBN. . . . . . . . . . . . . . . . . 296

10.27Melhor $\overline{F I T}$ obtido com os modelos ARX de alta ordem, ARX, FIR e ARMAX ajustados a partir de dados do experimento $\mathrm{C}$ quando excitados com o sinal de validação do tipo onda quadrada. . . . . . . . . . . 297

10.28SNR nas saídas da planta obtidas no conjunto de experimentos A. . . 298

10.29SNR nas saídas da planta obtidas no conjunto de experimentos B. . . 299

10.30SNR nas saídas da planta obtidas no conjunto de experimentos C. . . 300

10.31 Validação com sinais GBN em termos de $\overline{F I T}$ em função dos passos de predição dos modelos ARX de alta ordem obtidos de experimentos com sinais MLNL. . . . . . . . . . . . . . . . 306

10.32 Validação com sinais GBN em termos de $\overline{F I T}$ em função dos passos de predição dos modelos ARX de alta ordem obtidos de experimentos com sinais Gallev. . . . . . . . . . . . . . . . . . 307

10.33 Validação com sinais GBN em termos de $\overline{F I T}$ em função dos passos de predição dos modelos ARX de alta ordem obtidos de experimentos com sinais MLMH. . . . . . . . . . . . . . . . . . . 307

B.1 Modelo com estrutura não linear quadrática de Hammerstein (BARKER; GODFREY; TUCKER, 2000). . . . . . . . . . . . . . . 317

B.2 Modelo com estrutura não linearidade quadrática de Wiener (BARKER; GODFREY; TUCKER, 2000). . . . . . . . . . . . . . . 317

D.1 Resposta em frequência do ZOH. . . . . . . . . . . . . . . . . 323

D.2 Sinal binário amostrado de comprimento $N=7 \ldots \ldots$. . . . . . . 324

D.3 Sinal binário amostrado associado ao ZOH. . . . . . . . . . . . . . . 324

D.4 Resposta em frequência do sinal amostrado. . . . . . . . . . . . . 325

D.5 Resposta em frequência do sinal amostrado associado ao ZOH. . . . . 325

A.1 Circuito que implementa a recorrência linear . . . . . . . . . . . . . . 353 


\section{Lista de Tabelas}

3.1 Características desejáveis para sinais de excitação aplicáveis à indústria de processos. . . . . . . . . . . . . . .

3.2 Características desejáveis para sinais de excitação do ponto de vista

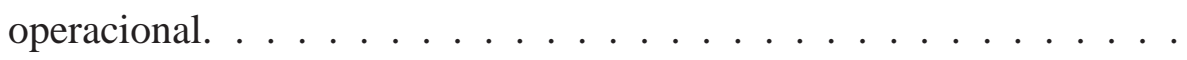

5.1 Índices de desempenho para o sinal BN branco apresentado de comprimento $N_{s}=100 \ldots \ldots \ldots \ldots \ldots \ldots \ldots$

5.2 Parâmetros de planta e do sinal de excitação para identificação do sistema de destilação de alta pureza de (GAIKWAD; RIVERA, 1996). . . .

5.3 Índices de desempenho para o sinal BN colorido apresentado de comprimento $N=700 \ldots \ldots \ldots \ldots \ldots \ldots$

5.4 Parametrização de um sinal GBN. . . . . . . . . . . . . . . 79

5.5 Índices de desempenho para o sinal GBN com $p=0,6869$ e comprimento $N_{s}=700 \ldots \ldots \ldots \ldots \ldots \ldots$

5.6 Índices de desempenho para o sinal Schroeder-SOH parametrizado com $T=60$ segundos, $N_{s}=700$ e $n_{s}=44 \ldots \ldots \ldots 11$

5.7 Índices de desempenho para o sinal Schroeder-SOH parametrizado com $T=60$ segundos, $N_{s}=700, n_{s}^{(1)}=n_{s}^{(2)}=n_{s}^{(3)}=14$ e $n_{s}=$ $n_{s}^{(1)}+n_{s}^{(2)}+n_{s}^{(3)}=42 \ldots \ldots \ldots \ldots \ldots \ldots$

5.8 Exemplos de níveis para o sinal primitivo $m(i)$ de forma a obter o sinal de excitação $u(i)$ com harmônicas múltiplas de 2 e 3 suprimidas e demais harmônicas uniformes. . . . . . . . . . . . . .

5.9 Exemplos de sinais primitivos que geram sinais ternários não correlacionados.

5.10 Índices de desempenho para os sinais PRT de comprimento $N_{s}=2.394$, período de chaveamento $T_{c l k}=420$ segundos, com período de amostragem de $T=60$ segundos. 
5.11 Índices de desempenho para os sinais PRML de comprimento $N_{s}=$ 2.394, com período de chaveamento $T_{c l k}=420$ segundos e período de amostragem de $T=60$ segundos. . . . . . . . . . . . . . . . 157

6.1 Alguns exemplos de conjuntos de sequências PRMO possíveis. . . . . 164

6.2 Exemplos de conjuntos de sequências MLNL propostos neste trabalho e de conjuntos de sequências Gallev. . . . . . . . . . . . . . . . 17

7.1 Comparação de características dos sinas de excitação estudados neste trabalho. . . . . . . . . . . . . . . . . .

7.2 Parâmetros dos sinas de excitação para comparação de índices de desempenho. . . . . . . . . . . . . . . . . . .

7.3 Comparação de índices de desempenho dos sinas de excitação. . . . . .

8.1 Principais características dos métodos de projeto de sinais de excitação para identificação de plantas mal condicionadas. . . . . . . . . . . .

8.2 Principais características das plantas originalmente empregadas para avaliar os métodos de projeto de sinais de excitação. . . . . . . . . . 206

8.3 Resumo dos resultados de simulação do modelo de primeira ordem da coluna de alta pureza $G_{1}(s) \ldots \ldots \ldots \ldots$

8.4 Resumo dos resultados de simulação do modelo de segunda ordem da coluna de alta pureza $G_{2}(s)$ para $\sigma_{e}^{2}=0,1$ e estrutura ARMAX. . . .

8.5 Resumo dos resultados de simulação do modelo de segunda ordem da coluna de alta pureza $G_{2}(s)$ para $\sigma_{e}^{2}=0,5$ e estrutura ARMAX. . . .

8.6 FIT de modelos ARX estimados a partir de dados da planta de segunda ordem da coluna de alta pureza $G_{2}(s) \operatorname{com} \sigma_{e}^{2}=0,1 \ldots \ldots$. . . .

8.7 Resumo dos resultados de simulações dos modelos de primeira e segunda ordem da coluna de alta pureza, $G_{1}(s)$ e $G_{2}(s)$, respectivamente, utilizando sinais rotacionados com restrições. . . . . . . . . . .

10.1 Variáveis manipuladas (MV), controladas (CV) e seus limites da planta FCC . . . . . . . . . . . . . . . .

10.2 Funções de transferência $G_{r, p}(s) \ldots \ldots \ldots 252$

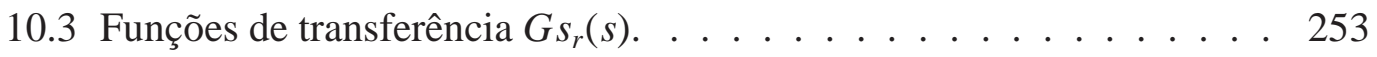

10.4 Características dos ruídos de medição e perturbação não medidas utilizados nos experimentos. . . . . . . . . . . . . 253 
10.5 Ordens dos polinômios $A, B, C$ e $k$, para as estruturas ARX e ARMAX. 254

10.6 Ordens da estrutura FIR. . . . . . . . . . . . . . . . . . 254

10.7 Tempos máximos e mínimos de acomodação da planta, constantes de tempo e frequências máximas e mínimas de interesse. . . . . . . . . 255

10.8 Características dos conjuntos de experimentos. . . . . . . . . . 257

10.9 Probabilidades $p$ de não chaveamento calculadas para cada um dos $n_{r}$ sinais GBN.

10.10Características dos sinais aplicados nos conjuntos de experimentos A e B de duração $T_{e}=5.115$ minutos. . . . . . . . . . . . . 260

10.11Características dos sinais aplicados no conjunto de experimentos $\mathrm{C}$ de duração $T_{e}=N_{s} \times T \ldots \ldots \ldots \ldots \ldots \ldots 26 \ldots \ldots \ldots$

10.12Medidas de desempenho dos sinais aplicados nos conjuntos de experimentos A e B. . . . . . . . . . . . . . . 263

10.13 Medidas de desempenho dos sinais aplicados no conjunto de experimentos C. . . . . . . . . . . . . . . . . 267

$10.14 \overline{F I T}$ e $\sigma_{F I T}$ dos modelos ARX ajustados a partir de dados de experimentos com excitações em degrau e validação com sinais GBN e sinais do tipo onda quadrada. . . . . . . . . . . . . . . . 276

10.15Médias, valores mínimos e máximos dos $\overline{F I T}$ obtidos em todas as saídas $y_{p}$, todos experimentos (A, B e C) e validação com sinais GBN e com sinais do tipo onda quadrada. . . . . . . . . . . . 301

10.16Médias, valores mínimos e máximos dos $\overline{F I T}$ obtidos em todas as saídas $y_{p}$, todos experimentos (A, B e C) e validação com sinais GBN. 302

10.17Médias, valores mínimos e máximos dos $\overline{F I T}$ obtidos em todas as saídas $y_{p}$, todos experimentos (A, B e C) e validação com sinais do tipo onda quadrada. . . . . . . . . . . . . . . . . 303

D.1 Exemplo de sinal associado a ZOH. . . . . . . . . . . . 323

B.1 Distribuição dos blocos em uma SMC . . . . . . . . . . . . . . 357 


\section{Lista de Abreviaturas e Siglas}

ARX modelo auto-regressivo com entradas exógenas (auto-regressive with exogenous inputs model).

ARMAX modelo auto-regressivo com média móvel e entradas exógenas (auto-regressive moving average with exogenous inputs model).

BJ modelo Box-Jenkins.

BN ruído binário (binary noise).

CBN ruído binário colorido (colored binary noise).

CF fator de crista (crest-factor).

CISS índice de comparação de conjunto de sinais para excitação (comparation index for set of signals).

clipping-SOH sinal $\mathrm{SOH}$ otimizado pelo método clipping.

CV variável controlada (controlled variable).

DCS sistema de controle distribuído (distributed control system).

DFT transformada discreta de Fourier (discrete Fourier transform).

DIB sinal binário de intervalo discreto (discrete interval binary signal).

DIT sinal ternário de intervalo discreto (discrete interval ternary signal).

DMC controle por matriz dinâmica (dynamic matrix control).

DV variável de perturbação (disturbance variable).

EMINE índice de razão mínima entre a amplitude de uma harmônica do sinal e sua respectiva amplitude especificada (Effective minimum ratio between the actual harmonic amplitude and the specified harmonic amplitude at any of the specified harmonics).

FC controle de vazão (flow control). 
FCC craqueamento catalítico fluido (fluid catalytic cracking).

FIR resposta impulsiva finita (finite impulse response).

FIT índice de ajuste.

FM modulado em frequência (frequency modulated).

FOPTD modelo de primeira ordem com tempo morto (first order plus time delay).

GBN ruído binário generalizado (generalized binary noise).

GMN ruído multinível generalizado (generalized multiple-level noise).

GMW sinal GMW (Gordon, Mills and Welch).

HAB sinal binário de Hall (Hall binary signal).

HIECON controle hierárquico com restrições (hierarchical constraint control).

IDCOM software para identificação e comando (identification and command).

IDCOM-M software para identificação e comando multivariável.

IDFT transformada inversa discreta de Fourier (inverse discrete Fourier transform).

iid variável aleatória independente e identicamente distribuída (independent and identically distributed).

IMC controle por modelo interno (internal model control).

LC controle de nível (level control).

LCZ zona de correlação reduzida (low correlation zone).

LL bloco antecipatório ou de retardo (lead-leag block).

LQG controlador linear quadrático Gaussiano (linear quadratic Gaussian controller).

LS mínimos quadrados (least-squares).

MIMO múltiplas entradas e múltiplas saídas (multiple input and multiple outputs).

MISO múltiplas entradas e saída única (multiple inputs and single output).

MLMH sinal multi harmônico multinível (multi-level multi-harmonic signal).

MLNL sinal não linear multinível (multilevel non linear signal).

MM vários modelos (multi-model). 
MOESP modelo multivariável de erro na saída em espaço de estados (multivariable output-error state space).

MPC controle preditivo por modelo (model predictive control).

MPHC controle heurístico preditivo por modelos (model predictive heuristic control).

MQ mínimos quadrados.

MV variável manipulada (manipulated variable).

PC controle de pressão (pressure control).

PCA análise em componentes principais (principal components analysis).

PDF função densidade de probabilidade (probability density function).

PE persistência da excitação.

PF fator de pico (peak factor).

PID proporcional, integral e derivativo.

PIPS índice de desempenho para sinais de excitação (performance index for perturbation signals).

PIPSE índice de desempenho efetivo para sinais de excitação (effective performance index for perturbation signals).

PRB sinal binário pseudo-aleatório (pseudo-random binary, PRB signal).

PRML sinal pseudo-aleatório multinível (pseudo-random multilevel signal).

PRMO sinal pseudo-aleatório multinível ortogonal (pseudorandom multilevel orthogonal signal).

PRNB sinal pseudo-aleatório quase-binário (pseudo-random near-binary signal).

PRT sinal pseudo-aleatório ternário (pseudo-random ternary signal).

PVC cloreto de polivilina (poly-vinyl chloride).

QDMC DMC com programação quadrática.

QRB sinal binário de resíduo quadrático (quadratic residue binary signal).

QRT sinal ternário de resíduo quadrático (quadratic residue ternary signal).

RGA matriz de ganhos relativos (relative gain array). 
RMS valor médio quadrático (root mean square).

SF fator de dispersão (scattering factor).

Schroeder-SOH sinal SOH otimizado pelo método de Schroeder.

SIMO entrada única e múltiplas saídas (single input and multiple outputs).

SISO entrada única e saída única (single input and single output).

SMC sequência de máximo comprimento.

SMCA arquitetura de controle multivariável da Setpoint (Setpoint Multivariable Control Architecture).

SMI identificação em subespaço (subspace ID, SMI).

SMOC controlador por otimização multivariável da Shell (Shell Multivariable Optimizing Controller).

SNR relação sinal ruído (signal-to-noise ratio).

SOH soma de harmônicos (sum of harmonics).

SOPTD modelo de segunda ordem com tempo morto (second order plus time delay).

SP ponto (ou valor) de ajuste (set point).

SVD decomposição em valores singulares (singular value decomposition).

TC controle de temperatura (temperature control).

TF fator de tempo (time factor).

TPB sinal binário de primos gêmeos (twin prime binary signal).

wsS processo aleatório estacionário no sentido amplo (wide-sense-stationary random process).

WGN processo ruído branco Gaussiano (white Gaussian noise).

ZCZ zona de correlação nula (zero correlation zone).

ZOH segurador de ordem zero (zero-order holder). 


\section{Lista de Símbolos}

Os símbolos principais e de maior ocorrência nas expressões matemáticas estão listados abaixo.

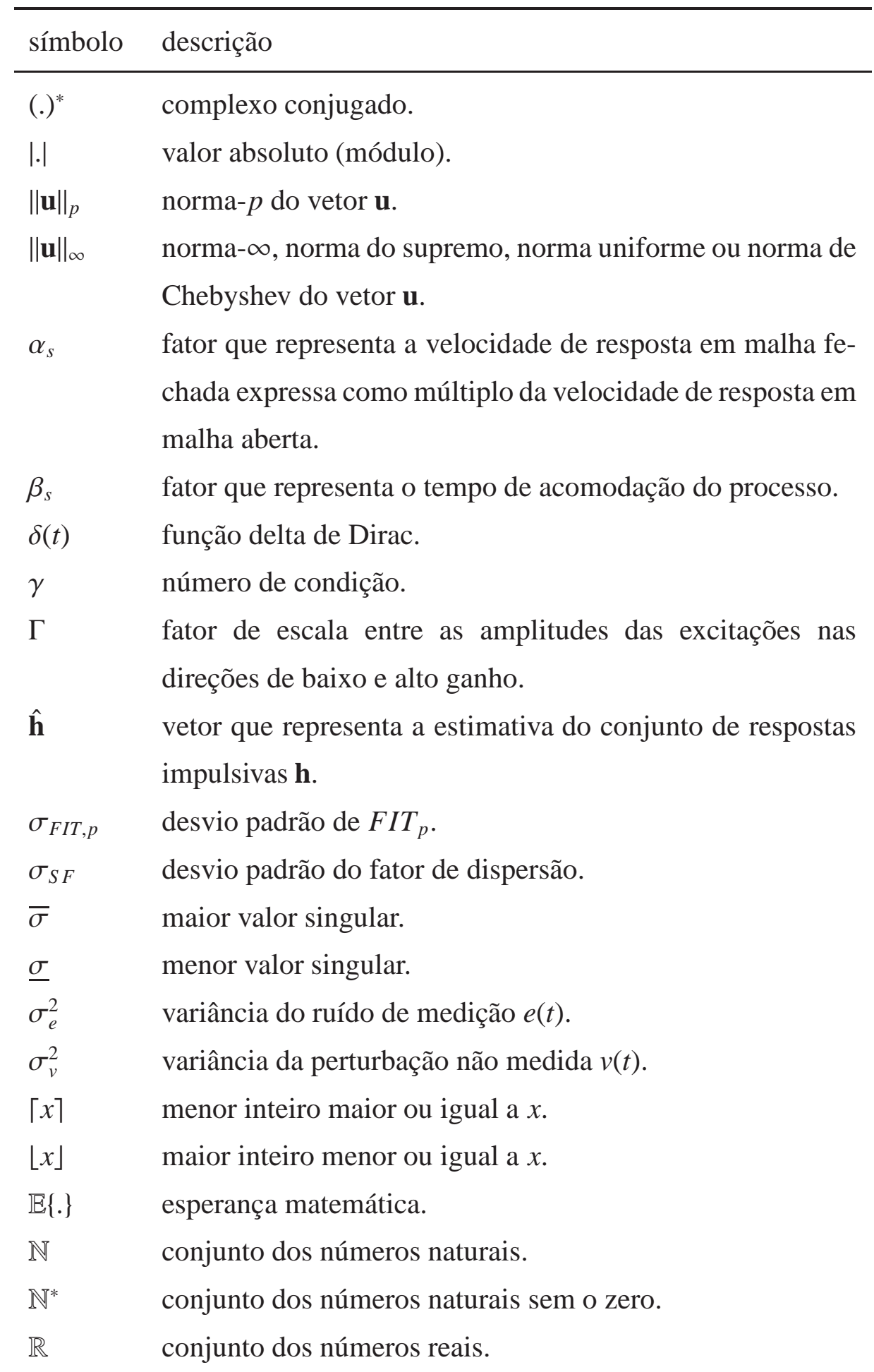




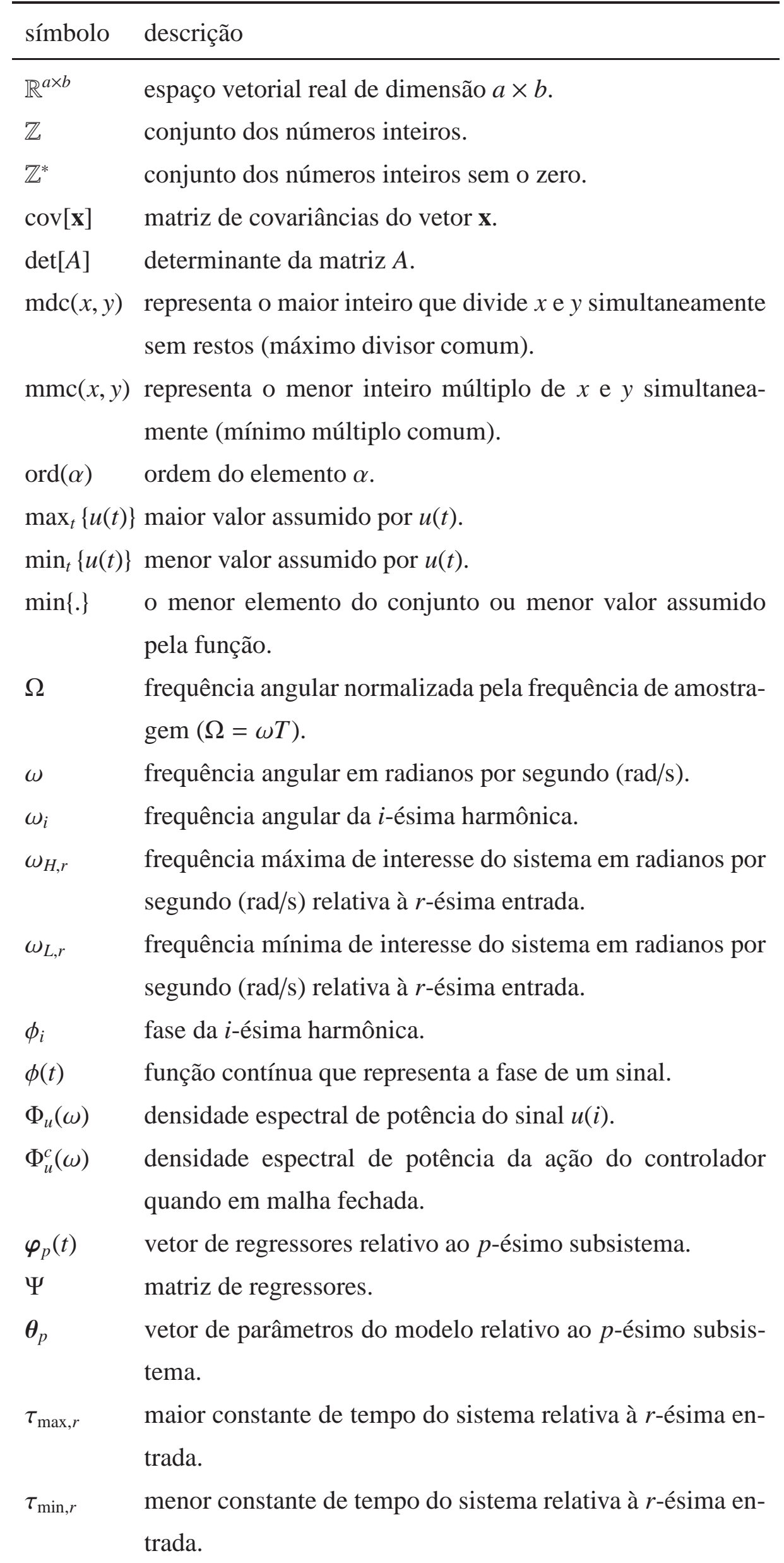




\begin{tabular}{|c|c|}
\hline símbolo & descrição \\
\hline h & $\begin{array}{l}\text { vetor que representa o conjunto de respostas impulsivas em } \\
\text { tempo discreto } h_{r}(i) \text {, com } r=1,2, \ldots, n_{r} \text {, do sistema de } n_{r} \\
\text { entradas. }\end{array}$ \\
\hline $\mathbf{R}$ & matriz composta de matrizes de correlação $R_{u_{q} u_{r}}$ \\
\hline $\mathbf{r}_{u u}$ & $\begin{array}{l}\text { vetor que representa a função de autocorrelação periódica } \\
r_{u u}(k) \text {. }\end{array}$ \\
\hline $\mathbf{r}_{u y}$ & $\begin{array}{l}\text { vetor que representa a função de correlação cruzada } \\
\text { periódica } r_{u y}(k) \text {. }\end{array}$ \\
\hline $\mathbf{u}_{r}$ & $\begin{array}{l}\text { vetor que representa a } r \text {-ésima entada do sistema em tempo } \\
\text { discreto. }\end{array}$ \\
\hline $\mathbf{v}_{p}$ & $\begin{array}{l}\text { vetor que representa perturbação não medida na } p \text {-ésima } \\
\text { saída do sistema. }\end{array}$ \\
\hline $\mathbf{y}$ & $\begin{array}{l}\text { vetor que representa a o conjunto de saídas em tempo dis- } \\
\text { creto } y_{p}(i), \text { com } p=1,2, \ldots, n_{p} \text {, do sistema de } n_{p} \text { saídas. }\end{array}$ \\
\hline$\tilde{r}_{u u}(k)$ & $\begin{array}{l}\text { função de autocorrelação periódica do sinal em tempo dis- } \\
\text { creto } u(i) \text { não estacionário, também denotada por } \tilde{r}(\mathbf{u}, \mathbf{u}, k) \text {. }\end{array}$ \\
\hline$\underline{u}(i-k)$ & $\begin{array}{l}\text { deslocamento cíclico de } k \text { posições do sinal } u(i)(\underline{u}(i-k)= \\
u(j), \operatorname{com} j=(i-k) \bmod N) \text {. }\end{array}$ \\
\hline$B W_{r}$ & $\begin{array}{l}\text { intervalo que define a largura de banda de interesse do sis- } \\
\text { tema relativa à } r \text {-ésima entrada. }\end{array}$ \\
\hline$D$ & $\begin{array}{l}\text { tempo de acomodação expresso em múltiplos do tempo de } \\
\text { chaveamento do sinal de excitação } T_{c l k} \text {. }\end{array}$ \\
\hline$E_{\min }$ & $\begin{array}{l}\text { menor razão entre a amplitude da harmônica sob avaliação } \\
\text { e a amplitude de qualquer harmônica especificada. }\end{array}$ \\
\hline$F$ & quantidade de harmônicas na banda de interesse. \\
\hline$f_{c l k}$ & $\begin{array}{l}\text { frequência de chaveamento do sinal de excitação em Hertz } \\
(\mathrm{Hz}) \text {. }\end{array}$ \\
\hline$f_{H}$ & frequência máxima de interesse do sistema em Hertz $(\mathrm{Hz})$. \\
\hline$f_{L}$ & frequência mínima de interesse do sistema em Hertz $(H z)$. \\
\hline$f_{s}$ & frequência de amostragem. \\
\hline$F I T_{p}$ & FIT da $p$-ésima saída. \\
\hline$\overline{F I T}_{p}$ & FIT médio da $p$-ésima saída. \\
\hline$G F(q)$ & $\begin{array}{l}\text { corpo de Galois } D \bmod q \text {, onde } D \text { é o conjunto fundamental } \\
\text { e } q \text { um número primo. }\end{array}$ \\
\hline$G^{0}$ & modelo nominal da planta. \\
\hline
\end{tabular}




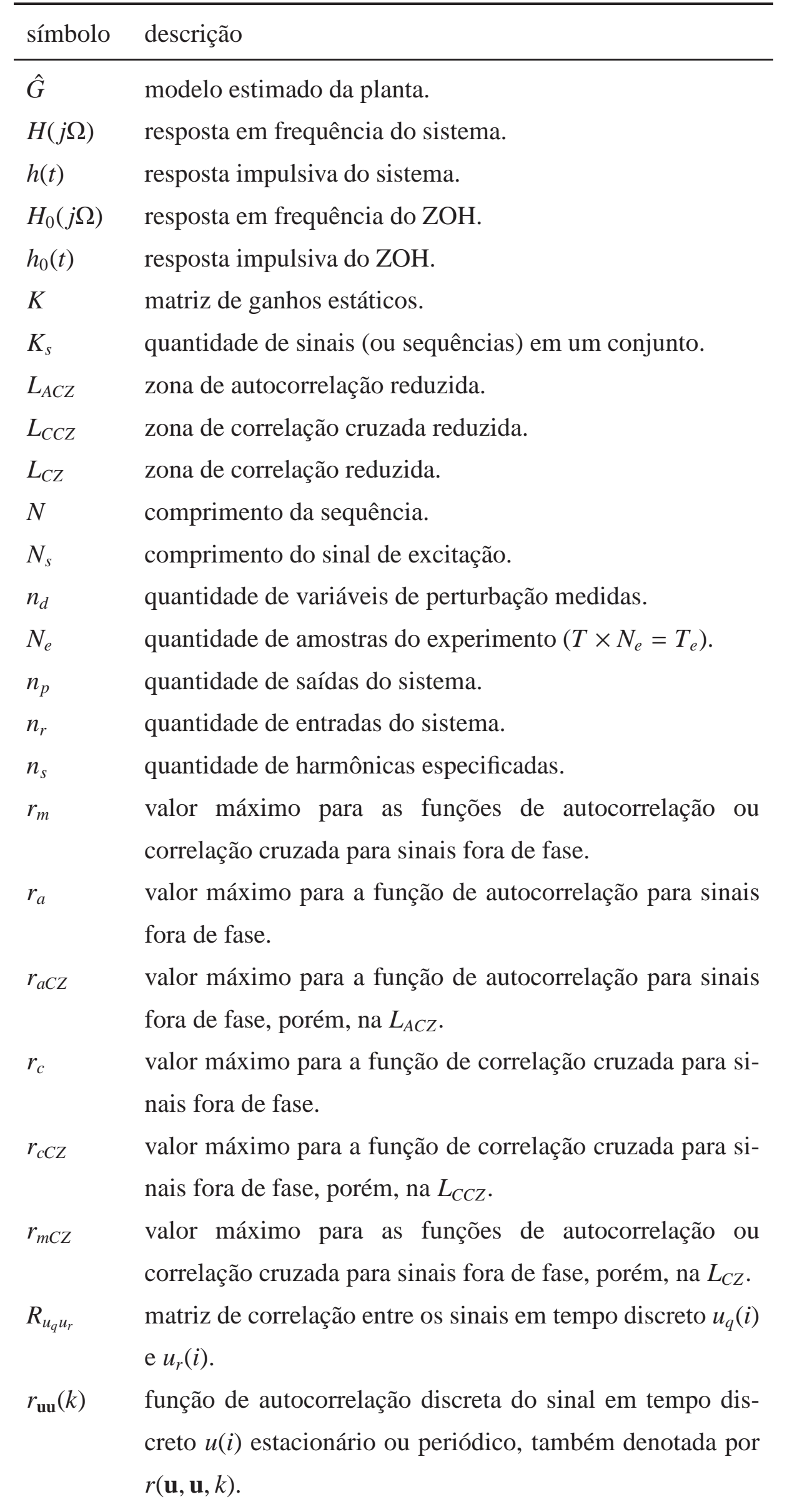

continua... 


\begin{tabular}{|c|c|}
\hline símbolo & descrição \\
\hline$r_{\mathbf{u v}}(k)$ & $\begin{array}{l}\text { função de correlação cruzada discreta entre os sinais em } \\
\text { tempo discreto } u(i) \text { e } v(i) \text { estacionários ou periódicos, } \\
\text { também denotada por } r(\mathbf{u}, \mathbf{v}, k) \text {. }\end{array}$ \\
\hline$\overline{S F}$ & fator de dispersão médio. \\
\hline$\overline{S N R}_{p}$ & SNR média na $p$-ésima saída. \\
\hline$T$ & período de amostragem. \\
\hline$T_{c l k}$ & período de chaveamento ou clock period. \\
\hline$T_{e}$ & Duração do experimento. \\
\hline$\tilde{T}_{e}$ & Tempo disponível para o experimento. \\
\hline$T_{e, r}$ & Duração do teste de identificação da $r$-ésima entrada. \\
\hline$T_{\max }^{s e t}$ & maior tempo de acomodação do sistema. \\
\hline$T_{\max , r}^{s e t}$ & $\begin{array}{l}\text { tempo de acomodação máximo do sistema relativo à } r \text { - } \\
\text { ésima entrada. }\end{array}$ \\
\hline$T_{\min , r}^{s e t}$ & $\begin{array}{l}\text { tempo de acomodação mínimo do sistema relativo à } r \text {-ésima } \\
\text { entrada. }\end{array}$ \\
\hline$T_{p, r}^{s e t}$ & $\begin{array}{l}\text { tempo de acomodação da } p \text {-ésima saída relativo à } r \text {-ésima } \\
\text { entrada. }\end{array}$ \\
\hline$T_{N_{s}}$ & período do sinal de excitação. \\
\hline $\operatorname{Tr}_{m}^{n}(\alpha)$ & $\begin{array}{l}\text { função traço de } \alpha \in G F\left(p^{n}\right) \text { resultando em elemento sobre } \\
G F\left(p^{m}\right) \text {. }\end{array}$ \\
\hline$U$ & matriz composta de vetores regressores $\mathbf{u}$. \\
\hline$U(k)$ & $\begin{array}{l}\text { transformada de Fourier (ou espectro de frequências) do si- } \\
\text { nal discreto } u(i) \text {. }\end{array}$ \\
\hline$u(t)$ & entada do sistema em tempo contínuo ou discreto. \\
\hline$u_{\max , r}$ & $\begin{array}{l}\text { valor máximo assumido pelo sinal estacionário ou periódico } \\
u_{r}(t) \text {. }\end{array}$ \\
\hline$u_{\min , r}$ & $\begin{array}{l}\text { valor mínimo assumido pelo sinal estacionário ou periódico } \\
u_{r}(t) \text {. }\end{array}$ \\
\hline$u_{\text {mean }}$ & $\begin{array}{l}\text { valor médio do sinal estacionário ou periódico } u(t) \text {, também } \\
\text { denotado por } \bar{u} \text {. }\end{array}$ \\
\hline$u_{r m s}$ & $\begin{array}{l}\text { valor médio quadrático (RMS) do sinal estacionário ou } \\
\text { periódico } u(t) \text {. }\end{array}$ \\
\hline$U_{\text {rmse }}$ & $\begin{array}{l}\text { valor médio quadrático (RMS) efetivo das componentes de } \\
\text { frequência de interesse. }\end{array}$ \\
\hline
\end{tabular}

continua... 
símbolo descrição

$u_{r m s e} \quad$ valor médio quadrático (RMS) efetivo do sinal estacionário ou periódico $u(t)$ em tempo contínuo ou discreto, o qual compreende a potência apenas na faixa de frequências de interesse.

$u_{r}(t) \quad r$-ésima entada do sistema de múltiplas entradas em tempo contínuo ou discreto.

$v_{p}(i) \quad$ perturbação não medida na $p$-ésima saída do sistema.

$y_{p}(t) \quad p$-ésima saída do sistema de múltiplas saídas em tempo contínuo ou discreto.

$Z_{A C Z} \quad$ zona de autocorrelação nula.

$Z_{C C Z} \quad$ zona de correlação cruzada nula.

$Z_{C Z} \quad$ zona de correlação nula. 


\section{Introdução}

A interação com um sistema de forma compreensível exige, pelo menos, algum conhecimento de como suas variáveis estão relacionadas umas com as outras. Grosso modo, pode-se denominar o conhecimento das relações das variáveis do sistema como modelo do sistema. Os modelos podem ter diferentes níveis de formalismo matemático, sendo que o grau de sofisticação requerido para o modelo depende de sua aplicabilidade (LJUNG, 1999) (AGUIRRE, 2007). Diariamente, nas nossas vidas, elaboramos muitos modelos mentais a partir do que observamos, o que não envolve qualquer formalismo matemático. O termo identificação de sistemas refere-se justamente à obtenção de modelos matemáticos dos sistemas a partir de observações (ZHU, 2001).

\subsection{Modelagem na indústria de processos}

Os modelos mentais podem levar muito tempo para serem formados além de outras limitações que restringem sua aplicabilidade (LJUNG, 1999) (ZHU, 2001) (AGUIRRE, 2007): por exemplo, para aplicação do modelo mental em equipamentos programáveis, ele necessita ser descrito em um código de programação. Fica evidente que, para as aplicações de integração de modelos a equipamentos na indústria, será útil dispor de modelos que possam ser representados por relações matemáticas ou simplesmente gráficos e tabelas. De fato, existem aplicações em que é suficiente representar sistemas lineares simplesmente pelas suas respostas impulsivas, ou resposta ao degrau ou ainda respostas em frequência, como os diagramas de Bode ou Nyquist (GARCIA, 2005). Esses modelos são representados simplesmente por gráficos ou tabelas e são comumente chamados de modelos gráficos ou modelos não paramétricos, por não possuir parâmetros que os caracterizem. Para aplicações avançadas pode ser necessário usar modelos que descrevam as relações entre as variáveis do sistema em termos de expressões matemáticas como as equações de diferenças, equações diferencias ou funções de transferência sobre determinados domínios. Esses modelos são chamados de modelos matemáticos, os quais são modelos paramétricos (LJUNG, 1999) (ZHU, 2001). Modelos para sistemas complexos são comumente codificados como 
um programa computacional, construído a partir de tabelas e diversas sub-rotinas interconectadas, sendo muitas vezes infactível descrever o sistema por um conjunto de equações diferenciais (GARCIA, 2005), por exemplo. Esses modelos são conhecidos como modelos computacionais (LJUNG, 1999).

Uma das técnicas de modelagem matemática é baseada na física ou na natureza do processo. Essa técnica é conhecida como modelagem analítica, modelagem de princípios primários, modelagem caixa branca, modelagem fenomenológica, modelagem conceitual ou, simplesmente, modelagem pela física ou natureza do processo (AGUIRRE, 2007). Em poucas situações práticas haverá tempo e conhecimento suficientes para desenvolver um modelo a partir das equações que regem a física do processo (AGUIRRE, 2007). O equacionamento dos fenômenos envolvidos nem sempre é viável.

A identificação de sistemas, conhecida como técnica de modelagem empírica ou modelagem caixa-preta, estuda técnicas alternativas à modelagem caixa branca (AGUIRRE, 2007). O termo identificação de sistemas está relacionado com o problema de construir modelos matemáticos de sistemas dinâmicos baseados nos dados observados provenientes de um sistema (ZHU, 2001). Os modelos podem ser mais ou menos formais matematicamente, mas possuem a característica básica de relacionar observações com um padrão. A aceitação de um modelo deve ser guiada pela sua aplicabilidade e utilidade e não simplesmente pela verossimilhança ou pelo nível de realismo (LJUNG, 1999). O que se pretende descrever com tais modelos são as relações de causa e efeito entre as variáveis de entrada e saída. As técnicas de identificação de sistemas têm vasta aplicação, visto que os sistemas dinâmicos são abundantes no nosso meio-ambiente. Uma das características da identificação de sistemas é que pouco, às vezes nenhum, conhecimento prévio do sistema é necessário. Por isso, essa técnica de modelagem é conhecida como modelagem (ou identificação) caixa preta ou modelagem empírica (AGUIRRE, 2007).

A motivação para o estudo de técnicas de identificação vem do fato de que frequentemente não se conhecem as equações envolvidas no funcionamento de um determinado sistema ou, se elas são conhecidas, não há tempo nem recurso para estimar e ajustar seus parâmetros. Adicionalmente, mesmo que as equações sejam obtidas, ainda é necessário estimar seus parâmetros. A compreensão e equacionamento dos fenômenos envolvidos pode levar a funções com um número elevado de parâmetros que ainda necessitam ser estimados e ajustados de acordo com o ponto de operação do sistema. $\mathrm{Na}$ indústria de $\operatorname{processos}^{1}$, dependendo da complexidade do sistema, pode

\footnotetext{
${ }^{1}$ As indústrias de processo utilizam plantas de processamento para produzir materiais (ou produtos) homogêneos ou energia. São exemplos de indústrias de processo: petrolíferas, químicas, de energia elétrica, de papel, de vidro, de mineração, metalúrgica, cimentícia, de medicamentos, de alimentos e de bebidas (ZHU, 2001).
} 
não haver tempo suficiente para estimar todos os parâmetros do modelo analítico, ou ainda, não ser viável economicamente implantar diversos pontos de medição na planta industrial para alimentar os estimadores de parâmetros.

Uma outra técnica de modelagem que pode ser compreendida como uma técnica intermediária entre a modelagem caixa branca e a modelagem caixa preta é chamada de modelagem (ou identificação) caixa cinza. Essa técnica utiliza, além das informações presentes nos dados de entrada e saída (causa e efeito) do sistema, informações auxiliares como o conhecimento dos fenômenos físicos envolvidos (AGUIRRE, 2007).

Para modelar empiricamente um processo dinâmico é necessário: projetar o experimento, escolher a estrutura do modelo, escolher o método de ajuste do modelo e definir um procedimento de validação do modelo obtido (LJUNG, 1999). A figura 1.1 transcreve o fluxograma do procedimento de identificação de sistemas apresentado em (LJUNG, 1999).

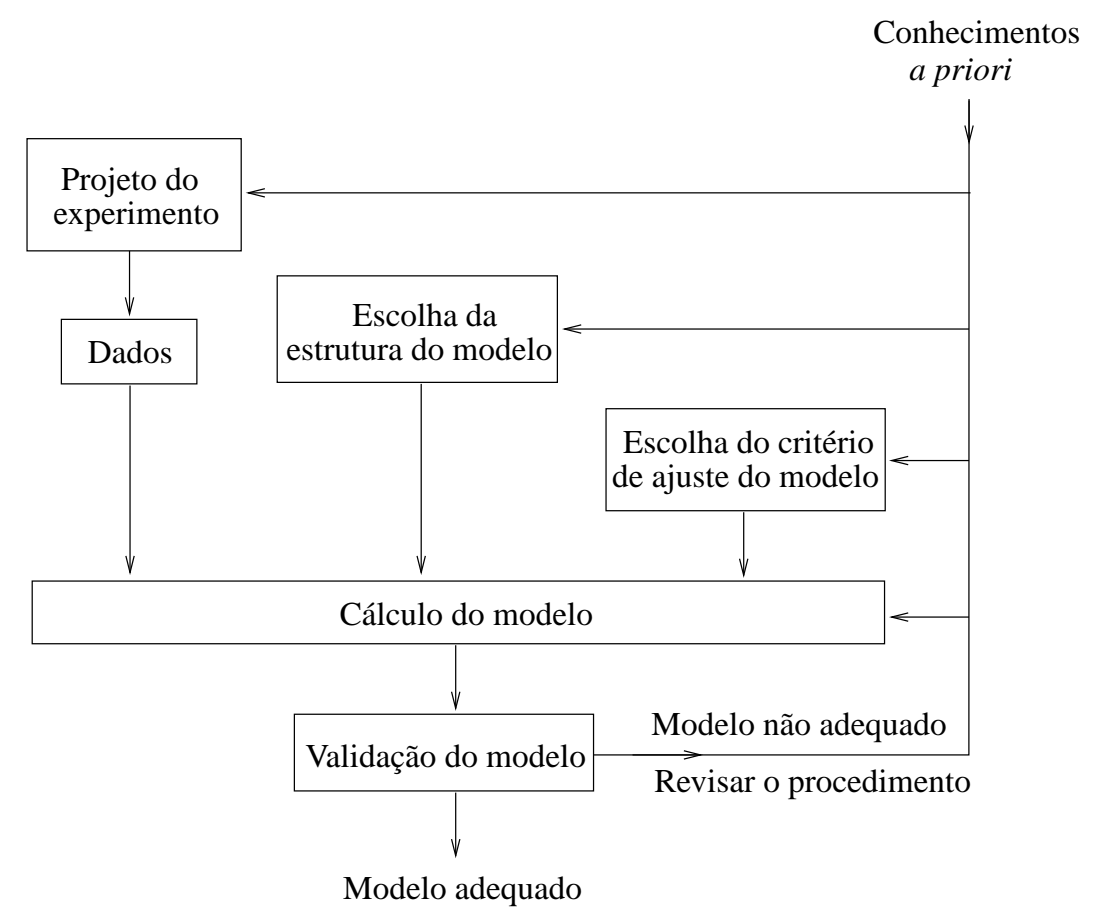

Figura 1.1: Fluxograma do procedimento de identificação de sistemas (LJUNG, 1999).

Os principais aspectos da identificação de sistemas são descritos abaixo em linhas gerais, como em (LJUNG, 1999), (ZHU, 2001) e (AGUIRRE, 2007):

- Projeto do experimento. Vários aspectos do procedimento de identificação de um sistema envolvem decisões e escolhas subjetivas (AGUIRRE, 2007) (LJUNG, 1999). Escolher quais e quantas variáveis irão compor o modelo não é uma tarefa óbvia. Evidentemente, se não houver nenhuma relação de causa e efeito entre as variáveis, não é justificável a obtenção de um modelo. Deve-se notar 
que variáveis correlacionadas não implicam necessariamente em uma relação causa e efeito. A função de correlação cruzada apresenta-se como uma ferramenta capaz de determinar se há correlação significativa entre duas variáveis candidatas a compor um modelo. Existem outras ferramentas mais elaboradas para avaliar correlações de variáveis: decomposição em valores singulares (singular value decomposition, SVD), análise em componentes principais (principal components analysis, PCA) e outras (AGUIRRE, 2007) (BACCALá; SAMESHIMA; VALLE, 1998).

- Testes dinâmicos e coleta de dados, também chamados de teste de identificação ou ainda experimento de identificação. A modelagem empírica se propõe a obter modelos a partir de dados. Assim, torna-se necessário obter os dados de operação normal do sistema ou, quando possível e desejável, efetuar testes de forma a extrair informação dinâmica nessa condição. Os problemas e desafios mais importantes relacionados a essa etapa são: a seleção (ou projeto) dos sinais de excitação e a execução do teste.

- Escolha da representação matemática a ser usada. É comum utilizar representações em tempo discreto. Os sistemas reais possuem inúmeras fontes de incerteza, necessitando assim, que os modelos lidem com variáveis aleatórias que são facilmente simuladas por sequências numéricas discretas geradas por computador. A modelagem em tempo contínuo exige outros cuidados, como evitar a estimação de derivadas visando não amplificar o ruído existente nos dados, originalmente (e inerentemente) presente no sinal medido, ou utilizar dados após criteriosa filtragem.

- Determinação da estrutura e da ordem do modelo. No caso de sistemas lineares, a escolha da estrutura e da ordem limita-se, basicamente, à escolha do número de polos e de zeros e do atraso puro de tempo, também conhecido como tempo morto. É reconhecido que, nessa etapa, o conhecimento a priori do sistema e dos fenômenos envolvidos, bem como a intuição combinadas com as propriedades matemáticas formais dos modelos são importantes para uma satisfatória determinação da estrutura do modelo.

- Estimação de parâmetros (ou cálculo do modelo). Nessa etapa, os parâmetros do modelo serão estimados. Inicialmente, escolhe-se o algoritmo de estimação de parâmetros. Os algoritmos mais utilizados são os de mínimos quadrados (MQ) e suas variantes, visto que comumente é satisfatório assumir que a representação escolhida no item anterior é linear nos parâmetros. 
- Validação do modelo. O modelo ou a família de modelos são os produtos finais da identificação. Esses necessitam ser validados para a aplicação que motivou sua construção. Assim, torna-se necessário saber como o modelo será utilizado para, então, julgar se ele incorpora, ou não, aquelas características do sistema real que são fundamentais para a aplicação em questão. Por exemplo, se um modelo foi obtido com a finalidade de fazer predições, então ele será válido se a soma dos quadrados dos erros do preditor, dada uma determinada quantidade de passos à frente de acordo com a aplicação, for suficientemente pequena. Uma vez que o modelo não é aceito dado o procedimento de validação adotado, é necessário revisar os passos do procedimento de identificação, que pode ser deficiente em vários aspectos: o conjunto de dados não é informativo o suficiente para a estimação de parâmetros do modelo, a estrutura e ordem do modelo não são adequadas para descrever as características necessárias para sua aplicação, problemas numéricos não permitem que o método adotado de ajuste do modelo obtenha resultados satisfatórios, etc.

A etapa prévia ao processo de identificação de sistemas, na qual obtém-se conhecimentos prévios ou preliminares do sistema (conhecimentos a priori) também pode se assemelhar de um experimento, porém, simplificado. A seção 3.2 descreve sucintamente tal etapa.

Na indústria de processos, testes de identificação são realizados comumente, por necessidade, com a planta em operação normal. Interromper a operação normal da planta significa prejudicar a produção daquela indústria. Assim, esse procedimento deve (RIVERA et al., 2009):

- Manter os desvios nas saídas da planta dentro de uma faixa controlada de forma a garantir sua operação segura e ocasionar o menor prejuízo (ou a menor possibilidade de prejuízo) quanto a variabilidade na qualidade do produto;

- O experimento deve ter curta duração de forma a minimizar as horas de engenharia e a quantidade de (ou a possibilidade de gerar) produtos fora de especificação;

- Manter as movimentações dos atuadores dentro de limites para não sobrecarregar os equipamentos de processos.

Esses cuidados derivam do conceito de identificação "amiga da planta" (plantfriendliness) (PEARSON; OGUNNAIKE; DOYLE, 1993).

Realizar uma identificação plant-friendliness significa promover experimentos suficientemente informativos sujeitos às restrições práticas que desencorajam os proce- 
dimentos extensos e que interrompem a produção da planta (RIVERA et al., 2003). No contexto da identificação de sistemas, dizer que um experimento é suficientemente informativo significa que esse gera um conjunto de dados com informações suficientes para a necessidade de modelagem (LJUNG, 1999). Conforme (RIVERA et al., 2003), o termo plant-friendliness apareceu pela primeira vez em texto escrito em (PEARSON; OGUNNAIKE; DOYLE, 1993).

A identificação de sistemas dinâmicos é uma atividade tratada com critério nas áreas de simulação de sistemas, predição e controle de processos. A qualidade dos dados gerados, ou obtidos, durante um experimento é vital para o sucesso da identificação do sistema. Conforme já mencionado, um dos problemas e desafios mais importantes relacionados à identificação de sistemas e, especificamente, à etapa de teste dinâmicos na planta é a escolha (ou projeto) dos sinais de excitação. A escolha adequada do sinal de excitação é fundamental para a identificação plant-friendliness.

O modelo empírico é obtido dos dados de teste do sistema. As propriedades que não estiverem representadas nos dados não poderão ser identificadas. As características dinâmicas e estáticas que não forem excitadas não aparecerão nos dados. Assim, a qualidade do modelo empírico está intimamente ligada à escolha adequada do sinal de excitação. Essa característica da modelagem empírica permite obter vantagens, como por exemplo, obter modelos lineares aplicáveis a determinadas faixas de operação de um sistema não linear. Um sistema não linear pode ser excitado em uma faixa linear em torno de seu ponto de operação. Assim, como as não linearidades não foram excitadas no teste, é possível ajustar um modelo linear aos dados obtidos.

Na literatura, há diversos métodos de projetos de sinais de excitação apropriados para identificação de dinâmicas de processo $^{2}$. Esses sinais são utilizados pela indústria para obtenção de modelos empíricos apropriados para controle preditivo, o qual no meio industrial é conhecido como um tipo de controle avançado, termo empregado para diferenciar do controle clássico regulatório realizado por controladores proporcional integral derivativo (proportional-integral-derivaive controller, PID controller). A próxima seção apresenta o histórico e panorama atual das técnicas de controle avançado aplicáveis à indústria de processos.

Este trabalho concentra-se na etapa de projeto do experimento, especificamente no projeto de sinais de excitação. As demais etapas da identificação também estarão no texto deste trabalho, pois estão inter-relacionadas conforme a figura 1.1. Porém, serão tratadas superficialmente.

\footnotetext{
${ }^{2}$ Um processo é uma planta de processamento (ZHU, 2001).
} 


\subsection{Controle na indústria de processos}

O mercado de derivados de petróleo é reconhecidamente dinâmico e inconstante, principalmente no aspecto dos preços dos produtos. Essa característica é devida, em grande parte, às variações de preço do petróleo (óleo crú) no mercado internacional. A demanda energética atual e a qualidade variável do petróleo, que impacta no custo e qualidade dos produtos derivados, impõem as variações de preço do petróleo (JR.; MOTTA, 2005) (SOUZA, 2007) (EPE, 2007). Essas características econômicas aliadas à concorrência no mercado de derivados exige da indústria de refino restrições operacionais cada vez mais severas (PROSDOSSIMO, 2003). Com a finalidade de se obter produtos com qualidade e custo competitivos, a indústria de refino tem buscado técnicas e procedimentos que visam (ZANIN; NETO; MORO, 2002):

- Melhoria na qualidade dos produtos;

- Aumento no rendimento de produtos mais nobres, ou seja, de maior valor agregado;

- Aumento da capacidade de produção da planta;

- Economia no consumo de energia, ou seja, processos mais eficientes energeticamente.

além de manter em níveis aceitáveis os aspectos de segurança da planta aos operadores e ao meio ambiente.

Devido ao avanço tecnológico das áreas de processamento digital de sinais, ao desenvolvimento da instrumentação industrial, à disseminação de sistemas de controle digital e às restrições mais estreitas de operação segura e lucrativa das plantas, estratégias clássicas de controle passaram a ser complementadas com estratégias avançadas (MORO, 1992). Nessa evolução, são aplicadas técnicas de controle adaptativo e preditivo, por exemplo, os quais necessitam de modelos do processo simples em estrutura, robustos, unicamente identificáveis e possíveis de serem atualizados on line (LARA, 2005). Adicionalmente, (GENTILIN, 2004) destaca que uma das principais características para o sucesso do sistema de controle avançado de processos é a sua capacidade de operar por um longo período de tempo sem necessidade de intervenção de um especialista, apresentando condições de estabilidade desejáveis, além de possibilitar uma abordagem geral para a solução do problema de controle.

A indústria de processos, tipicamente é composta de sistemas não lineares, multivariáveis, variantes no tempo, possuem consideráveis atrasos de transporte e diversas 
restrições que não devem ser violadas, mas que, conforme (PRETT; GILLETTE, 1980), determinam o ponto de operação ótimo. Adicionalmente, cada planta de processo possui características únicas, tornando custosa a obtenção de modelos para tais sistemas a partir de uma abordagem rigorosa das leis físicas e químicas (modelagem fenomenológica), além da complexidade do processo que também dificulta tal modelagem (QIN; BADGWELL, 2002). Esse cenário propiciou o desenvolvimento de modelos mais abrangentes (genéricos) no qual a solução do problema de controle seria calculada (ou atualizada) periodicamente, ou seja, durante a execução (on line). Assim, o modelo pode ser ajustado para as características peculiares de uma determinada planta industrial.

Essa abordagem de controle utiliza um modelo explícito do processo que, em princípio, pode assumir qualquer formulação matemática. As restrições das variáveis de entrada e saída são avaliadas e predições futuras de violação de restrição, dentro de um limite de tempo chamado horizonte de predição, são calculadas permitindo que o controlador atue antecipadamente e preventivamente no processo. Tais cálculos são atualizados periodicamente com base em medidas das variáveis de processo, também atualizadas. Para oferecer à industria maior flexibilidade para implementação dessa técnica de controle, foram aprimoradas também as metodologias de modelagem empírica da dinâmica do sistema (identificação de sistemas), as quais contribuíram para a redução de custo de implementação de tal técnica de controle. Esse método de controle avançado aplicável à indústria de processos chama-se, hoje, controle preditivo por modelos (model predictive control, MPC) (QIN; BADGWELL, 2002). Em (RAWLINGS, 2000) é apresentado um tutorial voltado às práticas de MPC.

Em plantas de processamento modernas, o controlador MPC é apenas uma parte de hierarquia (um nível) de funções de controle. A figura 1.2 apresenta a hierarquia convencional e moderna de controle, conforme as descrições em (RICHALET et al., 1978) (QIN; BADGWELL, 2002). O topo da estrutura é um otimizador de planta inteira, o qual determina os ajustes em regime permanente para cada uma das unidade de processamento inter-relacionadas e pertencentes à planta. Cada unidade de processamento também possui otimizadores locais que executam os cálculos (atualizações) dos ajustes em período menor, utilizando modelos mais elaborados que, devido à maior complexidade, não são possíveis de serem implementados no otimizador de planta inteira. Os otimizadores locais calculam ajustes para a manutenção do estado permanente ótimo do ponto de vista econômico. Esses ajustes, por sua vez, são enviados aos controladores da dinâmica do processo que objetivam atuar antecipadamente e preventivamente às violações futuras de restrições. Na estrutura convencional, tal controle é realizado com controladores PID, lógicas de seleção de maior e menor e blocos antecipatórios ou 
de retardo (lead-lag blocks, LL blocks). Há inúmeras restrições de implementação de tal controle com algoritmos convencionais, como por exemplo: limitações de tempomorto para ações antecipatórias e de sintonia agressiva, as quais limitam o desempenho do nível de controle dinâmico da hierarquia. Na hierarquia moderna de controle, esse conjunto de blocos de controle convencional é substituído por um controlador MPC (QIN; BADGWELL, 2002). O controle regulatório é realizado para qualquer uma das estruturas por meio de controladores PID, os quais são implementados em sistemas de controle distribuídos (distributed control systems, DCS), os quais são sistemas digitais configuráveis pelo usuário (BEGA, 2006). A figura 1.2 representa o controle regulatório por meio dos blocos: controles de vazão (flow control, FC), controle de pressão (pressure controler, PC), controle de temperatura (temperature control, TC) e controle de nível (level control, LC).

Apesar do desenvolvimento do MPC ter sido alavancado pela indústria, a ideia de controlar sistemas por meio de soluções de problemas dinâmicos de otimização já havia sido discutida em (PROPOI, 1963), conforme (QIN; BADGWELL, 2002). O conceito de controle avançado inciou-se com os trabalhos de Kalman na década de 60 (KALMAN, 1960a) (KALMAN, 1960b) com o controlador conhecido como controlador LQG (linear quadratic Gaussian controller, LQG controller). As principais razões para o LQG não ter sido difundido na indústria de processos descritas são (RICHALET et al., 1976) (GARCíA; PRETT; MORARI, 1989): dificuldade de incorporar as restrições; as não linearidades do sistema; as incertezas do modelo, o que implica em pouca robustez; etc.

A primeira aplicação do MPC na indústria foi apresentada em (RICHALET et al., 1976). Essa foi conhecida como controle heurístico preditivo por modelos (model predictive heuristic control, MPHC) devido à regra (ou lei) de controle não ser linear e não ser expressa por uma função de transferência. O software que implementa tal técnica foi chamado de IDCOM, uma sigla para identificação e comando (identification and command, IDCOM). A relação entre as variáveis de entrada, saída e variáveis internas, ou variáveis manipuladas (manipulated variables, MV), variáveis controladas (controlled variables, CV) e variáveis de perturbação (disturbance variables, DV), respectivamente, são representadas por um modelo de resposta impulsiva finita (finite impulse response, FIR). Tal modelo é obtido por meio de dados de testes (experimentos) realizados com a planta e um algoritmo para ajustar os parâmetros do modelo. O MPHC aplica ações de controle de forma a ajustar a trajetória futura predita para a variável de saída em questão à trajetória de referência, a qual é definida como um caminho de primeira ordem entre o valor de saída atual e o ponto (ou valor) de ajuste (set point, SP) desejado. A trajetória futura, a trajetória de referência, os valores de saída 
Estrutura convencional

Estrutura baseada em MPC

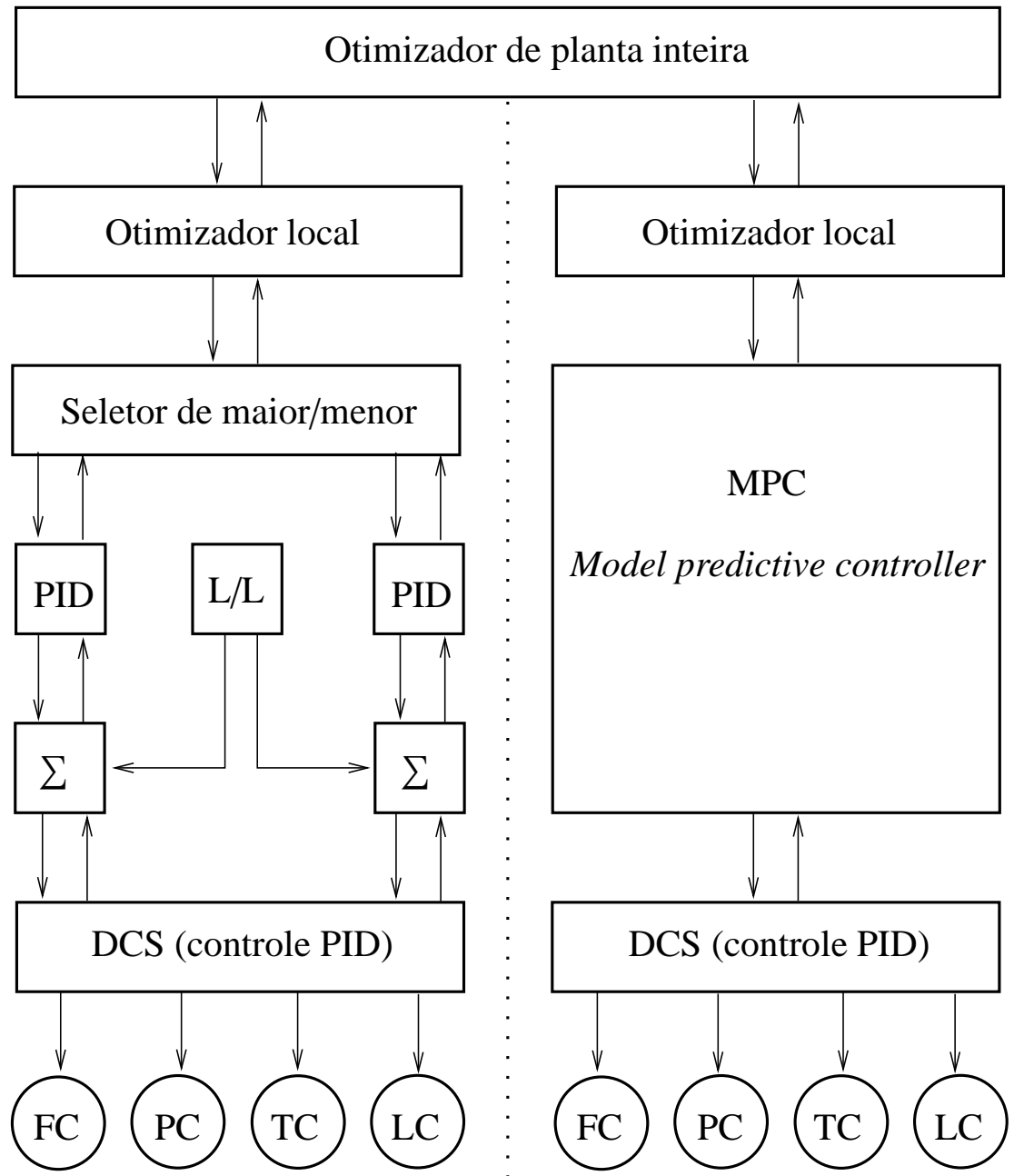

Figura 1.2: Representação das hierarquias de controle: a estrutura convencional e a estrutura baseada em MPC (RICHALET et al., 1978) (QIN; BADGWELL, 2002).

atual, os valores de ajuste e as ações de controle são todas atualizadas periodicamente dado um horizonte de controle e de predição finitos e previamente determinados. $\mathrm{O}$ horizonte de predição representa quantos instantes de tempo (períodos de cálculos) futuros estão sendo considerados para prever o comportamento do sistema para um determinado conjunto de ações definidas pelo horizonte de controle (BEQUETTE, 2003). O benefício do MPC não é simplesmente o fato de reduzir as amplitudes das variações das CV devido à dinâmica do sistema, mas permitir que o nível de otimização local (na hierarquia de controle, figura 1.2) conduza os set points das variáveis controladas mais próximos das restrições sem violá-las, maximizando os benefícios econômicos. Em (RICHALET et al., 1976), o MPHC foi aplicado a uma unidade de craqueamento catalítico fluido (fluid catalytic cracking, FCC), uma planta de geração de energia a 
vapor e uma planta de cloreto de polivilina (poly-vinyl chloride, PVC).

Cutler e Ramaker, engenheiros da Shell Oil segundo (QIN; BADGWELL, 2002), nos trabalhos (CUTLER; RAMAKER, 1979) e (CUTLER; RAMAKER, 1980), apresentaram algoritmos de controle sem restrições que chamaram de controle por matriz dinâmica (dynamic matrix control, DMC). Em (PRETT; GILLETTE, 1980) foi descrita a aplicação do DMC ao conjunto reator regenerador de uma unidade de FCC. Nesta aplicação, o algoritmo foi modificado para manipular não linearidades e restrições. O objetivo do controlador DMC é encaminhar a saída o mais próximo possível do set point, minimizando o erro quadrático por meio de penalizações nas variáveis manipuladas (MV). Assim como o IDCOM, a trajetória de referência do DMC provê robustez no tratamento do erro. Cutler e Ramaker, os desenvolvedores do DMC, demonstraram os ganhos da aplicação do DMC no controle de temperatura de um forno em comparação a um PID convencional.

O ponto fraco do IDCOM e DMC, que é a manipulação de variáveis sem restrições, foi solucionado pelo método descrito em (CUTLER; MORSHEDI; HAYDEL, 1983). Chamado de QDMC, tal método diferencia-se do DMC pela utilização de uma programação quadrática (motivo da letra “Q” precedendo a sigla DMC) como técnica de otimização, o que permite que as restrições de entrada e saída apareçam explicitamente (QIN; BADGWELL, 2002).

A limitação do QDMC vem, principalmente, do fato de como o controle deve tratar uma perturbação que recai em um problema de otimização inviável, ou seja, um problema não convexo para a programação quadrática. Na prática, por exemplo, perturbações podem ser variáveis de entrada ou saída do sistema medidas com erros devido falhas de hardware ou variáveis em valores saturados devido uma intervenção de emergência por parte do operador.

Uma forma de contornar esse problema é relaxar as restrições, por exemplo, permitindo que algumas restrições possam ser violadas dependendo do seu peso na função objetivo. Engenheiros da Adersa, Setpoint Inc. e Shell da França desenvolverem uma nova versão de MPC. A versão comercial da Setpoint Inc. foi chamada de IDCOMM e apresentada pela primeira vez em (GROSDIDIER; FROISY; HAMMANN, 1988). Essa versão implementava um algoritmo de controle multivariável, ou seja, os modelos eram de múltiplas entradas e múltiplas saídas (multiple inputs and multiple outputs, MIMO). Assim, a letra "M" do nome comercial IDCOM-M diferencia o algoritmo do antigo IDCOM, o qual utilizava modelos de entrada única e saída única (single input and single output, SISO). A versão comercial da Adersa foi chamada de controle hierárquico com restrições (hierarchical constraint control, HIECON). A principal diferença do algo- 
ritmo IDCOM-M é o uso de duas funções objetivo: uma para as variáveis de saída e outra para as variáveis de entrada (QIN; BADGWELL, 2002). Em (GROSDIDIER; FROISY; HAMMANN, 1988), foi apresentado o desempenho do IDCOM-M no controle multivariável de um conjunto reator-regenerador de uma planta de craqueamento catalítico fluido (FCC).

Engenheiros da Setpoint Inc. aprimoraram seu produto IDCOM-M combinandoo com ferramentas de identificação, simulação, configuração e controle em um único produto chamado de arquitetura de controle multivariável da Setpoint (Setpoint Multivariable Control Architecture, SMCA). Analogamente, engenheiros da Shell da França, no final da década de 1980, desenvolveram o controlador por otimização multivariável da Shell (Shell Multivariable Optimizing Controller, SMOC) (QIN; BADGWELL, 2002). Posteriormente, sugiram diversos produtos de tecnologia MPC. Por exemplo, a Honeywell e Profimatic se uniram e lançaram o RMPCT (resultado da junção do algoritmo RMPC da Honeywell com o algoritmo PCT da Profimatics), a Aspen Technology Inc. fundiu-se com a Setpoint Inc. e com a DMC Corporation desenvolvendo o produto DMC-plus, o qual foi resultado da junção das tecnologias (QIN; BADGWELL, 2002).

No Brasil, em 1991, a Petrobras implementou, com tecnologia própria, seu primeiro controlador preditivo multivariável em um complexo forno de destilação a vácuo da Refinaria Presidente Bernardes de Cubatão (RPBC). Em 1993, outros dois controladores preditivos multivariáveis foram comissionados: o sistema reator-regenerador da unidade de craqueamento catalítico em leito fluidizado (FCC) da Refinaria do Vale do Paraíba (REVAP) em São José dos Campos e uma fracionadora de petróleo da Refinaria de Paulínia (REPLAN) (MORO, 1997) (ZANIN; GOUVêA; ODLOAK, 2002).

Das diversas tecnologias de MPC apresentadas, observa-se, em geral, que os objetivos de um controlador MPC, em ordem de importância, são (QIN; BADGWELL, 2002):

1. Prevenir violações das restrições das variáveis de entrada e saída do sistema;

2. Conduzir as variáveis controladas para seus valores de estado permanente ótimos;

3. Usando os graus de liberdade remanescentes, conduzir as variáveis manipuladas para seus valores de estado permanente ótimos;

4. Prevenir o movimento excessivo das variáveis manipuladas;

5. Quando um sinal (medida) ou um atuador falhar, manter o desempenho de controle da planta o melhor possível. 
Os produtos comerciais de tecnologia MPC diferem-se tecnicamente, principalmente na modelagem da planta que eles utilizam (QIN; BADGWELL, 2002). A próxima seção aborda de forma resumida técnicas de modelagem utilizadas nos produtos comerciais que implementam MPC. Há pouca informação disponível sobre o desenvolvimento de tecnologias de identificação aplicada à indústria quando comparada à literatura técnica disponível sobre algoritmos de controle (QIN; BADGWELL, 2002).

\subsection{Modelagem para as técnicas atuais de controle}

Tanto a modelagem empírica como a modelagem analítica e a modelagem caixa cinza estão disponíveis em produtos comerciais. A grande vantagem de um modelo analítico sobre o modelo empírico é a possibilidade de aplicá-lo em condições de operações diferentes das condições do teste da planta utilizado para a modelagem empírica. Porém, conforme mencionado na seção 1.1, ainda nos modelos analíticos pode ser necessário estimar alguns parâmetros para ajustá-lo a cada faixa de operação da planta. A desvantagem do modelo analítico é o custo de desenvolvimento e a complexidade que pode inviabilizar seu uso, por exemplo, muitos parâmetros a serem estimados ou medidos. Assim, a modelagem caixa cinza torna-se atrativa para MPC aplicado à indústria: um modelo analítico pode ter seus parâmetros ajustados de acordo com um conjunto de dados de testes da planta ou um modelo empírico pode ser ajustado considerando algum fenômeno físico que envolve o processo. Em geral as ferramentas comerciais de identificação de sistemas para MPC utilizam modelos lineares empíricos, não lineares empíricos e não lineares analíticos, sendo que muitos são derivados de modelos não lineares em espaço de estados e tempo contínuo (QIN; BADGWELL, 2002).

Um modelo de uma planta degrada-se com o decorrer do tempo, ou seja, com o passar do tempo há mudanças na dinâmica da planta ou na ocorrência de distúrbios não medidos. As mudanças podem ser resultado de alterações nas condições operacionais ou especificações dos produtos, por exemplo. Os distúrbios mais comuns são: mudanças climáticas (pressão, umidade e temperatura ambiente), variabilidade e impurezas das entradas ou problemas em sistemas periféricos. Essa degradação do modelo faz com que o erro de predição do modelo aumente, prejudicando o desempenho do MPC. Para recuperar a boa predição do modelo, é necessário refazer parcialmente ou totalmente, dependendo do grau de degradação do modelo, o processo de identificação. Essa atividade de manutenção do MPC é conhecida como re-identificação e pode ser um processo periódico, dada a periodicidade da degradação do modelo.

Os modelos analíticos utilizados pelo algoritmo NOVA-NLC da empresa DOT Products são derivados das equações de balanço de massa e energia. Os parâmetros 
não conhecidos como coeficientes de transferência de calor ou de reações cinéticas são estimados previamente a partir de dados resultantes de testes da planta ou on-line usando filtro de Kalman extendido (extended Kalman filter, EKF) (QIN; BADGWELL, 2002). As aplicações típicas de modelagem de processos industriais podem ser compostas de 10 a 100 equações algébricas.

Para implantação de MPC, softwares comerciais de modelagem empírica disponibilizam como sinal de excitação a opção de sinal binário pseudo-aleatório (pseudorandom binary signal, PRB signal) (LJUNG, 1999) ou excitações em degrau com amplitudes variadas. Exemplos desses softwares são: DMC plus Model da empresa Aspen (ASPEN, 2011), RMPCT (Robust Multivariable Predictive Control Technology) da Honeywell (HONEYWELL, 2010), Connoisseur da Invensys (INVENSYS, 2010), AIDA (Advanced Identification and Data Analysis) da Yokogawa \& Shell (YOKOGAWA; SHELL, 1999), GLIDE da Adersa (QIN; BADGWELL, 2002) e Tai-Ji ID da Tai-Ji Control (TAI-JI, 2011).

O software de identificação GLIDE utiliza um sinal binário no qual os intervalos entre as transições são otimizados de acordo com as características da planta sob teste. Em (QIN; BADGWELL, 2002) não são reveladas mais características sobre esse sinal, porém, neste trabalho, será estudado o sinal ruído binário generalizado (generalized binary noise, GBN), para o qual podem ser ajustadas as transições de acordo com a resposta em frequência desejada. O software Tai-Ji ID disponibiliza o sinal GBN para os experimentos de identificação (ZHU, 2003).

Além de softwares comerciais de identificação, proprietários de plantas de processamento também tem desenvolvido softwares para identificação de suas próprias unidades. Por exemplo, a Statoil, empresa de energia internacional de origem norueguesa, desenvolveu o software SEPTIC (Statoil Estimation and Prediction Tool for Identification and Control). Em (STRAND; SAGLI, 2003), são relatadas as vantagens do desenvolvimento do software pelo proprietário da planta (in-house technology), a Statoil, sendo as principais: o baixo custo do software, de sua implantação em MPC e o acúmulo de conhecimento pela empresa para desenvolvimento de novos projetos visando melhoria contínua.

Há outras dezenas de propostas na literatura de métodos de construção de sinais de excitação pouco difundidas e não disponíveis em softwares comerciais de identificação. Alguns deles são pequenas variações de propostas mais antigas, outros generalizações de métodos conhecidos e alguns com aplicabilidade específica, como identificação de não linearidades em sistemas. Porém, os resultados obtidos com a aplicação desses vários sinais disponíveis na literatura ainda são pouco difundidos. 
Os modelos a serem ajustados disponíveis pelas ferramentas comerciais quase sempre incluem o modelo FIR (QIN; BADGWELL, 2002). Além do FIR, o software DMC plus possui a opção de identificação em subespaço (subspace ID, SMI) (ASPEN, 2011); o RMPCT disponibiliza a modelagem Box-Jenkins (BJ) (BOX; JENKINS, 1994) (QIN; BADGWELL, 2002); o Connoisseur permite modelar a planta utilizando vários tipos de modelos (multi-model, MM) (QIN; BADGWELL, 2002), incluindo modelo autoregressivo com entradas exógenas (auto-regressive with exogenous input, ARX) e redes reuronais (INVENSYS, 2010); o AIDA disponibiliza modelagens paramétricas, caixa cinza e redes neuronais (YOKOGAWA; SHELL, 1999) (YOKOGAWA, 2007); Tai-Ji ID utiliza modelos ARX, identificação no domínio da frequência e BJ (ZHU, 2003).

Antes de executar o teste da planta, um teste preliminar, chamado de pré-teste, pode ser necessário para perturbar cada uma das MV e ajustar os instrumentos e os controladores PID, obter o tempo de acomodação (tempo para atingir o estado estacionário (OGATA, 2003) de cada CV e obter demais dados (informações a priori) para uma identificação preliminar (QIN; BADGWELL, 2002).

Dependendo do número de variáveis de processos da unidade e suas características dinâmicas, a etapa de testes de identificação pode levar até 15 dias (QIN; BADGWELL, 2002). Durante o teste, as sintonias dos controladores PID não podem ser alteradas, porém, os operadores podem atuar manualmente na planta para evitar situações críticas para a segurança que não foram previstas e/ou contornadas na etapa de planejamento do teste. Experimentos com excitações de múltiplas entradas (MV) e observação de múltiplas saídas (CV) e a posterior identificação de modelos MIMO é chamada de identificação multivariável. Ela tem como principal objetivo reduzir a duração do teste. Assim, minimizam-se as horas de engenharia e a quantidade de (ou a possibilidade de gerar) produtos fora de especificação, conforme o conceito de identificação plantfriendliness, além de minimizar a possibilidade de ocorrer alterações na planta durante o teste que inviabilizem posteriormente o ajuste do modelo.

\subsection{Motivação e objetivos do trabalho}

A motivação para o desenvolvimento deste trabalho decorre da observação da lacuna existente entre as complexas teorias de sinais e os requisitos práticos para a identificação de plantas de processamento (identificação plant-friendliness). Como citado na seção 1.3, a maioria dos pacotes de softwares comerciais utilizam sinais triviais nos experimentos de identificação, fazendo com que haja poucos resultados difundidos da aplicação de outros sinais cujos métodos de construção são, em geral, mais complexos que os dos tradicionais sinais pseudo-aleatórios binários (PRB). Dada 
a diversidade de propostas de projeto de sinais de excitação encontradas na literatura e a relevância deles no processo de identificação multivariável e implantação do controle preditivo baseado em modelos (MPC) em plantas de processamento, este trabalho visa fornecer contribuições a essa área de conhecimento.

Conforme discutido na seção 1.1, uma das principais restrições impostas pela identificação plant-friendliness em relação à aplicação de sinais de excitação em plantas em operação é relativa ao período disponível para o experimento de identificação. Assim, para o bom uso desse período, faz-se necessário garantir o sucesso de um experimento previamente à sua realização.

Os objetivos principais deste trabalho são: avaliar comparativamente vários métodos de construção de sinais de excitação disponíveis na literatura para identificação multivariável com respeito à identificação plant-friendliness, propor aprimoramentos de alguns métodos e desenvolver avaliações de conjuntos de sinais de excitação que auxiliem a seleção adequada de conjuntos, dadas características da planta.

Resumidamente, dado um conjunto de características da planta conhecidas previamente (informaçãoes a priori), tem-se como objetivo selecionar um conjunto de sinais com características em conformidade com o conceito de identificação plantfriendliness.

Para atingir os objetivos expostos, ao longo do trabalho haverá:

1. Estudo das técnicas já estabelecidas de projeto de sinais de excitação de maneira padronizada de forma a permitir comparar as características dos sinais (período do sinal, amplitudes máximas e mínimas, forma do espectro de potência, propriedades de correlações, etc) gerados por meio de cada uma delas.

2. Aprimoramento dessas técnicas. Com o estudo dos método de projeto de sinais de excitação são identificadas oportunidades de aprimoramentos. São propostos três novos métodos de construção de sinais de excitação para identificação multivariável.

3. Estudo de medidas para avaliação (ou índices de desempenho) de sinais de excitação, as quais auxiliam a seleção de sinais para o experimento de identificação.

4. Desenvolvimento de novos índices de desempenho de conjuntos de sinais de excitação. Os índices propostos neste trabalho apresentam maior correlação com a qualidade do modelo (validação do modelo). 
5. Elaboração de um quadro comparativo dos métodos de projeto de sinais de excitação. A comparação será baseada nas características dos sinais de excitação e de seus métodos de construção. Esse estudo comparativo auxilia a seleção e parametrização adequada dos sinais de excitação dada características da planta.

6. Implementação de um conjunto de códigos em software MATLAB $®$ que possibilita: gerar sinais utilizando os métodos de projeto de sinais e calcular os índices de desempenho de sinais discutidos neste trabalho, formando uma completa ferramenta (toolbox) para estudo de sinais de excitação para identificação de plantas de processamento.

7. Avaliação dos sinais de excitação discutidos neste trabalho por meio de simulações de identificação de plantas típicas de refinarias de petróleo. As simulações também permitem avaliar a efetividade dos índices de desempenho de sinais de excitação discutidos aqui. Foram escolhidas para simulações um conjunto reator-regenerador de uma unidade de craqueamento catalítico em leito fluidizado (FCC) e uma coluna de destilação de alta pureza. Essas plantas tem características distintas que permitem avaliar os vários métodos de projeto de sinais de excitação discutidos neste trabalho. A planta de FCC possui várias variáveis (seis MV e sete CV) e a planta de destilação apenas quatro (duas MV e duas $\mathrm{CV})$, porém, possui a característica de direcionalidade de ganho ${ }^{3}$.

\subsection{Estrutura do trabalho}

No capítulo 1 descreveu-se os conceitos básicos que envolvem modelagem e identificação de sistemas, bem como de sinais de excitação. Foi feita uma breve apresentação do controle preditivo baseado em modelos (MPC) e das ferramentas de modelagem utilizadas comumente em plantas de processamento.

O capítulo 2 discute o projeto ótimo de sinais de excitação, o qual é possível quando se conhece o modelo nominal da planta. Apesar de contraditório com o objetivo da identificação, a partir de conceitos de projeto ótimo, no capítulo 3, são obtidos critérios para o projeto de sinais de excitação quando há pouco conhecimento da planta.

O capítulo 3 irá descrever cada uma das características relevantes do sinal de excitação, do ponto de vista de identificação, e como elas estão relacionadas com as informações a priori viáveis de serem obtidas da planta. O objetivo desse capítulo é, ao

\footnotetext{
${ }^{3}$ Direcionalidade de ganho (gain directionality) é um termo utilizado para descrever combinações das entradas do sistema que conduzem as saídas a variações de alta magnitude ou baixa magnitude (CONNER; SEBORG, 2004).
} 
final, listar as características desejáveis para os sinais de excitação para identificação de plantas de processamento.

Visando avaliar os sinais de excitação previamente à identificação, o capítulo 4 discute os índices de desempenho de sinais de excitação encontrados na literatura. Nesse capítulo, também é apresentada uma nova proposta de índice de desempenho baseado na aderência a critérios de projeto de sinais discutidos no capítulo 3 .

Os métodos de projeto de sinais de excitação são discutidos no capítulo 5. A discussão é restrita a métodos encontrados na literatura. Os detalhes de cada um deles são abordados com a profundidade necessária para que sejam implementados em códigos de computador. Nesse capítulo são apresentados alguns exemplos de parametrização de sinais de excitação dadas as características de uma planta (informações a priori).

As oportunidades de aprimoramentos dos métodos de projeto de sinais de excitação estudados no capítulo 5 são apresentadas no capítulo 6. Nesse capítulo são propostos dois métodos de construção de sinais de excitação para identificação multivariável de plantas de processamento.

O capítulo 7 deste trabalho reúne os sinais estudados aqui em um quadro comparativo, considerando as características dos sinais. A comparação, além de avaliar as características dos sinais é uma referência para a seleção de sinais que é discutida posteriormente no capítulo 9.

O estudo de caso de identificação multivariável de uma coluna de alta pureza, a qual apresenta a característica de direcionalidade de ganho, é apresentado no capítulo 8. São simulados experimentos de identificação com cinco métodos de construção de sinais de excitação encontrados na literatura para identificação de plantas com a característica de direcionalidade de ganho. As qualidades dos modelos obtidos são comparadas entre si e também com índices de avaliação de sinais de excitação. Essa comparação permite avaliar a aderência dos índices. Ainda no capítulo 8 é proposto um novo índice para avaliação de sinais de excitação para identificação de plantas com característica de direcionalidade de ganho. Propõe-se também um método de construção de sinais de excitação para identificação de plantas com característica de direcionalidade de ganho que objetiva restringir as saídas da planta a limites preestabelecidos atendendo ao conceito de identificação plant-friendliness.

O procedimento de parametrização e seleção de sinais de excitação para identificação multivariável é resumido no capítulo 9. Nesse procedimento são referenciados os critérios de projeto, métodos de projeto e índices de desempenho de sinais de excitação discutidos nos capítulos anteriores. 
O capítulo 10 apresenta simulações de identificação do conjunto reator-regenerado do FCC. Nas simulações são utilizados 22 métodos de projeto de sinais de excitação discutidos nos capítulos anteriores. Os índices de desempenho de sinais de excitação discutidos no capítulo 4 também são avaliados. Os resultados das simulações permitem avaliar a adequabilidade dos projetos de sinais de excitação, inclusive as propostas apresentadas neste trabalho. A aderência dos índices de desempenho calculados para cada um dos sinais de excitação também é discutida comparativamente com a qualidade dos modelos obtidos.

Finalmente, no capítulo 11 são sintetizadas as principais conclusões deste trabalho. Propostas para continuidade deste trabalho também são apresentadas neste capítulo como trabalhos futuros.

Revisões bibliográficas que complementam discussões realizadas nos capítulos deste trabalho são apresentadas nos apêndices. Os anexos transcrevem textos de (KURAMOTO, 2005) elaborados com base em (MCELIECE, 1987), (GOLOMB, 1982) e (LIDL; NIEDERREITER, 1997), os quais são fundamentais para a compreensão das principais propriedades dos sinais construídos algebricamente. 


\section{Projeto de sinais de excitação}

Neste capítulo discute-se a incongruência do projeto ótimo de sinais de excitação. No sentido estrito, o projeto ótimo de sinais de excitação é possível somente quando se conhece o modelo nominal da planta. Neste trabalho, assume-se que haja conhecimentos da planta previamente ao experimento de identificação, porém, limitados. Esses conhecimentos prévios são discutidos na seção 3.2 e são chamados aqui de conhecimentos (ou informações) a priori. A discussão sobre o projeto ótimo de sinais apresentada neste capítulo fundamenta os critérios para projeto de sinais considerando apenas os conhecimentos a priori da planta, a serem discutidos no capítulo 3.

\subsection{Projeto ótimo de sinais de excitação}

Seja o sistema em tempo discreto (com período de amostragem $T$ ) MIMO linear causal e invariante no tempo, com $n_{r}$ entradas e $n_{p}$ saídas, representado pelas $n_{p}$ equações de diferenças a seguir (ZHU, 2001):

$$
\begin{aligned}
y_{1}(t)= & a_{1}(1) y_{1}(t-1)+a_{1}(2) y_{1}(t-2)+\ldots+a_{1}\left(n_{a, 1}\right) y_{1}\left(t-n_{a, 1}\right)+ \\
& +b_{1,1}(0) u_{1}(t)+b_{1,1}(1) u_{1}(t-1)+\ldots+b_{1,1}\left(n_{b, 1,1}\right) u_{1}\left(t-n_{b, 1,1}\right)+ \\
& +b_{1,2}(0) u_{2}(t)+b_{1,2}(1) u_{2}(t-1)+\ldots+b_{1,2}\left(n_{b, 1,2}\right) u_{2}\left(t-n_{b, 1,2}\right)+\ldots+ \\
& +b_{1, n_{r}}(0) u_{n_{r}}(t)+b_{1, n_{r}}(1) u_{n_{r}}(t-1)+\ldots+b_{1, n_{r}}\left(n_{b, 1, n_{r}}\right) u_{n_{r}}\left(t-n_{b, 1, n_{r}}\right) \\
y_{2}(t)= & a_{2}(1) y_{2}(t-1)+a_{2}(2) y_{2}(t-2)+\ldots+a_{2}\left(n_{a, 2}\right) y_{2}\left(t-n_{a, 2}\right)+ \\
& +b_{2,1}(0) u_{1}(t)+b_{2,1}(1) u_{1}(t-1)+\ldots+b_{2,1}\left(n_{b, 2,1}\right) u_{1}\left(t-n_{b, 2,1}\right)+ \\
& +b_{2,2}(0) u_{2}(t)+b_{2,2}(1) u_{2}(t-1)+\ldots+b_{2,2}\left(n_{b, 2,2}\right) u_{2}\left(t-n_{b, 2,2}\right)+\ldots+ \\
& +b_{2, n_{r}}(0) u_{n_{r}}(t)+b_{2, n_{r}}(1) u_{n_{r}}(t-1)+\ldots+b_{2, n_{r}}\left(n_{b, 2, n_{r}}\right) u_{n_{r}}\left(t-n_{b, 2, n_{r}}\right) \\
\vdots \quad & \\
y_{n_{p}}(t)= & a_{n_{p}}(1) y_{n_{p}}(t-1)+a_{n_{p}}(2) y_{n_{p}}(t-2)+\ldots+a_{n_{p}}\left(n_{a, n_{p}}\right) y_{n_{p}}\left(t-n_{a, n_{p}}\right)+ \\
& +b_{n_{p}, 1}(0) u_{1}(t)+b_{n_{p}, 1}(1) u_{1}(t-1)+\ldots+b_{n_{p}, 1}\left(n_{b, n_{p}, 1}\right) u_{1}\left(t-n_{b, n_{p}, 1}\right)+ \\
& +b_{n_{p}, 2}(0) u_{2}(t)+b_{n_{p}, 2}(1) u_{2}(t-1)+\ldots+b_{n_{p}, 2}\left(n_{b, n_{p}, 2}\right) u_{2}\left(t-n_{b, n_{p}, 2}\right)+\ldots+
\end{aligned}
$$




$$
+b_{n_{p}, n_{r}}(0) u_{n_{r}}(t)+b_{n_{p}, n_{r}}(1) u_{n_{r}}(t-1)+\ldots+b_{n_{p}, n_{r}}\left(n_{b, n_{p}, n_{r}}\right) u_{n_{r}}\left(t-n_{b, n_{p}, n_{r}}\right)
$$

A representação matricial da $p$-ésima saída do sistema será:

$$
\begin{aligned}
& y_{p}(t)=a_{p}(1) y_{p}(t-1)+a_{p}(2) y_{p}(t-2)+\ldots+a_{p}\left(n_{a, p}\right) y_{p}\left(t-n_{a, p}\right)+ \\
& +b_{p, 1}(0) u_{1}(t)+b_{p, 1}(1) u_{1}(t-1)+\ldots+b_{p, 1}\left(n_{b, p, 1}\right) u_{1}\left(t-n_{b, p, 1}\right)+ \\
& +b_{p, 2}(0) u_{2}(t)+b_{p, 2}(1) u_{2}(t-1)+\ldots+b_{p, 2}\left(n_{b, p, 2}\right) u_{2}\left(t-n_{b, p, 2}\right)+\ldots+ \\
& +b_{p, n_{r}}(0) u_{n_{r}}(t)+b_{, n_{r}}(1) u_{n_{r}}(t-1)+\ldots+b_{p, n_{r}}\left(n_{b, p, n_{r}}\right) u_{n_{r}}\left(t-n_{b, p, n_{r}}\right) \\
& y_{p}(t)=\left[y_{p}(t-1) y_{p}(t-2) \cdots y_{p}\left(t-n_{a, p}\right)\right]\left[\begin{array}{c}
a_{p}(1) \\
a_{p}(2) \\
\vdots \\
a_{p}\left(n_{a, p}\right)
\end{array}\right]+ \\
& +\left[u_{1}(t) u_{1}(t-1) \cdots u_{1}\left(t-n_{b, p, 1}\right)\right]\left[\begin{array}{c}
b_{p, 1}(0) \\
b_{p, 1}(1) \\
\vdots \\
b_{p, 1}\left(n_{b, p, 1}\right)
\end{array}\right]+ \\
& +\left[u_{2}(t) u_{2}(t-1) \cdots u_{2}\left(t-n_{b, p, 2}\right)\right]\left[\begin{array}{c}
b_{p, 2}(0) \\
b_{p, 2}(1) \\
\vdots \\
b_{p, 2}\left(n_{b, p, 2}\right)
\end{array}\right]+\ldots+ \\
& +\left[u_{n_{r}}(t) u_{n_{r}}(t-1) \cdots u_{n_{r}}\left(t-n_{b, p, n_{r}}\right)\right]\left[\begin{array}{c}
b_{p, n_{r}}(0) \\
b_{p, n_{r}}(1) \\
\vdots \\
b_{p, n_{r}}\left(n_{b, p, n_{r}}\right)
\end{array}\right] \\
& y_{p}(t)=\varphi_{p}^{T}(t) \boldsymbol{\theta}_{p}
\end{aligned}
$$

onde:

$$
\begin{aligned}
\varphi_{p}^{T}(t)= & {\left[y_{p}(t-1) y_{p}(t-2) \cdots y_{p}\left(t-n_{a, p}\right)\right.} \\
& u_{1}(t) u_{1}(t-1) \cdots u_{1}\left(t-n_{b, p, 1}\right) \\
& u_{2}(t) u_{2}(t-1) \cdots u_{2}\left(t-n_{b, p, 2}\right) \cdots \\
& \left.\cdots u_{n_{r}}(t) u_{n_{r}}(t-1) \cdots u_{n_{r}}\left(t-n_{b, p, n_{r}}\right)\right]
\end{aligned}
$$


e:

$$
\begin{aligned}
\boldsymbol{\theta}_{p}^{T}= & {\left[a_{p}(1) a_{p}(2) \cdots a_{p}\left(n_{a, p}\right)\right.} \\
& b_{p, 1}(0) b_{p, 1}(1) \cdots b_{p, 1}\left(n_{b, p, 1}\right) \\
& b_{p, 2}(0) b_{p, 2}(1) \cdots b_{p, 2}\left(n_{b, p, 2}\right) \cdots \\
& \left.\cdots b_{p, n_{r}}(0) b_{p, n r}(1) \cdots b_{p, n_{r}}\left(n_{b, p, n_{r}}\right)\right]
\end{aligned}
$$

$\mathrm{O}$ vetor $\boldsymbol{\varphi}_{p}(t) \in \mathbb{R}^{n \times 1}$ é chamado de vetor de regressores, $\boldsymbol{\theta}_{p} \in \mathbb{R}^{n \times 1}$ é o vetor de parâmetros do modelo de ordem $n=n_{a, p}+n_{b, p, 1}+n_{b, p, 2}+\ldots+n_{b, p, n_{r}}+n_{r}$ do $p$-ésimo subsistema. Em sistemas amostrados há presença de seguradores de ordem zero (zeroorder holders, $\mathrm{ZOH}$ ) nas entradas resultando em $b_{p, r}=0, \forall p, r$. Assim, a ordem do modelo do $p$-ésimo subsistema (ou simplesmente $p$-ésimo submodelo) pode ser dada por $n=n_{a, p}+n_{b, p, 1}+n_{b, p, 2}+\ldots+n_{b, p, n_{r}}$.

Em um experimento com um planta onde são tomadas $N_{e}$ amostras a partir do instante $t=0$, as observações da $p$-ésima saída podem ser representadas por:

$$
\begin{gathered}
{\left[\begin{array}{c}
y_{p}(0) \\
y_{p}(1) \\
\vdots \\
y_{p}\left(N_{e}-1\right)
\end{array}\right]=\left[\begin{array}{c}
\boldsymbol{\varphi}_{p}^{T}(0) \\
\boldsymbol{\varphi}_{p}^{T}(1) \\
\vdots \\
\boldsymbol{\varphi}_{p}^{T}\left(N_{e}-1\right)
\end{array}\right] \boldsymbol{\theta}_{p}} \\
\mathbf{y}_{p}=\Psi \boldsymbol{\theta}_{p} \in \mathbb{R}^{N_{e} \times 1} \\
\Psi^{T}=\left[\boldsymbol{\varphi}_{p}(0) \boldsymbol{\varphi}_{p}(1) \cdots \boldsymbol{\varphi}_{p}\left(N_{e}-1\right)\right]
\end{gathered}
$$

onde $\Psi \in \mathbb{R}^{N_{e} \times n}$ é chamada de matriz de regressores.

Para simplificar a redação, neste trabalho o termo planta é utilizado em substituição ao modelo nominal da planta.

Considerando uma perturbação não medida $\mathbf{v}_{p} \in \mathbb{R}^{N_{e} \times 1}$ somada à $p$-ésima saída da planta, tem-se:

$$
\mathbf{y}_{p}=\Psi \boldsymbol{\theta}_{p}+\mathbf{v}_{p}
$$

onde: 


$$
\mathbf{v}_{p}^{T}=\left[v_{p}(0) v_{p}(1) \cdots v_{p}\left(N_{e}-1\right)\right]
$$

Sistemas lineares multivariáveis de múltiplas entradas e múltiplas saídas (multiple input multiple output, MIMO), para efeito de estudo, podem ser interpretados como um conjunto de subsistemas de múltiplas entradas e uma saída (multiple input single output, MISO), visto que em sistemas lineares o teorema da superposição é válido (AGUIRRE, 2007).

Seja um estimador linear caracterizado pela matriz $A \in \mathbb{R}^{n \times N_{e}}$. Utilizando esse estimador para estimar os parâmetros $\boldsymbol{\theta}_{p}$ do $p$-ésimo submodelo MISO de ordem $n$ a partir das $N_{e}$ observações, tem-se (LJUNG, 1999) (AGUIRRE, 2007) (ZHU, 2001):

$$
\hat{\boldsymbol{\theta}}_{p}=A \mathbf{y}_{p}
$$

O p-ésimo submodelo MISO estimado por tais parâmetros $\hat{G}_{p}$ representa o $p$ ésimo subsistema nominal $G_{p}^{o}$.

A matriz de covariâncias dos parâmetros estimados $\hat{\boldsymbol{\theta}}_{p}$ do modelo de ordem $n$ para as $N_{e}$ observações é:

$$
\operatorname{cov}\left[\hat{\boldsymbol{\theta}}_{p}\right]=\mathbb{E}\left[\left(\hat{\boldsymbol{\theta}}_{p}-\mathbb{E}\left[\hat{\boldsymbol{\theta}}_{p}\right]\right)\left(\hat{\boldsymbol{\theta}}_{p}-\mathbb{E}\left[\hat{\boldsymbol{\theta}}_{p}\right]\right)^{T}\right] \in \mathbb{R}^{n \times n}
$$

Seja agora o estimador caracterizado por $A^{\prime}$ pelo qual obtém-se os parâmetros $\hat{\boldsymbol{\theta}}^{\prime}$. Considerando estimadores não polarizados, o estimador $A^{\prime}$ será mais eficiente que o estimador $A$ quando (ZHU, 2001):

$$
\operatorname{cov}\left[\hat{\boldsymbol{\theta}}^{\prime}\right]<\operatorname{cov}[\hat{\boldsymbol{\theta}}]
$$

ou, equivalentemente (ZHU, 2001):

$$
\operatorname{det}\left[\operatorname{cov}\left[\hat{\boldsymbol{\theta}}^{\prime}\right]\right]<\operatorname{det}[\operatorname{cov}[\hat{\boldsymbol{\theta}}]]
$$

Além do determinante da matriz de covariância dos parâmetros estimados, as medidas: 
1. $\operatorname{Tr}[\operatorname{cov}[\hat{\boldsymbol{\theta}}]]$, chamada de A-optimality;

2. $\log [\operatorname{det}[\operatorname{cov}[\hat{\boldsymbol{\theta}}]]]$, chamada de D-optimality;

3. $\lambda_{\max }[\operatorname{cov}[\hat{\boldsymbol{\theta}}]]$, o qual representa o maior autovalor de $\operatorname{cov}[\hat{\boldsymbol{\theta}}]$, chamada de $E$ optimality;

têm sido utilizadas como funções custo para obter sinais ótimos (MEHRA, 1974) (YUAN; LJUNG, 1985) (LJUNG, 1999) (ZHU, 2001) (BARENTHIN, 2006) (HILDEBRAND; SOLARI, 2007). Os sinais que minimizam essas funções são chamados de sinais ótimos.

\subsubsection{Caso particular FIR SISO}

Considere a identificação de uma planta de uma entrada e uma saída (SISO) a partir de $N_{e}$ amostras. Se o estimador for não polarizado, desenvolvendo (2.10) para o caso SISO de ordem $n(\hat{\boldsymbol{\theta}}=A \mathbf{y})$, tem-se:

$$
\operatorname{cov}[\hat{\boldsymbol{\theta}}]=\mathbb{E}\left[A \mathbf{v} \mathbf{v}^{T} A^{T}\right]
$$

Se $\mathbf{v}=\mathbf{e} \in \mathbb{R}^{N_{e} \times 1}$ for ruído branco de variância $\sigma_{e}^{2}$, tem-se $\mathbb{E}\left[\mathbf{v v}^{T}\right]=\mathbb{E}\left[\mathbf{e e}^{T}\right]=$ $\sigma_{e}^{2} I \in \mathbb{R}^{N_{e} \times N_{e}}$. Nesse caso, a matriz de covariância dos parâmetros estimados é (AGUIRRE, 2007):

$$
\operatorname{cov}[\hat{\boldsymbol{\theta}}]=\mathbb{E}\left[A A^{T}\right] \sigma_{e}^{2}
$$

Considere o estimador de mínimos quadrados (least squares, LS):

$$
A=\left(\Psi^{T} \Psi\right)^{-1} \Psi^{T}
$$

De (2.14) e (2.15) tem-se a matriz de covariância dos parâmetros estimados do modelo:

$$
\operatorname{cov}[\hat{\boldsymbol{\theta}}]=\mathbb{E}\left[\left(\Psi^{T} \Psi\right)^{-1}\right] \sigma_{e}^{2}
$$

Caso a estrutura do modelo cujos parâmetros serão estimados seja FIR de ordem 
$n$, o vetor e a matriz de regressores, (2.3) e (2.6), respectivamente, dependerão apenas da entrada $u(t)$ :

$$
\begin{aligned}
\varphi^{T}(t) & =[u(t) u(t-1) \cdots u(t-n)] \\
\Psi^{T} & =\left[\boldsymbol{\varphi}_{p}(0) \varphi_{p}(1) \cdots \varphi_{p}\left(N_{e}-1\right)\right] \\
& =U^{T}
\end{aligned}
$$

Assim:

$$
\operatorname{cov}[\hat{\boldsymbol{\theta}}]=\mathbb{E}\left[\left(U^{T} U\right)^{-1}\right] \sigma_{e}^{2}
$$

O sinal $u(t)$ deve ser uma excitação persistente (persistent excitation, $\mathrm{PE}$ ) de ordem $n$. Isso significa que, para garantir a unicidade da solução de estimação de parâmetros e a existência do estimador $\left(A=\left(U^{T} U\right)^{-1} U^{T}\right)$, devem existir os limites a seguir e a matriz de correlações $R=\frac{1}{N_{e}} U^{T} U \in \mathbb{R}^{n \times n}$ deve ser não singular (AGUIRRE, 2007):

$$
\begin{aligned}
& \bar{u}=\lim _{N_{e} \rightarrow \infty} \frac{1}{N_{e}} \sum_{i=0}^{N_{e}-1} u(i) \\
& r_{\mathbf{u u}}(k)=\lim _{N_{e} \rightarrow \infty} \frac{1}{N_{e}} \sum_{i=0}^{N_{e}-1}(u(i)-\bar{u})(u(i+k)-\bar{u}) \\
& \operatorname{det}\left(\frac{1}{N_{e}} U^{T} U\right)=\operatorname{det}(R) \neq 0
\end{aligned}
$$

As duas primeiras condições de (2.20) são consequências de sinais estacionários, onde $r_{\mathbf{u u}}(k)$ é a função de autocorrelação de $\mathbf{u}$.

Caso a entrada seja excitação ruído branco, tem-se:

$$
\mathbb{E}\left[\left(U^{T} U\right)^{-1}\right]=\frac{1}{\mathbf{u}^{T} \mathbf{u}} I=\frac{1}{\sigma_{u}^{2}} I
$$

Portanto, matriz de covariância dos parâmetros estimados do modelo será: 


$$
\operatorname{cov}[\hat{\boldsymbol{\theta}}]=\frac{\sigma_{e}^{2}}{\sigma_{u}^{2}} I
$$

onde o inverso do termo $\frac{\sigma_{e}^{2}}{\sigma_{u}^{2}}$ é chamado de relação sinal ruído (signal-to-noise ratio, SNR):

$$
S N R_{u}=\frac{\sigma_{u}^{2}}{\sigma_{e}^{2}}
$$

Esse resultado evidencia que quanto maior a relação entre a potência da excitação e a potência do ruído menor tende a ser a variância dos parâmetros estimados do modelo. Considerando que o ruído seja inerente ao sistema e nada pode ser feito para reduzí-lo, tem-se um critério para projeto de sinais de excitação:

$$
\max _{\mathbf{u}}\left\{S N R_{u}\right\} \quad \text { ou } \quad \max _{\mathbf{u}}\left\{\mathbf{u}^{T} \mathbf{u}\right\}, \quad u_{\min } \leq u_{i} \leq u_{\max }
$$

onde $u_{\min }$ e $u_{\max }$ são limitações da planta para excursão do sinal $\mathbf{u}$.

\subsubsection{Critério para projeto ótimo de sinais de excitação}

Considere uma identificação SISO cuja aplicação do modelo será no controle SISO da planta. Para o experimento de identificação da planta com o controlador em malha aberta, foi mostrado que o espectro do sinal de excitação ótimo, ou seja, que minimiza (2.10), é (YUAN; LJUNG, 1985) (ZHU, 2001):

$$
\Phi_{u}^{o p}(\omega)=\mu \sqrt{\Phi_{u}^{c}(\omega) \Phi_{v}(\omega)}
$$

onde $\Phi_{v}(\omega)$ é a densidade espectral de potência (power spectrum density, PSD) da perturbação; $\Phi_{u}^{c}(\omega)$ é a PSD da ação do controlador quando em malha fechada. A contante $\mu$ é ajustada de forma que a máxima potência permitida para a excitação seja usada.

O resultado (2.25) é intuitivo. A potência da excitação deve ser maior nas frequências onde a potência da perturbação é maior, pois o objetivo é obter boa SNR na saída da planta durante o experimento. Adicionalmente, nas frequências onde a magnitude das ações do controlador são maiores (faixa de frequências de interesse para o modelo a ser utilizado com objetivo de controle), mais potência de excitação é necessária 
também com o objetivo de melhorar a identificação naquela faixa de frequências.

Para o projeto do sinal de excitação, pode-se relacionar $\Phi_{u}^{c}(\omega)$ com a resposta em malha fechada desejada, ou seja, o espectro desejado ou esperado para a ação do controlador projetado para a planta. O espectro $\Phi_{v}(\omega)$ pode ser estimado a partir de medidas da saída da planta em malha aberta e sem excitação na entrada ou obtido do erro residual de uma identificação anterior (ZHU, 2001).

Para obter o resultado (2.25), o qual é independente da planta SISO $G^{o}\left(e^{j \omega}\right)$, da teoria assintótica é assumida a aproximação para a variância do modelo estimado $\hat{G}\left(e^{j \omega}\right)$ quando $N_{e} \rightarrow \infty$ e $n \rightarrow \infty$ (YUAN; LJUNG, 1985) (ZHU, 2001):

$$
\operatorname{var}\left[\hat{G}\left(e^{j \omega}\right)\right] \approx \frac{n}{N_{e}} \frac{\Phi_{v}(\omega)}{\Phi_{u}(\omega)}
$$

onde $\Phi_{v}(\omega)$ e $\Phi_{u}(\omega)$ são as PSD da perturbação $\mathbf{v}$ e da entrada $\mathbf{u}$ da planta SISO. Considerando $\mathbf{v}$ e u processos aleatórios estacionários no sentido amplo (wide-sensestationary random process, wss), pelo Teorema de Wiener-Khinchin (PAPOULIS, 1991), tem-se:

$$
\begin{aligned}
& \Phi_{v}(\omega)=\sum_{k=-\infty}^{\infty} r_{v v}(k) e^{-j \omega k} \\
& \Phi_{u}(\omega)=\sum_{k=-\infty}^{\infty} r_{u u}(k) e^{-j \omega k}
\end{aligned}
$$

Considere agora a identificação da planta SISO em malha fechada. O modelo a ser identificado será utilizado em um esquema de controle por modelo interno (internal model control, IMC) com sinal de referência $r_{c}(t)$ de espectro $\Phi_{r_{c}}(\omega)$. O experimento de identificação é realizado com o IMC operando (malha fechada) e o sinal de excitação é aplicado no set point da planta em malha fechada.

O espectro ótimo para o sinal de excitação $r(t)$ aplicado no set point da planta em malha fechada é (ZHU, 2001):

$$
\Phi_{r}^{o p t}(\omega) \approx \mu\left|G^{o}\left(e^{j \omega}\right) Q\left(e^{j \omega}\right)\right| \sqrt{\Phi_{r_{c}}(\omega) \Phi_{v}(\omega)}
$$

onde $Q\left(e^{j \omega}\right)$ é o controlador.

O resultado (2.28), assim como (2.25), evidencia, o que é intuitivo, que a potência da excitação deve ser maior nas frequências onde a potência da perturbação é maior e nas frequências mais utilizadas pelo sinal de referência do controlador IMC. Observe 
que em (2.28) há dependência da planta $G^{o}\left(e^{j \omega}\right)$ para determinação do espectro ótimo do sinal de excitação para identificação em malha fechada.

Os resultados (2.25) e (2.28) formam a base teórica para o projeto de sinais de excitação. De forma simplificada, inclusive em identificação MIMO, tem-se considerado o seguinte critério de espectro ótimo para projeto de sinais de excitação $u(t)$ (ZHU, 2001):

$$
\Phi_{u}^{o p t}(\omega) \approx \mu \sqrt{\Phi_{u}^{c}(\omega) \Phi_{v}(\omega)}
$$

onde são necessárias as informações a priori: espectro de interesse para aplicação do modelo $\Phi_{u}^{c}(\omega)$, espectro da perturbação $\Phi_{v}(\omega)$ e o limite de potência permitido, necessário para ajustar a constante $\mu$.

\subsection{Projeto de sinais para identificação MIMO}

O cálculo de (2.10) e, consequentemente, das medidas A-optimality, D-optimality e E-optimality para modelos com estruturas de resposta infinita, como ARX ou modelo auto-regressivo com média móvel e entradas exógenas (auto-regressive moving average with exogenous inputs, ARMAX) (LJUNG, 1999), dependerá das saídas da planta. Isso ocorre pois tais estruturas possuem em suas matrizes de regressores as saídas da planta. Portanto, não é possível calcular a matriz de covariâncias dos parâmetros estimados anteriormente ao experimento de identificação

Dessa forma, para escolher (ou calcular) sinais ótimos para o experimento utilizando as medidas baseadas em covariâncias de estimadores deve-se conhecer completamente a planta. Essa condição é contraditória a um procedimento de identificação, cujo objetivo é estimar parâmetros de um modelo de forma a aproximar sua resposta à de uma planta que não se conhece (ou que pouco se conhece). Esse é o maior desafio para o projeto de sinais de excitação (YUAN; LJUNG, 1985) (ZHU, 2001) (BARENTHIN, 2006).

Em (BARENTHIN, 2006) foi proposto um método de dois passos para projetos de sinais ótimos. Inicialmente, estimam-se parâmetros do modelo a partir de dados obtidos com sinal de excitação PRB. No segundo passo, projeta-se o sinal ótimo a partir do conhecimento do modelo estimado no passo anterior. Há outros trabalhos na literatura que, de forma semelhante a (BARENTHIN, 2006), propõem identificação iterativa. Neste esquema de identificação, melhores projetos de sinais subótimos, utilizando as medidas baseadas em covariâncias de estimadores, são realizados à medida que se obtêm 
modelos estimados com maior aproximação ao modelo nominal (COOLEY; LEE, 2001) (GEVERS, 2002) (KAISARE; LEE, 2010). Porém, na prática, identificações sucessivas não são desejáveis, pois estendem o tempo no qual a planta é excitada.

Neste trabalho, são estudadas técnicas de projetos de sinais de excitação com o objetivo de construir sinais de excitação adequados a experimentos com plantas desconhecidas, ou que pouco se conhece, gerando dados suficientemente informativos para a identificação. Os requisitos do experimento de identificação são discutidos na seção 3.1. A partir da avaliação dos requisitos do experimento e dos critérios oriundos do projeto ótimo de sinais de excitação são definidos conhecimentos prévios mínimos necessários para o projeto de sinais para identificação multivariável. Esses conhecimentos prévios chamados de conhecimentos a priori serão listados na seção 3.2.

\subsubsection{Caso particular FIR MISO}

Utilizando a medida $D$-optimality $(\log [\operatorname{det}[\operatorname{cov}[\hat{\theta}]]])$, seção 2.1, e considerando que os parâmetros do $p$-ésimo submodelo MISO foram estimados com A (estimador não polarizado) em um único experimento de $N_{e}$ amostras em meio a perturbação $\mathbf{v}=\mathbf{e}$ ruído branco de variância $\sigma_{e}^{2}$, de (2.10), tem-se:

$$
\begin{aligned}
\operatorname{det}\left[\operatorname{cov}\left[\hat{\boldsymbol{\theta}}_{p}\right]\right] & =\operatorname{det}\left[\mathbb{E}\left[A \mathbf{e e}^{T} A^{T}\right]\right] \\
& =\operatorname{det}\left[A^{T} A\right] \sigma_{e}^{2}
\end{aligned}
$$

Para o estimador LS, tem-se:

$$
\begin{aligned}
\operatorname{det}\left[\operatorname{cov}\left[\hat{\boldsymbol{\theta}}_{p, L S}\right]\right] & =\sigma_{e}^{2} \operatorname{det}\left[\left(\left(\Psi^{T} \Psi\right)^{-1} \Psi^{T}\right)\left(\left(\Psi^{T} \Psi\right)^{-1} \Psi^{T}\right)^{T}\right] \\
& =\sigma_{e}^{2} \operatorname{det}\left[\left(\Psi^{T} \Psi\right)^{-1}\right] \\
& =\frac{\sigma_{e}^{2}}{\operatorname{det}\left[\left(\Psi^{T} \Psi\right)\right]}
\end{aligned}
$$

De acordo com (2.12) e (2.31), um estimador LS será mais eficiente quanto maior for o valor do termo $\operatorname{det}\left[\left(\Psi^{T} \Psi\right)\right]$.

Alternativamente à discussão da seção 2.2, para a estrutura FIR MISO de ordem $n=n_{1}+n_{2}+\ldots+n_{n_{r}}$ e $n_{r}$ entradas, os regressores não contêm dados de saída da planta. Assim, de (2.3) tem-se: 


$$
\begin{aligned}
\varphi^{T}(t)= & {\left[u_{1}(t) u_{1}(t-1) \cdots u_{1}\left(t-n_{1}\right)\right.} \\
& u_{2}(t) u_{2}(t-1) \cdots u_{2}\left(t-n_{2}\right) \cdots \\
& \left.\cdots u_{n_{r}}(t) u_{n_{r}}(t-1) \cdots u_{n_{r}}\left(t-n_{n_{r}}\right)\right] \\
\Psi^{T}= & {\left[\boldsymbol{\varphi}_{p}(0) \boldsymbol{\varphi}_{p}(1) \cdots \boldsymbol{\varphi}_{p}\left(N_{e}-1\right)\right] } \\
= & U^{T}
\end{aligned}
$$

permitindo calcular a variância desse estimador previamente ao experimento de identificação:

$$
\begin{aligned}
\operatorname{det}\left[\operatorname{cov}\left[\hat{\boldsymbol{\theta}}_{p}\right]\right] & =\frac{\sigma_{e}^{2}}{\operatorname{det}\left[\left(\Psi^{T} \Psi\right)\right]} \\
& =\frac{\sigma_{e}^{2}}{\operatorname{det}\left[\left(U^{T} U\right)\right]} \\
& =\frac{\sigma_{e}^{2}}{\operatorname{det}\left[N_{e} R\right]} \\
& =\frac{\sigma_{e}^{2}}{\operatorname{det}\left[N_{e} I\right][R]} \\
& =\frac{1}{N_{e}^{n_{1}+n_{2}+\ldots+n_{n r}}} \frac{\sigma_{e}^{2}}{\operatorname{det}[R]}
\end{aligned}
$$

onde $n_{n_{r}}$ é a ordem da subestrutura FIR relativa à $r$-ésima entrada suficiente para representar a resposta impulsiva da planta e $R$ a matriz de correlações das entradas dada por:

$$
R=\frac{1}{N_{e}} U^{T} U
$$

onde o termo $\left[U^{T} U\right]$ pode ser desenvolvido em: 


$$
\left[U^{T} U\right]=\left[\begin{array}{cccc}
u_{1}(0) & u_{1}(1) & \cdots & u_{1}\left(N_{e}-1\right) \\
u_{1}(-1) & u_{1}(0) & \cdots & u_{1}\left(N_{e}-2\right) \\
\vdots & \vdots & \ddots & \vdots \\
u_{1}\left(1-n_{1}\right) & u_{1}\left(2-n_{1}\right) & \cdots & u_{1}\left(N_{e}-n_{1}\right) \\
\vdots & \vdots & \ddots & \vdots \\
u_{r}(0) & u_{r}(1) & \cdots & u_{r}\left(N_{e}-1\right) \\
u_{r}(-1) & u_{r}(0) & \cdots & u_{r}\left(N_{e}-2\right) \\
\vdots & \vdots & \ddots & \vdots \\
u_{r}\left(1-n_{r}\right) & u_{r}\left(2-n_{r}\right) & \cdots & u_{r}\left(N_{e}-n_{r}\right)
\end{array}\right]
$$

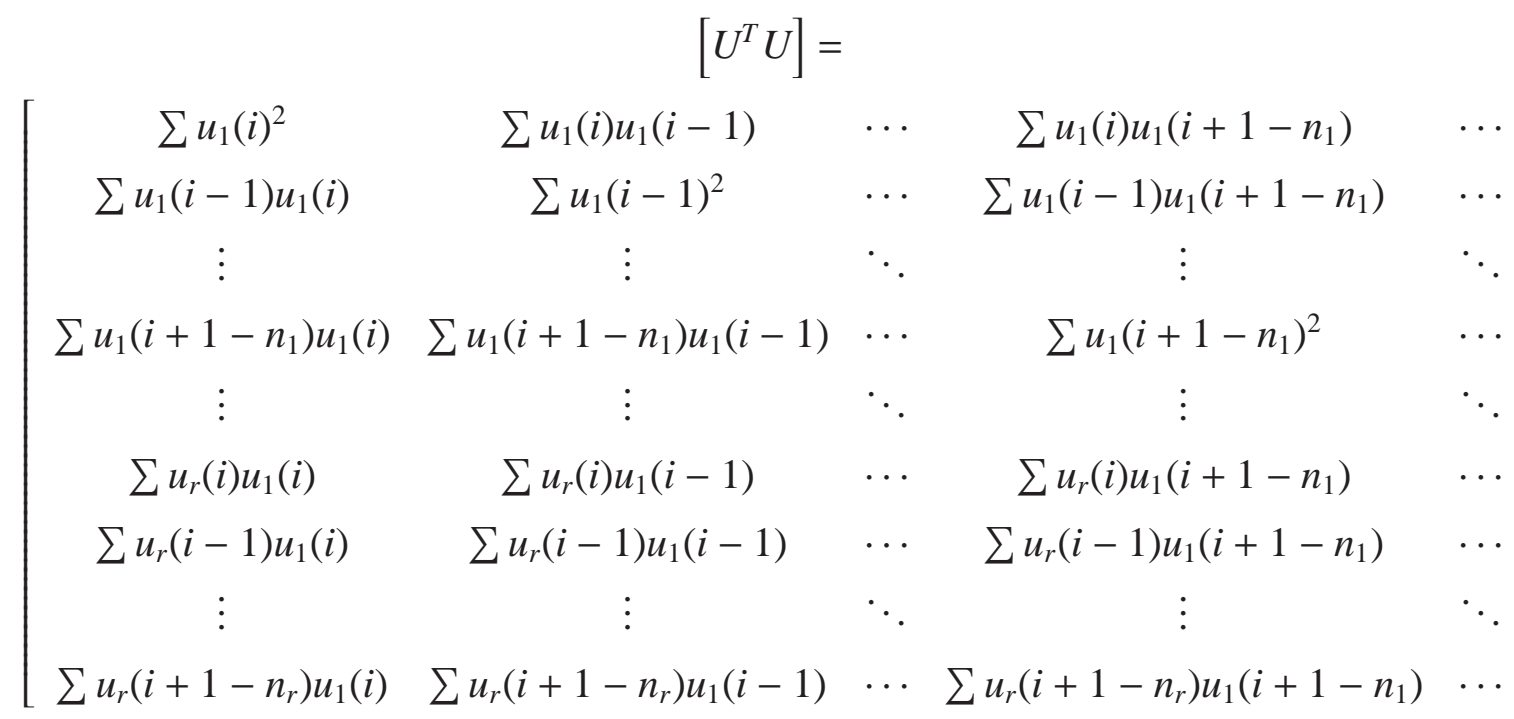




$\begin{array}{lcclc}\ldots & \sum u_{1}(i) u_{r}(i) & \sum u_{1}(i) u_{r}(i-1) & \cdots & \sum u_{1}(i) u_{r}\left(i+1-n_{r}\right) \\ \ldots & \sum u_{1}(i-1) u_{r}(i) & \sum u_{1}(i-1) u_{r}(i-1) & \cdots & \sum u_{1}(i-1) u_{r}\left(i+1-n_{r}\right) \\ \ldots & \vdots & \vdots & \ddots & \vdots \\ \ldots & \sum u_{1}\left(i+1-n_{1}\right) u_{r}(i) & \sum u_{1}\left(i+1-n_{1}\right) u_{r}(i-1) & \cdots & \sum u_{1}\left(i+1-n_{1}\right) u_{r}\left(i+1-n_{r}\right) \\ \ldots & \vdots & \vdots & \ddots & \vdots \\ \ldots & \sum u_{r}(i)^{2} & \sum u_{r}(i) u_{r}(i-1) & \cdots & \sum u_{r}(i) u_{r}\left(i+1-n_{r}\right) \\ \ldots & \sum u_{r}(i-1) u_{r}(i) & \sum u_{r}(i-1)^{2} & \cdots & \sum u_{r}(i-1) u_{r}\left(i+1-n_{r}\right) \\ \ldots & \vdots & \vdots & \ddots & \vdots \\ \ldots & \sum u_{r}\left(i+1-n_{r}\right) u_{r}(i) & \sum u_{r}\left(i+1-n_{r}\right) u_{r}(i-1) & \cdots & \sum u_{r}\left(i+1-n_{r}\right)^{2}\end{array}$

onde $\sum$ representa o somatório $\sum_{i=0}^{N_{e}-1}$.

Considerando $u_{1}(i), u_{2}(i), \ldots, u_{r}(i)$ sinais estacionários, tem-se a seguinte propriedade para a função de autocorrelação (AGUIRRE, 2007):

$$
r_{u u}(k)=\frac{1}{N_{e}} \sum_{i=0}^{N_{e}-1} u(i) u(i-k)=r_{u и}(-k)
$$

e a seguinte propriedade para a função de correlação cruzada:

$$
r_{u_{1} u_{r}}(k)=\frac{1}{N_{e}} \sum_{i=0}^{N_{e}-1} u_{1}(i) u_{r}(i-k)=r_{u_{r} u_{1}}(-k)
$$

De (2.37), (2.38) e (2.39), tem-se:

$$
\left[U^{T} U\right]=N_{e}\left[\begin{array}{ccccc}
r_{u_{1} u_{1}}(0) & r_{u_{1} u_{1}}(1) & \cdots & r_{u_{1} u_{1}}\left(n_{1}-1\right) & \cdots \\
r_{u_{1} u_{1}}(-1) & r_{u_{1} u_{1}}(0) & \cdots & r_{u_{1} u_{1}}\left(n_{1}-2\right) & \cdots \\
\vdots & \vdots & \ddots & \vdots & \ddots \\
r_{u_{1} u_{1}}\left(-n_{1}+1\right) & r_{u_{1} u_{1}}\left(-n_{1}+2\right) & \cdots & r_{u_{1} u_{1}}(0) & \cdots \\
\vdots & \vdots & \ddots & \vdots & \ddots \\
r_{u_{r} u_{1}}(0) & r_{u_{r} u_{1}}(1) & \cdots & r_{u_{r} u_{1}}\left(n_{1}-1\right) & \cdots \\
r_{u_{r} u_{1}}(-1) & r_{u_{r} u_{1}}(0) & \cdots & r_{u_{r} u_{1}}\left(n_{1}-2\right) & \cdots \\
\vdots & \vdots & \ddots & \vdots & \ddots \\
r_{u_{r} u_{1}}\left(-n_{r}+1\right) & r_{u_{r} u_{1}}\left(-n_{r}+2\right) & \cdots & r_{u_{r} u_{1}}\left(n_{1}-n_{r}\right) & \cdots
\end{array}\right.
$$




$$
\begin{aligned}
& \begin{array}{lllll}
\cdots & r_{u_{1} u_{r}}(0) & r_{u_{1} u_{r}}(1) & \cdots & r_{u_{1} u_{r}}\left(n_{r}-1\right)
\end{array} \\
& \begin{array}{lllll}
\cdots & r_{u_{1} u_{r}}(-1) & r_{u_{1} u_{r}}(0) & \cdots & r_{u_{1} u_{r}}\left(n_{r}-2\right)
\end{array} \\
& \begin{array}{lllll}
\ldots & \vdots & \vdots & \ddots & \vdots
\end{array} \\
& \begin{array}{lllll}
\cdots & r_{u_{1} u_{r}}\left(-n_{1}+1\right) & r_{u_{1} u_{r}}\left(-n_{1}+2\right) & \cdots & r_{u_{1} u_{r}}\left(n_{r}-n_{1}\right)
\end{array} \\
& \begin{array}{ccccc}
\ldots & \vdots & \vdots & \ddots & \vdots \\
\cdots & r_{u_{r} u_{r}}(0) & r_{u_{r} u_{r}}(1) & \cdots & r_{u_{r} u_{r}}\left(n_{r}-1\right)
\end{array} \\
& \begin{array}{lllll}
\cdots & r_{u_{r} u_{r}}(-1) & r_{u_{r} u_{r}}(0) & \cdots & r_{u_{r} u_{r}}\left(n_{r}-2\right)
\end{array} \\
& \begin{array}{ccccc}
\cdots & \vdots & \vdots & \ddots & \vdots \\
\cdots & r_{u_{r} u_{r}}\left(-n_{r}+1\right) & r_{u_{r} u_{r}}\left(-n_{r}+2\right) & \cdots & r_{u_{r} u_{r}}(0)
\end{array} \\
& =N_{e}\left[\begin{array}{cccc}
R_{u_{1} u_{1}} & R_{u_{1} u_{2}} & \cdots & R_{u_{1} u_{r}} \\
R_{u_{1} u_{2}}^{T} & R_{u_{2} u_{2}} & \cdots & R_{u_{2} u_{r}} \\
\vdots & \vdots & \ddots & \vdots \\
R_{u_{1} u_{r}}^{T} & R_{u_{2} u_{r}}^{T} & \cdots & R_{u_{r} u_{r}}
\end{array}\right] \\
& =N_{e} R
\end{aligned}
$$

onde $R_{u_{1} u_{r}}$ é a matriz de correlações entre os sinais $u_{1}$ e $u_{r}$ dada por:

$$
R_{u_{1} u_{r}}=\left[\begin{array}{cccc}
r_{u_{1} u_{r}}(0) & r_{u_{1} u_{r}}(1) & \cdots & r_{u_{1} u_{r}}\left(n_{r}-1\right) \\
r_{u_{1} u_{r}}(-1) & r_{u_{1} u_{r}}(0) & \cdots & r_{u_{1} u_{r}}\left(n_{r}-2\right) \\
\vdots & \vdots & \ddots & \vdots \\
r_{u_{1} u_{r}}\left(-n_{1}+1\right) & r_{u_{1} u_{r}}\left(-n_{1}+2\right) & \cdots & r_{u_{1} u_{r}}\left(n_{r}-n_{1}\right)
\end{array}\right]
$$

A partir de (2.34), verifica-se que a medida D-optimality e, consequentemente, a variância do estimador, são reduzidas à medida que a duração do experimento aumenta (aumenta $N_{e}$ ). Esse resultado é semelhante ao da teoria assintótica (2.26) (LJUNG, 1985) (YUAN; LJUNG, 1985) (ZHU, 2001). Adicionalmente, elas também são reduzidas com o aumento da ordem do modelo e do termo det $[R]$. Portanto, objetiva-se:

$$
\max _{U}\{\operatorname{det}[R]\}
$$

Observe que o máximo det $[R]$ para sinais $\mathbf{u}_{1}, \mathbf{u}_{2}, \ldots, \mathbf{u}_{n_{r}}$ de variância $\mathbf{u}_{r}^{T} \mathbf{u}_{r} \neq 0$, com $r=1,2, \ldots, n_{r}$, será atingido quando $R$ for diagonal. Nesse caso:

$$
\begin{aligned}
& r_{\mathbf{u}_{r} \mathbf{u}_{s}}(k)=0, \text { para } r \neq s \mathrm{e}-\max \left\{n_{r}, n_{s}\right\}+1 \leq k \leq \max \left\{n_{r}, n_{s}\right\}-1 \\
& r_{\mathbf{u}_{r} \mathbf{u}_{r}}(k)=0, \text { para }-n_{r}+1 \leq k \leq n_{r}-1
\end{aligned}
$$


Portanto a medida D-optimality para identificação com ruído branco aditivo de uma estrutura FIR de múltiplas entradas com sinais de excitação de variância não nula $\left(\mathbf{u}_{r}^{T} \mathbf{u}_{r} \neq 0\right.$, com $\left.r=1,2, \ldots, n_{r}\right)$, é mínima quando:

$$
\begin{array}{ll}
r_{\mathbf{u}_{r} \mathbf{u}_{s}}(k)=0, & \forall \mathbf{u}_{r}, \mathbf{u}_{s} \in\left\{\mathbf{u}_{1}, \mathbf{u}_{2}, \ldots, \mathbf{u}_{n_{r}}\right\}, \operatorname{com} r \neq s \mathrm{e} \\
& k \in\left\{-\max \left\{n_{1}, n_{2}, \ldots, n_{n_{r}}\right\}+1 ;+\max \left\{n_{1}, n_{2}, \ldots, n_{n_{r}}\right\}-1\right\} \\
r_{\mathbf{u}_{r} \mathbf{u}_{r}}(k)=0, & \forall \mathbf{u}_{r} \in\left\{\mathbf{u}_{1}, \mathbf{u}_{2}, \ldots, \mathbf{u}_{n_{r}}\right\}, \operatorname{com} \\
& k \in\left\{-n_{r}+1 ; n_{r}-1\right\} \text { e } k \neq 0
\end{array}
$$

Considerando a característica de espectro ótimo (2.29) para ruído não branco, temse que $r_{\mathbf{u}_{r} \mathbf{u}_{r}}(k)$ é definido por (2.27) e (2.29). Assim, obtém-se da medida D-optimality um critério para projeto de sinais para identificação MIMO:

$$
\begin{aligned}
& r_{\mathbf{u}_{r} \mathbf{u}_{s}}(k)=0, \quad \forall \mathbf{u}_{r}, \mathbf{u}_{s} \in\left\{\mathbf{u}_{1}, \mathbf{u}_{2}, \ldots, \mathbf{u}_{n_{r}}\right\}, \operatorname{com} r \neq s \mathrm{e} \\
& k \in\left\{-\max \left\{n_{1}, n_{2}, \ldots, n_{n_{r}}\right\}+1 ;+\max \left\{n_{1}, n_{2}, \ldots, n_{n_{r}}\right\}-1\right\}
\end{aligned}
$$

Em (LJUNG, 1999) e (AGUIRRE, 2007) resume-se que em identificação multivariável, onde as entradas são excitadas simultaneamente, é fundamental que os sinais utilizados para excitar cada uma das entradas sejam não correlacionados. Assim, é possível, pelo algoritmo de identificação, atribuir a uma entrada um efeito observado em uma determinada saída. 


\section{Critérios de projeto de sinais de excitação}

No capítulo 2 foram discutidos os critérios (2.29) e (2.45) para especificação do espectro e das funções de correlação cruzada, respectivamente, dos sinais de excitação

ótimos. É evidente que esses não são suficiente para especificar sinais de excitação do ponto de vista prático. As características de amplitude no domínio do tempo também devem ser levadas em consideração no projeto dos sinais. Por exemplo, sistemas físicos possuem limitações de excursão e, portanto, características não lineares podem ser reveladas ou não, dependendo da característica de amplitude do sinal de excitação. Adicionalmente, em identificação MIMO, é intuitivo que combinações de entradas possam levar a saídas elevadas ou até nulas. Neste capítulo são discutidos aspectos além dos critérios (2.29) e (2.45) para o projeto de sinais de excitação.

\subsection{Experimento de identificação}

Um experimento deve ser preparado para obter medidas com elevada relação sinal ruído (signal-to-noise ratio, SNR), conforme (2.24). Em sistemas práticos, há limitações de amplitudes de entrada devido basicamente a dois motivos: (a) não são desejáveis grandes variações que alterem a operação normal da planta e (b) não é desejável que a excitação atinja regiões não lineares do sistema em uma identificação linear (ZHU, 2001). Adicionalmente, do conceito de identificação plant friendly (seção 1.1) o experimento deve ter curta duração, de forma a minimizar as horas de engenharia e a quantidade de (ou a possibilidade de gerar) produtos fora de especificação. São esses requisitos de amplitudes e tempo de experimento que guiam o projeto de sinais de excitação para identificação MIMO.

No caso da indústria de processos, os requisitos de amplitude podem ser traduzidos como: limitar a amplitude do sinal de excitação de forma a não superar os limites dos atuadores e limites de operação de bombas, compressores e outros equipamentos, não atingindo regiões não lineares da planta, e ter o cuidado de manter significati- 
vas as dinâmicas na variável de processo observada (saídas da planta) em relação aos distúrbios inerentes do próprio sistema e ruídos provocados pelo sistema de medição. É desejável que uma variável de saída excursione dentro de uma faixa controlada, ocasionando o menor prejuízo quanto à variabilidade na qualidade do produto (plant friendly). Adicionalmente, a excursão do sinal de saída pode ser uma limitação física do sistema e, caso esses limites sejam atingidos, algum dano permanente pode ser causado no sistema. Assim, tem-se o seguinte requisito para excursões das entradas $u_{r} \mathrm{e}$ saídas $y_{p}$ da planta:

$$
\begin{gathered}
u_{\min , r} \leq u_{r} \leq u_{\max , r} \\
y_{\min , p} \leq y_{p} \leq y_{\max , p}
\end{gathered}
$$

onde $u_{\min , r}$ e $u_{\max , r}$ são os limites de excursões da $r$-ésima entrada e $y_{\min , p}$ e $y_{\max , p}$ são os limites de excursões da $p$-ésima saída.

Sistemas reais também podem aceitar (ou permitir) apenas uma quantidade limitada de níveis de amplitude de entradas, ou seja, amplitudes quantizadas: binárias, ternárias, etc.

Em identificação de plantas de múltiplas entradas, determinadas combinações das entradas da planta podem conduzir as saídas a variações de alta ou baixa magnitude. Essa característica é conhecida como direcionalidade de ganho (gain directionality) e uma planta com essa característica é chamada de planta mal condicionada (CONNER; SEBORG, 2004). Dessa forma, na identificação MIMO de uma planta com direcionalidade de ganho, elevada potência da entrada pode não conduzir a elevada potência na saída, o que torna o critério (2.24) insuficiente para um experimento com uma planta mal condicionada. Para uma boa identificação é desejável que tanto o sinal de entrada quanto o sinal de saída sejam suficientemente informativos (RIVERA et al., 2003). É evidente que combinações das entradas que praticamente anulam as saídas frente ao ruído, não permitirão obter boas estimativas dos parâmetros do modelo para essa combinação de entradas.

Considere as combinações de entradas $\left\{\mathbf{u}_{1}, \mathbf{u}_{2}, \ldots, \mathbf{u}_{n_{r}}\right\}$ que geram a saída $\mathbf{y}$ :

$$
\mathbf{y}=\Psi \boldsymbol{\theta}+\mathbf{e}
$$

Suponha que essa combinação de entradas resulte $\Psi \boldsymbol{\theta} \approx \mathbf{0}$. Assim: 


$$
\hat{\boldsymbol{\theta}} \approx A \mathbf{e}
$$

o que não será uma boa estimativa dos parâmetros $\boldsymbol{\theta}$ para as combinações de entradas $\left\{\mathbf{u}_{1}, \mathbf{u}_{2}, \ldots, \mathbf{u}_{n_{r}}\right\}$, apesar de poder resultar em reduzida variância dos parâmetros estimados caso a variância de e for reduzida.

Essa constatação é relevante para o projeto de sinais de excitação, pois as medidas baseadas na covariância dos parâmetros estimados do modelo podem falsear a indicação de que um modelo representa adequadamente a planta. No capítulo 10 serão mostrados, por meio de simulações, modelos com maiores variâncias de seus parâmetros resultando em melhores ajustes à planta.

Para projetar um sinal de entrada que resulte em um sinal de saída com características de amplitude predefinidas é necessário conhecer as características do sistema a ser identificado, o que em princípio é contraditório com a identificação de sistemas, onde há pouca ou nenhuma informação sobre o sistema a ser identificado. Porém, é intuitivo que apenas com o conhecimento dos ganhos estáticos da planta, é possível obter os requisitos de amplitude dos sinais de excitação, dadas restrições de amplitudes das saídas na condição estática da planta. Dessa forma, quando a identificação for realizada em plantas mal condicionadas sem sistemas de controle ou, equivalentemente, com os controladores operando em malha aberta, o conhecimento da matriz de ganhos estáticos da planta é um requisito para o projeto de sinais de excitação:

$$
\begin{aligned}
K & =G^{o}(0) \\
& =\left[\begin{array}{cccc}
k_{1,1} & k_{1,2} & \cdots & k_{1, n_{r}} \\
k_{2,1} & k_{2,2} & \cdots & k_{2, n_{r}} \\
\vdots & \vdots & \ddots & \vdots \\
k_{n_{p}, 1} & k_{n_{p}, 2} & \cdots & k_{n_{p}, n_{r}}
\end{array}\right]
\end{aligned}
$$

onde $k_{p, r}$ é o ganho estático do par $p$-ésima saída $r$-ésima entrada da planta.

As entradas e saídas na condição estática da planta se relacionam como: 


$$
\begin{aligned}
{\left[\begin{array}{c}
y_{1} \\
y_{2} \\
\vdots \\
y_{n_{p}}
\end{array}\right]=K\left[\begin{array}{c}
u_{1} \\
u_{2} \\
\vdots \\
u_{n_{r}}
\end{array}\right] } \\
=\left[\begin{array}{cccc}
k_{1,1} & k_{1,2} & \cdots & k_{1, n_{r}} \\
k_{2,1} & k_{2,2} & \cdots & k_{2, n_{r}} \\
\vdots & \vdots & \ddots & \vdots \\
k_{n_{p}, 1} & k_{n_{p}, 2} & \cdots & k_{n_{p, n_{r}}}
\end{array}\right]\left[\begin{array}{c}
u_{1} \\
u_{2} \\
\vdots \\
u_{n_{r}}
\end{array}\right]
\end{aligned}
$$

onde $y_{p}$ e $u_{r}$ são a $p$-ésima saída e a $r$-ésima entrada da planta na condição estática.

A seção 8.5 discute como estabelecer os requisitos de amplitude dos sinais de entrada visando as restrições de amplitudes de saída de uma planta mal condicionada.

As implicações, vantagens e desvantagens das identificações em malha fechada e aberta são discutidas no apêndice A.

Para identificação de não linearidades, é necessário excitar o sistema em uma faixa de amplitude que atinja as não linearidades do sistema. Quando isso não é possível, ao invés de se obter um modelo não linear que represente as não linearidades em uma ampla faixa de operação, pode-se obter vários modelos lineares que juntos compõem uma ampla faixa de operação. Adicionalmente, também é possível incorporar ao modelo linear informações sobre o comportamento do sistema em regiões de operação não visitadas pelos dados, inclusive considerar os fenômenos físicos envolvidos, como na modelagem caixa-cinza. Por outro lado, pode não ser possível lidar com excursões de pequena amplitude. Assim, os dados resultantes do teste podem ser utilizados para obter modelos não lineares globais, ou seja, modelos que tenham uma faixa de validade mais ampla do que os modelos lineares. Caso não seja desejado obter modelos globais, pode-se utilizar o estimador de mínimos quadrados ponderado (weighted least squares, WLS), que atribui pesos menores para os dados mais distantes do ponto de operação para o qual o modelo está sendo obtido (AGUIRRE, 2007). O apêndice B apresenta uma breve discussão sobre requisitos dos sinais de excitação para identificação de plantas com não linearidades.

\subsection{Conhecimentos a priori}

Para o projeto dos sinais de excitação, são necessários conhecimentos prévios da planta em relação aos limites de amplitude de entradas e saídas (3.1) e ganhos estáticos (3.4), 
conforme discutido na seção 3.1. Adicionalmente, conforme seção 2.1.2, são necessários conhecimentos relativos à resposta em frequência da planta e da perturbação (2.29). Conforme a figura 1.1, esses conhecimentos prévios utilizados para o projeto do experimento de identificação e dos sinais de excitação são chamados de conhecimentos a priori.

Os limites de excursão das entradas e saídas da planta podem ser obtidos a partir da documentação de projeto e manuais de operação da planta. Conhecimentos relativos a ganhos estáticos e resposta em frequência podem ser obtidos com a experiência de operação da planta (por meio dos operadores e engenheiros da planta e através dos dados históricos da operação). Testes preliminares (pré-identificação) também podem ser úteis para obtenção dessas informações ou complementar as informações disponíveis. Nos testes preliminares pode ser utilizada a excitação em degrau.

Degraus podem ser aplicados para identificar as constantes de tempo dominantes e ganhos estáticos do sistema. Com a resposta ao degrau, também pode-se verificar a sintonia adequada dos controles clássicos regulatórios, quando aplicados em malha fechada. Para a identificação do sistema em malha fechada é desejável que os controles regulatórios estejam funcionando adequadamente.

Sinais de excitação com espectro plano e amplitude controlada também são bons meios de obter informações preliminares. Deve-se iniciar a aplicação de sinais com amplitude reduzida para não colocar a planta, que em princípio não é conhecida, em situações extremas de operação. Com um sinal de excitação de apenas dois níveis de amplitude (binário) normalmente obtém-se mais facilmente a confiança da equipe de operação quanto à operação segura da planta, devido a esse sinal se assemelhar a uma sequência concatenada de excitações em degrau, as quais são há algum tempo familiares na identificação de plantas de processamento. Em (RIVERA; GAIKWAD; CHEN, 1994) e (GAIKWAD; RIVERA, 1996) sugere-se utilizar sinais com resposta plana na etapa de pré-identificação. Nessa etapa, são obtidos parâmetros do modelo que permitem ajustar um novo sinal de excitação para obter um modelo aprimorado para as frequências de interesse.

Os espectros de frequências das perturbações ou, equivalentemente, as funções de autocorrelação das perturbações de cada saída podem ser obtidas com as entradas (MV) de interesse em repouso em seus respectivos pontos de operação. Evidentemente, as demais entradas da planta, caso puderem ficar em repouso não só durante a obtenção da função de autocorrelação das perturbações, mas também durante a realização do experimento de identificação, há tendência de maior sucesso na identificação em virtude de menor potência de perturbações ou ruídos nas saídas de interesse (CV) da planta. 
Neste trabalho, é assumido que as seguintes informações são conhecimentos $a$ priori para projeto dos sinais de excitação:

1. Limites de operação ou de segurança de excursão das entradas $u_{r}$ e saídas $y_{p}$ (3.1).

2. Ganhos estáticos da planta $\left(K=G^{o}(0)\right)$, quando a identificação de uma planta mal condicionada for realizada em sistemas sem controle regulatório ou, equivalentemente, com o controle regulatório em malha aberta (3.4).

3. Maiores e menores tempos de acomodação dominantes observados nas $n_{p}$ saídas da planta para cada uma das suas entradas $u_{r}$, com $0 \leq r \leq n_{r}$ :

$$
\begin{aligned}
T_{\max , r}^{\text {set }} & =\max _{1 \leq p \leq n_{p}}\left\{T_{p, r}^{s e t}\right\} \\
T_{\min , r}^{\text {set }} & =\min _{1 \leq p \leq n_{p}}\left\{T_{p, r}^{\text {set }}\right\}
\end{aligned}
$$

onde $T_{p, r}^{\text {set }}$ é o tempo de acomodação do par $p$-ésima saída e $r$-ésima entrada, com $0 \leq r \leq n_{r}$.

Nas simulações apresentadas neste trabalho, as funções de autocorrelação das perturbações não são utilizadas para projetar os sinais de excitações.

Os tempos de acomodação dominantes são aqueles associados aos maiores ganhos. Preliminarmente é assumido que as constantes de tempo máximas e mínimas de um sistema aproximado de primeira ordem podem ser obtidas:

$$
\begin{aligned}
\tau_{\max , r} & =\frac{T_{\max , r}^{\text {set }}}{\beta_{s}} \\
\tau_{\min , r}= & \frac{T_{\min , r}^{\text {set }}}{\beta_{s}}
\end{aligned}
$$

onde $\beta_{s}$ é o fator que representa o tempo de acomodação de um sistema de primeira ordem, ou seja $\beta_{s}=3$ para a resposta atingir $95 \%$ de seu valor final (T95\%), $\beta_{s}=5$ para $\mathrm{T} 99 \%$, etc.

A partir dessas constantes de tempo, é possível obter os limites do espectro de interesse da planta $B W_{r}=\left\{\omega_{L, r} ; \omega_{H, r}\right\}$ considerando a aproximação de um sistema de primeira ordem (GAIKWAD; RIVERA, 1996):

$$
\omega_{L, r}=\frac{1}{\beta_{s} \tau_{\max , r}} \leq \omega \leq \frac{\alpha_{s}}{\tau_{\min , r}}=\omega_{H, r}
$$


onde $\alpha_{s}$ é o fator que representa a velocidade da resposta em malha fechada, escrita como um múltiplo da velocidade da resposta em malha aberta.

A maior frequência de interesse da planta $\omega_{H, r}$ também é necessária para a escolha adequada do período de amostragem $T$ a ser utilizado na identificação. O apêndice C apresenta uma breve discussão sobre a determinação do período de amostragem.

Em (TULLEKEN, 1990) afirma-se que em estimadores (preditores) de erro de um passo à frente, a eficiência desses estimadores aumenta com a frequência e, portanto, características rápidas do processo são geralmente bem identificadas, quando comparadas com as estimativas das características lentas ou frequências médias. Isso pode resultar em modelos ruins do ponto de vista de controle. Na literatura, encontram-se soluções para esse tipo de problema baseadas em estimadores de mais de um passo à frente, pré-filtragem ou pré-tratamento dos dados e projeto de experimento mais aprimorado. Nesse último caso, os sinais de excitação são projetados para terem mais energia nas frequências médias e baixas, de forma a compensar a limitação do estimador de um passo à frente.

\subsection{Critérios de projeto de sinais de excitação para iden- tificação MIMO}

A partir dos conhecimentos a priori da planta (seção 3.2), dos requisitos do experimento (seção 3.1) e da minimização da variância dos parâmetros estimados (seção 2.1) é possível estabelecer os seguintes critérios para as características dos sinais de excitação:

1. Resposta em frequência: de (3.8) e de (2.29), tem-se que a potência do sinal de excitação deve estar concentrada na faixa de frequências determinada pelo intervalo $B W_{r}=\left\{\omega_{L, r} ; \omega_{H, r}\right\}$ :

$$
\max \left\{\int_{\omega_{L, r}}^{\omega_{H, r}} \Phi_{u_{r}}(\omega) d \omega\right\}
$$

onde $\omega_{L, r}$ e $\omega_{H, r}$ são as frequências mínimas e máximas de interesse da planta, calculadas conforme (3.8).

2. Potência: de (2.24) e (3.1), tem-se o critério:

$$
\max \left\{\mathbf{u}_{r}^{T} \mathbf{u}_{r}\right\}, \quad u_{\min , r} \leq u_{r}(t) \leq u_{\max , r} \text { e } y_{\min , p} \leq y_{p}(t) \leq y_{\max , p}
$$


3. Correlações cruzadas: de (2.45) tem-se o critério:

$$
\begin{aligned}
\min \left\{r_{\mathbf{u}_{r} \mathbf{u}_{s}}(k)\right\}, \quad & \forall \mathbf{u}_{r}, \mathbf{u}_{s} \in\left\{\mathbf{u}_{1}, \mathbf{u}_{2}, \ldots, \mathbf{u}_{n_{r}}\right\}, \operatorname{com} r \neq s \mathrm{e} \\
& k \in\left\{-\max \left\{d_{1}, d_{2}, \ldots, d_{n_{r}}\right\}+1 ;+\max \left\{d_{1}, d_{2}, \ldots, d_{n_{r}}\right\}-1\right\}
\end{aligned}
$$

onde $d_{r}=\left\lceil\frac{T_{\text {max }, r}^{\text {set }}}{T}\right\rceil, T$ o período de amostragem utilizado no experimento e $\lceil$.$\rceil é o$ menor inteiro maior ou igual a (.).

4. Potência das saídas: deve-se garantir SNR elevada nas saídas da planta. No caso de identificação multivariável em sistemas com a característica de direcionalidade de ganho (e sem controladores ou com os controladores em malha aberta), deve-se garantir que todas as combinações das entradas gerem dados informativos na saída da planta.

Os requisitos de persistência da excitação (PE) não foram listados (2.20), porém, são requisitos para a posterior estimação dos parâmetros do modelo, conforme discutido na seção 2.1.1.

\subsection{Considerações sobre a duração do experimento}

Intuitivamente, o período do sinal de excitação $T_{N_{s}}$ e, consequentemente, a duração em que a respectiva entrada deve ser excitada $T_{e, r}$ deve ser proporcional à maior constante de tempo do sistema para aquela entrada $\tau_{\max , r}$, para que as dinâmicas mais lentas sejam "percebidas" na saída da planta pelo algoritmo de identificação. Porém, a determinação da duração do teste depende, além da maior constante de tempo, da relação sinal ruído possível de ser obtida na saída do sistema, da robustez do algoritmo de identificação, da exatidão desejada do modelo a ser obtido (equações (2.26) e (2.34)), etc. Assim, o teste comumente é planejado com uma duração $T_{e}=\max _{1 \leq r \leq n_{r}} T_{e, r}$ muito superior ao maior tempo de acomodação da planta $T_{\max }^{\text {set }}=\max _{1 \leq r \leq n_{r}} T_{\max , r}^{\text {set }}$, porém, limitada pela duração $\tilde{T}_{e}$ em que planta poderá operar com perturbações nas entradas e saídas. Cabe lembrar que perturbações na planta podem provocar perturbações nas especificação dos produtos e, portanto, é desejável que a duração do experimento seja limitada $T_{e} \leq \tilde{T}_{e}$.

Para garantir que a planta seja excitada nas frequências baixas próximas a $\omega_{L, r}, \mathrm{o}$ limite inferior da duração da excitação $T_{e, r}$ da $r$-ésima entrada é: 


$$
\begin{aligned}
\omega_{L, r} & =2 \pi f_{L, r} \geq 2 \pi \frac{1}{T_{N_{s}}} \geq 2 \pi \frac{1}{T_{e, r}} \\
T_{e, r} & \geq T_{N_{s}} \geq 2 \pi \beta_{s} \tau_{\max , r}
\end{aligned}
$$

Para cada entrada $u_{r}$ podem haver constantes de tempo máximas $\tau_{\max , r}$ associadas significativamente diferentes. A duração da excitação $T_{e, r}$ pode ser escolhida diferente para cada entrada. Porém, é prático adotar $T_{e, 1}=T_{e, 2}=\ldots=T_{e, n_{r}}=T_{e}$ em função do maior tempo de acomodação $\max _{r, 1 \leq r \leq n_{r}} T_{\text {max }, r}^{\text {set }}$ da planta:

$$
T_{e}=\max _{1 \leq r \leq n_{r}} T_{e, r} \geq \max _{1 \leq r \leq n_{r}} 2 \pi \beta_{s} \tau_{\max , r}
$$

Nesse caso os períodos dos sinais de excitação $T_{N}$ de todas as entradas também são escolhidos iguais $\left(T_{N_{s}}=T_{e}\right)$.

Durante a duração $T_{e}$, todas as entradas são excitadas. Mesmo que esse critério não seja adotado, durante a duração $T_{e}$ a planta estaria sendo excitada em pelo menos uma de suas entradas. Grosso modo, de qualquer forma, a planta será perturbada durante todo a duração $T_{e}$.

Em uma planta linear multivariável, onde o teorema da superposição é aplicável (AGUIRRE, 2007), conforme a seção 1.3, tipicamente em experimentos com excitações em degrau, testam-se sequencialmente uma MV por vez, mantendo as demais em estado estacionário. Posteriormente o modelo multivariável (MIMO ou MISO) é construído pela composição dos subsistemas identificados: SISO ou de entrada única e múltiplas saídas (single input and multiple outputs, SIMO). Esse processo pode ser longo, consequentemente custoso, dependendo da dinâmica dos subsistemas, da quantidade de MV a serem testadas (quantidade de subsistemas) e da quantidade de repetição dos testes em função de perturbações nas saídas (ZHU, 1998). Em (RIVERA et al., 2003) é mencionado que a etapa de identificação do sistema tem representado $75 \%$ dos custos associados a um projeto de implantação de MPC.

Conforme descrito na seção 1.1, um dos cuidados do conceito de identificação plant friendliness é o experimento ter curta duração, de forma a minimizar as horas de engenharia e a quantidade de (ou a possibilidade de gerar) produtos fora de especificação. Intuitivamente, imagina-se que haverá redução de tempo de experimento se as variáveis de processos forem excitadas simultaneamente ao invés de excitar cada uma delas separadamente durante o experimento. Nesse contexto surge a identificação multivariável, a qual é caracterizada pela excitação simultânea de mais 
de uma entrada do sistema. Ela tem como principal objetivo reduzir a duração do experimento, obtendo um modelo ainda adequado para sua aplicação.

Conforme (CONNER; SEBORG, 2004), alguns pacotes comerciais de identificação recomendam que a duração do teste seja $T_{e}=6\left(n_{r}+n_{d}\right) \tau_{\max }$, onde $n_{r}$ e $n_{d}$ são a quantidade de entradas e a quantidade de variáveis de distúrbio medidas, respectivamente. Em (ZHU, 1998) é registrada redução em geral de $60 \%$ na duração do teste com a identificação multivariável em relação ao teste em degrau sequencial das entradas. Relata-se também que uma planta de destilação de petróleo com 20 MV tipicamente necessita de 15 a 20 dias para a realização de testes em degrau. Com o uso de sinais adequados de excitação e testes de identificação multivariável, essa duração é reduzida para 5 dias.

\subsection{Funções de correlação dos sinais de excitação}

Considere o sistema em tempo discreto MISO linear causal e invariante no tempo com $n_{r}$ entradas:

$$
y(t)=\sum_{j_{1}=0}^{\infty} h_{1}\left(j_{1}\right) u_{1}\left(t-j_{1}\right)+\sum_{j_{2}=0}^{\infty} h_{2}\left(j_{2}\right) u_{2}\left(t-j_{2}\right)+\ldots+\sum_{j_{r}=0}^{\infty} h_{r}\left(j_{r}\right) u_{r}\left(t-j_{r}\right)
$$

onde $h_{n}(t)$ é a resposta impulsiva do subsistema $H_{n}$. Qualquer sistema linear de múltiplas entradas pode ser escrito na forma de (3.14).

Sem perda de generalidade, considere um experimento de duração $T_{e}=N_{e} T=$ $T_{N_{s}}$, resultando em um total de observações $N_{e}=N_{s}$. A forma matricial de (3.14) será:

$$
\mathbf{y}=U \mathbf{h}
$$

$$
\left[\begin{array}{c}
y(0) \\
y(1) \\
\vdots \\
y\left(N_{s}-1\right)
\end{array}\right]=\left[\begin{array}{ccccc}
u_{1}(0) & u_{1}(-1) & \cdots & u_{1}(1-n) & \cdots \\
u_{1}(1) & u_{1}(0) & \cdots & u_{1}(2-n) & \cdots \\
\vdots & \vdots & \vdots & \vdots & \ddots \\
u_{1}\left(N_{s}-1\right) & u_{1}\left(N_{s}-2\right) & \cdots & u_{1}\left(N_{s}-n\right) & \cdots
\end{array}\right.
$$




$$
\left.\begin{array}{ccccc}
\cdots & u_{r}(0) & u_{r}(-1) & \cdots & u_{r}(1-n) \\
\cdots & u_{r}(1) & u_{r}(0) & \cdots & u_{r}(2-n) \\
\ddots & \vdots & \vdots & \vdots & \vdots \\
\cdots & u_{r}\left(N_{s}-1\right) & u_{r}\left(N_{s}-2\right) & \cdots & u_{r}\left(N_{s}-n\right)
\end{array}\right]\left[\begin{array}{c}
h_{1}(0) \\
h_{1}(1) \\
\vdots \\
h_{1}(n-1) \\
\vdots \\
h_{r}(0) \\
h_{r}(1) \\
\vdots \\
h_{r}(n-1)
\end{array}\right]
$$

onde $n>\frac{T_{\text {max }, r}^{\text {set }}}{T}$, para $r=1,2, \ldots, n_{r}$, representa o total de pontos significativos da resposta impulsiva $\mathbf{h}$.

A estimativa da resposta impulsiva do sistema utilizando o estimador de mínimos quadrados (2.15) é dada por (AGUIRRE, 2007):

$$
\hat{\mathbf{h}}=\left[U^{T} U\right]^{-1} U^{T} \mathbf{y}
$$

O termo $U^{T} U$ de (3.17) será semelhante a (2.40) e o termo $U^{T} \mathbf{y}$ pode ser escrito como:

$$
U^{T} \mathbf{y}=\left[\begin{array}{cccc}
u_{1}(0) & u_{1}(1) & \cdots & u_{1}\left(N_{s}-1\right) \\
u_{1}(-1) & u_{1}(0) & \cdots & u_{1}\left(N_{s}-2\right) \\
\vdots & \vdots & \ddots & \vdots \\
u_{1}(1-n) & u_{1}(2-n) & \cdots & u_{1}\left(N_{s}-n\right) \\
\vdots & \vdots & \ddots & \vdots \\
u_{r}(0) & u_{r}(1) & \cdots & u_{r}\left(N_{s}-1\right) \\
u_{r}(-1) & u_{r}(0) & \cdots & u_{r}\left(N_{s}-2\right) \\
\vdots & \vdots & \ddots & \vdots \\
u_{r}(1-n) & u_{r}(2-n) & \cdots & u_{r}\left(N_{s}-n\right)
\end{array}\right]\left[\begin{array}{c}
y(0) \\
y(1) \\
\vdots \\
y\left(N_{s}-1\right)
\end{array}\right]
$$




$$
=N_{s}\left[\begin{array}{c}
r_{u_{1} y}(0) \\
r_{u_{1} y}(1) \\
\vdots \\
r_{u_{1} y}(n-1) \\
r_{u_{2} y}(0) \\
r_{u_{2} y}(1) \\
\vdots \\
r_{u_{2} y}(n-1) \\
\vdots \\
r_{u_{r} y}(0) \\
r_{u_{r} y}(1) \\
\vdots \\
r_{u_{r} y}(n-1)
\end{array}\right]=N_{s}\left[\begin{array}{c}
\mathbf{r}_{u_{1} y} \\
\mathbf{r}_{u_{2} y} \\
\vdots \\
\mathbf{r}_{u_{r} y}
\end{array}\right]
$$

De (3.17), (2.40) e (3.18), tem-se:

$$
\begin{aligned}
{\left[\begin{array}{c}
\hat{\mathbf{h}_{1}} \\
\hat{\mathbf{h}_{2}} \\
\vdots \\
\hat{\mathbf{h}_{r}}
\end{array}\right]=} & \frac{1}{N_{s}}\left[\begin{array}{cccc}
R_{u_{1} u_{1}} & R_{u_{1} u_{2}} & \cdots & R_{u_{1} u_{r}} \\
R_{u_{1} u_{2}}^{T} & R_{u_{2} u_{2}} & \cdots & R_{u_{2} u_{r}} \\
\vdots & \vdots & \ddots & \vdots \\
R_{u_{1} u_{r}}^{T} & R_{u_{2} u_{r}}^{T} & \cdots & R_{u_{r} u_{r}}
\end{array}\right]^{-1} N_{s}\left[\begin{array}{c}
\mathbf{r}_{u_{1} y} \\
\mathbf{r}_{u_{2} y} \\
\vdots \\
\mathbf{r}_{u_{r} y}
\end{array}\right] \\
= & {\left[\begin{array}{cccc}
R_{u_{1} u_{1}} & R_{u_{1} u_{2}} & \cdots & R_{u_{1} u_{r}} \\
R_{u_{1} u_{2}}^{T} & R_{u_{2} u_{2}} & \cdots & R_{u_{2} u_{r}} \\
\vdots & \vdots & \ddots & \vdots \\
R_{u_{1} u_{r}}^{T} & R_{u_{2} u_{r}}^{T} & \cdots & R_{u_{r} u_{r}}
\end{array}\right]^{-1}\left[\begin{array}{c}
\mathbf{r}_{u_{1} y} \\
\mathbf{r}_{u_{2} y} \\
\vdots \\
\mathbf{r}_{u_{r} y}
\end{array}\right] } \\
= & \mathbf{R}^{-1}\left[\begin{array}{c}
\mathbf{r}_{u_{1} y} \\
\mathbf{r}_{u_{2} y} \\
\vdots \\
\mathbf{r}_{u_{r} y}
\end{array}\right]
\end{aligned}
$$

onde $\mathbf{R}$ é a matriz de correlações entre os sinais $u_{1}, u_{2}, \ldots, u_{r}$.

Na seção 2.1.1, foi discutida para o caso SISO a necessidade do sinal PE para garantir a existência de $R^{-1}$. O caso MISO é equivalente. Há diferença na matriz de regressores (neste caso $U$ ) que contêm dados das múltiplas entradas. Assim, o sinal de excitação que possibilita $\mathbf{R}^{-1}$ em (3.19) e, consequentemente, a unicidade da solução de estimação de parâmetros, é conhecido como sinal persistentemente excitante (PE). Em outras palavras, o conjunto de entradas é suficientemente ativo para 
excitar as dinâmicas do sistema e promover um experimento suficientemente informativo (LJUNG, 1999) (AGUIRRE, 2007).

Se as funções de correlação cruzada $r_{u_{1} u_{2}}(k)$ para $-n+1 \leq k \leq n-1$ forem nulas e as funções de autocorrelação forem do tipo $r_{u u}(k)=0$ para $-n+1 \leq k<0$ e $0<k \leq n-1$, ou seja, como as funções de correlação do ruído branco, a matriz de correlações $\mathbf{R}$ de (3.19) poderá ser reduzida a:

$$
\mathbf{R}=\left[\begin{array}{cccc}
r_{u_{1} u_{1}}(0) I & 0 & \cdots & 0 \\
0 & r_{u_{2} u_{2}}(0) I & \cdots & 0 \\
\vdots & \vdots & \ddots & \vdots \\
0 & 0 & \cdots & r_{u_{r} u_{r}}(0) I
\end{array}\right]
$$

onde $I \in \mathbb{R}^{n \times n}$ é a matriz identidade.

Como consequência de (3.20):

$$
\begin{aligned}
\hat{\mathbf{h}}_{1} & =\frac{1}{r_{u_{1} u_{1}}(0)} I \mathbf{r}_{u_{1} y} \\
\hat{\mathbf{h}}_{2} & =\frac{1}{r_{u_{2} u_{2}}(0)} I \mathbf{r}_{u_{2} y} \\
\hat{\mathbf{h}}_{r} & =\frac{1}{r_{u_{r} u_{r}}(0)} I \mathbf{r}_{u_{r} y}
\end{aligned}
$$

Assim, verifica-se que as características de correlação (autocorrelação e correlação cruzada) dos sinais de excitação semelhantes às do ruído branco descorrelacionam perfeitamente as entradas do sistema contribuindo para a boa estimativa dos subsistemas.

Do ponto de vista numérico da estimação dos parâmetros do modelo por meio de regressores, quanto mais constante for o sinal de excitação, mais mal condicionada será a matriz de correlações $\mathbf{R}$ a ser invertida, uma vez que suas colunas tenderão a ser linearmente dependentes. A superamostragem também pode causar esse efeito (apêndice C). Adicionalmente, quanto mais correlacionados forem os sinais aplicados a entradas diferentes, mais mal condicionada também será a matriz de correlações $\mathbf{R}$.

Assim, a discussão desta seção corrobora uma das características desejáveis (2.45) para o conjunto de sinais de excitação para identificação multivariável apresentada na seção 3.3. Ou seja, os sinais de excitação adequados para identificação multivariável devem ser não correlacionados ou, pelo menos, apresentar uma zona de correlação reduzida (low correlation zone, LCZ), a qual representa o intervalo $|k| \leq Z$ onde as funções de correção cruzada $r_{u_{1} u_{r}}(k)$ apresentam valores reduzidos. Particularmente, quando os valores de correlação reduzidos forem nulos, a LCZ é chamada de zona de 
correlação nula (zero correlation zone, ZCZ) (TANG; FAN; MATSUFUJI, 2000).

Idealmente, os sinais de excitação devem ter características de ruído branco para que as entradas do sistema sejam perfeitamente descorrelacionadas, principalmente quando se tem pouco conhecimento da planta a ser modelada, quando dos testes preliminares. O ruído branco pode ser caracterizado como uma série temporal (sequência) aleatória infinita de variáveis independentes e identicamente distribuídas (independent and identically distributed, iid). Essa sequência possui função de autocorrelação idêntica à função delta de $\operatorname{Dirac}^{1} \mathrm{e}$, portanto, densidade espectral de potência constante para qualquer frequência (PAPOULIS, 1991). Contudo, tais sequências aleatórias infinitas iid não são factíveis de implementação prática pelo simples fato de elas serem infinitas (ou muito longas), terem espectro constante e, portanto, possuírem energia infinita. Esse problema de ordem prática pode ser contornado com o uso dos chamados sinais pseudo-aleatórios, os quais são determinísticos. Um sistema a ser identificado, do ponto de vista de sua dinâmica, possui modos dominantes em uma faixa finita de frequências. Um sinal pseudo-aleatório é interpretado como "branco" para um sistema se contiver energia suficiente e constante na faixa de frequências dominante. Portanto, exigir que o sinal de excitação seja branco, equivale a requerer que este excite completamente a dinâmica da planta, ou seja, característica de um sinal PE (AGUIRRE, 2007). O capítulo 5 apresenta métodos de obter sinais pseudo-aleatórios com as propriedades de correlação desejáveis para a identificação multivariável. Vários métodos apresentados originalmente foram desenvolvidos para obter sinais aplicáveis a sistemas de comunicação, radar, sonar, criptografia e sincronismo de redes (GOLOMB; GONG, 2005). Tais sinais possuem, inclusive, as propriedades de correlação desejáveis para a identificação multivariável. Cabe ressaltar que em identificação de plantas com característica de direcionalidade de ganho, as características de correlações de sinais "brancos" não são suficientes para que determinadas combinações de entradas gerem saídas com relação sinal ruído suficiente para a identificação.

No estudo de sinais determinísticos, ao invés de analisar as funções de correlação de sinais estacionários dadas por (2.38) e (2.39), analisa-se, equivalentemente, as funções de autocorrelação e correção cruzada periódica:

$$
r_{u u}(k)=\frac{1}{N_{s}} \sum_{i=0}^{N_{s}-1} u(i) \underline{u}(i-k)=r_{u u}(-k)
$$

e:

${ }^{1} \mathrm{~A}$ função delta de Dirac de uma variável discreta possui as propriedades $\delta(x)=0$ se $x \neq 0$ e $\delta(0)=\infty$. 


$$
r_{u_{q} u_{r}}(k)=\frac{1}{N_{s}} \sum_{i=0}^{N_{s}-1} u_{q}(i) \underline{u}_{r}(i-k)=r_{u_{r} u_{q}}(-k)
$$

onde:

$$
\underline{u}(i-k)=u(j), \operatorname{com} j=(i-k) \bmod N_{s}
$$

é o deslocamento cíclico de $k$ posições do sinal $u(i)$.

Observe que os resultados de (2.38) e (2.39) para sinais determinísticos repetidos continuamente, ou seja, estacionários, serão iguais aos resultados de (3.22) e (3.23). Observar um sinal s obtido a partir da concatenação de infinitos sinais determinísticos $\mathbf{u}$ de período $N_{s}, \mathbf{s}=\{\ldots, \mathbf{u}, \mathbf{u}, \mathbf{u}, \ldots\}$ será equivalente a observar deslocamentos cíclicos do sinal determinístico u de período $N_{s}$, ou seja, $s(i)=\underline{u}(j)$, com $j=i \bmod N_{s}$.

Caso seja utilizado um $\mathrm{ZOH}$ de fator $M$ associado ao sinal de excitação, esse não terá função de autocorrelação do tipo delta de Dirac (para $|j| \leq(n-1)$ ). Portanto, $R_{u и}$ não será diagonal, pois $r_{u u}(j)$, com $1 \leq|j| \leq M$, não será nulo, ou seja, o espectro de $u(i)$ não será plano. Essa característica da função de correlação é evidente. O apêndice D discute resumidamente as características do $\mathrm{ZOH}$.

Para simplificar a notação de índices subescritos, em alguns momentos neste trabalho será utilizada também a seguinte notação para as funções de correlação:

$$
\begin{array}{r}
r_{u u}(k)=r(\mathbf{u}, \mathbf{u}, k) \\
r_{u_{q} u_{r}}(k)=r\left(\mathbf{u}_{q}, \mathbf{u}_{r}, k\right)
\end{array}
$$

\subsection{Limites para as funções de correlação}

Neste trabalho, são chamadas de sequências as séries de números que são interpretadas como sinais em tempo discreto quando associados a um período de amostragem. É conveniente estudar as propriedades de correlação de sequências pois não há preocupação com a dimensão tempo. As propriedades observadas nas funções de correlação de sequências podem ser facilmente vertidas para sinais discretos.

Por exemplo, sejam as sequências $u_{q}$ e $u_{r}$ de comprimento $N$ (total de $N$ elementos em cada sequência). A partir dessas sequências, são gerados os sinais $u_{q}^{\prime}$ e $u_{r}^{\prime}$ em tempo discreto, respectivamente, com período de chaveamento mínimo $T_{c l k}$ e período de amostragem $T$ : 


$$
u_{q}^{\prime}(t)=u_{q}\left(\left\lfloor t \frac{T}{T_{c l k}}\right\rfloor\right)
$$

onde $\lfloor$.$\rfloor representa o maior inteiro menor ou igual a (.).$

As funções de correlação cruzada entre $u_{q}$ e $u_{r}$ e entre $u_{q}^{\prime}$ e $u_{r}^{\prime}$ estarão relacionadas:

$$
\begin{aligned}
& r_{u_{q}^{\prime} u_{r}^{\prime}}\left(k \frac{T_{c l k}}{T}\right)=\frac{1}{N_{e} \frac{T_{c l k}}{T}} \sum_{i=0}^{N_{e}} \sum_{\frac{T_{c l k}}{T}}^{T} u_{q}^{\prime}(i) u_{r}^{\prime}\left(i-k \frac{T_{c l k}}{T}\right) \\
& =\frac{1}{N_{e} \frac{T_{c l k}}{T}} \sum_{i=0}^{N_{e} \frac{T_{c l k}}{T}-1} u_{q}\left(\left\lfloor i \frac{T}{T_{c l k}}\right\rfloor\right) u_{r}\left(\left\lfloor i \frac{T}{T_{c l k}}-k \frac{T_{c l k}}{T} \frac{T}{T_{c l k}}\right\rfloor\right) \\
& =\frac{1}{N_{e}} \sum_{i=0}^{N_{e}-1} u_{q}(i) u_{r}(i-k) \\
& =r_{u_{q} u_{r}}(k)
\end{aligned}
$$

Esta seção apresenta um resumo da seção 1.2 de (KURAMOTO, 2005). São apresentadas expressões que relacionam limites máximos assumidos pelas funções de correlação periódica entre sequências de comprimento $N$ de um conjunto de $K_{s}$ sequências. Com esses limites, comprova-se que quanto maior o número de sequências $K_{s}$ de determinado comprimento $N$, maior serão os limites máximos assumidos pelas funções de correlação periódica. Esse é um grande desafio do projeto de sinais de excitação para identificação multivariável, pois é desejável excitar muitas entradas simultaneamente sem alterar a duração do experimento $T_{e}$ e mantendo reduzidas as correlações cruzadas entre os sinais de excitação.

Inicialmente em (WELCH, 1974), foi apresentado um limite que estabelece quão reduzidos podem ser os valores da função de correlação cruzada periódica e da função de autocorrelação periódica para um conjunto $A$ de $K_{s}$ sequências de comprimento $N$ compostas de elementos complexos de módulos unitários ${ }^{2}$ tal que $r_{u u}(0)=N$, com $\mathbf{u} \in A$. Esse limite é conhecido como limite de Welch e é dado por:

$$
\left(\frac{r_{m}}{N}\right)^{2} \geq \frac{K_{s}-1}{K_{s} N-1}
$$

onde:

\footnotetext{
${ }^{2}$ Neste trabalho, os elementos das sequências pertencem ao conjunto dos números reais. Portanto, os limites apresentados para as funções de correlação são aplicáveis às sequências cujos elementos são do tipo +1 ou -1 , ou seja, sinais binários de amplitude unitária.
} 


$$
\begin{aligned}
& r_{m}=\max \left\{r_{c}, r_{a}\right\} \\
& r_{c}=\max \left\{\left|r\left(\mathbf{u}_{q}, \mathbf{u}_{r}, d\right)\right|: \mathbf{u}_{q} \neq \mathbf{u}_{r},|d|<N\right\} \\
& r_{a}=\max \{|r(\mathbf{u}, \mathbf{u}, d)|: 0<|d|<N\}
\end{aligned}
$$

onde $\mathbf{u}_{q}, \mathbf{u}_{r} e \mathbf{u} \in A$.

Em (SARWATE, 1979), o autor faz a observação que se um conjunto de sequências possui boas propriedades de correlação cruzada, as propriedades de autocorrelação não serão muito boas. Essa observação qualitativa é verificada com limites inferiores que relacionam as funções de correlação cruzada e de autocorrelação. Para as funções de correlação periódica, o limite de Sarwate é dado por:

$$
\left(\frac{r_{c}^{2}}{N}\right)+\frac{N-1}{N\left(K_{s}-1\right)}\left(\frac{r_{a}^{2}}{N}\right) \geq 1
$$

Fazendo $r_{\max }=\max \left\{r_{c}, r_{a}\right\}$ em (3.31), obtém-se o limite de Welch (3.29). Assim, tem-se que os limites de Welch são casos particulares dos limites de Sarwate.

O limite de (3.31) mostra que não é possível obter conjuntos de sequências ideais. Considera-se ideais os conjuntos de sequências tais que:

$$
\begin{aligned}
\left|r\left(\mathbf{u}_{q}, \mathbf{u}_{r}, d\right)\right| & =0, \quad \text { para } \quad \mathbf{u}_{q} \neq \mathbf{u}_{r},|d|<N \\
|r(\mathbf{u}, \mathbf{u}, d)| & =0, \quad \text { para } 0<|d|<N
\end{aligned}
$$

A zona de correlação cruzada periódica reduzida para um conjunto $A$ de sequências é definida como:

$$
L_{C C Z}=\max \left\{\mathcal{Z}:\left|r\left(\mathbf{u}_{q}, \mathbf{u}_{r}, d\right)\right| \leq r_{c C Z}, \quad \forall \mathbf{u}_{q}, \mathbf{u}_{r} \in A, \quad \mathbf{u}_{q} \neq \mathbf{u}_{r}, \quad|d| \leq \mathcal{Z}\right\}
$$

A zona de autocorrelação periódica reduzida é definida como:

$$
L_{A C Z}=\max \left\{\mathcal{Z}:|r(\mathbf{u}, \mathbf{u}, d)| \leq r_{a C Z}, \forall \mathbf{u} \in A, 0<|d| \leq \mathcal{Z}\right\}
$$

e a zona de correlação reduzida (low correlation zone, LCZ) é definida como:

$$
L_{C Z}=\min \left\{L_{C C Z}, L_{A C Z}\right\}
$$


Quando $r_{m C Z}=\max \left\{r_{c C Z}, r_{a C Z}\right\}=0$, (3.33) define a zona de correlação cruzada nula $\left(Z_{C C Z}\right)$ e (3.34) define a zona de autocorrelação nula $\left(Z_{A C Z}\right)$. Consequentemente, (3.35) define a zona de correlação nula (zero correlation zone, ZCZ), conforme a seção 3.5 .

A partir da análise da seção anterior, tem-se que as funções de correlação devem ser observadas no intervalo $|d| \leq L_{C Z}$ ou $|d| \leq Z_{C Z}$ para a análise dos conjuntos de sequências que geram sinais de excitação para identificação de sistemas multivariáveis. Porém, na maioria dos casos será observado que para obter uma zona de correlação reduzida ou nula superior às constantes de tempo dos sistemas (tempo de acomodação do sistema), as sequências deverão ser extremamente longas o que pode tornar o teste inviável devido à sua duração extremamente longa. Assim, será importante também que as sequências resultem em valores controlados de correlação também fora da zona de correlação reduzida.

Em (TANG; FAN; MATSUFUJI, 2000) e (TANG; FAN, 2001a) foi apresentado o limite para as funções de correlação para o intervalo $|d| \leq L_{C Z}$, conhecido como limite de Tang-Fan:

$$
r_{m C Z}^{2} \geq N \frac{K_{s} L_{C Z}+K_{s}-N}{K_{s} L_{C Z}+K_{s}-1}
$$

Em (PENG; FAN, 2002) e (PENG; FAN, 2003a) foram derivados limites que relacionam as funções de correlação periódica para sequências binárias, respectivamente, considerando a zona de correlação reduzida (LCZ). Em (PENG; FAN, 2003b), o limite que relaciona a função de autocorrelação periódica com a função de correlação cruzada periódica considerando a LCZ foi generalizado para sequências compostas de elementos complexos de módulos unitários. Esse é dado por:

$$
\frac{1}{K_{s}}\left(1-\frac{1}{L_{C Z}+1}\right) r_{a C Z}^{2}+\left(1-\frac{1}{K_{s}}\right) r_{c C Z}^{2} \geq N-\frac{N^{2}}{K_{s}\left(L_{C Z}+1\right)}
$$

Fazendo $L_{C Z}=N-1, r_{a C Z}=r_{a}$ e $r_{c C Z}=r_{c}$ em (3.38), obtém-se o limite de Sarwate (3.31) para as funções de correlação periódica. Fazendo $r_{m}=\max \left\{r_{c C Z}, r_{a C Z}\right\}$ e $L_{C Z}=N-1$ em (3.38), obtém-se o limite de Welch (3.29) para as funções de correlação periódica. Como o limite de Sarwate para as funções de correlação periódica (3.31) é um caso particular de (3.38), este é conhecido como limite de Sarwate generalizado.

Apesar dos limites apresentados aqui terem sido derivados para sequências binárias 
ou sequências compostos de elementos complexos de módulo unitário, eles são boas referências também para o estudo de sequências de forma geral. Esses limites permitem compreender as relações entre tamanho da zona de correlação reduzida (LCZ ou ZCZ), valores reduzidos de correlação $\left(r_{m}, r_{a}, r_{c}, r_{a} C Z, r_{c} C Z, r_{m C Z}\right)$, comprimento das sequências $N$ e tamanho do conjunto de sequências $K_{s}$. Quanto melhor as características de autocorrelação (menor $r_{a}$ ou $r_{a C Z}$ e maiores $L_{A C Z}$ ou $Z_{A C Z}$ ) piores serão as características de correlação cruzada (maiores $r_{c}$ ou $r_{c Z C}$ e menores $L_{C C Z}$ ou $Z_{C C Z}$ )

A figura 3.1 ilustra as relações entre o limite de Welch e o de Sarwate. Segundo o limite de Welch (3.29), um ponto $\left\{\frac{r_{c}^{2}}{N}, \frac{r_{a}^{2}}{N}\right\}$ nunca estará no interior da região hachurada. Em contrapartida, o limite de Sarwate (3.31) garante que um ponto $\left\{\frac{r_{c}^{2}}{N}, \frac{r_{a}^{2}}{N}\right\}$ nunca estará no interior da região sombreada (abaixo da reta $\left(\frac{r_{c}^{2}}{N}\right)+\frac{N-1}{N\left(K_{s}-1\right)}\left(\frac{r_{a}^{2}}{N}\right)=1$ ). Assim, o limite de Sarwate é mais restritivo que o limite de Welch.

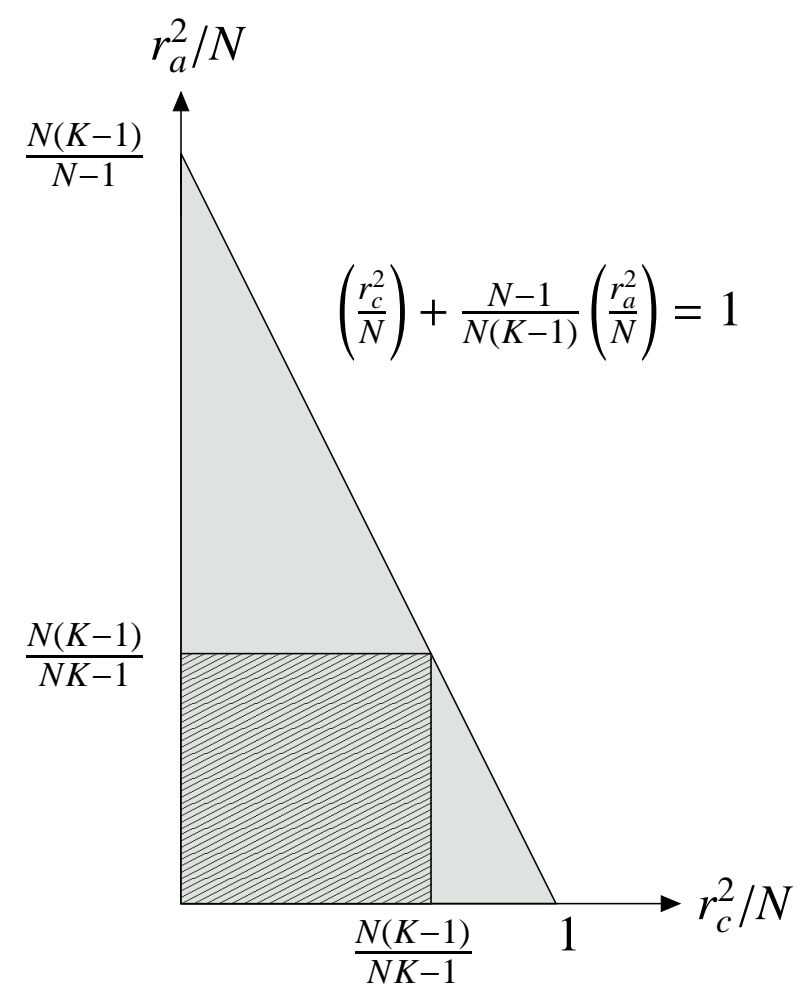

Figura 3.1: Esboço dos limites de Welch e Sarwate.

A figura 3.2 ilustra as relações entre os limites de Sarwate generalizado, TangFan, Welch e Sarwate. Segundo o limite de Tang-Fan (3.36), nenhum ponto $\left\{\frac{r_{c C Z}^{2}}{N}, \frac{r_{a C Z}^{2}}{N}\right\}$ estará no interior da região duplamente hachurada. O limite de Sarwate generalizado é mais restritivo, pois garante que nenhum ponto $\left\{\frac{r_{c C Z}^{2}}{N}, \frac{r_{c C Z}^{2}}{N}\right\}$ estará abaixo das retas $\frac{1}{K_{s}}\left(1-\frac{1}{L_{C Z}+1}\right) r_{a C Z}^{2}+\left(1-\frac{1}{K_{s}}\right) r_{c C Z}^{2}=N-\frac{N^{2}}{K_{s}\left(L_{C Z}+1\right)}$ definidas por $L_{C Z}$. Observe no gráfico que para $L_{C Z}=N-1$ obtém-se o esboço do limite de Sarwate e Welch, conforme já mencionado.

O esboço do limite de Sarwate mostra que quanto menor a zona de correlação re- 


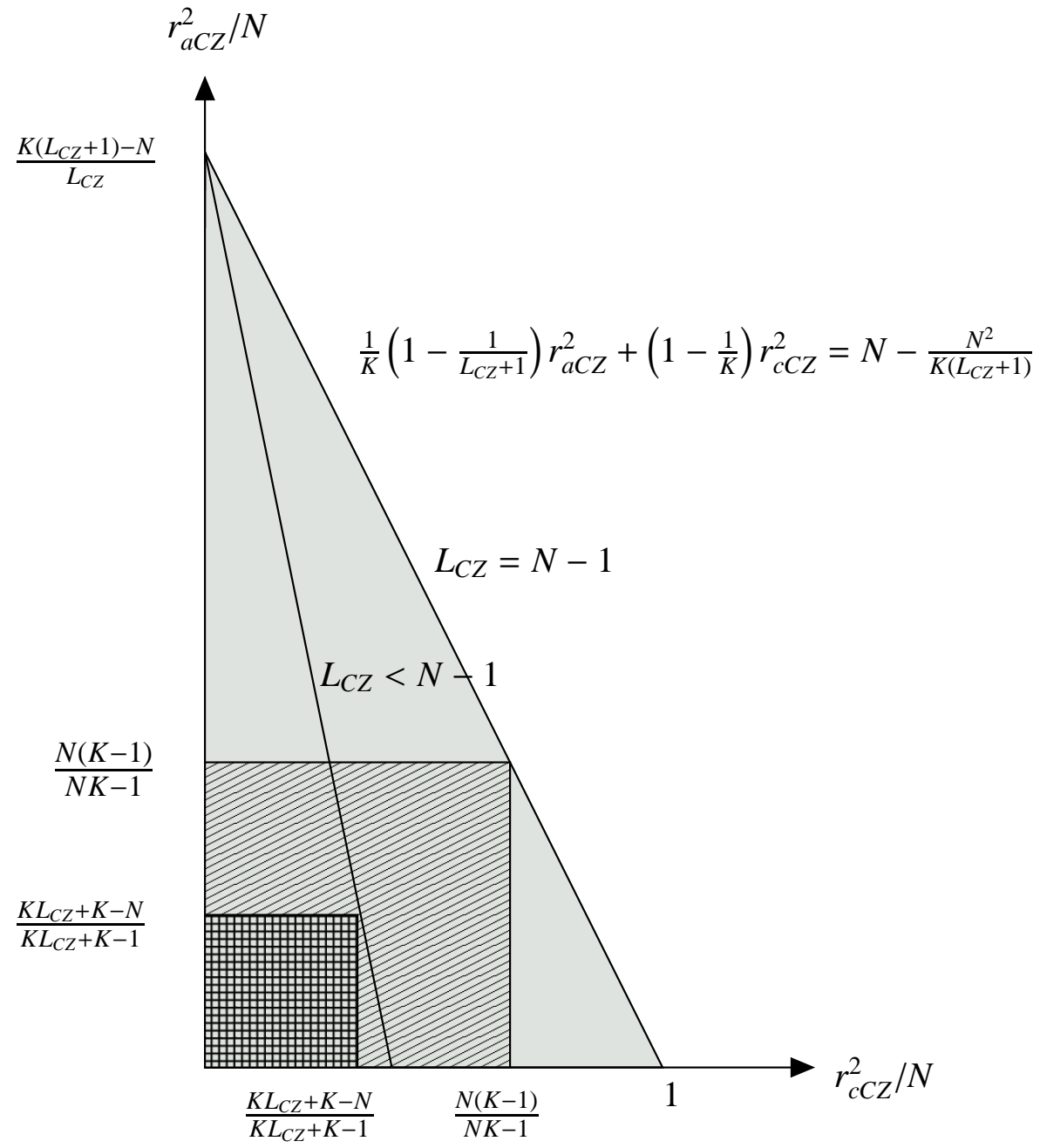

Figura 3.2: Esboço dos limites de Sarwate generalizado e Tang-Fan.

duzida (LCZ), maior será a região com pontos $\left\{\frac{r_{c C Z}^{2}}{N}, \frac{r_{a c Z}^{2}}{N}\right\}$ com reduzidos valores de $r_{c C Z}$ e $r_{a C Z}$. Na figura 3.2, observa-se também que aumentando-se a relação $\frac{N}{K_{s}}$, aumentase também a região com pontos $\left\{\frac{r_{c C Z}^{2}}{N}, \frac{r_{a C Z}^{2}}{N}\right\}$ com reduzidos valores de $r_{c C Z}$ e $r_{a C Z}$. O que é intuitivo, pois para um dado comprimento $N$, quanto mais sequências tiver um conjunto, haverá mais pares de sequências que apresentam valores mais elevados de correlação. Essa característica será verificada nos conjuntos de sequências que serão apresentados no próximo capítulo.

\subsection{Propriedades desejáveis para os sinais de excitação}

Em síntese, as características desejáveis para os sinais de excitação aplicáveis à indústria de processos são:

1. Capacidade de manter as movimentações das entradas e saídas da planta dentro de determinados limites (3.1); 
2. Período reduzido para viabilizar um experimento de curta duração de forma a minimizar o período de perturbação do processo e as horas de engenharia (conceito identificação plant-friendliness);

3. Possuir potência significativa na faixa de frequências que representam as dinâmicas de interesse (os modos) do sistema para a modelagem, dadas as restrições de amplitude (seção 3.3, itens 1 e 2);

4. Em modelagem multivariável é importante que os sinais utilizados para excitar as entradas sejam não correlacionados. Assim, é possível, pelo algoritmo de identificação, atribuir a uma entrada um efeito observado em uma determinada saída (AGUIRRE, 2007) (seção 3.3, item 3);

5. Produzir variações suficientes nas saídas para minimizar os efeitos dos ruídos durante a estimação de parâmetros do modelo (GODFREY et al., 2005) (seção 3.3, item 4);

6. Possuir amplitude suficiente para revelar as características não lineares, caso desejado; ou ter cuidado em não excitar as características não lineares do sistema, limitando a excursão do sinal de excitação. Realçar (ou suavizar) características desejadas (ou não desejadas) do sistema;

7. Supressão de harmônicos não desejáveis, os quais não devem ser excitados, por exemplo, para identificação de não linearidades (apêndice B);

A tabela 3.1 resume essas características desejáveis para os sinais de excitação aplicáveis à indústria de processos.

Diversos trabalhos apresentam índices de desempenho que medem a qualidade do sinal de excitação em relação às características desejáveis de amplitude e resposta em frequência apresentadas aqui. Conforme discutido no capítulo 1, para garantir o

Tabela 3.1: Características desejáveis para sinais de excitação aplicáveis à indústria de processos.

\begin{tabular}{ll}
\hline Item & Característica \\
\hline 1 & Manter controlados os desvios nas entradas e saídas da planta. \\
2 & Período reduzido. \\
3 & Potência significativa na faixa de frequências de interesse. \\
4 & Potência suficiente para minimizar os efeitos dos ruídos. \\
5 & Sinais não correlacionados para identificação multivariável. \\
6 & Amplitude suficiente para revelar não linearidades, caso desejado. \\
7 & Suprimir harmônicos não desejáveis. \\
\hline
\end{tabular}


sucesso de um experimento é necessário avaliar a qualidade dos sinais de excitação previamente à sua realização. Esses índices são apresentados no capítulo 4.

É reconhecida a importância de um projeto adequado de sinais de excitação e a escolha de um método adequado de processamento dos sinais de entrada e saída da planta. Com sinais de excitação associados a métodos de processamento de entradas e saídas, pode-se realçar (ou suavizar) características desejadas (ou não desejadas) do sistema (GODFREY et al., 2005). O capítulo 5 apresentará diversos métodos de geração de sinais de excitação atendendo as características desejáveis listadas anteriormente. Será observado que comumente os métodos atendem parcialmente a lista de características desejáveis, ou seja, não há um método que satisfaz completamente essas características a qualquer sistema. Isso mostra a importância de conhecer os métodos para aplicá-los e combiná-los de forma a obter o máximo de informação do sistema em um experimento, dadas as restrições práticas.

Do ponto de vista operacional, sinais com limites de amplitude constante como os sinais binários são mais aceitos que sinais com amplitude consideravelmente variável. A equipe de operação de um planta tende a aceitar mais facilmente em um experimento de identificação sinais cuja potência seja igualmente distribuída nas frequências a sinais com potência concentrada em frequências críticas (TULLEKEN, 1990). Porém, na maioria dos casos, as frequências críticas são as de maior interesse em um experimento suficientemente informativo com o objetivo de obter bons modelos para controle justamente na região de frequências críticas. A perturbação de uma variável por vez é preferível pelos operadores a perturbar múltiplas variáveis simultaneamente, pois durante o teste toda a atenção fica concentrada em apenas uma variável manipulada. Porém, o argumento da redução do tempo de experimento em uma identificação multivariável pode ser decisivo. O teste de apenas uma variável por vez e o tempo total de teste reduzido em princípio são características desejáveis contraditórias. A tabela 3.2 reúne as características desejáveis do ponto de vista operacional discutidas aqui.

Tabela 3.2: Características desejáveis para sinais de excitação do ponto de vista operacional.

\begin{tabular}{ll}
\hline Parâmetro & Valor \\
\hline Amplitude & Limitada e quantizada, preferencialmente binária. \\
Resposta em frequência & $\begin{array}{l}\text { Potência distribuída (não concentrada em frequências } \\
\text { críticas). }\end{array}$ \\
Variáveis & Excitar uma por vez. \\
Tempo do experimento & O menor possível. \\
\hline
\end{tabular}




\section{Avaliação de sinais de excitação}

Uma das restrições impostas pela identificação plant-friendliness é relativa à duração máxima do experimento (seção 3.4). Para que o tempo disponível para o experimento de identificação seja bem utilizado, é necessário um planejamento adequado do experimento que contemple avaliar os sinais de excitação candidatos a serem aplicados na planta. Neste capítulo serão discutidos alguns índices que permitem avaliar sinais de excitação a partir de limitado (ou nenhum) conhecimento da planta (informações $a$ priori).

Conforme a seção 3.3, item 2, é desejável elevada potência do sinal de excitação com restrições de amplitude. Há algumas formas clássicas de medida dessa propriedade de sinais. As medidas recorrentes encontradas na literatura são o fator de pico (peak factor, PF), o fator de crista (crest-factor, CF) e a dispersão, as quais são conhecidas na literatura como medidas para avaliação de distorção de senoides (GODFREY; BARKER; TUCKER, 1999). Há outras medidas que foram desenvolvidas recentemente especificamente para os problemas de sinais de excitação para identificação de sistemas. Uma delas, que será detalhada em uma próxima seção, fornece a noção de quanto tempo é necessário para atingir uma determinada exatidão do modelo estimado (variância do modelo) com um determinado sinal de excitação. Essa medida é chamada de fator de tempo (time factor, TF) e está relacionado com o fator de crista.

A medida de dispersão $\lambda_{u}$ de um sinal $u$ estacionário é definido como (GODFREY; BARKER; TUCKER, 1999):

$$
\lambda_{u}=\frac{u_{\mathrm{max}}-u_{\min }}{2 \sigma_{u}}=\frac{u_{\max }-u_{\min }}{2 \sqrt{u_{r m s}^{2}-u_{\text {mean }}^{2}}}
$$

onde $u_{r m s}, u_{\text {mean }}, u_{\max }$ e $u_{\min }$ são os valores médio quadrático (root mean square, RMS), médio, máximo e mínimo de um sinal $u$, respectivamente. Em tempo discreto, esses são dados por: 


$$
\begin{aligned}
u_{r m s} & =\left[\frac{1}{N_{s}} \sum_{t=0}^{N_{s}-1} u(t)^{2}\right]^{1 / 2} \\
u_{\text {mean }} & =\frac{1}{N_{s}} \sum_{t=0}^{N_{s}-1} u(t) \\
u_{\max } & =\max _{t \in\left[0 ; N_{s}-1\right]} u(t) \\
u_{\min } & =\min _{t \in\left[0 ; N_{s}-1\right]} u(t)
\end{aligned}
$$

A dispersão fornece uma ideia de quão compacto é o sinal. Observa-se que a dispersão independe da amplitude de $u(t)$ e possui o limite inferior $\lambda_{u}=1$, o qual pode ser obtido por um sinal binário balanceado onde $u_{\max }=a$ e $u_{\min }=-a$ possuem a mesma duração (em tempo contínuo) ou mesma ocorrência (em tempo discreto):

$$
\begin{aligned}
& u(t)= \pm a \\
& \sum_{t=0}^{N_{s}-1} u(t)=0
\end{aligned}
$$

A medida de dispersão não possui limite superior. Em engenharia é desejável que medidas de qualidade (ou medidas de desempenho) estejam limitadas entre 0 a $100 \%$, os quais representam o pior e o melhor caso.

Em (GODFREY; BARKER; TUCKER, 1999) são apresentados três procedimentos de medida da qualidade do sinal de excitação, também chamados de índices, com a característica de possuir limites inferior e superior: índice de desempenho para sinais de excitação (performance index for perturbation signals, PIPS), índice de desempenho efetivo para sinais de excitação (effective performance index for perturbation signals, PIPSE) e de razão mínima entre a amplitude de uma harmônica do sinal e sua respectiva amplitude especificada (Effective minimum ratio between the actual harmonic amplitude and the specifed harmonic amplitude at any of the specif ed harmonics, EMINE).

Em (PINTELON; SCHOUKENS, 2001) foi proposto o indicador chamado de fator de tempo (TF), que permite avaliar o tempo dispendido para obter uma boa estimação da resposta em frequência do sistema para qualquer uma das harmônicas especificadas no sinal de excitação (GODFREY et al., 2005) (BARKER et al., 2006).

Nos trabalhos (OUDERAA; SCHOUKENS; RENNEBOOG, 1988b) e (GUILLAUME et al., 1991) a medida da qualidade do sinal baseada no fator de crista (CF) é utilizada no projeto (otimização) do sinal de excitação. Nesse método, deseja-se minimizar o CF. 
A minimização do CF implica em maximização da relação sinal ruído (SNR) dadas as restrições de amplitudes do sinal (GUILLAUME et al., 1991).

\section{1 Índice de desempenho para sinais de excitação (PIPS)}

O PIPS é definido para um sinal em tempo contínuo ou discreto. Esse índice é inversamente proporcional à dispersão (GODFREY; BARKER; TUCKER, 1999) (GODFREY et al., 2005):

$$
\text { PIPS }=100 \lambda_{u}^{-1}=\frac{200\left(u_{r m s}^{2}-u_{\text {mean }}^{2}\right)^{1 / 2}}{u_{\max }-u_{\min }} \%
$$

Para um sinal binário onde os valores $u_{\max }$ e $u_{\min }$ apresentam a mesma duração, ou seja, um sinal binário balanceado (ou equiprovável no caso de sinal aleatório binário), o PIPS atinge o máximo de $100 \%$.

O PIPS pode também ser definido como (GODFREY; BARKER; TUCKER, 1999) (GODFREY et al., 2005):

$$
P I P S=\frac{200}{N\left(u_{\max }-u_{\min }\right)}\left(\sum_{k=1}^{N-1}|U(k)|^{2}\right)^{1 / 2} \%
$$

onde $U(k)$ é a transformada discreta de Fourier (discrete Fourier transform, DFT) dada por:

$$
U(k)=\sum_{i=0}^{N_{s}-1} u(i) e^{-j \frac{2 \pi k i}{N_{s}}}
$$

Observe que o PIPS é uma medida independente da aplicação do sinal de excitação e de seu ganho e é aplicável a todas os sinais estacionários. O PIPS assume valores entre $0 \%$ e $100 \%$ os quais representam o pior e melhor caso, respectivamente. Considerando sinais com as mesmas amplitudes de pico, quanto maior o PIPS, mais potência será injetada no sistema. A ausência da harmônica zero, $k=0$ na equação (4.8), confirma que o PIPS independe da média de $u(i)$. 


\section{2 Índice de desempenho efetivo para sinais de excita- ção (PIPSE)}

O PIPS pode ser aprimorado para aplicações práticas em identificação de sistemas. Sistemas práticos possuem resposta limitada em frequência e, portanto, algumas harmônicas podem não ser efetivas para a identificação. Neste contexto, foi proposto o índice de desempenho efetivo para sinais de excitação (effective performance index for perturbation signals, PIPSE).

Na prática, utiliza-se um segurador de ordem zero $(\mathrm{ZOH}$, apêndice $\mathrm{D})$ para gerar o sinal em tempo contínuo a partir do sinal em tempo discreto. Assim, o espectro de potência unilateral de frequências positivas do sinal será dado por (GODFREY; BARKER; TUCKER, 1999) (GODFREY et al., 2005):

$$
\left|C_{u}(k)\right|^{2}= \begin{cases}\left|\frac{U(k)}{N_{s}}\right|^{2} & , k=0 \\ 2\left|\left(\frac{\sin \left(\pi k / N_{s}\right)}{\pi k / N_{s}}\right)\left[\frac{U(k)}{N_{s}}\right]\right|^{2} & , k>0\end{cases}
$$

As harmônicas próximas da frequência de Nyquist $N_{s} / 2$ são atenuadas para minimizar (ou eliminar) o efeito de rebatimento (aliasing) e são, portanto, completamente não efetivas para a identificação. Se apenas as primeiras $F$ harmônicas são utilizadas para o processo de identificação, o PIPSE será dado por (GODFREY; BARKER; TUCKER, 1999) (GODFREY et al., 2005):

$$
\operatorname{PIPSE}=\frac{200}{u_{\max }-u_{\min }}\left(\sum_{k=1}^{F}\left|C_{u}(k)\right|^{2}\right)^{1 / 2} \%, F<N_{s} / 2
$$

O PIPSE será maximizado quando $F=\frac{N_{s}-2}{2}$ para $N_{s}$ par ou $F=\frac{N_{s}-1}{2}$ para $N_{s}$ impar.

\section{3 Índice EMINE}

Observa-se que se algumas harmônicas relevantes para a identificação possuem potência reduzida, o PIPS e, consequentemente, o PIPSE podem não indicar a baixa performance do sinal. Isso porque esses indicadores estão relacionados com a soma das potências das harmônicas.

Em (KOLLáR, 1994), foi proposto o índice $E_{\min }$ que avalia sinais construídos ou otimizados por algoritmos. As entradas desses algoritmos são amplitudes especificadas para as harmônicas dos sinais. O índice representa a menor razão entre a amplitude de 
uma harmônica do sinal e a respectiva amplitude especificada:

$$
E_{\min }=\min _{k} \frac{\left|C_{u}(k)\right|}{\left|C_{u}(k)\right|_{\text {specified }}}
$$

onde $\left|C_{u}(k)\right|_{\text {specified }}$ é a amplitude especificada para a $k$-ésima harmônica.

Essa medida foi modificada, definindo o $E_{\min }$ para as $F$ harmônicas de interesse da identificação. Tal medida de desempenho modificada foi chamada índice de razão mínima entre a amplitude de uma harmônica do sinal e a sua respectiva amplitude especificada (Effective minimum ratio between the actual harmonic amplitude and the specified harmonic amplitude at any of the specified harmonics, EMINE) (GODFREY; BARKER; TUCKER, 1999).

O EMINE, de forma diferente do PIPSE, pode ser aplicado tanto para especificações de espectro uniforme como para especificações de espectro não uniforme. Para especificação de espectro uniforme, o que é mais comum na prática quando não se conhece o espectro da perturbação, o EMINE é dado por (GODFREY; BARKER; TUCKER, 1999) (GODFREY et al., 2005):

$$
E M I N E=100 \min _{k=1,2, \ldots, F} \frac{\left|C_{u}(k)\right|}{\left(\frac{1}{F} \sum_{k=1}^{F}\left|C_{u}(k)\right|^{2}\right)^{1 / 2}} \%, F<N / 2
$$

Para especificação de espectro não uniforme, o EMINE é dado por (GODFREY; BARKER; TUCKER, 1999) (GODFREY et al., 2005):

$$
\text { EMINE }=100 \min _{k=1,2, \ldots, F} \frac{\left|C_{u}(k)\right|\left(\frac{1}{F} \sum_{k=1}^{F}\left|C_{u}(k)\right|_{\text {specified }}^{2}\right)^{1 / 2}}{\left|C_{u}(k)\right|_{\text {specified }}\left(\frac{1}{F} \sum_{k=1}^{F}\left|C_{u}(k)\right|^{2}\right)^{1 / 2}} \%, F<N / 2
$$

O EMINE é independente da média do sinal $\mathbb{E}\{u(t)\}$ e da escala de amplitude (ganho). O sinal de pior performance possui $E M I N E=0 \%$ e o de melhor performance possui $E M I N E=100 \%$

Observe que a potência das harmônicas especificadas aparecem no numerador do PIPSE e no denominador do EMINE. Esses índices de desempenho são complementares. Porém, quando observados isoladamente, o PIPSE é uma medida de maior relevância que o EMINE, pois um EMINE reduzido pode ser resultado de especificação de potência elevada em apenas uma das harmônicas com potência reduzida, por exemplo. 


\subsection{Fator de crista $(\mathrm{CF})$}

O fator de crista (crest-factor, $\mathrm{CF}$ ) de um sinal é definido como a relação entre o valor de pico e o valor RMS do sinal (GUILLAUME et al., 1991):

$$
C F=\frac{u_{\max }}{u_{r m s}}
$$

Assim, melhor é um sinal quanto menor for seu fator de crista. O limite inferior teórico de $C F$ é 1, conforme (4.15). Um sinal binário balanceado possui fator de crista $C F=1$. Conforme mencionado no início deste capítulo, assim como a dispersão $\lambda_{u}$, o fator de crista também fornece uma ideia de quão compacto é o sinal. Sinais com fatores de crista elevados injetam menos potência no sistema que sinais com a mesma amplitude de pico, porém, com fatores de crista reduzidos. Diferentemente da dispersão, do PIPS e do PIPSE, o CF leva em consideração o valor médio na potência do sinal.

Em (PINTELON; SCHOUKENS, 2001) o denominador de (4.15) foi limitado ao valor RMS efetivo do sinal $u_{\text {rmse }}$ o qual compreende a potência do sinal apenas na faixa de frequências de interesse para identificação do sistema. Assim:

$$
C F=\frac{u_{\max }}{u_{\text {rmse }}}=\frac{u_{\max }}{\left[\frac{1}{N_{s}}\left(\sum_{t=0}^{N_{s}-1} u(t)^{2}\right) \frac{P_{i}}{P_{T}}\right]^{1 / 2}}
$$

onde $P_{T}$ é a potência total do sinal e $P_{i}$ a potência do sinal na faixa de frequências de interesse, considerando a identificação de um sistema plano, ou seja, com resposta constante na faixa de frequências de interesse.

A medida do CF, conforme (4.15 ou 4.16), tem sua importância, pois minimizá-lo implica em maximizar a energia (ou o valor RMS) contida no sinal, dadas as restrições de amplitude. Nos exemplos apresentados neste trabalho, o CF é calculado conforme (4.15).

\subsection{Fator de tempo (TF)}

O fator de tempo (time factor, TF) de um sinal de excitação também está relacionado com a distribuição de potência do sinal nas frequências de interesse. Ele fornece a noção de quanto tempo é necessário para atingir uma determinada exatidão do modelo estimado (variância do modelo) com um determinado sinal de excitação. 
Uma determinada exatidão do modelo estimado (determinada variância do modelo estimado) é proporcional ao número de repetições $M_{e}$ do experimento e à potência do sinal de excitação (PINTELON; SCHOUKENS, 2001):

$$
\sigma_{G}^{2}(k) \sim \frac{1}{M_{e}|U(k)|^{2}}
$$

Assim, o número de repetições $M_{e}$ do experimento é proporcional à potência do sinal $\left(M_{e} \sim \frac{1}{|U(k)|^{2}}\right)$ e o tempo total do experimento é também proporcional ao número de repetições $M_{e}$ do experimento para uma determinada exatidão do modelo estimado. Para uma determinada qualidade de resultado do experimento, o tempo total do experimento $T_{e}$ é proporcional à potência da harmônica do sinal mais fraca entre as frequências de interesse:

$$
T_{e} \sim \max _{k} \frac{1}{|U(k)|^{2}}
$$

Considerando que há $F$ frequências de interesse no sistema e no sinal de excitação:

$$
\begin{gathered}
U_{r m s e}^{2}=\frac{\sum_{k=1}^{F}|U(k)|^{2}}{F} \\
u_{\text {rmse }}^{2}=2 F U_{r m s e}^{2}
\end{gathered}
$$

A partir das equações anteriores, (4.18) e (4.16), obtém-se o fator:

$$
\frac{T_{e}}{F} \sim \max _{k} \frac{1}{F|U(k)|^{2}} \sim \max _{k} \frac{U_{r m s e}^{2}}{F|U(k)|^{2} U_{r m s e}^{2}} \sim \max _{k} \frac{C F^{2} U_{r m s e}^{2}}{|U(k)|^{2}}
$$

Normalizando o fator acima para uma senoide, define-se o fator de tempo como:

$$
T F=\max _{k \in F} 0,5 \frac{C F^{2} U_{r m s e}^{2}}{|U(k)|^{2}}
$$

O TF para um sinal simétrico onde $u_{\min }=-u_{\max }$ também pode ser expresso em termos dos índices PIPSE e EMINE (GODFREY et al., 2005):

$$
T F=0,5\left(\frac{100}{P I P S E}\right)^{2}\left(\frac{100}{E M I N E}\right)^{2}
$$

Observe em (4.23), valores elevados de TF são resultados de valores reduzidos de PIPSE e/ou EMINE, ou seja, sinais que injetam pouca potência em harmônicas de 
interesse do sistema.

\subsection{Considerações sobre medidas de qualidade}

Apesar da observação anterior relativa ao mínimo CF e máximo PIPS obtidos com os sinais binários, deve-se lembrar que os sinais binários não são adequados para identificação de não linearidades. Deve-se atentar também que a distribuição do erro do modelo no domínio da frequência é afetada pelo espectro do sinal de excitação. Assim, o espectro do sinal de excitação é uma variável de projeto que deve ser otimizada visando o desempenho do controlador. Os métodos de projeto de sinais de excitação serão discutidos no capítulo 5 .

Os índices de avaliação de sinais de excitação propostos na literatura discutidos nas seções 4 a 4.5 consideram sinais isolados, ignorando as interações que ocorrem entre sinais aplicados simultaneamente em uma identificação multivariável (MISO ou MIMO). Essas medidas consideram relações de potência e amplitude, além de relações entre o espectro do sinal sob avaliação e o espectro desejado. Na próxima seção, são propostas medidas cujo objetivo é avaliar as relações de potência e amplitude em conjunto com as interações que ocorrem entre sinais de excitação aplicados simultaneamente em uma identificação multivariável.

\subsection{Proposta de avaliação de conjuntos de sinais de exci- tação}

Considere que sejam executados dois experimentos de mesma duração definida por $N_{e}$ para identificação de uma planta $G^{0}$ de $n_{r}$ entradas e $n_{p}$ saídas em meio à perturbação $\mathbf{v}=\mathbf{e}$, do tipo ruído branco de variância $\sigma_{e}^{2}$. Em um deles utiliza-se o conjunto de sinais $A$ e no outro o conjunto de sinais $B$. Considere o estimador LS de parâmetros do $p$-ésimo submodelo $G_{p}$ com estrutura FIR MISO de ordem $n$, conforme a seção 2.2.1. A estimação de parâmetros nos dois experimentos é realizada com estimadores não polarizados, resultando nas variâncias: $\operatorname{cov}\left[\hat{\boldsymbol{\theta}}_{A}\right]$ para o experimento com o conjunto de sinais $A$ e $\operatorname{cov}\left[\hat{\boldsymbol{\theta}}_{B}\right]$ para o experimento com o conjunto de sinais $B$. Considerando que o experimento com o conjunto de sinais $A$ resultou em menor variância dos parâmetros estimados, ou seja, maior eficiência para o estimador, tem-se:

$$
\operatorname{det}\left[\operatorname{cov}\left[\hat{\boldsymbol{\theta}}_{A}\right]\right]<\operatorname{det}\left[\operatorname{cov}\left[\hat{\boldsymbol{\theta}}_{B}\right]\right]
$$




$$
\begin{aligned}
\frac{\sigma_{e}^{2}}{\operatorname{det}\left[\Psi_{A}^{T} \Psi_{A}\right]} & <\frac{\sigma_{e}^{2}}{\operatorname{det}\left[\Psi_{B}^{T} \Psi_{B}\right]} \\
\frac{1}{N_{e}^{n \times n_{r}}} \frac{\sigma_{e}^{2}}{\operatorname{det}\left[R_{A}\right]} & <\frac{1}{N_{e}^{n \times n_{r}} \frac{\sigma_{e}^{2}}{\operatorname{det}\left[R_{B}\right]}} \\
\operatorname{det}\left[R_{A}^{-1}\right] & <\operatorname{det}\left[R_{B}^{-1}\right]
\end{aligned}
$$

O resultado (4.24) mostra que tanto melhor será a eficiência do estimador quanto maior for o determinante da matriz de correlações do conjunto de sinais utilizado como excitação. Dessa forma, propõe-se avaliar comparativamente sinais de excitação por meio da medida que foi intitulada índice de comparação de conjunto de sinais para excitação (comparation index for set of signals, CISS):

$$
\operatorname{CISS}\left(X, n_{r}, d_{1}, d_{2}, \ldots, d_{n_{r}}\right)=\log _{e}\left(\operatorname{det}\left[R_{x}^{-1}\right]\right)
$$

onde:

$$
\begin{aligned}
R_{x} & =\frac{1}{N_{s}} X^{T} X \\
X & =\left[\mathbf{x}_{\mathbf{1}}{ }^{(0)} /\left\|\mathbf{x}_{\mathbf{1}}\right\|_{\infty} \mathbf{x}_{\mathbf{1}}{ }^{(-1)} /\left\|\mathbf{x}_{\mathbf{1}}\right\|_{\infty} \mathbf{x}_{\mathbf{1}}{ }^{(-2)} /\left\|\mathbf{x}_{\mathbf{1}}\right\|_{\infty} \ldots \mathbf{x}_{\mathbf{1}}{ }^{\left(-d_{1}\right)} /\left\|\mathbf{x}_{\mathbf{1}}\right\|_{\infty} \ldots\right. \\
& \ldots \mathbf{x}_{\mathbf{2}}{ }^{(0)} /\left\|\mathbf{x}_{\mathbf{2}}\right\|_{\infty} \mathbf{x}_{\mathbf{2}}{ }^{(-1)} /\left\|\mathbf{x}_{\mathbf{2}}\right\|_{\infty} \mathbf{x}_{\mathbf{2}}{ }^{(-2)} /\left\|\mathbf{x}_{\mathbf{2}}\right\|_{\infty} \ldots \mathbf{x}_{\mathbf{2}}{ }^{\left(-d_{2}\right)} /\left\|\mathbf{x}_{\mathbf{2}}\right\|_{\infty} \ldots \\
& \left.\ldots \mathbf{x}_{\mathbf{n}_{\mathbf{r}}}{ }^{(0)} /\left\|\mathbf{x}_{\mathbf{n}_{\mathbf{r}}}\right\|_{\infty} \mathbf{x}_{\mathbf{n}_{\mathbf{r}}}{ }^{(-1)} /\left\|\mathbf{x}_{\mathbf{n}_{\mathbf{r}}}\right\|_{\infty} \mathbf{x}_{\mathbf{n}_{\mathbf{r}}}{ }^{(-2)} /\left\|\mathbf{x}_{\mathbf{n}_{\mathbf{r}}}\right\|_{\infty} \ldots \mathbf{x}_{\mathbf{n}_{\mathbf{r}}}{ }^{\left(-d_{n_{r}}\right)} /\left\|\mathbf{x}_{\mathbf{n}_{\mathbf{r}}}\right\|_{\infty}\right]
\end{aligned}
$$

onde $\mathbf{x}_{\mathbf{r}}{ }^{\left(-d_{r}\right)}$ é o sinal relativo à $r$-ésima entrada deslocado ciclicamente para direita de $d_{r}$ amostras, ou seja, $\mathbf{x}_{\mathbf{r}}{ }^{\left(-d_{r}\right)}=\left[x_{r}\left(-d_{r}\right) x_{r}\left(-d_{r}+1\right) x_{r}\left(-d_{r}+2\right) \ldots x_{r}\left(N_{s}-d_{r}\right)\right]^{T}$ subtraída a sua média:

$$
x_{r}(i)=u_{r}(i)-\frac{1}{N_{s}} \sum_{i=0}^{N_{s}-1} u_{r}(i)
$$

onde $\left\|\mathbf{x}_{\mathbf{r}}\right\|_{\infty}=\max _{i}\left|x_{r}(i)\right|$ é a norma infinita de $\mathbf{x}_{\mathbf{r}}$.

Quanto menor o CISS, maior será a eficiência do estimador de parâmetros de uma estrutura FIR, ou seja, menor variância dos parâmetros estimados.

Observa-se que $d_{r}$ define o tempo de acomodação $T_{\max , r}^{\text {set }}$ do subsistema em múltiplos do período de amostragem $T$ relativo à $r$-ésima entrada, ou seja, $T_{\max , r}^{s e t} \approx d_{r} T$. Assim, relaciona-se com a ordem $n$ de uma estrutura FIR SISO suficiente para identificação, $n \approx d_{r}+1$. Considerando apenas uma entrada e $d=0$, é fácil mostrar que o CISS será igual ao PIPS (4.7). 
O CISS não possui limite superior, assim como a dispersão, CF ou TF, e também não possui limite inferior, o que, conforme já discutido, não é desejável. Por esse motivo, o CISS é proposto não como uma medida absoluta, mas como um índice comparativo de conjuntos de sinais de excitação.

No cálculo do CISS não são considerados as menores constantes de tempo dominantes da planta $\left(\tau_{\min , r}\right)$ e também não há um espectro especificado, assim como o índice EMINE. Essa é uma deficiência desse índice que faz necessária a utilização dele em conjunto com o índice EMINE ou também com o PIPSE. Considerando o caso limite em que um conjunto de sinais de excitação possui potência nula em harmônicas que deveriam ser excitadas com potências elevadas, devido à presença de ruído, por exemplo, esse pode resultar em CISS reduzido, porém, os parâmetros serão estimados com variância elevada. Neste caso, o índice EMINE indicará a deficiência dos sinais.

Cabe ressaltar que (4.25) foi derivado a partir de um estimador LS com e como ruído branco. Nessa situação o estimador LS é o que resulta em menor variância entre todos estimadores do tipo $\hat{\boldsymbol{\theta}}=A \mathbf{y}$ não polarizados (AGUIRRE, 2007).

Mesmo que uma estrutura FIR não seja utilizada para modelar a planta, a utilização da matriz de correlações das entradas para avaliação dos sinais de excitação ainda é justificada. Em uma estrutura autoregressiva, a matriz de regressores, conforme (2.3) e (2.6), tem a seguinte forma (LJUNG, 1999) (AGUIRRE, 2007):

$$
\Psi=[Y \mid U]
$$

onde:

$$
Y^{T}=\left[\mathbf{y}(1) \mathbf{y}(2) \cdots \mathbf{y}\left(N_{e}\right)\right]
$$

e, portanto:

$$
\begin{aligned}
\operatorname{det}\left(\Psi^{T} \Psi\right) & =\operatorname{det}[Y \mid U]^{T}[Y \mid U] \\
& =\operatorname{det}\left[\begin{array}{c|c}
Y^{T} Y & Y^{T} U \\
\hline U^{T} Y & U^{T} U
\end{array}\right] \\
& =\operatorname{det}\left[\begin{array}{c|c}
Y^{T} Y & Y^{T} U \\
\hline U^{T} Y & R
\end{array}\right]
\end{aligned}
$$


Observa-se em (4.30) que quanto maior $n=n_{b, p, 1}+n_{b, p, 2}+\ldots+n_{b, p, n_{r}}$ maior será a influência da matriz de correlações $R=U^{T} U \in \mathbb{R}^{n_{b}}$ no resultado $\operatorname{de} \operatorname{det}[\operatorname{cov}[\hat{\boldsymbol{\theta}}]]$.

Caso o estimador seja polarizado, ou seja, exista correlação entre regressores e perturbação v , ao contrário da consideração para obter (2.13), sua polarização para um estimador LS será dada por (LJUNG, 1999) (ZHU, 2001) (AGUIRRE, 2007):

$$
b=\left[\Psi^{T} \Psi\right]^{-1} \Psi \mathbf{v}
$$

Observa-se que a polarização de cada parâmetro do modelo é dada pela correlação cruzada entre regressores $\Psi$ e perturbação $\mathbf{v}$, amplificada pela inversa da matriz de correlações dos regressores:

$$
\Psi^{T} \Psi=\left[\begin{array}{c|c}
Y^{T} Y & Y^{T} U \\
\hline U^{T} Y & R
\end{array}\right]
$$

Assim como na análise anterior, quanto maior $n_{b}$ maior será a influência da matriz de correlações $R$ na amplificação da polarização dos parâmetros estimados.

Essa análise reforça o argumento de procurar conjuntos de sinais de excitação que resultem em reduzidos valores de correlação cruzada entre os sinais. As funções de autocorrelação $r_{u_{r} u_{r}}(k)=0$, com $k \neq 0$, não têm essa característica, pois são resultado da formatação da envoltória espectral de cada sinal de excitação, conforme (3.9). Frequentemente, deseja-se excitar com maior potência as frequências mais baixas e, consequentemente, as funções de autocorrelação não terão a característica $r_{u_{r} u_{r}}(k)=0$, $\operatorname{com} k \neq 0$.

Observa-se que não há uma única medida para a avaliação de sinais de excitação quando há pouco conhecimento sobre a planta a ser identificada. As medidas apresentadas e a proposta aqui apresentada tentam fornecer avaliações quanto à aderência de sinais de excitação aos critérios apresentados na seção 3.3. Os índices PIPSE e EMINE são opções para verificar a aderência de sinais de excitação ao critério 1. Os índices PIPS e CF (e a dispersão $\lambda_{u}$ ) são opções para verificar a aderência de sinais de excitação ao critério 2. O índice TF pode ser uma medida comparativa de sinais quanto ao requisito do experimento com duração $T_{e}$ reduzida. A proposta CISS objetiva viabilizar comparações de sinais de excitação quanto aos critérios 2 e 3 simultaneamente. 


\section{Sinais de excitação}

Os métodos de construção de sinais de excitação que são encontrados na literatura podem ser classificados em quatro grandes grupos. Em um deles, os métodos consistem em construir sinais binários (ou multinível), onde a alteração de nível do sinal (o chaveamento) é uma variável aleatória iid. A probabilidade do chaveamento (ou a probabilidade de não chaveamento $p$ ) pode ser escolhida pelo usuário de forma ajustar o espectro de frequências do sinal para próximo do espectro desejado. Alternativamente, a probabilidade de chaveamento pode ser fixada em 0,5 resultando, a medida que $N \rightarrow \infty$, em um sinal com autocorrelação do tipo delta de Dirac e, portanto, espectro plano. O espectro do sinal, posteriormente, pode ser ajustado por meio de filtragem.

Outra forma de construir sinais consiste em aplicar conceitos de otimização para minimizar diferenças entre um espectro especificado (desejado) e o espectro do sinal de excitação (minimizando a medida EMINE). Além de soluções analíticas, é possível, por meio de algoritmos iterativos, provocar alterações adequadas no sinal com o objetivo de aproximar seu espectro do desejado. Esse método é chamado de projeto de sinais otimizados por computador. São incluídos nos objetivos (ou nas restrições) especificações relativas a amplitude (minimizar o CF ou maximizar a medida PIPSE). O método objetiva atender totalmente ou parcialmente tais critérios, pois pode-se ter sinais não realizáveis dependendo do espectro de potência e das restrições de amplitude especificadas (GODFREY et al., 2005).

A terceira forma utiliza propriedades da álgebra abstrata para gerar sinais com funções de autocorrelação e correlação cruzada específicas. Esse método é bastante poderoso pois, além de influenciar o espectro de potência por meio das funções de autocorrelação, as funções de correlação cruzada também podem ser controláveis, o que é fundamental na identificação multivariável. Na literatura, são chamados de sinais de espectro determinado ou de espectro fixo (GODFREY et al., 2005), pois não é utilizado nenhum algoritmo iterativo para moldar gradativamente seu espectro para próximo do especificado. Nas próximas seções serão apresentados métodos que utilizam cada uma dessas três formas básicas de gerar sinais de excitação. 
Em (TAN; GODFREY, 2009) é feita referência a uma quarta forma de construir sinais. Essa combina propriedades da álgebra e otimização na construção dos sinais, os quais são chamados de sinais híbridos. Conforme (TAN; GODFREY, 2009), apenas os sinais Gallev propostos em (TAN; GODFREY; BARKER, 2005) utilizam essa técnica. Como contribuição a essa área do conhecimento, no capítulo 6 é proposto um novo método para construção de sinais híbridos.

\subsection{Sinais aleatórios}

Sinais aleatórios são facilmente gerados por meio de softwares que geram números aleatórios. As principais características que justificam o uso de sinais aleatórios em identificação de sistemas são relativas às suas funções de correlação e à facilidade de gerá-los.

Seja um sinal aleatório em tempo discreto $u(i)$ de comprimento $N_{s}$, onde $u(i)$ e $u(i+j), \operatorname{com} j \neq 0$ e $i, j \in \mathbb{Z}$, são variáveis aleatórias iid. A função de autocorrelação desse sinal será dada por $r_{u}(j)=\delta(j), \operatorname{com} \delta(j)$ a função delta de Dirac e $j \in \mathbb{Z}$, quando $N_{s} \rightarrow \infty$. A função de correlação cruzada de sinais aleatórios distintos $u_{1}(i)$ e $u_{2}(i)$ ambos de comprimentos $N_{s}$, com $u_{1}(i) \neq u_{2}(i+j), \forall j \in \mathbb{Z}$, será dada por $r_{u_{1} u_{2}}(j)=0$ quando $N_{s} \rightarrow \infty$.

Observa-se que as boas características dos sinais aleatórios são garantidas quando $N \rightarrow \infty$. Na prática, deve-se ter o cuidado de escolher $N_{s}$ suficientemente grande para satisfazer às necessidades das características de correlação, $r_{u}(j) \approx \delta(j)$ e $r_{u_{1} u_{2}}(j) \approx$ 0 . A escolha de $N_{s}$ suficientemente grande pode ser feita com base nos conceitos estatísticos de intervalo de confiança, conforme apresentado em (AGUIRRE, 2007). Porém, em identificação de plantas de processo, comumente a maior limitação para o comprimento do sinal de excitação $N_{s}$ está no tempo disponível para o experimento $\left(T_{e}=N_{e} T\right.$, com $\left.N_{s} \leq N_{e}\right)$, conforme discutido no capítulo 3.

É possível ajustar o espectro de potência de sinais aleatórios para atender ao critério (3.9). As amplitudes dos sinais aleatórios também podem ser alteradas de forma a atender limitações do sistema a ser identificado (3.10). As próximas seções apresentam alguns métodos para gerar sinais aleatórios com amplitudes e espectros ajustados. O método proposto em (TULLEKEN, 1990), o qual gera o chamado sinal ruído binário generalizado (generalized binary noise, GBN), é amplamente utilizado em identificação de sistemas devido sua simplicidade e seus resultados satisfatórios. 


\subsubsection{Sinal ruído binário}

Uma forma imediata de gerar sinais de excitação com espectro desejado é aplicar um filtro linear em um processo ruído branco Gaussiano (white Gaussian noise, WGN) $e(t)$ transformando-o em um processo ruído colorido:

$$
u(t)=F(q) e(t)
$$

onde $F(q)=\sum_{k=1}^{\infty} g_{k} q^{-k}$ é o filtro linear e $q^{-1}$ é o operador atraso unitário $\left(q^{-1} u(t)=\right.$ $u(t-1))$. A resposta em frequência do sinal $u(t)$ será dada pelo formato da resposta em frequência do filtro $F(q)$ :

$$
\Phi_{u}(\omega)=\left|F\left(e^{j \omega}\right)\right| \lambda
$$

onde $\lambda$ é a variância de $e(t)$.

Um dos problemas desse método é que o WGN não é limitado em amplitude. Assim, um processo $x$ WGN pode assumir qualquer valor no intervalo $-\infty \leq x \leq \infty$. Essa característica não é desejada em um sinal de excitação (3.10). Portanto, limita-se o sinal ruído colorido ceifando-o em determinada amplitude. A forma mais comum de limitação do sinal ruído colorido utiliza a função sinal, gerando um sinal ruído binário (binary noise, $\mathrm{BN}$ ) colorido. A consequência de aplicar limitações no sinal é a alteração de seu espectro de frequências. Neste trabalho são intitulados sinais ruído binário $(\mathrm{BN})$ tantos sinais binários coloridos como sinais binários com espectro plano.

A figura 5.1 apresenta os sinais ruído colorido e ruído binário colorido. Os espectros dos sinais são apresentados na figura 5.2. O sinal ruído colorido foi gerado a partir de um WGN processado pelo seguinte filtro linear de primeira ordem passa-baixas adotado:

$$
F(z)=\frac{1}{1-0.7 z^{-1}}
$$

A figura 5.2 apresenta a resposta em frequência do filtro linear $F(z)$.

No caso de identificação multivariável (MIMO ou MISO), deve-se ter o cuidado em aplicar sinais não correlacionados nas entradas (2.45). Assim, os sinais devem ser construídos com geradores de números aleatórios iniciados por sementes diferentes. Em outras palavras, o gerador de números aleatórios deve ser iniciado de forma a gerar processos aleatórios não correlacionados.

O PIPS para um sinal WGN será reduzido, pois os valores máximo e mínimos 


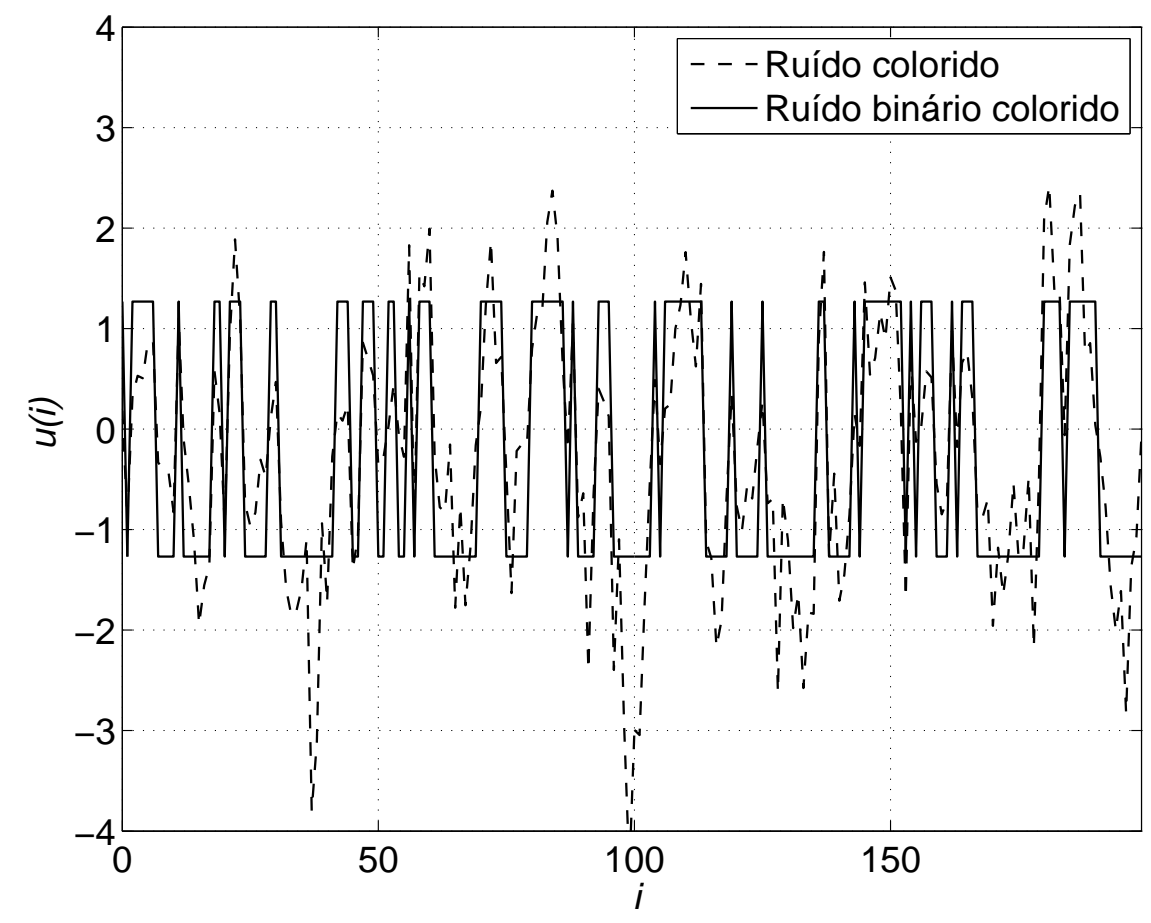

Figura 5.1: Sinal ruído colorido e ruído colorido binário de comprimento $N_{s}=200$.

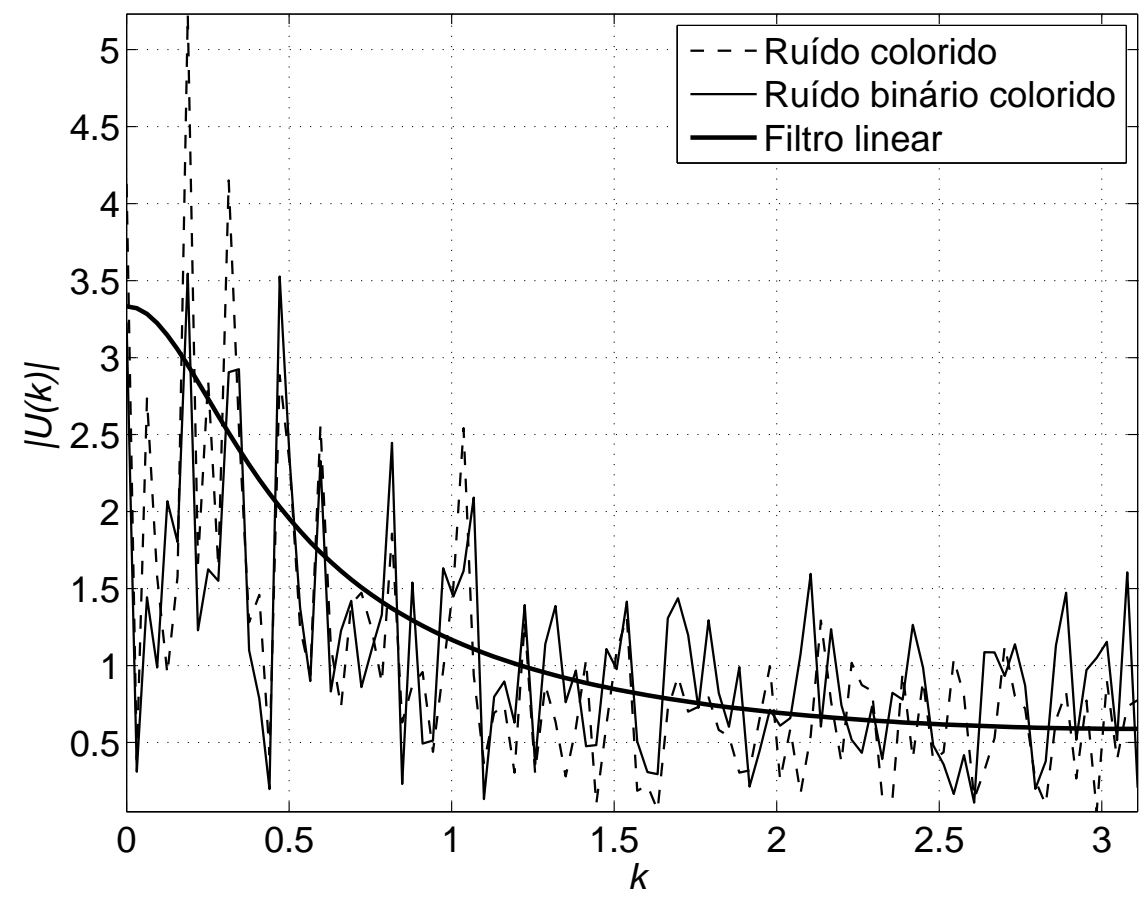

Figura 5.2: Espectros de amplitudes de sinais ruído colorido.

de $u(i)$ podem ser consideravelmente discrepantes. Quando o sinal é filtrado (ruído colorido) por um filtro passa baixa o PIPS tende a ser maior, visto que o filtro passa baixas possui a característica de reduzir os saltos de amplitude. Por outro lado, os sinais BN e BN colorido resultam em PIPS máximo (100\%) e CF mínimo (1), pois são sinais binários. 


\subsubsection{Parametrização do sinal ruído binário}

Em identificação multivariável, conhecida a menor constante de tempo dominante $\tau_{\min , r}$ entre as observadas nas $n_{p}$ saídas para a $r$-ésima entrada, pode-se gerar sinais ruídos binários $(\mathrm{BN})$ coloridos com resposta em frequência que se assemelha à resposta de um sistema de primeira ordem $G(s)$ com constante de tempo dada por $\tau=\tau_{\min , r}$ :

$$
G(s)=\frac{K}{\tau s+1}
$$

onde $K$ é o ganho estático do sistema que pode ser considerado unitários $(K=1)$.

A função de transferência discreta do sistema, considerando o uso do $\mathrm{ZOH}$ do processo de amostragem (apêndice D), será:

$$
H G(z)=\frac{K\left(1-e^{-T / \tau}\right) z^{-1}}{1-e^{-T / \tau} z^{-1}}
$$

Portanto, para obter um sinal com a envoltória da resposta em frequência semelhante à resposta de um sistema de primeira ordem com constante de tempo dada por $\tau=\tau_{\text {min, },}$, basta aplicar um ruído branco Gaussiano na entrada de um filtro digital $F(z)$ com polo em $e^{-T / \tau_{\min , r}}$, ou seja:

$$
F(z)=\frac{1}{1-e^{-T / \tau_{\min , r}} z^{-1}}
$$

O período do sinal deve atender a restrição dada por (3.13):

$$
\begin{aligned}
T_{N_{s}} & \geq 2 \pi \beta_{s} \tau_{\max , r} \\
N_{s} T & \geq 2 \pi \beta_{s} \tau_{\max , r} \\
N_{s} & \geq \frac{2 \pi \beta_{s} \tau_{\max , r}}{T}
\end{aligned}
$$

Observa-se que em um sinal aleatório em tempo discreto, o período mínimo observado entre alterações na amplitude do sinal, chamado simplesmente de período de chaveamento $\left(T_{c l k}\right)$, é $T_{c l k}=T$.

Caso seja desejável excitar o sistema com sinal de espectro plano, pode ser aplicado um sinal BN branco, ou seja, não realizar qualquer filtragem $(F(z)=1)$.

As figuras 5.3a e 5.3b apresentam sinais BN branco $u_{1}(i)$ e $u_{2}(i)$, respectivamente, de comprimentos $N_{s}=100$. 
(a)

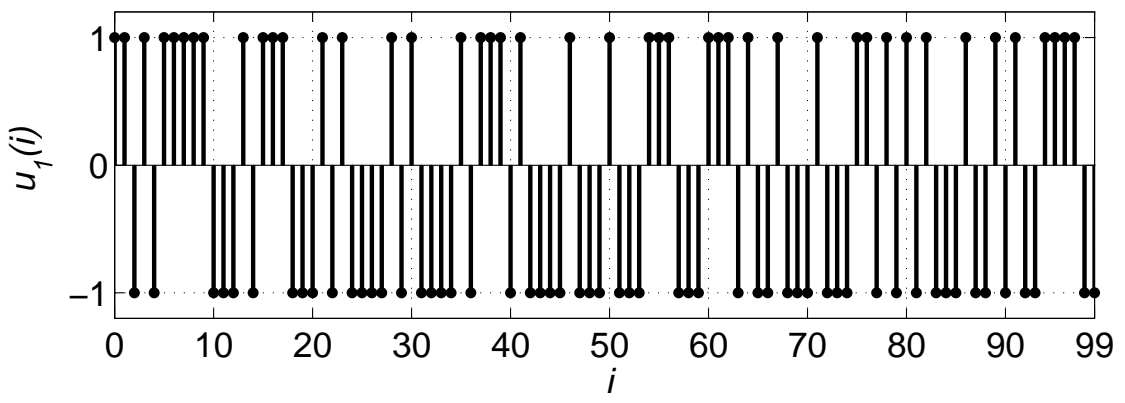

(b)

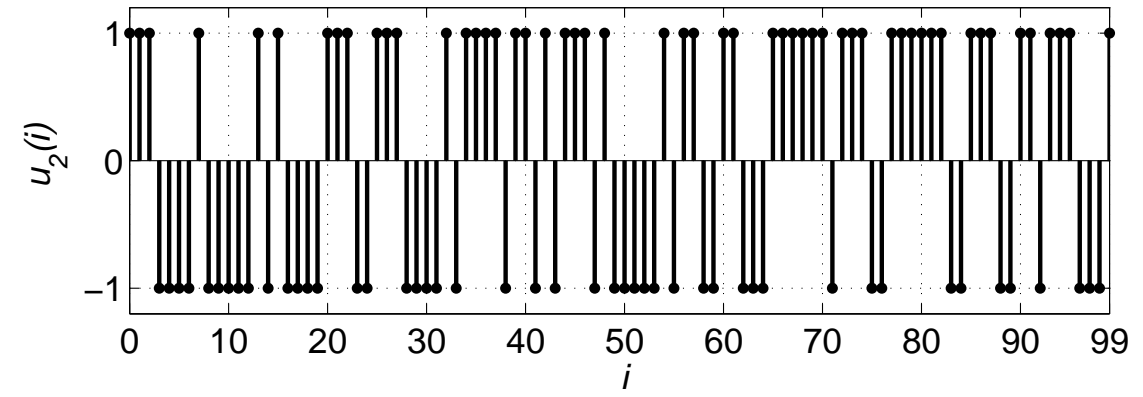

Figura 5.3: Sinais BN branco de comprimento $N_{s}=100$.

As figuras 5.4a e 5.4b apresentam os espectros $U_{1}(k)$ e $U_{2}(k)$ dos dois sinais BN braco $u_{1}(i)$ e $u_{2}(i)$, respectivamente. Observa-se que os sinais não possuem espectros perfeitamente planos apesar terem elementos iid. O espectro tenderá a ser plano quando $N_{s} \rightarrow \infty$.

(a)

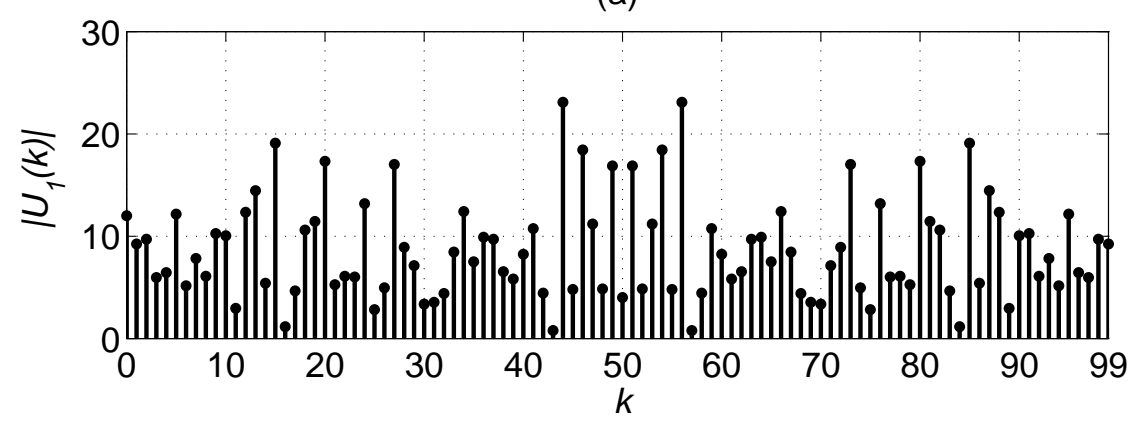

(b)

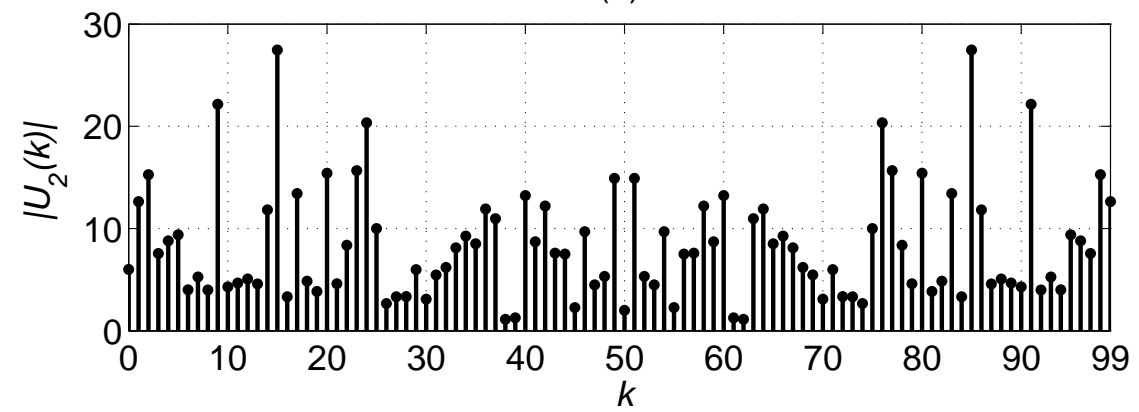

Figura 5.4: Módulo da DFT dos sinais BN branco de comprimento $N_{s}=100$.

A figura 5.5a e 5.5b apresentam as funções de autocorrelação periódica dos sinais 
BN branco $u_{1}(i)$ e $u_{2}(i)$. Assim como os espectro dos sinais não são planos, as funções de autocorrelação não são delta de Dirac.
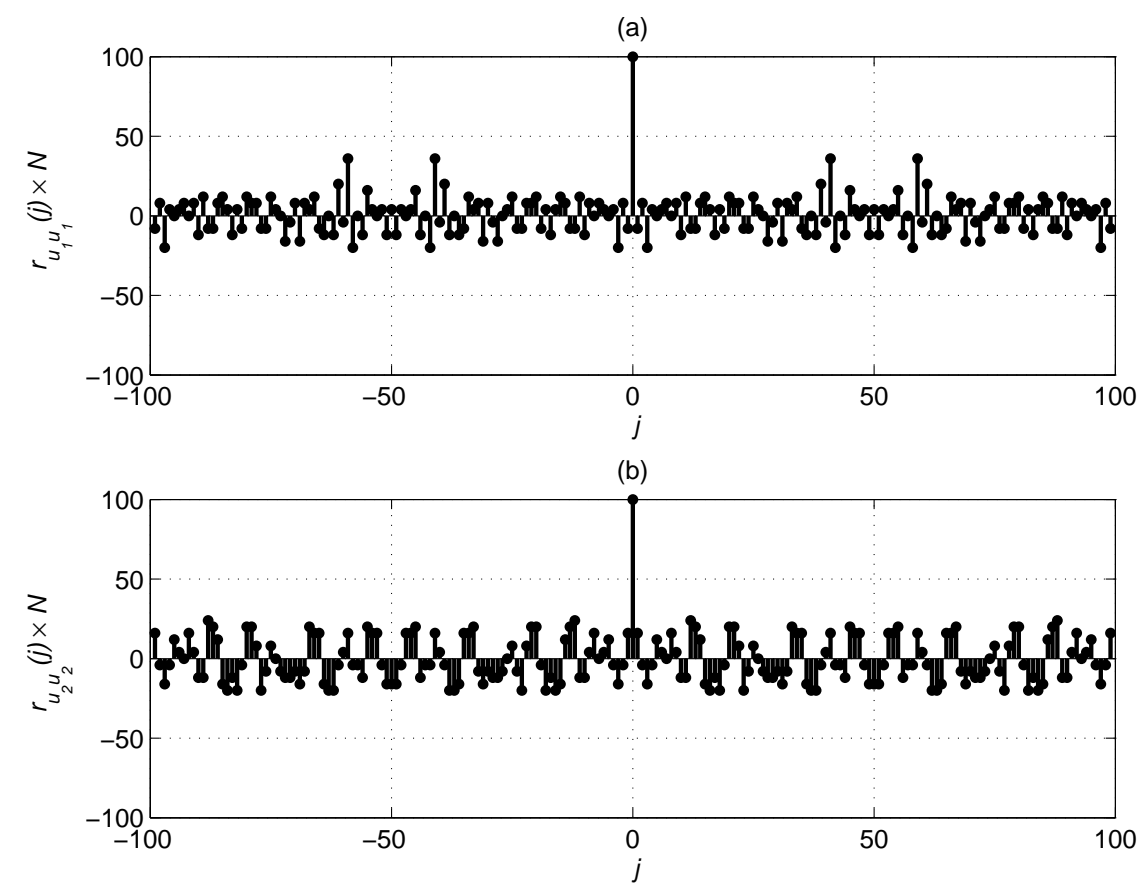

Figura 5.5: Função de autocorrelação periódica dos sinais $\mathrm{BN}$ branco de comprimento $N_{s}=100$.

A figura 5.6 apresenta a função de correlação cruzada entre os sinais BN branco $u_{1}(i)$ e $u_{2}(i)$. Observa-se que a função de correlação cruzada $r_{u_{1} u_{2}}(j)$ não é perfeitamente nula, demonstrando que há correlação reduzida entre os sinais. A correlação cruzada tenderá a ser nula quando $N_{s} \rightarrow \infty$.

Os índices de desempenho para o sinal BN branco da figura 5.3a, considerando o espectro plano como espectro especificado no cálculo dos índices EMINE e TF, são apresentados na tabela 5.1. O PIPS para sinais BN branco é máximo (100\%) e o CF é mínimo (1), pois são sinais binários, conforme observado na seção 5.1.1. O PIPSE não é $100 \%$ e o EMINE é reduzido devido o espectro do sinal apresentar alguns nulos para algumas harmônicas especificadas com amplitude não nula. À medida que $N_{s} \rightarrow \infty$ os índices PIPSE e EMINE tendem aos seus máximos. O TF é elevado em decorrência dos reduzidos índices PIPSE e EMINE.

Seja a planta com $\tau_{\max , r}=\tau_{\max }=33$ minutos, $\tau_{\min , r}=\tau_{\min }=5$ minutos $\mathrm{e}$ $T_{\text {set }}=165$ minutos, obtida do estudo de caso de uma destilação de alta pureza de (GAIKWAD; RIVERA, 1996). Deseja-se realizar o experimento com amostragem de $T=60$ segundos e fator $\beta_{s}=3$ que representa o tempo de acomodação do processo para a resposta atingir 95\% de seu valor final (T95\%). A resposta em malha fechada para o sistema foi considerada duas vezes mais rápida que a resposta em ma- 


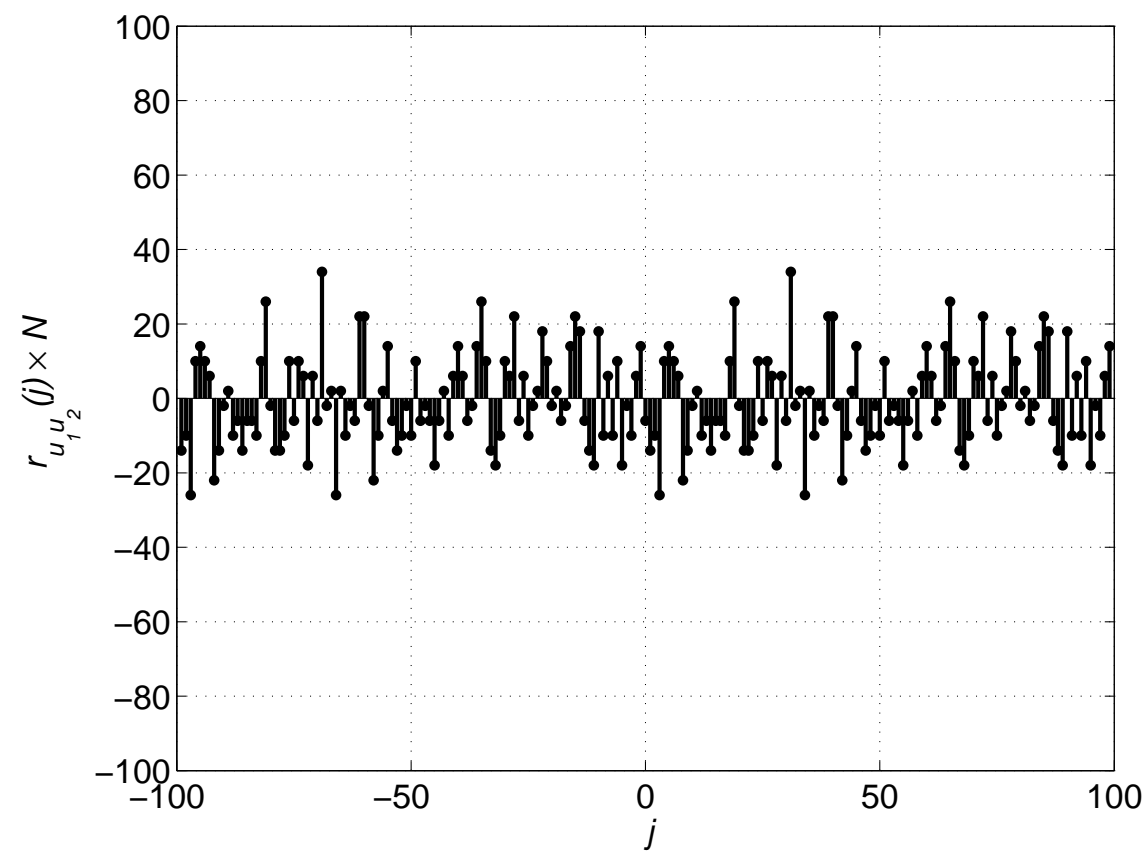

Figura 5.6: Função de correlação cruzada periódica entre os sinais BN branco de comprimento $N_{s}=100$.

Tabela 5.1: Índices de desempenho para o sinal BN branco apresentado de comprimento $N_{s}=100$.

\begin{tabular}{ll}
\hline Índice & Valor \\
\hline PIPS & $100 \%$ \\
PIPSE & $85,56 \%$ \\
EMINE & 6,63 \\
TF & 155,50 \\
CF & 1 \\
\hline
\end{tabular}

lha aberta, assim, $\alpha_{s}=2$. Os parâmetros citados, bem como as frequências máximas e mínimas do sinal de excitação para identificação do sistema calculadas conforme (3.8) são apresentadas na tabela 5.2.

O filtro digital para filtrar o ruído branco Gaussiano será dado por (5.6):

$$
\begin{aligned}
& F(z)=\frac{1}{1-e^{-T / \tau_{\min } z^{-1}}} \\
& F(z)=\frac{1}{1-0,8187 z^{-1}}
\end{aligned}
$$

O comprimento do sinal será definido de acordo com (5.7) será:

$$
N_{s} \geq \frac{2 \pi \beta_{s} \tau_{\max }}{T}
$$


Tabela 5.2: Parâmetros de planta e do sinal de excitação para identificação do sistema de destilação de alta pureza de (GAIKWAD; RIVERA, 1996).

\begin{tabular}{ll}
\hline Parâmetro & Valor \\
\hline Menor constante de tempo do sistema $\left(\tau_{\min }\right)$ & 5 minutos \\
Maior constante de tempo do sistema $\left(\tau_{\max }\right)$ & 33 minutos \\
Período de acomodação $\left(T_{\text {set }}\right)$ & 165 minutos \\
Período de amostragem $(T)$ & 60 segundos \\
Fator do período de acomodação $\left(\beta_{s}\right)$ & $3(\mathrm{~T} 95 \%)$ \\
Fator de velocidade de resposta $(\alpha)$ & 2 \\
Frequência mínima de interesse $\left(\omega_{L}\right)$ & $0,01 \mathrm{rad} / \mathrm{min}$ \\
Frequência máxima de interesse $\left(\omega_{H}\right)$ & $0,40 \mathrm{rad} / \mathrm{min}$ \\
\hline
\end{tabular}

$$
\begin{aligned}
& N_{s} \geq \frac{2 \pi 5 \times 33 \times T}{T} \\
& N_{s} \geq 2 \pi 5 \times 33 \\
& N_{s} \geq 622,03
\end{aligned}
$$

Neste exemplo adotou-se $N_{s}=700$, o que corresponde a um sinal com período $T_{N_{s}}=700 \times 60$ segundos.

A figura 5.7 apresenta os sinais ruído colorido e ruído binário colorido e a figura 5.8 apresenta seus espectros gerados com os parâmetros deste exemplo. A figura 5.8 apresenta também a resposta em frequência do filtro linear $F(z)$ da equação (5.8).

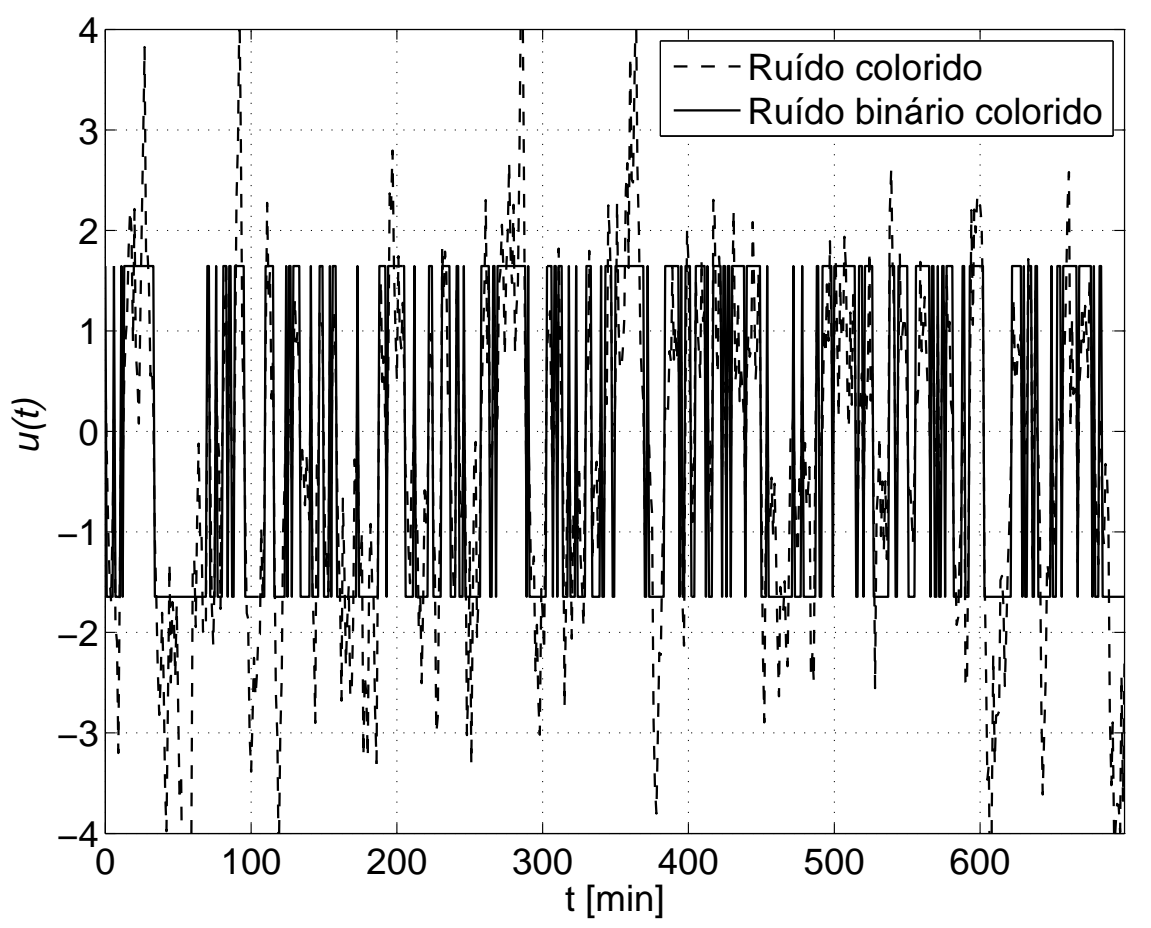

Figura 5.7: Sinal ruído colorido e ruído colorido binário de comprimento $N_{s}=700$.

Os índices de desempenho para o sinal BN colorido da figura 5.7, considerando 


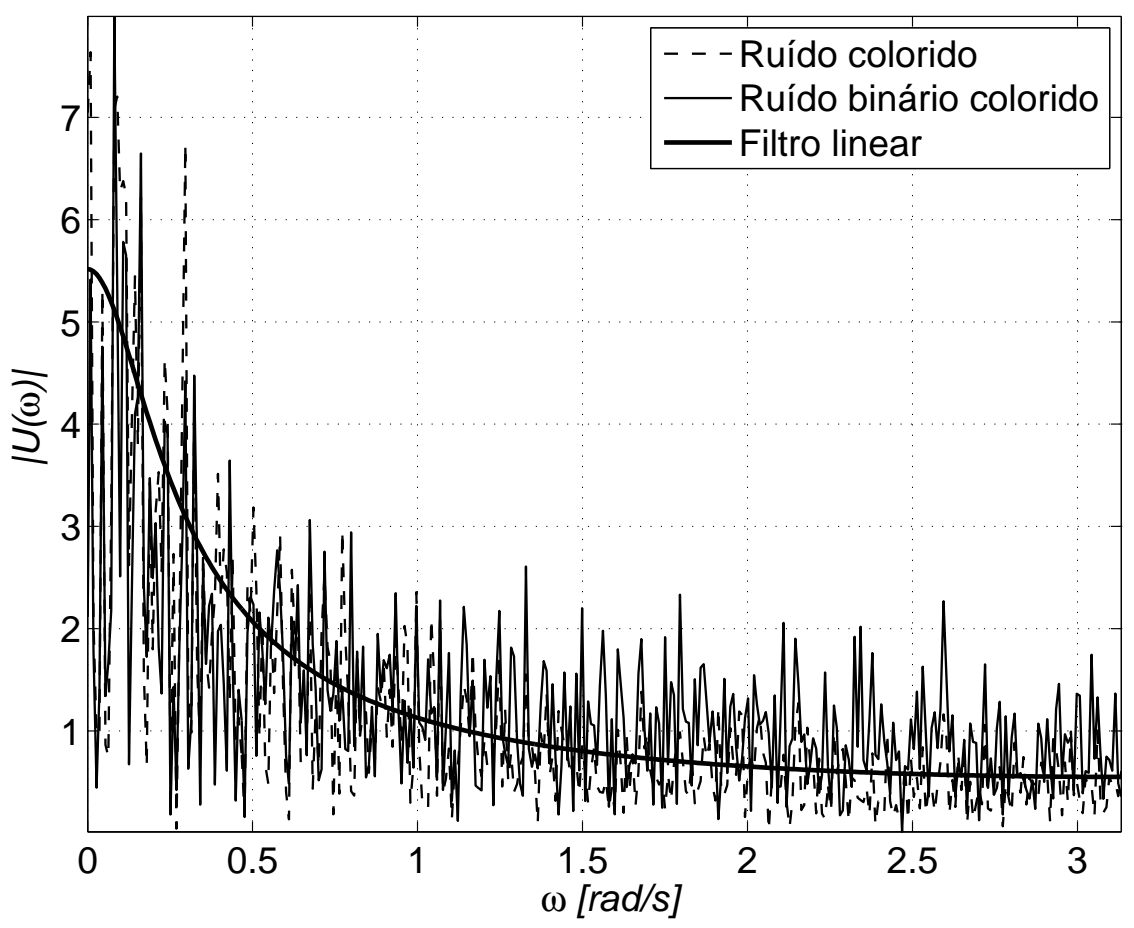

Figura 5.8: Espectros de amplitude de sinais ruído colorido.

Tabela 5.3: Índices de desempenho para o sinal BN colorido apresentado de comprimento $N=700$.

\begin{tabular}{ll}
\hline Índice & Valor \\
\hline PIPS & $100 \%$ \\
PIPSE & $95,37 \%$ \\
EMINE & 6,77 \\
TF & 120 \\
CF & 1 \\
\hline
\end{tabular}

$N_{s} / 2$ frequências de interesse e a resposta em frequência do filtro definido por (5.8) como espectro especificado para o cálculo dos índices, são apresentados na tabela 5.3. Para sinais BN colorido, os índices PIPS e CF são ótimos e os índices PIPSE, EMINE e TF não são pelos mesmos motivos descritos anteriormente em relação a sinais BN branco.

\subsubsection{Sinal ruído binário generalizado}

O sinal ruído binário generalizado (generalized binary noise, GBN) foi proposto em (TULLEKEN, 1990) como alternativa ao sinal ruído binário (BN) para se ter maior controle da resposta em frequência do sinal, o que é desejável em identificação de processos industriais (3.9). É possível gerar sinais GBN com maior potências em frequências de interesse para identificação. 
Um sinal GBN é binário e, portanto, assume apenas dois valores $\pm a$. $\mathrm{O}$ chaveamento do sinal GBN $u(i)$ entre as amplitudes $\pm a$ é não determinístico e dado pelas probabilidades:

$$
\begin{aligned}
P(u(i)=-u(i-1)) & =1-p \\
P(u(i)=u(i-1)) & =p
\end{aligned}
$$

onde $1-p$ é a probabilidade de chaveamento, ou seja, $p$ é a probabilidade de não chaveamento. Isso caracteriza uma distribuição de probabilidade do tipo tentativa de Bernoulli cujo sucesso, dado por $u(i)=u(i-1)$, ocorre com probabilidade $p$. Os eventos em momentos $i$ diferentes são independentes. Assim, $P(u(i)=a)=P(u(i)=$ $-a)$ e, portanto, a média de $u(i)$ será:

$$
\mathbb{E}\{u(i)\}=a P(u(i)=a)-a P(u(i)=-a)=0
$$

Associando o sinal $u(i)$ a um $\mathrm{ZOH}$ de tempo $T$, tem-se o período de chaveamento $T_{c l k}$ com a seguinte característica (TULLEKEN, 1990):

$$
P\left(T_{c l k}=k T\right)=p^{k-1}(1-p), k=1,2,3, \ldots
$$

ou seja, $\frac{T_{c l k}}{T}$ segue uma distribuição geométrica com parâmetro $p$ e, portanto:

$$
\mathbb{E}\left\{T_{c l k}\right\}=T \mathbb{E}\left\{\frac{T_{c l k}}{T}\right\}=T \sum_{k=1}^{\infty} k p^{k-1}(1-p)=T \frac{1}{p-1}
$$

Está demonstrado em (TULLEKEN, 1990) que a função de autocorrelação para um sinal GBN é dada por:

$$
\mathbb{E}\{u(i) u(i+j)\}=a^{2} q^{|j|}, q=2 p-1 \mathrm{e} i, j \in \mathbb{Z}
$$

Conforme (5.11) e (5.14) o sinal GBN é um processo estacionário no sentido amplo (wide-sense stationarity, WSS) e, portanto, o espectro de potência de $u(i)$ será dado pela transformada de Fourier de sua função de autocorrelação (PAPOULIS, 1991), resultando (SöDERSTRöM; STOICA, 1989) (TULLEKEN, 1990):

$$
\Phi_{u}(\Omega, q)=\frac{\left(1-q^{2}\right) T}{1-2 q \cos \Omega T+q^{2}}
$$

Em (ZHU, 2001), baseado em experiência em projetos de experimentos e em exercícios 
Tabela 5.4: Parametrização de um sinal GBN.

\begin{tabular}{ll}
\hline Parâmetro & Valor \\
\hline Tipo de sinal & GBN \\
Comprimento do sinal & $N_{s}=50$ \\
Probabilidade de chaveamento & $1-p=1-0,7=0,3$ \\
Período de amostragem (em segundos) & $T=1$ \\
Frequência de amostragem (em Hertz) & $f_{s}=1 / T=1$ \\
Período do sinal (em segundos) & $T_{N_{s}}=T \times N_{s}=50$ \\
\hline
\end{tabular}

simulados, propõe-se utilizar:

$$
T_{c l k}=(1-p) \frac{0,98 T_{\max , r}^{\text {set }}}{3}
$$

A figura 5.9 apresenta o espectro de potência $\Phi_{u}(\Omega, q)$ do sinal GBN para alguns valores de $q=2 p-1$. Observa-se que o valor de $p$ determina a envoltória do espectro de potência. Dessa forma, é possível gerar sinais GBN com espectro aproximado ao de interesse para a identificação.

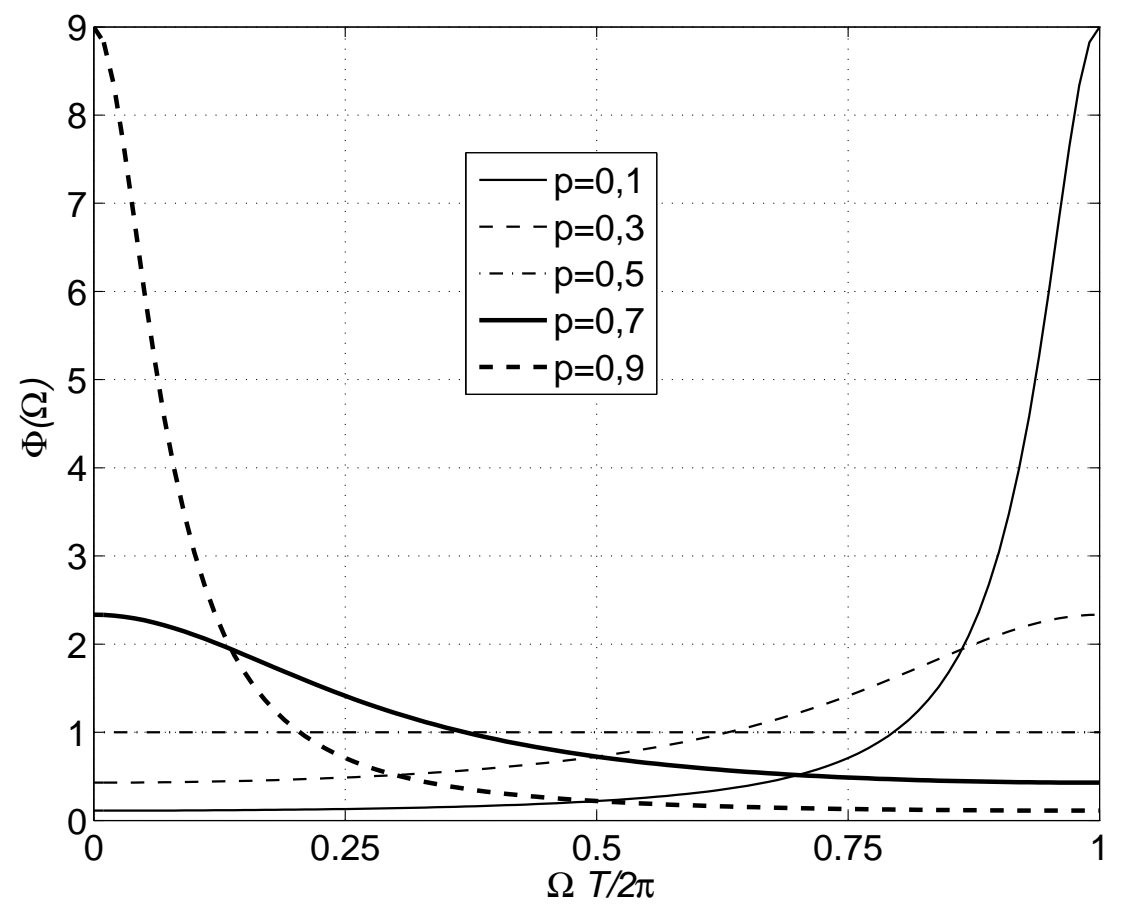

Figura 5.9: Espectros de potência de sinais GBN.

As figuras 5.10, 5.11 e 5.12 apresentam o sinal GBN com as características da tabela 5.4, seu espectro e sua função de autocorrelação, respectivamente.

A figura 5.13 apresenta o espectro de potência do sinal da tabela 5.4 calculado conforme (5.15) e calculado numericamente por meio da média de 1000 espectros de potência de sinais GBN construídos com as mesmas características definidas na 


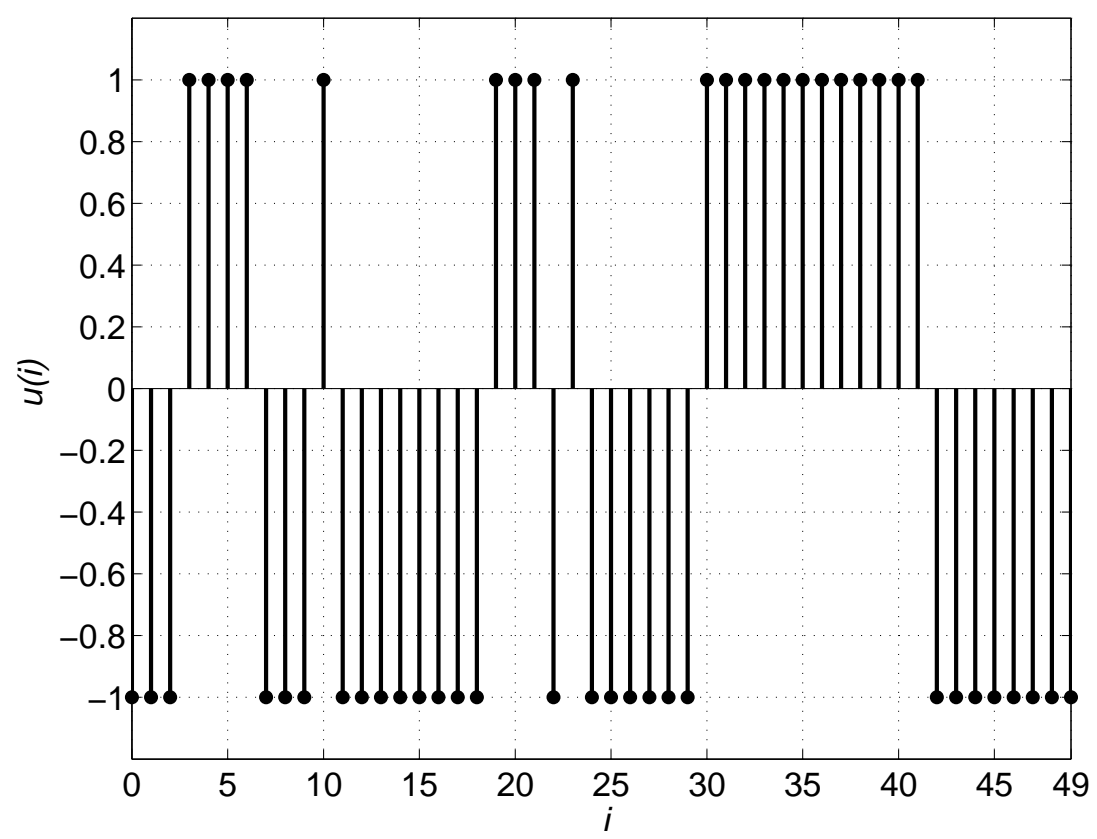

Figura 5.10: Sinal GBN de comprimento $N_{s}=50$ e $p=0,7$.

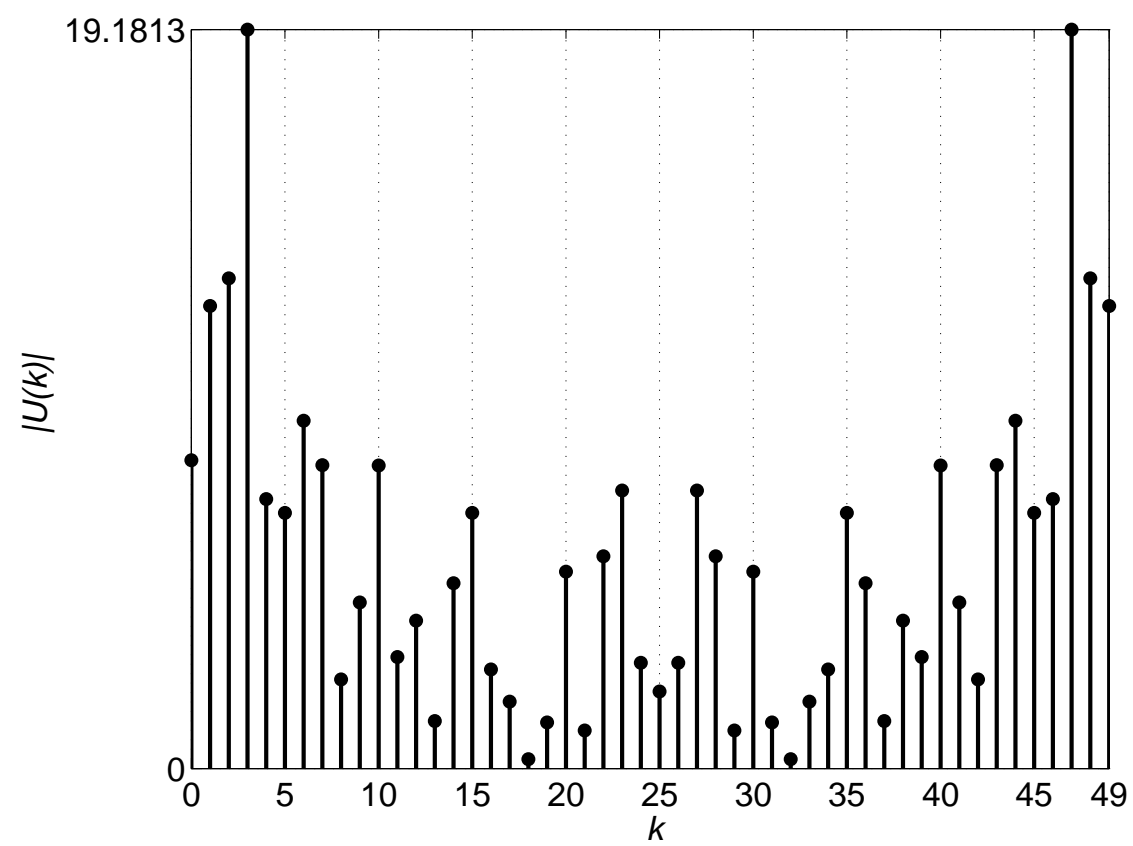

Figura 5.11: Módulo da DFT do sinal GBN de comprimento $N_{s}=50$ e $p=0,7$.

tabela 5.4, porém, obtidos por meio de geradores de números aleatórios iniciados com sementes diferentes.

Em (ZHU, 2001) foi proposta a construção do sinal ruído multinível generalizado (generalized multiple-level noise, GMN) para identificação de sistemas não lineares. A amplitude é uniformemente distribuída em um intervalo e pode ser quantizada (em níveis) ou contínua. O número de níveis é escolhido de forma a ser maior ou igual ao grau do polinômio não linear a ser identificado. 


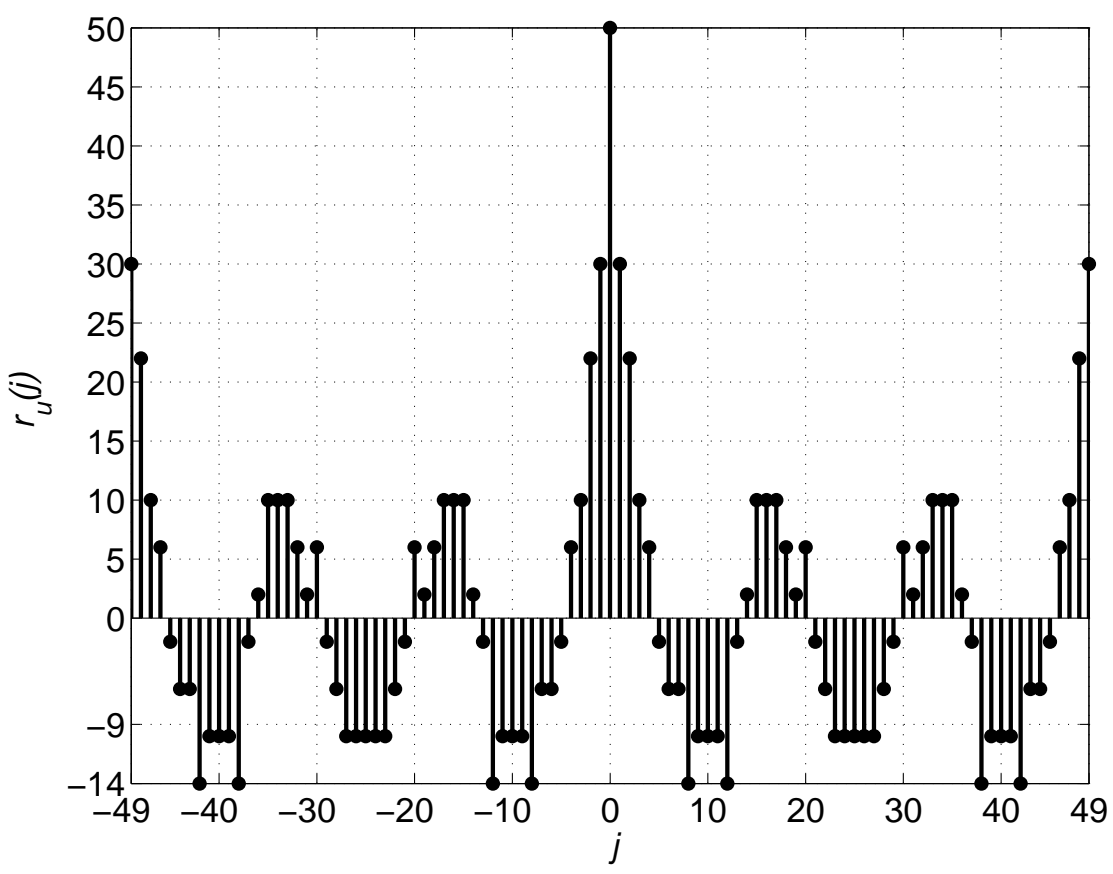

Figura 5.12: Função de autocorrelação periódica do sinal GBN de comprimento $N_{s}=50$ e $p=0,7$.

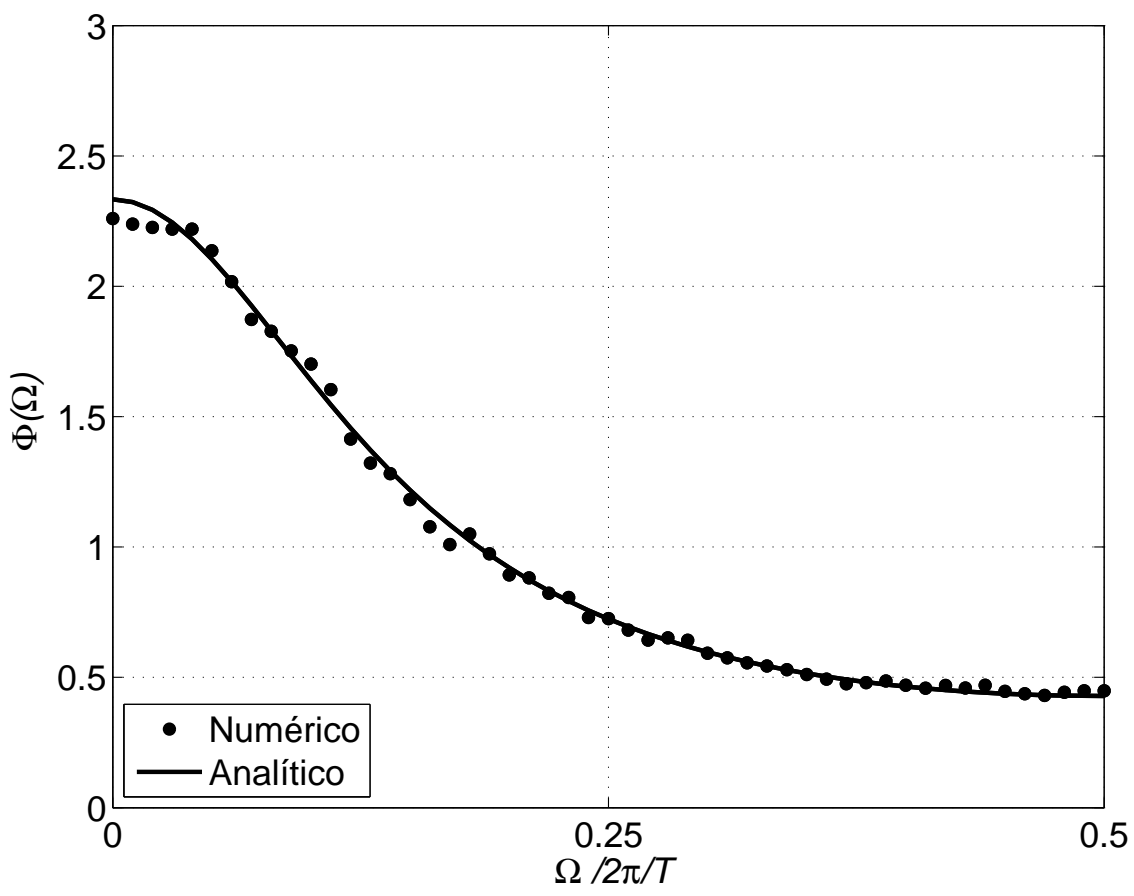

Figura 5.13: Espectro de potência do sinal GBN de comprimento $N_{s}=50$ e $p=0,7$.

\subsubsection{Parametrização do sinal ruído binário generalizado}

Em (TULLEKEN, 1990) foi apresentado um método para a escolha da probabilidade de não chaveamento $p$ adequada às características do sistema a ser identificado. Nesse método, $p$ é descrito em função da constante de tempo $\tau$ do sistema. Em (CHEN; YU, 
1997), foi apresentada uma expressão analítica para escolha de $p$ de acordo com a faixa de frequências $B W_{r}=\left\{\omega_{L, r} ; \omega_{H, r}\right\}$ de interesse:

$$
p=\frac{1}{1+\sqrt{\tan \left(\frac{\omega_{L, r} T}{2}\right) \tan \left(\frac{\omega_{H, r} T}{2}\right)}}
$$

onde $\omega_{L, r}$ e $\omega_{H, r} \in[0 ; \pi / T], \omega_{L, r} \leq \omega_{H, r}$, são as frequências mínima e máxima de interesse.

Para obter sinais GBN não correlacionados para identificação multivariável, os respectivos geradores de números aleatórios devem ser iniciados com sementes diferentes, assim como no caso de sinais BN.

Seja a planta com parâmetros definidos na tabela 5.2. O sinal GBN adequado para a identificação desta planta terá comprimento $N_{s}=700$, assim como o sinal $\mathrm{BN}$ da seção 5.1.1.1 (restrição dada por (5.9)) e $p$ dado por (5.17), resultando $p=0,6869$.

As figuras 5.14 e 5.15 apresentam o sinal GBN e seu espectro, respectivamente, construídos com os parâmetros deste exemplo. A figura 5.15 apresenta também o espectro de potência do sinal GBN calculado por (5.15) e a resposta em frequência desejada, assumindo um sistema de primeira ordem (5.8).

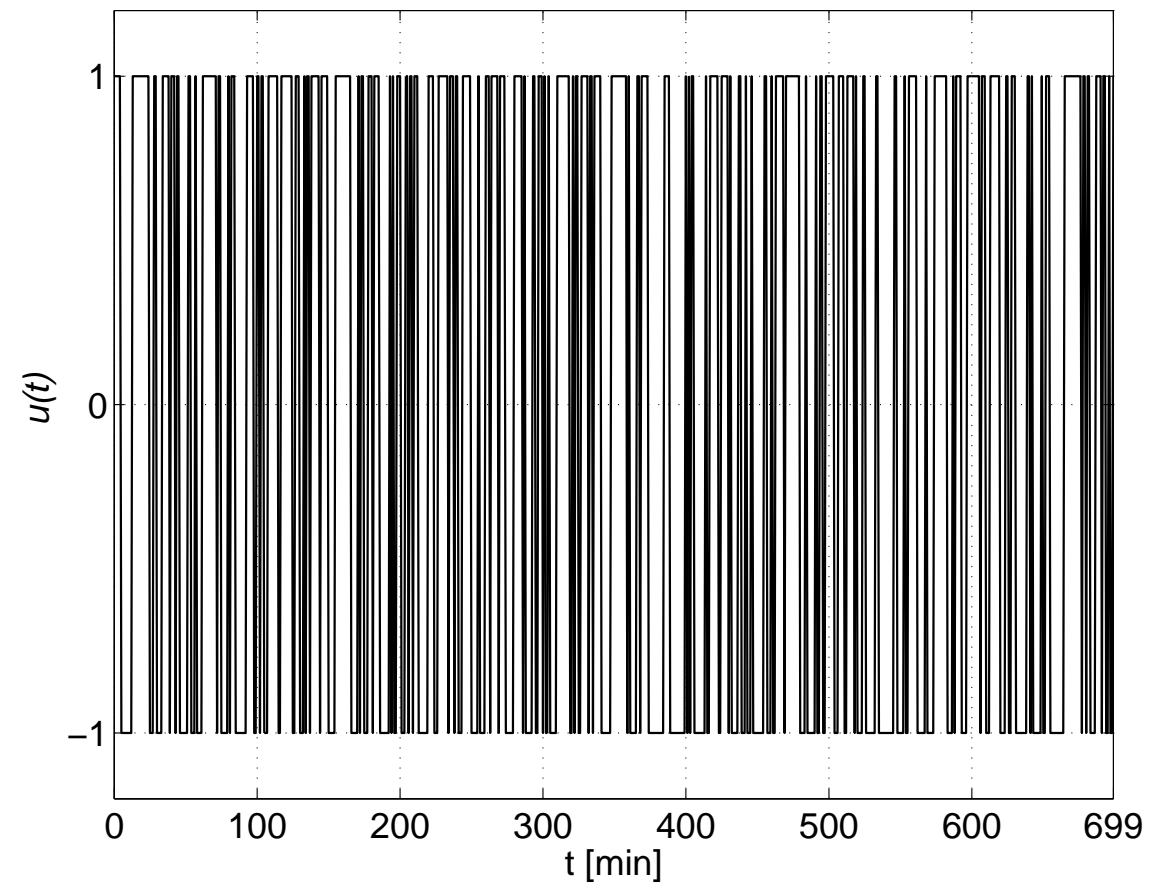

Figura 5.14: Sinal GBN com $p=0,6869$ e comprimento $N_{s}=700$.

Os índices de desempenho para o sinal GBN da figura 5.14, considerando $N_{s} / 2$ frequências de interesse e a resposta em frequência do filtro definido por (5.8) como espectro especificado para o cálculo dos índices, são apresentados na tabela 5.5. Para 


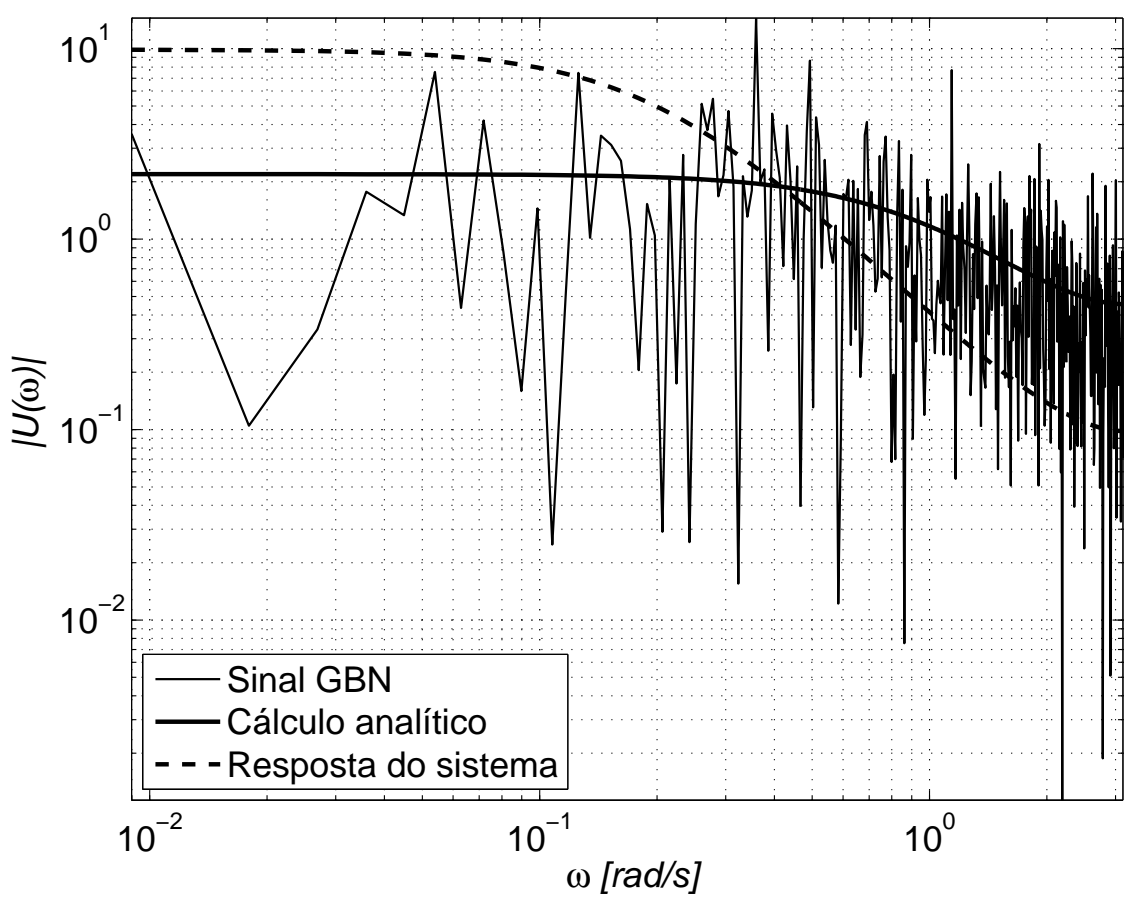

Figura 5.15: Espectros de potência do sinal GBN com $p=0,6869$ e comprimento $N_{s}=700$.

sinais GBN, os índices PIPS e CF são ótimos e os índices PIPSE, EMINE e TF não, pelos mesmos motivos descritos anteriormente em relação a sinais BN.

A figura 5.16a e 5.16b apresentam as funções de autocorrelação periódica dos sinais GBN $u_{1}(i)$ e $u_{2}(i)$ obtidos com geradores de números aleatórios iniciados com sementes diferentes. Assim como os espectros dos sinais não são planos, as funções de autocorrelação não são do tipo delta de Dirac.

A figura 5.17 apresenta a função de correlação cruzada entre os sinais GBN $u_{1}(i)$ e $u_{2}(i)$. Observa-se que a função de correlação cruzada $r_{u_{1} u_{2}}(j)$ não é perfeitamente nula, demonstrando que há correlação reduzida mesmo os sinais tendo sido obtidos a partir de geradores de números aleatórios iniciados com sementes diferentes. A correlação cruzada tenderá a ser nula quando $N_{s} \rightarrow \infty$.

Tabela 5.5: Índices de desempenho para o sinal GBN com $p=0,6869 \mathrm{e}$ comprimento $N_{s}=700$.

\begin{tabular}{ll}
\hline Índice & Valor \\
\hline PIPS & $100 \%$ \\
PIPSE & $93,41 \%$ \\
EMINE & $4,95 \%$ \\
TF & 233,73 \\
CF & 1 \\
\hline
\end{tabular}


(a)

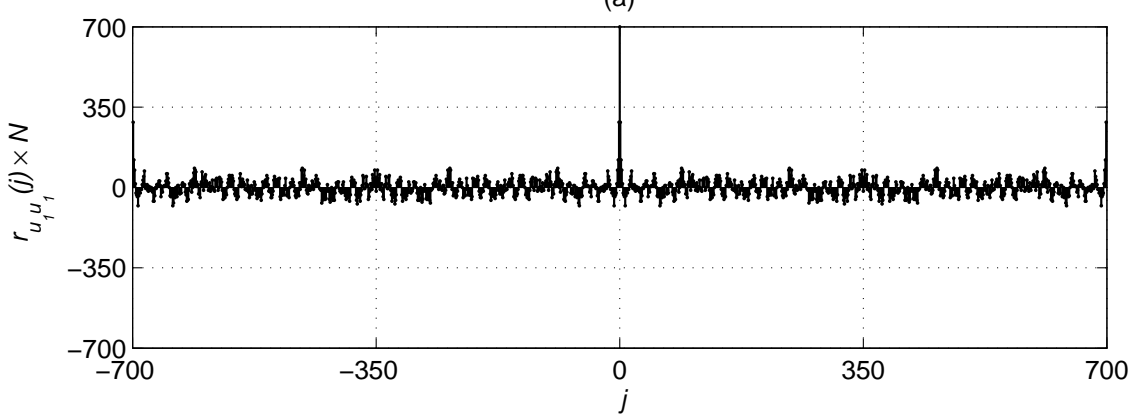

(b)

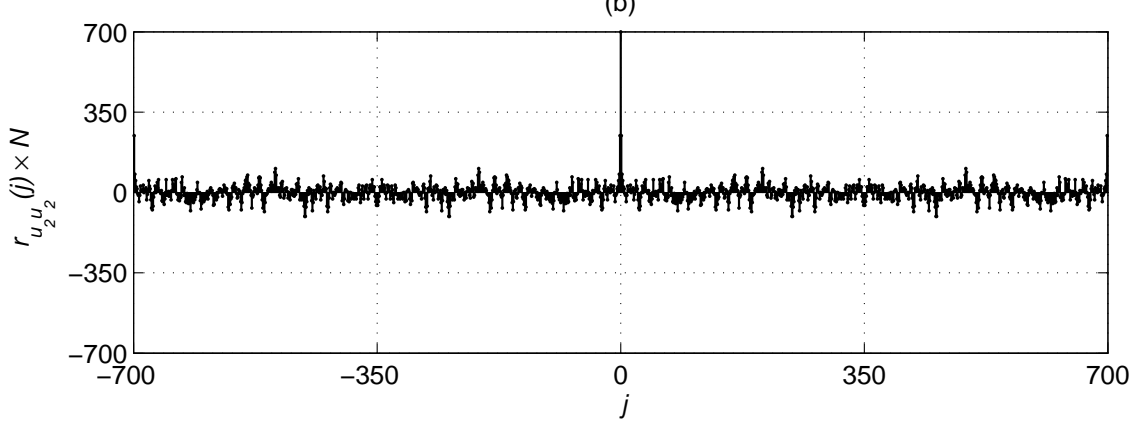

Figura 5.16: Função de autocorrelação periódica dos sinais GBN com $p=0,6869 \mathrm{e}$ comprimento $N_{s}=700$.

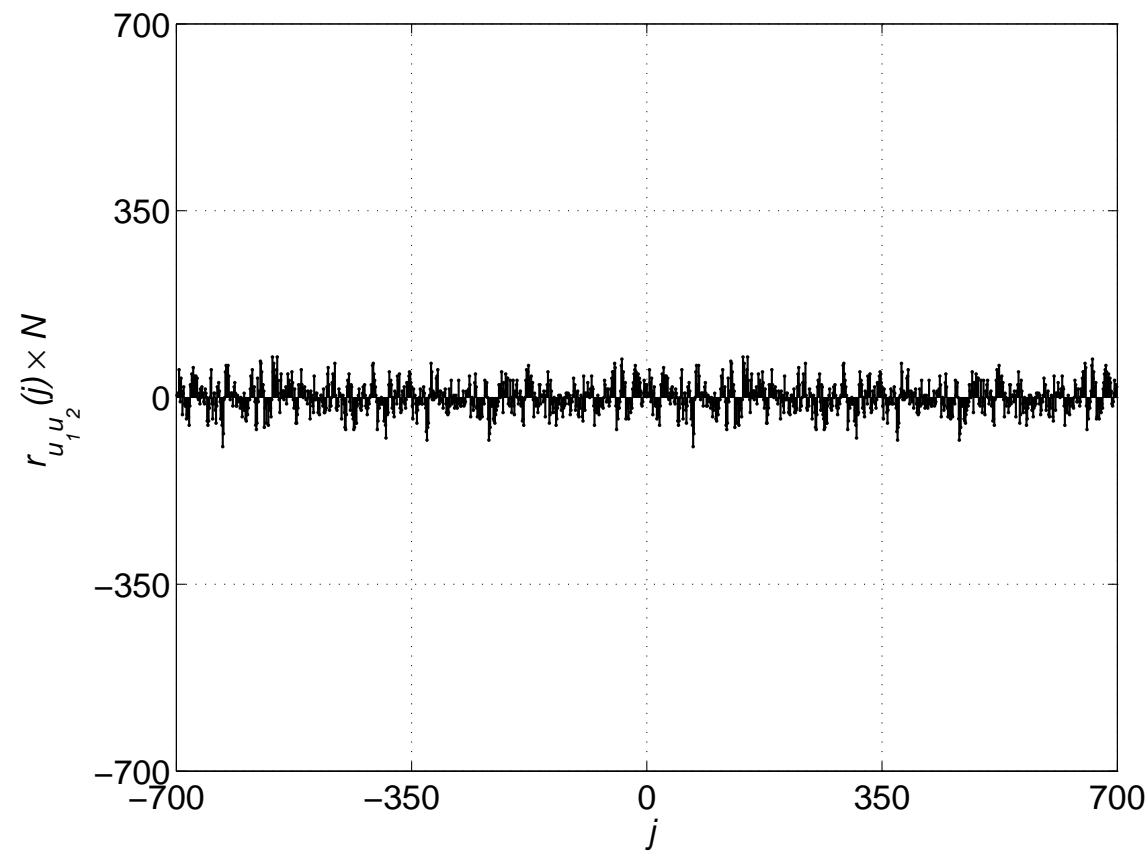

Figura 5.17: Função de correlação cruzada periódica entre os sinais GBN com $p=0,6869$ e comprimento $N_{s}=700$.

\subsection{Sinais otimizados por computador}

Os sinais otimizados por computador são fundamentais em processos de identificação nos quais a forma do espectro deve ser cuidadosamente definida. Por exemplo, quando é necessário evitar ressonância no sistema ou não evidenciar a dinâmica de um atua- 
dor suprimindo uma faixa de frequências (GODFREY et al., 2005). Pode-se otimizar um conjunto de sinais de forma que seus espectros sejam intercalados (zippered spectrum) gerando um conjunto de sinais ortogonais, conforme será discutido na seção 5.2.4. Conceitos de otimização são aplicados de forma a ajustar sinais de excitação maximizando medidas de qualidade como o EMINE, PIPS, PIPSE ou reduzindo o CF, TF etc. Restrições de amplitude também podem ser aplicadas, por exemplo, para obter sinais com um número determinado e finito de níveis. As próximas seções discutem algumas formas de se obter sinais por meio de otimizações.

\subsubsection{Sinais soma de harmônicos}

Um sinal do tipo soma de harmônicos (sum of harmonics, $\mathrm{SOH}$ ) é resultado de uma soma de senoides com fases adequadamente ajustadas (otimizadas). Diversos trabalhos exploraram o SOH como sinal de excitação para identificação de sistemas (GODFREY, 1993), (GODFREY; BARKER; TUCKER, 1999), (SCHOUKENS et al., 1988), (SCHOUKENS; PINTELON; DOBROWIECKI, 2001) e (GODFREY et al., 2005).

O SOH pode ser representado por (BARKER et al., 2006):

$$
u(t)=\lambda \sum_{i=1}^{n_{s}} \sqrt{2 \alpha_{i}} \cos \left(\omega_{i} t T+\phi_{i}\right), \quad \omega_{i}=\frac{2 \pi i}{N_{s} T}, \quad n_{s} \leq \frac{N_{s}}{2}
$$

onde $\lambda$ é um fator de escala, $\alpha_{i}$ é o coeficiente de Fourier para a $i$-ésima harmônica, $n_{s}$ é a quantidade de harmônicas especificadas, $N_{s}$ é o comprimento do sinal, $\omega_{i}$ é a frequência angular da $i$-ésima harmônica, $\phi_{i}$ é a fase da $i$-ésima harmônica e $T$ é o período de amostragem.

A escolha de cada fase $\phi_{i}$ é determinante para um sinal SOH ser realizável no domínio do tempo. Há décadas, pesquisas são orientadas para a escolha das fases das senoides do sinal $\mathrm{SOH}$, sendo que a maioria delas aborda a maximização do PIPS (ou, equivalentemente, a minimização do CF) (BARKER et al., 2006).

Em (SCHROEDER, 1970) é apresentado um método para a escolha das fases de um sinal SOH. Tal método, neste trabalho chamado de sinal Schroeder-SOH, apresenta um resultado razoável quando o espectro definido pelo usuário é plano ou aproximadamente constante para harmônicas consecutivas. Entretanto, quando o espectro não é plano ou é limitado a poucas harmônicas espaçadas e com potência significativa (espectro esparso), como no caso de muitos sinais com espectros intercalados (seção 5.2.4), o método de (SCHROEDER, 1970) não apresenta ganhos significativos em relação à escolha aleatória de fases (BARKER et al., 2006). Em aplicações industriais de identificação monovariável, tais restrições de espectro não são imposições 
comuns. Nesses casos, os sinais Shroeder-SOH têm se mostrado eficazes (BARKER et al., 2006).

Outros trabalhos relevantes que objetivam a maximização do PIPS para sinais $\mathrm{SOH}$ utilizam métodos de otimização para a escolha das fases. Em (OUDERAA; SCHOUKENS; RENNEBOOG, 1988b) foi apresentado o algoritmo clipping iterativo como solução de otimização. Em (GUILLAUME et al., 1991) foi utilizada a minimização da norma- $p$ ou da norma de Chebyshev do sinal para a escolha das fases. Em (RIVERA et al., 2003) o problema da escolha das fases foi solucionado por meio de otimização com restrições e programação não linear. Todos esses algoritmos geram sinais SOH com a característica chamada de "bola de neve", onde a potência é adicionada gradualmente às harmônicas de forma a maximizar o PIPS (BARKER et al., 2006).

\subsubsection{Método de Schroeder para escolhas das fases de um SOH}

O método de Schroeder para escolha das fases de um sinal SOH foi apresentado em (SCHROEDER, 1970). Considere um sinal $r(t)$ em tempo discreto de período de amostragem $T$ e limitado em banda:

$$
r(t)=\sum_{k=1}^{n_{s}}\left(\frac{p_{k}}{2}\right)^{1 / 2} \cos \left(\frac{2 \pi k t}{T}+\theta_{k}\right)
$$

onde $n_{s}$ é a quantidade de harmônicas, $p_{k}$ é a potência normalizada da $k$-ésima harmônica, ou seja, $\sum_{k=1}^{n_{s}} p_{k}=1$, e $\theta_{k}$ é a sua fase.

O problema de escolha das fases pode ser enunciado como: dado $p_{k}$ deve-se escolher $\theta_{k}$ que minimiza a amplitude do sinal $(\max \{r(t)\}-\min \{r(t)\})$, mantendo sua potência. Em outras palavras, escolher $\theta_{k}$ que maximiza o PIPS do sinal sem alterar $p_{k}$.

Considere o sinal modulado em fase abaixo:

$$
s(t)=\cos [\psi(t)]
$$

cuja fase $\psi(t)$ é linear por partes dada por:

$$
\psi(t)=\int_{0}^{t} \dot{\psi}(\tau) d \tau
$$

onde:

$$
\dot{\psi}(t)=\frac{2 \pi k}{T}, \quad t_{k-1} \leq t<t_{k}, \quad k=1,2, \ldots, n_{s}
$$


O instante $t_{k}$ no qual a frequência instantânea altera seu valor é dado por:

$$
t_{0}=0 \quad \text { e } \quad t_{k}=T \sum_{\ell=1}^{k} p_{\ell}, \quad k=1,2, \ldots, n_{s}
$$

A diferença $t_{k}-t_{k-1}$ é o intervalo de tempo durante o qual a frequência instantânea do sinal $s(t)$ é $k / T$.

O Teorema de Woodward (BLACHMAN; MCALPINE, 1969) afirma que o espectro de um sinal modulado em frequência (frequency modulated, FM) de ordem elevada é aproximadamente dado pela distribuição de probabilidades das frequências instantâneas. De outra forma, o espetro do sinal FM é aproximadamente dado pela distribuição monovariável do sinal modulante deslocado pela frequência da portadora. A demonstração do Teorema de Woodward (BLACHMAN; MCALPINE, 1969) é apresentada no apêndice E.

De acordo com (5.23), $t_{k}-t_{k-1}$ é proporcional à potência relativa $p_{k}$ da $k$-ésima harmônica. Fazendo referência ao Teorema de Woodward, para o caso limite de $n_{s}$ elevado $\left(n_{s}>>1\right)$, a envoltória do espectro do sinal $s(t)$, conforme definido em (5.20$5.23)$, se aproximará de $p_{k}, \operatorname{com} k=1,2, \ldots, n_{s}$.

A fase instantânea de $s(t)$ no $n$-ésimo intervalo de tempo $\left(t_{n-1} \leq t<t_{n}\right)$ será dada por:

$$
\begin{aligned}
\psi(t) & =\int_{0}^{t} \dot{\psi}(\tau) d \tau \\
& =\int_{0}^{t_{1}} \dot{\psi}(\tau) d \tau+\int_{t_{1}}^{t_{2}} \dot{\psi}(\tau) d \tau+\ldots+\int_{t_{n-2}}^{t_{n-1}} \dot{\psi}(\tau) d \tau+\int_{t_{n-1}}^{t} \dot{\psi}(\tau) d \tau \\
& =\int_{0}^{t_{1}} \dot{\psi}(\tau) d \tau+\int_{t_{1}}^{t_{2}} \dot{\psi}(\tau) d \tau+\ldots+\int_{t_{n-2}}^{t_{n-1}} \dot{\psi}(\tau) d \tau+\frac{2 \pi n}{T} t-\frac{2 \pi n}{T} t_{n-1} \\
\psi(t) & =\phi_{n}+\frac{2 \pi n}{T} t, \quad t_{n-1} \leq t<t_{n}
\end{aligned}
$$

Assim, tem-se:

$$
s(t)=\cos \left(\phi_{n}+\frac{2 \pi n}{T} t\right), \quad t_{n-1} \leq t<t_{n}
$$

Observa-se em (5.24) que a fase $\phi_{n}=\int_{0}^{t_{1}} \dot{\psi}(\tau) d \tau+\int_{t_{1}}^{t_{2}} \dot{\psi}(\tau) d \tau+\ldots+\int_{t_{n-2}}^{t_{n-1}} \dot{\psi}(\tau) d \tau-$ $\frac{2 \pi n}{T} t_{n-1}$, no caso limite de $n_{s}$ elevado $\left(n_{s}>>1\right)$, corresponderá à fase do $n$-ésimo componente de Fourier de $s(t)$ de potência $p_{n}$, conforme (5.25) e o Teorema de Woodward.

Assim, para o caso limite de $n_{s}$ elevado $\left(n_{s}>>1\right)$, tem-se que o espectro de $s(t)$ 
dados $p_{n}$ e $\phi_{n}$, com $n=1,2, \ldots, n_{s}$, se aproximará do espectro de $r(t)$ dados os valores de $p_{k}=p_{n}$ e $\theta_{k}=\phi_{n}, \operatorname{com} k=1,2, \ldots, n_{s}$ e $n=1,2, \ldots, n_{s}$.

Da definição (5.21) da fase do sinal $s(t)$, verifica-se que essa é contínua. Assim, (5.24) também deverá ser contínua em $t=t_{n-1}$ :

$$
\begin{aligned}
\phi_{n}+\frac{2 \pi n}{T} t_{n-1} & =\phi_{n-1}+\frac{2 \pi(n-1)}{T} t_{n-1} \\
\phi_{n} & =\phi_{n-1}-\frac{2 \pi}{T} t_{n-1}
\end{aligned}
$$

Desenvolvendo (5.26):

$$
\begin{aligned}
\phi_{n-1} & =\phi_{n-2}-\frac{2 \pi}{T} t_{n-2} \\
\phi_{n-2} & =\phi_{n-3}-\frac{2 \pi}{T} t_{n-3} \\
\ldots & \\
\phi_{2} & =\phi_{1}-\frac{2 \pi}{T} t_{1}
\end{aligned}
$$

Substituindo (5.27) em (5.26), tem-se:

$$
\phi_{n}=\phi_{1}-\frac{2 \pi}{T} \sum_{k=1}^{n-1} t_{k}
$$

Substituindo (5.23) em (5.28), tem-se:

$$
\phi_{n}=\phi_{1}-2 \pi \sum_{k=1}^{n-1} \sum_{\ell=1}^{k} p_{\ell}
$$

Invertendo a ordem dos somatórios, tem-se:

$$
\phi_{n}=\phi_{1}-2 \pi \sum_{\ell=1}^{n-1}(n-\ell) p_{\ell}, \quad n=1,2, \ldots, n_{s}
$$

As fases $\phi_{n}$ desejadas para um sinal $\mathrm{SOH}$ com espectro de potência normalizado dado por $p_{\ell}, \operatorname{com} k=1,2, \ldots, n_{s}$, são dadas por (5.30).

Para o caso especial de $s(t)$ possuir espectro plano, ou seja, $p_{\ell}=\frac{1}{n_{s}}$, tem-se de (5.30): 


$$
\begin{aligned}
\phi_{n} & =\phi_{1}-2 \pi \sum_{\ell=1}^{n-1}(n-\ell) p_{\ell}, \quad n=2, \ldots, n_{s} \\
& =\phi_{1}-2 \pi \sum_{\ell=1}^{n-1}(n-\ell) \frac{1}{n_{s}} \\
& =\phi_{1}-2 \frac{\pi}{n_{s}} \frac{(n-1) n}{2} \\
& =\phi_{1}-\frac{\pi n^{2}}{n_{s}}+\frac{\pi n}{n_{s}}
\end{aligned}
$$

Em (SCHROEDER, 1970) o autor omite o termo linear de (5.31). Assim, tem-se:

$$
\phi_{n}=\phi_{1}-\frac{\pi n^{2}}{n_{s}}, \quad n=2, \ldots, n_{s}
$$

Pode-se fazer com que as fases do sinal $\mathrm{SOH}$ assumam apenas os valores 0 e $\pi$. Com isso o sinal torna-se simétrico no domínio do tempo. Para obter essa condição, considere a frequência instantânea $\psi(t)$ de $s(t)$ variando de $\frac{1}{T}$ a $\frac{n_{s}}{T}$ em uma metade do período $T$ e de $\frac{n_{s}}{T}$ a $\frac{1}{T}$ na outra metade. Com essa consideração, reescreve-se (5.23) como:

$$
t_{0}=0 \quad \mathrm{e} \quad t_{k}=\frac{1}{2} T \sum_{\ell=1}^{k} p_{\ell}, \quad k=1,2, \ldots, n_{s}
$$

Substituindo (5.33) em (5.28), tem-se:

$$
\begin{aligned}
\phi_{n} & =\phi_{1}-\pi \sum_{k=1}^{n-1} \sum_{\ell=1}^{k} p_{\ell} \\
& =\phi_{1}-\pi \sum_{\ell=1}^{n-1}(n-\ell) p_{\ell}
\end{aligned}
$$

Como as fases do sinal SOH assumirão apenas os valores 0 e $\pi$, tem-se que $\phi_{n} \in$ $\{0 ; \pi ; 2 \pi ; 3 \pi ; \ldots\}$. Assim:

$$
\phi_{n}=\pi-\left\lceil\pi \sum_{\ell=1}^{n-1}(n-\ell) p_{\ell}\right\rceil
$$

$\mathrm{ou}$ 


$$
\phi_{n}=0-\left\lceil\pi \sum_{\ell=1}^{n-1}(n-\ell) p_{\ell}\right\rceil
$$

onde $\lceil x\rceil$ representa o maior inteiro menor que $x$.

A fase $\phi_{1}=0$ ou $\phi_{1}=\pi$, bem como o sinal da fase (positivo ou negativo), não alterará o espectro do sinal SOH. Assim:

$$
\phi_{n}=\pi\left\lceil\sum_{\ell=1}^{n-1}(n-\ell) p_{\ell}\right\rceil
$$

Considerando espectro plano para o sinal SOH, ou seja, $p_{\ell}=\frac{1}{n_{s}}$, tem-se de (5.37):

$$
\begin{aligned}
\phi_{n} & =\pi\left\lceil\sum_{\ell=1}^{n-1}(n-\ell) \frac{1}{n_{s}}\right\rceil \\
& =\pi\left\lceil\frac{1}{n_{s}} \sum_{\ell=1}^{n-1}(n-\ell)\right\rceil \\
& =\pi\left\lceil\frac{1}{n_{s}} \frac{(n-1)(n)}{2}\right\rceil \\
& =\pi\left\lceil\frac{n^{2}}{2 n_{s}}+\frac{n}{2 n_{s}}\right\rceil
\end{aligned}
$$

Em (SCHROEDER, 1970), novamente o autor omite o termo linear de (5.38). Assim, tem-se:

$$
\phi_{n}=\pi\left\lceil\frac{n^{2}}{2 n_{s}}\right\rceil
$$

As figuras 5.18, 5.19 e 5.20 apresentam um sinal Schroeder-SOH de comprimento $N_{s}=50$ com as 20 primeiras harmônicas com amplitudes iguais e as demais nulas (espectro plano), seu espectro e sua função de autocorrelação, respectivamente. Esse sinal SOH foi gerado pela soma de cossenos com fases pertencentes ao conjunto dos números reais. As fases calculadas conforme 5.30 são:

$$
\begin{aligned}
\left\{\phi_{n}\right\}=\quad & \{3,1416 ; 2,8274 ; 2,1991 ; 1,2566 ; 0 \\
& -1,5708 ;-3,4558 ;-5,6549 ;-8,1681 ;-10,9956 ; \\
& -14,1372 ;-17,5929 ;-21,3628 ;-25,4469 ;-29,8451 ;
\end{aligned}
$$


$-34,5575 ;-39,5841 ;-44,9248 ;-50,5796 ;-56,5487\}$

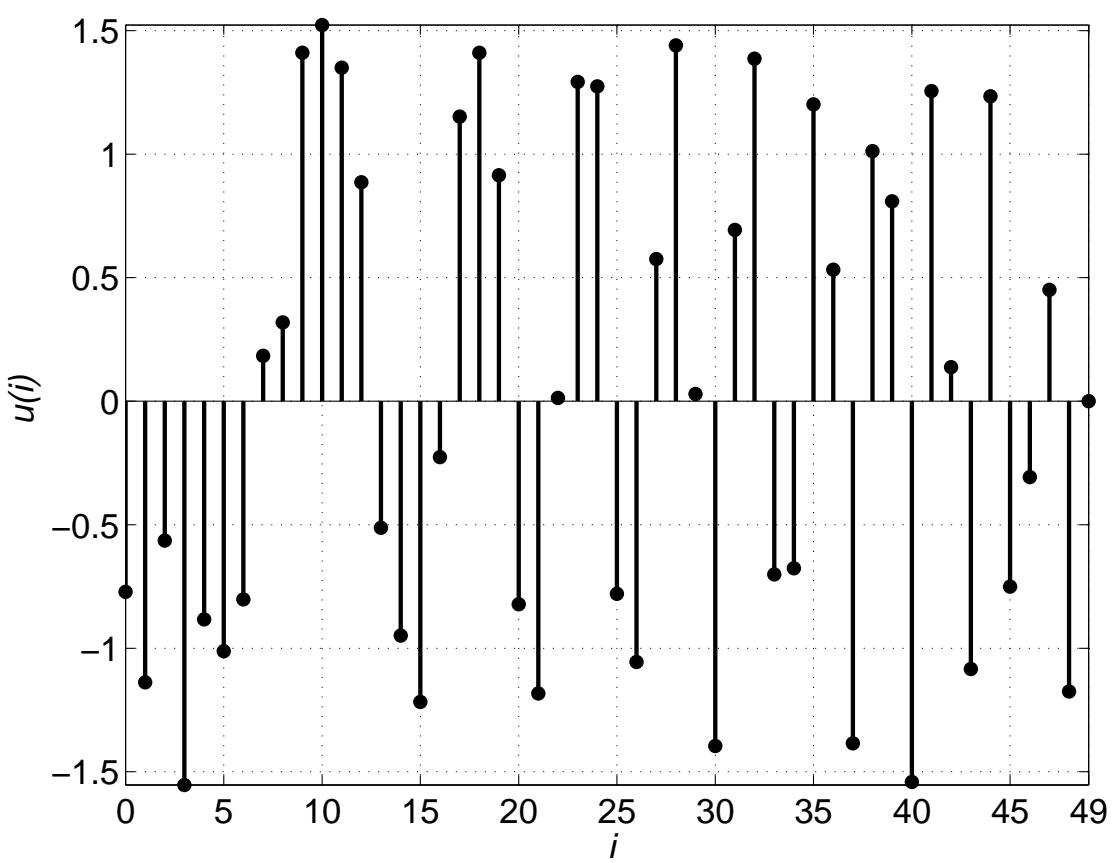

Figura 5.18: Sinal Schroeder-SOH de comprimento $N_{s}=50$ e espectro com as 20 primeiras harmônicas com amplitudes iguais e as demais nulas.

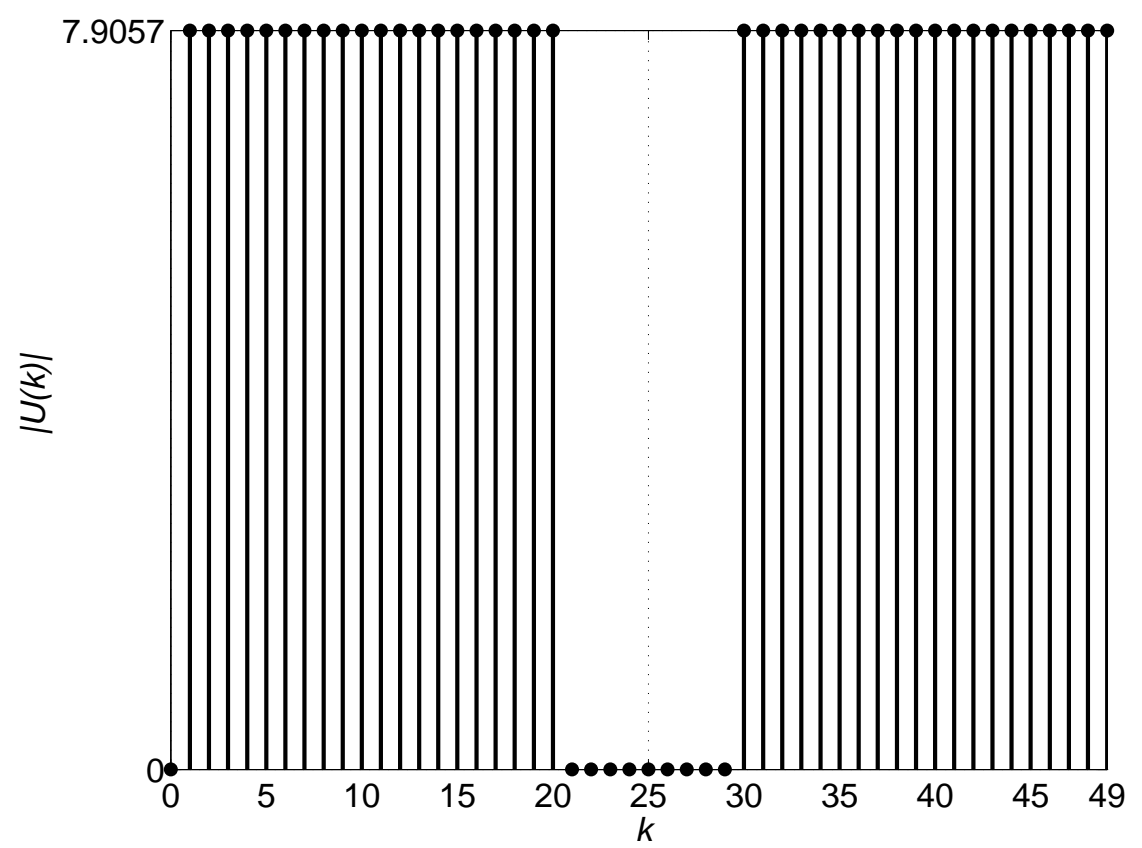

Figura 5.19: Módulo da DFT do sinal Schroeder-SOH de comprimento $N_{s}=50$ e espectro com as 20 primeiras harmônicas com amplitudes iguais e as demais nulas.

As figuras 5.21, 5.22 e 5.23 apresentam um sinal Schroeder-SOH de comprimento $N_{s}=50 \mathrm{com}$ as primeiras 10 harmônicas com amplitudes iguais e as próximas 10 com amplitude igual a metade das anteriores (as demais são nulas), seu espectro e sua 


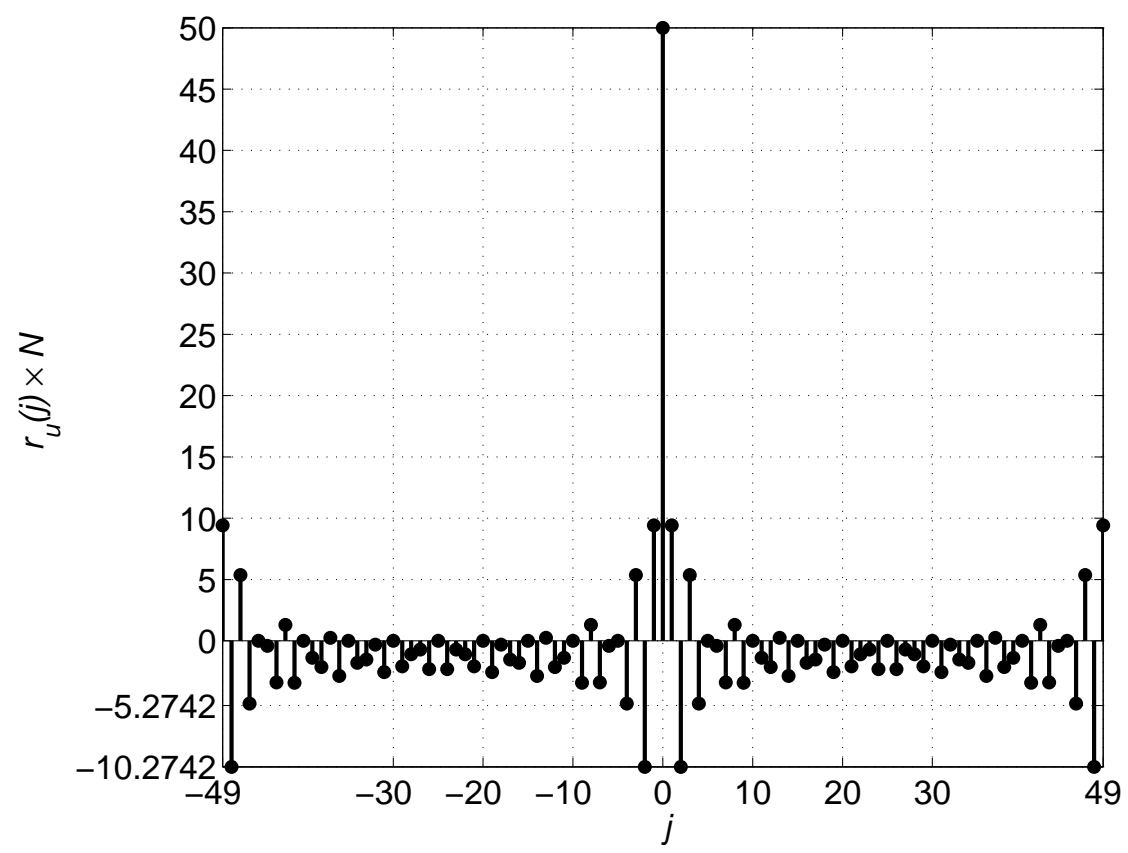

Figura 5.20: Função de autocorrelação periódica do sinal SOH de comprimento $N_{s}=50$ e espectro plano.

função de autocorrelação, respectivamente. Esse sinal SOH também foi gerado pela soma de cossenos com fases pertencentes ao conjunto dos números reais. As fases calculadas conforme 5.30 são:

$$
\begin{aligned}
\left\{\phi_{n}\right\}= & \{3,1416 ; 2,7227 ; 1,8850 ; 0,6283 ;-1,0472 ; \\
& -3,1416 ;-5,6549 ;-8,5870 ;-11,9381 ;-15,7080 \\
& -19,8968 ;-24,2950 ;-28,9027 ;-33,7198 ;-38,7463 ; \\
& \quad . .-43,9823 ;-49,4277 ;-55,0826 ;-60,9469 ;-67,0206\}
\end{aligned}
$$

Sinais SOH com fases não escolhidas adequadamente (fases não otimizadas) tendem a resultar em PIPS e CF mais elevados que sinais SOH com fases otimizadas (como Schroeder-SOH), visto que o objetivo da otimização de fases é reduzir a amplitude do SOH mantendo sua potência. Conforme (SCHROEDER, 1970), a otimização de fases pelo método de Schroeder produz bons resultados para espectro plano de magnitudes. Para esses casos, tipicamente, o fator de crista é $C F=1,67$ para 15 a 31 componentes harmônicos não nulos. Os capítulos 7 e 10 apresentam comparações entre os sinais descritos neste trabalho relativamente aos índices de desempenho, onde pode-se verificar a característica do CF para sinais Schroeder-SOH. 


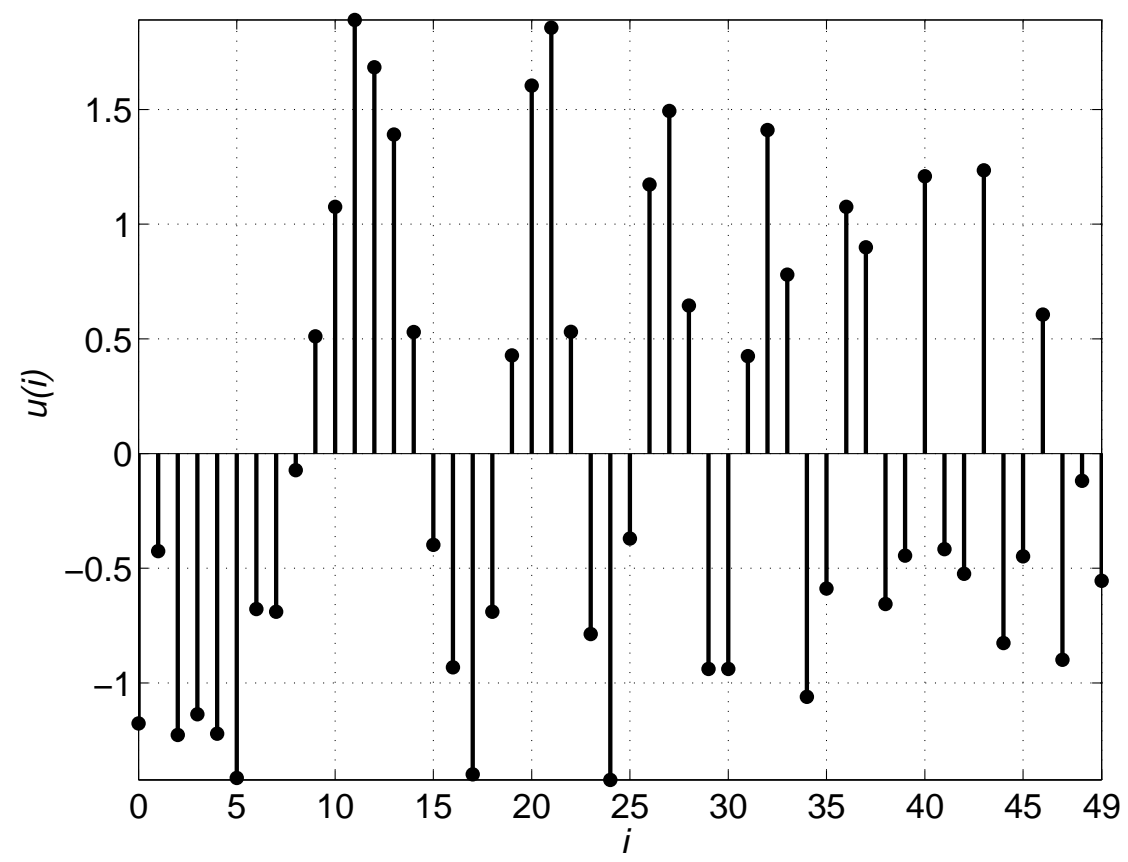

Figura 5.21: Sinal Schroeder-SOH de comprimento $N_{s}=50$ e espectro com as 10 primeiras harmônicas com amplitudes iguais, as próximas 10 com metade da amplitude das anteriores e as demais nulas.

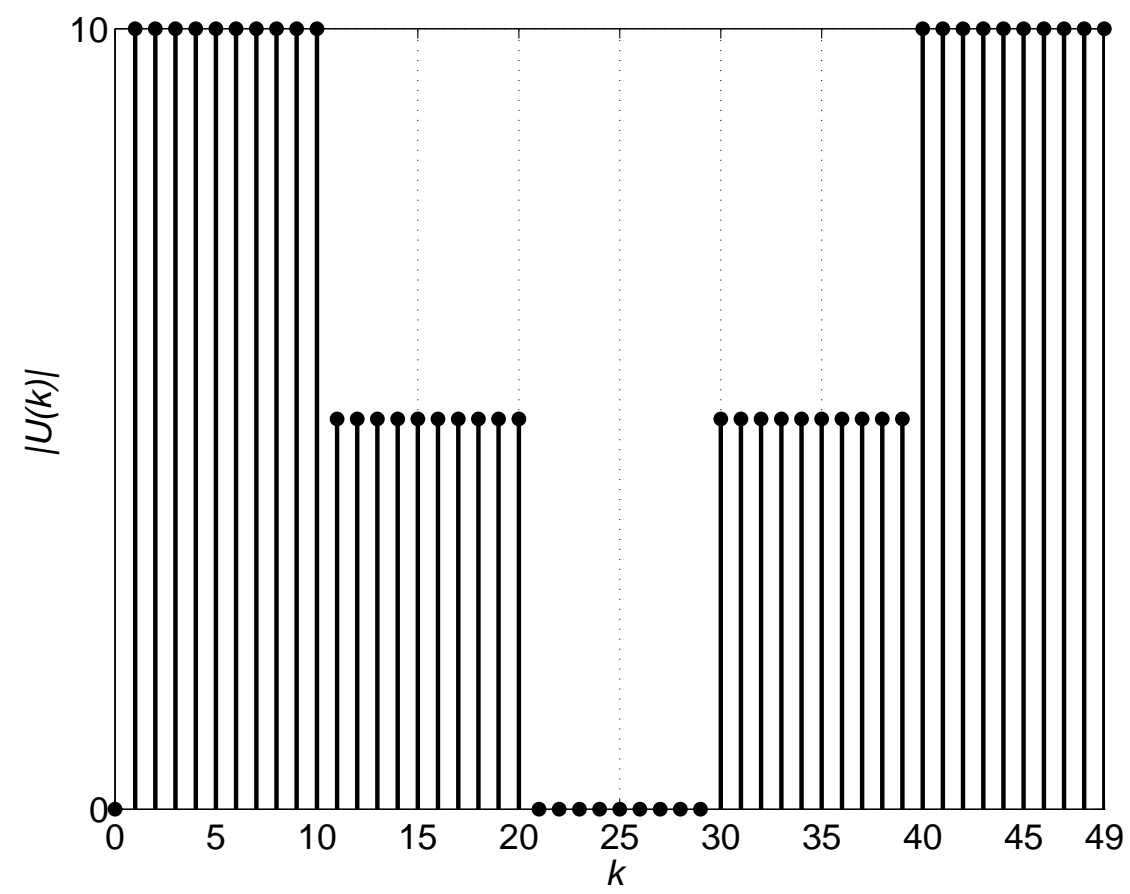

Figura 5.22: Módulo da DFT do sinal Schroeder-SOH de comprimento $N_{s}=50$ e espectro não plano.

\subsubsection{Algoritmo clipping iterativo}

O algoritmo clipping apresentado em (OUDERAA; SCHOUKENS; RENNEBOOG, 1988b) objetiva minimizar os picos de sinais $\mathrm{SOH}$ no domínio do tempo sem distorcer o espec- 


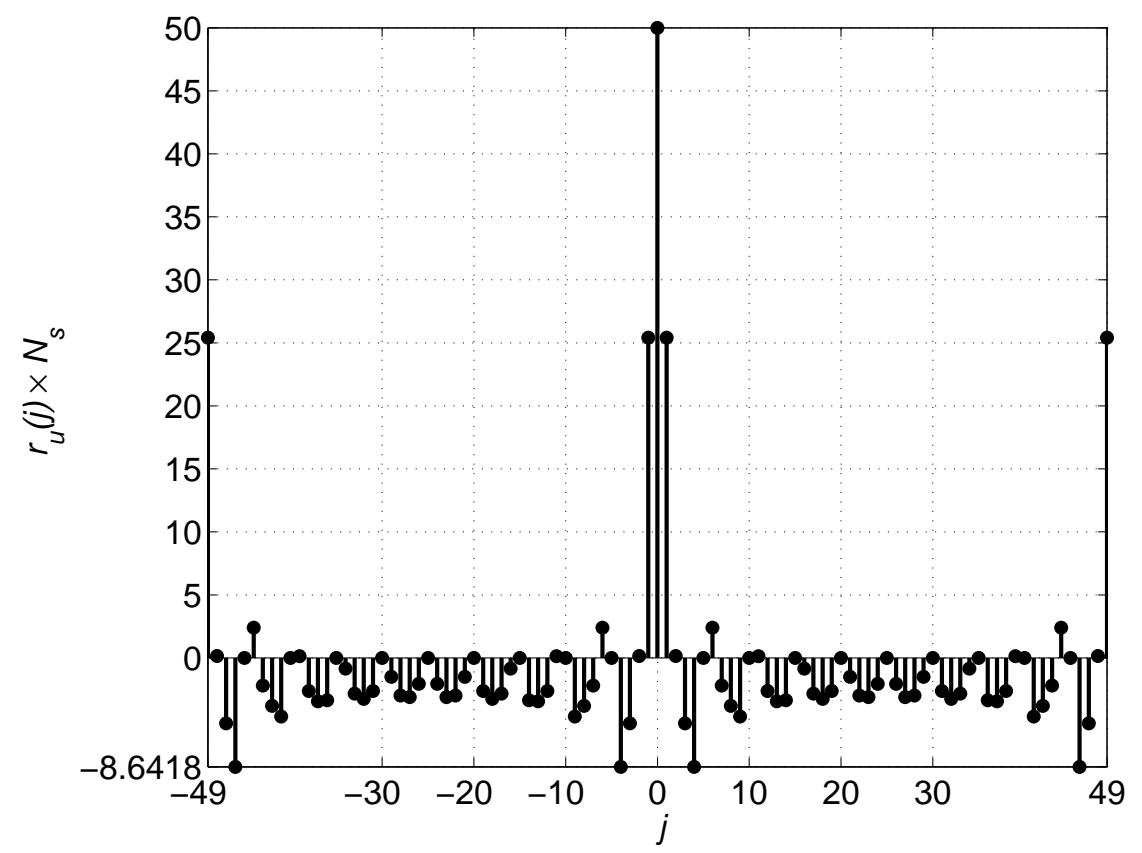

Figura 5.23: Função de autocorrelação periódica do sinal Schroeder-SOH de comprimento $N_{s}=50$ e espectro não plano.

tro de potência do sinal. Em outras palavras, o algoritmo minimiza o CF (ou PF) procurando manter o espectro de potência desejado para o sinal. Conforme mencionado na seção 5.2.1.1, o método de Schroeder produz bons resultados para espectro plano de magnitudes, porém, para o caso de espectro não plano, o método de Schroeder não apresenta ganho significativo em relação ao uso de códigos aleatórios. Em (GERTCHBERG; SAXTON, 1972) (BOS; KROL, 1979), mostrou-se que com pequenas alterações nas magnitudes das harmônicas é possível obter ganhos expressivos em relação à limitação do método de Schroeder. Em (OUDERAA; SCHOUKENS; RENNEBOOG, 1988b), com referência aos trabalhos de Van den Bos, Gerchberg e Saxton, foi proposto um algoritmo iterativo para ajustes das fases das harmônicas de um sinal SOH.

O algoritmo clipping consiste em comutar, de forma iterativa, os dois domínios obtidos pelas transformadas rápidas direta e inversa de Fourier (fast Fourier transform, FFT, e inverse fast Fourier transform, IFFT, respectivamente) impondo restrições em ambos domínios. Essa técnica de comutar entre domínios já havia sido aplicada anteriormente em (MARKS; REIGHTLEY, 1985).

O algoritmo é apresentado na figura 5.24. No domínio do tempo, o sinal é ceifado em determinado valor relacionado ao seu valor de pico com o objetivo de limitar sua amplitude. Em (OUDERAA; SCHOUKENS; RENNEBOOG, 1988b) afirma-se que, para obter uma boa convergência do algoritmo, o sinal deve ser ceifado em um nível maior que a amplitude de um sinal binário com a mesma energia. Tipicamente, esses valores 
estão entre $75 \%$ a $95 \%$ do valor de pico do sinal (OUDERAA; SCHOUKENS; RENNEBOOG, 1988b). Ceifamentos em níveis maiores que $95 \%$ do valor de pico resultarão em convergência lenta. Por outro lado, ceifamentos menores que $75 \%$ do valor de pico podem resultar em não convergência do algoritmo devido a significativa alteração no espectro de potência do sinal. A cada iteração do algoritmo, um novo nível de ceifamento deve ser calculado, baseado no valor de pico do sinal resultante da iteração anterior.

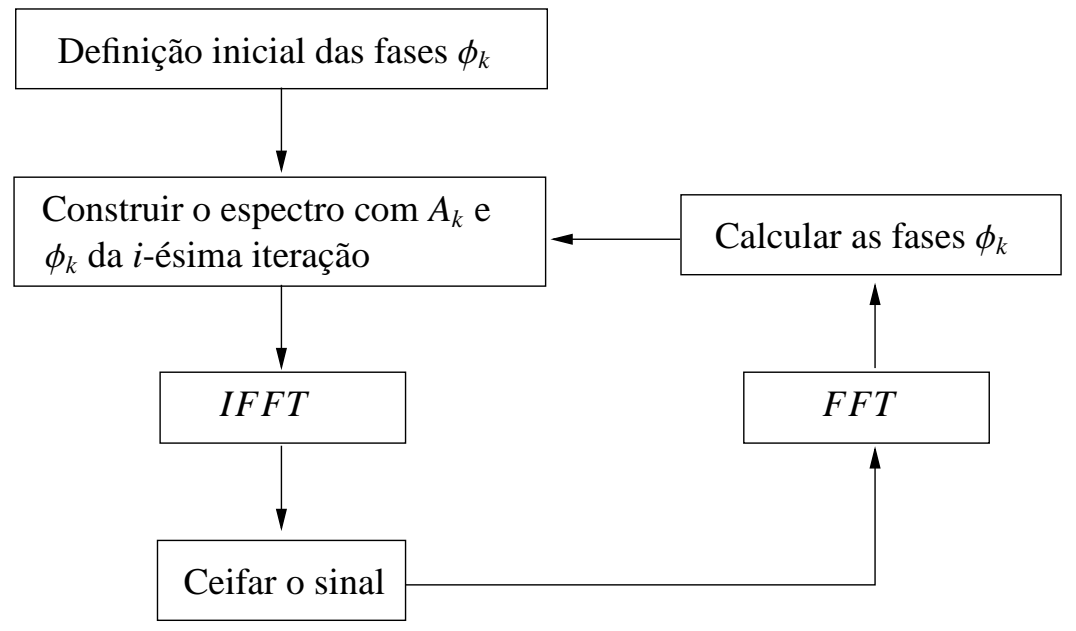

Figura 5.24: Algoritmo clipping.

Ao passar para o domínio da frequência, mantém-se as fases obtidas da iteração anterior e impõem-se as potências (ou amplitudes $A_{k}$ ) do espectro original. Assim, assegura-se o espectro de potência do sinal original não criando novos componentes de frequência que seriam originados do ceifamento realizado no domínio do tempo.

Observa-se que o algoritmo tem como objetivo minimizar a norma infinito do sinal $u(n)$, também conhecida como norma- $\infty$, norma do supremo, norma uniforme ou norma de Chebyshev, dada por:

$$
\|u(n, \phi)\|_{\infty}=\max _{n=0}^{N_{s}-1}|u(n, \phi)|
$$

Em (GERTCHBERG; SAXTON, 1972) Gerchberg e Saxton mostraram que o algoritmo clipping não diverge. Em (TOM; QUATIERI, 1981) é provado que a medida Euclideana:

$$
d\left(x_{i}, x_{i+1}\right)=\left\{\sum_{n=0}^{N_{s}-1}\left[x_{i}(n)-x_{i+1}(n)\right]^{2}\right\}^{1 / 2}
$$

com $x_{i}$ sendo o sinal da $i$-ésima iteração, não diverge para algoritmos inclusive do tipo do clipping de (GERTCHBERG; SAXTON, 1972). Assim, tem-se que o algoritmo 
clipping não diverge, porém, a convergência não é provada. A demonstração (TOM; QUATIERI, 1981) da não divergência é apresentada no Apêndice F no contexto do algoritmo clipping. Em (TOM; QUATIERI, 1981), verifica-se experimentalmente que o algoritmo converge para sinais com fator de crista menores que os iniciais. Os sinais SOH obtidos por meio do algoritmo clipping serão denominados neste trabalho como sinais clipping-SOH.

As figuras 5.25, 5.26 e 5.27 apresentam um sinal clipping-SOH de comprimento $N_{s}=50 \mathrm{com}$ as primeiras 10 harmônicas com amplitudes iguais e as próximas 10 com amplitude igual a metade das anteriores (as demais são nulas), seu espectro e sua função de autocorrelação, respectivamente. A figura 5.28 apresenta a evolução dos limites de amplitudes em função das iterações do algoritmo clipping do sinal SOH de comprimento $N_{s}=50$. O algoritmo foi interrompido quando a amplitude do sinal atendeu a amplitude máxima especificada de 1,9. O parâmetro de ceifamento do sinal do algortimo clipping foi adotado igual a 0,95 .

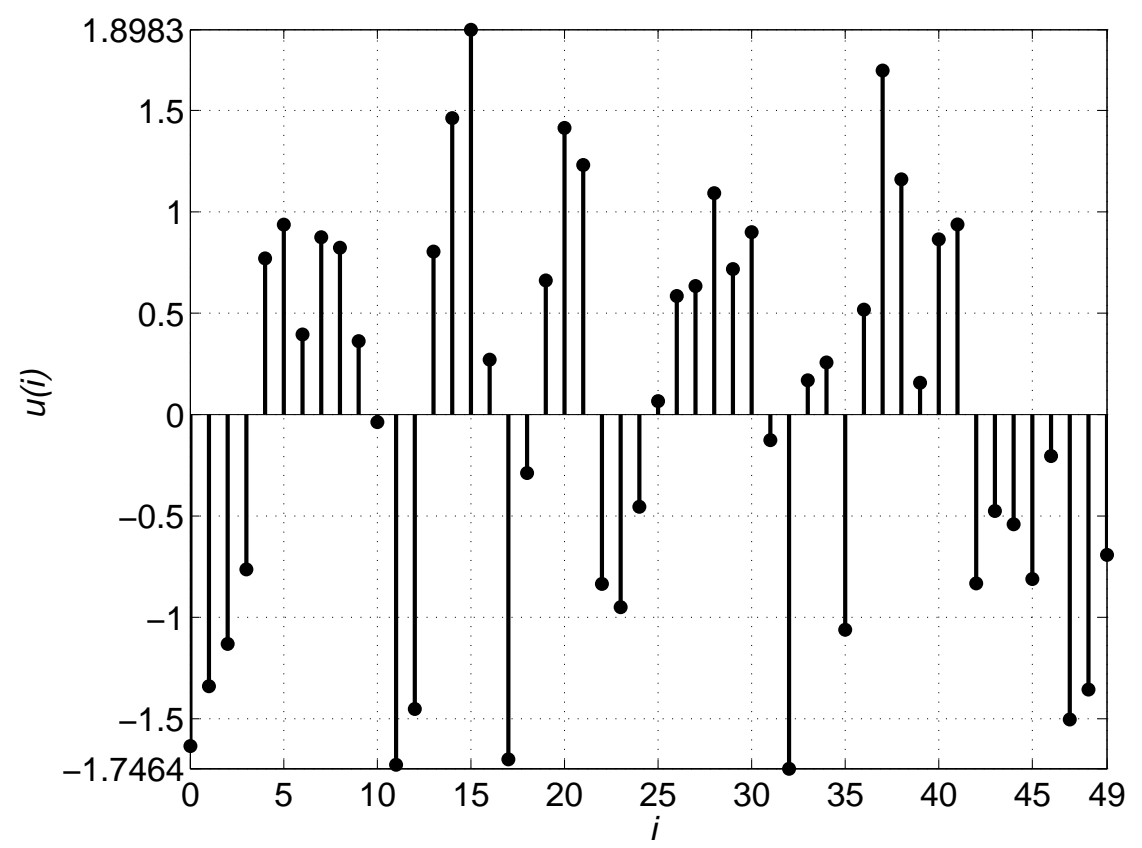

Figura 5.25: Sinal clipping-SOH de comprimento $N_{s}=50$ e espectro não plano obtido com o algoritmo clipping.

\subsubsection{Outros algoritmos de otimização de fases de sinais SOH}

O problema de otimização para maximizar o PIPS (ou minimizar o CF ou o PF) não é simples, pois a norma infinita é não convexa e não diferenciável. O trabalho de (GUILLAUME et al., 1991) apresenta uma abordagem que procura aproximar a minimização da norma infinito por meio de minimizações sucessivas da norma $p$ para $p=4,8,16, \ldots$ : 


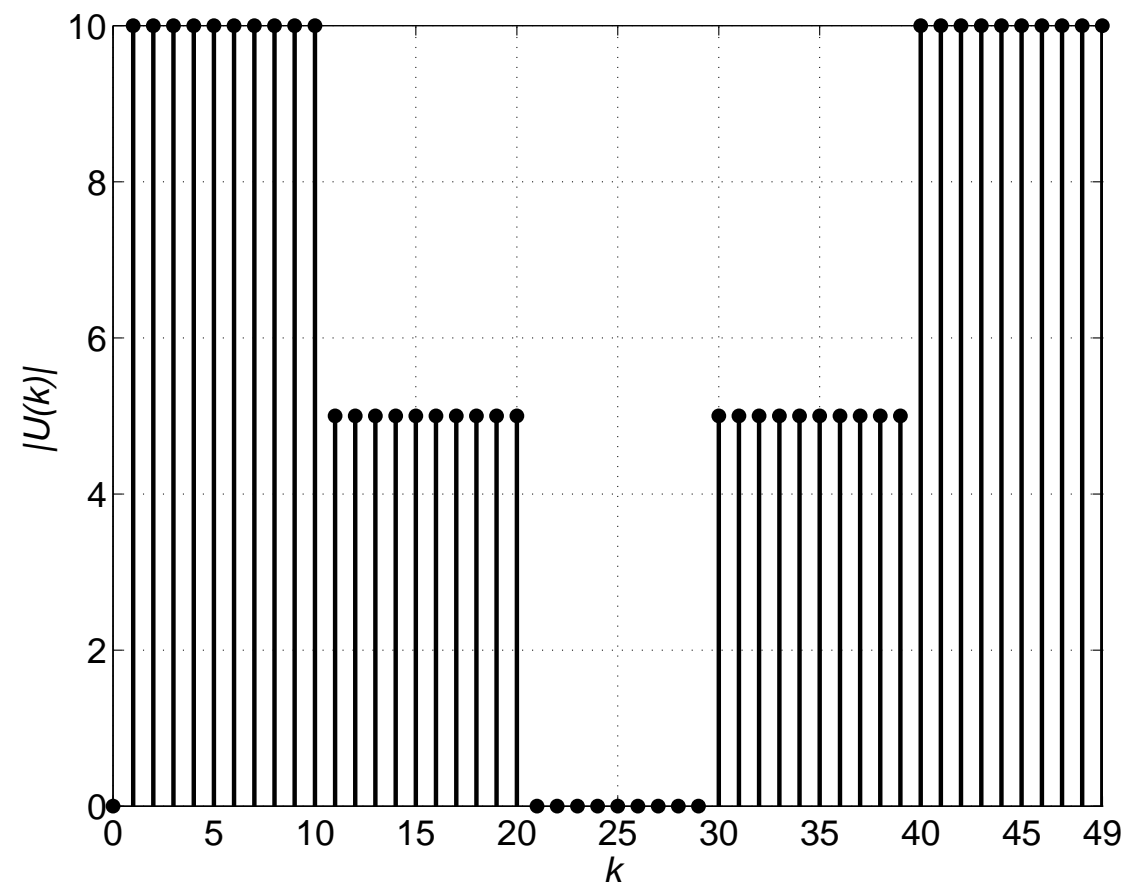

Figura 5.26: Módulo da DFT do sinal clipping-SOH de comprimento $N_{s}=50 \mathrm{e}$ espectro não plano obtido com o algoritmo clipping.

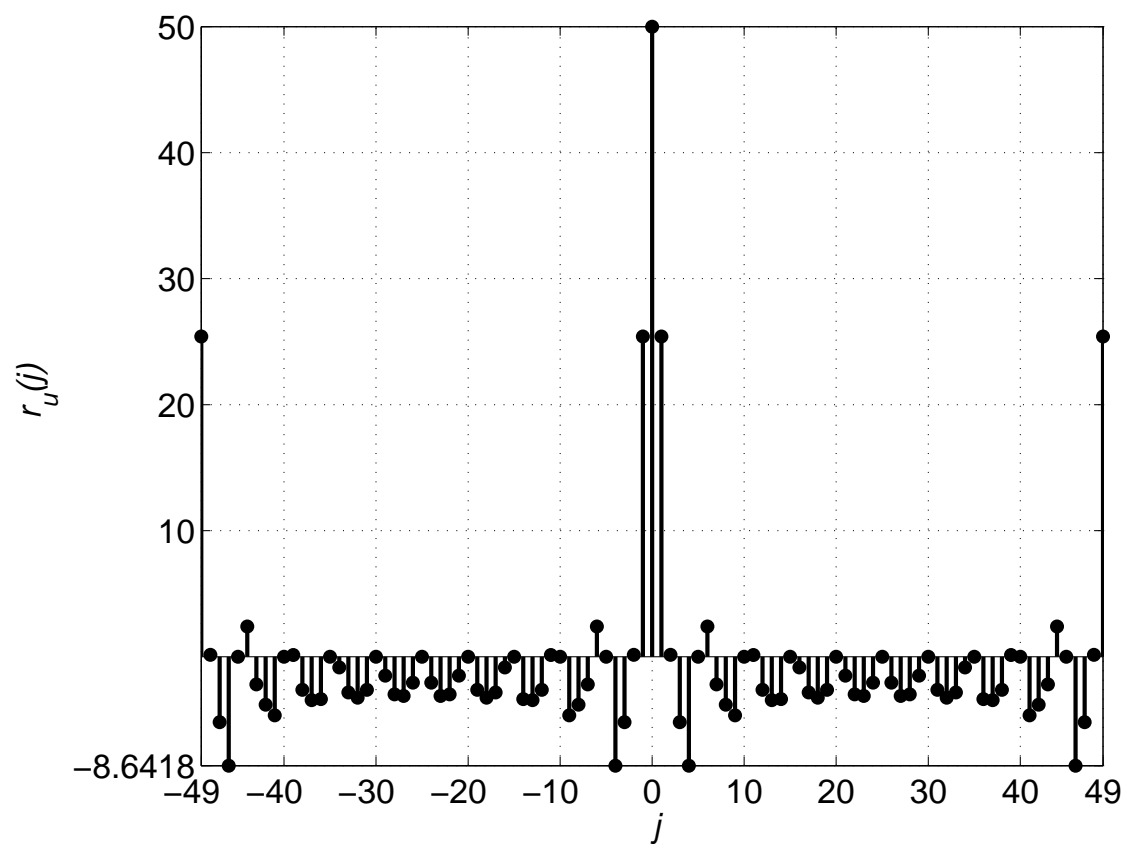

Figura 5.27: Função de autocorrelação periódica do sinal clipping-SOH de comprimento $N_{s}=50$ e espectro não plano obtido com o algoritmo clipping.

$$
\|u(n, \phi)\|_{p}=\left(\sum_{n=0}^{N-1}|u(n, \phi)|^{p}\right)^{1 / p}
$$

Embora uma solução global não possa ser garantida com essa abordagem, a maio- 


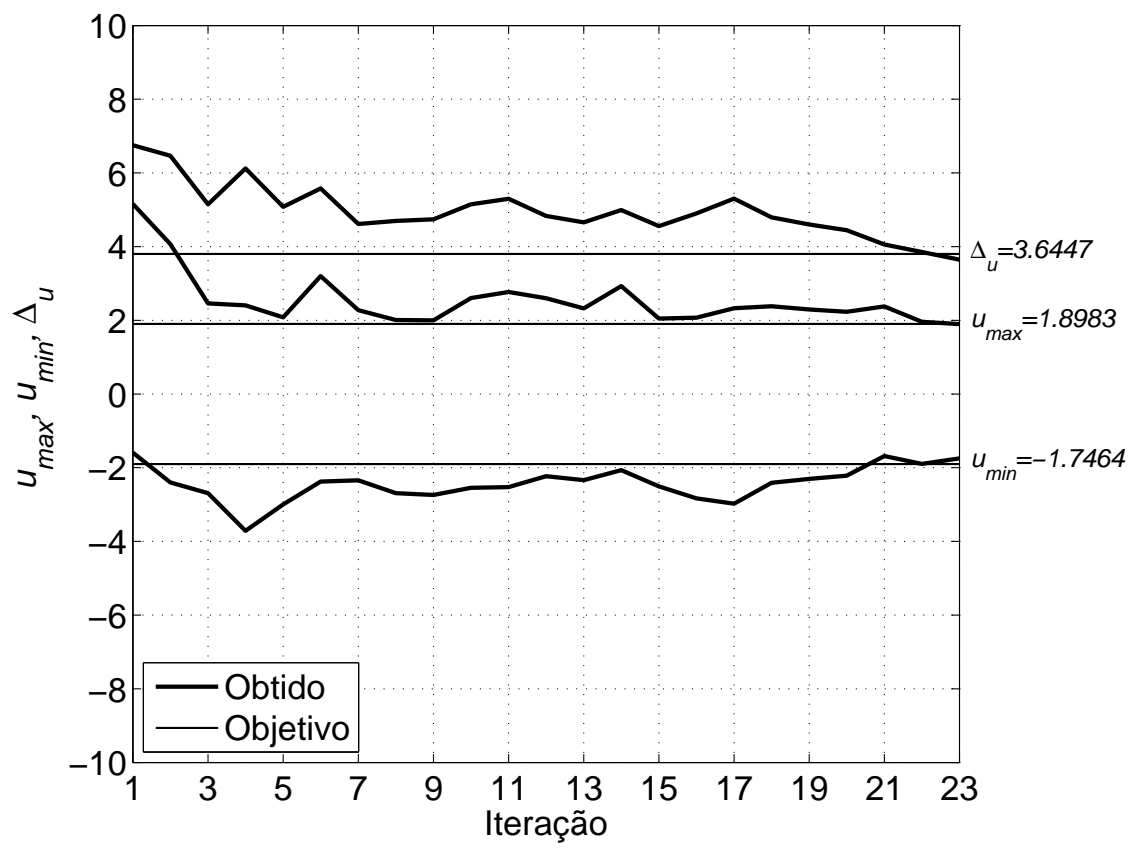

Figura 5.28: Evolução dos limites de amplitudes em função das iterações do algoritmo clipping do sinal $\mathrm{SOH}$ de comprimento $N_{s}=50$.

ria dos mínimos locais são evitados resultando em bons resultados.

Em (OUDERAA; SCHOUKENS; RENNEBOOG, 1988a) é apresentada uma extensão do método clipping onde há preocupação em reduzir o CF do sinal de entrada e de saída do sistema. Em outras palavras, objetiva-se encontrar um sinal de excitação de mínimo CF o qual, quando aplicado ao sistema, produz um sinal de saída também com CF mínimo. Reduzir o CF do sinal de saída também é desejável, pois amplitudes elevadas em variáveis controladas não são desejáveis em identificação plant-friendliness (RIVERA et al., 2003), conforme os critérios listados na seção 3.3. Porém, para que essa otimização seja viável, deve-se conhecer a planta nominal o que é contraditório ao objetivo da identificação de sistemas, onde há pouca informação sobre o sistema antes dele ser identificado, conforme discutido na seção 2.2.

O algoritmo de (OUDERAA; SCHOUKENS; RENNEBOOG, 1988a) consiste de dois algoritmos clipping acoplados em uma única iteração. Em uma mesma iteração ocorrem os ceifamentos do sinal de entrada e do sinal de saída, conforme a figura 5.29. O filtro citado no algoritmo é a função de transferência do sistema a ser identificado, o que evidencia que para a minimização conjunta do CF do sinal de entrada e saída é necessário o conhecimento prévio das características do sistema, inclusive dinâmicas, suficientes para garantir as restrições de amplitudes dos sinais de saída.

O conceito de minimização conjunta do CF do sinal de entrada e do sinal de saída foi aplicada em (OUDERAA; SCHOUKENS; RENNEBOOG, 1988a) apenas em sistemas 


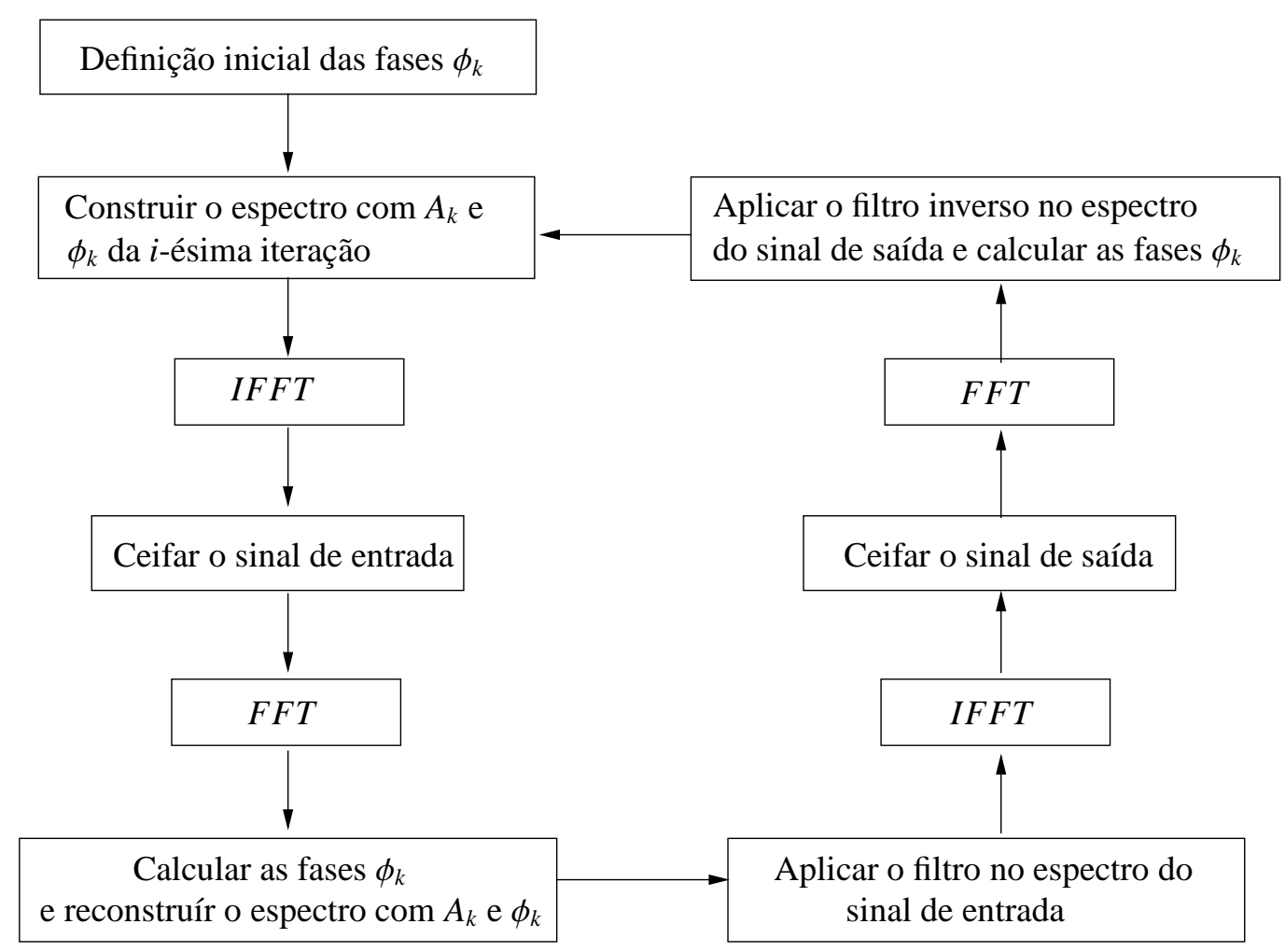

Figura 5.29: Algoritmo clipping com minimização conjunta do CF do sinal de entrada e saída.

SISO. Em (GUILLAUME et al., 1991), a ideia de minimização conjunta de sinais foi aplicada ao caso de sistemas MIMO.

Recentemente, em (RIVERA et al., 2003) e (LEE; RIVERA; MITTELMANN, 2003) são aplicadas técnicas mais avançadas de otimização no ajuste de fases de sinais $\mathrm{SOH}$. Nesses trabalhos, o problema da minimização da norma infinita é contornado e inclui restrições de amplitudes dos sinais de entrada e de saída da planta.

A geração de sinais utilizando algoritmos iterativos de otimização podem prover resultados aprimorados. Porém, é necessária a parametrização adequada dos algoritmos e verificação dos resultados, pois, conforme mencionado anteriormente, a solução global pode não ser garantida. Esse atividade cuidadosa para gerar sinais utilizando algoritmos iterativos de otimização dificulta a difusão da aplicação desses sinais em plantas industriais, visto que são desejáveis soluções ágeis e que não consumam muitas horas de engenharia em procedimentos de identificação. No capítulo 6 será apresentada uma proposta de geração de sinais baseados em sinais Schroeder-SOH, ou seja, que não depende de algoritmos iterativos de otimização de fases, com espectro esparso e elevado $\mathrm{CF}$, adequado para aplicações práticas em identificação multivariável de processos industriais. 


\subsubsection{Sinal binário e ternário de intervalo discreto}

Os sinais binários de intervalo discreto (discrete interval binary, DIB) são gerados, assim como os sinais $\mathrm{SOH}$, por meio de soma de senoides com fases adequadamente escolhidas de forma a obter o espectro desejado (especificado). Porém, diferentemente dos sinais $\mathrm{SOH}$, a amplitude do sinal DIB é quantizada de forma a resultar em um sinal binário. Assim como os sinais SOH, os sinais DIB são resultados de otimização, cujo objetivo é concentrar a maior quantidade de potência possível nas harmônicas especificadas, dadas as restrições de amplitude.

Em (SCHROEDER, 1970) é apresentada uma forma imediata de gerar sinais DIB com espectro plano. Porém, essa característica é facilmente obtida com sinais PRB, o qual será apresentado em seção posterior. Assim, o método de (SCHROEDER, 1970) para gerar sinais DIB é pouco aplicado. Uma vantagem do sinal DIB sobre o PRB é ele poder ser gerados com qualquer comprimento, diferentemente dos sinais PRB.

Em (BOS; KROL, 1979) foi proposto um algoritmo para gerar sinais DIB com espectro de potência especificado (não apenas espectro plano). A amplitude do espectro do DIB pode ser otimizada pela escolha adequada da chamada sequência de chaveamento (BOS; KROL, 1979). Assim, a energia fica concentrada nas frequências de interesse. O algoritmo proposto para gerar sinais DIB pode ser estendido para gerar sinais ternários de intervalo discreto (discrete interval ternary DIT) e sinais multi harmônicos multinível (multi-level multi-harmonic signals, MLMH). Assim, entende-se que os sinais DIB e DIT são casos particulares dos sinais MLMH, os quais serão apresentados na seção 5.2.3.

O valor do PIPS para um sinal DIB é próximo de 100\%, porque o sinal é binário e sua média é zero ou muito próxima a zero. Entretanto, é comum o valor do PIPSE ser menor que $100 \%$, assim como o valor do EMINE (GODFREY et al., 2005). Isso ocorre porque nem toda a energia está concentrada exatamente nas frequências especificadas, apesar da maior parte da energia estar confinada na banda de interesse (PINTELON; SCHOUKENS, 2001). Essa característica decorre da restrição de amplitude aplicada ao sinal, limitando a forma de seu espectro. Uma parcela significativa da potência total do sinal aparece em harmônicas não especificadas. Por outro lado, sinais SOH sem restrição de amplitude geralmente possuem mais potência concentrada nas harmônicas especificadas, porém, possuem valores mais elevados de amplitude de pico-a-pico para uma dada especificação de harmônicas (GODFREY et al., 2005). 


\subsubsection{Sinal multi harmônico multinível}

O sinais multi harmônicos multinível (multi-level multi-harmonic signals, MLMH signals) são projetados para unir vantagens dos sinais DIB e dos sinais clipping-SOH: amplitude quantizada e menos restrições para ajuste do espectro, respectivamente. Assim, sinais MLMH são úteis em aplicações em que existem restrições na quantidade de níveis do sinal e restrições na especificação harmônica. Por exemplo, identificação das dinâmicas lineares na presença de ruídos ou distorções não lineares (apêndice B) de um sistema que aceita uma quantidade limitada de níveis em suas entradas. Nesses casos, é importante suprimir as harmônicas múltiplas de dois ou três para eliminar o efeito das não linearidades de ordem par e ímpar (BARKER et al., 2006) (GODFREY et al., 2005).

O primeiro algoritmo para gerar sinais MLMH foi proposto em (BOS; KROL, 1979). Em (MCCOMARCK; GODFREY; FLOWER, 1994), aquele algoritmo foi aprimorado. Posteriormente, em (MCCOMARCK; GODFREY; FLOWER, 1995) adicionou-se o critério para maximizar o EMINE no projeto dos sinais MLMH. Em outro algoritmo proposto em (TAN; GODFREY, 2004a), obtém-se sinais MLMH minimizando o TF (equação (4.23)).

O algoritmo de (MCCOMARCK; GODFREY; FLOWER, 1995) é similar ao algoritmo clipping de (OUDERAA; SCHOUKENS; RENNEBOOG, 1988b) para gerar sinais SOH. A diferença consiste na existência de um quantizador em substituição ao ceifamento do sinal. O quantizador limita o sinal obtido a cada iteração em níveis predeterminados, conforme apresentado na figura 5.30 para o caso da quantidade de níveis do quantizador $n$ ímpar. O parâmetro $q$ do quantizador define os intervalos do sinal de entrada que serão mapeados nos sinais de saída e $L=u_{\max }-u_{\min }$ é a amplitude do sinal a ser quantizado. No caso de um quantizador com $n$ par, os níveis de saída serão $-V_{n / 2} \ldots V_{n / 2} \in \mathbb{Z}$ e não haverá o nível zero. A execução do algoritmo é interrompida quando o EMINE mínimo especificado é atingido.

Quanto maior o parâmetro $q$ do quantizador, mais o sinal multinível se assemelhará a um sinal binário. Assim, com o aumento de $q$ é possível aumentar a quantidade de potência do sinal, porém, maior será a diferença entre o espectro especificado e o obtido por meio da otimização. Em outras palavras, quanto maior o valor de $q$, mais próximo de $100 \%$ será o PIPS, porém, menor tenderá a ser o EMINE.

As figuras 5.31 e 5.32 apresentam a função de um quantizador de $n=5$ níveis com $q=2$ e este aplicado a uma função $\sin (\omega)$, com $0 \leq \omega \leq 2 \pi$, respectivamente. As figuras 5.33 e 5.34 apresentam resultados para um quantizador de $n=6$ níveis com $q=2$. 


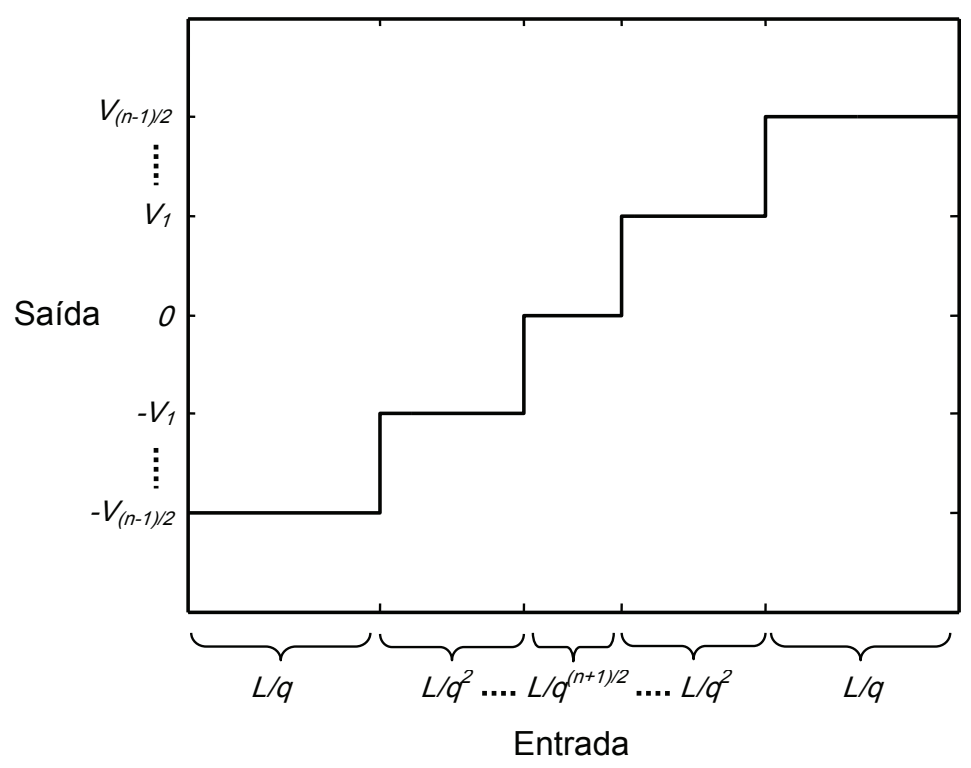

Figura 5.30: Quantizador de $n$ níveis, com $n$ ímpar, do algoritmo clipping para gerar sinais MLMH.

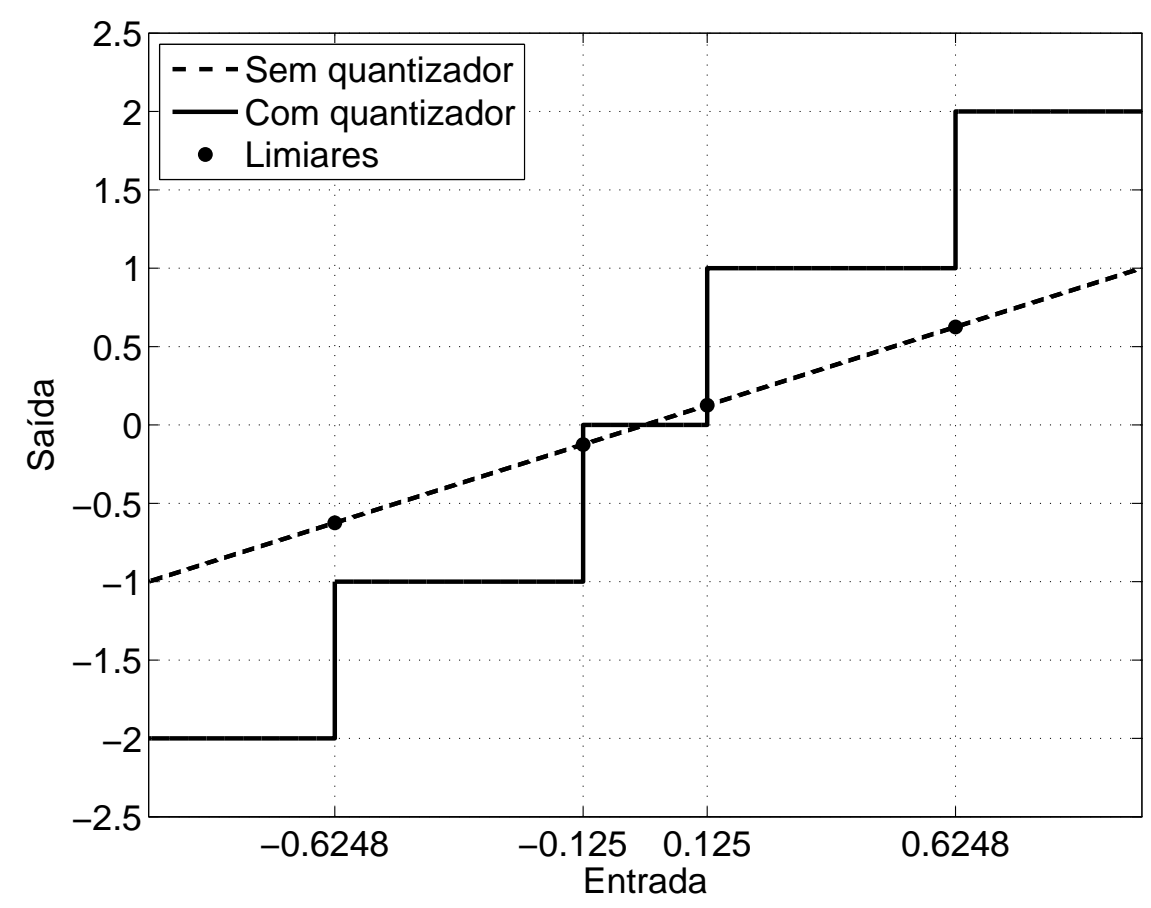

Figura 5.31: Exemplo de um quantizador de $n=5$ níveis com $q=2$.

As figuras 5.35, 5.36 e 5.37 apresentam um sinal MLMH de comprimento $N_{s}=50$ projetado com objetivo de se obter as primeiras 10 harmônicas com amplitudes iguais e as próximas 10 com amplitude igual a metade das anteriores (as demais são nulas), seu espectro e sua função de autocorrelação, respectivamente. A evolução do EMINE em função das iterações do algoritmo de otimização é apresentada na figura 5.38. O EMINE mínimo adotado para a parada do algoritmo foi $E M I N E=88$. Este valor 


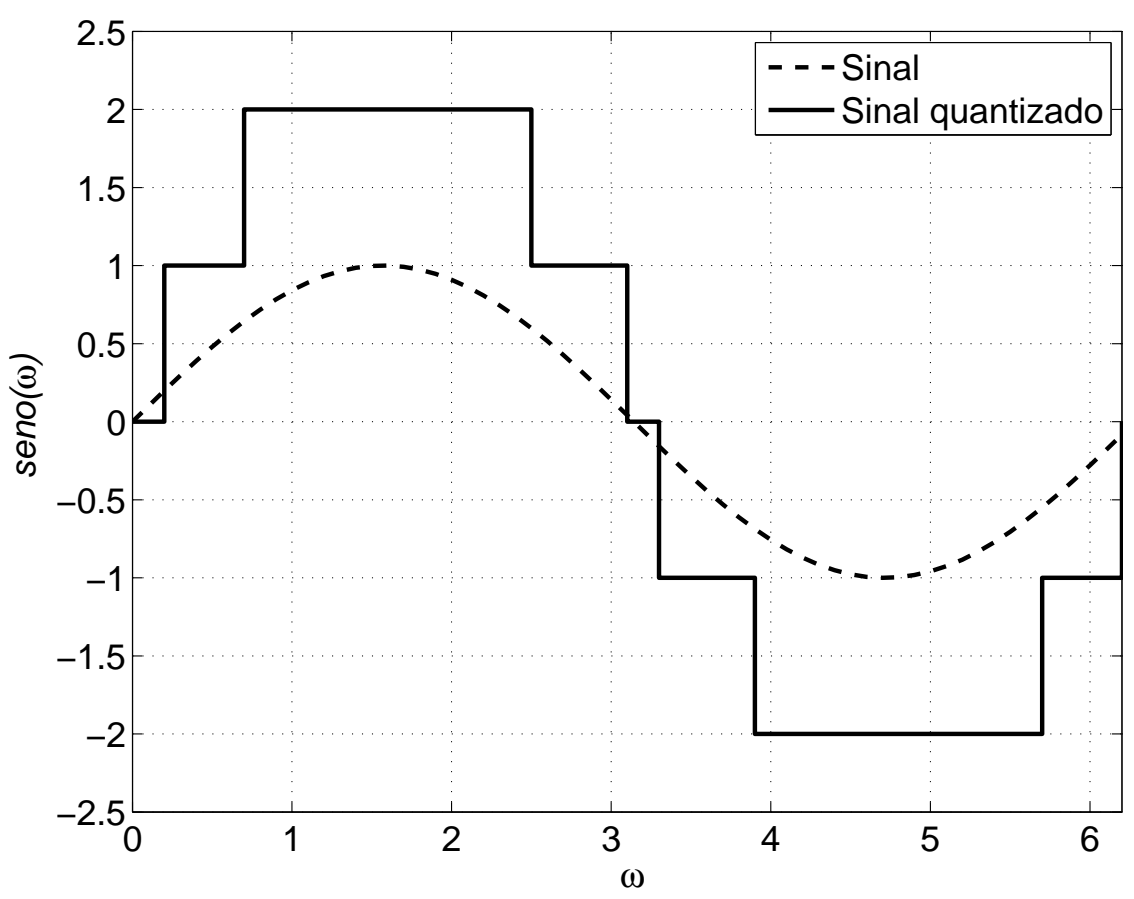

Figura 5.32: Exemplo de um quantizador de $n=5$ níveis $\operatorname{com} q=2$ aplicado a uma função $\sin (\omega), \operatorname{com} 0 \leq \omega \leq 2 \pi$.

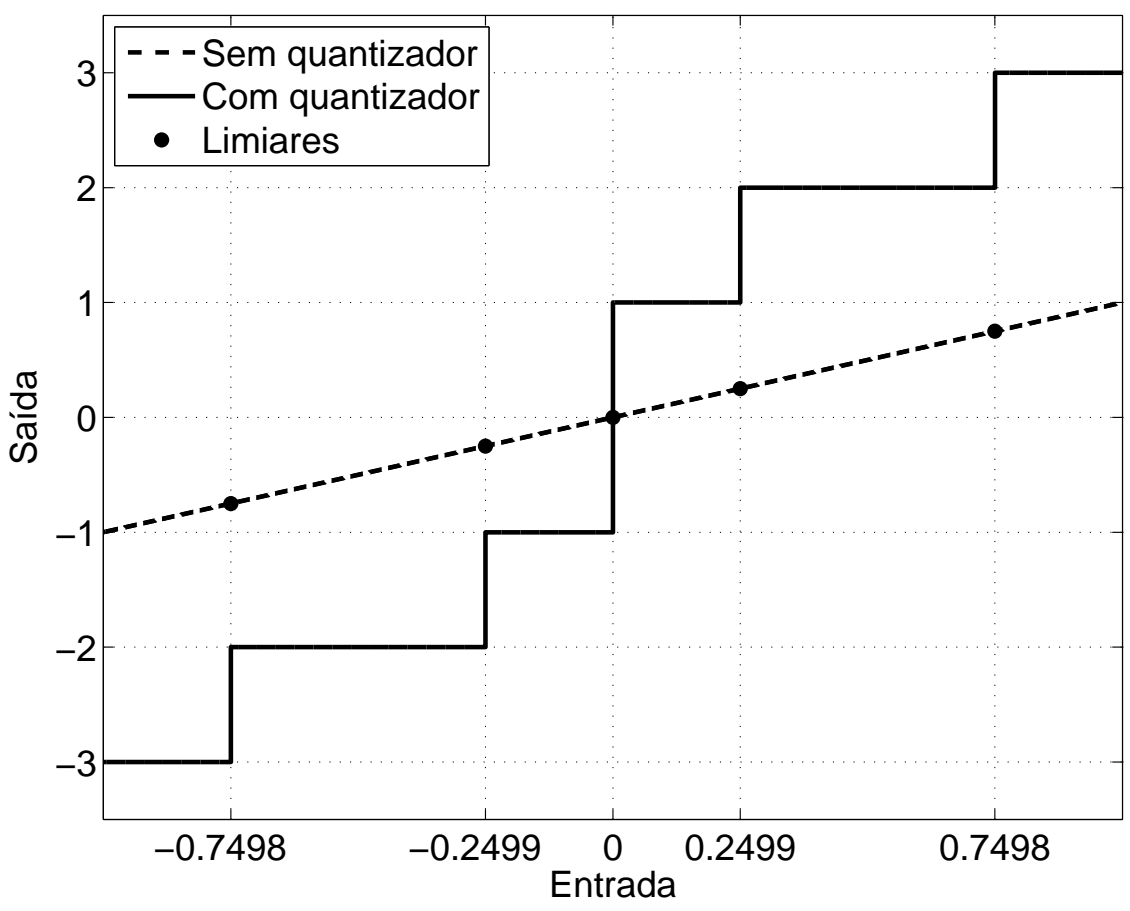

Figura 5.33: Exemplo de um quantizador de $n=6$ níveis com $q=2$.

foi obtido na iteração de número 33.183. Foi adotado $q=2,5$ como parâmetro do quantizador.

Conforme discutido anteriormente, para obter sinais com características aprimoradas utilizando algoritmos iterativos de otimização com reduzido número de iterações 


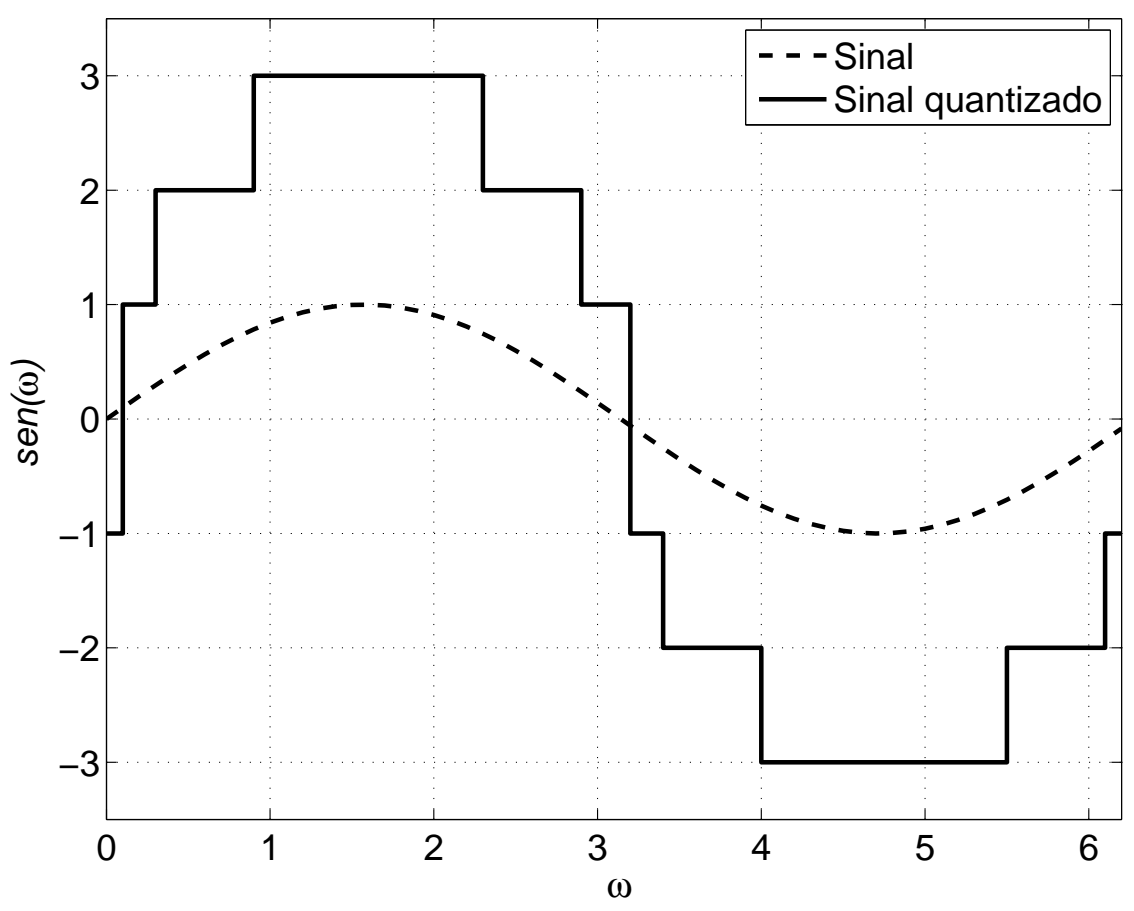

Figura 5.34: Exemplo de um quantizador de $n=6$ níveis $\operatorname{com} q=2$ aplicado a uma função $\sin (\omega)$, com $0 \leq \omega \leq 2 \pi$.

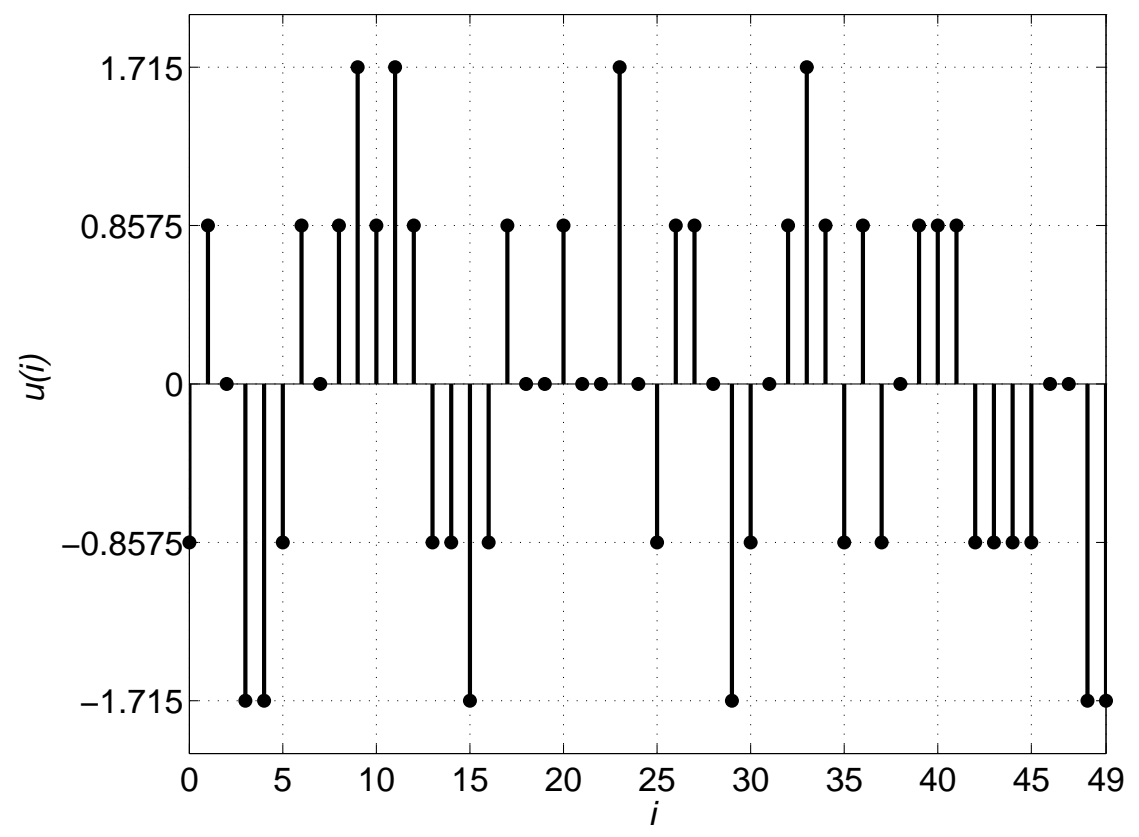

Figura 5.35: Sinal MLMH de comprimento $N_{s}=50$.

é necessária parametrização adequada dos algoritmos. Adicionalmente, a verificação dos resultados será necessária pois a solução global pode não ser garantida. Essa característica dos algoritmos iterativos de otimização de sinais dificulta sua aplicação em situações reais de identificação de plantas industriais, nas quais deseja-se minimizar as horas de engenharia utilizadas para implantação de MPC. 


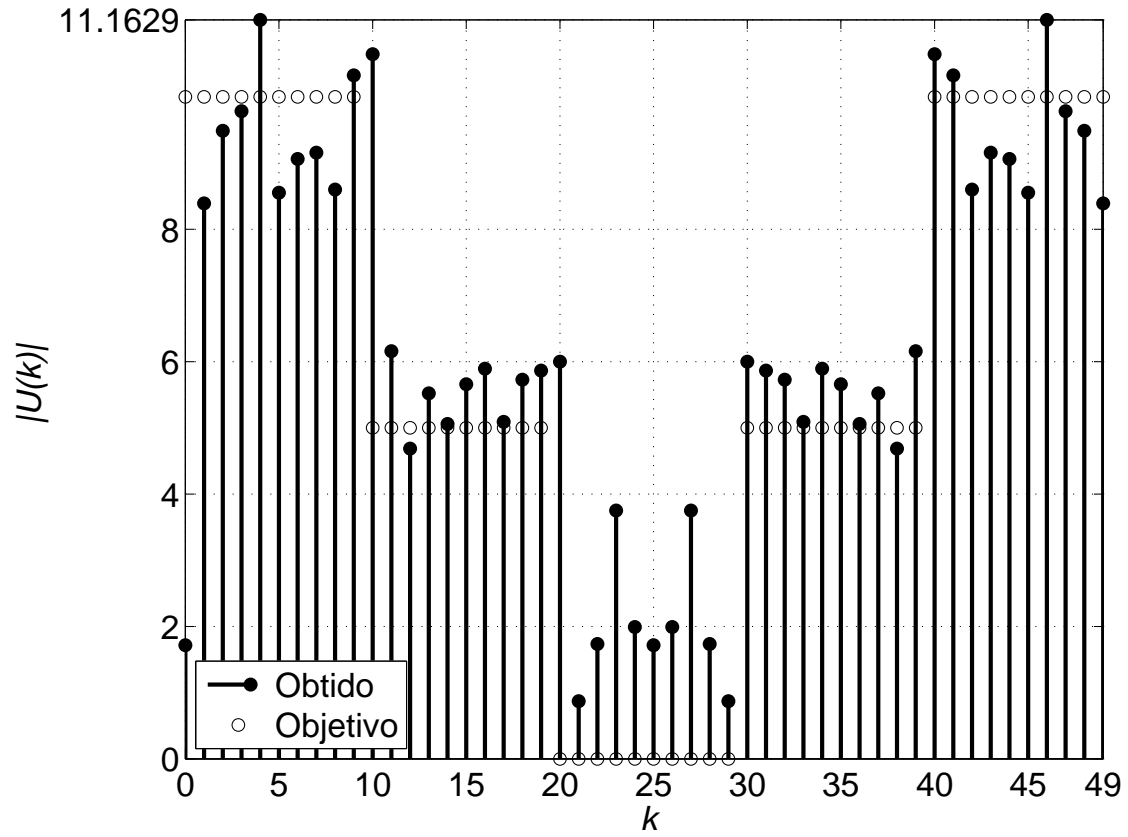

Figura 5.36: Módulo da DFT do sinal MLMH de comprimento $N_{s}=50$.

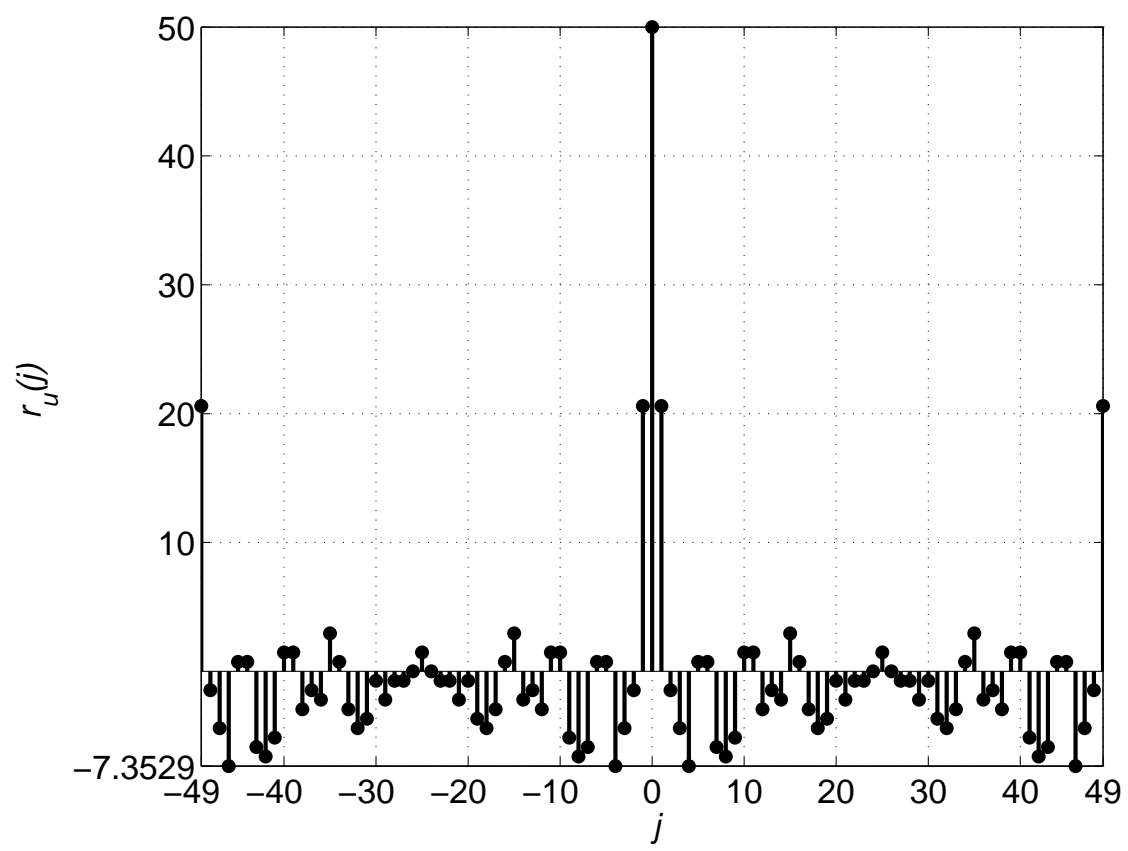

Figura 5.37: Função de autocorrelação periódica do sinal MLMH de comprimento $N_{s}=50$.

\subsubsection{Supressão de harmônicos}

Suprimir as harmônicas pares do sinal de excitação é útil para separar distorções não lineares de ordem par na saída do sistema (apêndice B). Com essa supressão, pode-se eliminar o efeito das distorções de ordem par nas estimativas das dinâmicas lineares do sistema (GODFREY et al., 2005). 


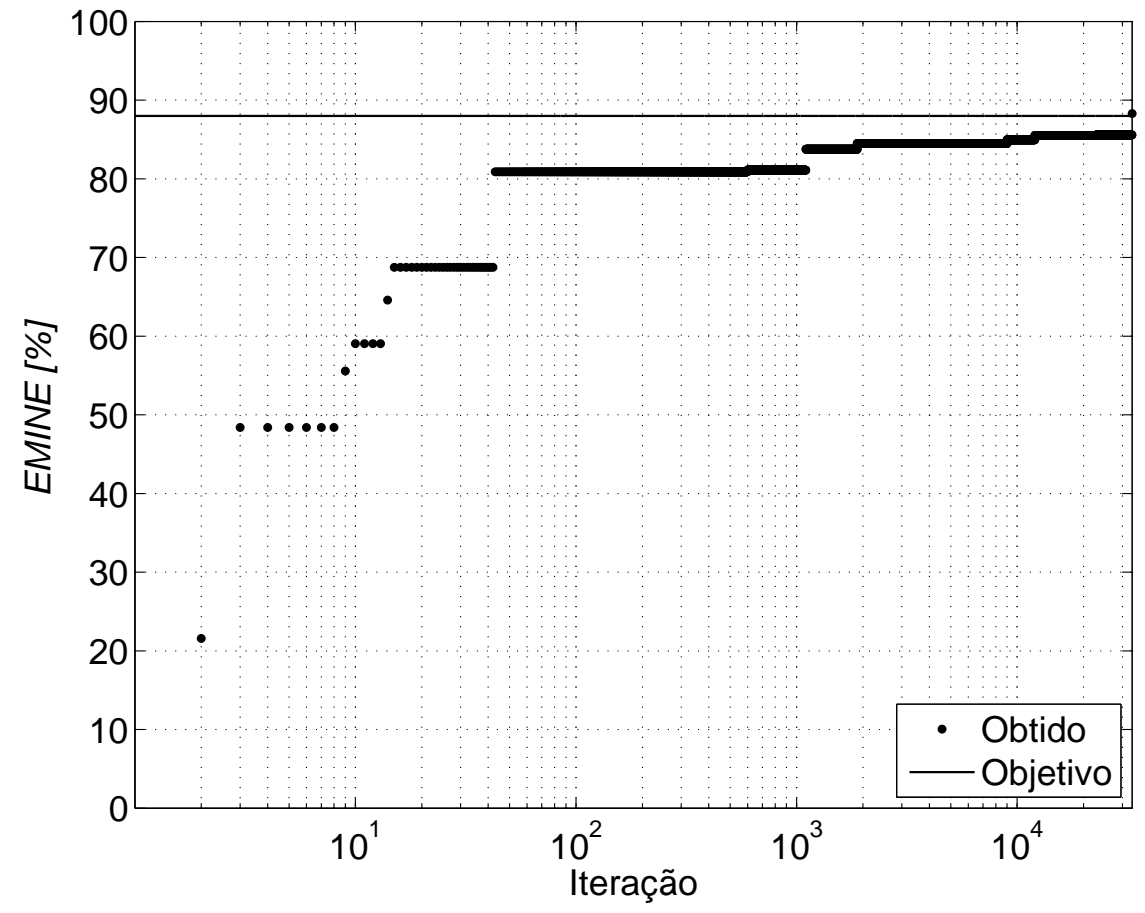

Figura 5.38: Evolução do EMINE em função das iterações do algoritmo de otimização do sinal MLMH de comprimento $N_{s}=50$.

Uma forma imediata de suprimir harmônicas pares do sinal de excitação $u_{1}(i)$ consiste em concatená-lo com o mesmo sinal repetido na forma inversa (GODFREY et al., 2005), resultando um sinal $u_{2}(i)=u_{1}(i)$ com $0 \leq i \leq N_{s}-1$ e $u_{2}(i)=-u_{1}\left(i-N_{s}\right)$ com $N_{s} \leq i \leq 2 N_{s}-1$. É imediato verificar que o sinal resultante $u_{2}(i)$ terá comprimento $2 N_{s}$ e as harmônicas pares serão suprimidas:

$$
\begin{aligned}
U_{2}(k) & =\sum_{i=0}^{2\left(N_{s}-1\right)} u_{2}(i) e^{-j \frac{2 \pi i k}{2 N_{s}}} \\
& =\sum_{i=0}^{N_{s}-1} u_{1}(i) e^{-j \frac{2 \pi i k}{2 N_{s}}}-\sum_{i=0}^{N_{s}-1} u_{1}(i) e^{-j \frac{2 \pi\left(i+N_{s}\right) k}{2 N_{s}}} \\
& =\sum_{i=0}^{N_{s}-1} u_{1}(i) e^{-j \frac{\pi i k}{N_{s}}}-\sum_{i=0}^{N_{s}-1} u_{1}(i) e^{-j \frac{\pi i k}{N_{s}}-j \frac{\pi N_{s} k}{N_{s}}} \\
& =\sum_{i=0}^{N_{s}-1} u_{1}(i) e^{-j \frac{\pi i k}{N_{s}}}-\sum_{i=0}^{N_{s}-1} u_{1}(i) e^{-j \frac{\pi i k}{N_{s}}-j \pi k} \\
& = \begin{cases}\sum_{i=0}^{N_{s}-1} u_{1}(i) e^{-j \frac{\pi i k}{N_{s}}}-\sum_{i=0}^{N_{s}-1} u_{1}(i) e^{-j \frac{\pi i k}{N_{s}}}, \text { com } k \text { nulo ou par. } \\
\sum_{i=0}^{N_{s}-1} u_{1}(i) e^{-j \frac{\pi i k}{N_{s}}}+\sum_{i=0}^{N_{s}-1} u_{1}(i) e^{-j \frac{\pi i k}{N_{s}}}, \text { com } k \text { ímpar. } \\
0, & \text { com } k \text { nulo ou par. } \\
2 \sum_{i=0}^{N_{s}-1} u_{1}(i) e^{-j \frac{\pi i k}{N_{s}}}, & \text { com } k \text { ímpar. }\end{cases}
\end{aligned}
$$


Outra forma de projetar sinais com supressão de harmônica foi apresentadas em (MCCOMARCK; GODFREY; FLOWER, 1994) e (MCCOMARCK; GODFREY; FLOWER, 1995) e consiste em otimizar um sinal por computador com a restrição de que não deve haver energia nas harmônicas predeterminadas. Em (BARKER; TAN; GODFREY, 2004a) e (TAN; FOO, 2006) outro método para supressão de harmônicas é apresentado. Nesse método, utilizam-se propriedades da álgebra abstrata para gerar sinais pseudo-aleatórios de múltiplos níveis com a característica de supressão de harmônicas múltiplas de 2 (pares) ou múltiplas de 2 e 3 simultaneamente. Esse método será discutido na seção 5.3.6.

Recentemente, em (BARKER; TAN; GODFREY, 2007) e (RIVERA et al., 2009) foi proposto utilizar a técnica de supressão de harmônicos para identificação multivariável. Nesse contexto é possível descorrelacionar as entradas de um sistema linear observando apenas o conteúdo harmônico das entradas e das saídas. Por exemplo, em um sistema linear de duas entradas, uma das entradas pode ser excitada apenas por harmônicas pares e a outra entrada apenas por harmônicas ímpares. Como os subsistemas que compõem o sistema são lineares, as componentes harmônicas pares da saída estão relacionadas apenas a entrada que foi excitada com harmônicas pares e as componentes harmônicas ímpares da saída estão relacionadas apenas com a entrada excitada com harmônicas ímpares. Dessa forma, as entradas são descorrelacionadas e os subsistemas lineares são identificados no domínio da frequência (PINTELON; SCHOUKENS, 2001) como sistemas SISO (ou SIMO) compondo o sistema MIMO (ou MISO), visto que o teorema da superposição é aplicável. Essa técnica foi chamada de ortogonalidade dos espectros de potência dos sinais ou sinais com espectros intercalados (zippered spectrum) (LEE; RIVERA; MITTELMANN, 2003) (RIVERA et al., 2009).

A ortogonalidade de sinais com zippered spectrum pode ser demonstrada pela relação de Parseval (OPPENHEIM; SCHAFER, 1999):

$$
\sum_{n=-\infty}^{\infty} x_{1}(n) x_{2}^{*}(n)=\frac{1}{2 \pi} \int_{-\pi}^{\pi} X_{1}\left(e^{j \omega}\right) X_{2}^{*}\left(e^{j \omega}\right) d \omega
$$

onde (.)* denota o complexo conjugado.

Sinais $x_{1}(n)$ e $x_{2}(n)$ que possuem espectros $\left|X_{1}\left(e^{j \omega}\right)\right|$ e $\left|X_{2}\left(e^{j \omega}\right)\right|$ não coincidentes (intercalados), ou seja, $\left|X_{1}\left(e^{j \omega}\right)\right|\left|X_{2}\left(e^{j \omega}\right)\right|=0$, resultarão $X_{1}\left(e^{j \omega}\right) X_{2}^{*}\left(e^{j \omega}\right)=0$. Nesse caso, conforme (5.46), resultará $\sum_{n=-\infty}^{\infty} x_{1}(n) x_{2}^{*}(n)=0 \mathrm{e}$, portanto, $r_{x_{1} x_{2}}(k)=0$ para $\forall k \in \mathbb{Z}$. 


\subsubsection{Parametrização de sinais otimizados por computador}

Em (GAIKWAD; RIVERA, 1996) foi apresentada uma diretriz para especificar o comprimento $N_{s}$ do sinal de excitação do tipo $\mathrm{SOH}$ :

$$
N_{s} \geq \max \left(\frac{2 \pi}{T \omega_{L, r}} ; \frac{2 \pi\left(n_{s}-1\right)}{T\left(\omega_{H, r}-\omega_{L, r}\right)}\right)
$$

Esse critério não foi demonstrado em (GAIKWAD; RIVERA, 1996), porém, sua demonstração é imediata. A menor componente de frequência representável por um sinal é dada pelo inverso do seu período $T_{N_{s}}$. Para que a menor frequência de interesse $f_{L, r}=\frac{\omega_{L, r}}{2 \pi}$ seja excitada, deve-se ter:

$$
\begin{aligned}
\frac{1}{T_{N_{s}}} & \leq \frac{\omega_{L, r}}{2 \pi} \\
\frac{1}{N_{s} T} & \leq \frac{\omega_{L, r}}{2 \pi} \\
N_{s} & \geq \frac{2 \pi}{T \omega_{L, r}}
\end{aligned}
$$

Como o espaçamento entre as harmônicas é dado pelo inverso do período $T_{N_{s}}$ do sinal e no intervalo de frequências $B W_{r}$ deseja-se excitar a planta com $n_{s}$ harmônicas, deve-se ter:

$$
\begin{aligned}
\frac{1}{T_{N_{s}}}\left(n_{s}-1\right) & \leq f_{H, r}-f_{L, r} \\
\frac{1}{N_{s} T}\left(n_{s}-1\right) & \leq \frac{1}{2 \pi}\left(\omega_{H, r}-\omega_{L, r}\right) \\
N_{s} & \geq \frac{2 \pi\left(n_{s}-1\right)}{T\left(\omega_{H, r}-\omega_{L, r}\right)}
\end{aligned}
$$

De (5.48) e (5.49), obtém-se a diretriz (5.47).

É conveniente aproximar o valor de $N_{s}$ para um número par para permitir simetria e média zero de sinais binários, por exemplo.

A seguinte restrição ao período de amostragem foi apresentada em (GAIKWAD; RIVERA, 1996):

$$
T \leq \min \left(\frac{\pi}{\omega_{H}} ; \frac{\pi\left(n_{s}-1\right)}{n_{s}\left(\omega_{H}-\omega_{L}\right)}\right)
$$

Esse critério também não foi demonstrado em (GAIKWAD; RIVERA, 1996). Da 
frequência de Nyquist, tem-se que a frequência de amostragem $f=\frac{1}{T}$ deve ser (OPPENHEIM; SCHAFER, 1999):

$$
\begin{aligned}
f & \geq 2 f_{H, r} \\
\frac{1}{T} & \geq 2 \frac{\omega_{H, r}}{2 \pi} \\
T & \leq \frac{\pi}{\omega_{H, r}}
\end{aligned}
$$

Da transformada discreta de Fourier (D.5) é possível especificar no máximo $2 n_{s}$ harmônicas para um sinal de $N_{s}$ amostras. Assim:

$$
\begin{aligned}
n_{s} & \leq \frac{N_{s}}{2} \\
2 n_{s} & \leq N_{s} \\
2 n_{s} & \leq \frac{2 \pi\left(n_{s}-1\right)}{T\left(\omega_{H, r}-\omega_{L, r}\right)} \\
T & \leq \frac{\pi\left(n_{s}-1\right)}{n_{s}\left(\omega_{H, r}-\omega_{L, r}\right)}
\end{aligned}
$$

De (5.51) e (5.52), obtém-se a diretriz (5.50).

As recomendações da seção C.1 devem ser seguidas em conjunto com (5.50) para evitar tornar a estimação dos parâmetros do modelo um problema mal condicionado.

O caso SISO de (5.47) e (5.50) foi apresentado anteriormente em (RIVERA; GAIKWAD; CHEN, 1994):

$$
\begin{aligned}
& N_{s} \geq \frac{2 \pi \beta_{s} \tau}{T} \\
& n_{s} \geq \frac{N_{s} T \alpha_{s}}{2 \pi \tau}
\end{aligned}
$$

Seja a planta com parâmetros definidos na tabela 5.2. Deseja-se excitar o sistema com um sinal de espectro plano na faixa de frequências de $\omega_{L}=0,01 \mathrm{rad} / \mathrm{min}$ a $\omega_{H}=$ $0,4 \mathrm{rad} / \mathrm{min}$. Utilizando período de amostragem $T=60$ segundos, o comprimento do sinal do tipo $\mathrm{SOH}$ adequado para a identificação desta planta será dado por (5.47):

$$
N_{s} \geq \max \left(\frac{2 \pi}{T \omega_{L}} ; \frac{2 \pi\left(n_{s}-1\right)}{T\left(\omega_{H}-\omega_{L}\right)}\right)
$$




$$
\begin{aligned}
& N_{s} \geq \max \left(\frac{2 \pi}{0,01} ; \frac{2 \pi\left(n_{s}-1\right)}{(0,40-0,01)}\right) \\
& N_{s} \geq \max \left(\frac{2 \pi}{0,01} ; \frac{2 \pi\left(n_{s}-1\right)}{0,39}\right) \\
& N_{s} \geq \max \left(622,03 ; 16,11\left(n_{s}-1\right)\right)
\end{aligned}
$$

Observa-se que o comprimento $N_{s}$ do sinal será pelo menos 623, por conta da frequência mais baixa de interesse $\omega_{L}=0,01 \mathrm{rad} / \mathrm{min}$. Adotando o comprimento $N_{s}=700$, verifica-se que com o número de harmônicas $n_{s}=44$, a restrição dada por (5.55) será atendida $(N \geq 692,94)$.

A restrição (5.50) imposta ao período de amostragem é:

$$
\begin{aligned}
T & \leq \min \left(\frac{\pi}{\omega_{H}} ; \frac{\pi\left(n_{s}-1\right)}{n_{s}\left(\omega_{H}-\omega_{L}\right)}\right) \\
T & \leq \min \left(\frac{\pi}{0,40} ; \frac{\pi\left(n_{s}-1\right)}{n_{s}(0,40-0,01)}\right) \\
T & \leq \min \left(\frac{\pi}{0,40} ; \frac{\pi\left(n_{s}-1\right)}{n_{s} 0,39}\right) \\
T & \leq \min \left(471,24 ; \frac{483,45\left(n_{s}-1\right)}{n_{s}}\right)
\end{aligned}
$$

Com $n_{s}=44$, a restrição (5.56) será:

$$
\begin{aligned}
T & \leq \min \left(471,24 ; \frac{483,45\left(n_{s}-1\right)}{n_{s}}\right) \\
T & \leq \min (471,24 ; 472,46) \\
T & \leq 472,46 \text { segundos }
\end{aligned}
$$

Portanto, a restrição é atendida para o tempo de amostragem adotado $T=60$ segundos.

Para a definição do formato do espectro plano na faixa de frequências de $\omega_{L}=$ $0,01 \mathrm{rad} / \mathrm{min}$ a $\omega_{H}=0,4 \mathrm{rad} / \mathrm{min}$, pode-se definir:

$$
p_{k}= \begin{cases}A & \left\lceil\frac{2 \pi}{N_{s} T} \omega_{L}\right\rceil \leq k \leq\left\lceil\frac{2 \pi}{N_{s} T} \omega_{H}\right\rceil \\ 0 & \text { caso contrário }\end{cases}
$$

Substituindo os parâmetros $T=60$ segundos, $N_{s}=700$ e $n_{s}=44$ adotados para o sinal, tem-se: 
Tabela 5.6: Índices de desempenho para o sinal Schroeder-SOH parametrizado com $T=60$ segundos, $N_{s}=700$ e $n_{s}=44$.

\begin{tabular}{ll}
\hline Índice & Valor \\
\hline PIPS & $57,74 \%$ \\
PIPSE & $57,60 \%$ \\
EMINE & $99,56 \%$ \\
CF & 1,8952 \\
\hline
\end{tabular}

$$
p_{k}= \begin{cases}A & 2 \leq k \leq 45 \\ 0 & \text { caso contrário }\end{cases}
$$

ou seja, $p_{k}=A$ para $n_{s}=44$ harmônicas. Neste exemplo, $A$ é qualquer valor diferente de zero, pois o sinal resultante tem sua potência normalizada.

As figuras 5.39, 5.40 e 5.41 apresentam o sinal Schroeder-SOH projetado, seu espectro e sua função de autocorrelação, respectivamente. Observa-se que o espectro é perfeitamente plano entre as frequências $\omega_{L}=0,01 \mathrm{rad} / \mathrm{min}$ a $\omega_{H}=0,4 \mathrm{rad} / \mathrm{min}$, conforme requisito de projeto.

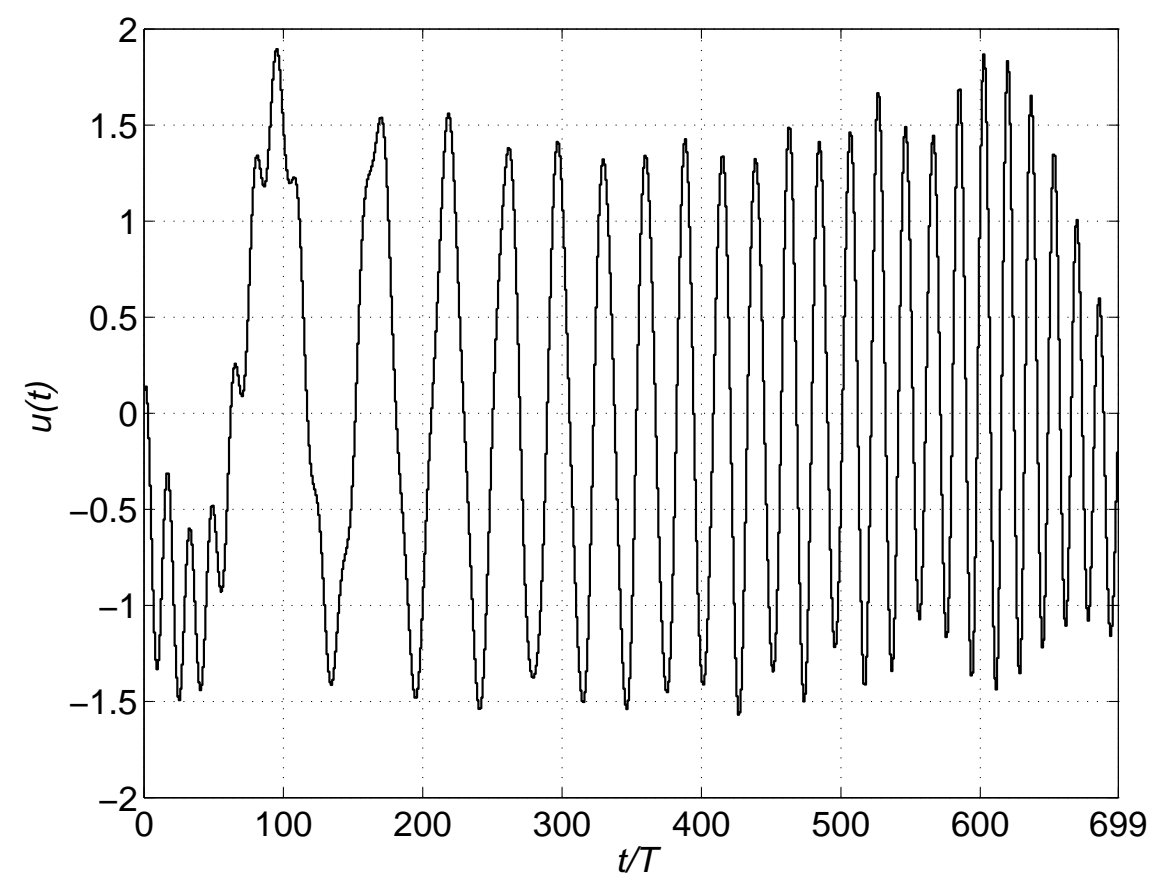

Figura 5.39: Sinal Schroeder-SOH parametrizado com $T=60$ segundos, $N_{s}=700 \mathrm{e}$ $n_{s}=44$.

Os índices de desempenho para o sinal Schroeder-SOH da figura 5.39, considerando o espectro plano definido por (5.58) e parâmetros $T=60$ segundos, $N_{s}=700$, $n_{s}=44, \omega_{L}=0,01 \mathrm{rad} / \mathrm{min}$ e $\omega_{H}=0,4 \mathrm{rad} / \mathrm{min}$ para o cálculo dos índices, são apresentados na tabela 5.6. 


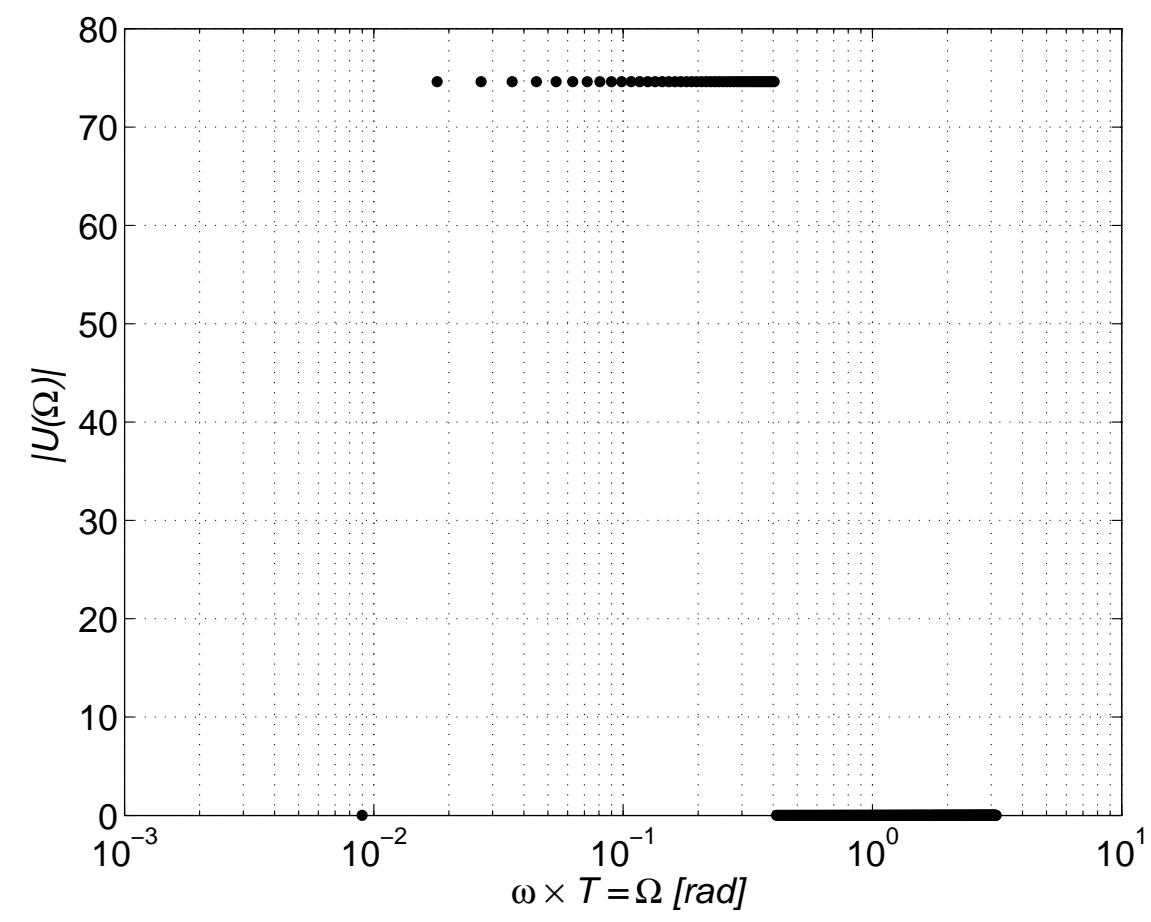

Figura 5.40: Módulo da DFT do sinal Schroeder-SOH parametrizado com $T=60$ segundos, $N_{s}=700$ e $n_{s}=44$.

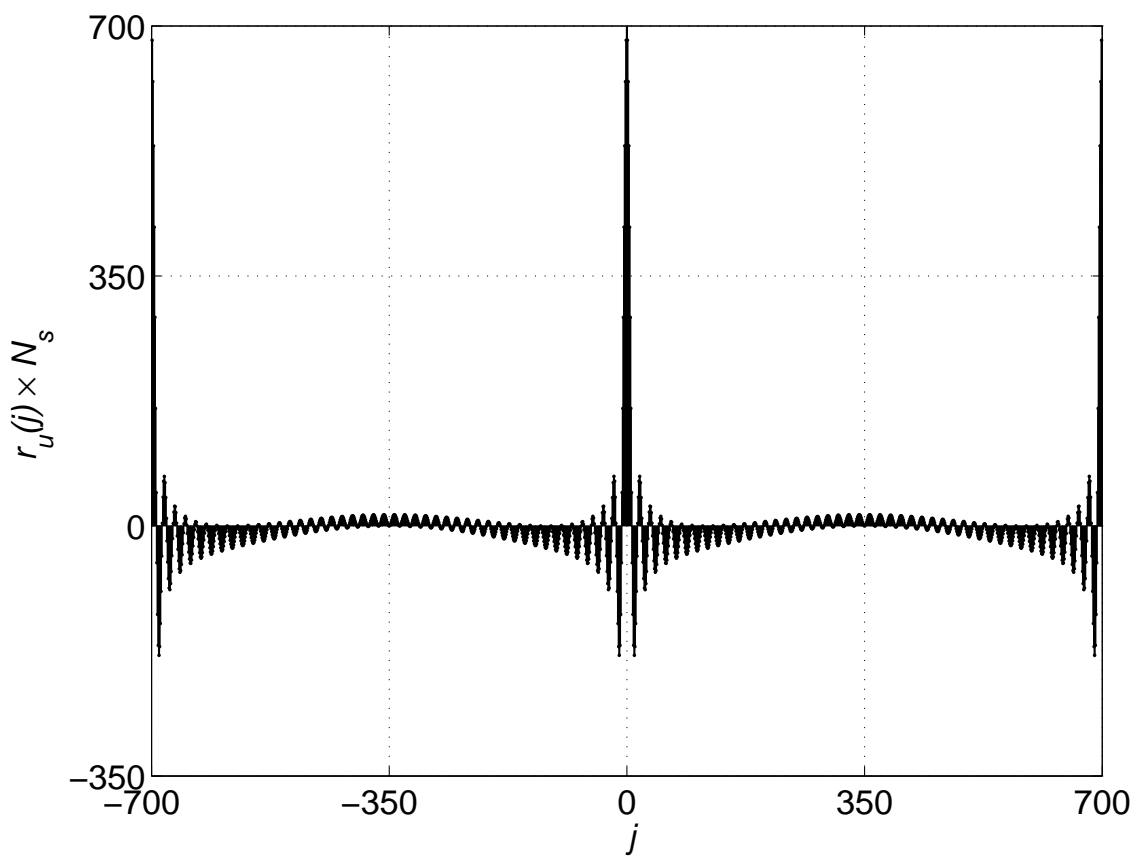

Figura 5.41: Função de autocorrelação periódica do sinal Schroeder-SOH parametrizado com $T=60$ segundos, $N_{s}=700$ e $n_{s}=44$.

A parametrização apresentada nesta seção pode ser aplicada a qualquer sinal do tipo SOH discutido neste trabalho: Schroeder-SOH, clipping-SOH, DIB, DIT e MLMH.

No caso de identificação multivariável (MISO ou MIMO), sinais SOH podem ser gerados com harmônicas intercaladas em seus espectros, ou seja, de forma que não 
haja harmônicas coincidentes entre os sinais (zippered spectrum) (RIVERA et al., 2009), conforme seção 5.2.4.

Seja a mesma planta com parâmetros definidos na tabela 5.2. Deseja-se obter 3 sinais Schroeder-SOH não correlacionados (zippered spectrum) para identificação multivariável. O espectro desejado é apresentado na figura 5.42.

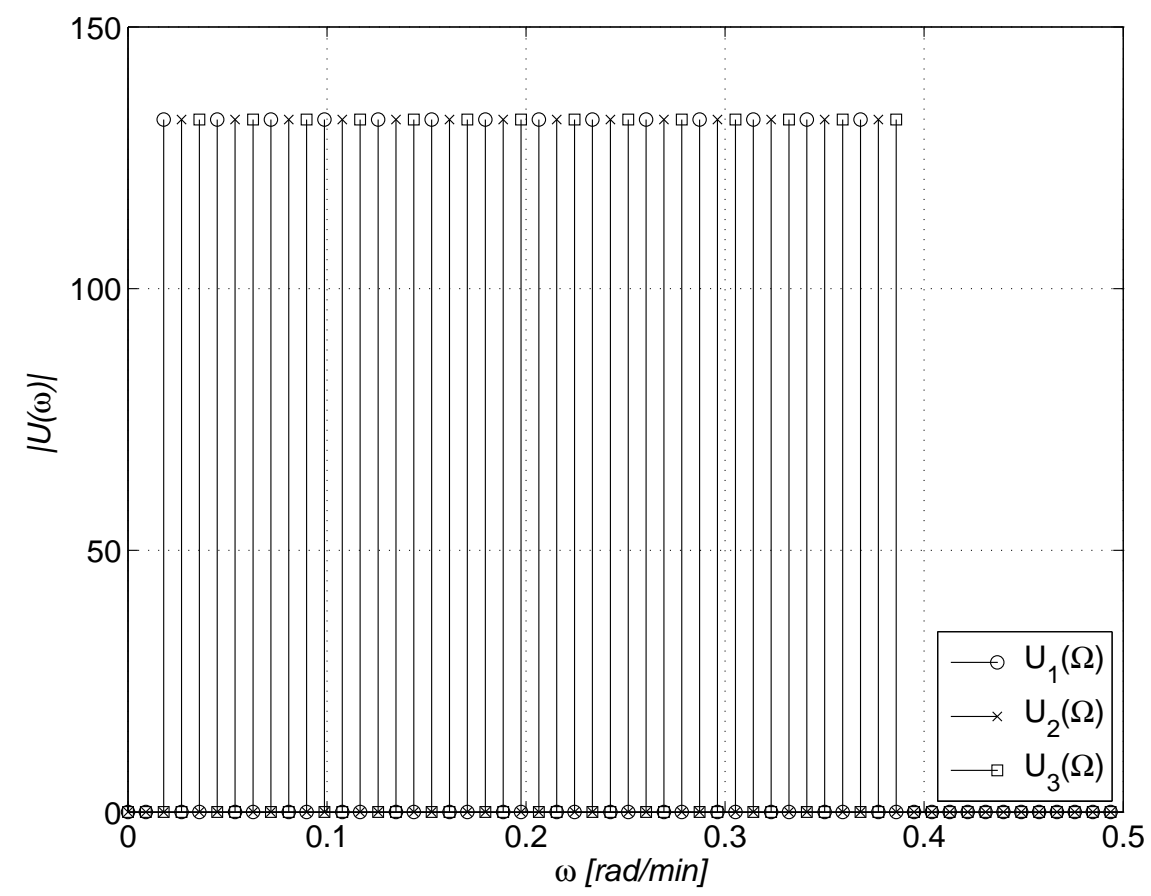

Figura 5.42: Módulo da DFT de sinais $\mathrm{SOH}$ com espectros intercalados parametrizados com $T=60$ segundos e $N_{s}=700$.

Utilizando parâmetros de sinal semelhantes ao do exemplo anterior (período de amostragem $T=60$ segundos e $N_{s}=700$ ), obtém-se os 3 sinais Schroeder-SOH da figura 5.43. Para cada um dos 3 sinais foram especificadas $n_{s}^{(1)}=n_{s}^{(2)}=n_{s}^{(3)}=$ 14 harmônicas distribuídas conforme mostrado na figura 5.42. A combinação de harmônicas dos 3 sinais somam $n_{s}=n_{s}^{(1)}+n_{s}^{(2)}+n_{s}^{(3)}=42$ harmônicas, atendendo as restrições dadas por (5.47) e (5.50).

A figura 5.44 apresenta os espectros dos 3 sinais Schroeder-SOH obtidos. As figuras 5.45 e 5.46 apresentam as funções de autocorrelação periódica e correlação cruzada periódica para os 3 sinais Schroeder-SOH obtidos, respectivamente. Observase que o espectro projetado intercalado para os sinais resulta em correlação cruzada periódica nula, de acordo com a relação de Parseval (5.46).

Os índices de desempenho para os três sinais Schroeder-SOH da figura 5.43, considerando o espectro plano definido por (5.58) e parâmetros $T=60$ segundos, $N_{s}=700$, $n_{s}^{(1)}=n_{s}^{(2)}=n_{s}^{(3)}=14, n_{s}=n_{s}^{(1)}+n_{s}^{(2)}+n_{s}^{(3)}=42, \omega_{L}=0,01 \mathrm{rad} / \mathrm{min}$ e $\omega_{H}=0,4$ $\mathrm{rad} / \mathrm{min}$, são apresentados na tabela 5.7. 

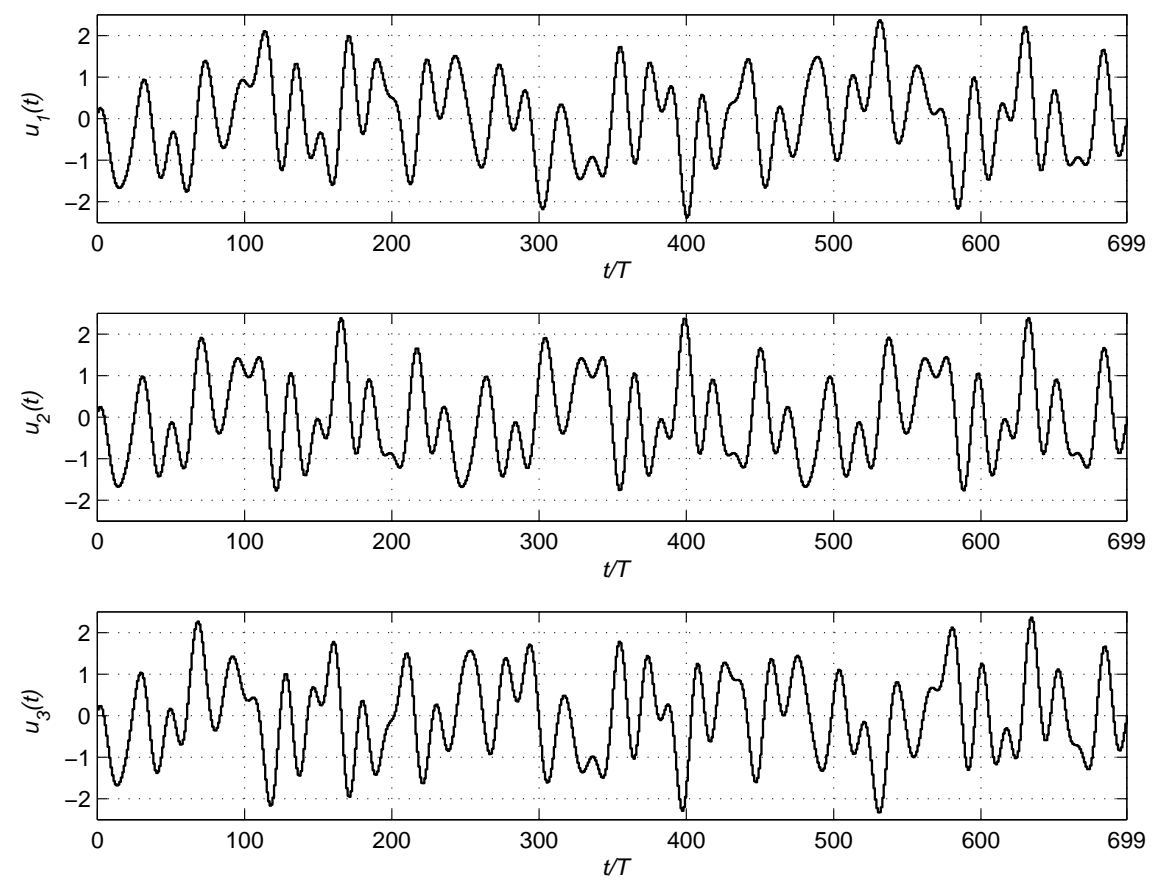

Figura 5.43: Sinais Schroeder-SOH com espectros intercalados parametrizados com $T=60$ segundos, $N_{s}=700, n_{s}^{(1)}=n_{s}^{(2)}=n_{s}^{(3)}=14$ e $n_{s}=n_{s}^{(1)}+n_{s}^{(2)}+n_{s}^{(3)}=42$.

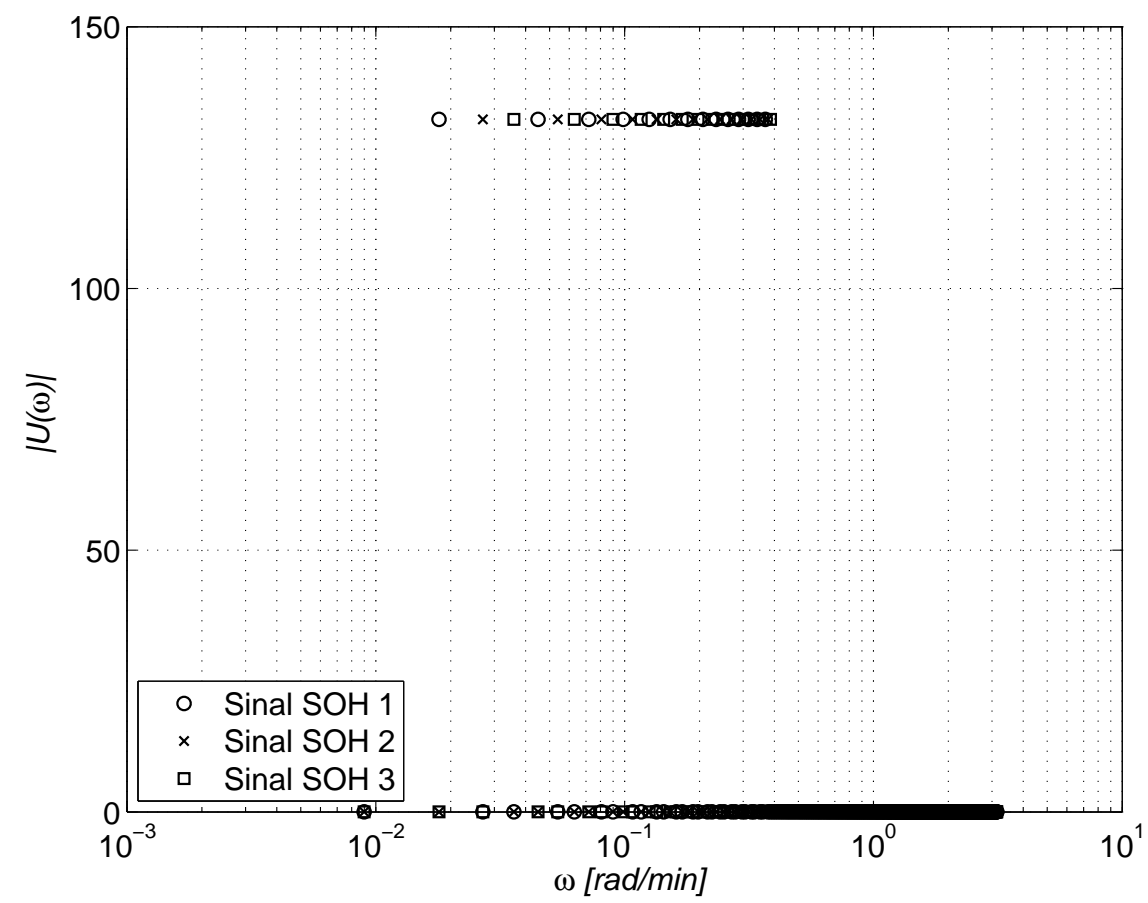

Figura 5.44: Módulo da DFT dos sinais Schroeder-SOH com espectros intercalados parametrizados com $T=60$ segundos, $N_{s}=700, n_{s}^{(1)}=n_{s}^{(2)}=n_{s}^{(3)}=14 \mathrm{e}$

$$
n_{s}=n_{s}^{(1)}+n_{s}^{(2)}+n_{s}^{(3)}=42 \text {. }
$$

Observa-se que o $\mathrm{CF}$ dos sinais Schroeder-SOH com espectros intercalados é mais elevado que o CF do sinal Schroeder-SOH parametrizado para a mesma faixa de frequências de interesse. Essa característica foi discutida na seção 5.2.1.1. Melhores $\mathrm{CF}$ podem ser obtidos por meio de otimização das fases dos sinais $\mathrm{SOH}$, por exem- 

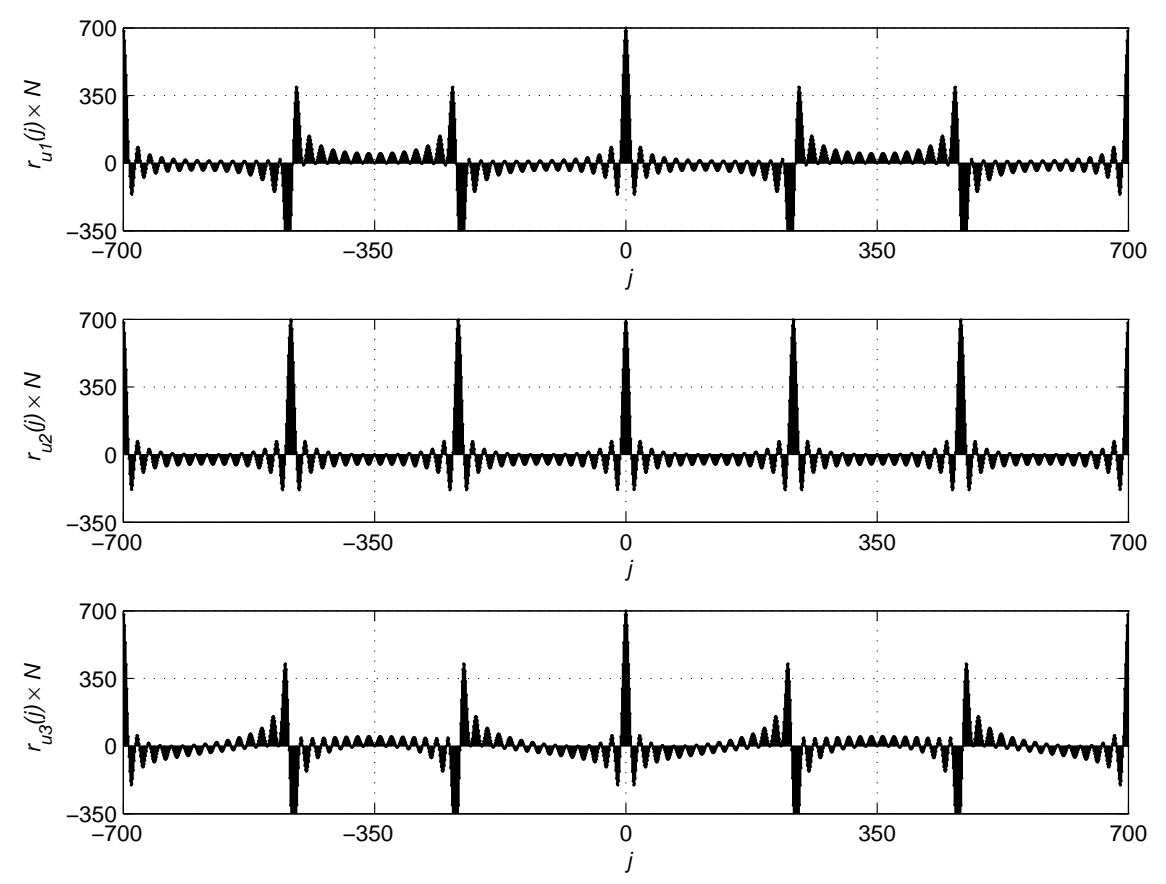

Figura 5.45: Funções de autocorrelação periódica dos sinais Schroeder-SOH com espectros intercalados parametrizados com $T=60$ segundos, $N_{s}=700$, $n_{s}^{(1)}=n_{s}^{(2)}=n_{s}^{(3)}=14$ e $n_{s}=n_{s}^{(1)}+n_{s}^{(2)}+n_{s}^{(3)}=42$.
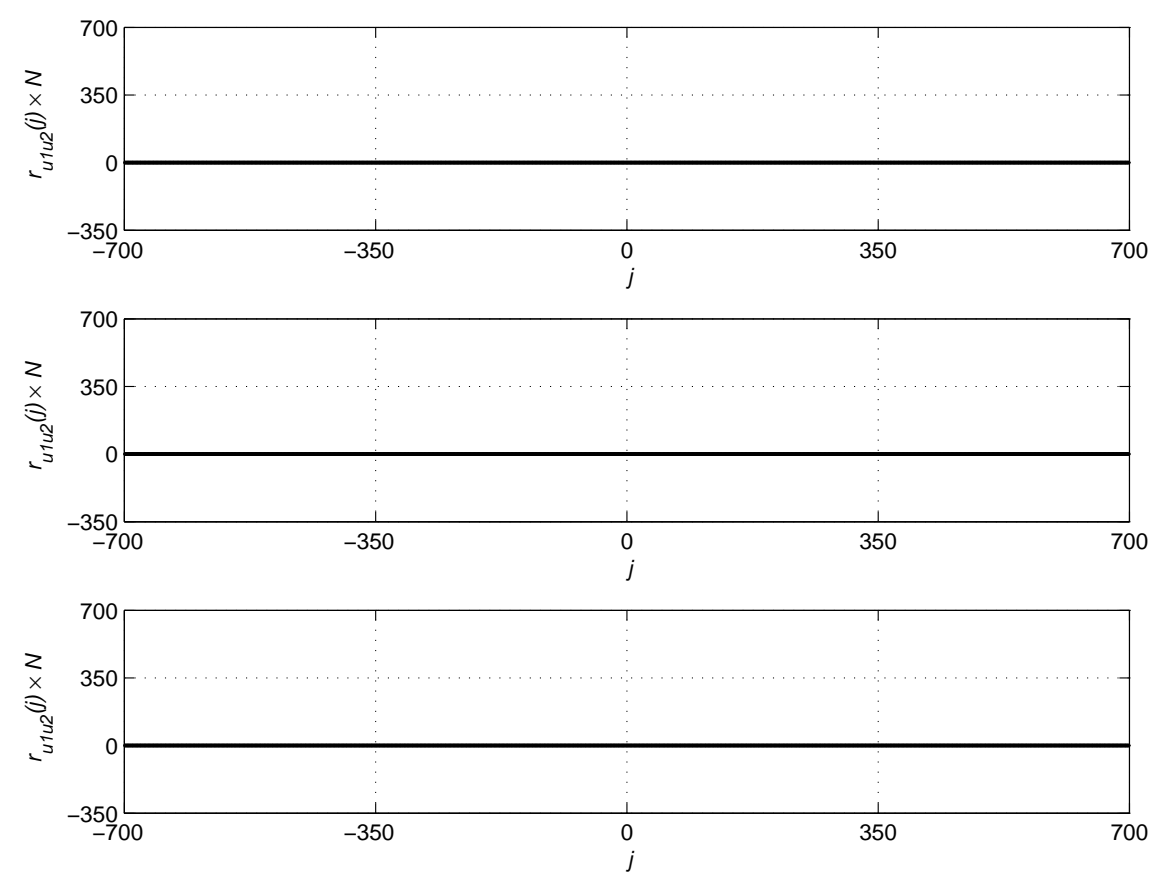

Figura 5.46: Funções de correlação cruzada periódica dos sinais Schroeder-SOH com espectros intercalados parametrizados com $T=60$ segundos, $N_{s}=700$,

$$
n_{s}^{(1)}=n_{s}^{(2)}=n_{s}^{(3)}=14 \text { e } n_{s}=n_{s}^{(1)}+n_{s}^{(2)}+n_{s}^{(3)}=42 .
$$

plo, com o algoritmo clipping iterativo (seção 5.2.1.2). Porém, conforme já discutido na seção 5.2.1.3, a utilização de algoritmo de otimização requer sua parametrização adequada e pode ser necessário tempo elevado para convergir para uma solução de CF reduzido. No capítulo 6 é proposto um método de geração de sinais de excitação com 
Tabela 5.7: Índices de desempenho para o sinal Schroeder-SOH parametrizado com $T=60$ segundos, $N_{s}=700, n_{s}^{(1)}=n_{s}^{(2)}=n_{s}^{(3)}=14$ e $n_{s}=n_{s}^{(1)}+n_{s}^{(2)}+n_{s}^{(3)}=42$.

\begin{tabular}{lll}
\hline Sinal & Índice & Valor \\
\hline$u_{1}(t)$ & PIPS & $42,07 \%$ \\
$u_{2}(t)$ & PIPS & $48,21 \%$ \\
$u_{3}(t)$ & PIPS & $42,61 \%$ \\
$u_{1}(t)$ & PIPSE & $41,98 \%$ \\
$u_{2}(t)$ & PIPSE & $48,11 \%$ \\
$u_{3}(t)$ & PIPSE & $42,51 \%$ \\
$u_{1}(t)$ & EMINE & $99,64 \%$ \\
$u_{2}(t)$ & EMINE & $99,63 \%$ \\
$u_{3}(t)$ & EMINE & $99,61 \%$ \\
$u_{1}(t)$ & CF & 2,39 \\
$u_{2}(t)$ & CF & 2,38 \\
$u_{3}(t)$ & CF & 2,36 \\
\hline
\end{tabular}

espectros intercalados com CF reduzido sem a necessidade de utilização de algoritmos iterativos de otimização.

\subsection{Sinais de espectro fixo}

Sinais de espectro fixo são determinísticos, porém, possuem propriedades chamadas pseudo-aleatórias que os fazem se assemelhar aos sinais aleatórios (seção 5.1). A propriedade pseudo-aleatória que se destaca é a semelhança da função de autocorrelação periódica $r_{u u}(j)$ com a função delta de Dirac para $|j|<N_{s}$ e, consequentemente, o espectro do sinal tenderá a ser plano, se assemelhando do espectro de um sinal aleatório com amostras iid. Por esse motivo, os sinais de espectro fixo apresentados aqui também são chamados de sinais pseudo-aleatórios.

Esses sinais são úteis para os processos de identificação de sistemas que necessitam da excitação com espectro uniforme em uma faixa ou um espectro com as múltiplas de uma determinada harmônica suprimida ou, ainda, quando a repetitividade do processo de identificação é importante (GODFREY et al., 2005).

Na construção de um sinal de excitação de espectro fixo, o espectro do sinal não é otimizado para se aproximar de um espectro especificado. Porém, alterar o espectro do sinal de excitação por meio de um ZOH não é um processo complexo e está detalhado no apêndice D. Adicionalmente, pode-se ajustar o espectro do sinal de excitação por meio de filtragem, conforme discutido anteriormente na geração de sinais BN (seção $5.1 .1)$.

Os sinais pseudo-aleatórios mais disseminados em identificação de sistemas são 
os sinais binários pseudo-aleatórios (pseudo-random binary signals, PRB signals) gerados a partir de sequências de máximo comprimento (SMC) binárias, também conhecidas como m-sequences. As SMC binárias vêm sendo estudadas há décadas, portanto, há bom domínio de suas propriedades e limitações. Elas existem apenas para comprimentos $N=2^{n}-1$, com $n>0 \in \mathbb{N}$ e, portanto, os sinais PRB derivados de SMC binárias estão disponíveis, em princípio, apenas nos períodos $T_{N_{s}}=\left(2^{n}-1\right) T_{c l k}$. Entretanto, essa limitação motiva o estudo de outras sequência com boas propriedades pseudo-aleatórias para uso em identificação de sistemas com o objetivo de se ter maior flexibilidade na escolha do comprimento $N_{s}$ do sinal. Neste contexto, esse trabalho propõe dois novos métodos de construção de sinais (capítulo 6).

A anexo A apresenta um resumo sobre a teoria de corpos finitos relacionada com a discussão sobre sequências pseudo-aleatórias deste trabalho. As propriedades das SMC referenciadas neste capítulo estão no anexo B.

Nas próximas seções serão apresentados 4 métodos de construção de sinais binários com propriedade de autocorrelação semelhante aos sinais PRB, porém, disponíveis em outros comprimentos. Sinais multinível gerados a partir de SMC sobre um corpo de Galois não binário $(G F(q)$, com $q>2$ e primo, apêndice $\mathrm{G})$ também podem ser alternativas para flexibilidade de comprimento. Além desses sinais possuírem boas propriedades de autocorrelação, eles podem ser gerados com supressão de harmônicas em seu espectro. Os sinais ternários e multinível gerados a partir de SMC também serão apresentados em seção posterior.

\subsubsection{Sinal binário de resíduo quadrático}

Sequências de resíduo quadrático, também conhecidas como sequências de Legendre (GOLOMB; GONG, 2005), possuem a característica de gerar sinais com função de autocorrelação periódica $r_{u u}(j)=-1 / N$, para $0<|j|<N$ e $|u(i)|=1$, o que a torna atrativa para aplicação em identificação de sistemas. As sequências de resíduo quadrático são binárias e possuem comprimento $N$ ímpar. Assim, uma sequência de resíduo quadrático gera um sinal $u(i)$ binário de resíduo quadrático (quadratic residue binary signal, QRB signal). O espectro $U(k)$ do sinal QRB de comprimento $N$, dado pela transformada de Fourier de $u(i)$, será constante para $0<k \leq N$. A magnitude na frequência zero não será nula devido às sequências de resíduo quadrático serem binárias e terem comprimento $N$ ímpar, ou seja, não são balanceadas.

Em (EVERETT, 1996) foi proposto um método para gerar sinais QRB. Os comprimentos existentes para as sequências de resíduo quadrático são dados por: $N=4 k-1$, com $k \in \mathbb{N}$ e $N$ primo (TAN; GODFREY, 2002) (GOLOMB; GONG, 2005). Assim, consi- 
derando $T_{c l k}=T$ e $N_{s}=N$, os comprimentos $N$ possíveis para os sinais QRB são: 3, $7,11,19,23,31,43,47,59,67,71,79,83,103,107,127, \ldots$

Uma sinal QRB com elementos unitários $|u(i)|=1$ é gerado conforme (TAN; GODFREY, 2002):

$$
u(i)= \begin{cases}+1, & \text { se } i \equiv r^{2} \bmod N, r \in \mathbb{N} \\ -1, & \text { caso contrário } \\ +1 \text { ou }-1 & \text { se } i=N\end{cases}
$$

Observa-se que o $N$-ésimo termo do sinal pode ser escolhido como positivo +1 ou negativo -1 , não alterando a característica de sua função de autocorrelação, $r_{u u}(j)=0$ para $0<|j|<N$.

A figura 5.47 apresenta um sinal QRB de amplitude unitária e de comprimento $N=47$ com $u(N)=-1$. As figuras 5.48 e 5.49 apresentam seu espectro, dado pelo módulo de sua DFT, e sua função de autocorrelação, respectivamente.

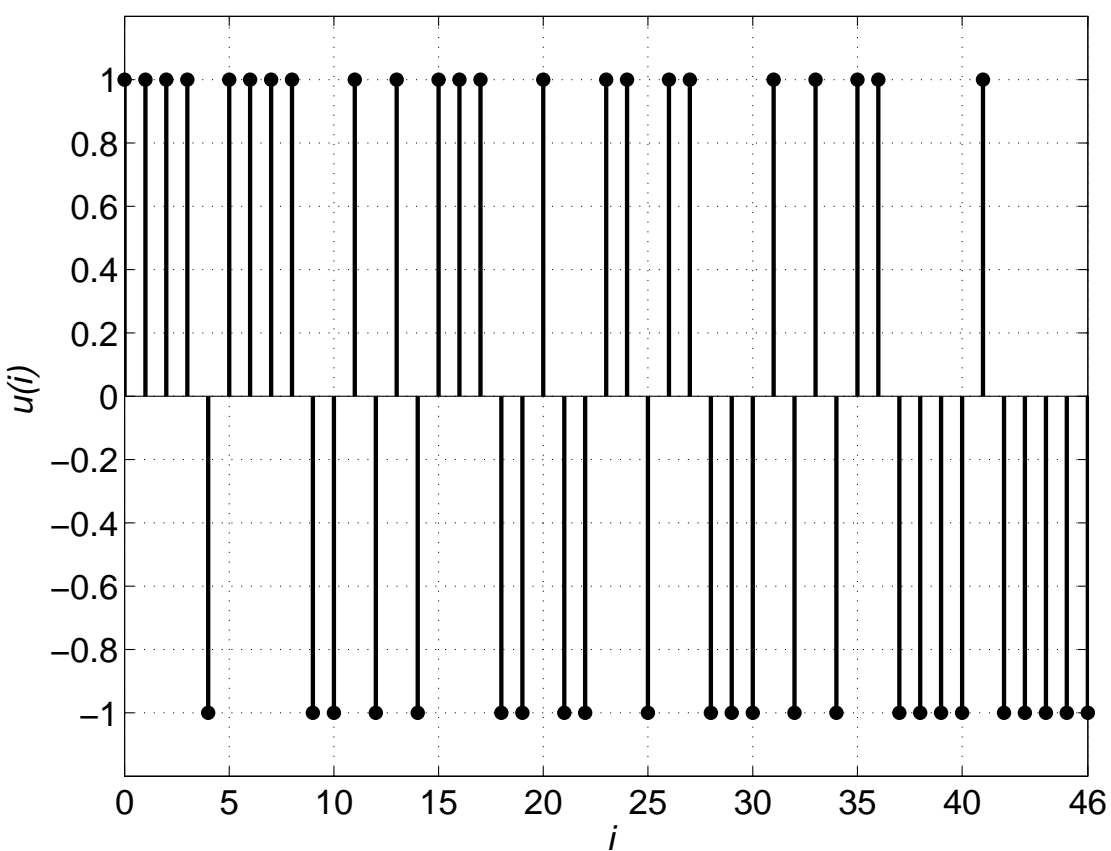

Figura 5.47: Sinal QRB de comprimento $N=47$ e $u(N)=-1$.

\subsubsection{Sinal ternário de resíduo quadrático}

Os sinais ternários de resíduo quadrático (quadratic residue ternary signal, QRT signal) são gerados por sequências semelhantes às sequências de resíduo quadrático. A diferença ocorre apenas no último elemento da sinal $u(N)=0$ (TAN; GODFREY, 2002). Assim, em um sinal QRT há $(N-1) / 2$ elementos positivos $(+1),(N-1) / 2$ 


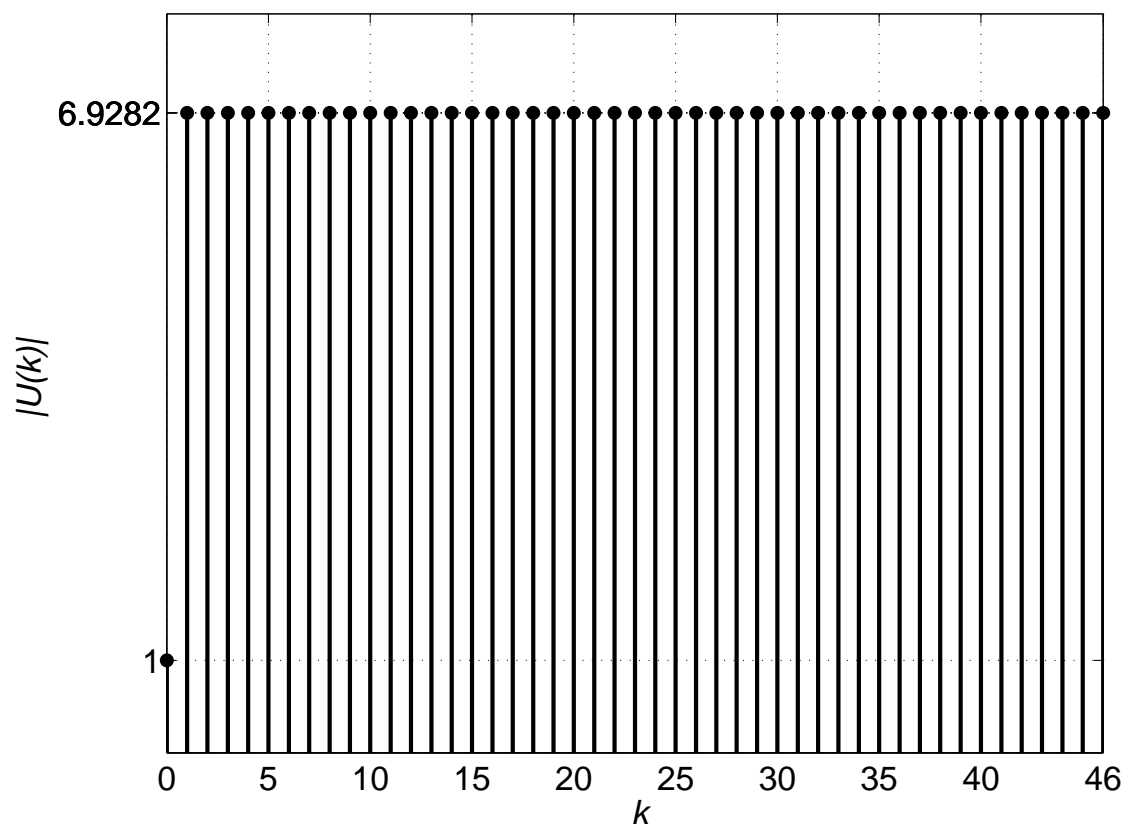

Figura 5.48: Módulo da DFT do sinal QRB de comprimento $N=47$ e $u(N)=-1$.

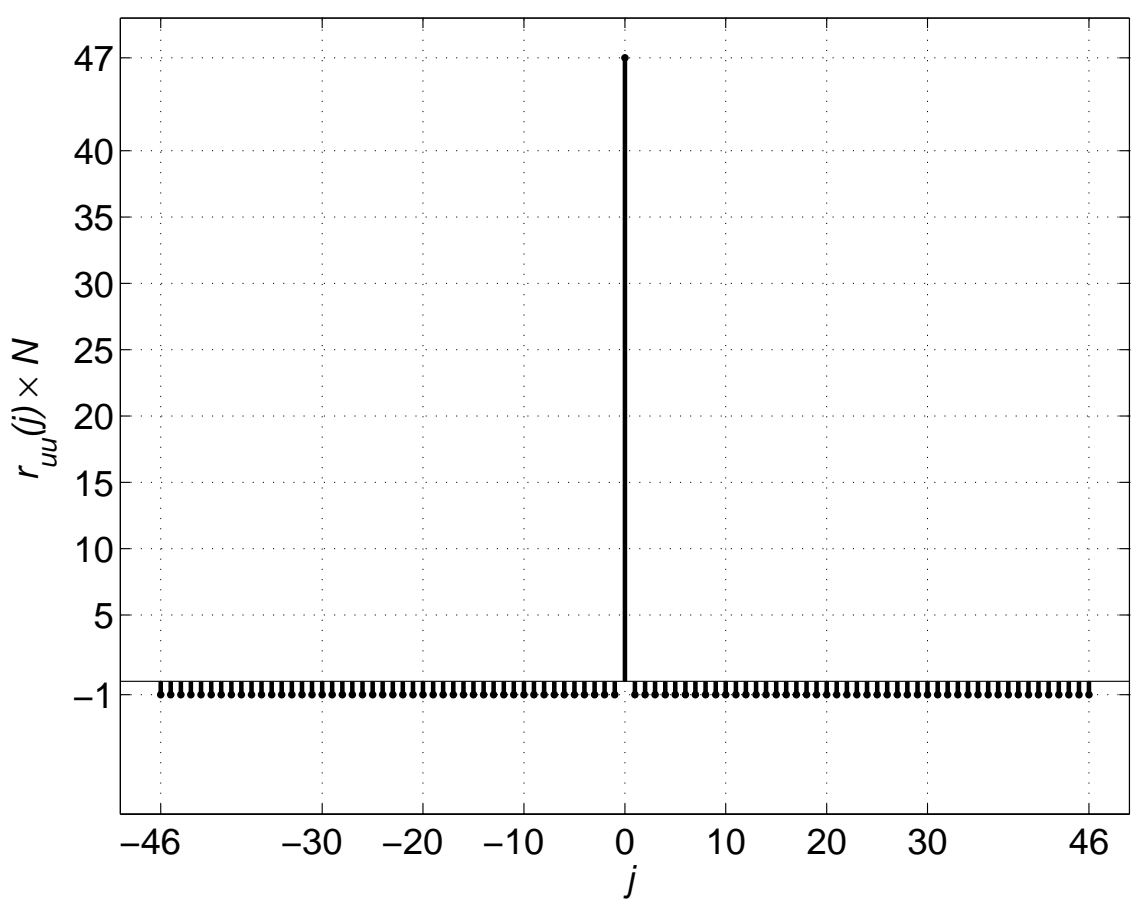

Figura 5.49: Função de autocorrelação periódica do sinal QRB de comprimento $N=47$ e $u(N)=-1$.

elementos negativos $(-1)$ e um elemento nulo $(u(N)=0)$. Por possuir apenas um elemento diferente de \pm 1 , o sinal QRT também é conhecido como de sinal pseudoaleatório quase-binário (pseudo-random near-binary signal, PRNB signal). A função de autocorrelação periódica também é semelhante à dos sinais $\mathrm{QRB}, r_{u и}(j)=-1 / N$ para $0<|j|<N$.

Os comprimentos existentes para sinais QRT, considerando $T_{c l k}=T$ e $N_{s}=N$, 
são dados por: $N=4 k \pm 1$, com $k \in \mathbb{N}$ e $N$ primo (TAN; GODFREY, 2002). Assim, os comprimentos $N$ possíveis são: 3, 5, 7, 11, 13, 17, 19, 23, 29, 31, 37, 41, 43, 47, 53, $59,61,67,71,73,79,83, \ldots$

A figura 5.50 apresenta um sinal QRT de amplitude unitária e de comprimento $N=59$. As figuras 5.51 e 5.52 apresentam seu espectro, dado pelo módulo de sua DFT, e sua função de autocorrelação, respectivamente.

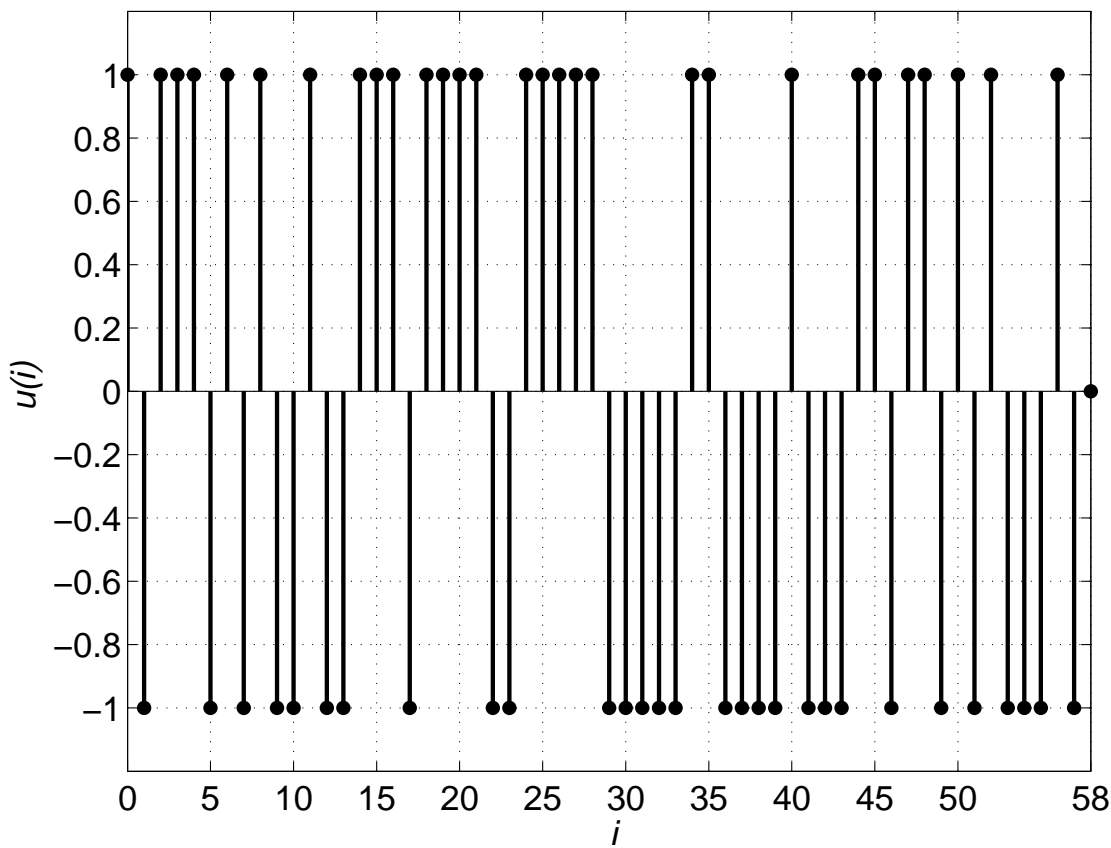

Figura 5.50: Sinal QRT de comprimento $N=59$.

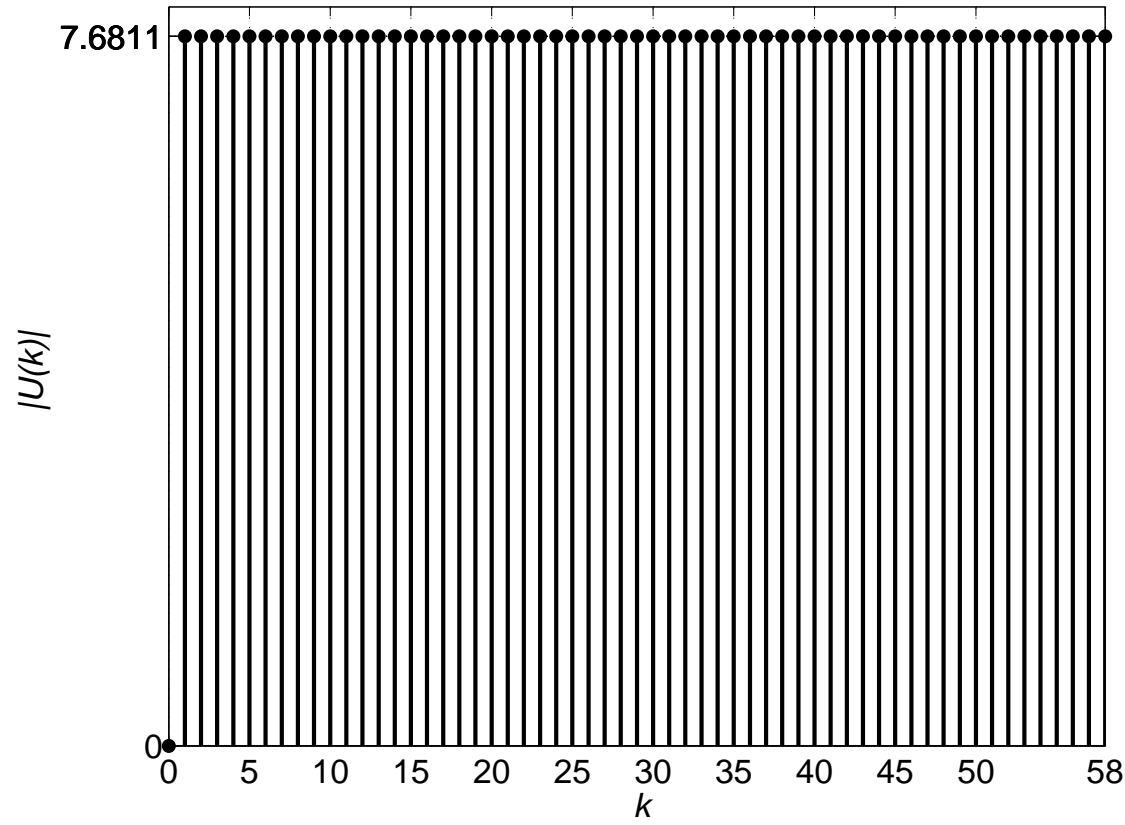

Figura 5.51: Módulo da DFT do sinal QRT de comprimento $N=59$. 


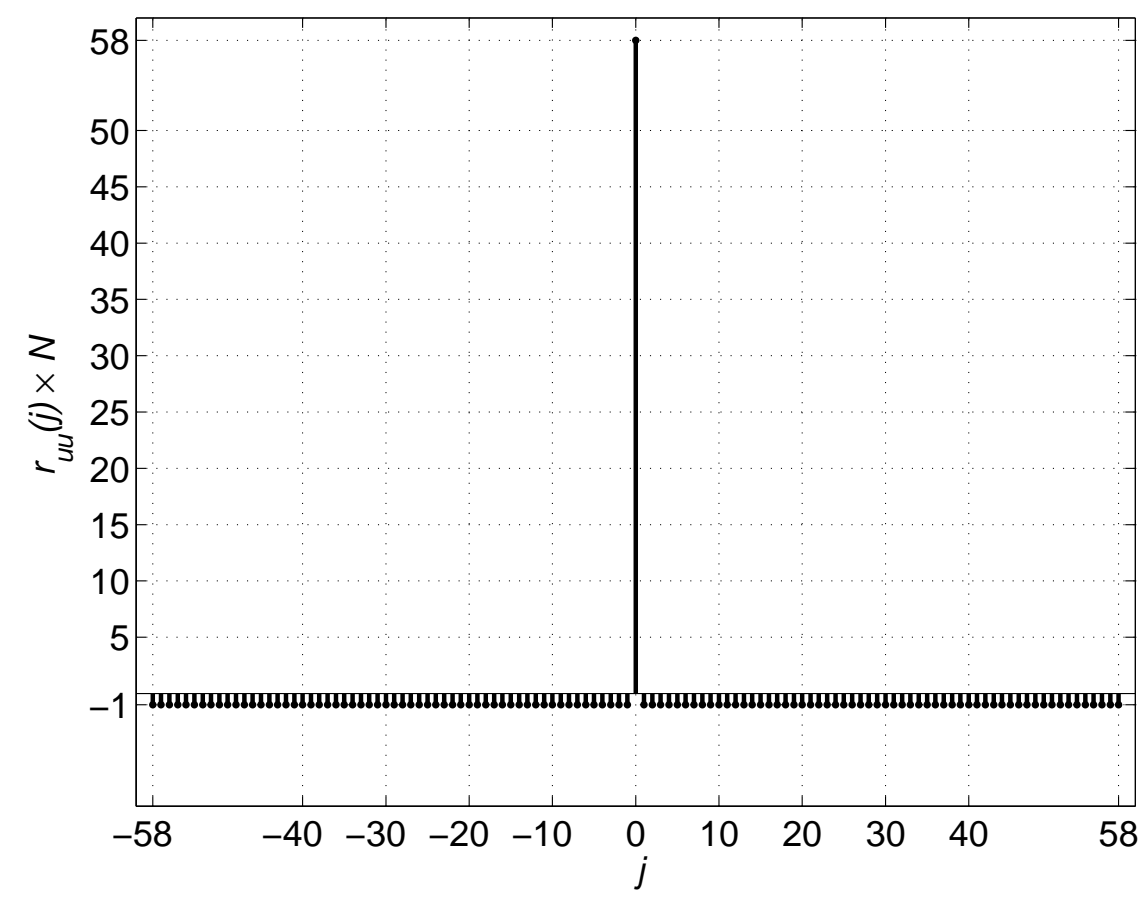

Figura 5.52: Função de autocorrelação periódica do sinal QRT de comprimento $N=59$.

\subsubsection{Sinal binário Hall}

As sequências de resíduo sêxtuplo, também conhecidas como sequências de Hall (GOLOMB; GONG, 2005) devido ao matemático Marshall Hall Jr. ter as estudado, também geram sinais com boa característica de autocorrelação $r_{u u}(j)=-1 / N$, para $0<|j|<N$ e $|u(i)|=1$. As sequências de Hall são binárias e possuem comprimento $N$ ímpar. Assim, uma sequência de Hall gera um sinal $u(i)$ binário de Hall (Hall binary signal, HAB signal). $\mathrm{O}$ espectro $U(k)$ do sinal HAB de comprimento $N$ será constante para $0<k \leq N$. A magnitude da frequência zero não será nula devido às sequências de resíduo quadrático serem binárias com comprimento $N$ ímpar.

Os comprimentos existentes para sinais $\mathrm{HAB}$ são dados por: $N=4 k^{2}+27$, com $k \in$ $\mathbb{N}$ e $N$ primo (TAN; GODFREY, 2002) (GOLOMB; GONG, 2005). Assim, os comprimentos $N$ possíveis, considerando $T_{c l k}=T$ e $N_{s}=N$, para os sinais HAB são: 43, 127, 223, $283,811,1051,1471,1627,2143,2731,3163,3391,4651, \ldots$

Um sinal HAB com elementos unitários $|u(i)|=1$ é construído conforme (TAN; GODFREY, 2002):

$$
u(i)= \begin{cases}+1, & \text { se } i \equiv r^{t} \bmod N, t \equiv 0,1 \text { ou } 3(\bmod 6) \text { e } r \in \mathbb{N} \\ -1, & \text { caso contrário }\end{cases}
$$


A figura 5.53 apresenta um sinal HAB de amplitude unitária e de comprimento $N=43$. As figuras 5.54 e 5.55 apresentam seu espectro, dado pelo módulo de sua DFT, e sua função de autocorrelação, respectivamente.

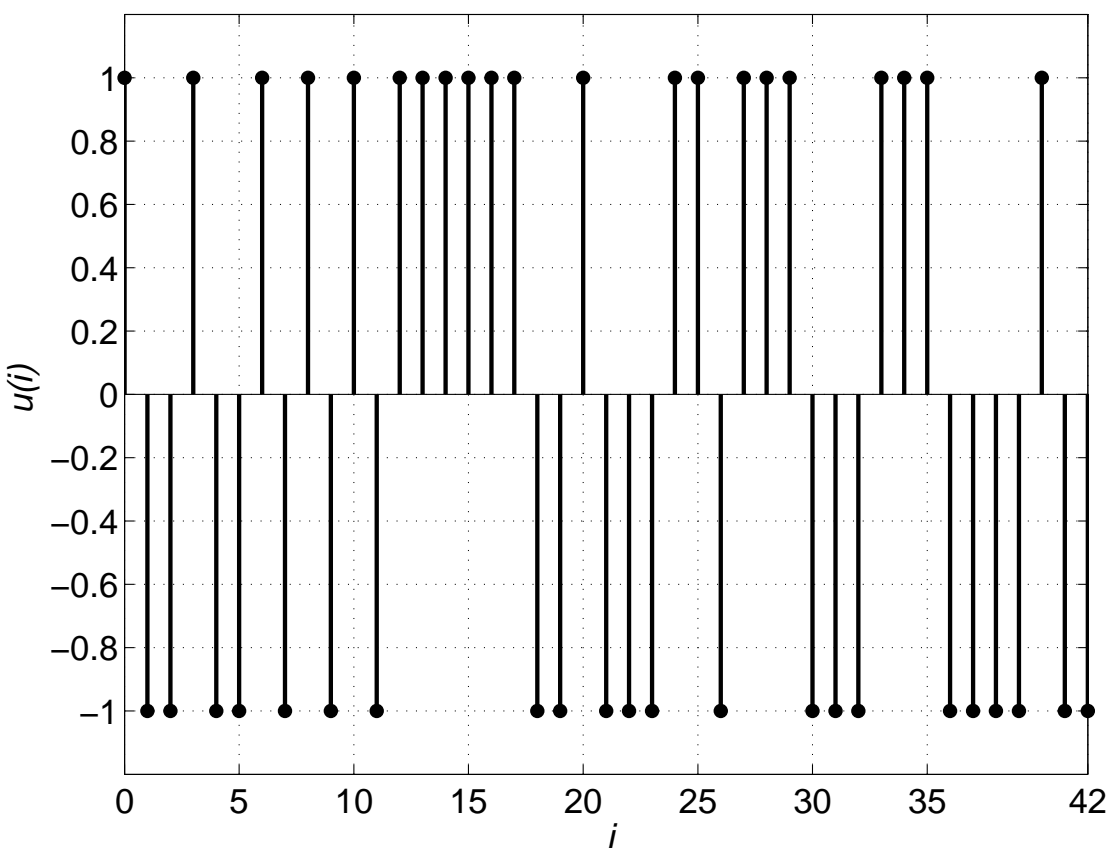

Figura 5.53: Sinal HAB de comprimento $N=43$.

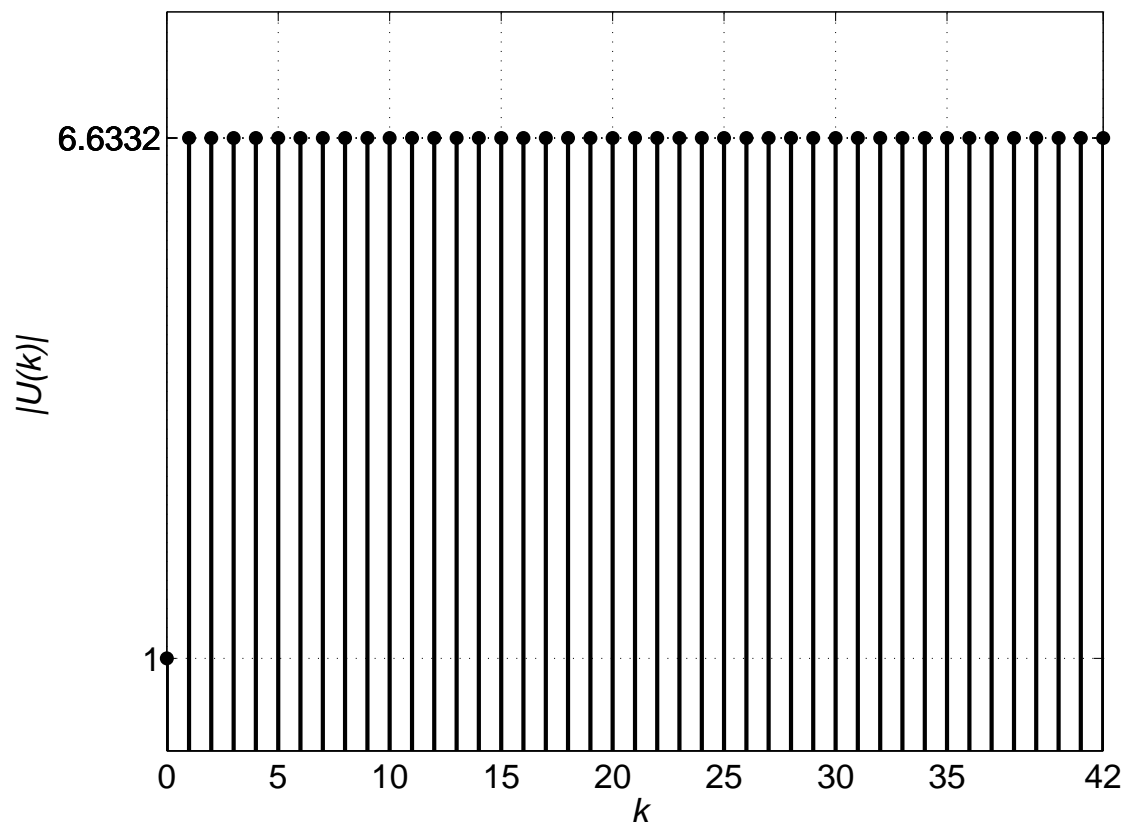

Figura 5.54: Módulo da DFT do sinal HAB de comprimento $N=43$.

\subsubsection{Sinal binário de primos gêmeos}

São chamados de primos gêmeos (twin prime) os números primos que diferem um do outro de apenas duas unidades, ou seja, se $k$ e $k+2$ são ambos primos, eles são primos 


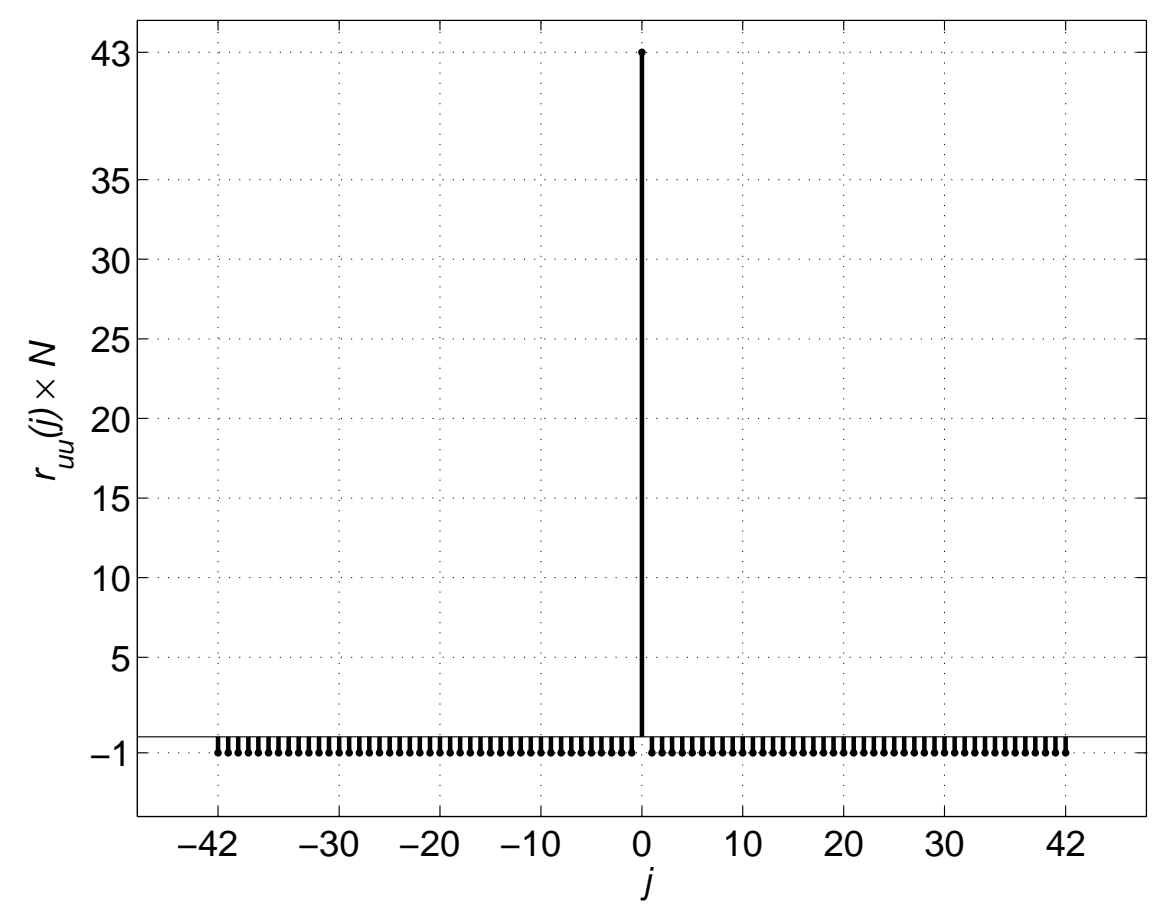

Figura 5.55: Função de autocorrelação periódica do sinal HAB de comprimento $N=43$.

gêmeos. Há exceção apenas para os números 2 e 3 que formam a menor diferença entre primos e são também primos gêmeos. As sequências binárias de primos gêmeos possuem comprimento $N=k(k+2)$, onde $k$ e $k+2$ são ambos primos, por isso levam esse nome (GOLOMB; GONG, 2005).

Assim como ocorre nos sinais QRB, QRT e HAB, a função de autocorrelação de um sinal binário de primos gêmeos (twin prime binary signal, TPB signal) $u(i)$, o qual é construído a partir de sequências binárias de primos gêmeos, é da forma: $r_{u u}(j)=-1 / N$ para $0<|j|<N$ e $|u(i)|=1$.

Os comprimentos $N$ possíveis para os sinais TPB são: 15, 35, 143, 323, 899, 1763, $3599,5183,10403,11663,19043, \ldots$

Para gerar um sinal TPB com elementos unitários $|u(i)|=1$ inicialmente constroemse dois sinais $a_{r}$ e $b_{r}$ de comprimentos $k$ e $k+2$, respectivamente, utilizando o mesmo método de construir sinais QRB, porém, não limitado aos comprimentos $N$ dos sinais QRB. O sinal TPB é definido por (EVERETT, 1996) (TAN; GODFREY, 2002):

$$
u(i)= \begin{cases}a_{i} b_{i}, & \text { se } i \neq 0 \bmod k \text { ou } \bmod (k+2) \\ +1, & \text { se } i \equiv 0 \bmod (k+2) \\ -1, & \text { se } i \equiv 0 \bmod k \text { e } i \equiv 0 \bmod (k+2)\end{cases}
$$

A figura 5.56 apresenta um sinal TPB de amplitude unitária e de comprimento 
$N=35$. As figuras 5.54 e 5.55 apresentam seu espectro, dado pelo módulo de sua DFT, e sua função de autocorrelação, respectivamente.

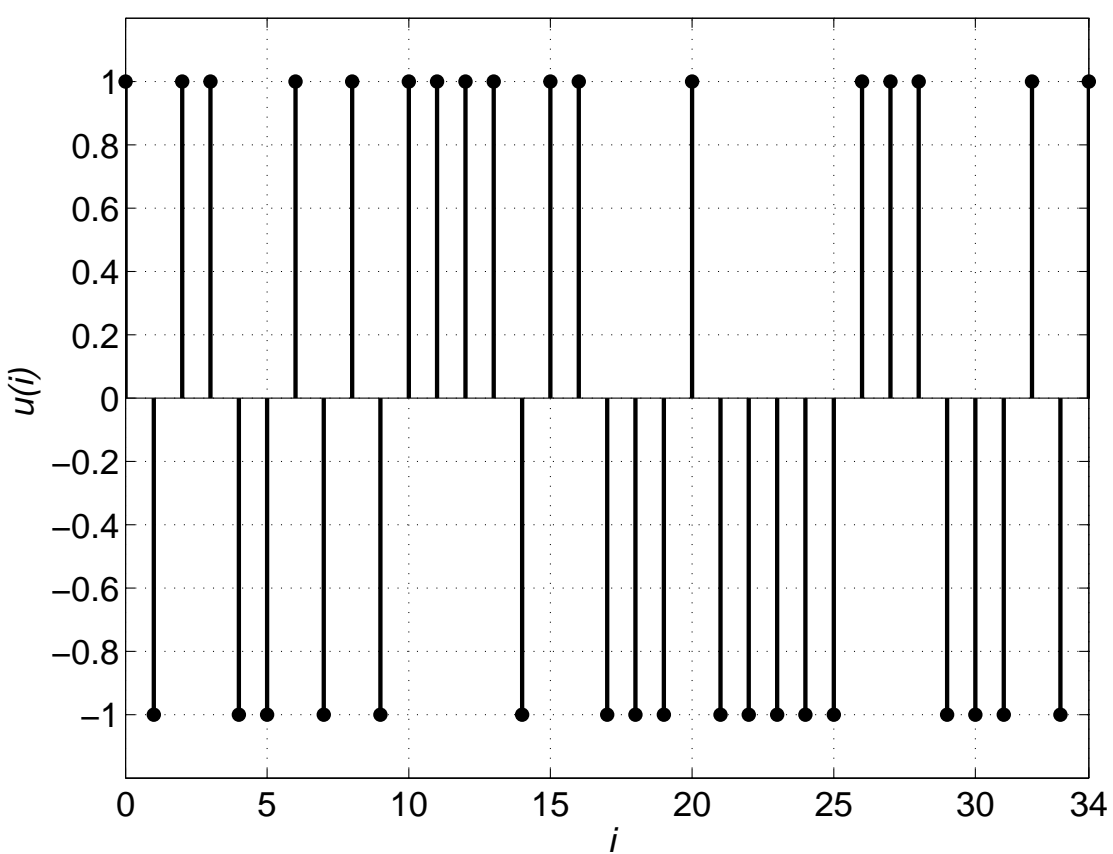

Figura 5.56: Sinal TPB de comprimento $N=35$.

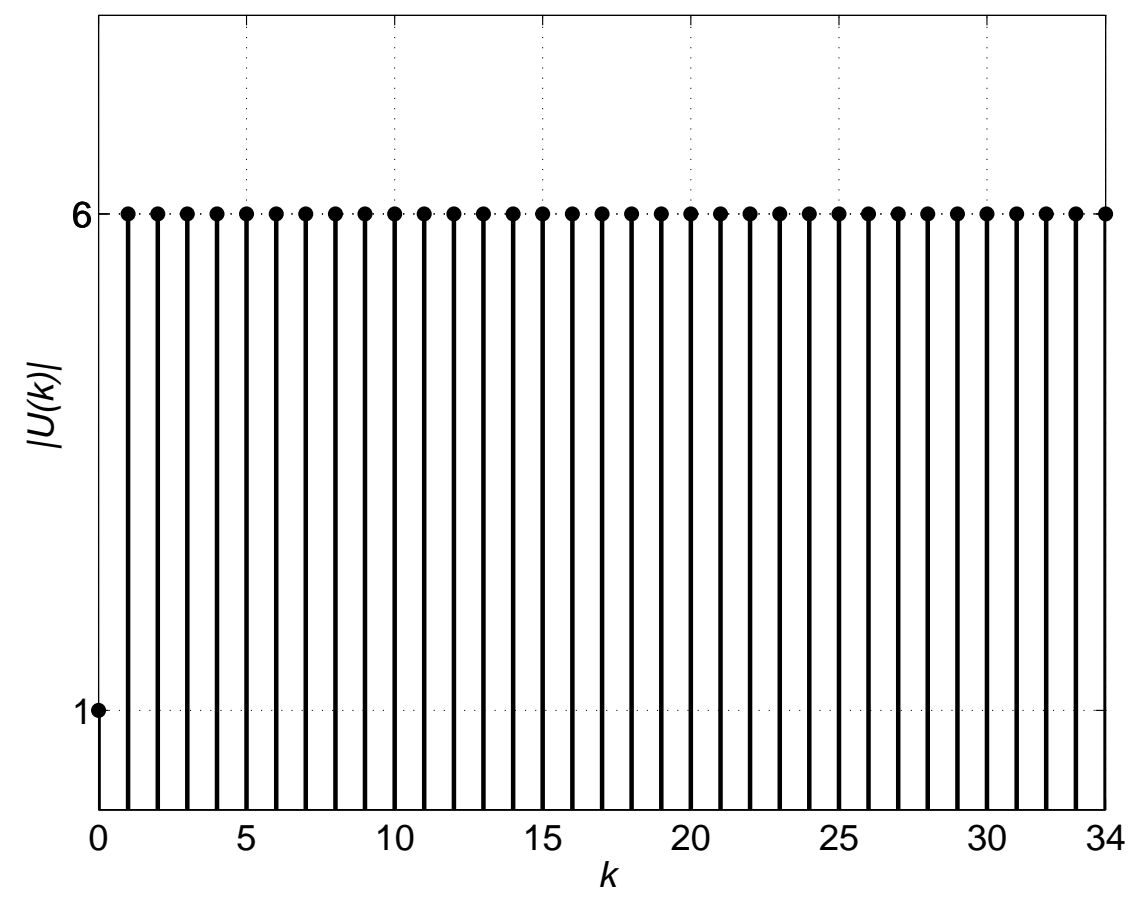

Figura 5.57: Módulo da DFT do sinal TPB de comprimento $N=35$.

\subsubsection{Sinal pseudo-aleatório binário}

Sinais pseudo-aleatórios binários (pseudo-random binary signals, PRB signals) são gerados a partir de sequências de máximo comprimento (SMC) binárias, também co- 


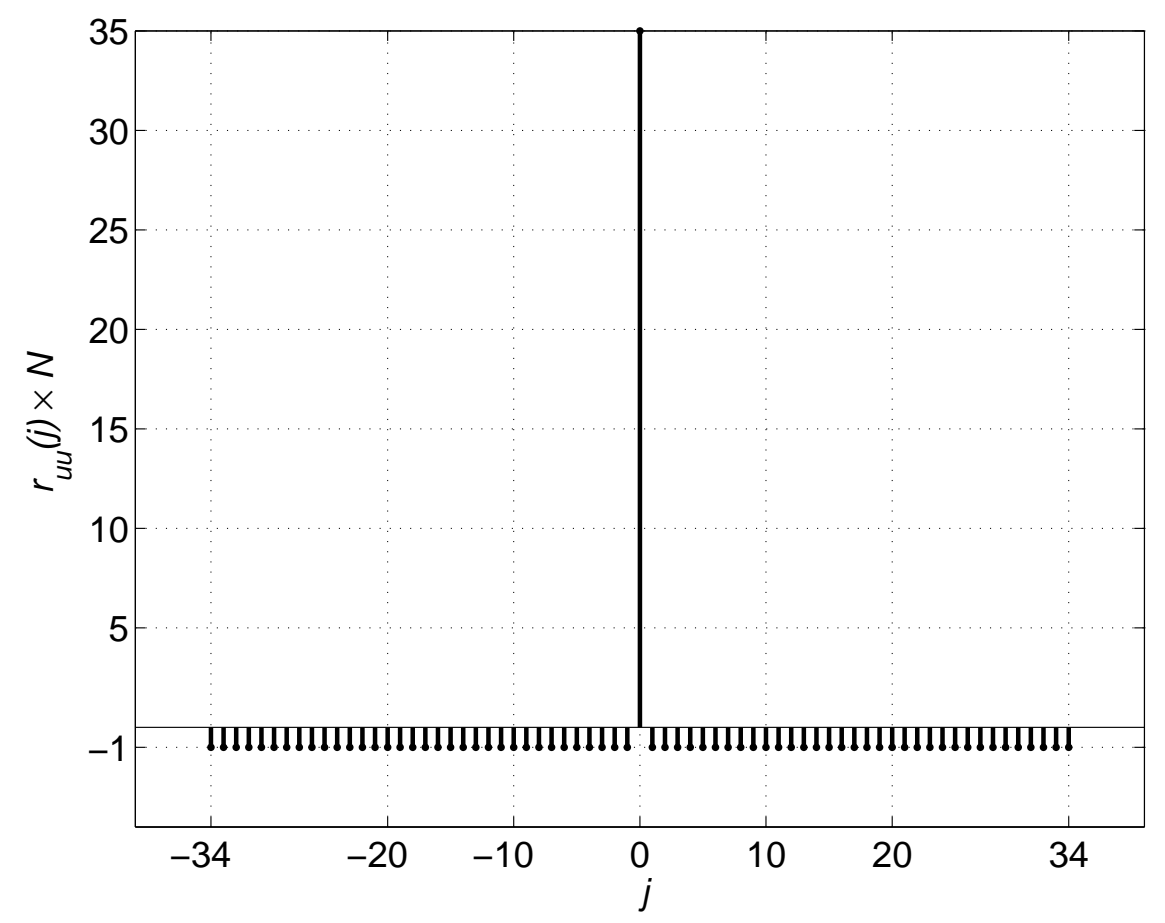

Figura 5.58: Função de autocorrelação periódica do sinal TPB de comprimento $N=35$.

nhecidas como m-sequences. Essas sequências possuem propriedades pseudo-aleatórias desejáveis para sinais de excitação. O anexo B trata das SMC binárias, ou seja, seus elementos estão no corpo fundamental ${ }^{1} G F(q)$, com $q=2$. No apêndice G são discutidas as características e propriedades de SMC não binárias, ou seja, sobre o corpo $G F(q), \operatorname{com} q>2$, a partir das quais são gerados sinais pseudo-aleatórios ternários e multinível.

Um sinal PRB é resultado do mapeamento dos elementos de $G F(2)$ de uma SMC em dois níveis $+A$ e $-A$. É comum adotar o mapeamento $u(i)=(-1)^{s_{i}}$, onde $s_{i}$ é a SMC binária definida conforme anexo B e de comprimento $N=2^{m}-1$ cujos elementos assumem valores 0 ou 1 , ou seja, elementos de $G F(2)$. Para obter um sinal PRB de amplitude $A$ basta multiplicar $u(i)$ por $A$.

A função de autocorrelação de sinais PRB binários $\left(u(i)=(-1)^{s_{i}}\right)$, conforme anexo B.1, será:

$$
r_{\text {uи }}(k)= \begin{cases}1 / N & \text { se } k \not \equiv 0(\bmod N) \\ -1 & \text { se } k \equiv 0(\bmod N)\end{cases}
$$

Observa-se que a função de autocorrelação de sinais PRB também não assume

\footnotetext{
${ }^{1} G F(q)$ é a notação usual para o corpo finito $D \bmod q$, onde $D$ é o conjunto fundamental e $q$ um número primo (anexo A.3)
} 
valor nulo pois o comprimento do sinal é um número ímpar $\left(N=2^{m}-1\right)$, ou seja, o sinal é não balanceado.

Para cada comprimento $N=2^{m}-1$ existem $\phi\left(2^{m}-1\right) / m$ SMC distintas e, portanto, o mesmo número de sinais PRB distintos, onde $\phi($.) representa a função de Euler (anexo A.6). Essa característica das sequências SMC é apresentada no anexo B.1.

A função de correlação cruzada entre SMC binárias $s_{i}$ distintas mapeadas em sinais PRB $u(i)=(-1)^{s_{i}}$ não é ótima como a função de autocorrelação (MCELIECE, 1987). Outras propriedades de correlação cruzada de SMC não apenas binárias estão disponíveis em (HELLESETH, 1976).

Devido essa característica de correlação cruzada não ótima das SMC binárias, não é prático excitar simultaneamente as entradas de um sistema com sinais PRB derivados de SMC binárias distintas. Como alternativa, modulam-se os sinais PRB por funções de Radmacher ou utilizam-se versões deslocadas do mesmo sinal PRB, conforme mostrado nas seções 5.3.7 e 5.3.10, respectivamente.

No apêndice D, as figuras D.2 e D.4 apresentam um sinal PRB de comprimento $N=2^{3}-1=7$ e seu espectro, respectivamente.

A próxima seção apresenta sinais multinível que representam a generalização dos sinais PRB.

\subsubsection{Sinal pseudo-aleatório multinível}

Sinais pseudo-aleatórios multinível (pseudo-random multilevel signal, PRML) são obtidos a partir de SMC cujos elementos estão no corpo fundamental $G F(q), \operatorname{com} q>2$ primo, ou seja, não binário. Os elementos da SMC não binária são mapeados em números reais gerando o PRML (BARKER; GODFREY, 1999). O apêndice G apresenta as principais características das $\mathrm{SMC}$ sobre $G F(q), \operatorname{com} q>2$ primo, as quais auxiliam compreender os sinais PRML.

Para identificação de sistemas não lineares pode ser necessário o uso de sinais de excitação multinível, conforme descrito na seção 3.7 (BARKER; GODFREY; TUCKER, 2000). As primeiras propostas de sinais de excitação multinível foram apresentadas em (GODFREY, 1993). Em (BARKER; TAN; GODFREY, 2004a) é apresentada uma evolução daquele método permitindo que harmônicas múltiplas de 2 e 3 sejam suprimidas e as harmônicas ímpares sejam uniformes, além de permitir que os níveis assumidos pelo sinal sejam escolhidos com certa liberdade. Esta característica é importante, pois foi mostrado em (BARKER; TAN; GODFREY, 2003a), (BARKER; TAN; GODFREY, 2003b) e (BARKER; TAN; GODFREY, 2004b) que a quantidade de níveis deve ser um parâmetro 
de escolha no processo de identificação de sistemas não lineares.

Em (BARKER; ZHUANG, 1997) e (BARKER, 2001) foi apresentado o software GALOIS, o qual gera sinais PRML. Este software foi aprimorado para possibilitar a supressão de harmônicas múltiplas de 2 e 3 como em (BARKER; TAN; GODFREY, 2004a). O software também permite escolher a quantidade de níveis assumidos pelo sinal.

Para gerar sinais PRML a partir de uma SMC $\mathbf{s}=\left\{s_{0}, s_{2}, \ldots s_{N-1}\right\}, \operatorname{com} N=q^{m}-1$, cada elemento $\alpha$ de $G F(q)$ deve ser mapeado em um nível de sinal $\ell(\alpha)$. O sinal em tempo discreto será dado por:

$$
u(i)=\ell\left(s_{i}\right), \operatorname{com} i=0,1, \ldots, N-1
$$

Apesar do corpo $G F(q)$ possuir $q$ elementos distintos, o sinal $u(i)$ pode ter $l<q$ níveis distintos, dependendo do mapeamento adotado.

Conforme (D.5), a DFT do sinal PRML $u(i)$ com de comprimento $N_{s}=N$, ou seja, $T_{c l k}=T$, será:

$$
U(k)=\sum_{i=0}^{N-1} u(i) \exp \left(-j \frac{2 \pi i k}{N}\right), \quad k=0,1, \ldots, N-1
$$

A sequência primitiva de uma SMC s é dada por $m_{i}=\alpha^{i \mathcal{T}}, \operatorname{com} i=0,1, \ldots, q-2$, onde $\mathcal{T}=\frac{q^{m}-1}{q-1}$ e $\alpha^{i \mathcal{T}}$ é o elemento primitivo de $G F(q)$, conforme descrito no apêndice G. A envoltória do módulo da DFT de um sinal oriundo de uma SMC é semelhante a de um sinal oriundo de sua sequência primitiva. Portanto, os níveis $\ell(\alpha)$ que oferecem propriedades adequadas a um sinal oriundo de uma SMC podem ser obtidos pela análise exaustiva de um sinal oriundo de sua sequência primitiva. Esta característica facilita escolher os níveis $\ell(\alpha)$, visto que as sequências primitivas $\mathbf{m}=\left\{m_{0}, m_{1}, \ldots, m_{q-2}\right\}$ possuem comprimento exponencialmente menor que as SMC $\mathbf{s}=\left\{s_{0}, s_{1}, \ldots, s_{q^{m}-2}\right\}$, resultando em um número de ensaios (procura exaustiva) exponencialmente menor.

A DFT do sinal $m(i)=\ell\left(m_{i}\right), \operatorname{com} i=0,1, \ldots, q-2$ e $T_{c l k}=T$, oriundo da sequência primitiva m, conforme a equação (D.5), será dada por:

$$
\begin{aligned}
M(k) & =\sum_{i=1}^{q-1} m(i) \exp \left(-j \frac{2 \pi i k}{q-1}\right) \\
& =\sum_{i=1}^{q-1} \ell\left(\alpha^{i \mathcal{T}}\right) \exp \left(-j \frac{2 \pi i k}{q-1}\right), \quad k=0,1, \ldots, q-2
\end{aligned}
$$


Fazendo $k=r N=r\left(q^{m}-1\right)$, com $r \in \mathbf{Z}$, em (5.66) e obtendo o valor absoluto, tem-se:

$$
\begin{aligned}
|M(k)| & =\left|\sum_{i=1}^{q-1} m(i) \exp \left(-j \frac{2 \pi i r\left(q^{m}-1\right)}{q-1}\right)\right| \\
& =\left|\sum_{i=1}^{q-1} m(i) \exp (-j 2 \pi i r \mathcal{T})\right| \\
& =\left|\sum_{i=1}^{q-1} m(i)\right|, \quad k=r N \operatorname{com} r \in \mathbf{Z}
\end{aligned}
$$

Analogamente, fazendo $k=r N$ em (5.65) e obtendo o valor absoluto, tem-se:

$$
\begin{aligned}
|U(k)| & =\left|\sum_{i=0}^{N-1} u(i) \exp \left(-j \frac{2 \pi i r N}{N}\right)\right| \\
& =\left|\sum_{i=0}^{N-1} u(i) \exp (-j 2 \pi i r)\right| \\
& =\left|\sum_{i=0}^{N-1} u(i)\right|, \quad k=r N \operatorname{com} r \in \mathbf{Z}
\end{aligned}
$$

Do apêndice $\mathrm{G}$, sabe-se que $|M(0)|=\left|\sum_{i=0}^{q-2} m(i)\right|$ é o somatório de todos os elementos de uma coluna não nula da matriz cujas linhas concatenadas resulta na SMC. Sabe-se também que o número de elementos nulos em uma SMC é dado por $q^{m-1}-1$ e existem $\frac{q^{m-1}-1}{q-1}$ colunas nulas na matriz. O somatório de todas os elementos da matriz é dado por $\left|\sum_{i=0}^{N-1} u(i)\right|=|U(k)|$, com $k=r N$, o qual pode ser calculado como:

$$
\begin{aligned}
|U(k)| & =\left|\sum_{i=0}^{N-1} u(i)\right| \\
& =|M(0)|\left(\left(\frac{q^{m}-1}{q-1}\right)-\left(\frac{q^{m-1}}{q-1}\right)\right) \\
& =|M(0)|\left(\frac{q^{m}-q^{m-1}}{q-1}\right)=|M(0)|\left(\frac{(q-1) q^{m-1}}{q-1}\right) \\
& =|M(0)| q^{m-1}, \quad k=r N \operatorname{com} r \in \mathbf{Z}
\end{aligned}
$$

Os cálculos para os casos de $|U(k)| \operatorname{com} k=s(q-1) \neq r N$ e $k \neq s(q-1)$, com $r$ e $s \in \mathbf{Z}$ são apresentados em (GODFREY, 1993). Esse desenvolvimento mostra que as magnitudes dos harmônicos do sinal $u(i)$ são funções das magnitudes do sinal $m(i)$ : 


$$
\begin{array}{ll}
|U(k)|=|M(0)| q^{m-1} & k=r N, \text { com } r \in \mathbf{Z} \\
|U(k)|=|M(0)| q^{\frac{m-2}{2}} & k=s(q-1) \neq r N \text { com } r, s \in \mathbf{Z} \\
|U(k)|=|M(k)| q^{\frac{m-1}{2}} & k \neq s(q-1) \operatorname{com} s \in \mathbf{Z}
\end{array}
$$

Com os resultados de (5.70), observa-se que a supressão de harmônicos pares do sinal $u(i)$ pode ser obtida suprimindo os harmônicos pares de $m(i)$. Para tanto, basta escolher um mapeamento dos elementos de $G F(q)$ em níveis $\ell(\alpha)$ que resulte na supressão dos harmônicos pares de $m(i)$. Conforme mencionado anteriormente, essa é uma boa estratégia, visto que o número de elementos em $m(i)$ é exponencialmente menor que o número de elementos em $u(i)\left(q-1\right.$ contra $q^{m}-1$ elementos).

Considerando $k$ par em 5.66, tem-se:

$$
\begin{aligned}
|M(k)| & =\left|\sum_{i=1}^{q-1} m(i) \exp \left(-j \frac{2 \pi i k}{q-1}\right)\right| \\
& =\left|\sum_{i=1}^{(q-1) / 2} m(i) \exp \left(-j \frac{2 \pi i k}{q-1}\right)+\sum_{i=(q-1) / 2+1}^{q-1} m(i) \exp \left(-j \frac{2 \pi i k}{q-1}\right)\right| \\
& =\left|\sum_{i=1}^{(q-1) / 2} m(i) \exp \left(-j \frac{2 \pi i k}{q-1}\right)+\sum_{i=1}^{(q-1) / 2} m(i+(q-1) / 2) \exp \left(-j \frac{2 \pi i k}{q-1}\right)\right| \\
& =\left|\sum_{i=1}^{(q-1) / 2}(m(i)+m(i+(q-1) / 2)) \exp \left(-j \frac{2 \pi i k}{q-1}\right)\right|, \text { para } k \text { par }
\end{aligned}
$$

Fazendo:

$$
(m(i)+m(i+(q-1) / 2))=0
$$

tem-se:

$$
|M(k)|=0 \text { para } k \text { par }
$$

ou seja, os harmônicos pares de $m(i)$ serão suprimidos. Consequentemente, os harmônicos pares de $u(i)$ serão também suprimidos, conforme (5.70). A condição de (5.72) significa que $m(i)$ deve ter a característica de repetição inversa.

Do teorema de Wiener-Kinchin para o caso de sinais amostrados, a densidade espectral de potência de um sinal amostrado pode ser obtida da transformada discreta de Fourier da função de autocorrelação periódica do sinal amostrado (OPPENHEIM; 
SCHAFER, 1999):

$$
\begin{aligned}
\Phi_{m}(k) & =\frac{1}{N}|M(k)|^{2}=\left|D F T\left(r_{m m}(i)\right)\right| \\
\Phi_{m}(k) & =\left|\sum_{d=0}^{q-2} r_{m m}(d) e^{-j \frac{2 \pi k d}{q-1}}\right|
\end{aligned}
$$

Caso $r_{m m}(d)=0$, para $d \neq \frac{r(q-1)}{2}$, tem-se:

$$
\begin{aligned}
\Phi_{m}(k) & =\left|r_{m m}(0) e^{-j \frac{2 \pi k 0}{q-1}}+r_{m m}\left(\frac{q-1}{2}\right) e^{-j \frac{2 \pi k(q-1)}{2(q-1)} \mid}\right| \\
& =\left|r_{m m}(0)+r_{m m}\left(\frac{q-1}{2}\right) e^{-j \pi k}\right| \\
& = \begin{cases}r_{m m}(0)+r_{m m}\left(\frac{q-1}{2}\right), & \text { para } k \text { par e } k \neq 0 \\
r_{m m}(0)-r_{m m}\left(\frac{q-1}{2}\right), & \text { para } k \text { ímpar }\end{cases}
\end{aligned}
$$

Dada a condição de repetição inversa do sinal dada por (5.72), tem-se:

$$
\begin{aligned}
r_{m m}\left(\frac{q-1}{2}\right) & =\frac{1}{q-1} \sum_{i=1}^{q-1} m(i) m\left(i+\frac{q-1}{2}\right) \\
& =\frac{-1}{q-1} \sum_{i=1}^{q-1} m(i) m(i) \\
& =-r_{m m}(0)
\end{aligned}
$$

Portanto:

$$
\Phi_{m}(k)= \begin{cases}0, & \text { para } k \text { par e } k \neq 0 \\ 2 r_{m m}(0), & \text { para } k \text { ímpar }\end{cases}
$$

ou seja, para se ter o sinal PRML $u(i)$ com as harmônicas pares suprimidas e as harmônicas ímpares com potência uniforme as seguintes condições para o sinal $m(i)$ devem ser satisfeitas:

$$
\begin{aligned}
& (m(i)+m(i+(q-1) / 2))=0 \\
& r_{m m}(d)=0, \quad \text { para } d \neq \frac{r(q-1)}{2}
\end{aligned}
$$


Realizando análise semelhante para $k$ múltiplo de 3 , conclui-se que se $(m(i)+m(i+$ $(q-1) / 3)+m(i+2(q-1) / 3))=0$, tem-se $|M(k)|=0$, para $k$ múltiplo de 3, ou seja, os harmônicos múltiplo de 3 de $m(i)$ serão suprimidos. Consequentemente, os harmônicos múltiplos de 3 de $u(i)$ serão também suprimidos. Para um sinal possuir harmônicos não nulos e uniformes para $k$ não múltiplo de 2 e 3 , sua função de autocorrelação periódica $r_{m m}(d)$ deve ser nula para $d \neq r(q-1) /(2 \times 3)$.

Portanto, para um sinal $u(i)$ possuir harmônicos nulos múltiplos de 2 e 3 e demais harmônicos uniformes, deve-se obter um sinal $m(i)$ com as características:

$$
\begin{aligned}
& (m(i)+m(i+(q-1) / 2))=0 \\
& (m(i)+m(i+(q-1) / 3)+m(i+2(q-1) / 3))=0 \\
& r_{m m}(d)=0, \text { para } d \neq r(q-1) / 6
\end{aligned}
$$

É imediato observar que as condições de (5.78) para um corpo $G F(3)$, ou seja, com $q=3$, são satisfeitas quando $m(2)=-m(1)$. Em (BARKER; TAN; GODFREY, 2004a), é apresentada uma tabela com todos os mapeamentos de $m(i)$ para que as condições de (5.78) sejam satisfeitas para corpos $G F(q), \operatorname{com} q=3,5,7,9,11$ e 13.

Em (BARKER; TAN; GODFREY, 2004a) mostrou-se também que para o corpo $G F(7)$, as condições de (5.79) são satisfeitas quando:

$$
\begin{aligned}
& m(4)=-m(1) \\
& m(5)=-m(2) \\
& m(6)=-m(3) \\
& m(3)=m(2)-m(1)
\end{aligned}
$$

Os níveis para $m(1)$ e $m(2)$ podem ser escolhidos livremente. Os níveis para $m(3)$, $m(4), m(5)$ e $m(6)$ são obtidos de (5.80).

Para o corpo $G F(13)$, as condições de (5.79) são satisfeitas quando (BARKER; TAN; GODFREY, 2004a):

$$
\begin{aligned}
& m(7)=-m(1) \\
& m(8)=-m(2) \\
& m(9)=-m(3)
\end{aligned}
$$




$$
\begin{aligned}
m(10) & =-m(4) \\
m(11) & =-m(5) \\
m(12) & =-m(6) \\
m(4) & =\frac{m(2) \times m(1)}{m(1)-m(3)} \\
m(5) & =m(3)-m(1) \\
m(6) & =m(4)-m(2)
\end{aligned}
$$

Os níveis para $m(1), m(2)$ e $m(3)$ podem ser escolhidos livremente. Os níveis para $m(4), m(5), \ldots, m(12)$ são obtidos de (5.81).

A tabela 5.8 apresenta alguns exemplos obtidos de (BARKER; TAN; GODFREY, 2004a) de sinais $m(i)$ que satisfazem as condições de (5.80) e (5.81).

Tabela 5.8: Exemplos de níveis para o sinal primitivo $m(i)$ de forma a obter o sinal de excitação $u(i)$ com harmônicas múltiplas de 2 e 3 suprimidas e demais harmônicas uniformes.

\begin{tabular}{cccccccc}
\hline Corpo & \# de níveis $l$ & $m(1)$ & $m(2)$ & $m(3)$ & $m(4)$ & $m(5)$ & $m(6)$ \\
\hline$G F(7)$ & 3 & $a$ & $a$ & 0 & & & \\
& 5 & $a$ & $2 a$ & $a$ & & & \\
$G F(13)$ & 7 & $a$ & $b$ & $b-a$ & & & \\
& 3 & $a$ & 0 & $a$ & 0 & 0 & 0 \\
& 5 & $a$ & 0 & $-a$ & 0 & $-2 a$ & 0 \\
& 7 & $a$ & 0 & $b$ & 0 & $b-a$ & 0 \\
\hline
\end{tabular}

A figura 5.59 apresenta o sinal PRML obtido por meio da SMC sobre $G F(p)$, com $p=7$, construído a partir do polinômio primitivo $2+x+x^{2}$ de grau $m=2$ e, portanto, de comprimento $N=p^{m}-1=7^{2}-1=48$. Foram adotados $l=7$ níveis, com $a=1$ e $b=3$. A figura 5.60 apresenta o módulo da DFT do sinal PRML. Observa-se que os harmônicos múltiplos de 2 e 3 estão suprimidos e os demais são uniformes. A função de autocorrelação do sinal é apresentada na figura 5.61.

\subsubsection{Conjunto de sinais pseudo-aleatórios binários}

Em (BRIGGS; GODFREY, 1966) foi proposto um método sistemático para excitação simultânea das entradas de um sistema multivariável. Neste método, uma sequência QRB, QRT, HAB, TPB ou PRB de comprimento $N$ é modulada por $n_{r}$ funções Rademacher (BRIGGS; GODFREY, 1966) para gerar um conjunto de $n_{r}$ sequências binárias (ou quase binárias no caso da sequência QRT) não correlacionadas de comprimento $N \times 2^{n_{r}-1}$. O espectro de potência das sequências será intercalado (zippered spectrum), porém, não é garantida potência uniforme para as harmônicas não nulas. Neste trabalho, essas sequências serão chamadas de Rademacher-QRB, Rademacher-QRT, 


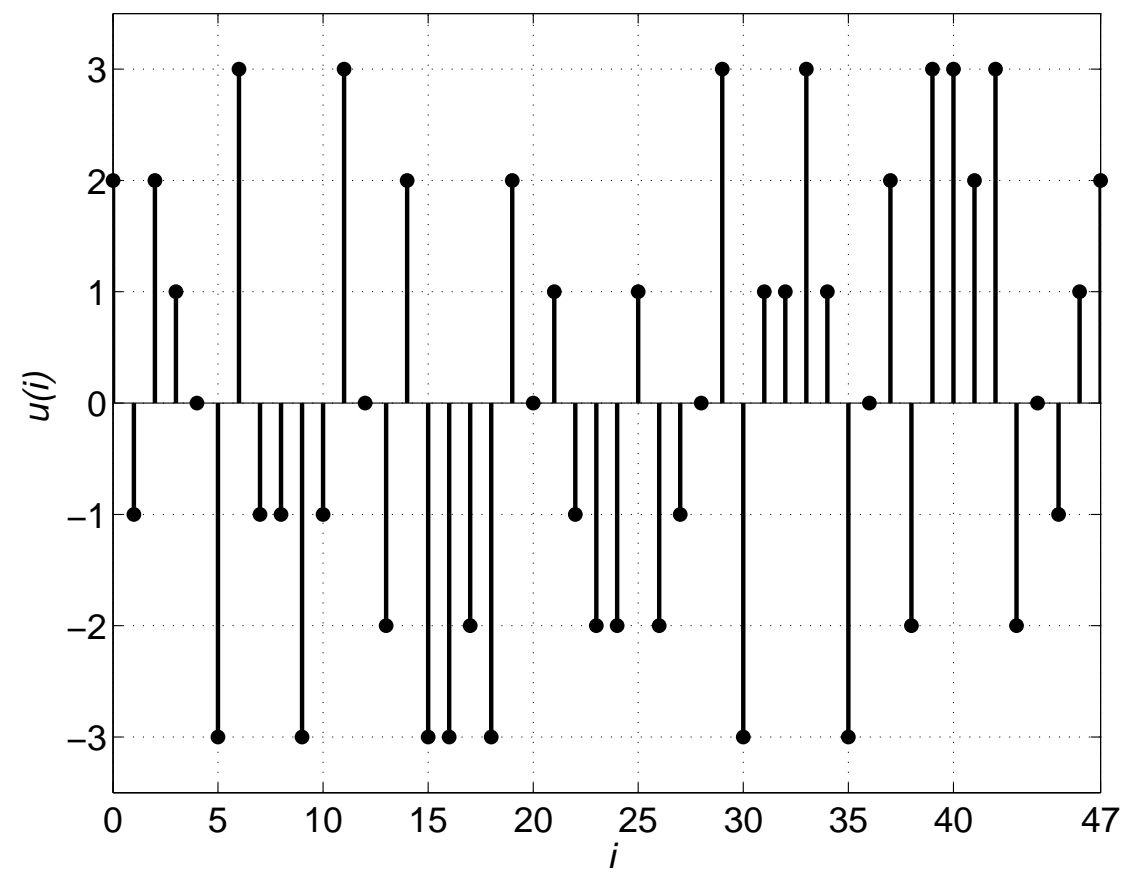

Figura 5.59: Sinal PRML de $l=7$ níveis e comprimento $N=48$.

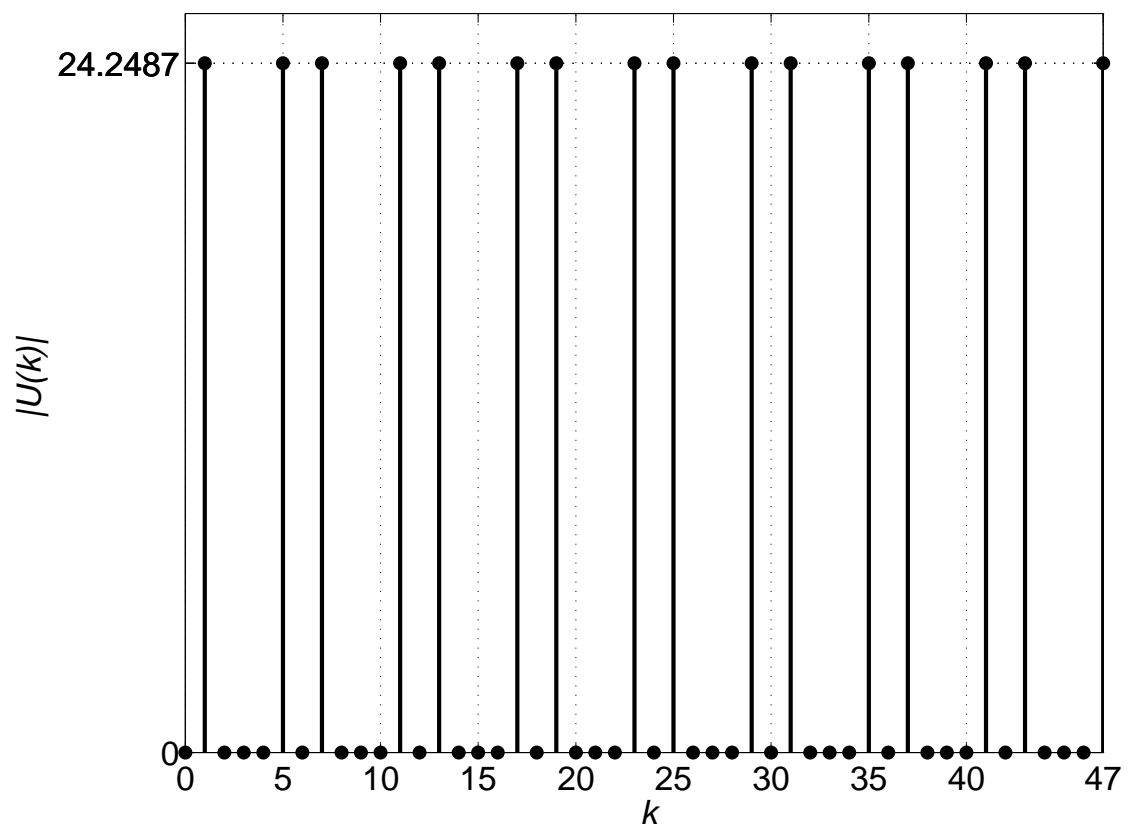

Figura 5.60: Módulo da DFT do Sinal PRML de $l=7$ níveis e comprimento $N=48$.

Rademacher-HAB, Rademacher-TPB ou Rademacher-PRB, dependendo das sequências utilizadas em suas construções.

Seja uma sequência binária $\mathbf{a}=\{a(i)\}=\{a(0) a(1) a(2) \ldots a(L-1)\}$ de comprimento $L=2^{n}-1$ obtida do mapeamento de uma SMC sobre $G F(2)$ de comprimento $2^{n}-1$ conforme discutido na seção 5.3.5. Considere também a sequência $\mathbf{b}=\{b(i)\}=\left\{(-1)^{i}\right\}$. Em (BRIGGS; GODFREY, 1966), foi mostrado que a função de autocorrelação da sequência: 


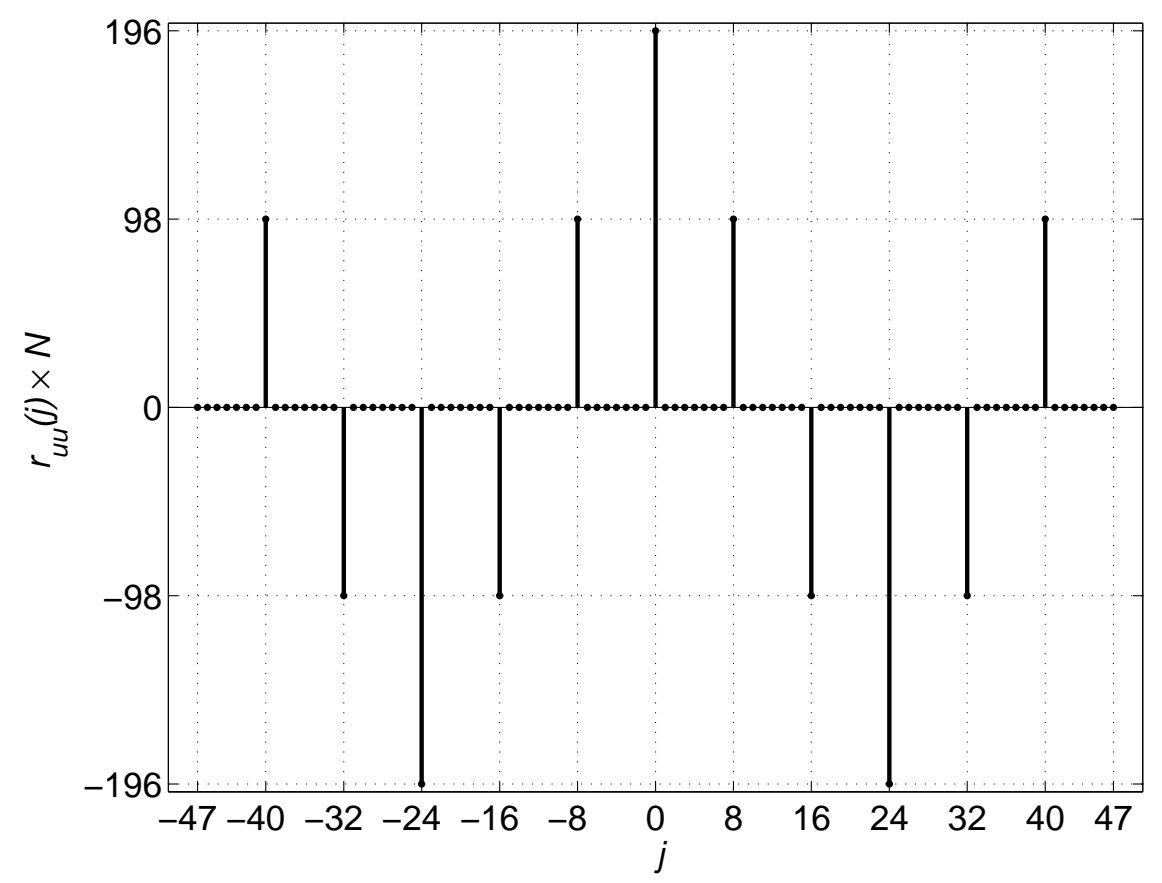

Figura 5.61: Função de autocorrelação periódica do sinal PRML de comprimento $N=48$.

$$
\mathbf{c}=\{c(j)\}=\{a(j) b(j)\}=\left\{(-1)^{j} a(j)\right\}, \quad \operatorname{com} j=0,1,2, \ldots, L-1(\bmod N)
$$

será $r_{c c}(k)=0$ para $k \neq 0(\bmod L)$.

Considere matriz de Hadamard $H_{p}$ (PROAKIS, 1995):

$$
H_{p}=\left[\begin{array}{cc}
H_{p-1} & H_{p-1} \\
H_{p-1} & -H_{p-1}
\end{array}\right], \quad H_{0}=[1]
$$

Considere as funções Rademacher dadas pelas linhas $0,1,2,4, \ldots, 2^{p-1}$ da matriz Hadamard de dimensão $2^{p} \times 2^{p}$. Seja $\mathbf{g}_{\mathbf{r}}=\left\{g_{r}(i)\right\}, \operatorname{com} i=0,1,2, \ldots, 2^{p}-1\left(\bmod 2^{p}\right)$, a função de Rademacher relativa à $r$-ésima linha da matriz de Hadamard de dimensão $2^{p} \times 2^{p}$.

As sequências:

$$
\mathbf{d}_{\mathbf{r}}=\left\{d_{r}(j)\right\}=\left\{g_{r}(j) c(j)\right\}
$$

de comprimento $N=2^{p} \times L=2^{p} \times\left(2^{n}-1\right)$ serão ortogonais (BRIGGS; GODFREY, 1966): 


$$
\begin{aligned}
r_{d_{r} d_{s}}(k) & =\frac{1}{2^{p} L} \sum_{j=0}^{2^{p} L-1} d_{r}(j) d_{s}(j-k) \\
& =\frac{1}{2^{p} L} \sum_{j=0}^{2^{p} L-1} g_{r}(j) c(j) g_{s}(j-k) c(j-k) \\
& =\frac{1}{2^{p} L} \sum_{i=0}^{2^{p}-1} g_{r}(i) g_{s}(i-k) \sum_{j=0}^{L-1} c(j) c(j-k) \\
& =\frac{1}{2^{p}} \sum_{i=0}^{2^{p}-1} g_{r}(i) g_{s}(i-k) \frac{1}{L} \sum_{j=0}^{L-1} c(j) c(j-k) \\
& =r_{g_{r} g_{s}}(k) r_{c c}(k) \\
& =0
\end{aligned}
$$

pois $r_{g_{r} g_{s}}(k)=0$ para $k=0\left(\bmod 2^{p}\right), r_{c c}(k)=0$ para $k \neq 0(\bmod L)$ e $2^{p}$ é primo relativo de $L=2^{n}-1$.

Para obter $n_{r}$ sequências não correlacionadas a partir da sequência $\mathbf{c}$ de comprimento $L=2^{n}-1$, escolhe-se a matriz Hadamard de dimensão $2^{n_{r}-1} \times 2^{n_{r}-1}$ e as sequências $\mathbf{g}_{\mathbf{r}}$ dada pelas linhas $0,1,2,4, \ldots, 2^{n_{r}-2}$ da matriz. As $n_{r}$ sequências binárias ortogonais de comprimento $N=2^{n_{r}-1}\left(2^{n}-1\right)$ serão:

$$
\mathbf{d}_{\mathbf{r}}=\left\{d_{r}(j)\right\}=\left\{g_{r}(j) c(j)\right\}, \quad \operatorname{com} r=0,1,2, \ldots, n_{r}-1
$$

as quais são chamadas de Rademacher-PRB neste trabalho.

Em (BRIGGS; GODFREY, 1966) a metodologia de modulação de sequências binárias por sequências Rademacher foi estendida para o caso de sequencias ternárias. Assim, são construídos conjuntos de sequências ternárias ortogonais. No capítulo 6 é proposto um método para obter conjuntos de sequências ortogonais multinível.

Observa-se que o comprimento das sequências moduladas por funções de Rademacher $N=\left(2^{n_{r}-1}\right) L$ aumenta exponencialmente com o tamanho do conjunto de sequências $K_{s}=n_{r}$. Essa característica não é desejável, visto que a duração do experimento aumentará exponencialmente com o aumento das entradas excitadas simultaneamente. Adicionalmente, os comprimentos disponíveis das sequências estão limitados também por $L$.

As figuras 5.62a, 5.62b e 5.62c apresentam as sequências Rademacher-PRB $u_{1}(i)$, $u_{2}(i)$ e $u_{3}(i)$, respectivamente, ortogonais construídas a partir do polinômio primitivo $x^{5}+x^{2}+1$ sobre o corpo $G F(2)$. O comprimento das 3 sequências será $N=2^{n_{r}-1}\left(2^{n}-\right.$ $1)=2^{3-1}\left(2^{5}-1\right)=124$. A figura 5.63 apresenta os espectros $U_{1}(k), U_{2}(k)$ e $U_{3}(k)$ das 
sequências PRML $u_{1}(i), u_{2}(i)$ e $u_{3}(i)$, respectivamente. Observa-se que as sequências possuem espectros intercalados (zippered power spectrum).

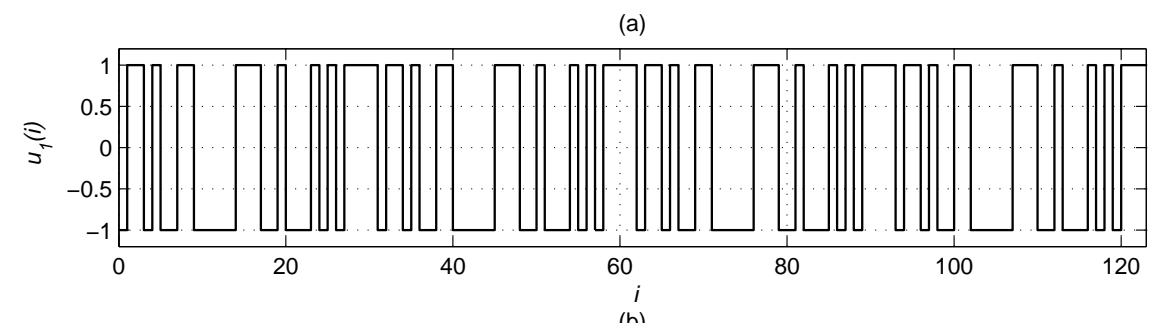

(b)

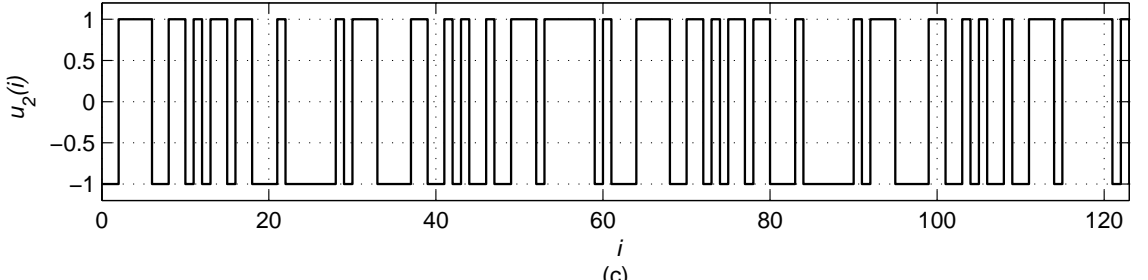

(c)

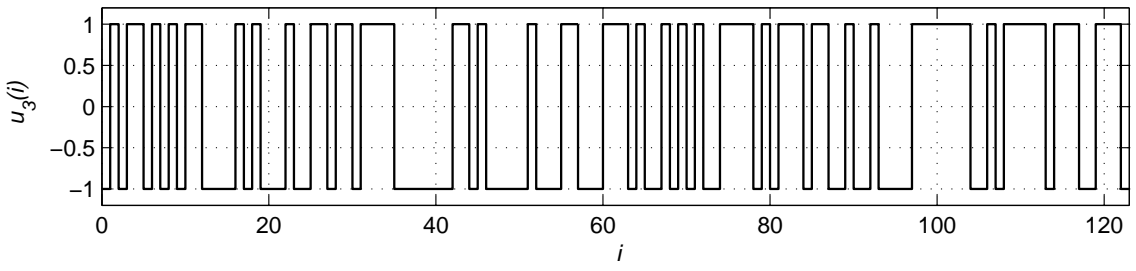

Figura 5.62: Conjunto de sequências Rademacher-PRB de comprimento $N=124$.

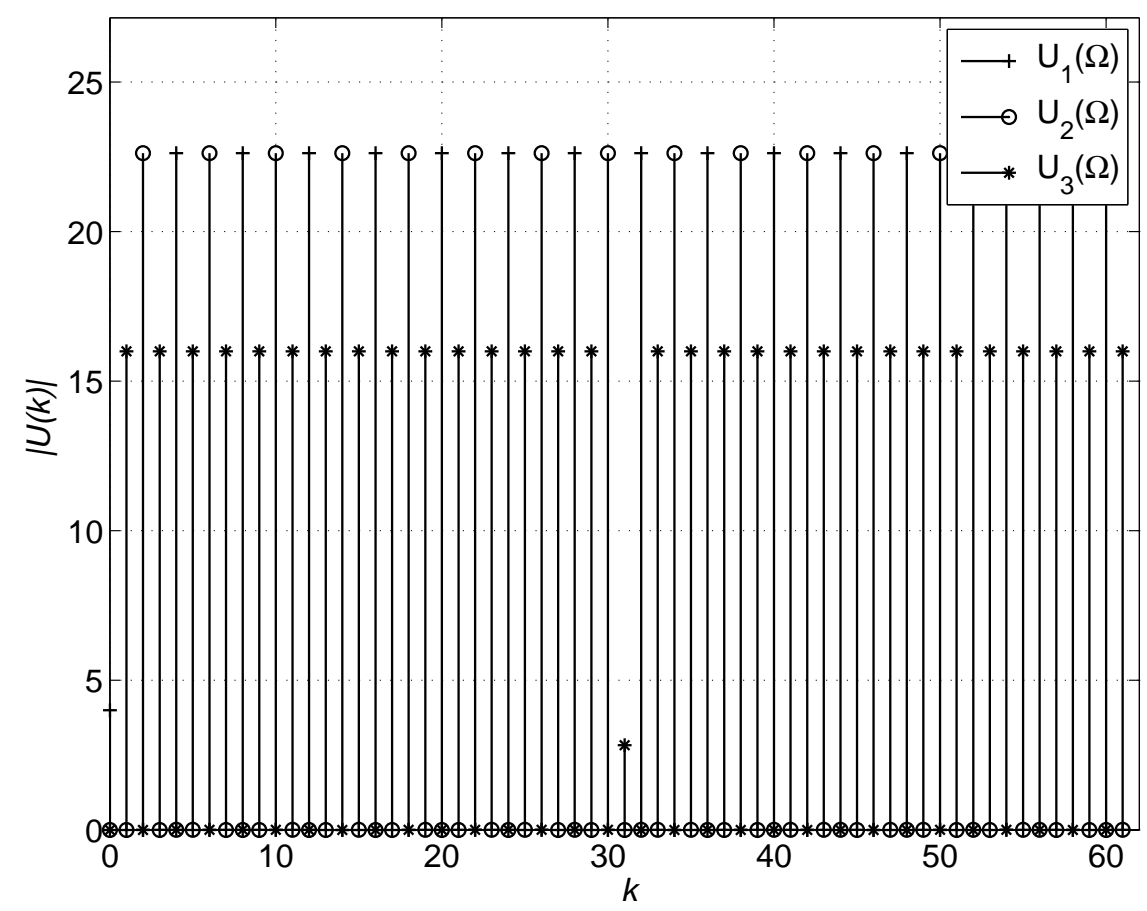

Figura 5.63: Módulo da DFT das sequências Rademacher-PRB de comprimento $N=124$.

As figuras 5.64a, 5.64b e 5.64c apresentam as funções de autocorrelação periódica das sequências Rademacher-PRB $u_{1}(i), u_{2}(i)$ e $u_{3}(i)$, respectivamente. Observa-se que 
as funções de autocorrelação $r_{u u}(j)$ apresentam picos para $j \neq(\bmod N)$. Essa característica confere os espectros intercalados (supressão de harmônicas).

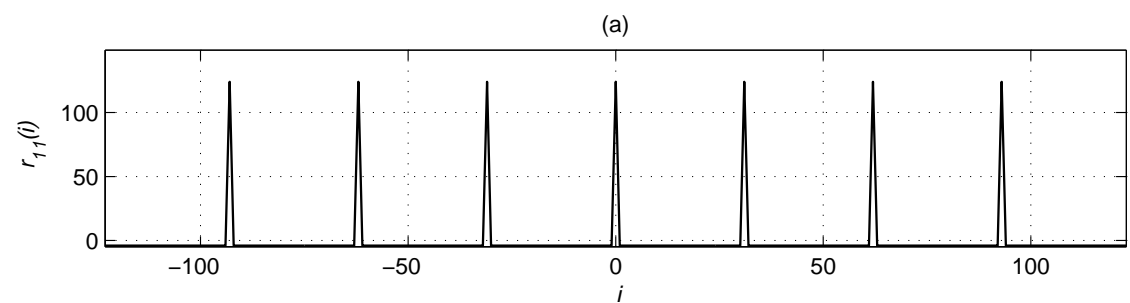

(b)

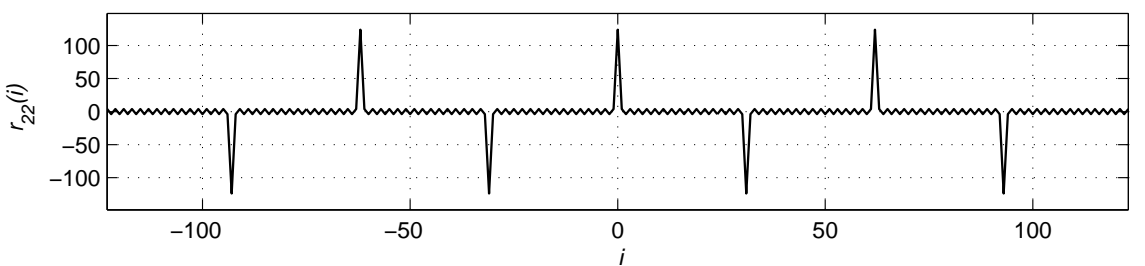

(c)

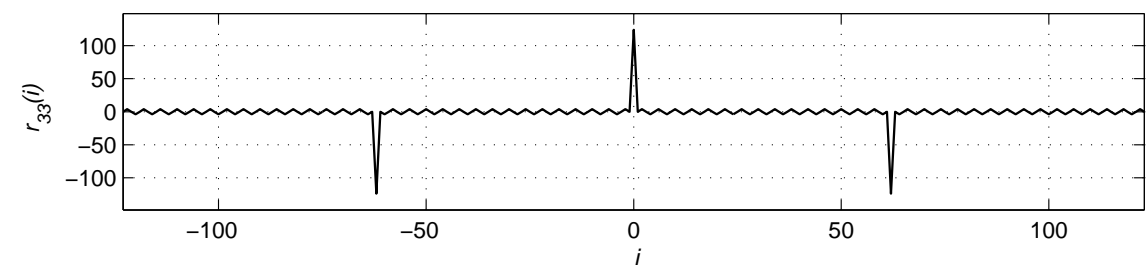

Figura 5.64: Função de autocorrelação periódica das sequências Rademacher-PRB de comprimento $N=124$.

A figura 5.65 apresenta as funções de correlação cruzada entre as sequências Rademacher-PRB $u_{1}(i), u_{2}(i)$ e $u_{3}(i)$. Observa-se que a função de correlação cruzada $r_{u_{r} u_{s}}(j)$ é nula para qualquer valor de $j$, o que significa que as sequências RademacherPRB $u_{1}(i), u_{2}(i)$ são ortogonais. Observando a figura 5.63 também pode-se concluir que os sinais são ortogonais, pois nas harmônicas onde há potência para uma das sequências, para a outra não há (espectros intercalados).

\subsubsection{Conjunto de sinais pseudo-aleatórios ternários}

Em (BARKER; TAN; GODFREY, 2007) foram apresentados métodos para gerar conjuntos de sinais ternários (pseudo-random ternary signal, PRT) não correlacionados para identificação MIMO. Os sinais possuem a característica de espectros intercalados (zippered spectrum) e harmônicas não nulas com amplitude uniforme. Foram apresentadas duas formas de gerar os sinais. Uma delas utiliza sinais QRT e a outra utiliza sinais derivados de SMC. A restrição desses métodos reside nos comprimentos disponíveis, assim como os sinais modulados por funções de Rademacher. Dado um comprimento $L$ básico, o comprimento dos sinais será $N_{s}=2 L \frac{T_{c l k}}{T}, 4 L \frac{T_{c l k}}{T}, 8 L \frac{T_{c l k}}{T}, \ldots$, para um conjunto de $2,3,4, \ldots$ sinais não correlacionados, respectivamente. 
(a)

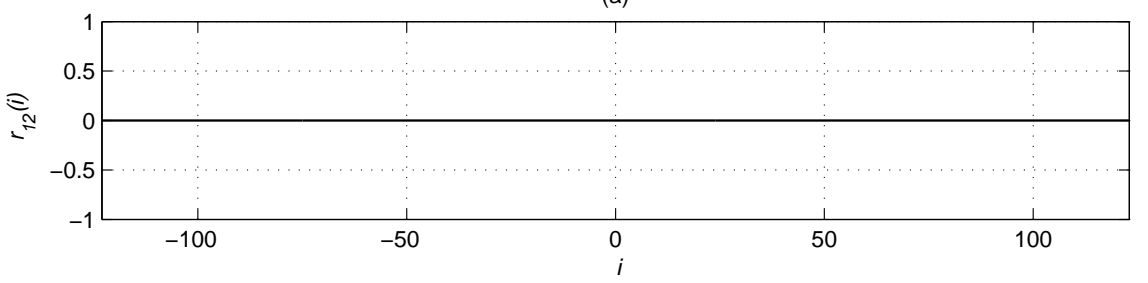

(b)

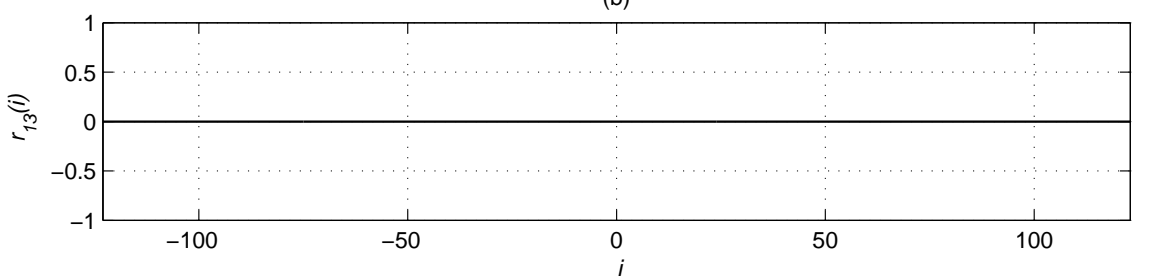

(c)

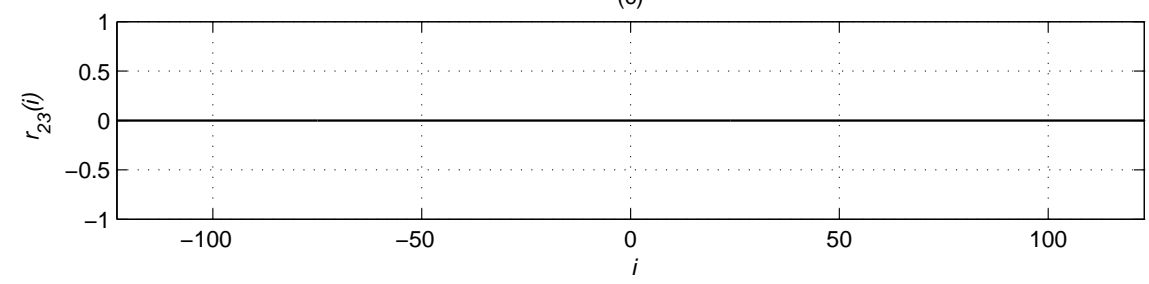

Figura 5.65: Função de correlação cruzada periódica das sequências Rademacher-PRB de comprimento $N=124$.

Tal restrição no comprimento dos sinais foi contornada com a proposta apresentada em (TAN, 2007) (TAN; GODFREY; BARKER, 2009). Essa proposta gera sinais com o mesmo método apresentado na seção 5.3.6, com diferença apenas no mapeamento da sequência primitiva. Os conjuntos de sinais não correlacionados apresentados em (TAN; GODFREY; BARKER, 2009) são resultados da combinação sinais gerados por diferentes métodos de supressão de harmônicas já conhecidos e também por procuras exaustivas por mapeamentos que também resultam em sinais ternários com supressão de harmônicas. No caso de sinais com harmônicas múltiplas de 2 e 3 suprimidas, a condição (5.79) deve ser atendida e, portanto, só é possível para sinais sobre $G F(q)$, com $q-1$ múltiplo de 6, conforme (TAN; FOO, 2006).

Em uma SMC sobre $G F\left(q^{m}\right)$, o elemento 0 aparece $q^{m-1}-1$ vezes e os demais elementos de $G F\left(q^{m}\right)$ aparecem $q^{m-1}$ vezes, conforme discutido na seção 5.3.6. Nos métodos de geração de sinais PRML, e também PRT, o elemento 0 da SMC é sempre mapeado como $\ell(0)=0$. Assim, o PIPS pode ser escrito em função do PIPS do sinal primitivo $m(i)$, o qual representa o mapeamento de todos os elementos não nulos de $G F(q)$ :

$$
\text { PIPS }=\sqrt{\frac{\sum \text { elementos não nulos de } u(i)}{\sum \text { elementos de } u(i)}} \times \text { PIPS }_{m}
$$


Tabela 5.9: Exemplos de sinais primitivos que geram sinais ternários não correlacionados.

\begin{tabular}{lllcl}
\hline$q$ & $m(i)$ & PIPS $_{m}$ & $\begin{array}{c}\text { harmônicas } \\
\text { não nulas }\end{array}$ & $|M(k)|$ \\
\hline 5 & $\{1 ; 1 ;-1 ;-1\}$ & 100 & $1 ; 3$ & 2,83 \\
5 & $\{1 ;-1 ; 1 ;-1\}$ & 100 & 2 & 4 \\
\hline 7 & $\{1 ; 1 ; 0 ;-1 ;-1 ; 0\}$ & 81,65 & $1 ; 5$ & 3,46 \\
7 & $\{1 ;-1 ; 0 ; 1 ;-1 ; 0\}$ & 81,65 & $2 ; 4$ & 3,46 \\
7 & $\{1 ;-1 ; 1 ;-1 ; 1 ;-1\}$ & 100 & 3 & 6 \\
\hline 9 & $\{0 ; 1 ; 1 ;-1 ; 0 ;-1 ;-1 ; 1\}$ & 86,60 & $1 ; 3 ; 5 ; 7$ & 3,46 \\
9 & $\{1 ; 1 ;-1 ;-1 ; 1 ; 1 ;-1 ;-1\}$ & 100 & $2 ; 4$ & 5,66 \\
9 & $\{1 ;-1 ; 1 ;-1 ; 1 ;-1 ; 1 ;-1\}$ & 100 & 3 & 8 \\
\hline
\end{tabular}

$$
\begin{aligned}
& =\sqrt{\frac{\left(q^{m}-1\right)\left(q^{m-1}-1\right)}{q^{m}-1}} \times \text { PIPS }_{m} \\
& =\sqrt{\frac{q^{m}-q^{m-1}}{q^{m}-1}} \times \text { PIPS }_{m}
\end{aligned}
$$

onde $P_{P I P S_{m}}$ é o valor do PIPS do sinal primitivo $m(i)$.

A tabela 5.9 apresenta alguns exemplos de mapeamentos das sequências primitivas $\mathbf{m}=\left\{m_{0}, m_{1}, \ldots, m_{q-2}\right\}$ resultando nos sinais primitivos $m(i)=\ell\left(m_{i}\right)$, com $i=$ $0,1, \ldots, q-2$ que geram os sinais ternários não correlacionados.

Neste trabalho, a sigla PRT é usada para sinais gerados conforme o método apresentado nesta seção.

As figuras 5.66a, 5.66b e 5.66c apresentam os sinais PRT $u_{1}(i), u_{2}(i)$ e $u_{3}(i)$, respectivamente, sobre $G F\left(q^{m}\right)$, com $q=7$ e $m=2$, que formam um conjunto de sinais ternários não correlacionados de comprimento $N=7^{2}-1=48$, com $T_{c l k}=T$.

Os espectros $\left|U_{1}(k)\right|,\left|U_{2}(k)\right|$ e $\left|U_{3}(k)\right|$ dos dois sinais PRT $u_{1}(i), u_{2}(i)$ e $u_{3}(i)$, respectivamente, são mostrados na figura 5.67. Os sinais primitivos $m_{1}(i), m_{2}(i)$ e $m_{3}(i)$ que geram os sinais PRT $u_{1}(i), u_{2}(i)$ e $u_{3}(i)$, respectivamente, possuem média zero. De acordo com (5.70), os sinais PRT $u_{1}(i), u_{2}(i)$ e $u_{3}(i)$ terão harmônicas múltiplas de $q-1=7-1=6$ suprimidas. A figura 5.67 confirma essa característica.

As figuras 5.68a, 5.68b e 5.68c mostram as funções de autocorrelação periódica dos sinais PRT $u_{1}(i), u_{2}(i)$ e $u_{3}(i)$, respectivamente. Observa-se que as funções de autocorrelação possuem picos devidamente alocados de forma que seus espectros possuam energias em harmônicos não coincidentes, ou seja, espectros intercalados (zippered spectrum).

Conforme previsto, as funções de correlação cruzada entre os sinais PRT $u_{1}(i)$, $u_{2}(i)$ e $u_{3}(i)$, figura 5.69 , são nulas para qualquer valor de $j$, o que confirma que os 


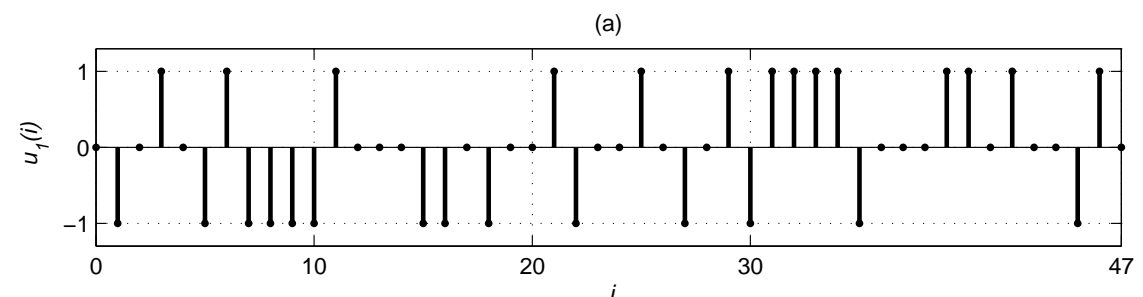

(b)

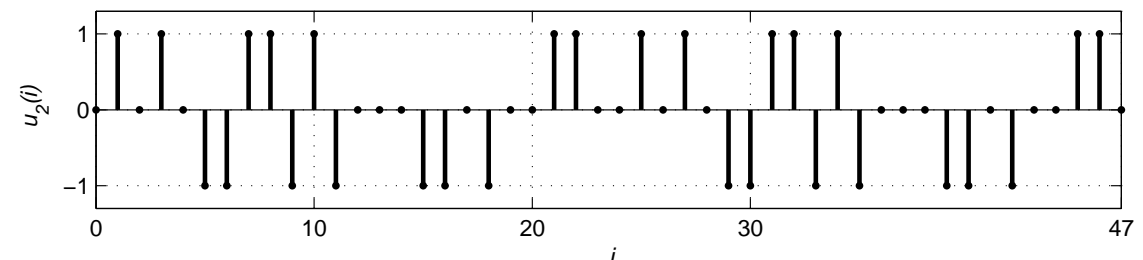

(c)

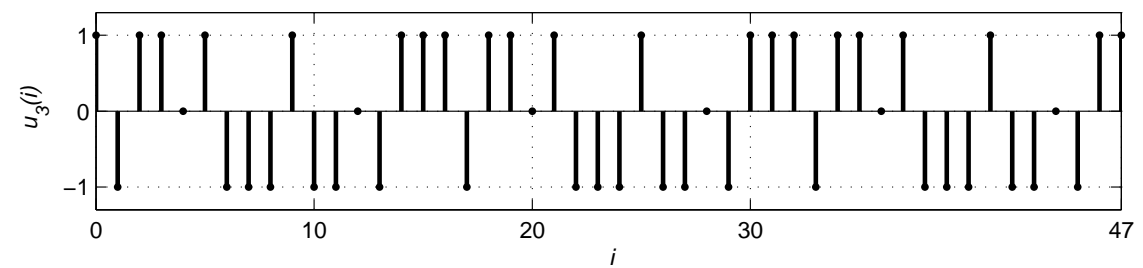

Figura 5.66: Conjunto de sinais PRT de comprimento $N=48$.

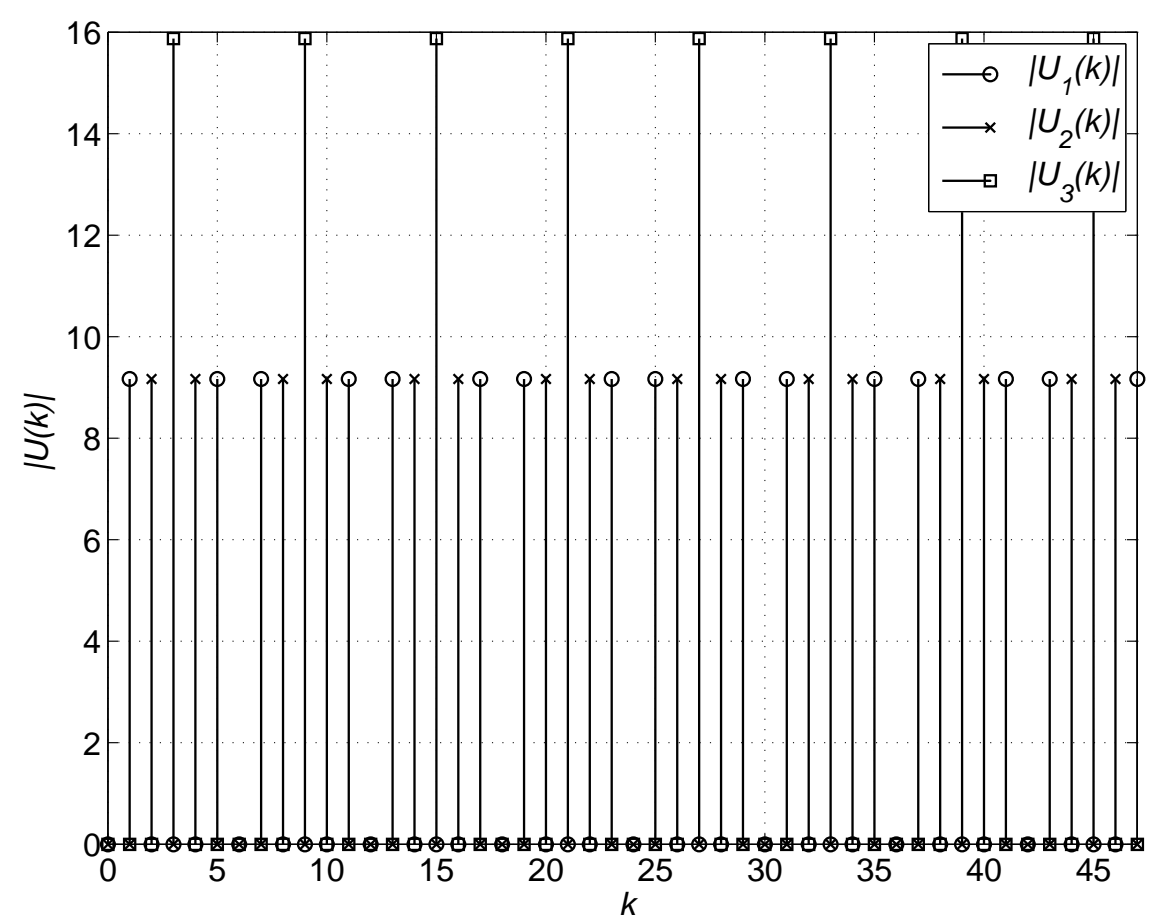

Figura 5.67: Módulo da DFT dos sinais PRT de comprimento $N=48$.

sinais $u_{1}(i), u_{2}(i)$ e $u_{3}(i)$ são ortogonais. A figura 5.67 também evidencia que os sinais são ortogonais, pois nas harmônicas em que há potência para um dos sinais, para os demais não há (zippered spectrum). 
(a)
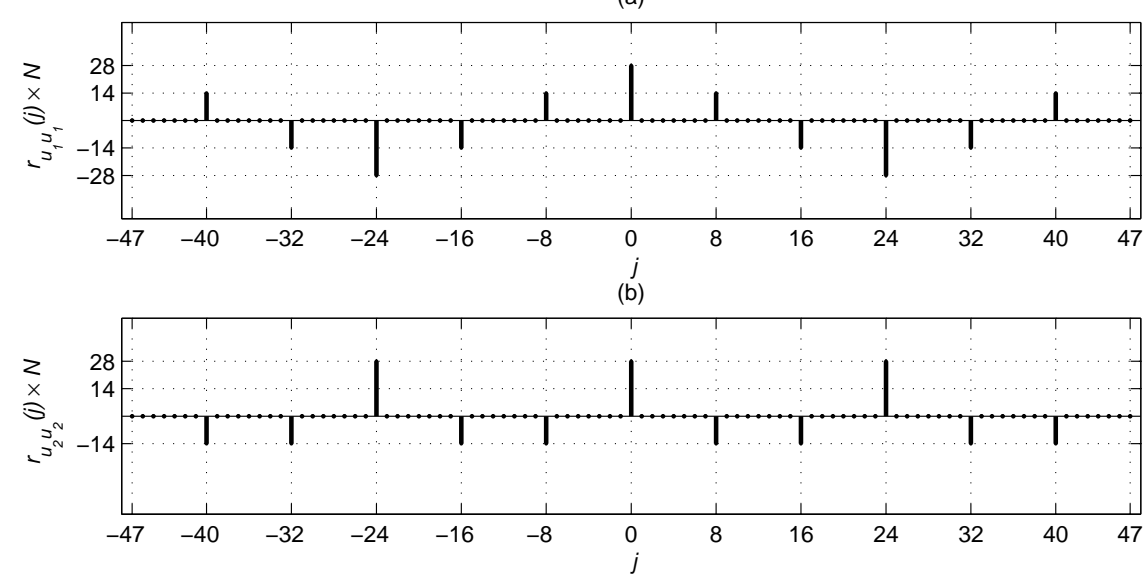

(c)

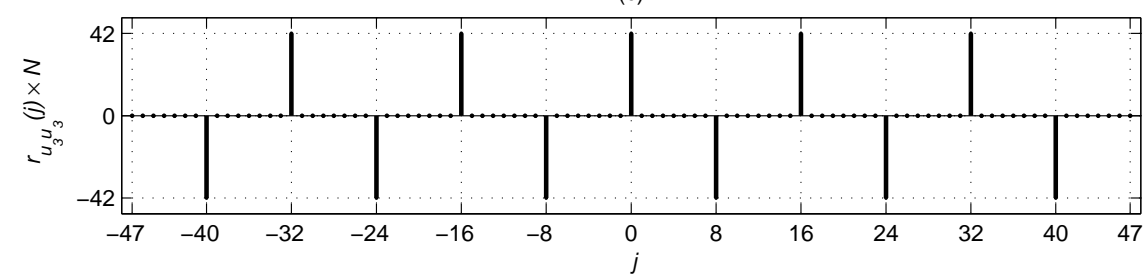

Figura 5.68: Função de autocorrelação periódica dos sinais PRT de comprimento $N=48$.
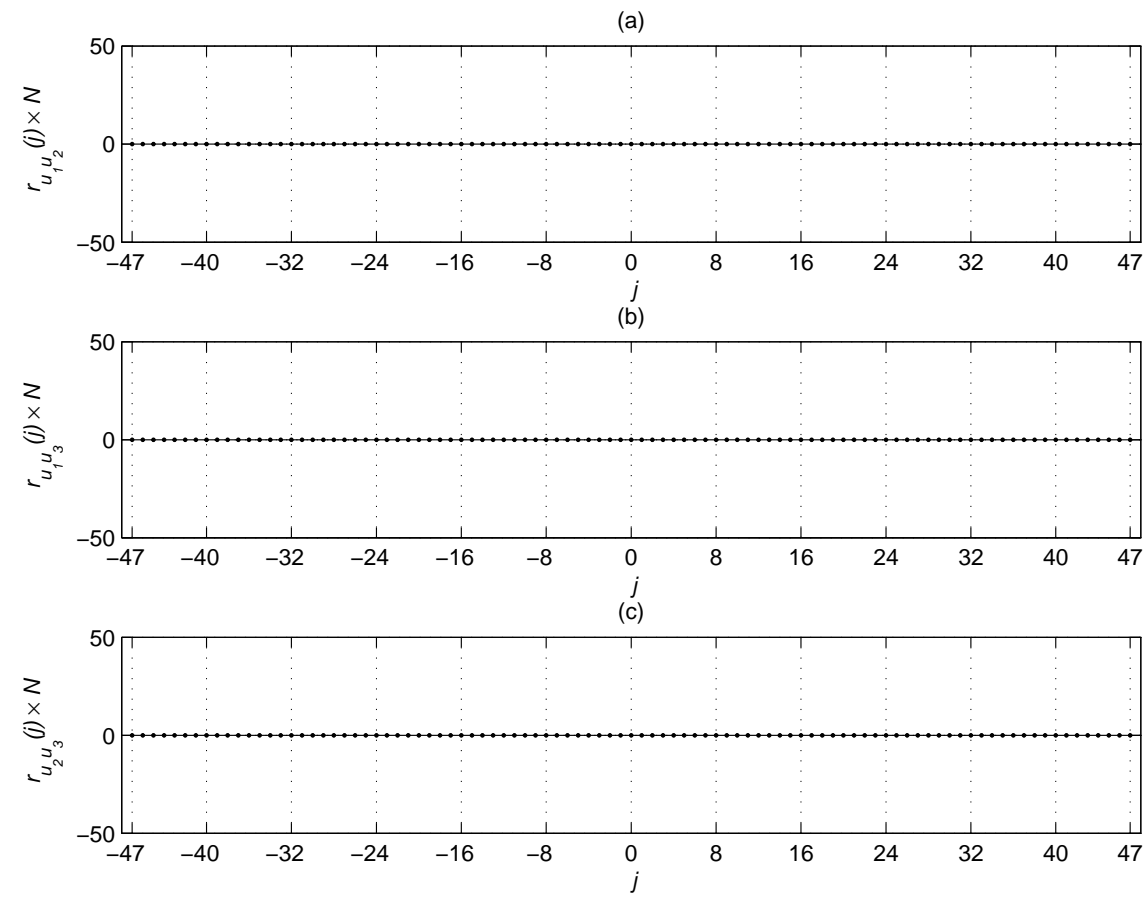

Figura 5.69: Função de correlação cruzada periódica entre os sinais PRT de comprimento $N=48$.

\subsubsection{Período do sinal de excitação e de chaveamento}

O período de chaveamento (clock period) do sinal de excitação $T_{c l k}$ é dado pelo menor período em que um sinal de excitação discreto em amplitude se mantém constante. É 
intuitiva a conclusão de que quanto maior o período de chaveamento maior potência é direcionada às frequências mais baixas. Neste capítulo, foram discutidos métodos de geração de sinais de excitação. Em vários métodos parte-se da especificação do espectro de frequências desejado para obter o sinal de excitação como resultado, como é o caso dos sinais discutidos nas seções 5.1 e 5.2. Nesses métodos, tem-se um sinal no domínio do tempo cujo período de chaveamento $T_{c l k}$ não é especificado, mas resultado do método de construção do sinal. Para os métodos em que não há especificação do espectro desejado como entrada do algoritmo de construção, como os métodos de construção de sinais de espectro fixo discutidos nesta seção, o sinal de excitação obtido deve ter o período de chaveamento $T_{c l k}$ ajustado para aproximar seu espectro do desejado. Tais sinais são chamados de sinais de espectro fixo. A seção D apresenta como o período de chaveamento influencia o espectro de potência do sinal de excitação.

Há dois aspectos a serem observados na determinação do período de chaveamento do sinal de excitação. Um deles é o espectro de frequência do sinal. O período de chaveamento deve ser escolhido de forma a privilegiar as frequências críticas para a identificação. O outro aspecto é a resposta do sistema no domínio do tempo. Observase que para um período de chaveamento reduzido, o espectro do sinal não será privilegiado nas frequências baixas, tendendo a um espectro plano dependendo da aleatoriedade do sinal. Porém, um sinal com período de chaveamento extremamente reduzido comparado à constante de tempo do sistema excitado poderá não ter energia suficiente em frequências baixas para provocar alterações significativas na saída do sistema, dificultando sua identificação. Em um caso limite a saída não irá sofrer alterações com a excitação extremamente rápida. Em outras palavras o sistema não terá tempo responder à excitação, o que não é desejável, conforme o critério 4 discutido na seção 3.3. Por outro lado, o período de chaveamento extremamente longo comparado à constante de tempo do sistema excitado se assemelhará a excitações em degrau, as quais não são ótimas para muitos casos de identificação. Em outras palavras, o experimento será equivalente a excitações degrau seguidas e nenhum ganho devido às propriedades pseudo-aleatórias do sinal para identificação das dinâmicas de maior frequência será alcançado.

Resumidamente, o período de chaveamento deve ser suficientemente longo para dar tempo ao sistema responder à excitação, mas deve ser curto demais de forma que o sistema não atinja o regime permanente como na excitação em degrau (AGUIRRE, 2007).

Adicionalmente, em identificação multivariável, ao definir o período de chaveamento dos sinais de excitação de espectro fixo, ele deve ser exatamente o mesmo para todos os sinais para que as propriedades de correlação cruzada das sequências que ori- 
ginaram os sinais sejam mantidas. Assim, para definir o período de chaveamento $T_{c l k}$, deve-se obter o maior e o menor tempo de acomodação do sistema:

$$
\begin{aligned}
T_{\max }^{\text {set }} & =\max _{r, 1 \leq r \leq n_{n_{r}}} T_{\text {max }, r}^{\text {set }} \\
T_{\min }^{\text {set }} & =\max _{r, 1 \leq r \leq n_{n_{r}}} T_{\min , r}^{\text {set }}
\end{aligned}
$$

onde $T_{\max , r}^{\text {set }}$ e $T_{\min , r}^{\text {set }}$ estão definidos em (3.6) e, consequentemente:

$$
\begin{aligned}
\tau_{\max } & =\frac{T_{\max }^{\text {set }}}{\beta_{s}} \\
\tau_{\min } & =\frac{T_{\min }^{\text {set }}}{\beta_{s}}
\end{aligned}
$$

e $B W=\left\{\omega_{L} ; \omega_{H}\right\}$ com:

$$
\omega_{L}=\frac{1}{\beta_{s} \tau_{\max }} \leq \omega \leq \frac{\alpha_{s}}{\tau_{\min }}=\omega_{H}
$$

Em (AGUIRRE, 2007) sugere-se heuristicamente que o período de chaveamento seja escolhido conforme:

$$
\frac{\tau_{\min }}{10} \leq T_{c l k} \leq \frac{\tau_{\min }}{3}
$$

Ou (AGUIRRE, 2007):

$$
3 T \leq T_{c l k} \leq 5 T
$$

Observa-se que considerando a frequência de amostragem $f$ igual a 15 vezes a maior frequência de interesse do sistema estimada $f_{H} \approx \frac{1}{\tau_{\min }}$, tem-se:

$$
\begin{aligned}
\frac{1}{T}=f=15 f_{H} & \approx \frac{15}{\tau_{\min }} \\
T & \approx \frac{\tau_{\min }}{15}
\end{aligned}
$$

Com esse parâmetro para o período de amostragem $T$ e (5.92), obtém-se resultado semelhante a (5.91): 


$$
\frac{\tau_{\min }}{5} \leq T_{c l k} \leq \frac{\tau_{\min }}{3}
$$

Pode-se escolher o período de chaveamento mais próximo do limite inferior ou do limite superior de (5.91) dependendo do espectro da excitação que se deseja, conforme mencionado anteriormente. Em (AGUIRRE, 2007), afirma-se que bons resultados na identificação de sistema lineares são obtidos com o período de chaveamento próximo do limite inferior. Na identificação de sistemas não lineares, bons resultados são obtidos com o período de chaveamento próximo do limite superior.

Um sinal associado a um segurador de ordem zero (zero-order holder, $\mathrm{ZOH}$ ) possui aproximadamente a metade de sua energia no primeiro lóbulo de seu espectro que corresponde ao intervalo $-f_{c l k}<f<f_{c l k}=1 / T_{c l k}$, onde $f_{c l k}$ é a frequência de chaveamento do sinal de excitação (OPPENHEIM; SCHAFER, 1999). O espectro do sinal associado ao ZOH é mostrado no apêndice D. Para que a maior frequência de interesse do sistema seja garantidamente excitada, pode-se adotar a frequência de chaveamento pelo menos duas vezes maior que a maior frequência de interesse do sistema $\omega_{H}=2 \pi f_{H}$. Assim:

$$
\begin{aligned}
f_{c l k} & \geq 2 f_{H} \\
\frac{1}{T_{c l k}} & \geq 2 \frac{\omega_{H}}{2 \pi} \\
T_{c l k} & \leq \frac{\pi}{\omega_{H}} \\
T_{c l k} & \leq \pi \frac{\tau_{\min }}{\alpha_{s}}
\end{aligned}
$$

Para ser mais restritivo, pode-se adotar como limite o período de chaveamento $T_{c l k}$ com valor 10\% menor, ou seja, uma frequência de chaveamento 11,11\% maior. Assim, obtém-se a mesma restrição para o tempo de chaveamento de sinais PRB apresentada em (GAIKWAD; RIVERA, 1996):

$$
\begin{aligned}
T_{c l k} & \leq \pi \frac{\tau_{\min }}{\alpha_{s}} \\
T_{c l k} & \leq 0,9 \pi \frac{\tau_{\min }}{\alpha_{s}} \\
T_{c l k} & \leq \frac{2,8 \tau_{\min }}{\alpha_{s}}
\end{aligned}
$$

O caso SISO, foi apresentado anteriormente em (RIVERA; CHEN; BAYARD, 1993) e (RIVERA; GAIKWAD; CHEN, 1994): 


$$
\begin{gathered}
\omega_{L}=\frac{1}{\beta_{s} \tau} \leq \omega \leq \frac{\alpha_{s}}{\tau}=\omega_{H} \\
T_{c l k} \leq \frac{2,8 \tau}{\alpha_{s}}
\end{gathered}
$$

onde $\tau$ é a constante de tempo dominante do sistema SISO.

Na prática, o tempo de amostragem do sistema determinado pelo DCS é constante, conforme explanado no apêndice C. Assim, o período de chaveamento será múltiplos do período de amostragem dada a restrição (5.96). O apêndice D apresenta como o período de chaveamento influencia o espectro do sinal de excitação.

O limite inferior para o período do sinal de excitação de forma a garantir que as frequências baixas próximas a $\omega_{L}$ sejam excitadas, conforme (3.13), será:

$$
\begin{aligned}
T_{N} & \geq 2 \pi \beta_{s} \tau_{\max } \\
N \times T_{c l k} & \geq 2 \pi \beta_{s} \tau_{\max } \\
N & \geq \frac{2 \pi \beta_{s} \tau_{\max }}{T_{c l k}}
\end{aligned}
$$

Esse limite foi apresentado em (GAIKWAD; RIVERA, 1996) para sinais PRB em identificação em malha fechada. O caso SISO, foi apresentado anteriormente em (RIVERA; CHEN; BAYARD, 1993) e (RIVERA; GAIKWAD; CHEN, 1994):

$$
N \geq \frac{2 \pi \beta_{s} \tau}{T_{c l k}}=\frac{\pi \alpha_{s} \beta_{s}}{1,4}
$$

Os critérios (5.96), (5.98), (5.99) e (5.100) podem ser aplicados a qualquer sinal de excitação de espectro fixo, apesar de (GAIKWAD; RIVERA, 1996) (RIVERA; CHEN; BAYARD, 1993) e (RIVERA; GAIKWAD; CHEN, 1994) apresentá-los para parametrização de sinais PRB.

\subsubsection{Influência das funções de correlação dos sinais na duração do experimento}

Conforme a seção 3.3, um dos critérios de projeto de sinais de excitação para identificação multivariável é relativo à função de correlação cruzada dos sinais. Abaixo a transcrição do critério (2.45): 


$$
\begin{aligned}
& \min \left\{r_{\mathbf{u}_{r} \mathbf{u}_{s}}(k)\right\}, \quad \forall \mathbf{u}_{r}, \mathbf{u}_{s} \in\left\{\mathbf{u}_{1}, \mathbf{u}_{2}, \ldots, \mathbf{u}_{n_{r}}\right\}, \operatorname{com} r \neq s \mathrm{e} \\
& k \in\left\{-\max \left\{n_{1}, n_{2}, \ldots, n_{n_{r}}\right\}+1 ;+\max \left\{n_{1}, n_{2}, \ldots, n_{n_{r}}\right\}-1\right\}
\end{aligned}
$$

onde $n_{r}=\frac{T_{\text {max }, r}^{\text {set }}}{T}$ e $T$ o período de amostragem utilizado no experimento.

Conforme as seções 5.3.7 e 5.3.8 quando aumenta-se a quantidade de sinais $K_{s}$ não correlacionados em um conjunto, aumenta-se exponencialmente o comprimento $N$ dos sinais e, consequentemente, aumenta-se a duração do experimento. Essa característica não é desejável, visto que é requisito do experimento que ele seja executado em um tempo reduzido (seção 3.1).

No caso dos conjuntos de sinais PRB modulados por funções de Rademacher (seção 5.3.7), tem-se $N=\left(2^{n_{r}-1}\right)\left(2^{n}-1\right)$. No caso do conjunto de sinais PRT (seção 5.3.8), não há uma expressão analítica para $N$, pois esse depende da procura exaustiva de sequências primitivas com espectros intercalados. Porém, também observa-se o aumento exponencial de $N$ em relação a $K_{s}=n_{r}$.

Considerando que a resposta impulsiva de um sistema é não significativa para $t$ superior ao maior tempo de acomodação $\left(T_{\max }^{\text {set }}\right)$, a análise das funções de autocorrelação e correlação cruzada $r_{u_{r} u_{s}}(j)$ em (2.41) se restringem apenas ao intervalo $-\frac{T_{\max }^{\text {set }}}{T_{c l k}}-1 \leq$ $j \leq \frac{T_{\max }^{\text {set }}}{T_{c l k}}-1$.

Assim, sinais com função de correlação do tipo $r_{u u}\left(j \frac{T_{c l k}}{T}\right) \approx 0$, para $j \neq 0(\bmod N)$, como os sinais QRB, QRT, HAB, TPB e PRB, podem ser copiados e atrasados (deslocados ciclicamente conforme a equação (3.24)) para excitar as $n_{r}$ entradas da planta. Observa-se que a função de autocorrelação periódica será máxima apenas quando os sinais estão em fase $(j=0, \pm N, \pm 2 N, \ldots)$. Assim, ajustando os deslocamentos cíclicos de $n_{r}$ cópias dos sinais (um para cada entrada) de forma que os deslocamentos relativos entre os sinais sejam $\pm D \geq \frac{T_{\max }^{\text {set }}}{T_{c l k}}$ deslocamentos, ter-se-á:

$$
\begin{aligned}
& u_{1}(i)=u(i) \\
& u_{2}(i)=u\left(i+D \frac{T_{c l k}}{T}\right) \\
& u_{3}(i)=u\left(i+2 D \frac{T_{c l k}}{T}\right) \\
& u_{4}(i)=u\left(i+3 D \frac{T_{c l k}}{T}\right) \\
& u_{r}(i)=u\left(i+(r-1) D \frac{T_{c l k}}{T}\right)
\end{aligned}
$$




$$
u_{n_{r}}(i)=u\left(i+\left(n_{r}-1\right) D \frac{T_{c l k}}{T}\right)
$$

onde $r_{u_{r} u_{r}}(j)=r_{u u}(j)$ e $r_{u_{r} u_{v}}\left(j \frac{T_{c l k}}{T}\right)=0$ para $j \neq 0(\bmod D)$ e $j \neq 0(\bmod N)$, caso contrário $r_{u_{r} u_{v}}\left(j \frac{T_{c l k}}{T}\right)=r_{u u}(0)$.

Em resumo, para se obter um conjunto de sinais conforme (5.102) com as características de correlação descritas, deve-se ter:

$$
\begin{aligned}
& D \geq \frac{T_{\max }^{\text {set }}}{T_{c l k}} \\
& N \geq n_{r} D \geq n_{r} \frac{T_{\text {max }}^{\text {set }}}{T_{c l k}}
\end{aligned}
$$

Uma forma sistemática para a escolha de $D$ dado $N$ é:

$$
D=\frac{N}{n_{r}}
$$

Os conjuntos de sinais para identificação multivariável construídos por meio de cópias deslocadas ciclicamente de sinais QRB, QRT, HAB, TPB e PRB serão chamadas neste trabalho de conjunto shift-QRB, shift-QRT, shift-HAB, shift-TPB e shift$\mathrm{PRB}$, respectivamente. Pode-se obter também conjuntos shift-PRML por meio de cópias deslocadas ciclicamente de sinais PRML. Porém, sinais PRML não possuem a caractetística de correlação $r_{u u}\left(j \frac{T_{c l k}}{T}\right) \approx 0$, para $j \neq 0(\bmod N)$. Devido à supressão de harmônicas pares, tem-se $r_{u u}\left(j \frac{T_{c l k}}{T}\right) \approx 0$, para $j \neq 0(\bmod N)$ e $j \neq \frac{N}{2}(\bmod N)$. Neste caso, deve-se adotar $D=\frac{N}{2 n_{r}}$ ao invés de (5.104).

Observa-se que essa forma de escolher os sinais das $n_{r}$ entradas não contribui para a redução do tempo do experimento $T_{e}=N \times T_{c l k}=n_{r} \times D \times T_{c l k}$ em relação à identificação realizada individual e sequencialmente entrada por entrada do sistema. Caso as entradas fossem excitadas individualmente, cada uma com um sinal de comprimento $D \times T_{c l k}$, o tempo total do experimento também seria $T_{e} \approx n_{r} \times D \times T_{c l k}$.

Uma das vantagens da identificação multivariável é que durante toda a duração do experimento $T_{e}$ são coletados dados referentes a todas as entradas e saídas da planta. Assim, o experimento torna-se mais informativo. Adicionalmente, pode-se permitir alguma correlação entre as excitações nas entradas do sistema de forma reduzir o tempo do experimento, fazendo $N \leq n_{r} D$. 


\subsubsection{Parametrização de sinais de espectro fixo}

Seja a planta com parâmetros definidos na tabela 5.2. Deseja-se identificar o sistema excitando 3 entradas simultaneamente. Dessa forma, é necessário projetar um conjunto de 3 sinais de excitação não correlacionados com características que os façam capazes de excitar toda a faixa de frequências de interesse do sistema, definida por $\omega_{L}$ e $\omega_{H}$.

Utilizando a restrição de (GAIKWAD; RIVERA, 1996) para escolha do período de chaveamento dada pela equação (5.96), tem-se:

$$
\begin{aligned}
T_{c l k} & \leq \frac{2,8 \tau_{\min }}{\alpha_{s}} \\
T_{c l k} & \leq \frac{2,8 \times 5 \times 60}{2} \\
T_{c l k} & \leq 420 \text { segundos }
\end{aligned}
$$

Adotando período de amostragem $T=60$ segundos, tem-se uma frequência de amostragem mais de 10 vezes maior que a maior frequência de interesse do sistema, ou seja, $\frac{1}{60}=0,0167>>\frac{\omega_{H}}{2 \pi}=0,0011 \mathrm{~Hz}$. Para esse período de amostragem, observase que o maior valor para o período de chaveamento será $T_{c l k} \leq 420=7 T$ segundos. Para este exemplo, adotou-se $T_{c l k}=7 T=420$ segundos.

A restrição de (GAIKWAD; RIVERA, 1996) para escolha do período do sinal de excitação dada pela equação (3.13), no caso dessa planta (tabela 5.2) será:

$$
\begin{aligned}
& N \geq \frac{2 \pi \beta_{s} \tau_{\max }}{T_{c l k}} \\
& N \geq \frac{2 \pi 3 \times 33 \times 60}{7 \times 60} \\
& N \geq 88,86
\end{aligned}
$$

De acordo com a seção 5.3.8, o conjunto de sinais PRT com o menor comprimento $N$ maior que 88,86 é obtido a partir do corpo GF(7) com $m=3$, resultanto em $N=$ $7^{3}-1=342$.

As figuras 5.70a, 5.70b e 5.70c apresentam os sinais ternários $u_{1}(i), u_{2}(i)$ e $u_{3}(i)$, respectivamente, que formam o conjunto de sinais ortogonais de comprimento $N_{s}=$ $342 \times 7=2.394$, período de chaveamento $T_{c l k}=420$ segundos, com período de amostragem de $T=60$ segundos.

A figura 5.71 apresenta os espectros $\left|U_{1}(k)\right|,\left|U_{2}(k)\right|$ e $\left|U_{3}(k)\right|$ dos sinais multinível 

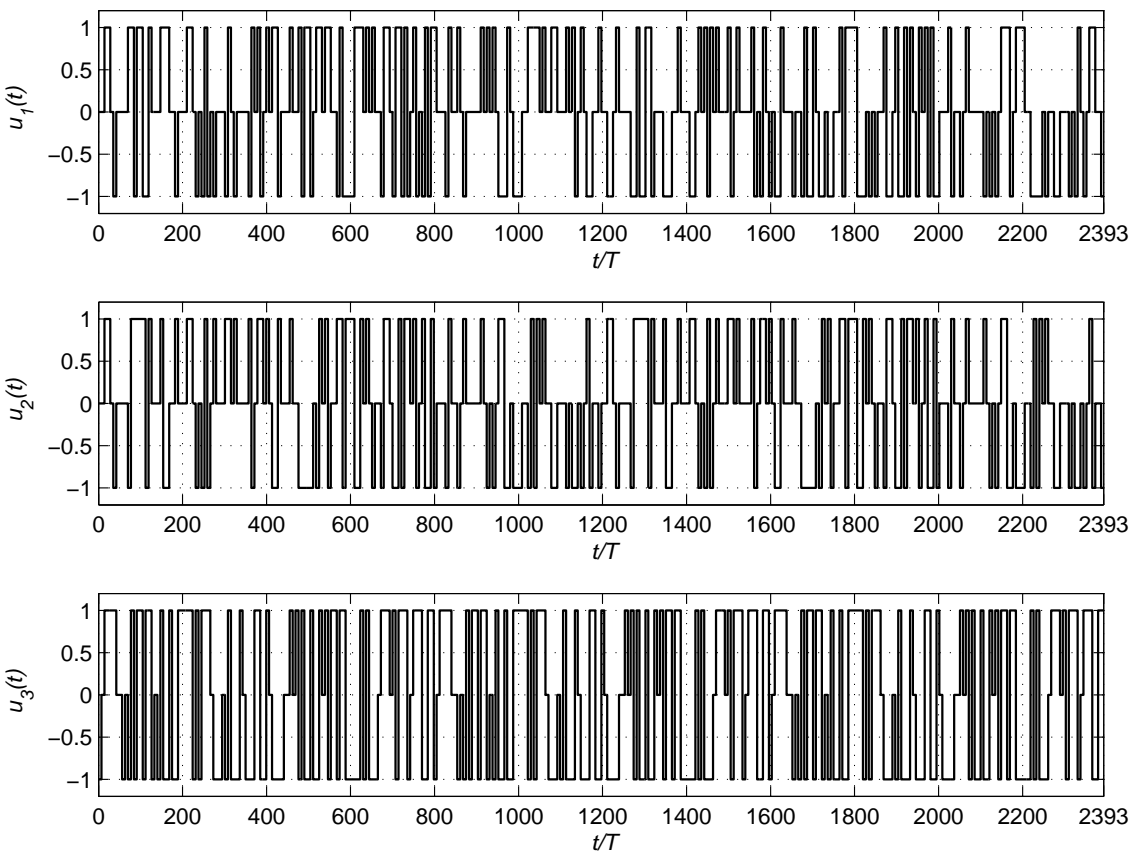

Figura 5.70: Conjunto de sinais PRT de comprimento $N_{s}=2.394$, período de chaveamento $T_{c l k}=420$ segundos, com período de amostragem de $T=60$ segundos.

$u_{1}(i), u_{2}(i)$ e $u_{3}(i)$, respectivamente.

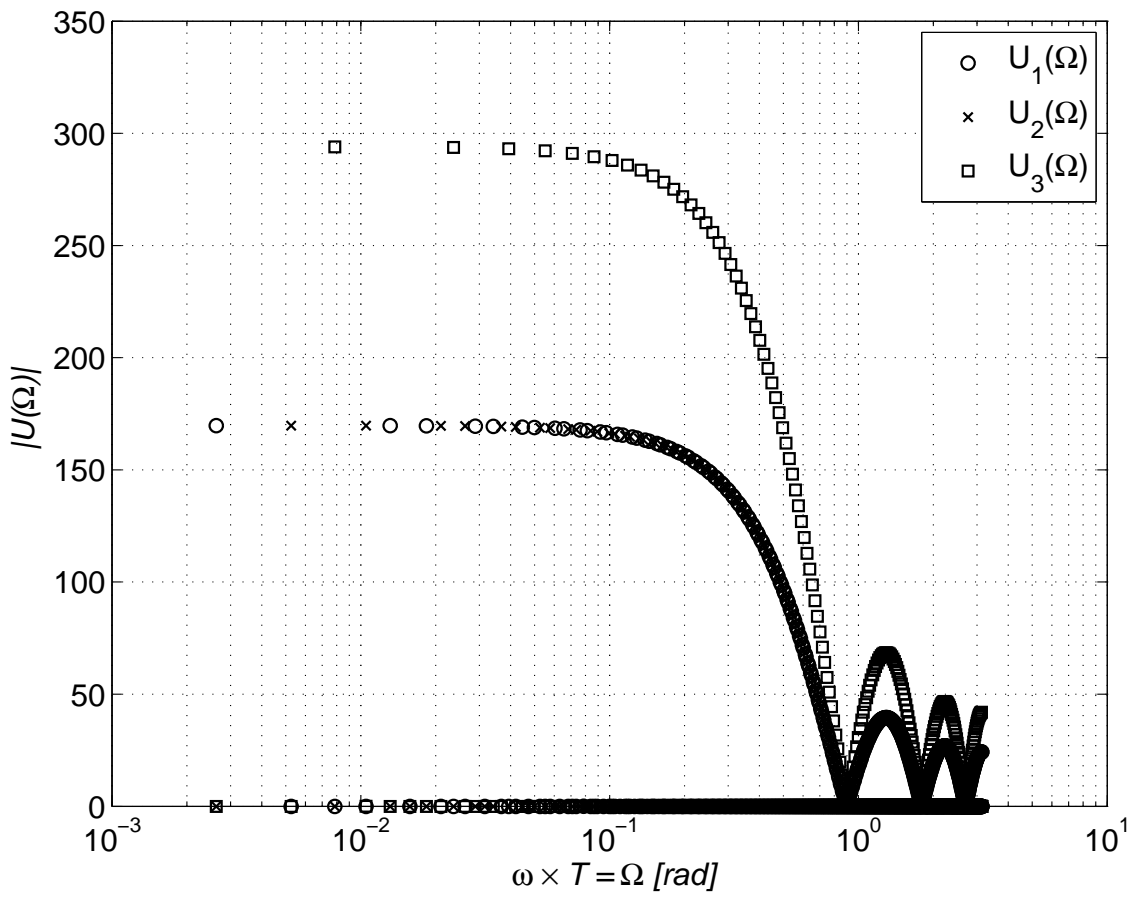

Figura 5.71: Módulo da DFT em escala logarítmica dos sinais PRT de comprimento $N_{s}=2.394$, período de chaveamento $T_{c l k}=420$ segundos, com período de amostragem de $T=60$ segundos.

Na figura 5.72 é possível verificar que a faixa de frequências de interesse do sistema, $\omega_{L} T=0,01$ radianos a $\omega_{H} T=0,4$ radianos, está sendo excitada com potência significativa. Observa-se que os harmônicos múltiplos de 6 são suprimidos nos 3 si- 
nais. Nas harmônicas em que há potência para um dos sinais, para os demais não há (detalhe da figura 5.73).

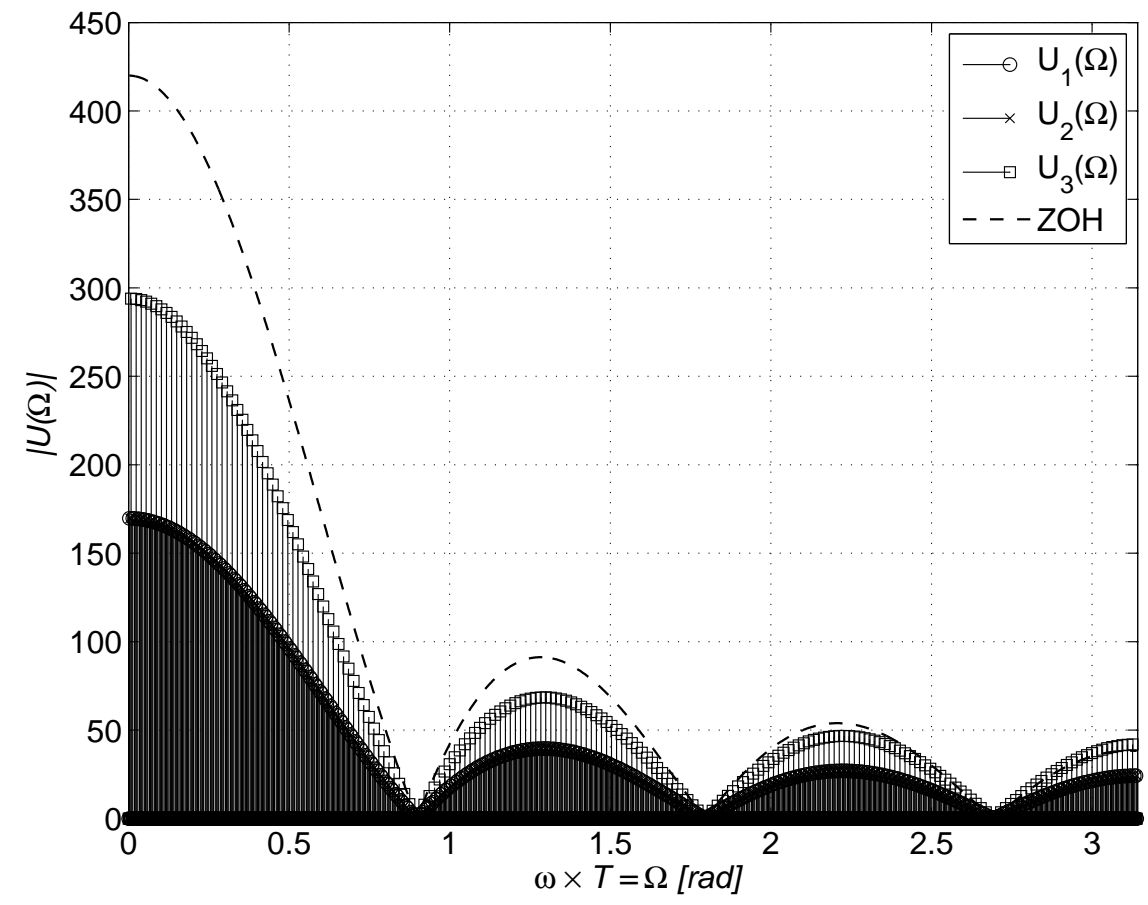

Figura 5.72: Módulo da DFT dos sinais PRT de comprimento $N_{s}=2.394$, período de chaveamento $T_{c l k}=420$ segundos, com período de amostragem de $T=60$ segundos.

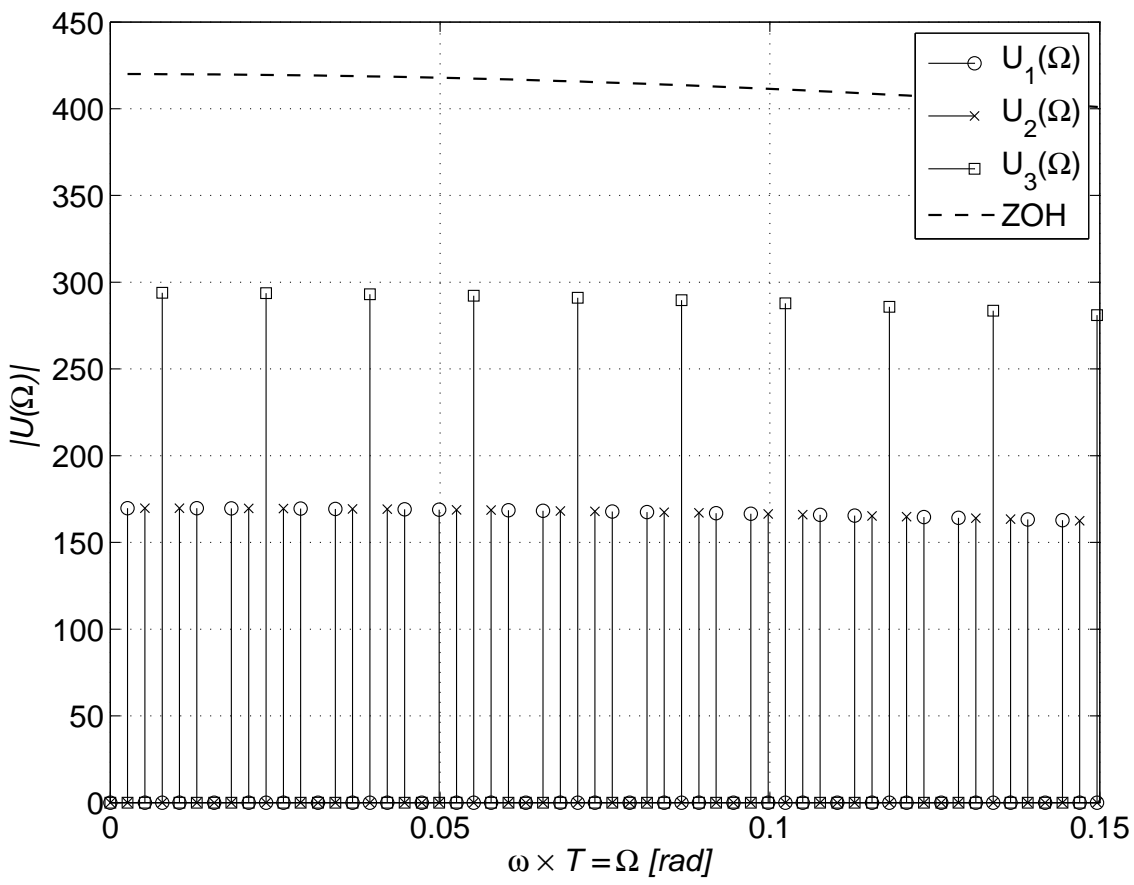

Figura 5.73: Detalhe do módulo da DFT dos sinais PRT: harmônicos múltiplos de 6 são suprimidos nos 3 sinais.

As figuras 5.74a, 5.74b e 5.74c apresentam as funções de autocorrelação periódica 
dos sinais ternários $u_{1}(i), u_{2}(i)$ e $u_{3}(i)$, respectivamente. Observa-se que a zona de correlação $Z_{C Z}=\frac{399 \times 60}{420}=57$ é maior que $\frac{T_{\text {max }}^{\text {set }}}{T_{c l k}}=\frac{165 \times 60}{420}=23,57$ e, portanto, a matriz de correlações $\mathbf{R}$ será diagonal, garantindo o atendimento ao critério (2.45) e a persistência da excitação.
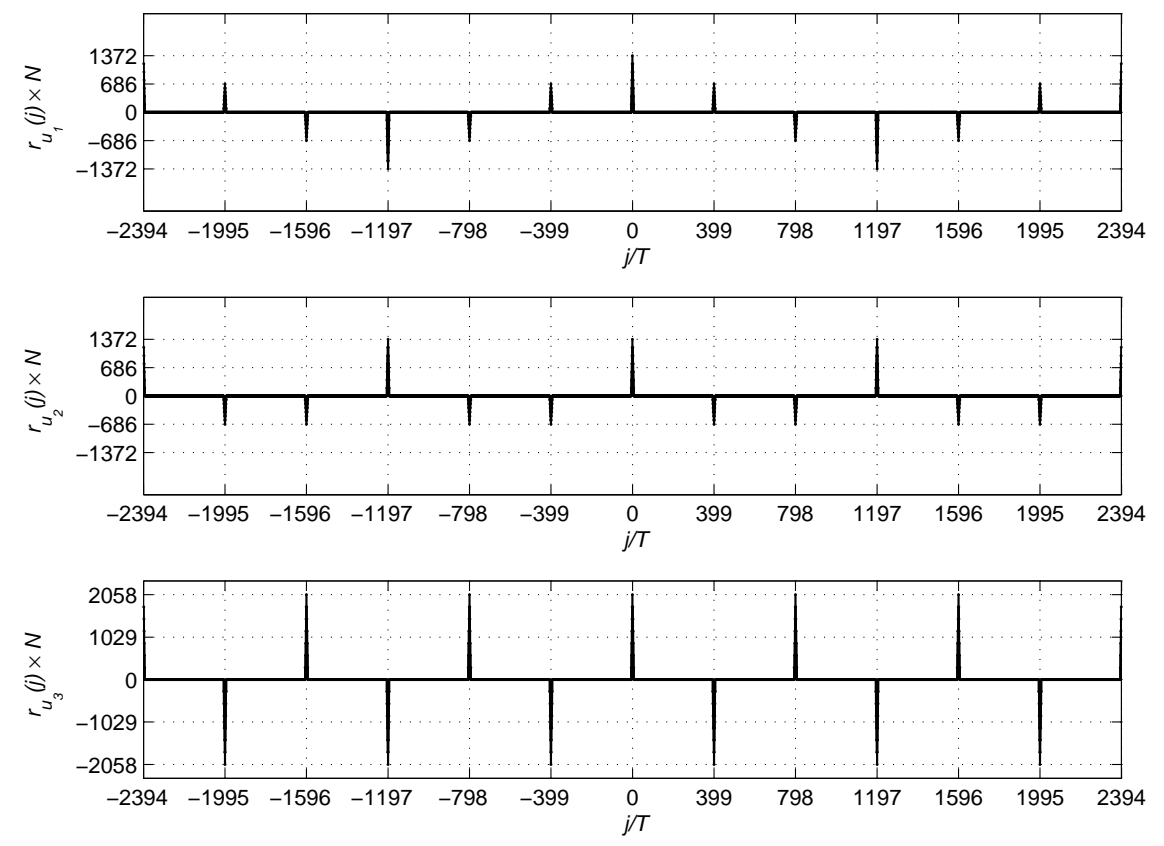

Figura 5.74: Função de autocorrelação periódica dos sinais PRT de comprimento $N_{s}=2.394$, período de chaveamento $T_{c l k}=420$ segundos, com período de amostragem de $T=60$ segundos.

A figura 5.75 apresenta a função de correlação cruzada entre os sinais ternários $u_{1}(i), u_{2}(i)$ e $u_{3}(i)$. Conforme mostrado na seção 5.3.8, as funções de correlação cruzada são nulas para qualquer valor de $j$, o que significa que os sinais ternários $u_{1}(i), u_{2}(i) \mathrm{e}$ $u_{3}(i)$ são ortogonais.

Os índices de desempenho para os três sinais PRT da figura 5.70, considerando o espectro do segurador de ordem zero $(\mathrm{ZOH})$ com $T_{c l k}=420$ segundos como espectro especificado no cálculo dos índices, são apresentados na tabela 5.10.

Outra forma de excitar as 3 entradas da planta simultaneamente com parâmetros definidos na tabela 5.2 é utilizando versões deslocadas ciclicamente de um sinal com boas propriedades de autocorrelação, conforme mostrado na equação (5.102) da seção 5.3.10.

Deseja-se utilizar o sinal PRML para que se houver distorções não lineares de ordem 2 essas possam ser detectadas e separadas, conforme apêndice B. Assim, o sinal PRML terá harmônicas múltiplas de 2 suprimidas.

Os limites para o período de chaveamento do sinal e para a duração do experimento 

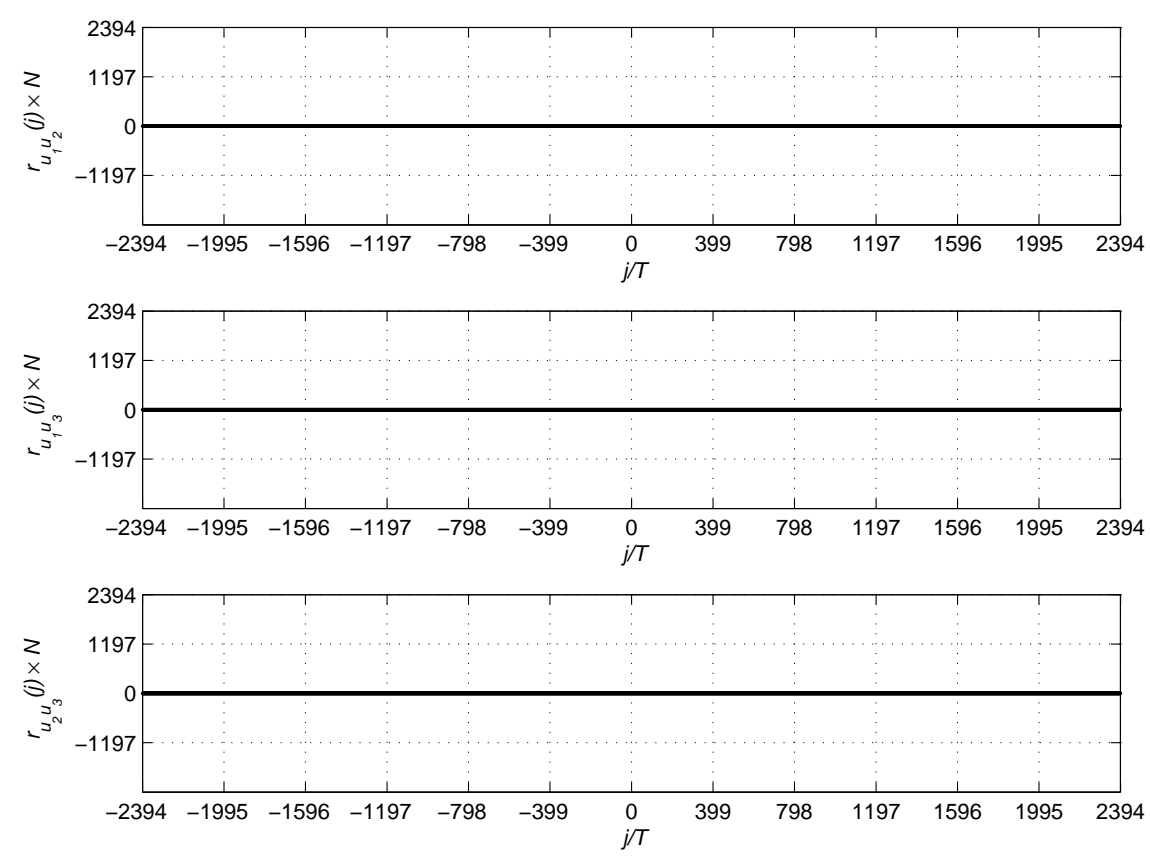

Figura 5.75: Função de correlação cruzada periódica entre os sinais PRT de comprimento $N_{s}=2.394$, período de chaveamento $T_{c l k}=420$ segundos, com período de amostragem de $T=60$ segundos.

estão definidos: $T_{c l k} \leq 420$ segundos e $N \geq 88,86$, respectivamente, para o período de amostragem de $T=60$ segundos.

O tempo de acomodação do sistema $T_{\max }^{\text {set }}$ será limitante para o deslocamento cíclico $D$, conforme equação (5.103):

$$
\begin{aligned}
D & \geq \frac{T_{\max }^{\text {set }}}{T_{c l k}} \\
D & \geq \frac{165 \times 60}{420} \\
D & \geq 23,57
\end{aligned}
$$

O sinal PRML com harmônicas múltiplas de 2 suprimidas e harmônicas ímpares uniformes possui função de autocorrelação periódica $r_{u u}(j)$ com picos em $j=0 \mathrm{e}$ $j=N / 2$.

O sinal PRML construído a partir do corpo estendido $G F\left(7^{3}\right)$, ou seja, $p=7$ e $m=3$ terá comprimento $N=p^{m}-1=7^{3}-1=342$ atendendo à restrição:

$$
\begin{aligned}
D & \leq \frac{N}{2 n_{r}} \\
D & \leq \frac{342}{6}
\end{aligned}
$$


Tabela 5.10: Índices de desempenho para os sinais PRT de comprimento $N_{s}=2.394$, período de chaveamento $T_{c l k}=420$ segundos, com período de amostragem de $T=60$ segundos.

\begin{tabular}{lll}
\hline Sinal & Índice & Valor \\
\hline$u_{1}(t)$ & PIPS & $75,70 \%$ \\
$u_{2}(t)$ & PIPS & $75,70 \%$ \\
$u_{3}(t)$ & PIPS & $92,72 \%$ \\
$u_{1}(t)$ & PIPSE & $74,59 \%$ \\
$u_{2}(t)$ & PIPSE & $74,59 \%$ \\
$u_{3}(t)$ & PIPSE & $91,35 \%$ \\
$u_{1}(t)$ & EMINE & $100 \%$ \\
$u_{2}(t)$ & EMINE & $100 \%$ \\
$u_{3}(t)$ & EMINE & $100 \%$ \\
$u_{1}(t)$ & TF & 0,8986 \\
$u_{2}(t)$ & TF & 0,8986 \\
$u_{3}(t)$ & TF & 0,5991 \\
$u_{1}(t)$ & CF & 1,3209 \\
$u_{2}(t)$ & CF & 1,3209 \\
$u_{3}(t)$ & CF & 1,0785 \\
\hline
\end{tabular}

$$
D \leq 57 \geq 23,57
$$

Neste exemplo, adota-se $D=57$. Assim, estão estabelecidos os parâmetros para o sinal PRML: período de amostragem $T=60$ segundos, período de chaveamento $T_{c l k}=420$ segundos, comprimento do sinal $N_{s}=2.394$ e deslocamento cíclico entre os 3 sinais dados por $D=57$. Foi escolhido mapeamento do sinal em 7 níveis, com $a=1$ e $b=3$, conforme seção 5.3.6. A duração do experimento será $T_{e}=2.394$ minutos.

As figuras 5.76a, 5.76b e 5.76c apresentam os sinais PRML $u_{1}(i), u_{2}(i)$ e $u_{3}(i)$, respectivamente. Observa-se que os sinais possuem 7 níveis: $\{-3 ;-1.5 ;-1 ; 0 ; 1 ; 1,5 ; 3\}$.

A figura 5.77 apresenta os espectros $\left|U_{1}(k)\right|,\left|U_{2}(k)\right|$ e $\left|U_{3}(k)\right|$ dos sinais PRML $u_{1}(i), u_{2}(i)$ e $u_{3}(i)$, respectivamente.

Na figura 5.78 é possível verificar que a faixa de frequências de interesse do sistema está sendo excitada com potência significativa, $\omega_{L} T=0,01$ radianos a $\omega_{H} T=$ 0,4 radianos. No detalhe da figura 5.79, observa-se que os harmônicos múltiplos de 2 são suprimidos, conforme especificado, e todos os sinais possuem exatamente o mesmo espectro, pois são cópias deslocadas ciclicamente de $D$ elementos.

As figuras 5.80a, 5.80b e 5.80c apresentam as funções de autocorrelação periódica dos sinais PRML $u_{1}(i), u_{2}(i)$ e $u_{3}(i)$, respectivamente.

A figura 5.81 apresenta a função de correlação cruzada entre os sinais multinível 

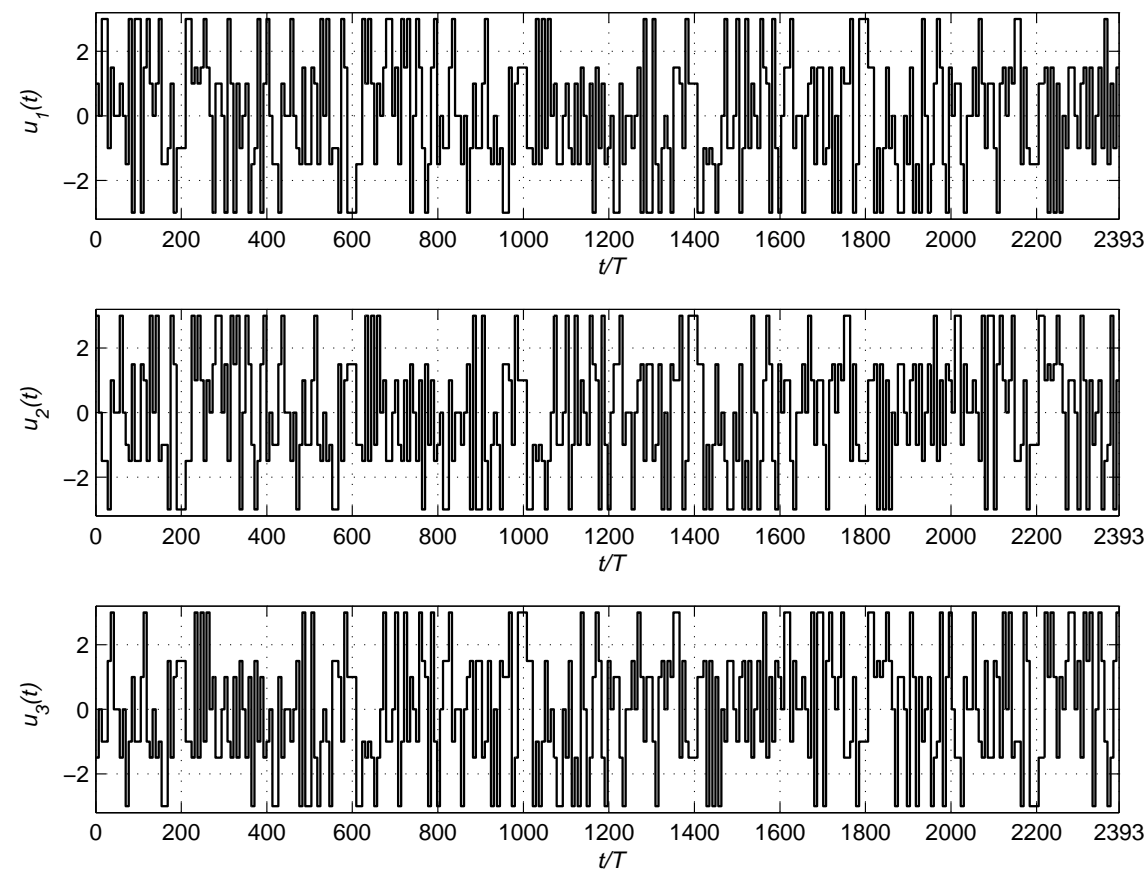

Figura 5.76: Conjunto de sinais PRML de comprimento $N_{s}=2.394$, com período de chaveamento $T_{c l k}=420$ segundos e período de amostragem de $T=60$ segundos.

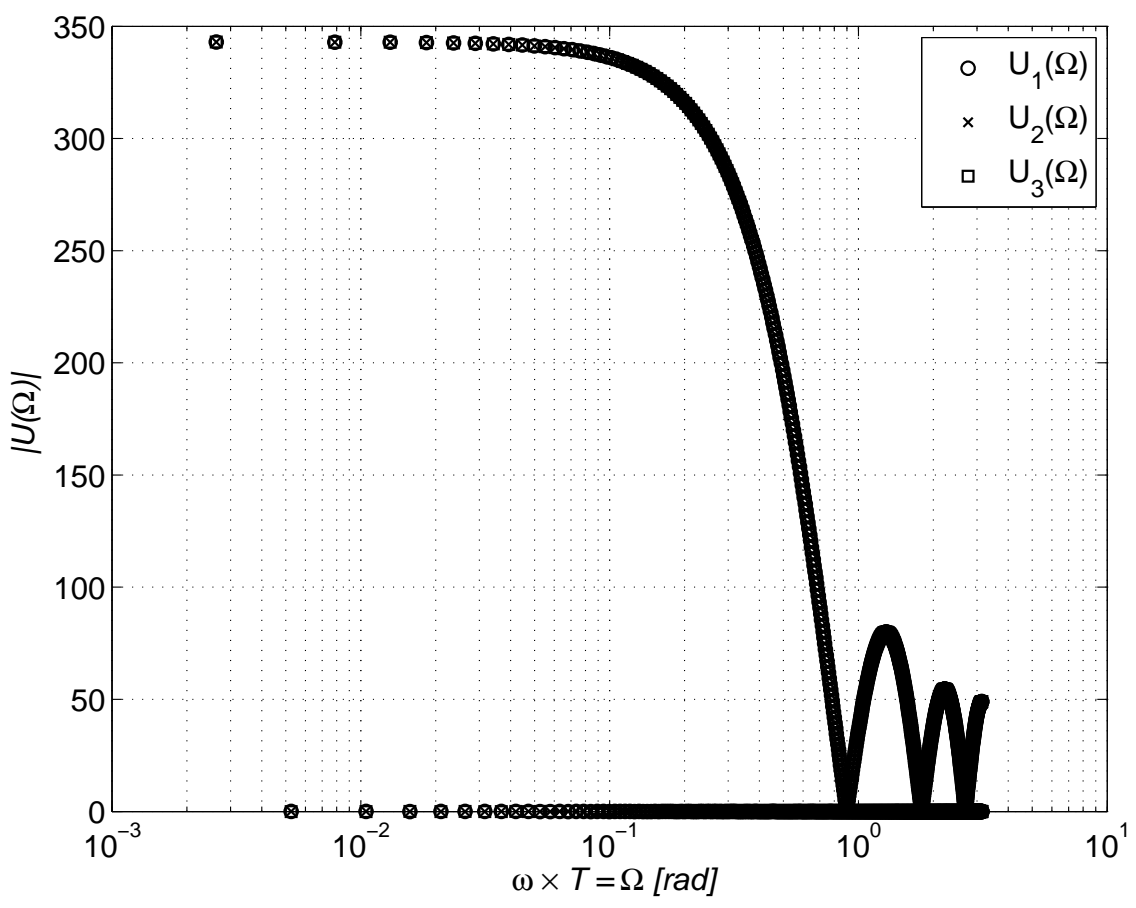

Figura 5.77: Módulo da DFT em escala logarítmica dos sinais PRML de comprimento $N_{s}=2.394$, com período de chaveamento $T_{c l k}=420$ segundos e período de amostragem de $T=60$ segundos.

$u_{1}(i), u_{2}(i)$ e $u_{3}(i)$. Conforme especificado, as funções de correlação cruzada são nulas para $|j| \leq D \times T_{c l k}=399$ minutos, e, portanto, a matriz de correlações $\mathbf{R}$ será diagonal, garantindo o atendimento ao critério (2.45) e a persistência da excitação. 


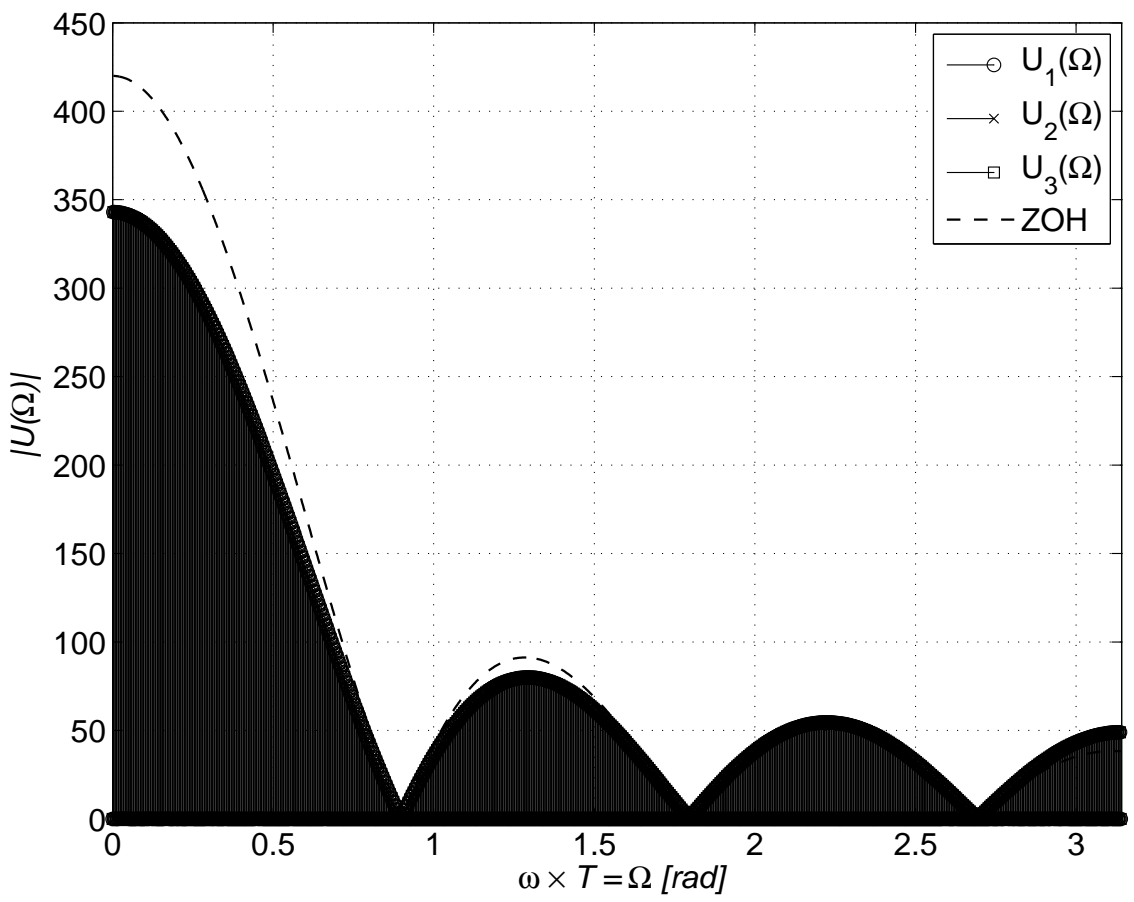

Figura 5.78: Módulo da DFT dos sinais PRML de comprimento $N_{s}=2.394$, com período de chaveamento $T_{c l k}=420$ segundos e período de amostragem de $T=60$ segundos.

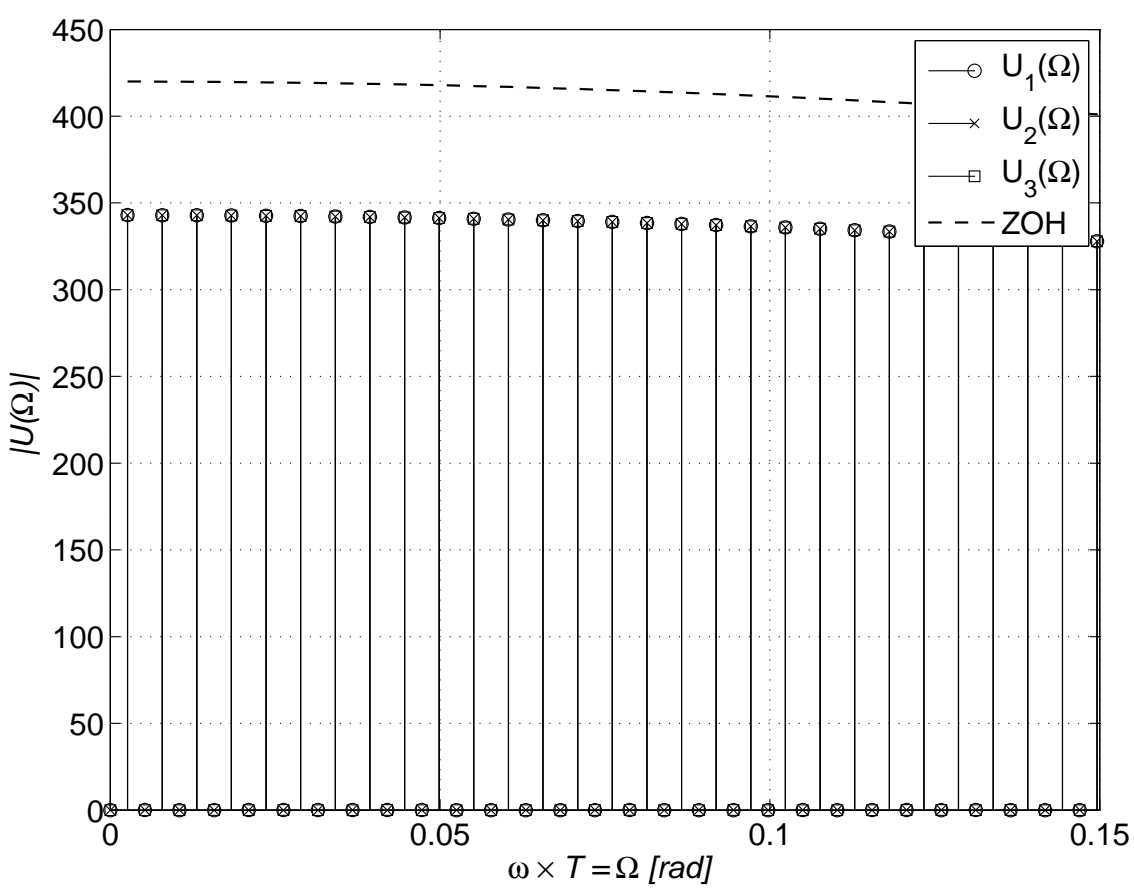

Figura 5.79: Detalhe do módulo da DFT dos sinais PRM: harmônicos múltiplos de 2 são suprimidos e os 3 sinais possuem exatamente o mesmo espectro.

Os índices de desempenho para os três sinais PRML da figura 5.76, considerando o espectro do segurador de ordem zero $(\mathrm{ZOH})$ com $T_{c l k}=420$ como espectro especificado no cálculo dos índices, são apresentados na tabela 5.11. Como os três sinais 

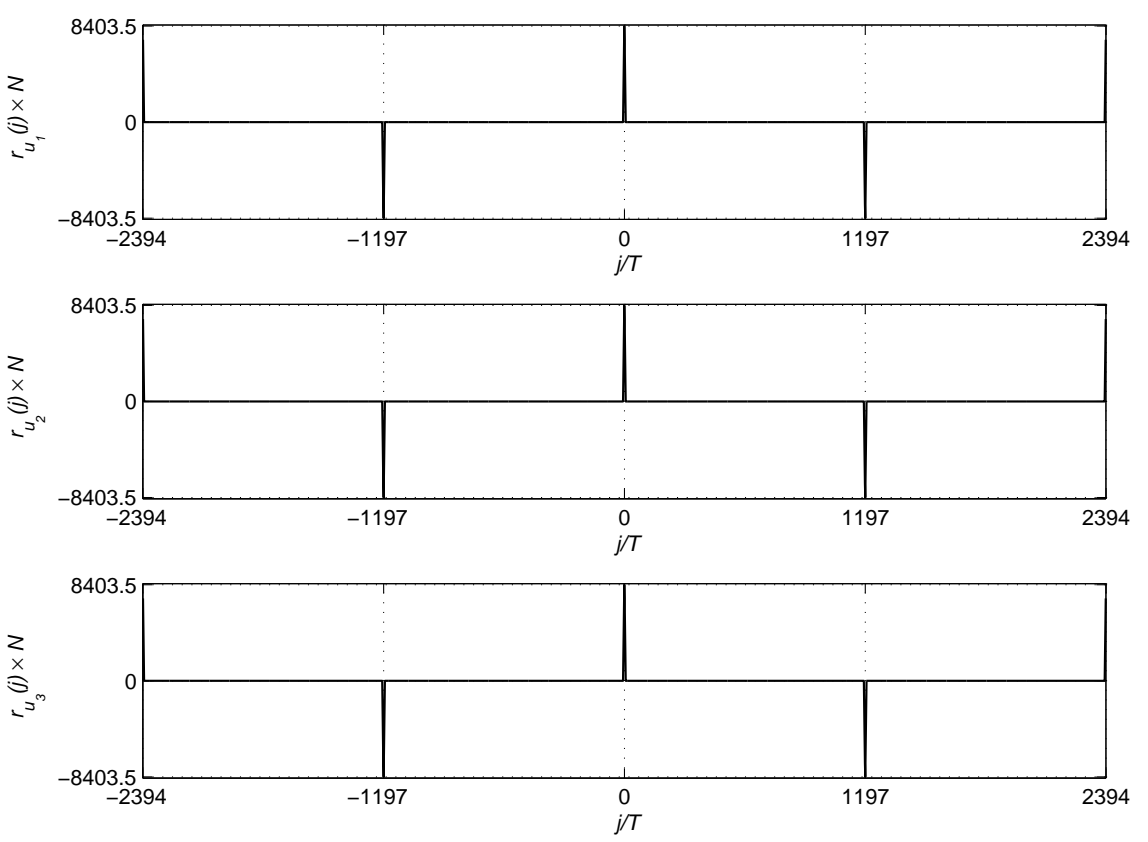

Figura 5.80: Função de autocorrelação periódica dos sinais PRML de comprimento $N_{s}=2.394$, com período de chaveamento $T_{c l k}=420$ segundos e período de amostragem de $T=60$ segundos.
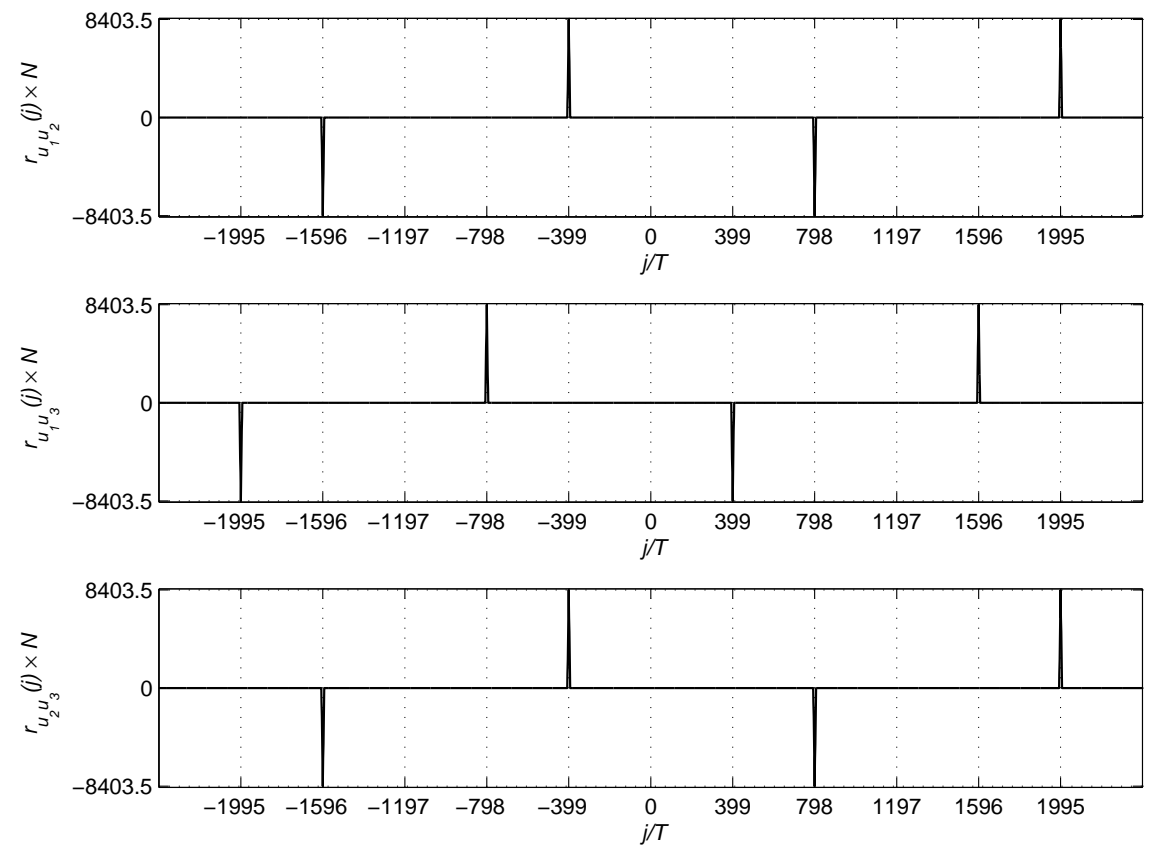

Figura 5.81: Função de correlação cruzada periódica entre os sinais PRML de comprimento $N_{s}=2.394$, com período de chaveamento $T_{c l k}=420$ segundos e período de amostragem de $T=60$ segundos.

diferem apenas de deslocamentos cíclicos, observa-se que cada um dos índices são iguais para os três sinais. Melhores valores para os índices são obtidos com menores amplitudes mantendo a potência do sinal. Assim, sinais PRML com menor quantidade de níveis tendem a resultar em melhores índices de desempenho. 
Tabela 5.11: Índices de desempenho para os sinais PRML de comprimento $N_{s}=2.394$, com período de chaveamento $T_{c l k}=420$ segundos e período de amostragem de $T=60$ segundos.

\begin{tabular}{lll}
\hline Sinal & Índice & Valor \\
\hline$u_{1}(t)$ & PIPS & $62,45 \%$ \\
$u_{2}(t)$ & PIPS & $62,45 \%$ \\
$u_{3}(t)$ & PIPS & $62,45 \%$ \\
$u_{1}(t)$ & PIPSE & $61,54 \%$ \\
$u_{2}(t)$ & PIPSE & $61,54 \%$ \\
$u_{3}(t)$ & PIPSE & $61,54 \%$ \\
$u_{1}(t)$ & EMINE & $100 \%$ \\
$u_{2}(t)$ & EMINE & $100 \%$ \\
$u_{3}(t)$ & EMINE & $100 \%$ \\
$u_{1}(t)$ & TF & 1,32 \\
$u_{2}(t)$ & TF & 1,32 \\
$u_{3}(t)$ & TF & 1,32 \\
$u_{1}(t)$ & CF & 1,60 \\
$u_{2}(t)$ & CF & 1,60 \\
$u_{3}(t)$ & CF & 1,60 \\
\hline
\end{tabular}

\subsection{Sinais híbridos e outros sinais}

Além dos sinais de excitação discutidos neste trabalho, há outros sinais propostos na literatura para identificação de sistemas. Porém, não foram discutidos aqui pois consistem de pequenas modificações dos sinais apresentados ou alguns de seus casos particulares e, portanto, com pouca contribuição para o estudo de sinais para identificação de sistemas.

Por exemplo, em (TAN; GODFREY; BARKER, 2005) foi apresentada uma forma híbrida de gerar sinais com supressão de harmônicas. Essa utiliza o método de gerar sinais MLMH combinado com o método de gerar sinais PRML. Os sinais gerados são chamados de sinais Gallev, nome resultante da contração de Galois e multilevel. O método em geral é semelhante ao que gera sinais PRML apresentado na seção 5.3.6. Assim como o método de gerar sinais PRT, a diferença reside no mapeamento da sequência primitiva $\mathbf{m}$. Conhecida a relação entre o espectro do sinal primitivo $m(i)$ e o espectro do sinal PRML $u(i)$ (equação (5.70)), o sinal primitivo é otimizado de forma a possuir as características espectrais desejáveis para o espectro do sinal resultante (sinal Gallev). A otimização do sinal primitivo é feita utilizando o algoritmo clipping, ou seja, o sinal primitivo $m(i)$ é exatamente um sinal MLMH. Assim, obtém-se o mapeamento da sequência primitiva $\mathbf{m}=\left\{m_{0}, m_{1}, \ldots, m_{q-2}\right\}$ no sinal primitivo MLMH $m(i)$ e, então, o sinal Gallev é obtido.

A vantagem dos sinais Gallev sobre os sinais MLMH é relativa à otimização de 
fases dos sinais $\mathrm{SOH}$ (por exemplo o algoritmo clipping, seção 5.2.1.2). Para os sinais Gallev de comprimento $N=q^{n}-1$ o algoritmo de otimização trata sequências primitivas MLMH de comprimento $q-1$. Comparativamente, otimizar fases de sinais $\mathrm{SOH}$ para gerar sinais MLMH de comprimento $N=q^{m}-1$ é um problema de otimização exponencialmente maior ao anterior. Essa característica torna os sinais Gallev uma alternativa aos sinais MLMH e também ao sinais PRML, onde são necessárias procuras exaustivas por mapeamentos de sequências primitivas sobre $G F(q)$ para elementos de $\mathbb{R}$.

Em (TAN; GODFREY, 2009) afirma-se que a proposta de (TAN; GODFREY; BARKER, 2005) é o único método de construção de sinais híbridos encontrado na literatura. No capítulo 6 é proposto um novo método para construção de sinais híbridos.

Na literatura, encontra-se uma grande quantidade de métodos de construção sinais para outras aplicações correlatas com a identificação de sistemas: equalização de canais de comunicação, radar, sistema de comunicação de múltiplo acesso por espalhamento espectral, criptografia, etc (GORDON; MILLS; WELCH, 1962) (GOLD, 1967) (KASAMI, 1968) (SCHOLTZ; WELCH, 1984). Cada uma dessas aplicações exigem características particulares para os sinais. No caso da identificação de plantas de processo, as características desejáveis foram apresentadas na seção 3.7 . 


\section{Propostas de projeto de conjuntos de sinais de excitação}

Neste capítulo são propostos dois métodos para construir conjuntos de sinais multinível com características apropriadas para identificação multivariável. Essas duas propostas são generalizações de métodos encontrados na literatura e apresentados no capítulo 5.

O principal requisito adicional aos sinais utilizados em identificação monovariável para aplicações em identificação multivariável é relativo às suas funções de correlação cruzada (2.45).

No capítulo 5 foram apresentados os seguintes métodos de construção de conjuntos de sinais para identificação multivariável:

1. Sinais aleatórios (BN e GBN) construídos com sementes distintas (seção 5.1);

2. Sinais do tipo SOH (Schroeder-SOH, clipping-SOH, DIB, DIT e MLMH) com espectros intercalados (seção 5.2.4);

3. Modulação de sinais binários pseudo-aleatórios (QRB, QRT, HAB, TPB e PRB) por funções de Rademacher (seção 5.3.7);

4. Conjunto de sinais ternários pseudo-aleatórios (PRT) (seção 5.3.8);

5. Cópias deslocadas ciclicamente de um mesmo sinal com característica pseudoaleatória (seção 5.3.10).

Na seção 5.3.7 foi apresentado o método proposto em (BRIGGS; GODFREY, 1966). Os autores apresentaram o método aplicável a construir conjuntos de sinais binários ou ternários pseudo-aleatórios não correlacionados. Tal método continua sendo utilizado e recomendado em trabalhos atuais (TAN; GODFREY, 2009). A proposta apresentada neste capítulo permite gerar sinais pseudo-aleatórios multinível não correlacionados, ou seja, com mais de 2 níveis, a partir de sinais PRML. Essa abordagem permite obter conjuntos de sequências de comprimento $N$ complementares aos obtidos com a proposta de (BRIGGS; GODFREY, 1966) e com sequências PRT (seção 5.3.8). Assim, há 
maior flexibilidade para gerar e utilizar conjuntos de sinais não correlacionados. Adicionalmente, os sinais multinível, diferentemente dos sinais binários, são eficazes na identificação em meio a distorções não lineares (apêndice B).

Ainda neste capítulo é apresentado um método alternativo de utilização dos sinais SOH ou PRT com espectros intercalados. Conforme a seção 5.2.1.1, o método analítico de Schroeder para obter sinais $\mathrm{SOH}$ resulta em CF em torno de 1,67, o qual se eleva quando espectro é esparso. Quanto maior a quantidade de sinais de excitação com espectros intercalados mais esparsos são seus espectros. Há propostas cujos objetivos são obter menores CF por meio de otimização das fases dos sinais SOH (seção 5.2.1.2). Porém, conforme discutido na seção 5.2.1.3, a utilização de algoritmo de otimização requer sua parametrização adequada, além de poder ser necessário tempo elevado de convergência para uma solução de CF reduzido. Com o método proposto neste capítulo, são obtidos sinais derivados de $\mathrm{SOH}$ com $\mathrm{CF}$ reduzidos. Esse método representa a generalização do método de construções de sinais Gallev (TAN; GODFREY; BARKER, 2005). A principal vantagem do método proposto em relação aos sinais SOH ou PRT é a redução do comprimento das sementes, conferindo mais rápida convergência do algoritmo de otimização de fases de sinais $\mathrm{SOH}$ ou mais rápida convergência do algoritmo de busca de sementes ortogonais. Adicionalmente, os comprimentos $N_{s}$ possíveis de serem obtidos com o método proposto são complementares aos comprimentos disponíveis dos sinais Gallev.

\subsection{Conjunto de sinais pseudo-aleatórios multinível or- togonais}

Na seção 5.3.7, foi descrito o método para construir conjuntos de sinais pseudo-aleatórios binários não correlacionados para identificação multivariável. Na literatura, além do método discutido na seção 5.3.8, encontram-se outros métodos para construir algebricamente conjuntos de sinais ternários (TAN; FOO, 2006) (TAN, 2007) (TAN; GODFREY, 2009) ou com mais níveis (WILSON, 1982). Nesta seção, propõe-se utilizar sinais PRML modificados para construir sinais multinível não correlacionados, intitulados neste trabalho de sinais pseudo-aleatórios multinível ortogonais (pseudorandom multilevel orthogonal signals, PRMO).

As sequências PRML, quando moduladas por funções de Rademacher, não resultam em um conjunto de sequências ortogonais, como ocorre com as sequências QRB, QRT, HAB, TPB e PRB. A seguir, são evidenciadas as características das sequências PRML que não permitem essa ortogonalidade. Posteriormente, são feitas modificações 
nas sequências PRML para possibilitar a ortogonalidade, quando moduladas por funções de Rademacher.

Seja uma sequência multinível $\mathbf{a}=\{a(i)\}=\{a(0) a(1) a(2) \ldots a(L-1)\}$ de comprimento $L=q^{m}-1$ obtida do mapeamento de uma SMC sobre $G F(q)$, com $q>2$ e $q$ primo, de comprimento $q^{m}-1$, conforme discutido na seção 5.3.6.

Considere as funções de Rademacher dadas pelas linhas $0,1,2,4, \ldots, 2^{p-1}$ da matriz Hadamard de dimensão $2^{p} \times 2^{p}$ (5.83). Seja $\mathbf{g}_{\mathbf{r}}=\left\{g_{r}(i)\right\}$, com $i=0,1,2, \ldots, 2^{p}-$ $1\left(\bmod 2^{p}\right)$, a sequência relativa à $r$-ésima linha da matriz de Hadamard de dimensão $2^{p} \times 2^{p}$.

As sequências resultantes da modulação das sequências PRML por funções de Rademacher serão:

$$
\mathbf{d}_{\mathbf{r}}=\left\{d_{r}(j)\right\}=\left\{g_{r}(j) a(j)\right\}
$$

de comprimento $N=2^{p} L$.

As funções de correlação cruzada dessas sequências são:

$$
\begin{aligned}
r_{d_{r} d_{s}}(k) & =\frac{1}{2^{p} L} \sum_{j=0}^{2^{p} L-1} d_{r}(j) d_{s}(j-k) \\
& =\frac{1}{2^{p} L} \sum_{j=0}^{2^{p} L-1} g_{r}(j) a(j) g_{s}(j-k) a(j-k) \\
& =\frac{1}{2^{p} L} \sum_{i=0}^{2^{p}-1} g_{r}(i) g_{s}(i-k) \sum_{j=0}^{L-1} a(j) a(j-k) \\
& =\frac{1}{2^{p}} \sum_{i=0}^{2^{p}-1} g_{r}(i) g_{s}(i-k) \frac{1}{L} \sum_{j=0}^{L-1} a(j) a(j-k) \\
& =r_{g_{r} g_{s}}(k) r_{a a}(k)
\end{aligned}
$$

Sequências PRML com harmônicas pares suprimidas têm função de autocorrelação $r_{a a}(k) \neq 0$ para $k=\frac{L}{2}(\bmod L)$ e sequências PRML com harmônicas pares e múltiplas de 3 suprimidas têm $r_{a a}(k) \neq 0$ adicionalmente para $k=\frac{L}{6}(\bmod L)$. De $(5.83)$, tem-se $r_{g_{r} g_{s}}(k) \neq 0$ para $k=0\left(\bmod 2^{p}\right)$.

Como $L=q^{m}-1$, $\operatorname{com} q>2$ e primo, tem-se que $q$ é ímpar e, portanto, $L=q^{m}-1$ é par. Assim, $2^{p}$ não é primo relativo de $L$. Consequentemente, $r_{d_{r} d_{s}}(k) \neq 0$ para, pelo menos, $k=r \times \operatorname{mmc}\left(L, 2^{p}\right)(\bmod N)$ e $k=r \times \operatorname{mmc}\left(\frac{L}{2}, 2^{p}\right)(\bmod N)$, com $r \in \mathbb{Z}$, no caso de sequências PRML com harmônicas pares suprimidas. O operador $\operatorname{mmc}(a, b)$ repre- 
senta o menor inteiro múltiplo de $a$ e $b$ simultaneamente (mínimo múltiplo comum).

Portanto, as sequências PRML de comprimento $L=q^{m}-1$ moduladas por funções de Rademacher não são ortogonais. O motivo da não ortogonalidade decorre de:

1. $r_{a a}(k) \neq 0$ para: $k=0(\bmod L), k=\frac{L}{2}(\bmod L)$, no caso de harmônicas pares suprimidas e, adicionalmente, $k \neq \frac{L}{6}(\bmod L)$, no caso de harmônicas pares e múltiplas de 3 suprimidas.

2. $L=q^{m}-1, \operatorname{com} q>2$ e primo, é par.

Em (DARNELL; FAN; JIN, 1995) foi apresentado um método que modifica as sequências pseudo-aleatórias multinível (PRML), obtidas a partir de SMC sobre $G F(q)$, com $q>2$ e $q$ primo. Essa modificação é tal que resulta em sequências PRML de comprimento $L$ ímpar e função de autocorrelação $r_{u u}(k)=0$ para $k \neq 0(\bmod L)$. Assim, as sequências PRML modificadas de (DARNELL; FAN; JIN, 1995) são perfeitamente adequadas à modulação por funções de Rademacher, com o objetivo de gerar conjuntos de sequências ortogonais. A seguir é apresentada a proposta de (DARNELL; FAN; JIN, 1995).

Seja uma sequência multinível $\mathbf{a}=\{a(i)\}=\{a(0) a(1) a(2) \ldots a(L-1)\}$ de comprimento $L=q^{m}-1$ obtida do mapeamento de uma SMC sobre $G F(q)$, com $q>2 \mathrm{e}$ $q$ primo, de comprimento $q^{m}-1$. Considere também a sequência $\mathbf{b}=\{b(i)\}=\left\{(-1)^{i}\right\}$. Em (DARNELL; FAN; JIN, 1995), para $M=\frac{L}{2}$ ímpar, foi mostrado que a função de autocorrelação da sequência:

$$
\mathbf{c}=\{c(i)\}=\{a(i) b(i)\}=\left\{(-1)^{j} a(i)\right\}, \quad \operatorname{com} i=0,1,2, \ldots, M-1(\bmod M)
$$

é $r_{c c}(k)=0$ para $k \neq 0 \bmod M$.

Considere as de funções Rademacher dadas pelas linhas $0,1,2,4, \ldots, 2^{p-1}$ da matriz Hadamard de dimensão $2^{p} \times 2^{p}$. Seja $\mathbf{g}_{\mathbf{r}}=\left\{g_{r}(i)\right\}, \operatorname{com} i=0,1,2, \ldots, 2^{p}-1\left(\bmod 2^{p}\right)$, a sequência relativa à $r$-ésima linha da matriz de Hadamard de dimensão $2^{p} \times 2^{p}$.

As sequências resultantes da modulação das sequências PRML modificadas (DARNELL; FAN; JIN, 1995) por funções de Rademacher são:

$$
\mathbf{d}_{\mathbf{r}}=\left\{d_{r}(i)\right\}=\left\{g_{r}(i) c(i)\right\}
$$

de comprimento $N=2^{p} M$.

As funções de correlação cruzada dessas sequências são: 


$$
\begin{aligned}
r_{d_{r} d_{s}}(k) & =\frac{1}{2^{p} M} \sum_{j=0}^{2^{p} M-1} d_{r}(j) d_{s}(j-k) \\
& =\frac{1}{2^{p} M} \sum_{j=0}^{2^{p} M-1} g_{r}(j) c(j) g_{s}(j-k) c(j-k) \\
& =\frac{1}{2^{p} M} \sum_{i=0}^{2^{p}-1} g_{r}(i) g_{s}(i-k) \sum_{j=0}^{M-1} c(j) c(j-k) \\
& =\frac{1}{2^{p}} \sum_{i=0}^{2^{p}-1} g_{r}(i) g_{s}(i-k) \frac{1}{M} \sum_{j=0}^{M-1} c(j) c(j-k) \\
& =r_{g_{r} g_{s}}(k) r_{c c}(k) \\
& =0
\end{aligned}
$$

pois $r_{g_{r} g_{s}}(k)=0$ para $k \neq 0\left(\bmod 2^{p}\right)$ e:

1. $r_{c c}(k)=0$ para $k \neq 0(\bmod M)$

2. $2^{p}$ é primo relativo de $M=\frac{L}{2}=\frac{q^{m}-1}{2}$, o qual é ímpar.

Assim, para obter $n_{r}$ sequências não correlacionadas a partir da sequência c, escolhese a matriz Hadamard de dimensão $2^{n_{r}-1} \times 2^{n_{r}-1}$ e as sequências $\mathbf{g}_{\mathbf{r}}$ dadas pelas linhas $0,1,2,4, \ldots, 2^{n_{r}-2}$ da matriz. As $n_{r}$ sequências pseudo-aleatórias multinível ortogonais (PRMO) são:

$$
\mathbf{d}_{\mathbf{r}}=\left\{d_{r}(j)\right\}=\left\{g_{r}(j) c(j)\right\}, \quad \operatorname{com} r=0,1,2, \ldots, n_{r}
$$

Observa-se que os comprimentos possíveis para as sequências, dados por $N=$ $2^{n_{r}-1}\left(\frac{q^{m}-1}{2}\right)$, são limitados, pois além de estarem relacionados com a quantidade $n_{r}$ de sequências no conjunto, $q$ e $m$ devem ser escolhidos de forma a $\frac{q^{m}-1}{2}$ ser ímpar. Por exemplo, para $q=3,7$ ou 11 , tem-se $m=3,5,7,9,11,13,15, \ldots$ Para $q=5$ não há $m$ que satisfaça $\frac{q^{m}-1}{2}$ ímpar, pois $5^{m}-1$ é múltiplo de 4 para qualquer $m>0$. Com $q=2$, tem-se $q^{m}-1$ ímpar e, portanto, a condição $\frac{q^{m}-1}{2}$ ímpar não é satisfeita.

A tabela 6.1 resume alguns exemplos de conjuntos de sequências PRMO possíveis de serem obtidos com o método descrito nesta seção.

Na seção 5.3.7 foi observada a limitação de comprimentos possíveis de sequências binárias não correlacionadas. As sequências PRMO propostas neste trabalho podem ser alternativas para excitação de sistemas lineares para o caso de não haver disponíveis sequências binárias com o comprimento $N$ requerido. 
Tabela 6.1: Alguns exemplos de conjuntos de sequências PRMO possíveis.

\begin{tabular}{cll|cccccc}
\hline \multirow{2}{*}{$q$} & $\begin{array}{l}\text { Quant. } \\
\text { de níveis }\end{array}$ & $m$ & \multicolumn{5}{|c}{ Comprimento $N$} & $2^{n_{r}-1}\left(\frac{q^{m}-1}{2}\right)$ para $n_{r}=$ \\
& & 1 & 2 & 3 & 4 & 5 & 6 \\
\hline 3 & 3 & 3 & 13 & 26 & 52 & 104 & 208 & 416 \\
3 & 3 & 5 & 121 & 242 & 484 & 968 & 1936 & 3872 \\
7 & 3,5 ou 7 & 3 & 171 & 342 & 684 & 1368 & 2736 & 5472 \\
7 & 3,5 ou 7 & 5 & 8403 & 16806 & 33612 & 67224 & 134448 & 268896 \\
11 & 3,5 ou 7 & 3 & 665 & 1330 & 2660 & 5320 & 10640 & 21280 \\
11 & 3,5 ou 7 & 5 & 80525 & 161050 & 322100 & 644200 & 1288400 & 2576800 \\
\hline
\end{tabular}

(a)

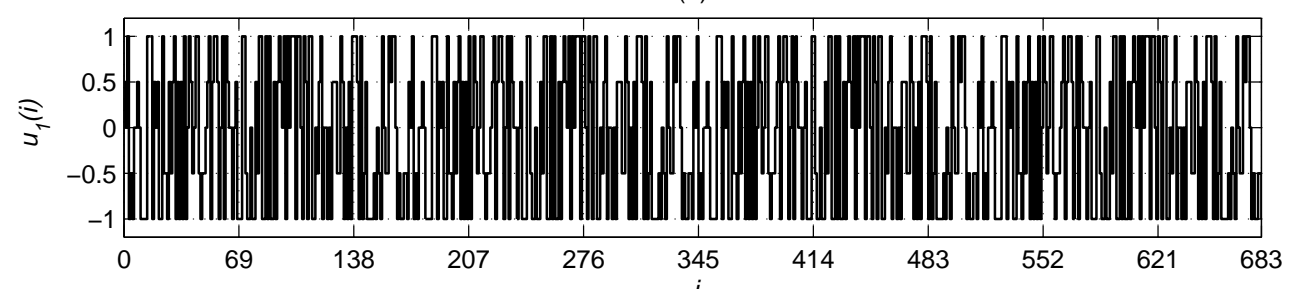

(b)

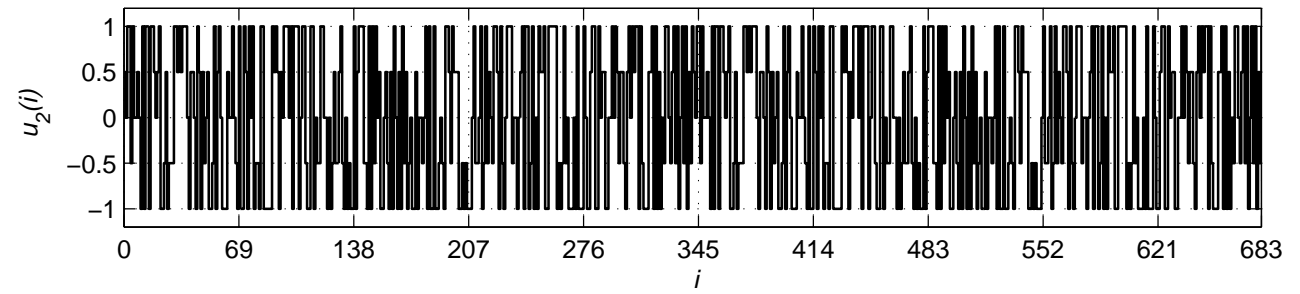

(c)

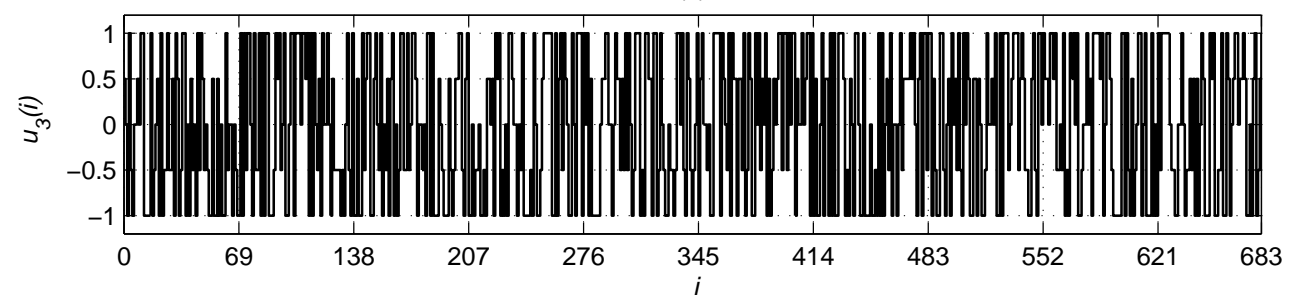

Figura 6.1: Conjunto de sequências PRMO de 5 níveis e de comprimento $N=684$.

As figuras 6.1a, 6.1b e 6.1c apresentam as sequências PRMO $u_{1}(i), u_{2}(i)$ e $u_{3}(i)$, respectivamente, construídas a partir do polinômio primitivo $x^{3}+3 x+2$ sobre o corpo $G F\left(7^{3}\right)$. O comprimento das 3 sequências será $N=684$. A figura 6.2 apresenta partes dos espectros $U_{1}(k), U_{2}(k)$ e $U_{3}(k)$ das sequências PRMO $u_{1}(i), u_{2}(i)$ e $u_{3}(i)$, respectivamente. Observa-se que as sequências possuem espectros intercalados (zippered power spectrum), onde as harmônicas não nulas possuem potência constante. Essa característica de potência constante não é garantida com a modulação por funções de Rademacher. Quando o número de sequências ortogonais $n_{r}$ é maior que 3, as harmônicas não nulas de $u_{n_{r}}$, com $n_{r} \geq 4$, não têm potência constante.

As figuras $6.3 \mathrm{a}, 6.3 \mathrm{~b}$ e $6.3 \mathrm{c}$ apresentam as funções de autocorrelação periódica das sequências PRMO $u_{1}(i), u_{2}(i)$ e $u_{3}(i)$, respectivamente. 


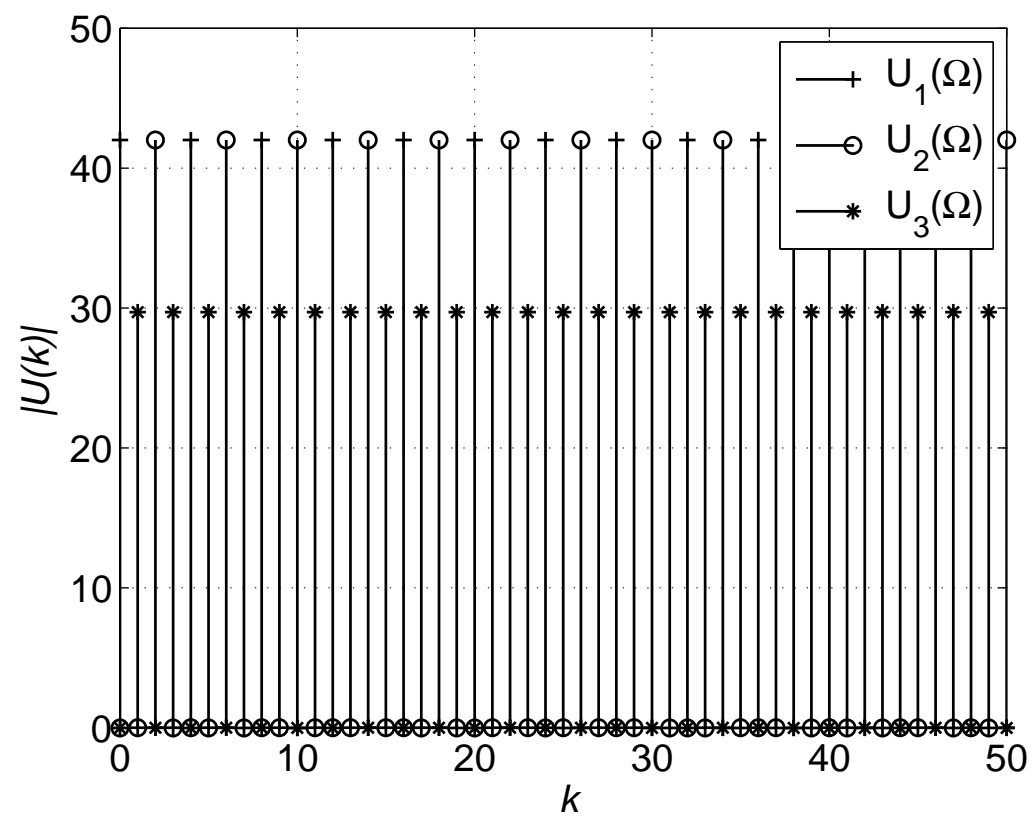

Figura 6.2: Módulo da DFT das sequências PRMO de 5 níveis e de comprimento $N=684$ do conjunto.
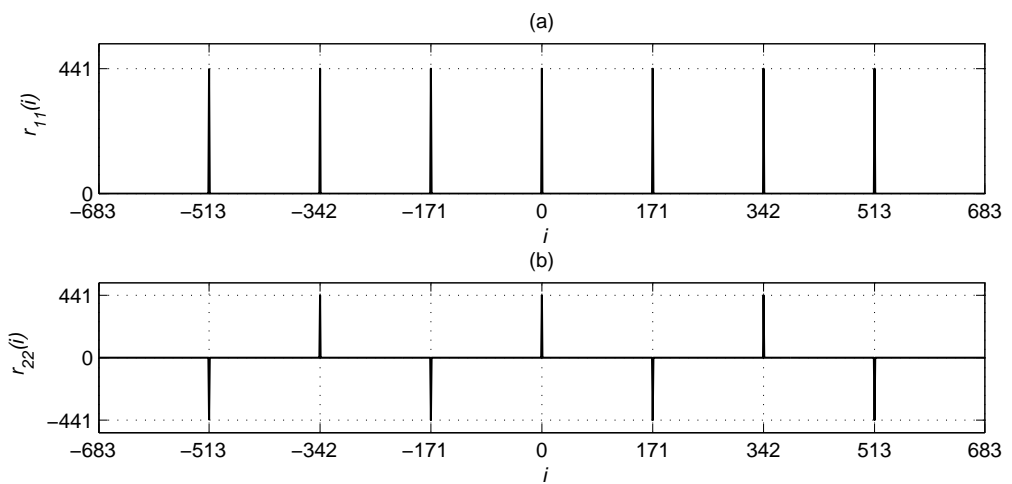

(c)

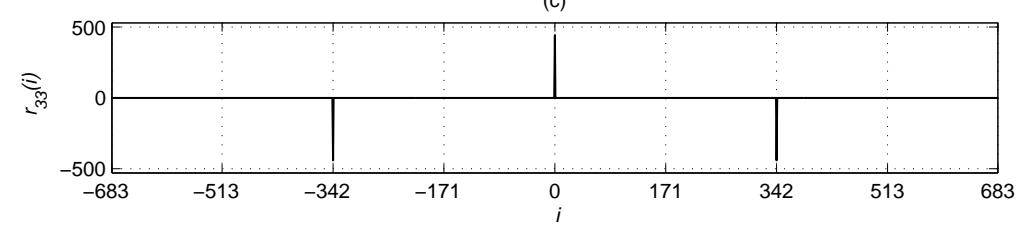

Figura 6.3: Função de autocorrelação periódica das sequências PRMO de comprimento $N=684$.

A figura 6.4 apresenta a função de correlação cruzada entre as sequências multinível $u_{1}(i), u_{2}(i)$ e $u_{3}(i)$. Observa-se que a função de correlação cruzada $r_{u_{r} u_{s}}(j)$ é nula para qualquer valor de $j$, o que significa que os sinais multinível $u_{1}(i), u_{2}(i)$ e $u_{3}(i)$ são ortogonais. Observando-se a figura 6.2 também se pode concluir que os sinais são ortogonais, pois nas harmônicas onde há potência para um dos sinais, para o outro não há (espectros intercalados). 
Os sinais PRMO, os quais são do tipo espectro fixo, podem ser parametrizados conforme mostrado na seção 5.3.11.
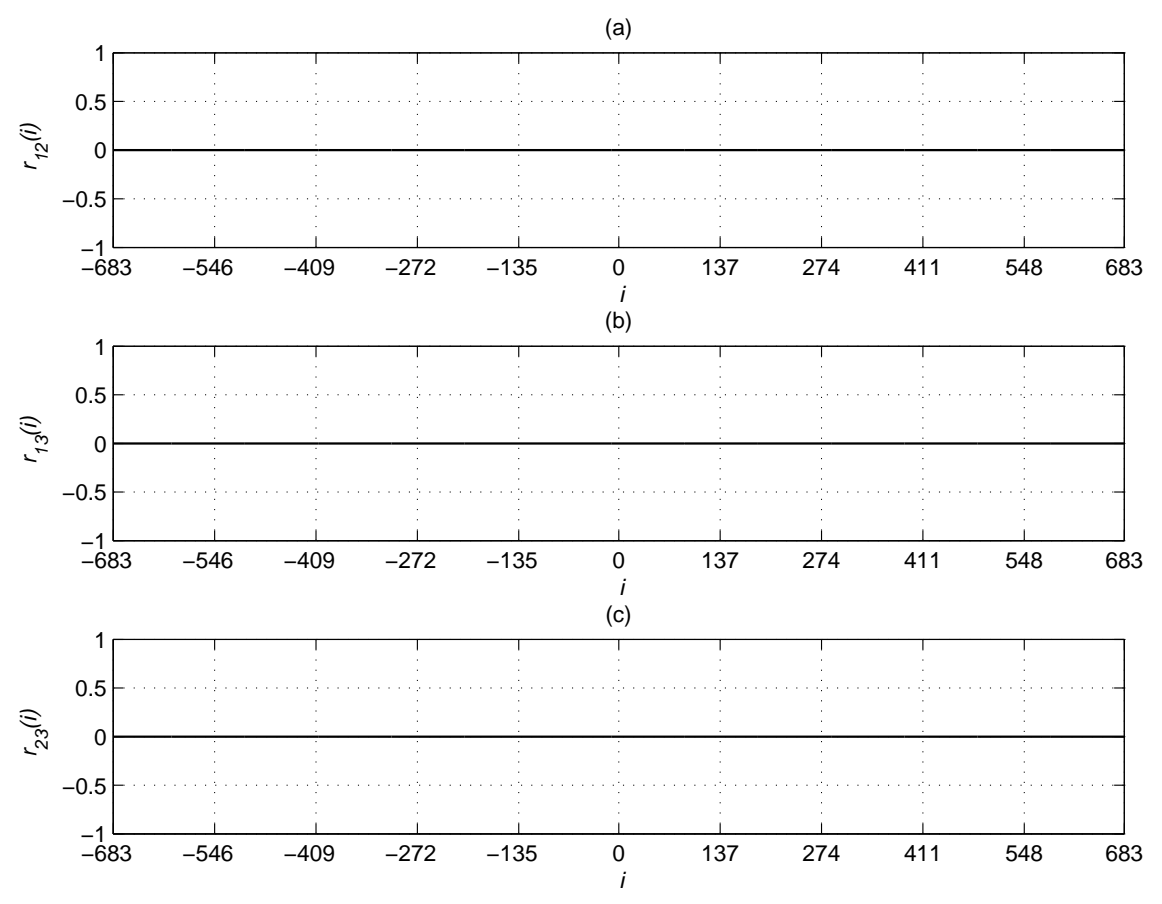

Figura 6.4: Função de correlação cruzada periódica entre as sequências PRMO de comprimento $N=684$.

\subsection{Conjunto de sinais não lineares multinível}

Na seção 5.4 foram discutidas as vantagens dos sinais Gallev (TAN; GODFREY; BARKER, 2009) como alternativa aos sinais MLMH e PRML. Nesta seção é proposto um método de geração de sinais multinível híbridos, assim como os sinais Gallev. Porém, com tal método é possível gerar conjuntos adicionais de sequências com comprimentos $N$ diferentes dos sinais Gallev, o que permite maior flexibilidade para escolha do comprimento $N_{s}$ dos sinais de excitação.

Os métodos algébricos propostos na literatura e discutidos neste trabalho para construir sinais multinível consideram apenas sequências lineares sobre $G F(p)$, como os sinais PRML e PRT. As sequências lineares são aquelas que podem ser representadas por uma equação de recorrência linear (anexo seção A.9). O método proposto aqui utiliza sequências não lineares sobre $G F(q)$, conhecidas como sequências GMW, e mapeamentos de seus elementos em números reais. Sequências binárias ou multinível geradas por esse método são denominadas neste trabalho de sequências não lineares multinível (multilevel non linear sequences, MLNL sequences) e, consequentemente, sinais oriundos destas sequências são denominados sinais não lineares multinível (mul- 
tilevel non linear signals, MLNL signals).

As sequências GMW foram propostas em (SCHOLTZ; WELCH, 1984) com base em estudos de Gordon, Mills e Welch (GMW) (GORDON; MILLS; WELCH, 1962). Suas características de autocorrelação e correlação cruzada são atrativas para aplicações em sistemas de comunicação e radar (GOLOMB; GONG, 2005). Adicionalmente, as sequências GMW são aplicadas em sistemas de criptografia, por ter construção não linear, o que garante maior complexidade para interceptação de mensagens criptografadas com o uso delas (GOLOMB; GONG, 2005).

Há diversos trabalhos que estudaram as funções de correlação de sequências GMW, cujos elementos são binários (sobre $G F(2)$ ) (GOLOMB; GONG, 2005) ou cujos elementos sobre $G F(q)$, com $q>2$ e primo, estão mapeados em números complexos de módulo unitário (complexos sobre o círculo unitário) ((TANG; FAN, 2001b) e suas referências).

Neste trabalho, foi constatado que as características das funções de correlação das sequências GMW, quando mapeadas sobre $\mathbb{R}$ (não necessariamente de módulo unitário), também são atrativas para aplicação em identificação de sistemas.

Uma sequência GMW pode ser interpretada como um entrelaçamento de SMC. Uma SMC de comprimento $M=2^{m}-1$ é entrelaçada para gerar uma sequência GMW de comprimento $N=2^{n}-1$, com $m, n>2 \in \mathbb{Z}$ e $m$ fator de $n$. Neste trabalho, a sequência de comprimento menor $(M)$, a qual é entrelaçada, é chamada de semente. A proposta apresentada aqui consiste em um conjunto de sequências GMW que utilizam sementes multinível, não necessariamente mapeamentos de SMC sobre $G F(q)$, com $q>2$ e primo, para elementos de $\mathbb{R}$. As sequências resultantes têm espectros intercalados, conferindo boas propriedades de correlação cruzada assim como as sequências GMW, além de reduzidos CF. O método proposto aqui também é uma alternativa ao uso dos sinais Schroeder-SOH, pois supera sua principal limitação na identificação multivariável: tendem a ter elevados CF à medida que seus espectros tornam-se esparsos (a medida que aumentam-se os sinais com espectros intercalados, conforme seção 5.2.1.1).

\subsubsection{Funções de correlação de sequências não lineares}

Em (LIN; CHANG, 1997) foram derivadas as funções de autocorrelação e correlação cruzada periódica para sequências GMW binárias (sobre $G F(2)$ ), em passos convenientes para a análise que se pretende nesta seção. Assim, os passos apresentados aqui são similares aos apresentados em (LIN; CHANG, 1997), porém, diferentemente, aqui 
as funções de correlação são derivadas para sequências GMW sobre $G F(q), \operatorname{com} q>2$ e primo. Em (TANG; FAN, 2001b) também foram derivadas as funções de correlação para sequências GMW sobre $G F(q)$, porém, com passos diferentes e convenientes para o mapeamento dos elementos de $G F(q)$ em números complexos de módulo unitário (complexos sobre o círculo unitário), o qual não é o objetivo aqui.

Analogamente à GMW binária (SCHOLTZ; WELCH, 1984), considere a sequência GMW $\left\{a_{t}\right\}$ sobre $G F(q)$ :

$$
a_{t}=\operatorname{Tr}_{1}^{m}\left\{\left[\operatorname{Tr}_{m}^{n}\left(\alpha^{t}\right)\right]^{r}\right\}
$$

onde $m$ é fator de $n$ (ou seja, $m \mid n$ ), $\alpha$ é um elemento primitivo de $G F\left(q^{n}\right)$ e $r$ um inteiro primo relativo à $q^{m}-1$, definido no intervalo $1 \leq r<q^{m}-1$.

A sequência $\left\{a_{t}\right\}$ em (6.7) é dita não linear, pois não é construída apenas por uma equação de recorrência linear de elementos de $G F\left(q^{n}\right)$. Há uma função não linear $(.)^{r}$ em sua construção.

A ordem de $\alpha$, elemento primitivo de $G F\left(q^{n}\right)$, é $q^{n}-1$. Assim, $\alpha^{t}$ percorre todos os elementos não nulos de $G F\left(q^{n}\right)$, resultando em uma sequência de comprimento $N=q^{n}-1$. Observe que se $r=1$, da propriedade 4 do traço (anexo seção A.8), a sequência (6.7) é uma SMC sobre $G F(q)$. Assim, pode-se afirmar que as sequências GMW representam a generalização das SMC (SCHOLTZ; WELCH, 1984).

Considere o seguinte parâmetro (TANG; FAN, 2001b):

$$
\mathcal{T}=\frac{q^{n}-1}{q^{m}-1}
$$

Organizando os elementos de (6.7) em forma matricial utilizando o parâmetro $\mathcal{T}$, tem-se:

$$
\mathbf{A}=\left[\begin{array}{cccc}
\operatorname{Tr}_{1}^{m}\left\{\left[\operatorname{Tr}_{m}^{n}\left(\alpha^{0}\right)\right]^{r}\right\} & \operatorname{Tr}_{1}^{m}\left\{\left[\operatorname{Tr}_{m}^{n}\left(\alpha^{1}\right)\right]^{r}\right\} & \ldots & \operatorname{Tr}_{1}^{m}\left\{\left[\operatorname{Tr}_{m}^{n}\left(\alpha^{\mathcal{T}-1}\right)\right]^{r}\right\} \\
\operatorname{Tr}_{1}^{m}\left\{\left[\operatorname{Tr}_{m}^{n}\left(\alpha^{\mathcal{T}}\right)\right]^{r}\right\} & \operatorname{Tr}_{1}^{m}\left\{\left[\operatorname{Tr}_{m}^{n}\left(\alpha^{\mathcal{T}+1}\right)\right]^{r}\right\} & \ldots & \operatorname{Tr}_{1}^{m}\left\{\left[\operatorname{Tr}_{m}^{n}\left(\alpha^{2 \mathcal{T}-1}\right)\right]^{r}\right\} \\
\operatorname{Tr}_{1}^{m}\left\{\left[\operatorname{Tr}_{m}^{n}\left(\alpha^{2 \mathcal{T}}\right)\right]^{r}\right\} & \operatorname{Tr}_{1}^{m}\left\{\left[\operatorname{Tr}_{m}^{n}\left(\alpha^{2 \mathcal{T}+1}\right)\right]^{r}\right\} & \ldots & \operatorname{Tr}_{1}^{m}\left\{\left[\operatorname{Tr}_{m}^{n}\left(\alpha^{3 \mathcal{T}-1}\right)\right]^{r}\right\} \\
\vdots & \vdots & \ddots & \vdots \\
\operatorname{Tr}_{1}^{m}\left\{\left[\operatorname{Tr}_{m}^{n}\left(\alpha^{\left(q^{m}-2\right) \mathcal{T}}\right)\right]^{r}\right\} & \operatorname{Tr}_{1}^{m}\left\{\left[\operatorname{Tr}_{m}^{n}\left(\alpha^{\left(q^{m}-2\right) \mathcal{T}+1}\right)\right]^{r}\right\} & \ldots & \operatorname{Tr}_{1}^{m}\left\{\left[\operatorname{Tr}_{m}^{n}\left(\alpha^{\left(q^{m}-1\right) \mathcal{T}}\right)\right]^{r}\right\}
\end{array}\right]
$$

onde a sequência $\left\{a_{t}\right\}$ é obtida da concatenação das linhas de $\mathbf{A}$.

A ordem de $\alpha^{\mathcal{T}}$ é $q^{m}$, pois: 


$$
\begin{aligned}
\left(\alpha^{\mathcal{T}}\right)^{q^{m}} & =\left(\alpha^{\mathcal{T}}\right)^{q^{m}-1+1}=\left(\alpha^{\mathcal{T}}\right)^{q^{m}-1}\left(\alpha^{\mathcal{T}}\right)^{1}=\left(\alpha^{q^{q^{n}-1}}\right)^{q^{m}-1}\left(\alpha^{\mathcal{T}}\right)^{1}=\left(\alpha^{q^{n}-1}\right)\left(\alpha^{\mathcal{T}}\right) \\
& =\alpha^{\mathcal{T}}
\end{aligned}
$$

o que significa que $\alpha^{\mathcal{T}} \in G F\left(2^{m}\right)$. Assim, a propriedade 3 da função traço (anexo seção A.8) pode ser aplicada nos termos $\operatorname{Tr}_{1}^{m}\left\{\left[\operatorname{Tr}_{m}^{n}\left(\alpha^{k \mathcal{T}+i}\right)\right]^{r}\right\}=\operatorname{Tr}_{1}^{m}\left\{\alpha^{r k \mathcal{T}}\left[\operatorname{Tr}_{m}^{n}\left(\alpha^{i}\right)\right]^{r}\right\}$ de (6.9), resultando em:

$$
\mathbf{A}=\left[\begin{array}{cccc}
\operatorname{Tr}_{1}^{m}\left\{\alpha^{0 r \mathcal{T}}\left[\operatorname{Tr}_{m}^{n}\left(\alpha^{0}\right)\right]^{r}\right\} & \operatorname{Tr}_{1}^{m}\left\{\alpha^{0 r \mathcal{T}}\left[\operatorname{Tr}_{m}^{n}\left(\alpha^{1}\right)\right]^{r}\right\} & \ldots & \operatorname{Tr}_{1}^{m}\left\{\alpha^{0 r \mathcal{T}}\left[\operatorname{Tr}_{m}^{n}\left(\alpha^{\mathcal{T}-1}\right)\right]^{r}\right\} \\
\operatorname{Tr}_{1}^{m}\left\{\alpha^{r \mathcal{T}}\left[\operatorname{Tr}_{m}^{n}\left(\alpha^{0}\right)\right]^{r}\right\} & \operatorname{Tr}_{1}^{m}\left\{\alpha^{r \mathcal{T}}\left[\operatorname{Tr}_{m}^{n}\left(\alpha^{1}\right)\right]^{r}\right\} & \ldots & \operatorname{Tr}_{1}^{m}\left\{\alpha^{r \mathcal{T}}\left[\operatorname{Tr}_{m}^{n}\left(\alpha^{\mathcal{T}-1}\right)\right]^{r}\right\} \\
\operatorname{Tr}_{1}^{m}\left\{\alpha^{2 r \mathcal{T}}\left[\operatorname{Tr}_{m}^{n}\left(\alpha^{0}\right)\right]^{r}\right\} & \operatorname{Tr}_{1}^{m}\left\{\alpha^{2 r \mathcal{T}}\left[\operatorname{Tr}_{m}^{n}\left(\alpha^{1}\right)\right]^{r}\right\} & \ldots & \operatorname{Tr}_{1}^{m}\left\{\alpha^{2 r \mathcal{T}}\left[\operatorname{Tr}_{m}^{n}\left(\alpha^{\mathcal{T}-1}\right)\right]^{r}\right\} \\
\vdots & \vdots & \ddots & \vdots \\
\operatorname{Tr}_{1}^{m}\left\{\alpha^{\left(p^{m}-2\right) r \mathcal{T}}\left[\operatorname{Tr}_{m}^{n}\left(\alpha^{0}\right)\right]^{r}\right\} & \operatorname{Tr}_{1}^{m}\left\{\alpha^{\left(p^{m}-2\right) r \mathcal{T}}\left[\operatorname{Tr}_{m}^{n}\left(\alpha^{1}\right)\right]^{r}\right\} & \ldots & \operatorname{Tr}_{1}^{m}\left\{\alpha^{\left(p^{m}-2\right) r \mathcal{T}}\left[\operatorname{Tr}_{m}^{n}\left(\alpha^{\mathcal{T}-1}\right)\right]^{r}\right\}
\end{array}\right]
$$

Reescrevendo-se as colunas da matriz (6.11) como:

$$
\operatorname{Tr}_{1}^{m}\left\{\alpha^{k r \mathcal{T}}[\theta]^{r}\right\}
$$

com $k=0,1,2, \ldots, q^{m}-2$ e $\theta \in G F\left(p^{m}\right)$ constante, onde $\theta=\operatorname{Tr}_{m}^{n}\left(\alpha^{j}\right)=\alpha^{d \mathcal{T}}, j=$ $0,1,2, \ldots, \mathcal{T}-1$ e $d=0,1,2, \ldots, q^{m}-2, \infty$.

Nota-se que (6.12) é uma SMC de comprimento $q^{m}-1$ dada por:

$$
\left\{u_{k+d}\right\}=\left\{\operatorname{Tr}_{1}^{m}\left\{\alpha^{k r \mathcal{T}} \alpha^{d r \mathcal{T}}\right\}\right\}=\left\{\operatorname{Tr}_{1}^{m}\left\{\alpha^{(k+d) r \mathcal{T}}\right\}\right\}
$$

cuja fase $d$ é definida por $\theta$ (apêndice G).

O inteiro $r$ é expoente de elementos $\alpha^{k \mathcal{T}} \in G F\left(p^{m}\right)$, assim, ele é definido na faixa $0 \leq r<q^{m}-1$. Adicionalmente, a SMC dada por $u_{k}=\operatorname{Tr}_{1}^{m}\left\{\alpha^{k r \mathcal{T}}\right\}$, com $k=0,1,2, \ldots, q^{m}-2$, é a decimação $r$ da SMC dada por $u_{k}=\operatorname{Tr}_{1}^{m}\left\{\alpha^{k \mathcal{T}}\right\}$. O comprimento da sequência decimada é $q^{m}-1 / \operatorname{mdc}\left(r, q^{m}-1\right.$ ) (anexo Lema A.4.1). Para que a sequência decimada seja $\mathrm{SMC}, r$ deve satisfazer $\operatorname{mdc}\left(r, q^{m}-1\right)=1$. O operador mdc $(a, b)$ representa o maior inteiro que divide $a$ e $b$ simultaneamente sem restos (máximo divisor comum).

Então, para obter uma sequência GMW basta obter uma semente SMC e calcular fases $\theta$ apropriadas. O conjunto de fases $\theta=\operatorname{Tr}_{m}^{n}\left(\alpha^{j}\right)=\alpha^{d \mathcal{T}}$ é dado pela sequência $s$ composta pelos expoentes $d$ de $\alpha^{\mathcal{T}}$ : 


$$
s=\left(s_{0}, s_{1}, s_{2}, \ldots, s_{\mathcal{T}-1}\right)
$$

onde $s_{j}=d, \operatorname{com} \operatorname{Tr}_{m}^{n}\left(\alpha^{j}\right)=\alpha^{d \mathcal{T}}$, em que $d$ pode assumir os valores $d=0,1,2, \ldots, q^{m}-$ 2 e $\infty$; este último ocorre quando $\operatorname{Tr}_{m}^{n}\left(\alpha^{j}\right)=0$. Então, quando $s_{j}=\infty, \operatorname{Tr}_{m}^{n}\left(\alpha^{j}\right)=0$ e, portanto, todos os elementos da $j$-ésima coluna de (6.11) são zero.

A SMC dada por $u_{k}=\operatorname{Tr}_{1}^{m}\left\{\alpha^{k r \mathcal{T}}\right\}=\operatorname{Tr}_{1}^{m}\left\{\left(\alpha^{r \mathcal{T}}\right)^{k}\right\}$ com $\alpha$ sendo um elemento primitivo de $G F\left(q^{n}\right)$, construído com o polinômio primitivo $f(x)$, pode ser escrita como $u_{k}=\operatorname{Tr}_{1}^{m}\left\{(\beta)^{k}\right\} \operatorname{com} \beta$ um elemento primitivo de $G F\left(q^{m}\right)$ construído com o polinômio mínimo de $\alpha^{r \mathcal{T}}$, o qual é primitivo, pois $\operatorname{mdc}\left(r, q^{m}-1\right)=1$, e de grau $m$, pois, como foi mostrado anteriormente, a ordem de $\alpha^{r \mathcal{T}}$ é $q^{m}$. Assim, na construção da GMW, alternativamente a definir o elemento primitivo $\alpha$ de $G F\left(q^{n}\right)$ e $r$, podem ser definidos os elementos primitivos $\alpha$ de $G F\left(q^{n}\right)$ e $\beta$ de $G F\left(q^{m}\right)$. A sequência u é chamada de sequência primitiva ou semente.

Considere a sequência GMW sobre $G F(q)$ resultante da concatenação das linhas da matriz:

$$
\mathbf{A}=\left[\begin{array}{ccccc}
u_{s_{0}} & u_{s_{1}} & u_{s_{2}} & \ldots & u_{\mathcal{T}_{\mathcal{T}-1}} \\
u_{1+s_{0}} & u_{1+s_{1}} & u_{1+s_{2}} & \ldots & u_{1+s_{\mathcal{T}-1}} \\
u_{2+s_{0}} & u_{2+s_{1}} & u_{2+s_{2}} & \ldots & u_{2+s_{\mathcal{T}-1}} \\
\vdots & \vdots & \vdots & \ddots & \vdots \\
u_{q^{m}-2+s_{0}} & u_{q^{m}-2+s_{1}} & u_{q^{m}-2+s_{2}} & \ldots & u_{q^{m}-2+s_{\mathcal{T}-1}}
\end{array}\right]
$$

Analogamente, considere uma segunda sequência GMW $\left\{b_{t}\right\}$ com deslocamento de $\tau=\tau_{0} \mathcal{T}+\tau_{1}$ resultante da concatenação das linhas da matriz:

$$
\mathbf{B}^{\tau}=\left[\begin{array}{ccccc}
v_{\tau_{0}+s_{\tau_{1}}} & v_{\tau_{0}+s_{\tau_{1}+1}} & v_{\tau_{0}+s_{\tau_{1}+2}} & \ldots & v_{\tau_{0}+s_{\tau_{1}+\mathcal{T}-1}} \\
v_{\tau_{0}+1+s_{\tau_{1}}} & v_{\tau_{0}+1+s_{\tau_{1}+1}} & v_{\tau_{0}+1+s_{\tau_{1}+2}} & \ldots & v_{\tau_{0}+1+s_{\tau_{1}+\mathcal{T}-1}} \\
v_{\tau_{0}+2+s_{\tau_{1}}} & v_{\tau_{0}+2+s_{\tau_{1}+1}} & v_{\tau_{0}+2+s_{\tau_{1}+2}} & \ldots & v_{\tau_{0}+2+s_{\tau_{1}+\mathcal{T}-1}} \\
\vdots & \vdots & \vdots & \ddots & \vdots \\
v_{\tau_{0}+q^{m}-2+s_{\tau_{1}}} & v_{\tau_{0}+q^{m}-2+s_{\tau_{1}+1}} & v_{\tau_{0}+q^{m}-2+s_{\tau_{1}+2}} & \ldots & v_{\tau_{0}+q^{m}-2+s_{\tau_{1}+\mathcal{T}-1}}
\end{array}\right]
$$

A função de correlação cruzada periódica entre as sequências GMW $\left\{a_{t}\right\}$ e $\left\{b_{t}\right\}$ é:

$$
\begin{gathered}
r_{\mathbf{a b}}(\tau)=\sum_{i=0}^{q^{n}-2} a_{i} b_{i+\tau} \\
=u_{s_{0}} v_{\left(\tau_{0}+s_{\tau_{1}}\right)}+u_{s_{1}} v_{\left(\tau_{0}+s_{\tau_{1}+1}\right)}+\ldots+u_{s_{(\mathcal{T}-1)}} v_{\left(\tau_{0}+s_{\left(\tau_{1}+\mathcal{T}-1\right)}\right)}+
\end{gathered}
$$




$$
\begin{aligned}
& +u_{\left(1+s_{0}\right)} v_{\left(\tau_{0}+1+s_{\tau_{1}}\right)}+u_{\left(1+s_{1}\right)} v_{\left(\tau_{0}+1+s_{\left(\tau_{1}+1\right)}\right)}+\ldots+u_{\left(1+s_{\mathcal{T}-1}\right)} v_{\left(\tau_{0}+1+s_{\left(\tau_{1}+\mathcal{T}-1\right)}\right)}+ \\
& +\ldots+ \\
& +u_{\left(2^{m}-2+s_{0}\right)} v_{\left(\tau_{0}+2^{m}-2+s_{\tau_{1}}\right)}+u_{\left(2^{m}-2+s_{1}\right)} v_{\left(\tau_{0}+2^{m}-2+s_{\left(\tau_{1}+1\right)}\right)}+\ldots+u_{\left(2^{m}-2+s_{\mathcal{T}-1}\right)} v_{\left(\tau_{0}+2^{m}-2+s_{\left(\tau_{1}+\mathcal{T}-1\right)}\right)} \\
& =r_{\mathbf{u v}}\left(\tau_{0}+s_{\tau_{1}}-s_{0}\right)+r_{\mathbf{u v}}\left(\tau_{0}+s_{\tau_{1}+1}-s_{1}\right)+r_{\mathbf{u v}}\left(\tau_{0}+s_{\tau_{1}+2}-s_{2}\right)+\ldots+ \\
& +r_{\mathbf{u v}}\left(\tau_{0}+s_{\tau_{1}+\mathcal{T}-1}-s_{\mathcal{T}-1}\right) \\
& =\sum_{j=0}^{\mathcal{T}-1} r_{\mathbf{u v}}\left(\tau_{0}+s_{\tau_{1}+j}-s_{j}\right)
\end{aligned}
$$

Assim, a função de correlação cruzada periódica entre as sequências GMW $\left\{a_{t}\right\}$ e $\left\{b_{t}\right\}$ pode ser escrita em função das sementes:

$$
r_{\mathbf{a b}}(\tau)=\sum_{j=0}^{\mathcal{T}-1} r_{u v}\left(s_{\tau+j}-s_{j}\right)
$$

Para que as sequências sobre $G F(q)$ possam gerar sinais físicos adequados para identificação de plantas, os elementos das sementes sobre $G F(q)$ devem ser mapeados em números reais $(\mathbb{R})$. Esse mapeamento é representado por $\ell(\alpha)$, onde $\alpha$ é elemento de $G F(q)$. Reescrevendo-se (6.18) em função das sementes mapeadas $\left\{x_{t}\right\}=\left\{\ell\left(u_{t}\right)\right\}$ e $\left\{y_{t}\right\}=\left\{\ell\left(v_{t}\right)\right\}$, tem-se:

$$
r_{\mathbf{a b}}(\tau)=\sum_{j=0}^{\mathcal{T}-1} r_{\mathbf{x y}}\left(s_{\tau+j}-s_{j}\right)
$$

Para obter os possíveis valores assumidos pela função de correlação cruzada periódica entre as sequências GMW é utilizado um lema apresentado em (LIN; CHANG, 1997) obtido dos Teoremas 1 e 2 de (GAMES, 1984), os quais foram derivados de resultados de (SINGER, 1938). O Lema apresentado considera sequências GMW sobre $G F(2)$. Aqui, esse é reescrito para sequências GMW sobre $G F(q)$, com $q$ primo, utilizando resultados apresentados em (HELLESETH, 1976).

Lema 6.2.1 Se $\tau \neq(0 \bmod \mathcal{T})$, na sequência $\left\{s_{\tau}-s_{0}, s_{\tau+1}-s_{1}, \ldots, s_{\tau+\mathcal{T}-1}-s_{\mathcal{T}-1}\right\} \bmod \left(q^{m}-\right.$ 2) o elemento $\infty-\infty$ aparecerá $q^{n-2 m-1} /\left(q^{m}-1\right)$ vezes, o elemento $\infty$ aparecerá $q^{n-2 m+1}$ vezes e os elementos $\left\{0,1,2, \ldots, q^{m}-2\right\}$ aparecerão $q^{n-2 m}$ vezes cada um. Se $\tau=d \mathcal{T}$, o elemento $\infty-\infty$ aparecerá $\left(q^{n-m}-1\right) /\left(q^{m}-1\right)$ vezes e o elemento d aparecerá $q^{n-m}$ vezes.

Com esse lema, pode-se reescrever (6.19) como: 


$$
\begin{aligned}
& r_{\mathbf{a} \mathbf{b}}(\tau)= \\
& = \begin{cases}\frac{q^{n-2 m}-1}{q^{m}-1} r_{\mathbf{x y}}(\infty-\infty)+q^{n-2 m+1} r_{\mathbf{x y}}(\infty)+q^{n-2 m} \sum_{k=0}^{q^{m}-2} r_{\mathbf{x y}}(k), & \tau \neq(0 \bmod \mathcal{T}) \\
\frac{q^{n-m}-1}{q^{m}-1} r_{\mathbf{x y}}(\infty-\infty)+q^{n-m} r_{\mathbf{x y}}(d), & \tau=d \mathcal{T}\end{cases}
\end{aligned}
$$

Desenvolvendo o termo $r_{\mathbf{x y}}(\infty-\infty)$, tem-se:

$$
\begin{aligned}
r_{\mathbf{x y}}(\infty-\infty) & =\sum_{i=0}^{q^{m}-2} \ell\left(u_{(i-\infty)}\right) \ell\left(v_{(i-\infty)}\right) \\
& =\sum_{i=0}^{q^{m}-2} \ell\left(\operatorname{Tr}_{1}^{m}\left(\alpha^{(i-\infty)}\right)\right) \ell\left(\operatorname{Tr}_{1}^{m}\left(\beta^{(i-\infty)}\right)\right) \\
& =\sum_{i=0}^{q^{m}-2} \ell\left(\operatorname{Tr}_{1}^{m}\left(\alpha^{-\infty}\right)\right) \ell\left(\operatorname{Tr}_{1}^{m}\left(\beta^{-\infty}\right)\right) \\
& =\sum_{i=0}^{q^{m}-2} \ell(0) \ell(0) \\
& =\ell(0)^{2}\left(q^{m}-1\right)
\end{aligned}
$$

Desenvolvendo o termo $r_{\mathbf{x y}}(\infty)$, tem-se:

$$
\begin{aligned}
r_{\mathbf{x y}}(\infty) & =\sum_{i=0}^{q^{m}-2} \ell\left(u_{i-\infty}\right) \ell\left(v_{i}\right) \\
& =\sum_{i=0}^{q^{m}-2} \ell\left(\operatorname{Tr}_{1}^{m}\left(\alpha^{(i-\infty)}\right)\right) \ell\left(v_{i}\right) \\
& =\sum_{i=0}^{q^{m}-2} \ell\left(\operatorname{Tr}_{1}^{m}\left(\alpha^{-\infty}\right)\right) \ell\left(v_{i}\right) \\
& =\sum_{i=0}^{q^{m}-2} \ell(0) \ell\left(v_{i}\right) \\
& =\ell(0) \sum_{i=0}^{q^{m}-2} \ell\left(v_{i}\right)
\end{aligned}
$$

Substituindo-se (6.21) e (6.22) em (6.20), tem-se: 


$$
\begin{aligned}
& r_{\mathbf{a b}}(\tau) N= \\
& = \begin{cases}\frac{q^{n-2 m}-1}{q^{m}-1} \ell(0)^{2}\left(q^{m}-1\right)+q^{n-2 m+1} \ell(0) \sum_{i=0}^{q^{m}-1} \ell\left(v_{i}\right)+\ldots \\
\ldots+q^{n-2 m} \sum_{k=0}^{q^{m}-2} r_{\mathbf{x y}}(k)\left(q^{m}-1\right), & \tau \neq(0 \bmod \mathcal{T}) \\
\frac{q^{n-m}-1}{q^{m}-1} \ell(0)^{2}\left(q^{m}-1\right)+q^{n-m} r_{\mathbf{x y}}(d)\left(q^{m}-1\right), & \tau=d \mathcal{T}\end{cases} \\
& = \begin{cases}\left(q^{n-2 m}-1\right) \ell(0)^{2}+q^{n-2 m+1} \ell(0) \sum_{i=0}^{q^{m}-1} \ell\left(v_{i}\right)+\ldots & \tau \neq(0 \bmod \mathcal{T}) \\
\ldots+q^{n-2 m} \sum_{k=0}^{q^{m}-2} r_{\mathbf{x y}}(k)\left(q^{m}-1\right), & \tau=d \mathcal{T} \\
\left(q^{n-m}-1\right) \ell(0)^{2}+q^{n-m} r_{\mathbf{x y}}(d)\left(q^{m}-1\right), & \end{cases}
\end{aligned}
$$

Estabelecendo o mapeamento do elemento nulo de $G F(q)$ no número real nulo $(\ell(0)=0)$, tem-se:

$$
r_{\mathbf{a b}}(\tau) N= \begin{cases}q^{n-2 m} \sum_{k=0}^{q^{m}-2} r_{\mathbf{x y}}(k)\left(q^{m}-1\right), & \tau \neq(0 \bmod \mathcal{T}) \\ q^{n-m} r_{\mathbf{x y}}(d)\left(q^{m}-1\right), & \tau=d \mathcal{T}\end{cases}
$$

É importante notar que o resultado (6.24) é obtido mesmo quando as sequências $\mathbf{x}$ e y não forem resultados de mapeamentos dos elementos de SMC em números reais. Durante a construção das matrizes $\mathbf{A}$ e $\mathbf{B}^{\tau}$, suas colunas associadas à fase $\infty$ são nulas. O mapeamento do elemento nulo de $G F(q)$ no número real nulo $(\ell(0)=0)$ é suficiente para obter o resultado mostrado em (6.24), independentemente se as sequências $\mathbf{u}$ e $\mathbf{v}$ são SMC ou não.

Desenvolvendo-se o termo $\sum_{k=0}^{q^{m}-2} r_{\mathbf{x y}}$ de (6.24), tem-se:

$$
\begin{aligned}
\sum_{k=0}^{q^{m}-2} r_{\mathbf{x y}}(k) & =\sum_{k=0}^{q^{m}-2} \sum_{i=0}^{q^{m}-2} x_{i} y_{i+k} \\
& =\sum_{i=0}^{q^{m}-2} x_{i} \sum_{k=0}^{q^{m}-2} y_{i+k}
\end{aligned}
$$

Escolhendo-se sequências balanceadas, ou seja, $\sum_{i=0}^{p^{m}-2} x_{i}=0$ e $\sum_{k=0}^{p^{m}-2} y_{i+k}=0$, pode-se garantir que qualquer sequência construída da forma descrita nesta seção tem função de correlação dada por:

$$
r_{\mathbf{a b}}(\tau) N= \begin{cases}0, & \tau \neq(0 \bmod \mathcal{T}) \\ q^{n-m} r_{\mathbf{x y}}(d)\left(q^{m}-1\right), & \tau=d \mathcal{T}\end{cases}
$$


Observa-se que se $r_{\mathbf{x y}}(d)=0$, para qualquer $d$, tem-se a e b sequências ortogonais. Se $r_{\mathbf{x y}}(d)=0$, para $d=0\left(\bmod q^{m}-1\right)$, tem a e b sequências com a característica de zona de correlação nula com $Z_{C Z}=\mathcal{T}-1$.

Essa característica da função de correlação (6.26) de sequências compostas de elementos em $\mathbb{R}$ é desejável para identificação de sistemas. As sequências de elementos reais com as características de correlação descritas nesta seção são chamadas neste trabalho de sequências não lineares multinível (multilevel non linear sequences, MLNL sequences). A próxima seção resume o procedimento de construção das sequências MLNL.

No caso particular de $r=1$, tem-se a e $\mathbf{b}$ sequências originalmente SMC e $\mathbf{x}$ e $\mathbf{y}$ sequências primitivas que, quando mapeadas em $\mathbb{R}$, resultam em sequências PRML. Ainda neste caso, utilizando-se $q=2$, tem-se sequências PRB.

Quando $\mathbf{x}$ e $\mathbf{y}$ forem resultados do mapeamento $\left\{x_{i}\right\}=\left\{(-1)^{u_{i}}\right\}$ e $\left\{y_{i}\right\}=\left\{(-1)^{v_{i}}\right\}$, com u e v SMC, tem-se a e b sequências GMW (GOLOMB; GONG, 2005). Quando x e $\mathbf{y}$ forem mapeamentos de SMC $\mathbf{u}$ e $\mathbf{v}$ em números complexos de módulo unitário (complexos sobre o círculo unitário), tem-se as sequências propostas em (TANG; FAN, 2001b).

Para obter sequências MLNL ortogonais, as sementes também devem ser ortogonais. Neste caso, as sementes podem ser sinais $\mathrm{SOH}$ com espectro intercalado ( $\mathrm{SOH}$ Schroeder, MLMH, DIB e DIT). Nesse caso, os sinais resultantes têm CF menor que sinais Schroeder-SOH de mesmo comprimento $N_{s}$.

Assim como discutido em relação aos sinais Gallev (seção 5.4), a vantagem dos sinais MLNL sobre os sinais MLMH é relativa à otimização de fases dos sinais $\mathrm{SOH}$. Para os sinais MLNL de comprimento $N_{s}=\left(q^{n}-1\right) \frac{T_{c l k}}{T}$, o algoritmo de otimização trata sequências sementes MLMH de comprimento $q^{m}-1$, com $m$ fator de $n$. Comparativamente, a otimização das fases de sinais SOH para gerar sinais MLMH do mesmo comprimento $N_{s}$ irá tratar de um problema de otimização exponencialmente maior ao anterior, visto que $m$ é fator de $n$. Essa característica torna os sinais MLNL, assim como os sinais Gallev, alternativas aos sinais MLMH e também aos sinais PRML, onde são necessárias buscas exaustivas por mapeamentos de sequências primitivas sobre $G F(q)$ para elementos de $\mathbb{R}$.

Alternativamente, as sementes dos sinais MLNL podem não ser do tipo $\mathrm{SOH}$, desde que sejam ortogonais. Por meio de algoritmos de otimização combinatória (PAPADIMITRIOU; STEIGLITZ, 1998) (KURAMOTO et al., 2012), podem ser obtidas sementes multinível ortogonais para sinais MLNL. Observa-se que há vantagem em obter se- 
mentes em vez da sequência completa, pois otimizar as sementes de comprimento $L=q^{m}-1$ é um problema de otimização combinatória de ordem exponencialmente menor comparado ao comprimento dos sinais MLNL $N=q^{n}-1$, pois $m$ é fator de $n$. Na próxima seção é resumido e exemplificado o método de geração de sinais MLNL.

\subsubsection{Construção do conjunto de sinais MLNL}

Para identificação multivariável, estabelecida a quantidade de entradas $\left(n_{r}\right)$, o período de amostragem (apêndice C), o período de chaveamento máximo (5.96), a duração mínima do experimento (3.13) e o comprimento mínimo da sequência, os sinais MLNL podem ser construídos conforme os seguintes passos:

1. A quantidade de entradas $\left(n_{r}\right)$ determina o comprimento mínimo da semente. Para obter sinais com espectro intercalado, deve haver pelo menos uma harmônica definida para cada entrada. Por exemplo, no caso de $n_{r}=4$, o comprimento da semente deve ser no mínimo 8, conforme seção 5.2.1. Assim, adotam-se valores para $q$ primo e $m$ inteiro, tal que $q^{m}-1$ seja maior ou igual ao comprimento mínimo da semente.

2. Escolhe-se $n$ múltiplo de $m$ de forma que $q^{n}-1$ atenda o comprimento $N$ mínimo da sequência MLNL.

3. Escolhe-se um polinômio primitivo de grau $n$ para gerar o corpo $G F\left(q^{n}\right)$.

4. Calcula-se a sequência de fases pela equação (6.14).

5. Constroem-se as $n_{r}$ sementes $\left\{x_{i}\right\}$ que podem ser qualquer sequência balanceada (ou seja, $\sum_{i=0}^{q^{m}-2} x_{i}=0$ ), o que garante a característica de correlação dada pela equação (6.26), e de comprimento definido por $q^{m}-1$.

6. Para cada uma das $\left(n_{r}\right)$ sementes, constroem-se as matrizes conforme (6.15), utilizando a mesma sequência de fases (equação (6.14)).

7. Cada sequência é obtida a partir da concatenação das linhas de cada uma das $n_{r}$ matrizes.

8. Os $n_{r}$ sinais são obtidos ajustando-se seus espectros conforme o apêndice D, respeitando o período de chaveamento máximo.

As figuras 6.5a, 6.5b e 6.5c apresentam sequências MLNL ortogonais $u_{1}(i), u_{2}(i)$ e $u_{3}(i)$, respectivamente, construídas a partir do polinômio primitivo $x^{4}+x+2$ sobre 
o corpo $G F\left(3^{4}\right)$. O comprimento das 3 sequências é $N=q^{n}-1=3^{4}-1=80$. As sementes são sinais Schroeder-SOH de comprimento $q^{m}-1=3^{2}-1=8$ com espectros intercalados. Consequentemente, as sequências MLNL $u_{1}(i), u_{2}(i)$ e $u_{3}(i)$ têm espectros intercalados, função de correlação cruzada nula para qualquer argumento e função de autocorrelação com $Z_{a C Z}=\mathcal{T}-1=\frac{q^{n}-1}{q^{m}-1}-1=\frac{3^{4}-1}{3^{2}-1}-1=9$.

A figura 6.6 apresenta os espectros $U_{1}(k), U_{2}(k)$ e $U_{3}(k)$ das sequências MLNL $u_{1}(i), u_{2}(i)$ e $u_{3}(i)$, respectivamente. Conforme mencionado anteriormente, as sequências possuem espectros intercalados (zippered power spectrum), com harmônicas não nulas com potência uniforme.
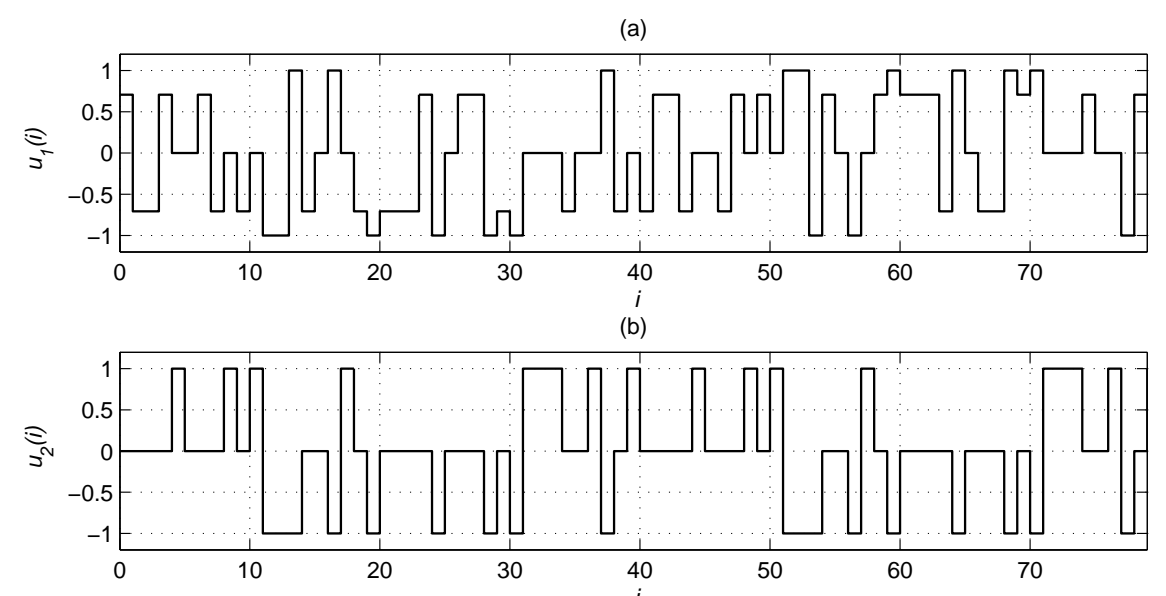

(c)

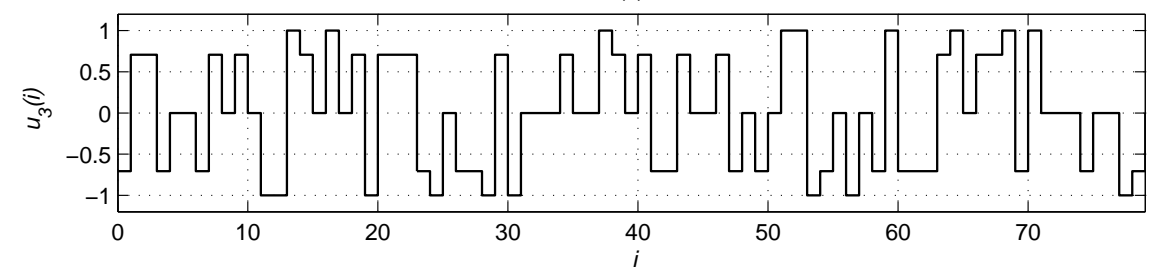

Figura 6.5: Conjunto de sequências MLNL de comprimento $N=80$.

As figuras 6.7a, 6.7b e 6.7c apresentam as funções de autocorrelação periódica das sequências MLNL $u_{1}(i), u_{2}(i)$ e $u_{3}(i)$, respectivamente. Observa-se que a função de autocorrelação do sinal $u_{1}(i)$ possui picos $r_{u_{r} u_{r}}(j)$, para $j$ múltiplo de $\mathcal{T}=\frac{q^{n}-1}{q^{m}-1}=10$, conforme a equação (6.26).

A figura 6.8 apresenta a função de correlação cruzada entre as sequências MLNL $u_{1}(i), u_{2}(i)$ e $u_{3}(i)$. Observa-se que a função de correlação cruzada $r_{u_{r}} u_{s}(j)$ é nula para qualquer valor de $j$, o que significa que as sequências $\operatorname{MLNL} u_{1}(i), u_{2}(i)$ e $u_{3}(i)$ geradas aqui são ortogonais. Essa característica é garantida, conforme a equação (6.26), devido às sementes serem balanceadas e ortogonais (espectros intercalados). 


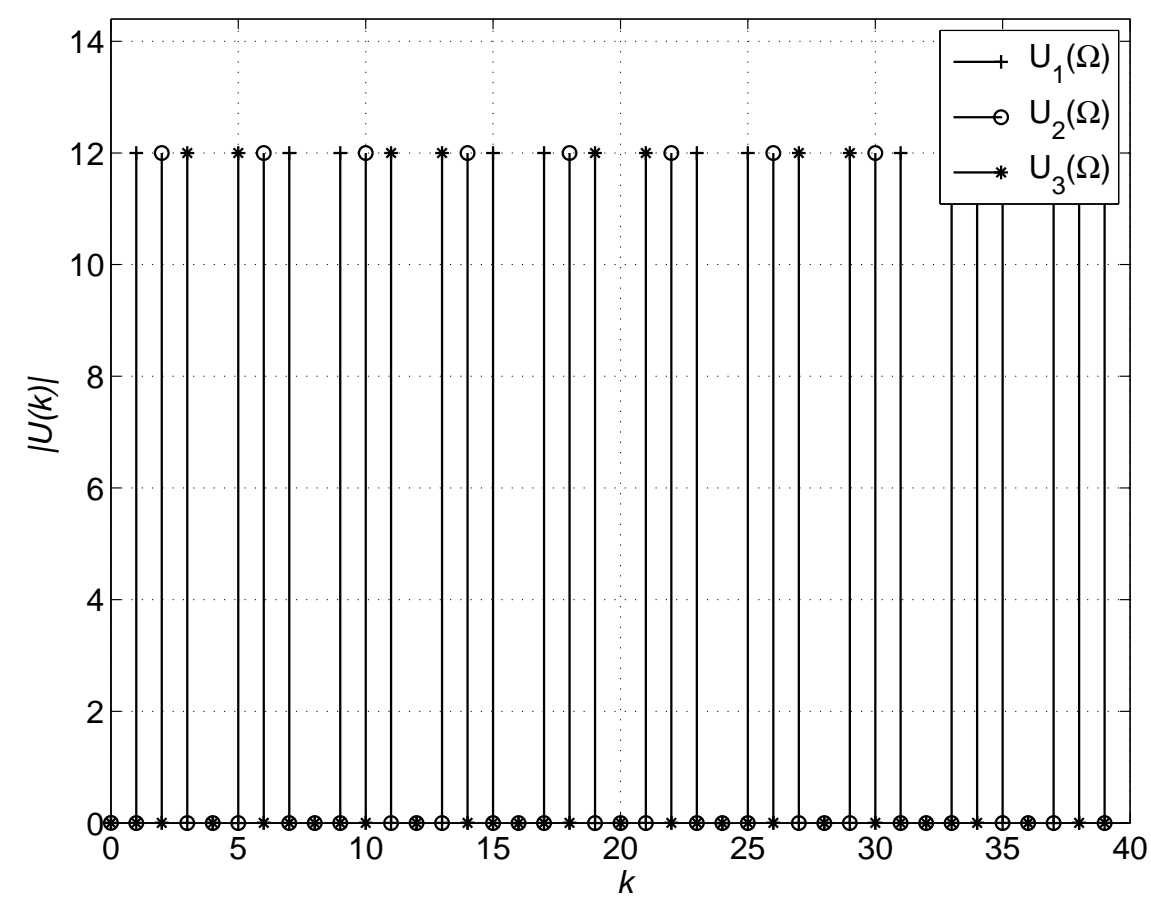

Figura 6.6: Módulo da DFT das sequências MLNL de comprimento $N=80$.
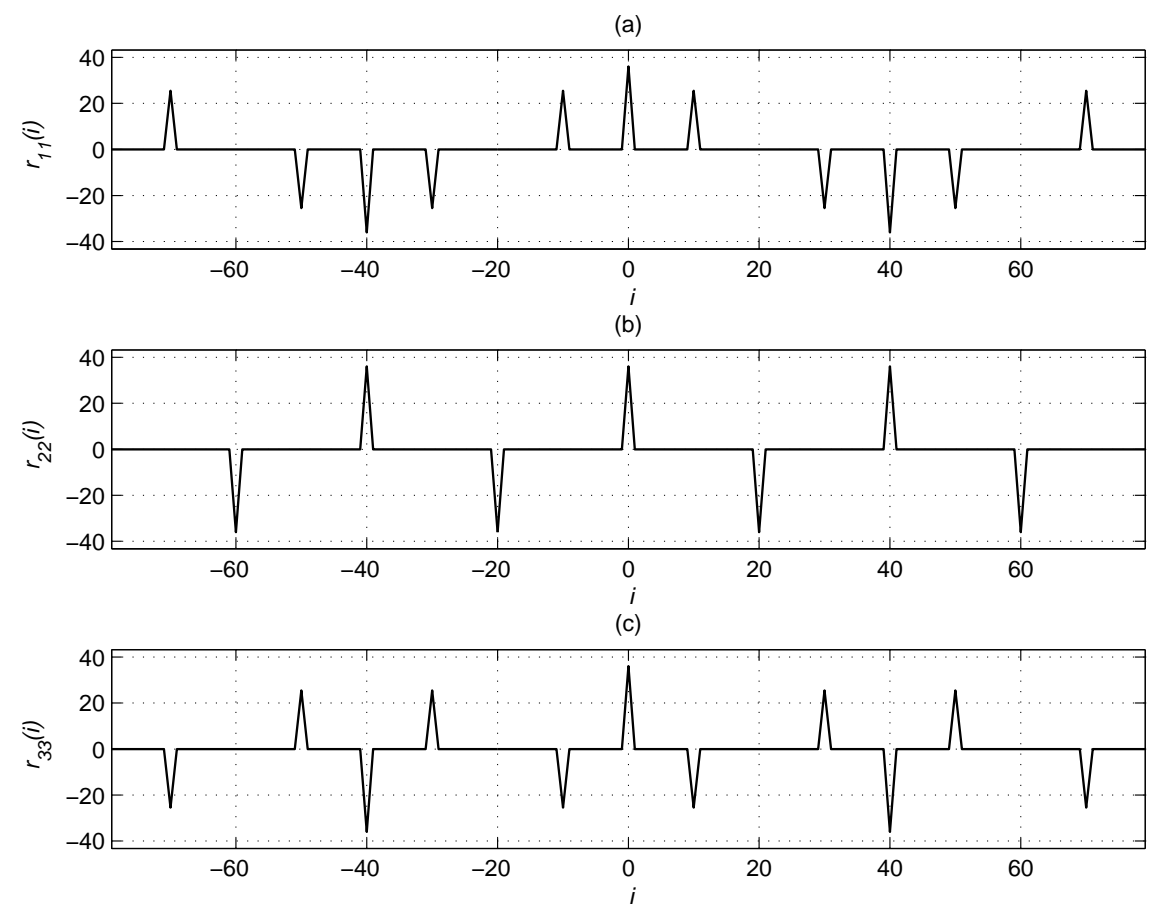

Figura 6.7: Função de autocorrelação periódica das sequências MLNL de comprimento $N=80$.

\subsubsection{Resumo das características do conjunto de sinais MLNL}

As boas características do método proposto aqui para gerar os sinais MLNL são listadas abaixo: 
(a)

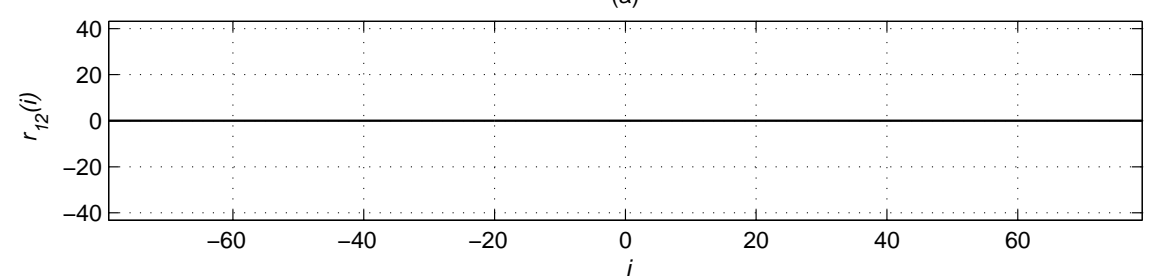

(b)

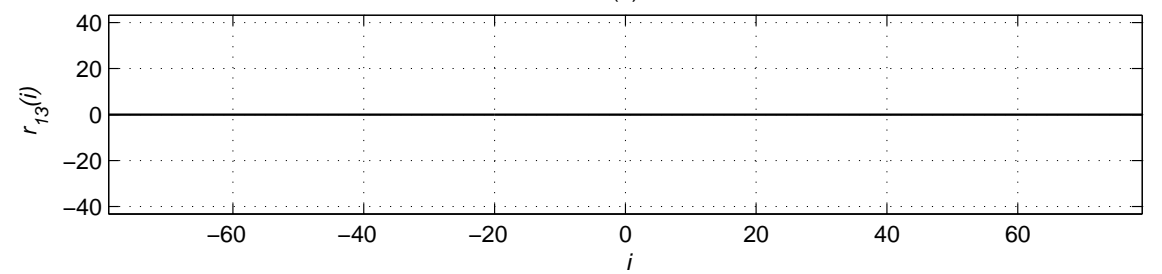

(c)

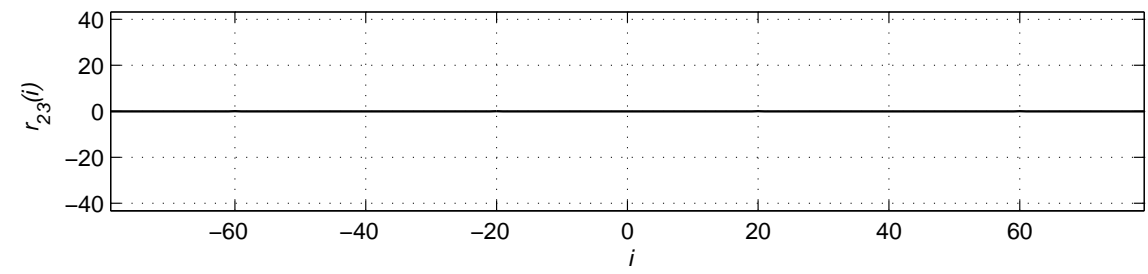

Figura 6.8: Função de correlação cruzada periódica entre as sequências MLNL de comprimento $N=80$.

1. Possibilidade de gerar sinais multinível com qualquer quantidade de níveis;

2. Zona de correlação reduzida (LCZ) garantida, dada por $\frac{q^{n}-1}{q^{m}-1}$, sendo necessário apenas que as sementes possuam correlação cruzada $r_{u v}(d)=0$ nula para $d=0$ e sejam balanceadas;

3. Maior PIPS em relação aos sinais SOH. Por exemplo, um conjunto MLNL de 3 sinais com $q=2, m=3, n=6$, resulta em $N=63$ e PIPS $=70,14$. Sinais Schroeder-SOH $u_{1}, u_{2}$ e $u_{3}$ com espectro intercalado, resultam em PIPS = 47,$81 ; 48,36 ; 57,04$, respectivamente. A zona de correlação reduzida desse conjunto MLNL é de $\frac{q^{n}-1}{q^{m}-1}=9$. O conjunto de sinais Schroeder-SOH não tem zona de correlação reduzida. Adicionalmente, um dos sinais tem período igual a 21, ou seja, picos de autocorrelação a cada 21 deslocamentos;

4. Caso seja desejável limitar a quantidade de níveis dos sinais MLNL, as sementes podem ser sinais MLMH. Essa construção possui a vantagem em relação à construção de sinais MLMH, pois o algoritmo de otimização de fases trata de sequências sementes de comprimento $q^{m}-1$, o que é exponencialmente menor que o comprimento das sequências propriamente ditas $N=q^{n}-1$, com $m$ fator de $n$.

5. Possibilidade de comprimentos $N$ e quantidade de sinais ortogonais diferentes dos obtidos com a geração de sinais Gallev com espectro intercalado. A tabela 
6.2 apresenta alguns exemplos.

Tabela 6.2: Exemplos de conjuntos de sequências MLNL propostos neste trabalho e de conjuntos de sequências Gallev.

\begin{tabular}{ccccccc}
\hline Método & $n_{r}$ & $N$ & $q(G F(q))$ & $n$ & $m$ & $L$ \\
\hline Gallev & 2 & 24 & 5 & 2 & NA & 4 \\
Gallev & 3 & 48 & 7 & 2 & NA & 6 \\
MLNL & 3 & 63 & 2 & 6 & 3 & 7 \\
MLNL & 4 & 80 & 3 & 4 & 2 & 8 \\
Gallev & 5 & 120 & 11 & 2 & NA & 10 \\
Gallev & 6 & 168 & 13 & 2 & NA & 12 \\
MLNL & 7 & 255 & 2 & 8 & 4 & 15 \\
Gallev & 8 & 288 & 17 & 2 & NA & 16 \\
Gallev & 9 & 360 & 19 & 2 & NA & 18 \\
Gallev & 11 & 528 & 23 & 2 & NA & 22 \\
MLNL & 12 & 624 & 5 & 4 & 2 & 24 \\
MLNL & 13 & 728 & 3 & 6 & 3 & 26 \\
Gallev & 14 & 840 & 29 & 2 & NA & 28 \\
Gallev & 15 & 960 & 31 & 2 & NA & 30 \\
MLNL & 15 & 1023 & 2 & 10 & 5 & 31 \\
Gallev & 18 & 1368 & 37 & 2 & NA & 36 \\
Gallev & 20 & 1680 & 41 & 2 & NA & 40 \\
Gallev & 21 & 1848 & 43 & 2 & NA & 42 \\
Gallev & 23 & 2208 & 47 & 2 & NA & 46 \\
MLNL & 24 & 2400 & 7 & 4 & 2 & 41 \\
Gallev & 26 & 2808 & 53 & 2 & NA & 52 \\
Gallev & 29 & 3480 & 59 & 2 & NA & 58 \\
Gallev & 30 & 3720 & 61 & 2 & NA & 60 \\
MLNL & 31 & 4095 & 2 & 12 & 6 & 63 \\
\hline
\end{tabular}




\section{Comparação dos sinais de excitação}

Neste capítulo, é apresentado um resumo comparativo das características dos sinais de excitação discutidos no capítulos 5 e 6 . São observadas as seguintes características:

1. Comprimentos $N_{s}$ disponíveis;

2. Amplitude quantizada ou contínua;

3. Flexibilidade de modelar a envoltória do espectro;

4. Disponibilidade de conjuntos de sinais de ortogonais para identificação multivariável;

5. Possibilidade de supressão de harmônicas para identificação de plantas com distorções não lineares;

6. Valores obtidos para os índices de desempenho nos exemplos do capítulo anterior: PIPS, PIPSE, EMINE, TF e CF.

Os sinais de excitação estudados neste trabalho são listados abaixo.

1. Sinais aleatórios:

(a) Ruído binário (BN) com sementes distintas;

(b) Ruído binário generalizado (GBN) com sementes distintas.

2. Sinais SOH:

(a) Schroeder-SOH com espectros intercalados;

(b) clipping-SOH com espectros intercalados;

(c) Binário de intervalo discreto (DIB) com espectros intercalados;

(d) Ternário de intervalo discreto (DIT) com espectros intercalados; 
(e) Multi harmônico multinível (MLMH) com espectros intercalados.

3. Sinais de espectro fixo:

(a) Binário de resíduo quadrático $(\mathrm{QRB})$;

(b) Ternário de resíduo quadrático (QRT);

(c) Binário Hall (HAB);

(d) Binário de primos gêmeos (TPB);

(e) Pseudo-aleatório binário (PRB);

(f) Pseudo-aleatório multinível (PRML);

4. Conjuntos de sinais de espectro fixo:

(a) Pseudo-aleatório ternário (PRT).

(b) Binários ou quase binários modulados por funções de Rademacher (Rademacher-QRB, Rademacher-QRT, Rademacher-HAB, Rademacher-TPB e Rademacher-PRB);

(c) Cópias de sinais ciclicamente deslocados (shift-QRB, shift-QRT, shift-HAB, shift-TPB e shift-PRB);

5. Conjuntos de sinais de híbridos:

(a) Gallev.

6. Propostas de conjuntos de sinais:

(a) Pseudo-aleatórios multinível ortogonais (PRMO), os quais são de espectro fixo;

(b) Não lineares multinível (MLNL), os quais são híbridos;

\subsection{Quadro comparativo dos sinais de excitação}

A tabela 7.1 resume comparativamente as características desses sinais. Os sinais aleatórios e $\mathrm{SOH}$ podem ser gerados em qualquer comprimento $N_{s}$. A restrição do comprimento está relacionada com a faixa de frequências que se deseja excitar $\left(\omega_{L} \mathrm{e}\right.$ $\omega_{H}$ ), período de amostragem $T$ e, no caso dos sinais $\mathrm{SOH}$, quantidade de harmônicas especificadas $n_{s}$, conforme (5.47) e (5.50). Diferentemente, os sinais de espectro fixo e híbridos apresentam limitações na escolha do comprimento $N_{s}=\frac{T_{c l k}}{T} N$, devido limitações do comprimento $N$ das sequências geradoras. A tabela 7.1 apresenta as 
expressões analíticas para os comprimentos $N$ disponíveis para os sinais de espectro fixo.

Sinais $\mathrm{SOH}$ possuem a característica do espectro poder ser construído livremente conforme a necessidade. As restrições para definição da envoltória do sinal se resumem ao comprimento $N_{s}$ do sinal e o período de amostragem $T$ expressas por (5.47) e (5.50). Os sinais DIB, DIT e MLMH são sinais SOH de amplitude quantizada. Essa característica é desejável em aplicações práticas onde a MV aceita apenas uma quantidade limitada de níveis de excitação. Adicionalmente, do ponto de vista operacional, há maior aceitação por sinais quantizados, conforme tabela 3.2.

Um sinal BN, conforme a seção 5.1.1, pode ter seu espectro moldado por meio de filtragem, tornando-se um sinal BN colorido. Alternativamente, o sinal GBN é gerado com espectro definido por (5.15). O formato do espectro é ajustado pelo parâmetro $p$, o qual representa a probabilidade de não chaveamento do sinal, conforme a figura 5.9. Observa-se que não há grande liberdade para ajuste do espectro do GBN. A ortogonalidade de sinais aleatórios é garantida quando $N_{s} \rightarrow \infty$.

Todos os sinais de espectro fixo sem supressão de harmônicas possuem espectro plano quando $\frac{T_{c} l k}{T}=1$. Os sinais binários (ou quase binários) QRB, QRT, HAB, TPB e PRB possuem características de correlação e índices de desempenho praticamente iguais. Assim, a escolha do sinal pode ser direcionada pelo comprimento $N$ disponível da sequência que melhor se adapta à aplicação. A principal vantagem do sinal PRML é a possibilidade de supressão de harmônicas, o que é desejável em identificação de plantas com distorções não lineares. Os sinais PRT também possuem a característica de supressão de harmônicas. Porém, a supressão tem como objetivo obter sinais com espectros intercalados (zippered spectrum) e, portanto, sinais ortogonais. Essa característica é desejável para identificação multivariável (2.45).

A modulação de sinais binários ou quase binários por funções de Rademacher resulta em um conjunto de sinais com espectros intercalados. É possível obter sinais multinível ortogonais com a proposta apresentada neste trabalho (seção 6.1). Os sinais PRMO preenchem a lacuna de disponibilidade de sinais multinível com espectros intercalados construídos algebricamente.

É possível também obter sinais $\mathrm{SOH}$ ortogonais, definindo os espectros dos sinais com harmônicas não coincidentes. Os sinais Schroeder-SOH com espectros intercalados tendem a ter reduzidos PIPS (e elevados CF), quando a quantidade de sinais do conjunto se eleva, o que não é desejável (3.10). Alternativamente, os sinais Gallev e os sinais MLNL permitem gerar sinais multinível com elevados PIPS (seção 6.2). Os sinais MLNL, propostos neste trabalho, oferecem comprimentos $N_{s}$ complementares 
aos disponíveis pelos sinais Gallev, conforme seção 6.2 (exemplos na tabela 6.2).

Em resumo, para todos os casos de espectro definido pelo usuário ou zippered indicados na tabela 7.1, podem-se gerar sinais cuja correlação cruzada seja nula ou aproximadamente nula, o que é desejável em identificação multivariável (2.45). Dessa forma, para obter uma matriz de correlações $R$ não singular em um experimento de identificação multivariável, a parametrização dos sinais restringe-se apenas ao tempo de acomodação $T_{\max }^{\text {set }}$ ajustado à função de autocorrelação, pois as funções de correlação cruzada entre os sinais serão sempre nulas.

Para realizar a comparação de índices de desempenho dos sinais de excitação estudados neste trabalho, considera-se a planta cujos parâmetros são apresentados na tabela 5.2. Os parâmetros para sinais do tipo aleatório BN e GBN são aqueles apresentados na seções 5.1.1.1 e 5.1.2.1, respectivamente. Para sinais do tipo $\mathrm{SOH}$, os parâmetros são aqueles apresentados na seção 5.2.5. Os parâmetros para sinais de espectro fixo, foram apresentados na seção 5.3.11. Todos esses parâmetros estão transcritos na tabela 7.2 .

A tabela 7.3 apresenta uma comparação de índices de desempenho para os sinais estudados neste trabalho. Os índices de desempenho PIPS e CF são calculados apenas com informação do sinal de excitação. Já para o cálculo do índice PIPSE é necessário ter a informação de quais harmônicas são de interesse no sistema. Para o cálculo dos índices EMINE e TF, além da informação de quais harmônicas são de interesse, é necessário especificar as amplitudes das harmônicas desejáveis para o espectro do sinal.

Os sinais binários apresentam PIPS $=100 \%$ e $C F=1$. Para o cálculo do EMINE e do TF para os sinais BN e GBN, utilizou-se como referência a resposta do mesmo filtro que gerou o sinal $\mathrm{BN}$ colorido a partir do sinal BN (seção 5.1.1.1). Os resultados para os índices EMINE e TF para esses sinais não são bons devido seus espectros serem aleatórios e apresentarem amplitude reduzida comparativamente a pelo menos uma das harmônicas não nulas especificadas. A medida que $N_{s} \rightarrow \infty$, seus espectros tenderão à envoltória especificada e, consequentemente, os índices EMINE e TF tendem a melhorar. Observa-se, portanto, que a desvantagem desses sinais é a necessidade de $N_{s}$ elevado para que seus espectros se aproximem do especificado.

Sinais SOH com fases não otimizadas apresentam PIPS e PIPSE reduzidos e CF elevados, devido aos picos de amplitude dos sinais no domínio do tempo serem elevados. Com a otimização de fases (sinais Schroeder-SOH e clipping-SOH) esses picos de amplitude são reduzidos fazendo com que os índices PIPS e PIPSE sejam elevados e o CF seja reduzido. Quanto mais esparso for o espectro do sinal, o que ocorre 
com o aumento de sinais com espectros intercalados, conforme discutido nas seções 5.2.1.1, 5.4 e 6.2, menos eficaz é a otimização de fases pelo método de Schroeder para obter reduzido CF. Alternativamente, podem ser utilizados os sinais Gallev ou MLNL, os quais resultam em PIPS e PIPSE reduzidos e CF elevado. Exemplos comparativos com esses sinais serão apresentados no capítulo 10.

Observa-se que a quantização de amplitude do sinal SOH gerando um sinal DIB, DIT ou MLMH faz com que os índices PIPS, PIPSE e CF melhorem em detrimento da distorção de seu espectro, a qual faz o índice EMINE diminuir. Por outro lado, o índice EMINE para os sinais SOH contínuos é muito próximo do máximo, pois os espectros desses sinais atendem quase que perfeitamente o espectro especificado.

Os sinais PRML, PRMO e PRT, por não serem binários possuem CF maior que 1 e PIPS e PIPSE menores que 100\%. A maior quantidade de níveis não permite que a energia do sinal seja máxima dada as amplitudes de pico do sinal. Porém, o EMINE para esses sinais é máximo, pois seus espectros são determinísticos e atendem fielmente o espectro e as supressões de harmônicas definidos para essa avaliação. 
Tabela 7.1: Comparação de características dos sinas de excitação estudados neste trabalho.

\begin{tabular}{|c|c|c|c|c|c|c|}
\hline Tipo de sinal & Sinal & $\begin{array}{l}\text { Quantidade } \\
\text { de níveis }\end{array}$ & $\begin{array}{l}\text { Comprimento } N_{s} \\
(N \text { para sinais de } \\
\text { espectro fixo) }\end{array}$ & $\begin{array}{l}\text { Característica } \\
\text { do espectro }\end{array}$ & $\begin{array}{l}\text { Sinais } \\
\text { ortogonais }\end{array}$ & $\begin{array}{l}\text { Supressão de } \\
\text { harmônicas pares e } \\
\text { múltiplas de } 3\end{array}$ \\
\hline Aleatório & $\mathrm{BN}$ & 2 & Qualquer & Plano quando $N \rightarrow \infty$ ou filtrado & Não & Não \\
\hline Aleatório & GBN & 2 & Qualquer & Pouco ajustável (equação (5.15)) & Não & Não \\
\hline $\mathrm{SOH}$ & Schroeder-SOH & Contínuo & Qualquer & Definido pelo usuário & Sim & Sim \\
\hline $\mathrm{SOH}$ & Clipping-SOH & Contínuo & Qualquer & Definido pelo usuário & Sim & Sim \\
\hline $\mathrm{SOH}$ & DIB & 2 & Qualquer & Definido pelo usuário com limitações ${ }^{1}$ & Sim & Sim \\
\hline $\mathrm{SOH}$ & DIT & 3 & Qualquer & Definido pelo usuário com limitações ${ }^{1}$ & Sim & Sim \\
\hline $\mathrm{SOH}$ & MLMH & Pelo usuário & Qualquer & Definido pelo usuário com limitações ${ }^{1}$ & Sim & Sim \\
\hline Espectro fixo & QRB & 2 & $4 k-1, N$ primo & Plano & Não & Não \\
\hline Espectro fixo & QRT & 3 & $4 k, N$ primo & Plano & Não & Não \\
\hline Espectro fixo & HAB & 2 & $4 k^{2}+27, N$ primo & Plano & Não & Não \\
\hline Espectro fixo & TPB & 2 & $k(k+2), k$ e $k+2$ primos & Plano & Não & Não \\
\hline Espectro fixo & PRB & 2 & $2^{m}-1$ & Plano & Não & Não \\
\hline Espectro fixo & PRML & 3,5 ou 7 & $q^{m}-1,2<q \leq 13$ primo & Plano com supressão de harmônicas ${ }^{2}$ & Não & Não \\
\hline Espectro fixo & PRML & 3,5 ou 7 & $q^{m}-1, q=7$ ou 13 & Plano com supressão de harmônicas ${ }^{3}$ & Não & Sim \\
\hline Espectro fixo & PRT & 3 & $q^{m}-1, q>3$ e primo & Zippered & Sim & Não \\
\hline Espectro fixo & Rademacher-(.. $)^{4}$ & nota 4 & $2^{n_{r}-1} L$ & Zippered & Sim & Não \\
\hline Espectro fixo & shift- $(.)^{5}$ & nota 5 & nota 5 & nota 5 & Não & Não \\
\hline Espectro fixo & PRMO & 3,5 ou 7 & $q^{m}-1,2<q \leq 13$ primo e $\frac{q^{m}-1}{2}$ ímpar & Zippered & Sim & Não \\
\hline Híbrido & Gallev & Pelo usuário & $q^{n}-1, q^{2}$ e primo & Zippered & Sim & Não \\
\hline Híbrido & MLNL & Pelo usuário & $q^{n}-1, q$ primo, $m \mid n$ e $m>1$ & Zippered & Sim & Não \\
\hline
\end{tabular}

Notas:

$k, m, n \in \mathbb{N} * ; n_{r}$ é a quantidade de sinais (quantidade de entradas da planta)

${ }^{1}$ Limitações devido a quantização do sinal contínuo SOH. ${ }^{2}$ Harmônicas pares são suprimidas. ${ }^{3}$ Harmônicas múltiplas de 2 e 3 são suprimidas.

${ }^{4}$ Os sinais QRB, QRT, HAB, TPB ou PRB podem ser modulados por funções de Rademacher (seção 5.3.7).

${ }^{5}$ Sinais QRB, QRT, HAB, TPB, PRB ou PRML deslocados ciclicamente (seção 5.3.10). 
Tabela 7.2: Parâmetros dos sinas de excitação para comparação de índices de desempenho.

\begin{tabular}{|c|c|c|c|c|c|c|c|}
\hline Tipo de sinal & $\begin{array}{c}\text { Sinal / } \\
\text { supressão de } \\
\text { harmônicas }\end{array}$ & $\begin{array}{l}\text { Número } \\
\text { de níveis }\end{array}$ & $\begin{array}{c}\text { Período de } \\
\text { amostragem } \\
T \\
\text { (segundos) }\end{array}$ & $\begin{array}{c}\text { Período de } \\
\text { chaveamento } \\
T_{c l k} \\
\text { (segundos) }\end{array}$ & $\begin{array}{l}\text { Comprimento } \\
\text { do sinal } N\end{array}$ & $\begin{array}{c}\text { Número de } \\
\text { harmônicas } \\
\text { especificadas } \\
n_{s}\end{array}$ & $\begin{array}{l}\text { Amplitude das } \\
\text { harmônicas } \\
\text { especificadas }\end{array}$ \\
\hline Aleatório & $\mathrm{BN}$ & 2 & 60 & 60 & 700 & $N / 2=350$ & \multirow{2}{*}{ Resposta de $\frac{1}{1-e^{\left(-T / \tau_{\min }\right)} z^{-1}}$} \\
\hline Aleatório & GBN & 2 & 60 & 60 & 700 & $N / 2=350$ & \\
\hline $\mathrm{SOH}$ & SOH não otimizado & Contínuo & 60 & 60 & 700 & 44 & \multirow{6}{*}{$\begin{array}{l}\text { Uniforme } \\
\text { Uniforme }\end{array}$} \\
\hline $\mathrm{SOH}$ & Schroeder-SOH & Contínuo & 60 & 60 & 700 & 44 & \\
\hline $\mathrm{SOH}$ & Clipping-SOH & Contínuo & 60 & 60 & 700 & 44 & \\
\hline $\mathrm{SOH}$ & DIB & 2 & 60 & 60 & 700 & 44 & \\
\hline $\mathrm{SOH}$ & DIT & 2 & 60 & 60 & 700 & 44 & \\
\hline $\mathrm{SOH}$ & MLMH & 5 & 60 & 60 & 700 & 44 & \\
\hline Espectro fixo & QRB & 2 & 60 & 420 & 347 & $\lfloor N / 2\rfloor=173$ & \multirow{5}{*}{ Resposta do $\mathrm{ZOH}$} \\
\hline Espectro fixo & QRT & 3 & 60 & 420 & 347 & $\lfloor N / 2\rfloor=173$ & \\
\hline Espectro fixo & HAB & 2 & 60 & 420 & 282 & $N / 2=141$ & \\
\hline Espectro fixo & ТPB & 2 & 60 & 420 & 323 & $\lfloor N / 2\rfloor=161$ & \\
\hline Espectro fixo & PRB & 2 & 60 & 420 & 255 & $\lfloor N / 2\rfloor=127$ & \\
\hline Espectro fixo & PRML / \{2\} & 5 & 60 & 420 & 342 & $\lfloor N / 2\rfloor=171$ & \multirow{3}{*}{$\begin{array}{l}\text { Resposta do } \mathrm{ZOH} \text { com } \\
\text { sup. de harmônicas }\end{array}$} \\
\hline Espectro fixo & PRML / $\{2 ; 3\}$ & 5 & 60 & 420 & 342 & $\lfloor N / 2\rfloor=171$ & \\
\hline Espectro fixo & PRT / \{2\} & 3 & 60 & 420 & 342 & $\lfloor N / 2\rfloor=171$ & \\
\hline
\end{tabular}


Tabela 7.3: Comparação de índices de desempenho dos sinas de excitação.

\begin{tabular}{llllll}
\hline $\begin{array}{l}\text { Sinal / } \\
\text { supressão de } \\
\text { harmônicas }\end{array}$ & PIPS (\%) & PIPSE (\%) & EMINE (\%) & TF & CF \\
\hline BN & 100,00 & 95,06 & 10,93 & 46,29 & 1,00 \\
GBN & 100,00 & 93,36 & 5,99 & 159,96 & 1,00 \\
SOH não otimizado & 16,94 & 16,90 & 99,56 & NA & 9,38 \\
Schroeder-SOH & 57,74 & 57,60 & 99,56 & NA & 1,90 \\
Clipping-SOH & 32,26 & 32,19 & 99,56 & NA & 3,30 \\
DIB & 100,00 & 88,96 & 73,87 & 1,16 & 1,00 \\
DIT & 93,20 & 86,84 & 78,74 & 1,07 & 1,07 \\
MLMH & 79,53 & 77,31 & 84,17 & 1,18 & 1,26 \\
QRB & 100,00 & 98,53 & 100,00 & 0,52 & 1,00 \\
QRT & 99,86 & 98,39 & 100,00 & 0,52 & 1,00 \\
HAB & 100,00 & 98,53 & 100,00 & 0,52 & 1,00 \\
TPB & 100,00 & 98,53 & 100,00 & 0,52 & 1,00 \\
PRB & 100,00 & 98,53 & 100,00 & 0,52 & 1,00 \\
PRML / \{2\} & 62,45 & 61,54 & 100,00 & 1,32 & 1,60 \\
PRML / \{2;3\} & 66,76 & 65,79 & 100,00 & 1,16 & 1,50 \\
PRT / \{2\} & 75,70 & 74,60 & 100,00 & 0,90 & 1,32 \\
\hline
\end{tabular}




\section{Direcionalidade de ganho e plantas mal condicionadas}

Direcionalidade de ganho (gain directionality) é um termo utilizado para descrever combinações das entradas do sistema que conduzem as saídas a variações de alta ou baixa magnitude (CONNER; SEBORG, 2004). É dita que uma combinação de entradas conduz a uma direção de baixo ganho quando elas produzem variações de baixa magnitude nas saídas do sistema. Combinações de entradas que produzem variações de alta magnitude nas saídas conduzem à direção de alto ganho. As direções de ganho são determinadas por decomposição em valores singulares (singular value decomposition, SVD) da matriz de ganhos do sistema em estado estacionário, chamada matriz de ganhos estacionários (ANDERSEN; KüMMEL, 1991) (ANDERSEN; KüMMEL, 1992) (CONNER; SEBORG, 2004). Uma planta que apresenta ganhos significativamente distintos para diferentes direções de excitação são chamadas de plantas mal condicionadas.

Plantas mal condicionadas podem ser encontradas com frequência na indústria. Exemplos desse tipo de planta são: colunas de destilação de alta pureza, redes de trocadores de calor, gaseificadores (RIVERA et al., 2007) e também máquinas industriais de papel, as quais são sistemas de grande porte (large scale systems), pois envolvem dezenas de variáveis (FEATHERSTONE; BRAATZ, 1998).

As colunas de alta pureza são empregadas na separação de produtos cujos pontos de ebulição são bastante próximos, como por exemplo, propeno (propileno) e propano. Em (SKOGESTAD; MORARI, 1987) e (SKOGESTAD, 1997) discutem-se as características de uma coluna de destilação de alta pureza e as razões físicas para seu comportamento mal condicionado.

O comportamento estacionário e dinâmico particular de um processo mal condicionado pode dificultar não só o projeto do sistema de controle, mas também sua identificação (WALLER, 2003), (RIVERA et al., 2007). Em (ZHU, 2001) é mostrado que essa dificuldade não é causada pela estrutura de modelo ou método de identificação inadequado, mas ela está relacionada à escassez de dados, quando simples sinais PRB ou GBN são usados como sinais de entrada. A identificação de sistemas mal condicio- 
nados pode exigir sinais de excitação com características adicionais àquelas discutidas nos capítulos 5 e 6 . Nas direções de baixo ganho, as variações das saídas podem ser reduzidas a ponto de serem "encobertas" pelas perturbações, ou seja, podem resultar em reduzidas SNR nas saídas da planta. Portanto, o projeto dos sinais de excitação deve garantir que todas as combinações das entradas, inclusive nas direções de baixo ganho, gerem dados informativos nas saídas da planta (critério 4 discutido na seção 3.3) (MISRA; NIKOLAOU, 2003).

Os sinais de excitação podem ser ajustados de acordo com a direcionalidade de ganho para produzir variações de alta ou baixa magnitude. Assim, o conhecimento da direcionalidade de ganho da planta é importante para obter experimentos com boas SNR nas direções de alto e baixo ganho e também não exceder os limites da planta. A identificação efetiva das dinâmicas do processo implica que as direções de alto e baixo ganho devem ser adequadamente excitadas.

Várias abordagens têm sido discutidas nos últimos anos com o objetivo de superar limitações comuns do uso de sinais tradicionais, quando um processo mal condicionado é identificado (STEC; ZHU, 2001b), (LEE; RIVERA; MITTELMANN, 2003), (LEE, 2006), (TAN; GODFREY; BARKER, 2009). Todas essas procuram condicionar os sinais de entrada para superar os reduzidos ganhos em determinadas direções. Os métodos de projeto de sinais de excitação encontrados na literatura são variações de métodos tradicionais discutidos no capítulo 5.

Neste capítulo são comparadas as eficácias de cinco métodos de projeto de sinais de excitação por meio de simulações de identificação de processos mal condicionados. Adicionalmente, propõe-se um fator para avaliar o efeito dos sinais nas saídas da planta. O fator é uma medida da dispersão das saídas. Os seguintes métodos de projeto de sinais de excitação são comparados neste trabalho: entradas rotacionadas (KOUNG; MACGREGOR, 1993) (CONNER; SEBORG, 2004); métodos de dois passos (ZHU, 2001) (ZHU; STEC, 2006); sinais ternários com harmônicas correlacionadas (TAN; GODFREY; BARKER, 2009) e sinais do tipo soma de harmônicos (SOH) com espectro de potência intercalado modificado (LEE; RIVERA; MITTELMANN, 2003) (LEE et al., 2003).

Na próxima seção é feita uma breve descrição sobre processos mal condicionados e sobre o caso típico da coluna de destilação de alta pureza. Os métodos de geração de sinais de entrada citados anteriormente são discutidos na seção 8.2. Propõe-se na seção 8.3 um novo fator para medir as direções das saídas do processo mal condicionado. A seção 8.4 apresenta os resultados de simulação de identificação de colunas de destilação de alta pureza (SKOGESTAD; MORARI; DOYLE, 1988) (JACOBSEN; SKOGESTAD, 1994) empregando cada um dos métodos de geração de sinais estuda- 
dos. Considerações acerca das simulações são apresentadas na seção 8.4.3. Na seção 8.5 é proposto um aprimoramento no condicionamento de sinais para identificação de processos mal condicionados. Nessa proposta, objetiva-se restringir as excursões dos sinais de saída para próximo de seus limites, sem violá-los. Assim, maximizam-se as SNR das saídas, o que é desejável no experimento de identificação, conforme seção 3.3 .

\subsection{Coluna de destilação de alta pureza}

O mal condicionamento de uma planta é um comportamento principalmente associado ao processo altamente interativo. Uma planta que exibe este comportamento se caracteriza por ganhos significativamente diferentes, dependendo da direção das entradas.

Uma solução imediata para a identificação de uma planta mal condicionada é projetar controladores eficazes para a planta e identificá-la em malha fechada. Controladores adequados eliminam (ou minimizam) o efeito do mal condicionamento, pois desacoplam as saídas. Porém, bons controladores raramente estão disponíveis para um processo mal condicionado ou para obtê-los é necessário previamente identificar o processo (STEC; ZHU, 2001a) (ZHU; STEC, 2006). Essa limitação reitera a justificativa de obter sinais adequados para identificação de processos mal condicionados.

Um sistema linear MIMO, com ganhos estáticos de malha aberta dada pela matriz $K$, pode ser fatorado por meio de uma decomposição em valores singulares (SVD) como:

$$
K=M \Sigma V^{T}
$$

onde $M \in \mathbb{R}^{n_{p} \times n_{p}}$ e $V \in \mathbb{R}^{n_{r} \times n_{r}}$ são matrizes unitárias de rotação das saídas e entradas, respectivamente, e $\Sigma \in \mathbb{R}^{n_{p} \times n_{r}}$ é uma matriz diagonal de valores singulares não negativos $\sigma_{i}$, com $i=1,2, \ldots, \min \left\{n_{p} ; n_{r}\right\}$, arranjados em ordem descendente ao longo da pseudodiagonal principal.

A relação entre o máximo $\left(\max \left\{\sigma_{i}\right\}=\bar{\sigma}\right)$ e o mínimo $\left(\min \left\{\sigma_{i}\right\}=\underline{\sigma}\right)$ valor singular presente em $\Sigma$ é conhecida como número de condição:

$$
\gamma=\frac{\bar{\sigma}}{\underline{\sigma}}
$$

Em uma planta mal condicionada, tem-se $\gamma>>1$, o que indica que os valores das saídas do sistema dependem fortemente da direção de suas entradas e, consequente- 
mente, há altos e baixos ganhos na resposta da planta. Esse critério é dependente de escala, portanto, a fim de obter resultados consistentes, devem ser analisados valores normalizados das variáveis manipuladas (MV) e variáveis controladas (CV), garantindo que elas estejam no mesmo intervalo numérico. Em (WALLER; WALLER, 1996) é apresentada uma discussão sobre os meios de se medir a direcionalidade. Um processo altamente interativo é sempre mal condicionado, enquanto o contrário nem sempre é verdadeiro (JACOBSEN; SKOGESTAD, 1994).

A matriz de ganhos relativos (relative gain array, RGA) (BRISTOL, 1966) é uma abordagem independente de escala para detecção de interatividade e, portanto, um método alternativo para determinar o comportamento mal condicionado da planta. A RGA representada por $\Lambda$ pode ser expressa como (ZHU; STEC, 2006):

$$
\Lambda=K . *\left(K^{-1}\right)^{T}
$$

onde (.*) denota a multiplicação elemento a elemento da matriz.

Mais especificamente, $\Lambda$ pode ser entendido como:

$$
\Lambda=\left[\lambda_{i j}\right]_{n_{p} \times n_{r}}
$$

onde $\lambda_{i j}$ é o quociente entre $k_{i j}$, ganho do $i j$-ésimo subsistema de $G$ com todas as malhas abertas, e $k_{i j}^{*}$, ganho do $i j$-ésimo subsistema de $G$ com apenas a $i$-ésima malha aberta:

$$
\lambda_{i j}=\left[\frac{k_{i j}}{k *_{i j}}\right]
$$

Para um sistema linear MIMO de duas entradas e duas saídas $(2 \times 2)$, considerando $\lambda=\lambda_{11}=\lambda_{22} ; 1-\lambda=\lambda_{12}=\lambda_{21}$ (CONNER; SEBORG, 2004), $\Lambda$ pode ser expresso como:

$$
\Lambda=\left[\begin{array}{cc}
\lambda & 1-\lambda \\
1-\lambda & \lambda
\end{array}\right]
$$

Em um processo interativo, tem-se $|\lambda|>>1$, o que implica em uma planta com comportamento mal condicionado.

O comportamento mal condicionado e altamente interativo do processo pode ser também avaliado utilizando (8.1) e (8.3) no domínio da frequência. Considerando $G(j \omega)$ a matriz de transferência do processo, tem-se (ZHU; STEC, 2006): 


$$
G(j \omega)=M(j \omega) \Sigma(j \omega) V(j \omega)^{T}
$$

$$
\Lambda(j \omega)=G(j \omega) . *\left(G(j \omega)^{-1}\right)^{T}
$$

De forma similar ao estado estacionário, valores de $\gamma(j \omega)$ e $\lambda(j \omega)$ maiores que a unidade implicam em comportamento mal condicionado e altamente interativo do processo.

Neste trabalho, o problema de construir sinais de entrada para identificação de processos mal condicionados é exemplificado utilizando dois modelos simplificados e linearizados (chamados aqui simplesmente de plantas) de uma coluna de destilação de alta pureza (SKOGESTAD; MORARI; DOYLE, 1988) (SKOGESTAD, 1997). As razões para a escolha dessas plantas são comentadas na seção 8.2.

O diagrama simplificado da coluna operando na configuração L-V é mostrado na Figura 8.1. Nessa configuração $L$ (vazão de refluxo) e $V$ (vazão no refervedor) são as entradas da planta (MV) e $y_{D}$ (composição do destilado) e $x_{B}$ (composição do produto de fundo) são as saídas (CV). Ambas composições são dadas como fração molar do produto leve. Neste trabalho, as entradas $u_{1}$ e $u_{2}$ das plantas referem-se a $L / F$ e $V / F$ em torno de seus pontos de operação, $\operatorname{com} F$ a vazão de carga da coluna. As saídas $y_{1}$ e $y_{2}$ referem-se às composições $y_{D}$ e $x_{B}$, respectivamente.

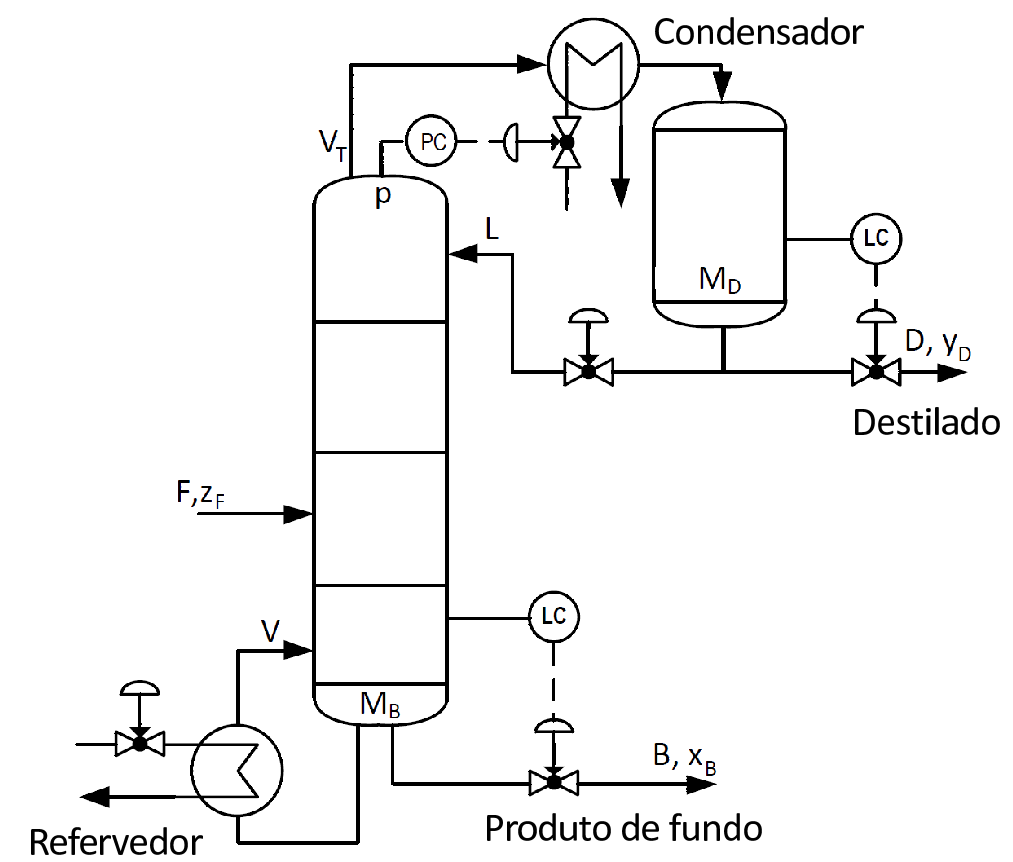

Figura 8.1: Coluna de alta pureza operando na configuração L-V (SKOGESTAD, 1997). 
Um modelo fenomenológico linearizado da coluna com 82 pratos foi apresentado em (JACOBSEN, 1994). Em (SKOGESTAD; MORARI; DOYLE, 1988) foi discutido um modelo simplificado de primeira ordem para essa coluna. Em (JACOBSEN; SKOGESTAD, $1994)$ as respostas dinâmicas de modelos de primeira $\left(G_{1}(s)\right)$ e segunda ordem $\left(G_{2}(s)\right)$ desta coluna foram comparadas com respostas do modelo fenomenológico de 82 pratos. Bons ajustes da resposta dinâmica foram obtidos com o modelo de segunda ordem, chamado de caso N2 em (JACOBSEN; SKOGESTAD, 1994). As plantas $G_{1}(s)$ e $G_{2}(s)$ são:

$$
G_{1}(s)=\frac{1}{\tau s+1}\left[\begin{array}{ll}
k_{11} & k_{12} \\
k_{21} & k_{22}
\end{array}\right]
$$

onde $\tau=75$ minutos, $k_{11}=87,8, k_{12}=-86,4, k_{21}=108,2$ e $k_{22}=-109,6$,

$$
G_{2}(s)=\left[\begin{array}{ll}
\frac{k_{11}}{1+\tau_{1} s} & \frac{k_{11}+k_{12}}{1+\tau_{2} s}-\frac{k_{11}}{1+\tau_{1} s} \\
\frac{k_{21}}{1+\tau_{1} s} & \frac{k_{21}+k_{22}}{1+\tau_{2} s}-\frac{k_{21}}{1+\tau_{1} s}
\end{array}\right]
$$

onde $\tau_{1}=194$ minutos, $\tau_{2}=15$ minutos e $k_{11}, k_{12}, k_{21}$ e $k_{22}$ os mesmos da planta de primeira ordem $G_{1}(s)$.

A planta $G_{2}(s)$ incorpora duas constantes de tempo, as quais correspondem às dinâmicas diferentes nas direções de baixo e alto ganho. A direção de baixo ganho apresenta dinâmicas mais rápidas que a de alto ganho $\left(\tau_{1} \gg \tau_{2}\right)$. Essa característica de dinâmicas distintas nas diferentes direções dos ganhos é um comportamento comum de plantas mal condicionadas (JACOBSEN, 1994). A planta $G_{1}(s)$, mais simplificada, apresenta dinâmicas iguais para as direções de alto e baixo ganho.

A direcionalidade de ganho da coluna de destilação de alta pureza está associada a diferenças das respostas frente a alterações nas vazões internas e externas. Alterações nas vazões internas ocorrem com alterações simultâneas em $\frac{L}{F}$ e $\frac{V}{F}$, mantendo as vazões do destilado $(D)$ e do produto de fundo $(B)$ constantes. Entende-se como alterações nas vazões externas qualquer variação que implique em alterações na relação $\frac{D}{B}$.

O comportamento mal condicionado dessa planta faz com que a direção do vetor de entrada $[1,1]^{T}$ ( $\frac{L}{F}$ e $\frac{V}{F}$ na figura 8.1) produza um pequeno efeito (direção de baixo ganho) nas saídas $y_{1}$ e $y_{2}$ (composições $y_{D}$ e $x_{B}$ ) e, para a planta de segunda ordem $\left(G_{2}(s)\right)$, com reduzida constante de tempo, conforme (8.10). Contudo, a direção do vetor de entrada $[1,-1]^{T}$ (direção de alto ganho) provoca significativas variações nas saídas e, para a planta de segunda ordem $\left(G_{2}(s)\right)$, com elevada constante de tempo, conforme (8.10). Para a planta de primeira ordem $G_{1}(s)$ as constantes de tempo são 
iguais e independentes das direções de ganho (8.9).

Essas direções de alto e baixo ganho são indicadas na figura 8.2 sobre o plano de saídas $\left\{y_{1} ; y_{2}\right\}$, resultado de um teste com um sinal PRB. Sinais de entrada projetados para identificação de plantas mal condicionadas devem garantir efeitos nas direções de alto e baixo ganho e, ao mesmo tempo, não exceder as restrições operacionais.

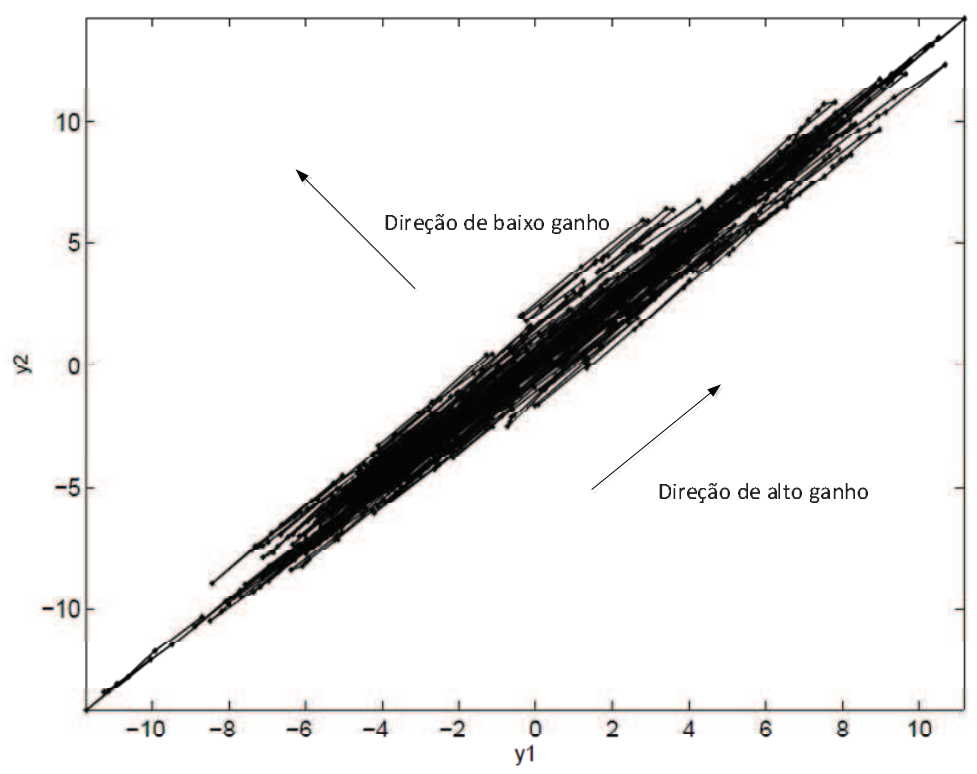

Figura 8.2: Plano de saídas $\left\{y_{1} ; y_{2}\right\}$ resultado de um teste com sinal PRB no modelo $G_{2}(s)$ da coluna de destilação de alta pureza.

Na planta de segunda ordem $G_{2}(s)$, observa-se uma redução do efeito do mal condicionamento (redução de $\gamma(j \omega)$ ) em frequências elevadas, conforme a figura 8.3. Na planta de primeira ordem $G_{1}(s), \gamma(j \omega)$ se mantém constante, não apresentando a variação em frequência do efeito do mal condicionamento (figura 8.4).

De (8.9) e (8.10), tem-se que as plantas $G_{1}(s)$ e $G_{2}(s)$ possuem a mesma matriz de ganhos estáticos $K$ :

$$
K=\left[\begin{array}{cc}
87,8 & -86,4 \\
108,2 & -109,6
\end{array}\right]
$$

Essa matriz $K$ resulta em $\lambda=35,068$, calculado por (8.5), e no número de condição $\gamma=141,73$, calculado por (8.2). Isso significa que os modelos $G_{1}(s)$ e $G_{2}(s)$ da coluna de alta pureza são altamente interativos e mal condicionados.

Para a planta de primeira ordem $G_{1}(s)$, tem-se $\tau_{\max }=\tau_{\min }=\tau$. Adotando $\beta_{s}=5 \mathrm{e}$ $\alpha_{s}=1$, a faixa de frequências de interesse é $B W_{1}=B W_{2}=B W$ : 


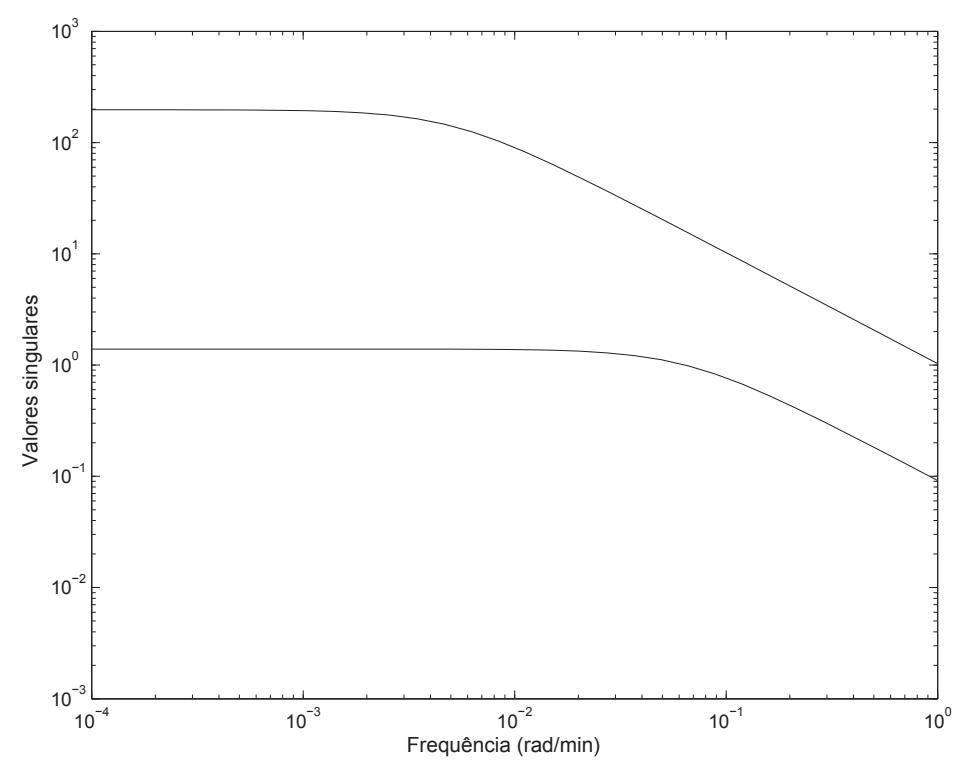

Figura 8.3: Valores singulares do modelo $G_{2}(s)$ da coluna de destilação de alta pureza.

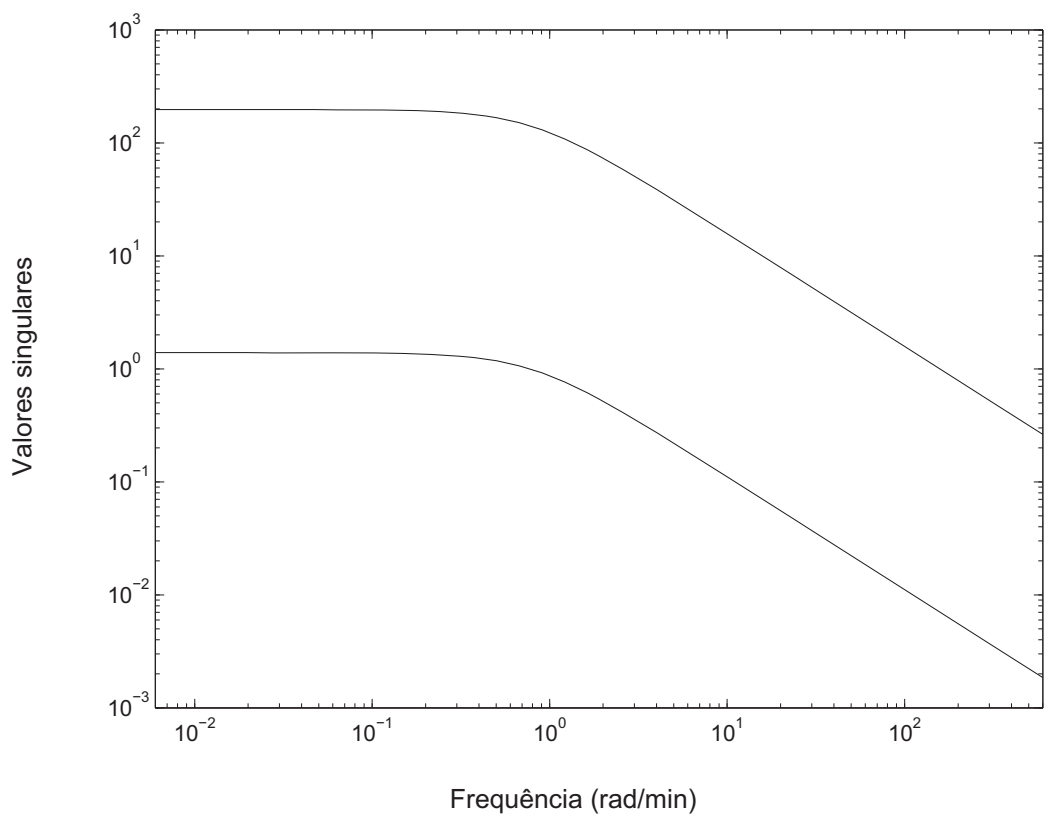

Figura 8.4: Valores singulares do modelo $G_{1}(s)$ da coluna de destilação de alta pureza.

$$
\begin{aligned}
B W & =\left\{\omega_{L} ; \omega_{H}\right\} \\
\omega_{L} & =\frac{1}{\beta_{s} \tau_{\max }} \leq \omega \leq \frac{\alpha_{s}}{\tau_{\min }}=\omega_{H} \\
\omega_{L} & =0,0026 \leq \omega \leq 0,0133=\omega_{H} \mathrm{rad} / \mathrm{min}
\end{aligned}
$$

Conforme discutido anteriormente, a planta de segunda ordem $G_{2}(s)$ apresenta dinâmicas diferentes dependendo da combinação das entradas, ou seja, dependendo 
das direções de ganhos. Por esse motivo, a faixa de frequências de interesse da planta é definida a mesma para ambas as entradas $B W_{1}=B W_{2}=B W$, cobrindo todo o espectro para qualquer combinação de entradas, assim como foi estabelecido na parametrização dos conjuntos de sinais de espectro fixo (5.88), (5.89) e (5.90).

Sendo $\tau_{\max }=\max \left\{\tau_{1} ; \tau_{2}\right\}=\max \{194 ; 15\}=194$ minutos, $\tau_{\min }=\min \left\{\tau_{1} ; \tau_{2}\right\}=$ $\min \{194 ; 15\}=15$ minutos e adotando-se $\beta_{s}=5$ e $\alpha_{s}=1$, tem-se a faixa de frequência de interesse da planta $G_{2}(s)$, a qual representa o conteúdo harmônico que deve estar presente nos sinais de excitação:

$$
\begin{aligned}
B W & =\left\{\omega_{L} ; \omega_{H}\right\} \\
\omega_{L} & =\frac{1}{\beta_{s} \tau_{\max }} \leq \omega \leq \frac{\alpha_{s}}{\tau_{\min }}=\omega_{H} \\
\omega_{L} & =0,0010 \leq \omega \leq 0,0667=\omega_{H} \mathrm{rad} / \mathrm{min}
\end{aligned}
$$

Para as simulações com a planta de primeira ordem $G_{1}(s)$, o período de amostragem adotado foi $T=2$ minutos, o que corresponde a uma taxa de amostragem aproximadamente 5 vezes maior que a maior frequência de interesse (8.12). Para as simulações com a planta de segunda ordem $G_{2}(s)$, foi adotado $T=1$ minuto, o que corresponde a uma taxa de amostragem aproximadamente 2 vezes maior que a maior frequência de interesse (8.13).

\subsection{Métodos de projeto de sinais de excitação para plan- tas mal condicionadas}

Para excitação de plantas mal condicionadas em malha aberta, a variância das excitações poderia ser aumentada de forma a tornar a variância das saídas na direção de baixo ganho representativa frente às perturbações. Porém, provavelmente na direção de alto ganho a variação das saídas iria extrapolar os limites operacionais da planta, assim como na figura 8.2. Apesar dos ganhos discrepantes, os requisitos práticos da identificação (plant-friendliness) devem ser respeitados. A identificação efetiva de um processo mal condicionado implica que as direções de alto e baixo ganho devem ser excitadas proporcionalmente.

Sinais de excitação para identificação de processos mal condicionados devem garantir efeito oposto ao causado pelos sinais não correlacionados, tipicamente empregados em identificação de sistemas "bem condicionados". Cinco métodos de geração de sinais para excitação de plantas mal-condicionadas são discutidos nas próximas seções. 


\subsubsection{Sinais rotacionados}

Em (KOUNG; MACGREGOR, 1993) foi proposto um método de projeto que utiliza sinais altamente correlacionados para identificação de plantas mal condicionadas $2 \times 2$. Em (CONNER; SEBORG, 2004), o método foi generalizado para plantas $n_{r} \times n_{p}$. Esse método é capaz de excitar o processo nas direções de alto e baixo ganho. O método utiliza entradas rotacionadas, a fim de evitar a geração de dados predominantemente alinhados na direção de alto ganho, enfatizando a direção de baixo ganho. A rotação das entradas é realizada a partir da matriz de rotação $V$ resultante da SVD da matriz de ganhos estáticos da planta (8.1).

Seja o conjunto $U$ de sinais de excitação:

$$
U=\left[\begin{array}{llll}
\mathbf{u}_{1} & \mathbf{u}_{2} & \ldots & \mathbf{u}_{\mathbf{n}_{\mathbf{r}}}
\end{array}\right]
$$

Em (CONNER; SEBORG, 2004), um conjunto $U$ de sinais PRB é rotacionado e amplificado, resultando nos sinais rotacionados:

$$
U^{\prime}=\alpha\left[\mathbf{u}_{1} \frac{\sigma_{1}}{\sigma_{2}} \mathbf{u}_{2} \ldots \frac{\sigma_{1}}{\sigma_{n_{r}}} \mathbf{u}_{\mathbf{n}_{\mathbf{r}}}\right] V^{T}
$$

onde $V$ é a matriz de rotação das entradas da SVD da matriz de ganhos estáticos $K$, $\sigma_{r}$ são os valores singulares de $K$ e $\alpha$ um fator a ser ajustado para que os limites operacionais da planta sejam respeitados.

Para verificar a efetividade de (8.15), sejam as saídas da planta $n_{p} \times n_{r}$, com $n_{p}=$ $n_{r}=n$, em estado estático:

$$
Y=\left[\begin{array}{llll}
\mathbf{y}_{1} & \mathbf{y}_{2} & \ldots & \mathbf{y}_{n}
\end{array}\right]
$$

$$
\begin{aligned}
Y^{T} & =K U^{T} \\
{\left[\begin{array}{c}
\mathbf{y}_{\mathbf{1}}{ }^{T} \\
\mathbf{y}_{\mathbf{2}}{ }^{T} \\
\vdots \\
\mathbf{y}_{\mathbf{n}}{ }^{T}
\end{array}\right] } & =\alpha M \Sigma V^{T} V\left[\begin{array}{c}
\mathbf{u}_{\mathbf{1}}{ }^{T} \\
\frac{\sigma_{1}}{\sigma_{2}} \mathbf{u}_{\mathbf{2}}{ }^{T} \\
\vdots \\
\frac{\sigma_{1}}{\sigma_{n}} \mathbf{u}_{\mathbf{n}}{ }^{T}
\end{array}\right]
\end{aligned}
$$




$$
\begin{aligned}
& =\alpha M\left[\begin{array}{cccc}
\sigma_{1} & 0 & \cdots & 0 \\
0 & \sigma_{2} & \cdots & 0 \\
\vdots & \vdots & \ddots & \vdots \\
0 & 0 & \cdots & \sigma_{n}
\end{array}\right]\left[\begin{array}{c}
\mathbf{u}_{\mathbf{1}}{ }^{T} \\
\frac{\sigma_{1}}{\sigma_{2}} \mathbf{u}_{2}{ }^{T} \\
\vdots \\
\frac{\sigma_{1}}{\sigma_{n}} \mathbf{u}_{\mathbf{n}}{ }^{T}
\end{array}\right] \\
& =\alpha \sigma_{1} M\left[\begin{array}{c}
\mathbf{u}_{1}{ }^{T} \\
\mathbf{u}_{2}{ }^{T} \\
\vdots \\
\mathbf{u}_{\mathbf{n}}{ }^{T}
\end{array}\right]
\end{aligned}
$$

A magnitude do vetor de saída é proporcional à magnitude do vetor de entrada:

$$
\begin{aligned}
\left\|\begin{array}{c}
y_{1}(i) \\
y_{2}(i) \\
\vdots \\
y_{n}(i)
\end{array}\right\|_{2} & =\left\|\alpha \sigma_{1} M\left[\begin{array}{c}
u_{1}(i) \\
u_{2}(i) \\
\vdots \\
u_{n}(i)
\end{array}\right]\right\|_{2} \\
& =\alpha \sigma_{1}\left\|\begin{array}{c}
u_{1}(i) \\
u_{2}(i) \\
\vdots \\
u_{n}(i)
\end{array}\right\|_{2}
\end{aligned}
$$

Assim, verifica-se que os sinais rotacionados são efetivos na condição estática para excitação de quaisquer direções de ganho. Na seção 8.4 é verificada, por meio de simulações, a efetividade dos sinais rotacionados na condição dinâmica.

Observe que a magnitude do vetor de saída (8.18) deve ser ajustada por meio do fator $\alpha$ para garantir que os limites operacionais da planta não sejam violados. $\mathrm{O}$ fator $\alpha$ amplifica ou atenua as variações das saídas $\mathbf{y}_{1}, \mathbf{y}_{2}, \ldots \mathbf{y}_{n}$ conjuntamente. Não é possível ajustar as variações das saídas de forma independente. Na seção 8.5 é proposta uma rotação dos sinais de excitação, onde são estabelecidas restrições independentes para cada uma das saídas da planta de forma a maximizar as variações das saídas, respeitando os limites operacionais da planta.

A figura 8.5 apresenta um exemplo de sinais rotacionados resultantes da rotação de sinais binários. Observe que os sinais rotacionados não são binários como os sinais originais.

Uma avaliação de sinais PRB rotacionados em identificação de sistemas foi apresentada em (CONNER; SEBORG, 2004), utilizando um modelo de primeira ordem de uma coluna de destilação (WOOD; BERRY, 1973). 

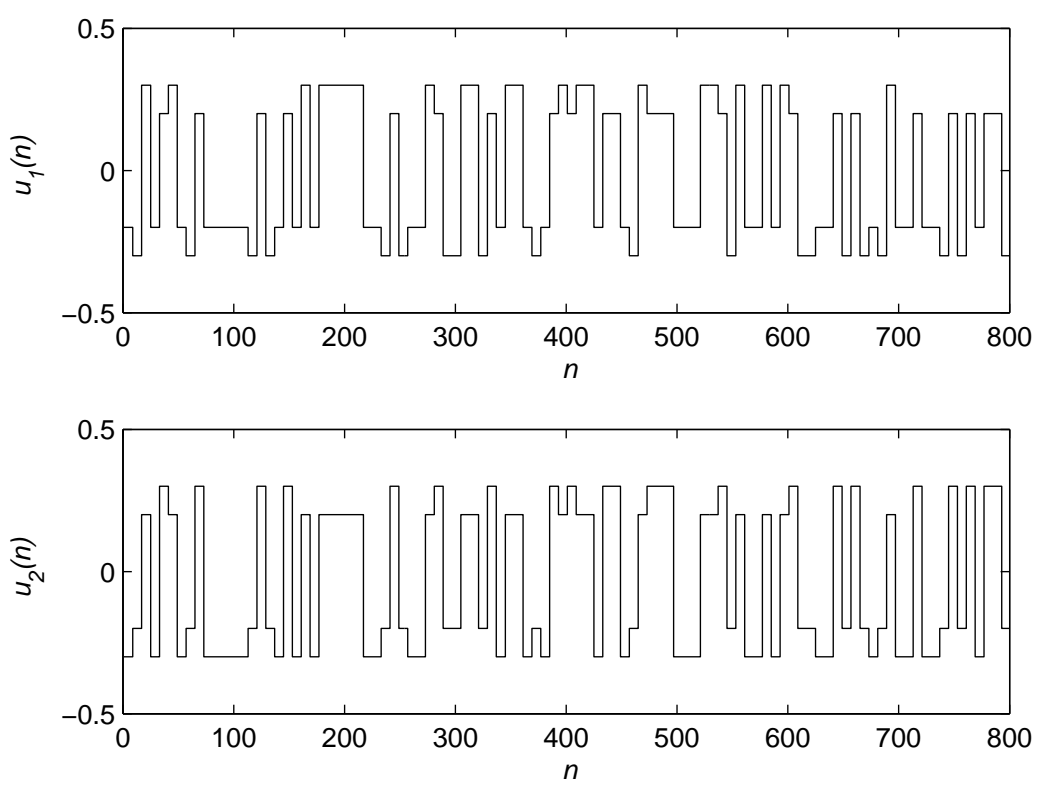

Figura 8.5: Exemplo de sinais rotacionados resultantes da rotação de sinais binários.

Observe que a rotação implica em criar correlações entre os sinais de entrada, o que não é desejável para a posterior estimação de parâmetros, conforme discutido nos capítulos 2 e 3 . Porém, a adequada correlação dos sinais de excitação faz com que as direções de baixo ganho sejam excitadas com mais energia, permitindo ao algoritmo de estimação de parâmetros obter bons ajustes em cenários de perturbações. Observe que existe um compromisso entre as correlações das entradas para permitir a excitação na direção de baixo ganho, sem prejudicar excessivamente a variância dos parâmetros estimados e mantendo a unicidade da solução de estimação de parâmetros. Isso significa que os sinais devem se manter PE de ordem adequada ao modelo a ser ajustado.

Nas próximas seções é observado que esse conceito de criar correlações entre os sinais de excitação é aplicado de forma geral nas propostas da literatura relativas ao projeto de sinais de excitação para plantas mal condicionadas (ZHU, 2001) (MISRA; NIKOLAOU, 2003) (LEE et al., 2003) (CONNER; SEBORG, 2004) (ZHU; STEC, 2006) (TAN; GODFREY; BARKER, 2009).

\subsubsection{Métodos de dois passos}

Em (ZHU, 2001) foi proposto um método de dois passos para obter bons dados para identificação de plantas mal condicionadas com duas entradas. No primeiro passo é realizado um teste utilizando sinais binários não correlacionados (tipicamente GBN). Esses sinais fornecem bons dados para estimativas da direção de alto ganho. No segundo passo é realizado um teste consistindo em dois períodos bem definidos: em um 
deles os sinais binários são de alta amplitude e iguais para ambas as entradas e no outro período os sinais binários são não correlacionados e de baixa amplitude. Os períodos de sinais idênticos e de alta amplitude criam a forte correlação necessária para identificar a direção de baixo ganho. $\mathrm{O}$ fator de escala $\Gamma$ entre as amplitudes altas e baixas dos períodos pode ser determinado a partir dos ganhos estimados no primeiro passo. Uma diretriz para a determinação desse fator foi proposta em (ZHU; STEC, 2006): se o número de condição da planta para o caso estático for $\gamma$, então a amplitude dos sinais no período de maior amplitude será até $\gamma$ vezes a amplitude dos sinais no período de menor amplitude. Então, tem-se a diretriz:

$$
\Gamma \leq \gamma
$$

Para a coluna de destilação da figura 8.1, incrementos na vazão de refluxo causam efeito oposto ao incremento da vazão de fundo. Então, nos períodos em que os sinais são correlacionados, eles possuem o mesmo sinal. O método pode ser implementado mesmo sem conhecimento quantitativo da saída da planta na direção de baixo ganho, pois, neste caso, é considerado próximo a $[1,1]^{T}$.

A figura 8.6 apresenta um exemplo de sinais obtidos com o método de dois passos.
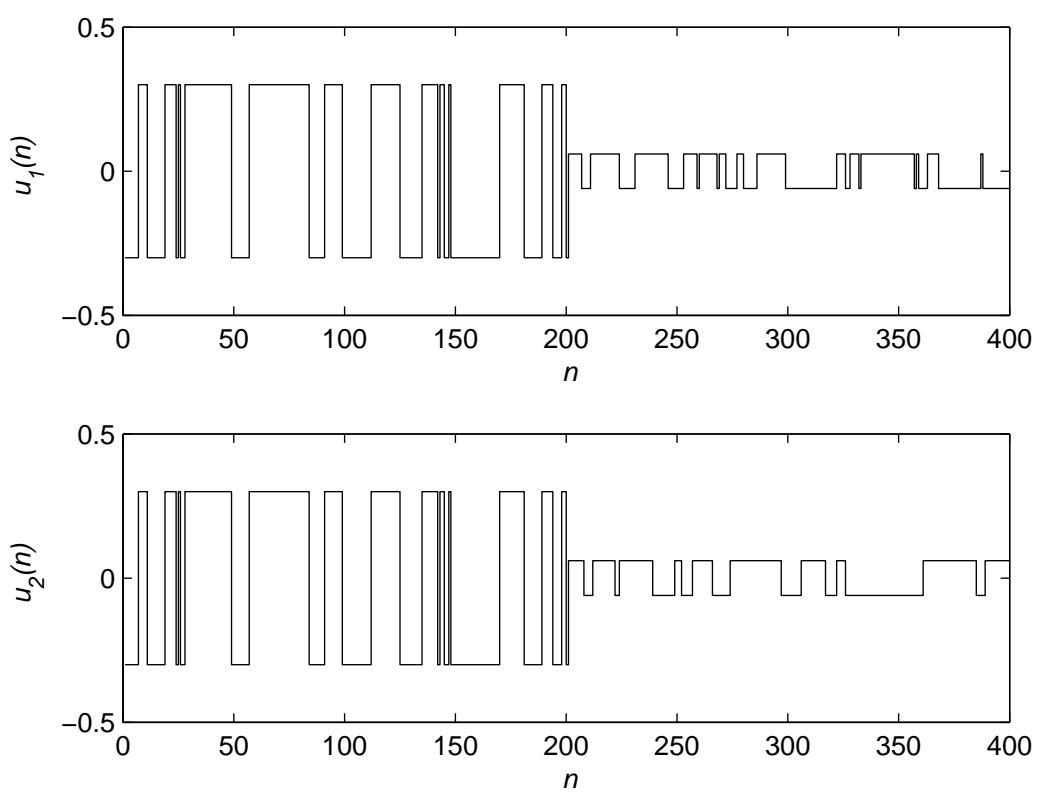

Figura 8.6: Exemplo de sinais utilizados no método de dois passos.

Em (ZHU; STEC, 2006), um segundo método foi proposto consistindo na superposição dos dois trechos de cada sinal gerado pelo método anterior (ZHU, 2001). Para diferenciá-los, neste trabalho, a proposta de 2006 é denominada método 2 de dois passos e o método descrito anteriormente denominado método 1 de dois passos. Para um expe- 
rimento de mesmo período e mesma variância das entradas, é fácil verificar que essa abordagem reduz de $\sqrt{2}$ a amplitude do sinal do método anterior. A efetividade desse método foi apresentada em (ZHU; STEC, 2006), onde se comparou esses resultados com os obtidos com sinais GBN.

A figura 8.7 apresenta um exemplo de sinais utilizados no método 2 de dois passos. Observe que esses sinais, grosso modo, se assemelham aos sinais rotacionados.
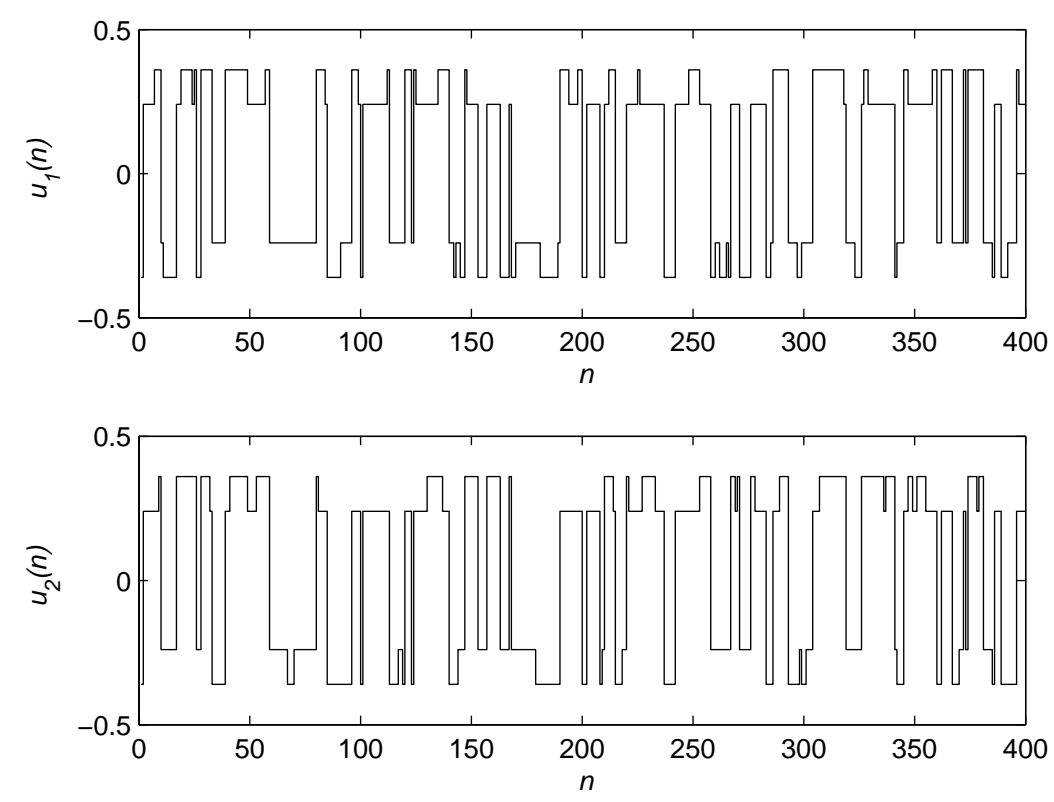

Figura 8.7: Espectros de sinais utilizados no método 2 de dois passos.

Ambos métodos de dois passos são construídos com sinais GBN. Assim, a probabilidade de não chaveamento $p$ deve ser ajustada conforme discussão da seção 5.1.2.1.

\subsubsection{Sinais com espectros intercalados modificados}

A ideia de se criar uma forte correlação no domínio do tempo entre os sinais, observada nos sinais rotacionados e sinais gerados com os métodos de dois passos e necessária para identificar direções de baixo ganho, foi modificada em (LEE et al., 2003) (LEE, 2006). Nessa proposta criam-se correlações no domínio da frequência, definindo uma modificação no espectro de potência de um conjunto de sinais $\mathrm{SOH}$. Os sinais resultantes possuem harmônicas intercaladas, mas também incluem harmônicas correlacionadas com elevadas potências, as quais permitem realçar direções de baixo ganho nos dados de saída.

As harmônicas correlacionadas são rotacionadas pela matriz de rotação de entradas $V$ da SVD da matriz de ganhos estáticos $K$ da planta. A relação entre as potências das 
harmônicas correlacionadas e não correlacionadas foi apresentada posteriormente em (RIVERA et al., 2009). Nessa proposta, as harmônicas correlacionadas, as quais excitam as direções de baixo ganho, são multiplicadas pelo fator $\Gamma$. Esse fator é escolhido de forma que os sinais de saída relativos às harmônicas correlacionadas permaneçam no mesmo intervalo das saídas relativas às harmônicas não correlacionadas. Assim, para uma planta $2 \times 2$, $\Gamma$ deve estar no intervalo (RIVERA et al., 2009):

$$
\begin{gathered}
\Gamma^{L} \leq \Gamma \leq \Gamma^{U} \\
\Gamma^{L}=\sqrt{\min \left\{\frac{\min \left(k_{11}^{2}, k_{12}^{2}\right)}{\left(k_{11}+k_{12}\right)^{2}}, \frac{\min \left(k_{21}^{2}, k_{22}^{2}\right)}{\left(k_{21}+k_{22}\right)^{2}}\right\}} \\
\Gamma^{U}=\sqrt{\max \left\{\frac{\max \left(k_{11}^{2}, k_{12}^{2}\right)}{\left(k_{11}+k_{12}\right)^{2}}, \frac{\max \left(k_{21}^{2}, k_{22}^{2}\right)}{\left(k_{21}+k_{22}\right)^{2}}\right\}}
\end{gathered}
$$

Diferentemente dos métodos de dois passos, esse método necessita de conhecimento quantitativo das direções de ganhos. Assim, é necessário conhecer a priori a matriz de ganhos estáticos da planta, conhecimento também necessário para gerar os sinais rotacionados (seção 8.2.1). Se essa informação não estiver disponível, ela pode ser obtida a partir de testes preliminares de identificação (ZHU, 2001).

As figuras 8.8 e 8.9 apresentam exemplos de sinais $\mathrm{SOH}$ com espectros intercalados modificados e seus espectros de amplitudes.
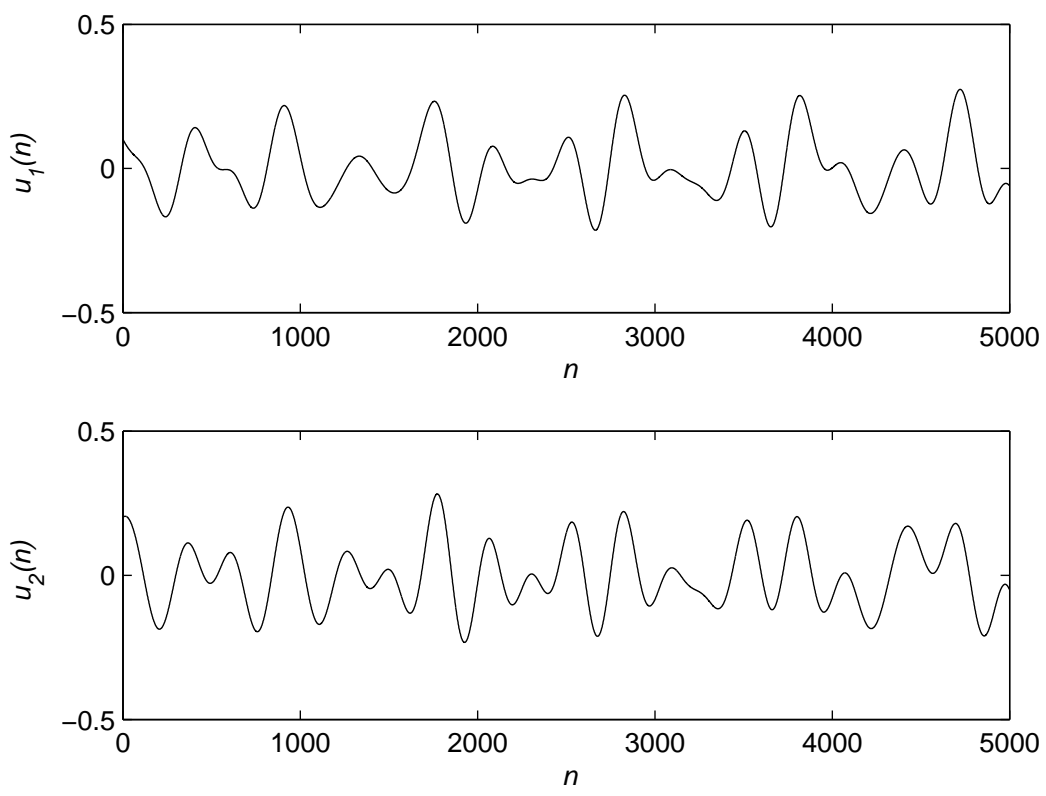

Figura 8.8: Exemplo de sinais $\mathrm{SOH}$ com espectros intercalados modificados.

Os sinais com espectros intercalados modificados foram avaliados em (LEE et al., 2003) no modelo de primeira ordem da coluna binária descrita em (JACOBSEN; SKO- 


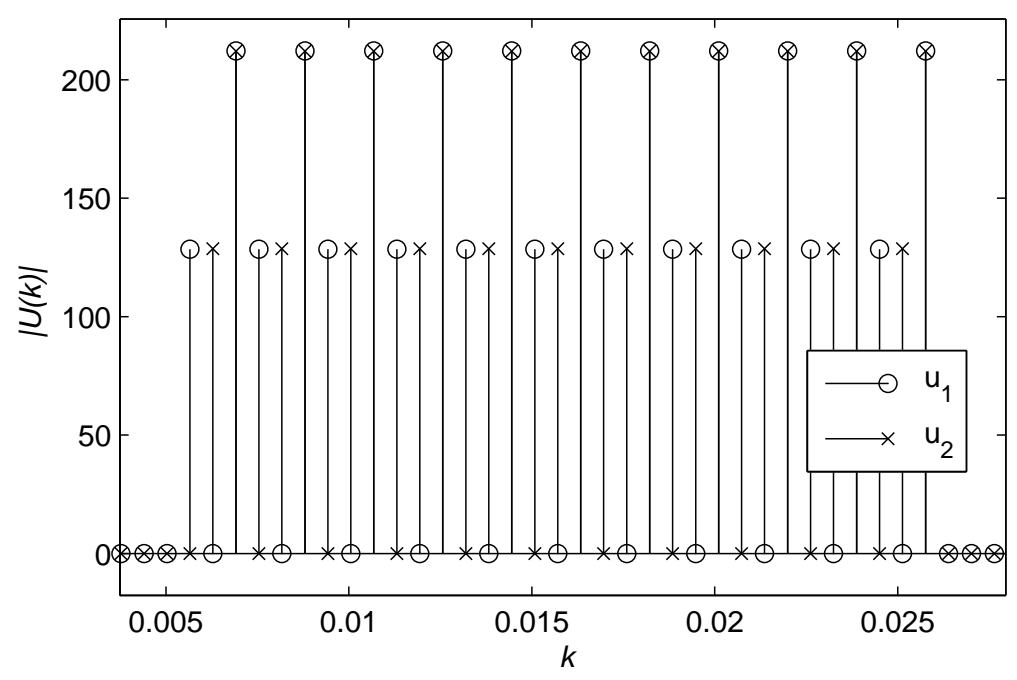

Figura 8.9: Espectros de sinais $\mathrm{SOH}$ com espectros intercalados modificados.

GESTAD, 1994).

A principal vantagem de se utilizar sinais $\mathrm{SOH}$ em relação aos sinais GBN, utilizados nos métodos de dois passos, é a flexibilidade para formatação da envoltória do espectro dos sinais.

Um passo de otimização adicional para projeto de sinais $\mathrm{SOH}$ foi introduzido em (LEE, 2006). Foi proposto minimizar o fator de crista (CF) sobre todas as saídas, por meio da otimização das fases e amplitudes das harmônicas que compõem cada um dos sinais. Para essa otimização, é necessário que conhecimentos quantitativos das dinâmicas da planta estejam disponíveis, o que raramente ocorre, pois é contraditório aos objetivos da identificação.

\subsubsection{Sinais ternários com harmônicas correlacionadas}

Uma idéia similar à apresentada em (LEE, 2006) foi proposta em (TAN; GODFREY; BARKER, 2009). Essa abordagem também cria correlações no domínio da frequência, mas o número de níveis dos sinais é limitado em três. Sinais PRT são gerados com espectros intercalados, porém, com harmônicas correlacionadas, assim como os sinais $\mathrm{SOH}$ com espectros intercalados modificados. Não há flexibilidade para especificar o espectro devido a restrições impostas pelo limitado número de níveis do sinal (três níveis), conforme discutido na seção 5.3.8. Assim como os métodos de dois passos, a geração do sinal PRT não requer conhecimento quantitativo sobre a direção de baixo ganho.

As figuras 8.10 e 8.11 apresentam exemplos de sinais PRT com harmônicas correlacionadas e seus espectros de amplitudes. 

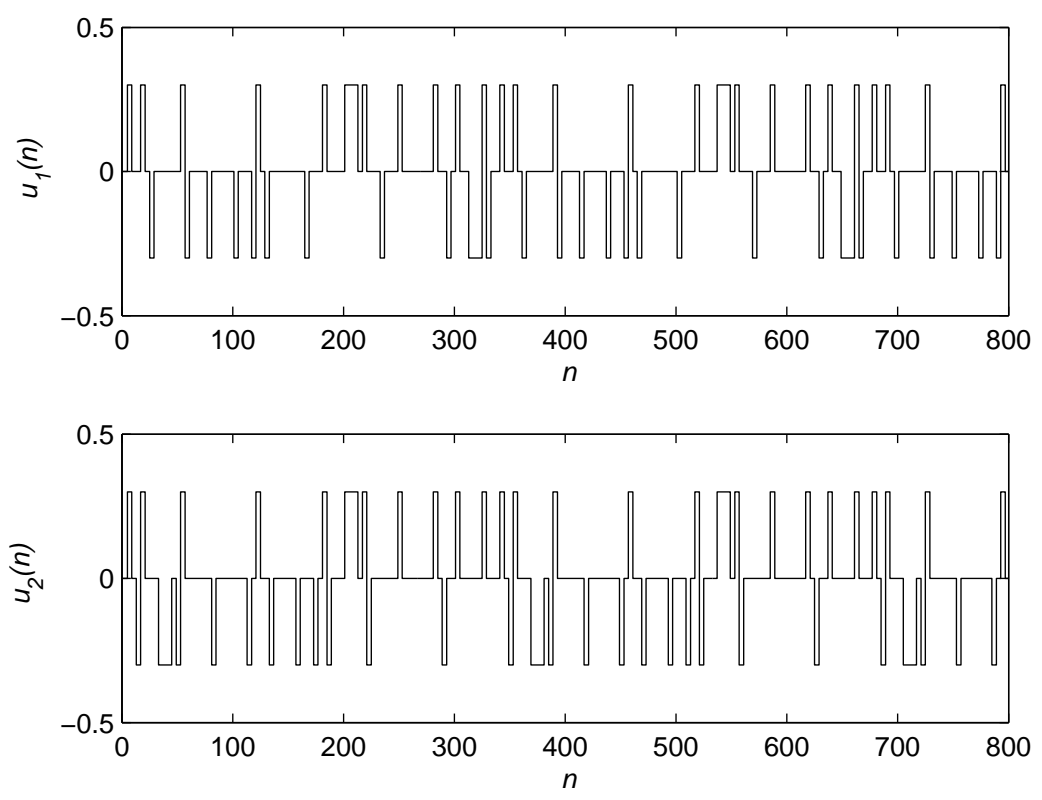

Figura 8.10: Exemplo de sinais PRT com harmônicas correlacionadas.

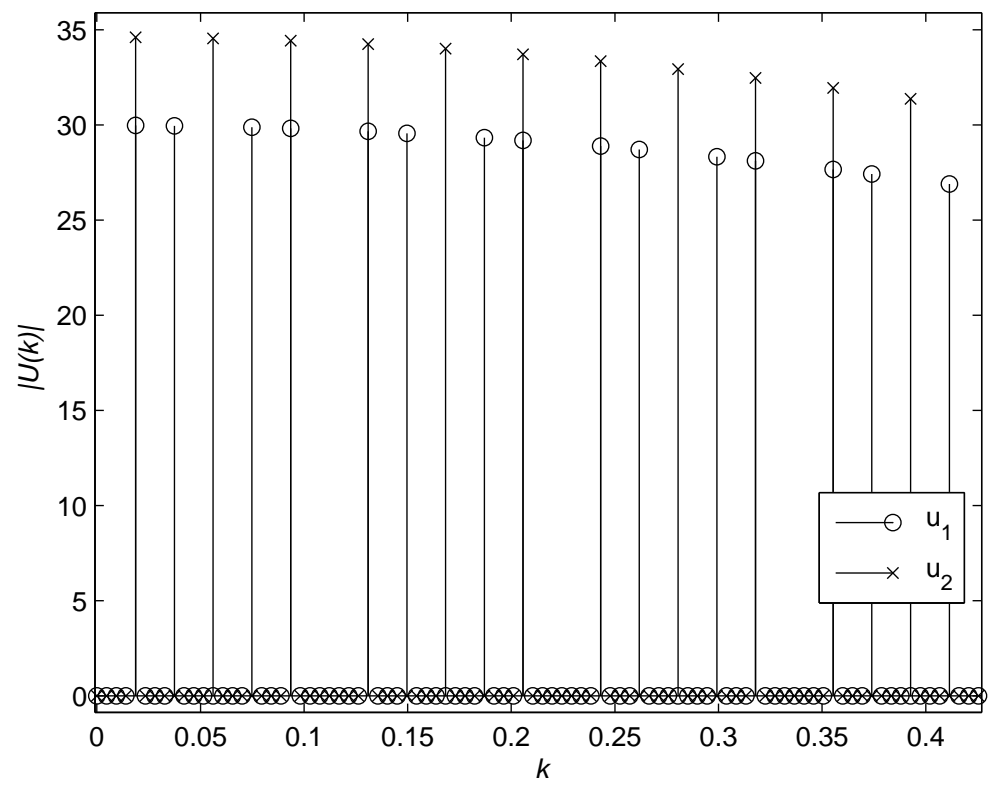

Figura 8.11: Espectros de sinais PRT com harmônicas correlacionadas.

Os sinais PRT possuem a desvantagem de um restrito número de sinais disponíveis para um dado comprimento $N=q^{n}-1$ da sequência sobre $G F(q)$. Por outro lado, o número limitado de 3 níveis assumidos pelos sinais pode ser útil em identificação de sistemas em que apenas um número restrito de níveis de entrada é aceito (BARKER; GODFREY, 1999) (TAN; GODFREY, 2004b) (TAN; GODFREY; BARKER, 2009).

Em (TAN; GODFREY; BARKER, 2009) foram avaliados sinais PRT com harmônicas 
correlacionadas em uma coluna de destilação descrita em (OGUNNAIKE; LEMAIRE; MORARI, 1983), a qual é mal condicionada, porém, não interativa.

Há outras propostas para projeto de sinais utilizados para excitação de sistemas mal condicionados e interativos. Elas são em sua maioria variações ou evoluções, como inclusão de alguma otimização numérica, das cinco ideias básicas resumidas nesta seção. Porém, métodos de projetos ótimos (RIVERA et al., 2009) necessitam de conhecimento sobre as dinâmicas do sistema, o que raramente está disponível em plantas industriais, conforme discutido no capítulo 2. Em (DARBY; NIKOLAOU, 2009) foi apresentado um estudo que associa o conceito de controlabilidade com o projeto ótimo de entradas rotacionadas. Os resultados vão além de sistemas $2 \times 2$ e se estendem a sistemas de grande porte. Essa abordagem também envolve o conhecimento da matriz de transferência do processo real.

A tabela 8.1 resume as principais características dos cinco métodos descritos nesta seção. Na tabela 8.2 são apresentadas as características das plantas nas quais os sinais de excitação foram originalmente avaliados. Há significativas diferenças entre as plantas, como o $\gamma$, o qual varia de valores reduzidos (para a coluna de destilação de (WOOD; BERRY, 1973) empregada na avaliação original dos sinais rotacionados) a valores significativamente elevados (para a coluna de segunda ordem mais tempo morto (OGUNNAIKE; LEMAIRE; MORARI, 1983) usada para avaliar sinais PRT com harmônicas correlacionadas). Entretanto, essas duas colunas de destilação apresentam valores de $\lambda$ praticamente iguais e reduzidos.

Tabela 8.1: Principais características dos métodos de projeto de sinais de excitação para identificação de plantas mal condicionadas.

\begin{tabular}{|c|c|c|c|c|}
\hline Método & $\begin{array}{l}\text { Conhecimentos } \\
\text { a priori requeridos }\end{array}$ & $\begin{array}{l}\text { Princípio } \\
\text { de cálculo }\end{array}$ & $\begin{array}{c}\text { Características } \\
\text { de amplitude }\end{array}$ & $\begin{array}{c}\text { Características } \\
\text { do espectro }\end{array}$ \\
\hline $\begin{array}{c}\text { Sinais rotacionados } \\
\text { (KOUNG; MACGREGOR, 1993) } \\
(\text { CONNER; SEBORG, 2004) }\end{array}$ & $\begin{array}{l}\text { Matriz de ganhos } \\
\text { estáticos da planta }\end{array}$ & $\begin{array}{c}\text { Rotação pela matriz } \\
\text { de rotação da SVD }\end{array}$ & Quatro níveis & $\begin{array}{c}\text { Fixo } \\
\text { (não flexível) }\end{array}$ \\
\hline $\begin{array}{c}\text { Método } 1 \text { de dois passos } \\
\text { (ZHU, 2001) }\end{array}$ & $\begin{array}{l}\text { Direção de } \\
\text { baixo ganho }\end{array}$ & Concatenar sinais & Quatro níveis & Aleatório \\
\hline $\begin{array}{l}\text { Método } 2 \text { de dois passos } \\
\quad(\text { ZHU; STEC, 2006) }\end{array}$ & $\begin{array}{l}\text { Direção de } \\
\text { baixo ganho }\end{array}$ & Concatenar sinais & Quatro níveis & Aleatório \\
\hline $\begin{array}{c}\text { SOH com espectros } \\
\text { intercalados modificados } \\
\text { (LEE, 2006) (RIVERA et al., 2009) }\end{array}$ & $\begin{array}{l}\text { Matriz de ganhos } \\
\text { estáticos da planta }\end{array}$ & $\begin{array}{l}\text { Otimização de } \\
\text { fases e rotação }\end{array}$ & Contínua & Flexível \\
\hline $\begin{array}{c}\text { PRT } \\
\text { (TAN; GODFREY; BARKER, 2009) }\end{array}$ & $\begin{array}{l}\text { Direção de } \\
\text { baixo ganho }\end{array}$ & $\begin{array}{l}\text { Aritmética sobre } \\
\text { corpos finitos }\end{array}$ & Três níveis & $\begin{array}{c}\text { Fixo } \\
\text { (não flexível) }\end{array}$ \\
\hline
\end{tabular}

\subsubsection{Parametrização dos sinais de excitação}

Nesta seção, os cinco tipos de sinais discutidos na seção 8.2 são parametrizados para simulações de identificação da coluna de alta pureza (seção 8.1). 
Tabela 8.2: Principais características das plantas originalmente empregadas para avaliar os métodos de projeto de sinais de excitação.

\begin{tabular}{|c|c|c|c|c|}
\hline Método & $\begin{array}{c}\text { Referência da } \\
\text { planta empregada }\end{array}$ & $\begin{array}{c}\text { Ordem } \\
\text { da planta }\end{array}$ & $\begin{array}{l}\lambda \\
\gamma\end{array}$ & $\begin{array}{c}\text { Técnica de identificação } \\
\text { ou estrutura do modelo } \\
\text { estimado }\end{array}$ \\
\hline Sinais rotacionados & (WOOD; BERRY, 1973) & $\begin{array}{c}\text { FOPTD }^{1} \\
2 \times 2\end{array}$ & $\begin{array}{c}2,009 \\
7,48\end{array}$ & $\begin{array}{c}\text { ARX baixa ordem, } \\
\text { FIR }\end{array}$ \\
\hline $\begin{array}{l}\text { Método } 1 \text { de } \\
\text { dois passos }\end{array}$ & (JACOBSEN; SKOGESTAD, 1994) & $\begin{array}{c}2^{\underline{a}} \text { ordem } \\
2 \times 2\end{array}$ & $\begin{array}{l}35,068 \\
141,73\end{array}$ & $\begin{array}{l}\text { ARMAX, BJ, } \\
\text { MOESP }^{3}\end{array}$ \\
\hline $\begin{array}{l}\text { Método } 2 \text { de } \\
\text { dois passos }\end{array}$ & (JACOBSEN; SKOGESTAD, 1994) & $\begin{array}{c}2^{a} \text { ordem } \\
2 \times 2\end{array}$ & $\begin{array}{l}35,068 \\
141,73\end{array}$ & $\begin{array}{l}\text { ARMAX, } \\
\text { MOESP }\end{array}$ \\
\hline $\begin{array}{l}\text { SOH com espectros } \\
\text { intercalados modificados }\end{array}$ & (JACOBSEN; SKOGESTAD, 1994) & $\begin{array}{c}1 \stackrel{a}{ } \text { ordem } \\
2 \times 2\end{array}$ & $\begin{array}{l}35,068 \\
141,73\end{array}$ & $\begin{array}{c}\text { ARX, } \\
\text { NARX }^{4}\end{array}$ \\
\hline PRT & (OGUNNAIKE; LEMAIRE; MORARI, 1983) & $\begin{array}{c}\text { SOPTD }^{2} \\
3 \times 3\end{array}$ & $\begin{array}{l}2,008 \\
3540\end{array}$ & $\begin{array}{c}\text { Identificação no } \\
\text { domínio da frequência }\end{array}$ \\
\hline
\end{tabular}

${ }^{1}$ modelo de primeira ordem com tempo morto (first order plus time delay, FOPTD).

${ }^{2}$ modelo de segunda ordem com tempo morto (second order plus time delay,

SOPTD). ${ }^{3}$ modelo multivariável de erro na saída em espaço de estados (multivariable output-error state space, MOESP). ${ }^{4}$ modelo ARX não linear (non-linear ARX, NARX).

\subsubsection{Sinais rotacionados}

Os sinais rotacionados foram gerados a partir de sinais PRB, os quais foram rotacionados e amplificados para excitar direções de baixo ganho.

Para a identificação do modelo da coluna binária de primeira ordem $G_{1}(s)$, foram adotados os parâmetros $N=436$ e período de chaveamento $T_{c l k}=8$, resultando em um tempo total do experimento $T_{e}=T_{N_{s}}=426 \times 8=3.408$ minutos.

Para a identificação do modelo de segunda ordem $G_{2}(s)$, foram adotados $N=231$ e $T_{c l k}=40$, resultando em $T_{e}=T_{N_{s}}=231 \times 40=9.240$ minutos. A figura 8.12 apresenta segmentos desses sinais. Observa-se que os sinais são predominantemente correlacionados. Isso ocorre pois o ganho na direção $[1 ; 1]^{T}$ é significativamente menor que o ganho na direção $[1 ;-1]^{T}$. A rotação dos sinais objetiva compensar a diferença dos ganhos, excitando a direção de menor ganho com maior amplitude.

O fator $\alpha$ foi ajustado de forma a resultar em amplitude de pico de 0,3 para ambos os sinais. Os parâmetros $N$ e $T_{c l k}$ adotados atendem aos critérios (5.96) e (5.99), respectivamente, e os tempos de experimento $T_{e}$ atendem (3.13).

\subsubsection{Método 1 de dois passos}

Os sinais GBN foram utilizados para gerar os sinais dos métodos de dois passos.

Para a identificação da planta de primeira ordem $G_{1}(s)$, a probabilidade de não chaveamento calculada por meio de (5.17) e (8.12) é $p=0,88$. O fator de escala aplicado à amplitude dos sinais para enfatizar a direção de baixo ganho é $\Gamma=78$, em 

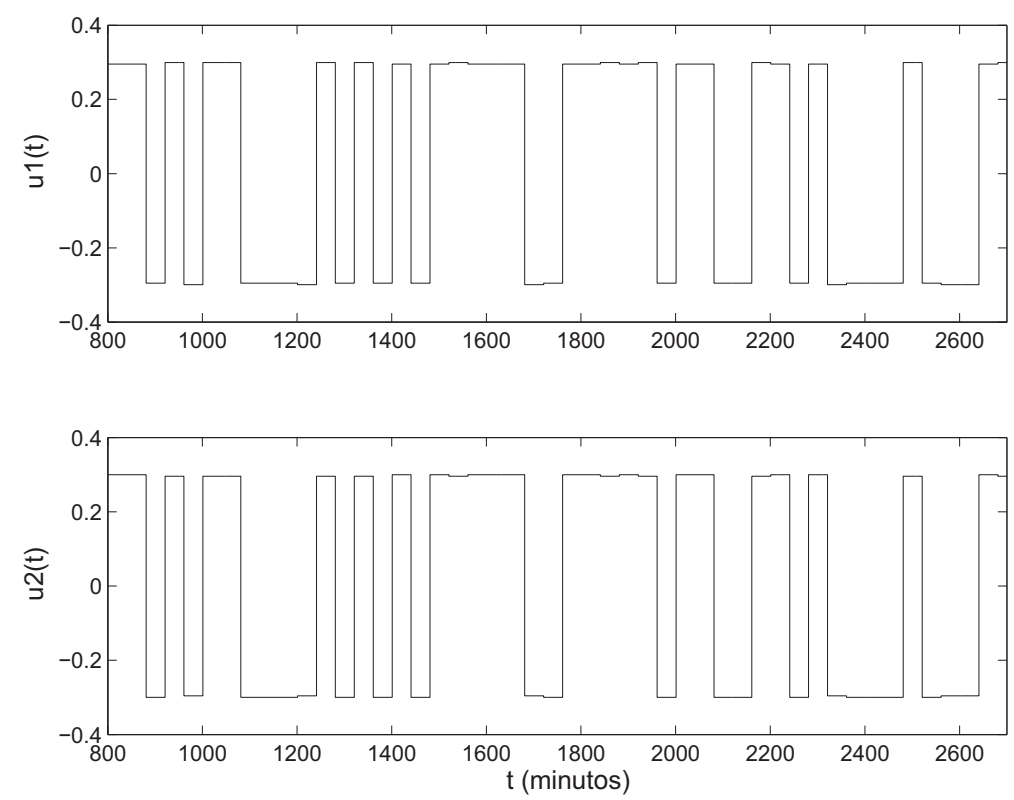

Figura 8.12: Segmentos dos sinais rotacionados parametrizados para identificação do modelo de segunda ordem da coluna de alta pureza.

torno da metade do máximo valor estimado por (8.19). A duração do experimento foi definida a mesma para o experimento com sinais rotacionados: $T_{e}=3.408$ minutos.

Para a identificação da planta de segunda ordem $G_{2}(s)$, de (5.17) e (8.13), tem-se $p=0,84$. Foi adotado $\Gamma=61,71$ e duração do experimento $T_{e}=9.240$ minutos, assim como o experimento com sinais rotacionados. Como para a planta de segunda ordem na direção $[1 ; 1]^{T}$ a resposta dinâmica da planta é muito mais rápida que na direção $[1 ;-1]^{T}\left(\tau_{2}=15\right.$ minutos contra $\tau_{1}=194$ minutos $)$, o trecho de sinais não correlacionados foi adotado 10 vezes maior que o trecho de sinais correlacionados. As amplitudes de pico para ambos os sinais foi ajustada em 0,3. A figura 8.13 apresenta segmentos desses sinais gerados pelo método 1 de dois passos.

\subsubsection{Método 2 de dois passos}

Com o método 2 de dois passos, foi utilizado sinal GBN com mesmos $p$ e $\Gamma$. Os tempos de experimento também foram os mesmos adotados para o método 1 de dois passos. A figura 8.14 apresenta segmentos dos sinais gerados pelo método 2 de dois passos para identificação da planta de segunda ordem.

\subsubsection{Sinais SOH com espectros intercalados modificados}

Para a identificação da planta de primeira ordem $G_{1}(s)$ com sinais SOH com espectros intercalados com amostragem de $T=2$ minutos, o comprimento do sinal $N_{s}=1704$ resulta em uma duração de experimento idêntica às realizadas com os sinais discutidos 

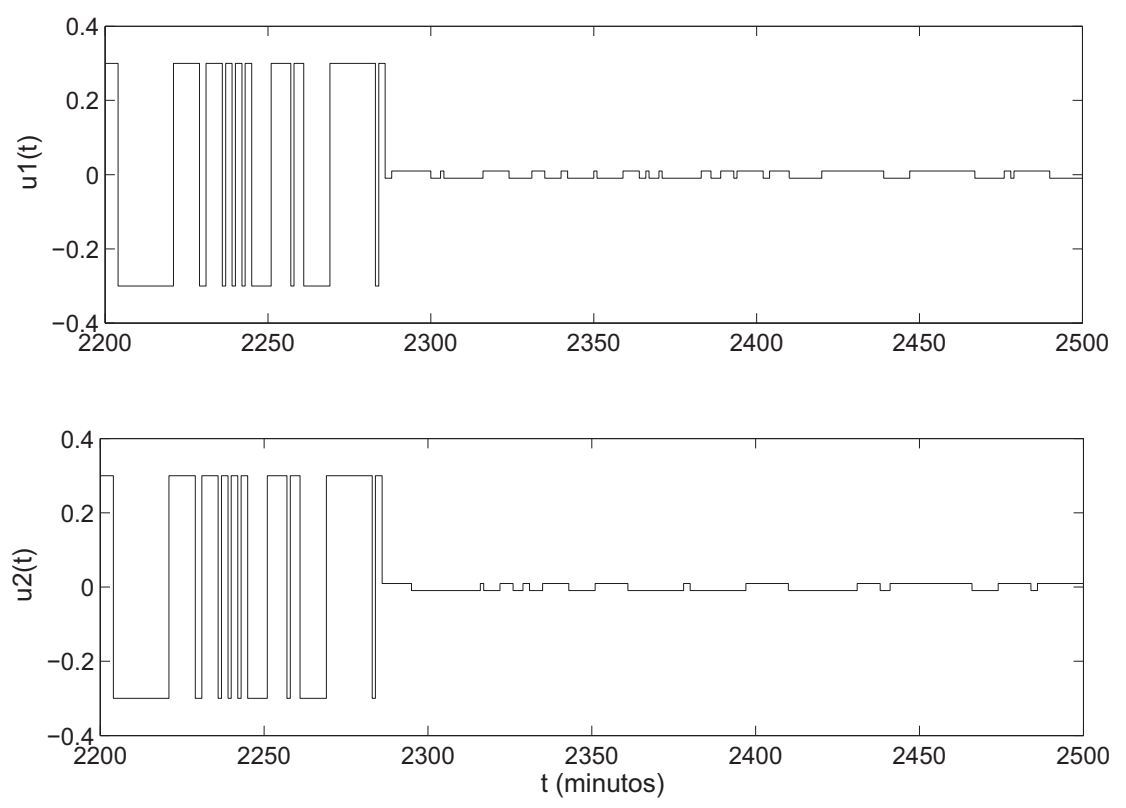

Figura 8.13: Segmentos dos sinais gerados pelo método 1 de dois passos para identificação do modelo de segunda ordem da coluna de alta pureza.
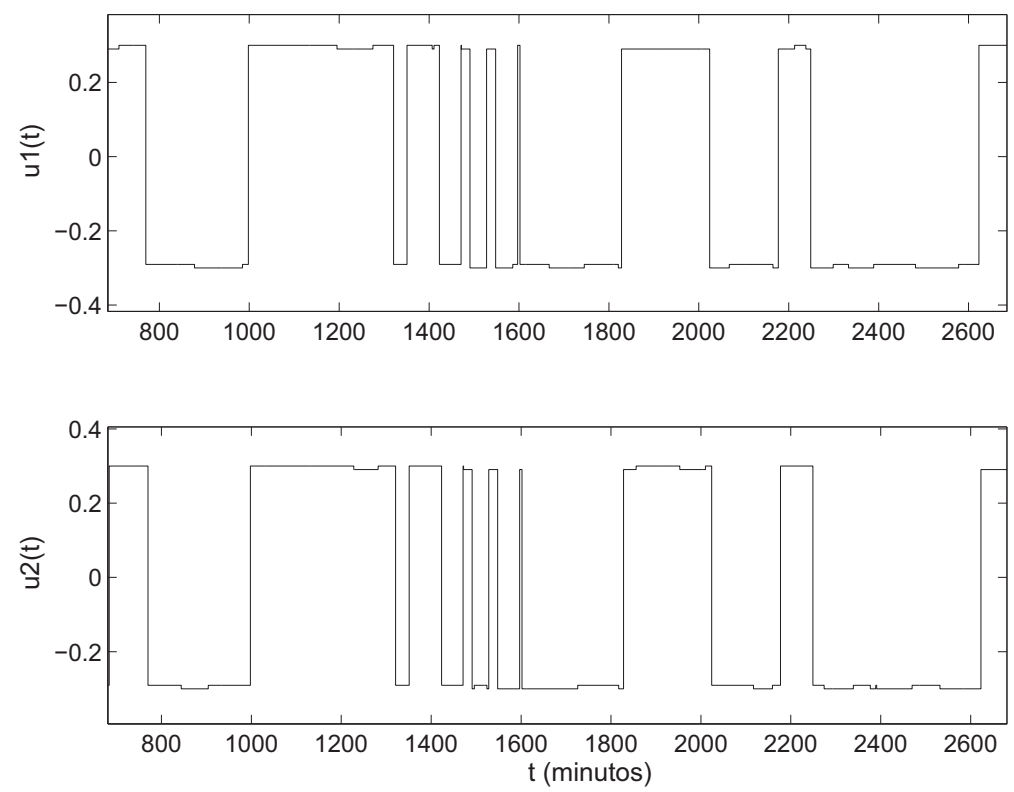

Figura 8.14: Segmentos dos sinais gerados pelo método 2 de dois passos para identificação do modelo de segunda ordem da coluna de alta pureza.

anteriormente $T_{e}=N_{s} \times T=1.704 \times 2=3.408$ minutos. A quantidade de harmônicas especificadas para a faixa de frequências $B W(8.12)$ foi $n_{s}=13$. Essas escolhas de $T$, $N_{s}$ e $n_{s}$ atendem (5.47) e (5.50). O valor adotado do fator de escala foi $\Gamma=78$, o qual está na faixa estimada por (8.20).

Para a identificação da planta de segunda ordem $G_{2}(s) \operatorname{com} T=1$ minuto, escolheuse $N_{s}=9.240$ resultando em $T_{e}=9.240$ minutos, igual aos experimentos com os demais sinais com a planta de segunda ordem. A quantidade de harmônicas especificadas 
adotada foi $n_{s}=40$. Essas escolhas de $T, N_{s}$ e $n_{s}$ também atendem (5.47) e (5.50). Adotou-se $\Gamma=78$. A amplitude de pico dos sinais foi ajustada para 0,3. A figura 8.15 apresenta segmentos desses sinais e a figura 8.16 apresenta seus espectros. Observamse harmônicas de alta amplitude e correlacionadas e harmônicas de reduzida amplitude não correlacionadas.

Nenhuma otimização ou restrições (LEE et al., 2003) (LEE, 2006) foram aplicadas a esses sinais resultantes. Para o procedimento de otimização que objetiva limitar a resposta dinâmica das saídas, são necessários conhecimentos a priori quantitativos das dinâmicas da planta (LEE et al., 2003), (LEE, 2006), (RIVERA et al., 2009). Aqui assumiuse que são conhecidos apenas os tempos de acomodação dominantes e ganhos estáticos da planta. A seção 8.5 apresenta uma proposta para limitar as amplitudes das saídas sem utilizar algoritmos iterativos de otimização.
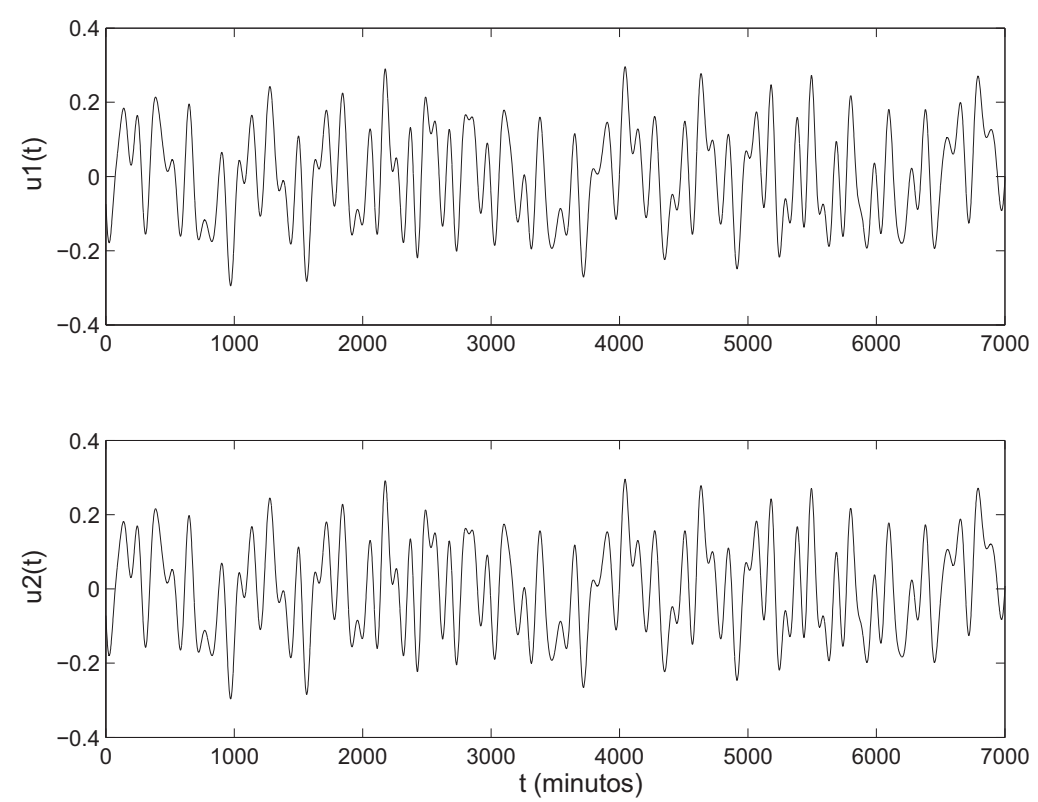

Figura 8.15: Segmentos dos sinais $\mathrm{SOH}$ com espectros intercalados modificados para identificação do modelo de segunda ordem da coluna de alta pureza.

\subsubsection{Sinais PRT com harmônicas correlacionadas}

Tanto no experimento de identificação de $G_{1}(s)$ quanto $G_{2}(s)$, os sinais PRT com harmônicas correlacionadas foram construídos com o polinômio primitivo $f(x)=$ $x^{2}+x+2$ gerador do corpo de Galois $G F\left(q^{m}\right)$, com $q=13$ e $m=2$. Assim, as sequências PRT possuem comprimento $N=q^{m}-1=13^{2}-1=168$. Foram escolhidas as sequências primitivas $C$ e $D$ da tabela I de (TAN; GODFREY; BARKER, 2009), para gerar os sinais $\mathbf{u}_{1}$ e $\mathbf{u}_{2}$, respectivamente.

Para o experimento de identificação de $G_{1}(s)$, foi adotado $T_{c l k}=8$ minutos, re- 


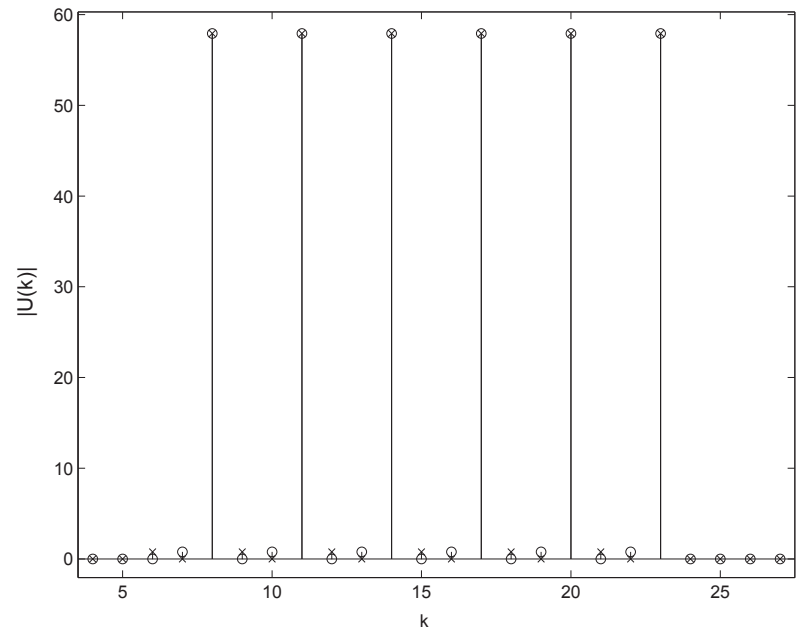

Figura 8.16: Espectros dos sinais $\mathrm{SOH}$ com espectros intercalados modificados para identificação do modelo de segunda ordem da coluna de alta pureza. As marcas "o" e " $\mathrm{x}$ " identificam as entradas $u_{1}$ e $u_{2}$ da planta, respectivamente.

sultando em sinais de período $T_{N}=N \times T_{c l k}=168 \times 8=1.334$ minutos. Os sinais são ciclicamente repetidos para completar a duração do experimento de $T_{e}=3.408$ minutos.

Para o experimento de identificação de $G_{2}(s)$, adotou-se $T_{c l k}=40$ minutos, resultando em $T_{N}=N \times T_{c l k}=168 \times 40=6.720$ minutos. Para o tempo de experimento atingir $T_{e}=9.240$ minutos, os sinais são ciclicamente repetidos. Segmentos desses sinais são apresentados na figura 8.17.
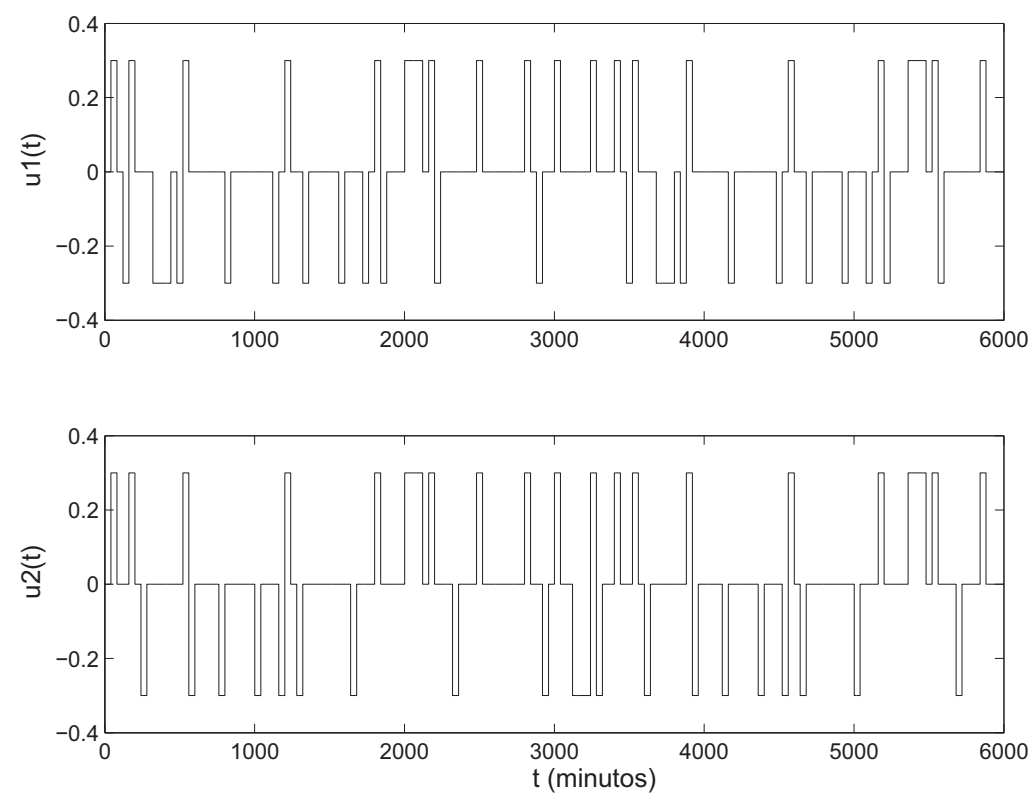

Figura 8.17: Segmentos dos sinais PRT com harmônicas correlacionadas para identificação do modelo de segunda ordem da coluna de alta pureza.

As amplitudes de pico dos sinais foram ajustadas para 0,3 . Os parâmetros $N$ e $T_{c l k}$ adotados atendem aos critérios (5.96) e (5.99), respectivamente. 


\subsection{Proposta de avaliação de sinais para identificação de plantas mal condicionadas}

Neste trabalho, propõe-se utilizar o coeficiente de correlação como uma medida da dispersão das saídas da planta. Essa medida, chamada de fator de dispersão (scattering factor, SF), é dada pelo complementar do coeficiente de correlação entre a $i$-ésima e j-ésima saída da planta:

$$
S F_{i, j}=\left(1-\frac{c_{i, j}}{\sqrt{c_{i, i} c_{j, j}}}\right) \times 100[\%], \quad i \neq j
$$

onde $c_{i, j}$ é o elemento correspondente à $i$-ésima linha e $j$-ésima coluna da matriz de covariância das saídas $C\left(\mathbf{y}_{1}, \mathbf{y}_{2}, \ldots, \mathbf{y}_{n_{p}}\right)$, com $\mathbf{y}_{p} \in \mathbb{R}^{N_{e} \times 1}$, dada por:

$$
\begin{aligned}
C\left(\mathbf{y}_{1}, \mathbf{y}_{2}, \ldots, \mathbf{y}_{n_{p}}\right) & =\frac{1}{N_{e}}\left[\begin{array}{lll}
\mathbf{y}_{1} & \mathbf{y}_{2} \cdots \mathbf{y}_{n_{p}}
\end{array}\right]^{T}\left[\begin{array}{lll}
\mathbf{y}_{1} & \mathbf{y}_{2} \cdots \mathbf{y}_{n_{p}}
\end{array}\right] \\
& =\frac{1}{N_{e}} Y^{T} Y
\end{aligned}
$$

Se o valor de SF for elevado, os sinais de entrada são capazes de excitar a planta nas direções de baixo e de alto ganho aproximadamente na mesma proporção. Por outro lado, reduzidos valores de SF refletem claramente a característica de direcionalidade de ganho. Nesse caso, os sinais de entrada excitaram a planta predominantemente em uma (ou algumas) das direções, geralmente a direção de alto ganho. O fator de dispersão definido no intervalo [0;100\%] permite avaliar numericamente a efetividade dos método de projeto de sinal de excitação, independentemente da sua natureza. É evidente que, para essa medida, valores reduzidos de SNR (signal-to-noise ratio) devem ser evitados, minimizando a contribuição das perturbações no cálculo do SF.

A avaliação da dispersão das saídas pode ser realizada para o caso estático previamente ao experimento de identificação, desde que conhecida a matriz de ganhos estáticos da planta (8.1). As saídas na condição estática serão dadas por:

$$
Y^{T}=K U^{T}
$$

O SF calculado a partir de (8.25) permite avaliar a efetividade dos sinais de excitação na condição estacionária. Conforme é discutido na seção 8.5, a medida para o caso estático é representativa também na condição dinâmica quando $\gamma(j \omega)$ é aproximadamente constante. 
Na identificação dos modelos $G_{1}(s)$ e $G_{2}(s)$ da coluna de alta pureza, o SF é uma medida da dispersão das saídas no plano $\left\{y_{1} ; y_{2}\right\}$. No caso de uma planta de $n_{p}$ saídas, o SF mede a dispersão das saídas no espaço $\left\{y_{1} ; y_{2} ; \ldots ; y_{n_{p}}\right\}$.

\subsection{Resultados de simulações}

Foram realizadas simulações de identificação das plantas de primeira e segunda ordem $\left(G_{1}(s)\right.$ e $\left.G_{2}(s)\right)$ da coluna de destilação de alta pureza, utilizando cada um dos cinco métodos para geração dos sinais de excitação. Os parâmetros de simulação e configuração dos sinais de excitação foram discutidos nas seções anteriores deste capítulo.

Para avaliar comparativamente os resultados da identificação, foi utilizado o índice FIT baseado na raiz do erro médio quadrático normalizado (normalized root-meansquare error, NRMSE) (ARMSTRONG; COLLOPY, 1992):

$$
\operatorname{FIT}_{p}=\left(1-\frac{\sqrt{\sum_{i=0}^{N_{e}-1}\left(\hat{y}_{p}(i)-y_{p}(i)\right)^{2}}}{\sqrt{\sum_{i=0}^{N_{e}-1}\left(y_{p}(i)-\bar{y}_{p}\right)^{2}}}\right) \times 100[\%]
$$

onde $y_{p}(i)$ é a $p$-ésima saída medida; $\hat{y}(i)_{p}$ e $\bar{y}_{p}$ são as correspondentes saída estimada e sua média.

Os resultados serão apresentados em termos do FIT médio $(\overline{F I T})$ das iterações das simulações de Monte-Carlo. O $\overline{F I T}$ para a $p$-ésima saída da planta é:

$$
\overline{F I T}_{p}=\frac{1}{M C} \sum_{i=1}^{M C} F I T_{p}
$$

onde $M C$ é a quantidade de realizações das simulações de Monte-Carlo.

São apresentados também os desvios-padrão $\sigma_{F I T, p}$ de $F I T_{p}$, calculados como:

$$
\sigma_{F I T, p}=\sqrt{\frac{1}{M C-1} \sum_{i=1}^{M C}\left(F I T_{p}-\overline{F I T}_{p}\right)^{2}}
$$

Para o cálculo do índice FIT os modelos ajustados e as plantas foram excitadas por sinais de validação do tipo GBN consistindo de duas seções de sinais GBN de mesmo período. Na primeira seção, ambos sinais são correlacionados e, na segunda, são não correlacionados. Na validação de modelos para a planta de primeira ordem, a probabilidade de não chaveamento $p=0,88$ foi adotada para ambas as seções. No caso da validação de modelos para a planta de segunda ordem, foi adotado $p=0,84$. 
Para avaliar a potência dos sinais de entrada foi utilizado o CF calculado por (4.15).

A cada uma das saídas $y_{1}$ e $y_{2}$ foi somado ruído branco Gaussiano de variância $\sigma_{e}^{2}$ filtrado por um modelo de perturbação de primeira ordem com constante de tempo $\tau_{d}=$ 100 minutos. As cinco simulações com a planta de primeira ordem foram realizadas com $\sigma_{e}^{2}=0,1$. Com a planta de segunda ordem, para avaliar a robustez dos sinais de excitação em meio a perturbações, foram realizadas simulações com $\sigma_{e}^{2}=0,1 \mathrm{e}$ também $\sigma_{e}^{2}=0,5$, com cada um dos cinco métodos de geração de sinais de excitação. Assim, no total foram realizadas 15 simulações Monte-Carlo. Para cada simulação foram realizadas 100 iterações.

Com os dados das simulações da planta de primeira ordem $G_{1}(s)$, foram estimados parâmetros de estruturas ARX de ordem 1 (resultados na tabela 8.3). Os dados das simulações da planta de segunda ordem $G_{2}(s)$ ajustaram parâmetros de estruturas ARMAX de ordem 10 (resultados nas tabelas 8.4 e 8.5). Os resultados de ajustes de parâmetros de estrutura ARX com os dados de simulações da planta de segunda ordem foram insatisfatórios, conforme apresentados na tabela 8.6. A maior liberdade no ajuste do modelo de perturbação da estrutura ARMAX permitiu ajuste (FIT) significativamente superior ao obtido com a estrutura ARX.

As tabelas apresentam a média do $\mathrm{SF}(\overline{S F})$ calculada com os dados completos de cada simulação de 100 iterações e o respectivo desvio padrão $\left(\sigma_{S F}\right)$. De forma análoga, são calculados os FIT médios $(\overline{F I T})$ e seus desvios padrões $\left(\sigma_{F I T}\right)$. Os valores de SNR médio $(\overline{S N R})$ são as médias do quociente entre a variância de cada saída e a correspondente variância da perturbação. São apresentados também os respectivos desvios padrões $\left(\sigma_{S N R}\right)$.

Tabela 8.3: Resumo dos resultados de simulação do modelo de primeira ordem da coluna de alta pureza $G_{1}(s)$.

\begin{tabular}{|c|c|c|c|c|c|c|c|}
\hline Método & $\overline{S F}[\%]$ & $\sigma_{S F}$ & Saída & $\overline{F I T}[\%]$ & $\sigma_{F I T}$ & $\overline{S N R}$ & $\sigma_{S N R}$ \\
\hline \multirow[b]{2}{*}{ PRB } & \multirow{2}{*}{0,012} & \multirow[b]{2}{*}{0,004} & $y_{1}$ & 40,88 & 32,72 & $1,3 \times 10^{5}$ & $3,9 \times 10^{4}$ \\
\hline & & & $y_{2}$ & 40,45 & 37,38 & $1,2 \times 10^{5}$ & $6,1 \times 10^{4}$ \\
\hline \multirow{2}{*}{ Sinais rotacionados } & \multirow{2}{*}{88,61} & \multirow{2}{*}{8,02} & $y_{1}$ & 70,07 & 5,91 & 35,39 & 9,26 \\
\hline & & & $y$ & 72,43 & 5,04 & 35,52 & 10,39 \\
\hline \multirow{2}{*}{$\begin{array}{l}\text { Método } 1 \text { de } \\
\text { dois passos }\end{array}$} & \multirow{2}{*}{78,24} & \multirow{2}{*}{13,38} & $y$ & 68,12 & 4,34 & 18,99 & 5,04 \\
\hline & & & $y_{2}$ & 70,20 & 3,87 & 24,81 & 6,32 \\
\hline \multirow{2}{*}{$\begin{array}{c}\text { Método } 2 \text { de } \\
\text { dois passos }\end{array}$} & \multirow{2}{*}{62,67} & \multirow{2}{*}{12,17} & $y_{1}$ & 67,60 & 4,87 & 64,51 & 16,73 \\
\hline & & & $y_{2}$ & 70,19 & 4,59 & 17,16 & 3,91 \\
\hline \multirow{2}{*}{$\begin{array}{l}\text { SOH com espectros } \\
\text { intercalados modificados }\end{array}$} & \multirow{2}{*}{65,43} & \multirow{2}{*}{2,46} & $y_{1}$ & 75,21 & 4,10 & 83,72 & 13,20 \\
\hline & & & $y_{2}$ & 75,42 & 6,16 & 108,16 & 20,45 \\
\hline \multirow{2}{*}{ PRT } & \multirow{2}{*}{0,048} & \multirow{2}{*}{0,006} & $y_{1}$ & 56,14 & 6,91 & $9,1 \times 10^{3}$ & $1,5 \times 10^{3}$ \\
\hline & & & $y_{2}$ & 57,97 & 5,36 & $1,5 \times 10^{4}$ & $2,5 \times 10^{3}$ \\
\hline
\end{tabular}

${ }^{1}$ No caso do PRB, o $\overline{F I T}[\%]$ foi calculado apenas com os dados relativos à seção de sinais de validação não correlacionados. 
Tabela 8.4: Resumo dos resultados de simulação do modelo de segunda ordem da coluna de alta pureza $G_{2}(s)$ para $\sigma_{e}^{2}=0,1$ e estrutura ARMAX.

\begin{tabular}{|c|c|c|c|c|c|c|c|c|}
\hline Método & $\overline{S F}[\%]$ & $\sigma_{S F}$ & Saída & $\overline{F I T}[\%]$ & $\sigma_{F I T}$ & $\overline{S N R}$ & $\sigma_{S N R}$ & $C F$ \\
\hline \multirow{2}{*}{ PRB } & \multirow{2}{*}{0,88} & \multirow{2}{*}{0,0285} & $y_{1}$ & 62,03 & 2,34 & $2,85 \times 10^{4}$ & $6,91 \times 10^{3}$ & \multirow{2}{*}{1,0} \\
\hline & & & $y_{2}$ & 60,06 & 4,80 & $4,53 \times 10^{4}$ & $1,02 \times 10^{4}$ & \\
\hline \multirow{2}{*}{ Sinais rotacionados } & \multirow{2}{*}{84,60} & \multirow{2}{*}{4,55} & $y_{1}$ & 92,09 & 2,06 & 26,37 & 3,51 & \multirow{2}{*}{1,01} \\
\hline & & & $y_{2}$ & 93,05 & 2,64 & 25,91 & 3,29 & \\
\hline \multirow{2}{*}{$\begin{array}{l}\text { Método } 1 \text { de } \\
\text { dois passos }\end{array}$} & \multirow{2}{*}{94,37} & \multirow{2}{*}{1,83} & $y_{1}$ & 91,69 & 1,12 & 52,44 & 5,47 & \multirow{2}{*}{1,41} \\
\hline & & & $y_{2}$ & 92,65 & 1,04 & 65,65 & 8,54 & \\
\hline \multirow{2}{*}{$\begin{array}{l}\text { Método } 2 \text { de } \\
\text { dois passos }\end{array}$} & \multirow{2}{*}{91,02} & \multirow{2}{*}{6,32} & $y_{1}$ & 92,53 & 1,29 & 46,58 & 8,15 & \multirow{2}{*}{1,02} \\
\hline & & & $y_{2}$ & 92,54 & 2,07 & 61,10 & 13,60 & \\
\hline \multirow{2}{*}{$\begin{array}{c}\text { SOH com espectros } \\
\text { intercalados modificados }\end{array}$} & \multirow{2}{*}{81,34} & \multirow{2}{*}{0,31} & $y_{1}$ & 89,38 & 2,63 & 80,19 & 9,34 & \multirow{2}{*}{2,21} \\
\hline & & & $y_{2}$ & 92,37 & 1,85 & 97,39 & 11,20 & \\
\hline \multirow{2}{*}{ PRT } & \multirow{2}{*}{0,81} & \multirow{2}{*}{0,011} & $y_{1}$ & 67,91 & 2,27 & $4,09 \times 10^{3}$ & 384,02 & \multirow{2}{*}{1,79} \\
\hline & & & $y_{2}$ & 68,40 & 4,86 & $6,29 \times 10^{3}$ & 646,49 & \\
\hline
\end{tabular}

${ }^{1}$ No caso do PRB, o $\overline{F I T}[\%]$ foi calculado apenas com os dados relativos à seção de sinais de validação não correlacionados.

Tabela 8.5: Resumo dos resultados de simulação do modelo de segunda ordem da coluna de alta pureza $G_{2}(s)$ para $\sigma_{e}^{2}=0,5$ e estrutura ARMAX.

\begin{tabular}{|c|c|c|c|c|c|c|c|c|}
\hline Método & $\overline{S F}[\%]$ & $\sigma_{S F}$ & Saídas & $\overline{F I T}[\%]$ & $\sigma_{F I T}$ & $\overline{S N R}$ & $\sigma_{S N R}$ & $C F$ \\
\hline \multirow{2}{*}{ PRB } & \multirow{2}{*}{1.05} & \multirow{2}{*}{0.031} & $y_{1}$ & 53,30 & $4, \overline{4,96}$ & $\overline{5,62 \times 10^{3}}$ & $1,32 \times 10^{3}$ & \multirow{2}{*}{1,0} \\
\hline & & & $y_{2}$ & 59,59 & 4,02 & $8,75 \times 10^{3}$ & $1,86 \times 10^{3}$ & \\
\hline \multirow{2}{*}{ Sinais rotacionados } & \multirow{2}{*}{85,78} & \multirow{2}{*}{4,87} & $y_{1}$ & 82,43 & 2,18 & 13,48 & 2,03 & \multirow{2}{*}{1,01} \\
\hline & & & $y_{2}$ & 84,36 & 2,10 & 12,91 & 3,02 & \\
\hline \multirow{2}{*}{$\begin{array}{c}\text { Método } 1 \text { de } \\
\text { dois passos }\end{array}$} & \multirow{2}{*}{92,97} & \multirow{2}{*}{3,69} & $y_{1}$ & 81,45 & 2,20 & 11,64 & 1,41 & \multirow{2}{*}{1,41} \\
\hline & & & $y_{2}$ & 83,64 & 2,25 & 13,94 & 1,62 & \\
\hline \multirow{2}{*}{$\begin{array}{c}\text { Método } 2 \text { de } \\
\text { dois passos }\end{array}$} & \multirow{2}{*}{91,50} & \multirow{2}{*}{6,44} & $y_{1}$ & 83,74 & 1,65 & 25,93 & 6,80 & \multirow{2}{*}{1,02} \\
\hline & & & $y_{2}$ & 85,33 & 1,67 & 31,64 & 7,52 & \\
\hline \multirow{2}{*}{$\begin{array}{c}\text { SOH com espectros } \\
\text { intercalados modificados }\end{array}$} & \multirow{2}{*}{83,56} & \multirow{2}{*}{0,31} & $y_{1}$ & 81,83 & 2,34 & 15,67 & 1,61 & \multirow{2}{*}{2,42} \\
\hline & & & $y_{2}$ & 81,74 & 4,60 & 18,52 & 2,11 & \\
\hline \multirow{2}{*}{ PRT } & \multirow{2}{*}{0,391} & \multirow{2}{*}{0,026} & $y_{1}$ & 53,79 & 5,51 & 808,54 & 91,632 & \multirow{2}{*}{1,81} \\
\hline & & & $y_{2}$ & 58,37 & 5,41 & 1276,7 & 132,52 & \\
\hline
\end{tabular}

${ }^{1}$ No caso do PRB, o $\overline{F I T}$ [\%] foi calculado apenas com os dados relativos à seção de sinais de validação não correlacionados.

Tabela 8.6: FIT de modelos ARX estimados a partir de dados da planta de segunda ordem da coluna de alta pureza $G_{2}(s) \operatorname{com} \sigma_{e}^{2}=0,1$.

\begin{tabular}{cccccccc}
\hline Método & Saída & $\overline{F I T}[\%]$ & $\sigma_{F I T}$ & Método & Saída & $\overline{F I T}[\%]$ & $\sigma_{F I T}$ \\
\hline \hline \multirow{2}{*}{ PRB } & $y_{1}$ & 59,41 & 6,60 & \multirow{2}{*}{ Sinais rotacionados } & $y_{1}$ & 63,42 & 4,51 \\
& $y_{2}$ & 55,01 & 6,61 & & $y_{2}$ & 67,68 & 4,07 \\
\hline Método 1 de & $y_{1}$ & 67,74 & 2,81 & Método 2 de & $y_{1}$ & 70,52 & 1,29 \\
dois passos & $y_{2}$ & 71,40 & 2,89 & dois passos & $y_{2}$ & 70,54 & 1,03 \\
\hline SOH com espectros & $y_{1}$ & 25,25 & 1,87 & \multirow{2}{*}{ PRT } & $y_{1}$ & 42,56 & 10,32 \\
intercalados modificados & $y_{2}$ & 24,17 & 1,85 & & $y_{2}$ & 48,41 & 8,63 \\
\hline
\end{tabular}

${ }^{1}$ Foram empregados nas simulações modelos ARX de ordem 10 exceto no caso dos sinais $\mathrm{SOH}$ com espectros intercalados onde foi empregado ARX de ordem 3.

\subsubsection{Resultados de simulações da planta de primeira ordem}

Observa-se significativa melhora dos resultados (maiores FIT) quando sinais de excitação diferentes do PRB são utilizados. O maior FIT foi obtido usando sinais SOH com 
espectros intercalados modificados. Os FIT obtidos utilizando os métodos 1 e 2 de dois passos são similares e piores que os obtidos com sinais rotacionados. Cabe ressaltar que para projetar tanto sinais $\mathrm{SOH}$ com espectros intercalados modificados quanto sinais rotacionados é necessário conhecimento a priori da matriz de ganhos estáticos da planta (tabela 8.1). Essa é uma desvantagem desses métodos quando comparados com os métodos 1 e 2 de dois passos. O desempenho dos sinais PRT foi insatisfatório. Apesar desses sinais possuírem harmônicas correlacionadas e resultarem em elevados valores de SNR, as saídas ficaram alinhadas predominantemente na direção de alto ganho e pouco conseguiram enfatizar a direção de baixo ganho (analogamente ao PRB). Esses dados de saídas não são suficientes para obter boas estimativas na direção de baixo ganho.

As figuras 8.18 a 8.22 apresentam os planos de saída do sistema simulado para cada um dos cinco métodos de geração de sinais. Na figura 8.19 pode ser observada a característica de concatenação de períodos de sinais de excitação: um excita a direção de baixo ganho no início do experimento e outro excita a direção de alto ganho em outro momento do experimento. Um padrão diferente de dispersão das saídas é observado na figura 8.20, pois esse método excita simultaneamente as direções de baixo e alto ganho, similar aos sinais rotacionados (figura 8.18). Os sinais $\mathrm{SOH}$ com espectro de potência intercalado modificado são contínuos no tempo (tabela 8.1), portanto, o padrão de espalhamento das saídas apresenta linhas mais contínuas que os outros métodos. A figura 8.27 mostra que os dados de saída dos sinais PRT estão em sua maioria alinhados com a direção de mais alto ganho e fracamente excita a direção de baixo ganho.

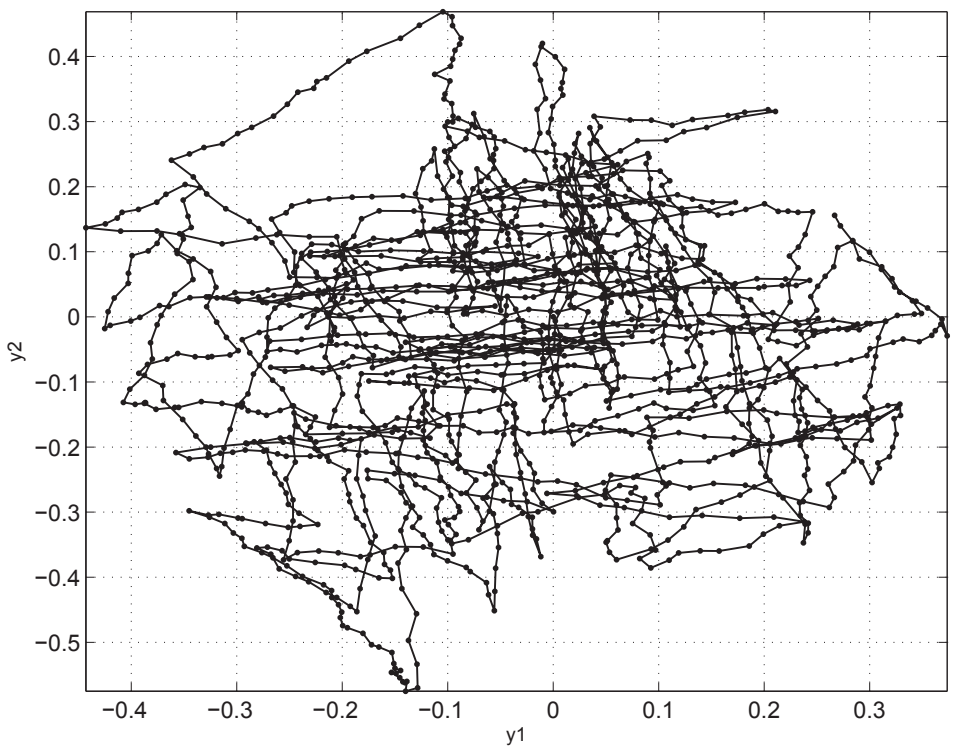

Figura 8.18: Plano de saídas $\left\{y_{1} ; y_{2}\right\}$ do modelo de primeira ordem da coluna de alta pureza excitada com sinais rotacionados. 


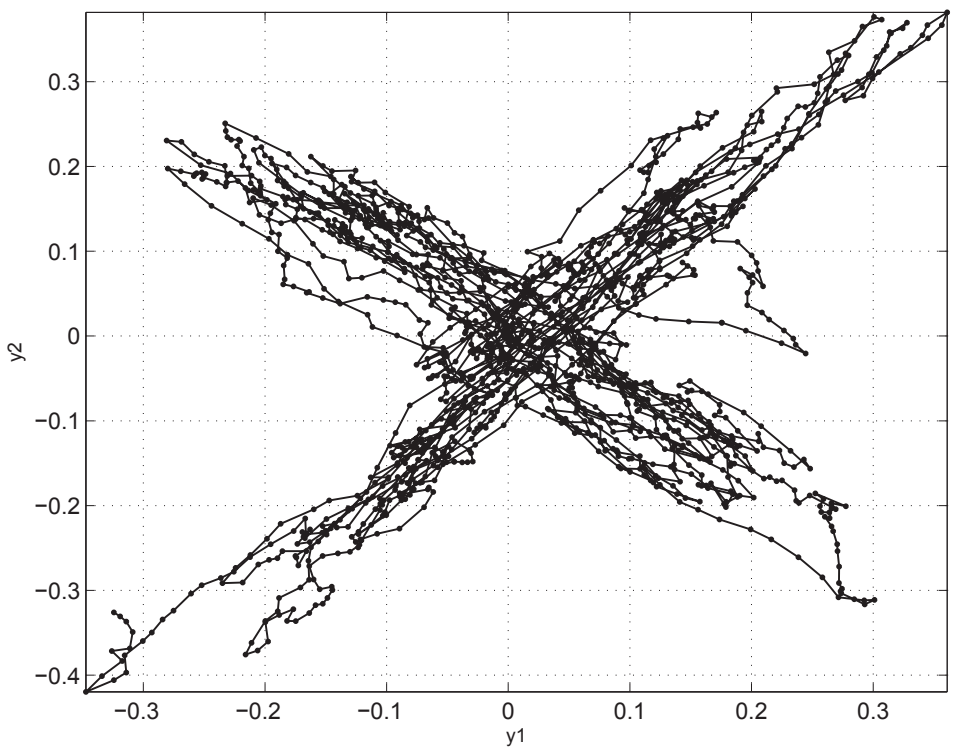

Figura 8.19: Plano de saídas $\left\{y_{1} ; y_{2}\right\}$ do modelo de primeira ordem da coluna de alta pureza excitada com sinais gerados pelo método 1 de dois passos.

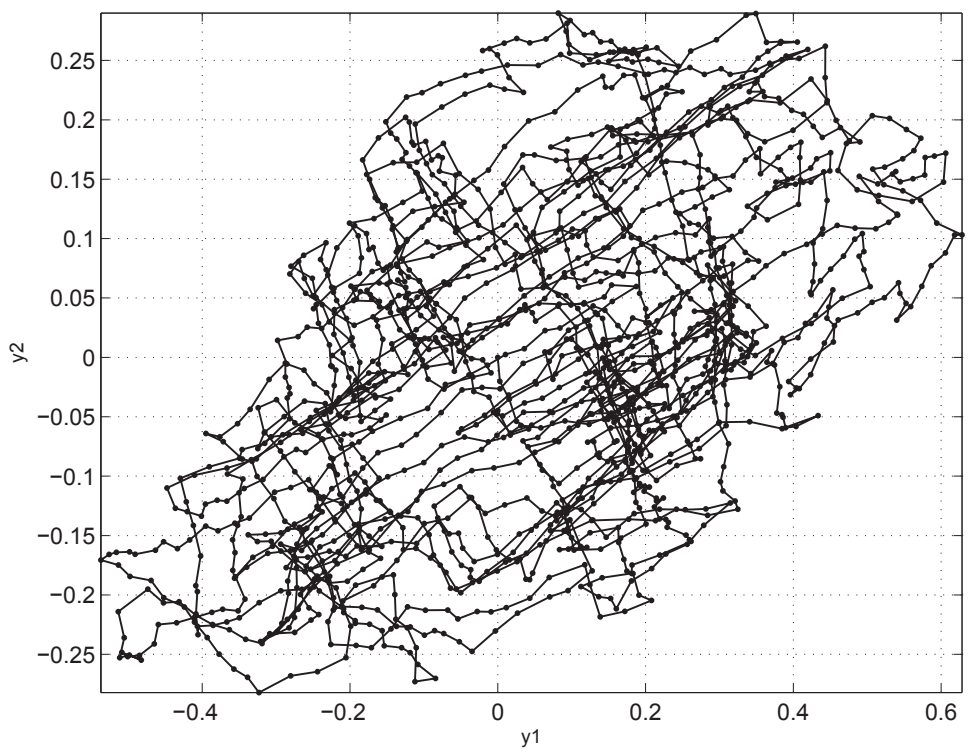

Figura 8.20: Plano de saídas $\left\{y_{1} ; y_{2}\right\}$ do modelo de primeira ordem da coluna de alta pureza excitada com sinais gerados pelo método 2 de dois passos.

Os SF calculados para as saídas dos experimentos com PRB e PRT foram baixos $(<1 \%)$, mostrando que esses sinais não são capazes de excitar a planta nas direções de baixo e alto ganho na mesma proporção. Entretanto, para os quatro outros métodos, o SF não é baixo e as excitações em ambas as direções estão balanceadas. Visualmente, saídas obtidas com sinais rotacionados e sinais do método 1 de dois passos estão quase simétricas e, portanto, os respectivos valores de SF são elevados $(\approx 80 \%)$. O melhor FIT foi obtido com os sinais $\mathrm{SOH}$ com espectros intercalados modificados, que estabelecem um compromisso entre valores de SF e SNR. 


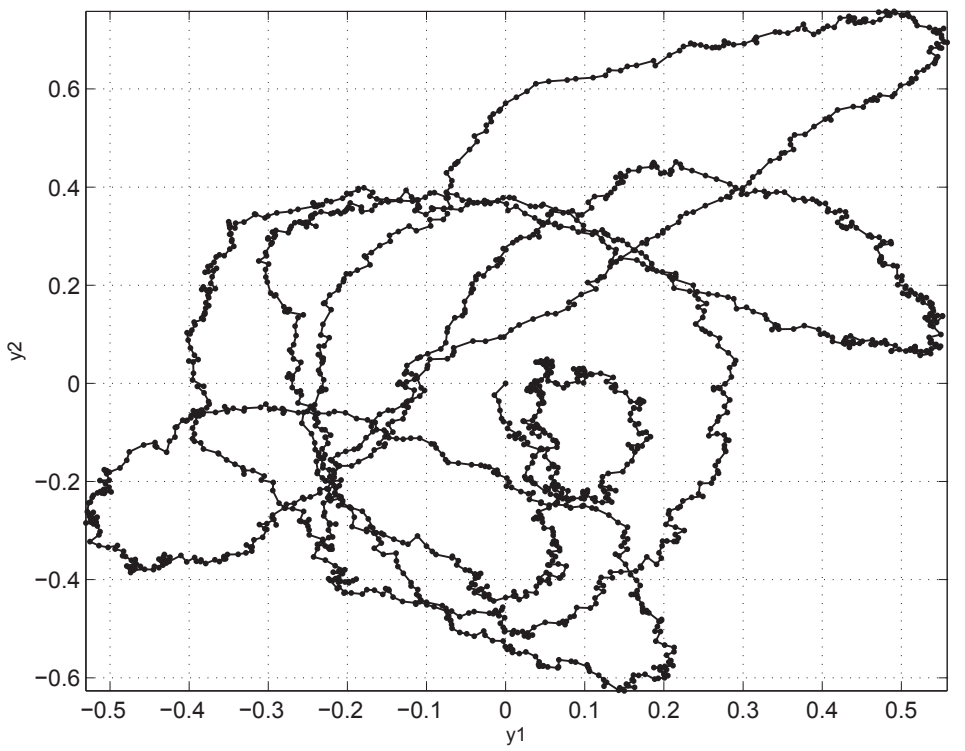

Figura 8.21: Plano de saídas $\left\{y_{1} ; y_{2}\right\}$ do modelo de primeira ordem da coluna de alta pureza excitada com sinais $\mathrm{SOH}$ com espectros intercalados modificados.

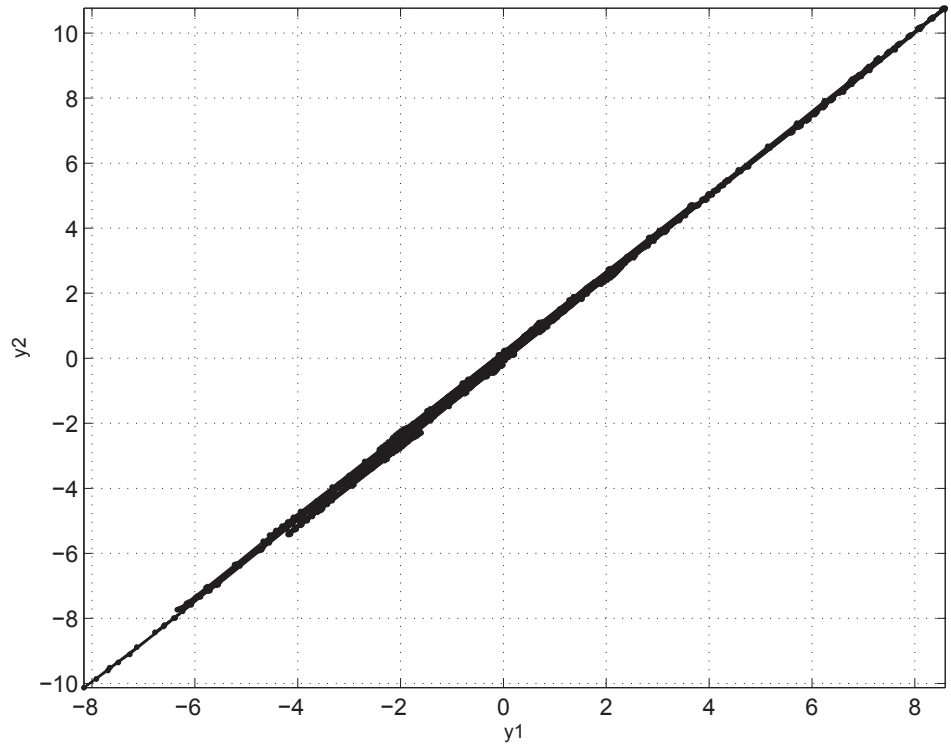

Figura 8.22: Plano de saídas $\left\{y_{1} ; y_{2}\right\}$ do modelo de primeira ordem da coluna de alta pureza excitada com sinais PRT com harmônicas correlacionadas.

\subsubsection{Resultados de simulações da planta de segunda ordem}

Assim como nas simulações com a planta de primeira ordem, nos dois cenários de perturbação $\left(\sigma_{e}^{2}=0,1\right.$ e $\left.\sigma_{e}^{2}=0,5\right)$ melhores ajustes dos modelos (maiores FIT) foram obtidos quando a planta é excitada com sinais diferentes do PRB e PRT (tabelas 8.4 e 8.5). Os FIT obtidos com os sinais rotacionados, sinais de excitação gerados pelos métodos de dois passos e sinais $\mathrm{SOH}$ com espectros intercalados modificados foram elevados e semelhantes.

As figuras 8.23 a 8.27 apresentam o plano das saídas $\left\{y_{1} ; y_{2}\right\}$ da planta de segunda 
ordem $G_{2}(s)$ para cada um dos métodos de excitação de plantas mal condicionadas discutidos neste capítulo.

Observando a figura 8.23, verifica-se que a rotação dos sinais PRB (sinais rotacionados) os torna capaz de excitar tanto a direção de baixo quanto de alto ganho.

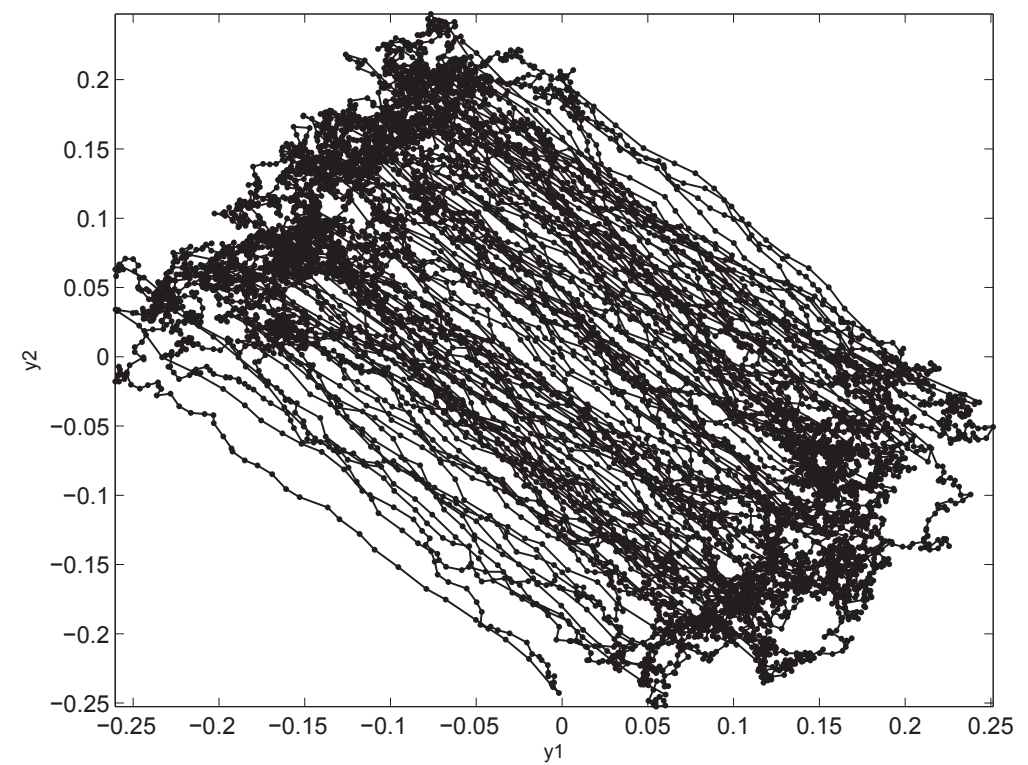

Figura 8.23: Plano de saídas $\left\{y_{1} ; y_{2}\right\}$ do modelo de segunda ordem da coluna de alta pureza excitada com sinais rotacionados.

Assim como nas saídas da planta de primeira ordem, na figura 8.24 observa-se a característica de concatenação de sinais correlacionados e não correlacionados do método 1 de dois passos. As direções de alto e baixo ganho são excitadas em momentos diferentes do experimento. Com esses sinais, obteve-se o maior SF entre os 5 experimentos realizados com a planta de segunda ordem.

Diferentemente do método 1 de dois passos, com o método 2 de dois passos, as direções de alto e baixo ganho são excitadas simultaneamente. Isso pode ser observado no padrão do plano das saídas na figura 8.25. Essa característica é semelhante à dos sinais rotacionados. Com o método 2 de dois passos, obteve-se também um bom SF, porém, menor que o obtido com o método 1 de dois passos.

Os sinais SOH com espectros intercalados modificados são contínuos em amplitude. Essa característica pode ser observada na figura 8.26. Verifica-se nessa figura que esses sinais são capazes de excitar tanto as direções de baixo como as de alto ganho, resultando em elevado SF.

Na figura 8.27, observa-se que as saídas obtidas com os sinais PRT com harmônicas correlacionadas estão predominantemente alinhadas na direção da alto ganho. Essa característica prejudica a obtenção de bons ajustes do modelo na direção de baixo ganho. O desempenho insuficiente dos sinais PRT decorre de seu procedimento de construção 


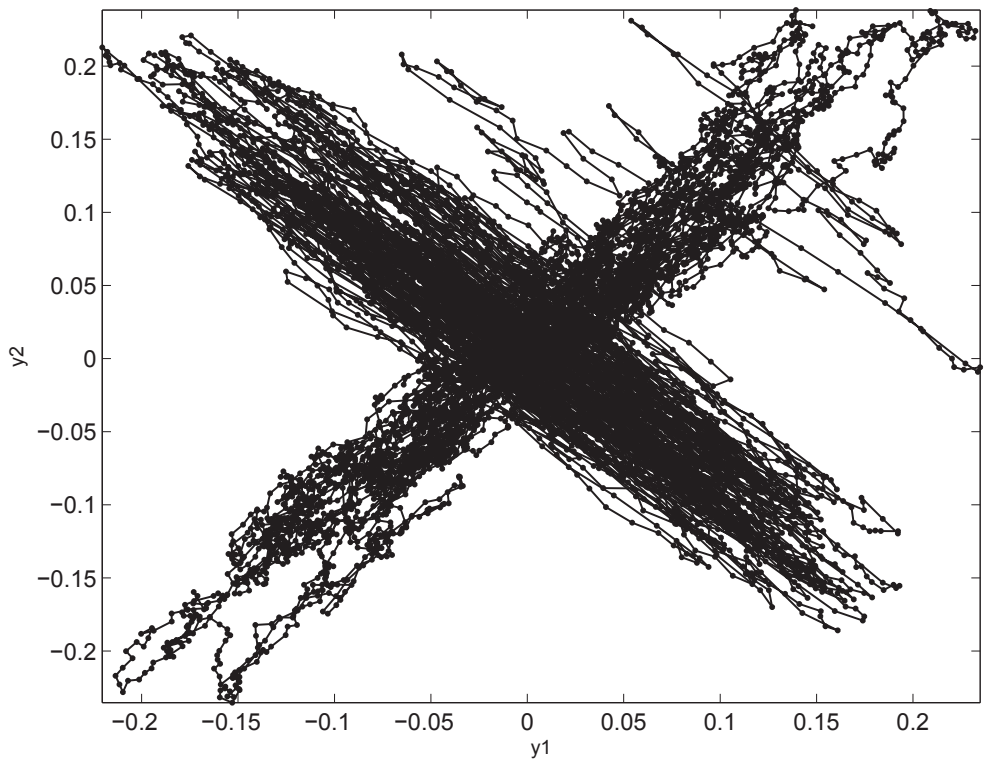

Figura 8.24: Plano de saídas $\left\{y_{1} ; y_{2}\right\}$ do modelo de segunda ordem da coluna de alta pureza excitada com sinais gerados pelo método 1 de dois passos.

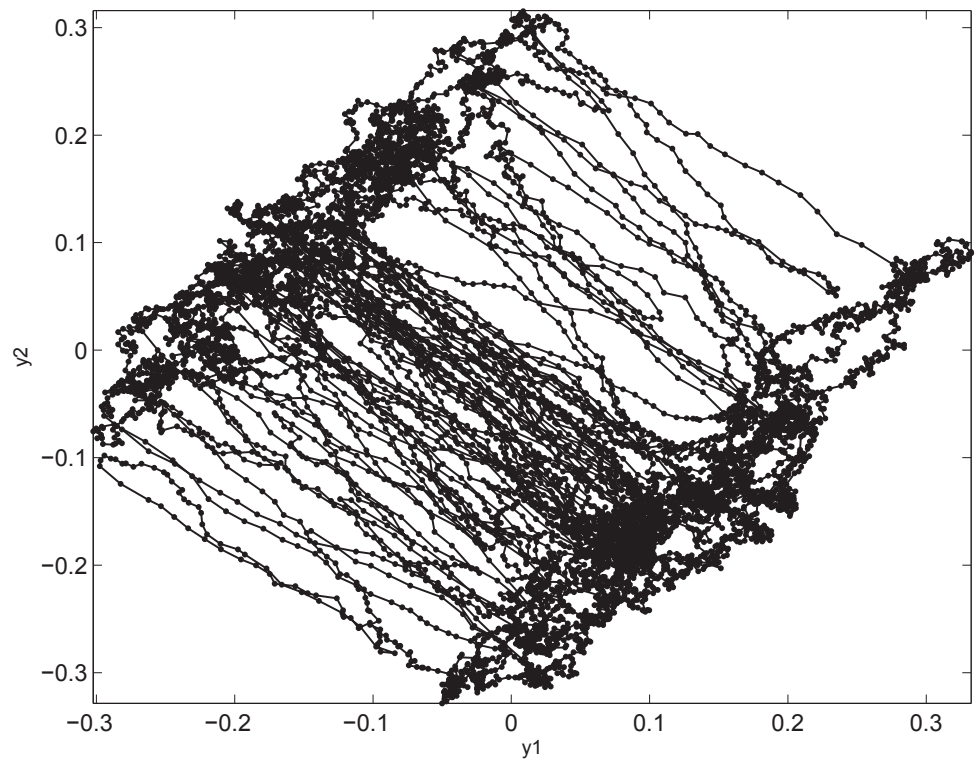

Figura 8.25: Plano de saídas $\left\{y_{1} ; y_{2}\right\}$ do modelo de segunda ordem da coluna de alta pureza excitada com sinais gerados pelo método 2 de dois passos.

não utilizar informações relativas aos ganhos da planta nas diferentes direções. Sem esses conhecimentos, não é possível enfatizar adequadamente a direção de baixo ganho com o objetivo de descorrelacionar as saídas, tornando limitada a aplicação dos sinais PRT em identificação de processos mal condicionados. Bons resultados foram apresentados em (TAN; GODFREY; BARKER, 2009) especificamente na identificação da planta (OGUNNAIKE; LEMAIRE; MORARI, 1983), o que mostra a adequação dos sinais PRT para essa planta e pouca flexibilidade para ajuste a outras plantas.

Assim como nas simulações da planta de primeira ordem, os SF das saídas da planta excitada com sinais PRB e PRT foram reduzidos $(<2 \%)$ (tabelas 8.4 e 8.5), 


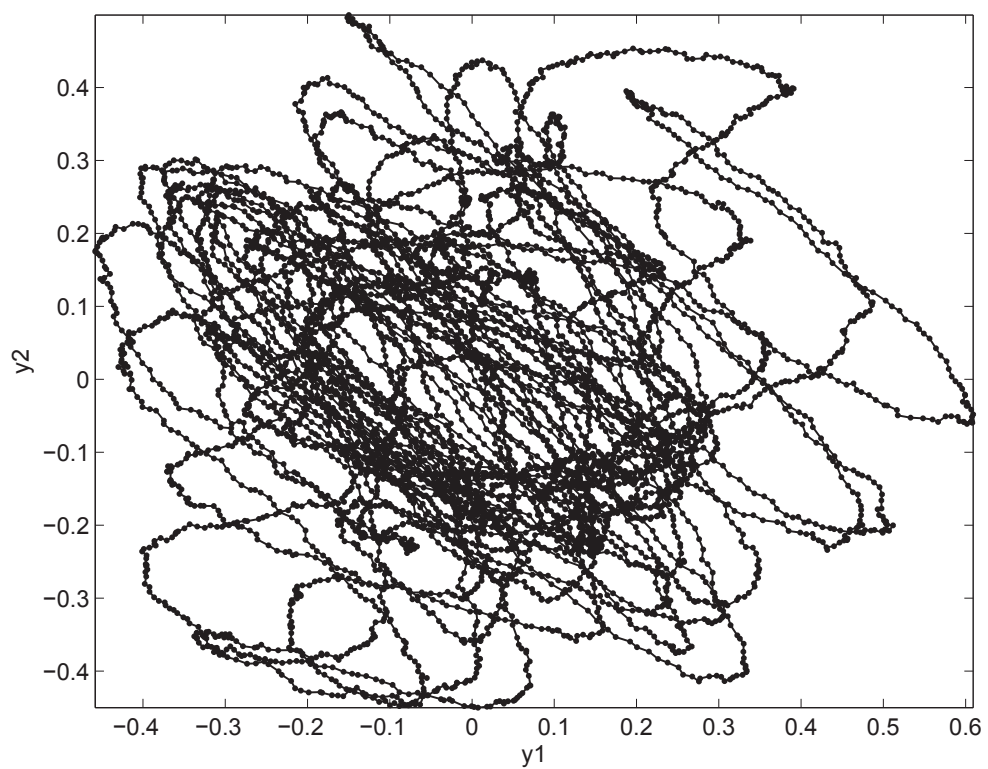

Figura 8.26: Plano de saídas $\left\{y_{1} ; y_{2}\right\}$ do modelo de segunda ordem da coluna de alta pureza excitada com sinais $\mathrm{SOH}$ com espectros intercalados modificados.

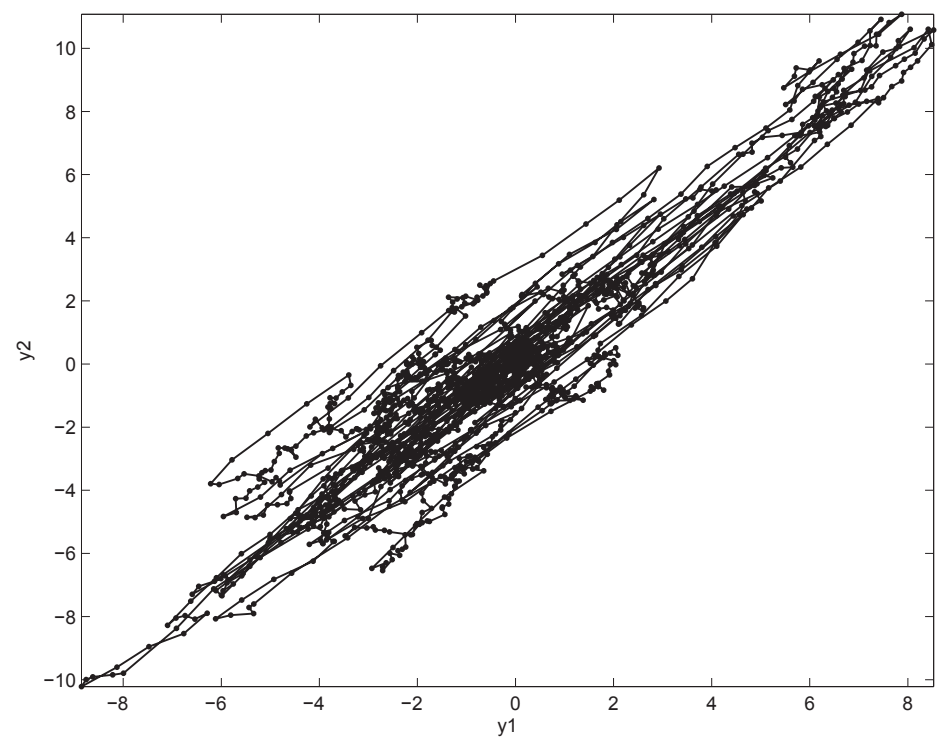

Figura 8.27: Plano de saídas $\left\{y_{1} ; y_{2}\right\}$ do modelo de segunda ordem da coluna de alta pureza excitada com sinais PRT com harmônicas correlacionadas.

mostrando que esses sinais não são capazes de excitar a planta nas direções de baixo e alto ganho na mesma proporção. Os valores elevados de SNR obtidos com sinais PRB e PRT não são suficientes para resultar em elevados FIT, pois as saídas estão predominantemente na direção de alto ganho, sendo pouco excitada a direção de baixo ganho. Com relação aos demais sinais, os SF calculados foram maiores que $60 \%$ e as saídas apresentaram balanceamento das excitações nas direções de alto e baixo ganho. Os FIT nesses casos também foram elevados, confirmando que a medida SF proposta é uma boa avaliação de desempenho do experimento. Assim, SF elevado implica em FIT elevado. 
Os sinais $\mathrm{SOH}$ com espectros intercalados modificados apresentaram os piores (maiores) CF (tabelas 8.3, 8.4 e 8.5), porém, resultaram em ótimo ajuste dos modelos (FIT elevados). Os sinais PRB e PRT apresentaram melhores (menores) CF, porém, o ajuste dos modelos não foi bom (FIT reduzidos). Isso decorre da capacidade dos sinais SOH com espectros intercalados modificados excitar equilibradamente as direções de baixo e alto ganho, o que não foi possível com os sinas PRB e PRT.

As figuras 8.28 e 8.29 apresentam o comportamento dinâmico dos valores singulares $\bar{\sigma}(j \omega)$ e $\underline{\sigma}(j \omega)$ dos modelos ARMAX estimados da planta de segunda ordem $G_{2}(s)$ nos dois cenários de perturbação: $\sigma_{e}^{2}=0,1$ e $\sigma_{e}^{2}=0,5$, respectivamente. Os valores singulares da planta de segunda ordem $G_{2}(s)$, apresentados previamente na figura 8.3, são também colocados nas figuras 8.28 e 8.29. Os valores singulares dos modelos obtidos com os cinco métodos de geração de sinais em ambos os cenários de perturbação são semelhantes, aumentando o desvio em relação à planta em frequências mais altas. Observa-se que para os modelos estimados a partir dos resultados de excitações PRB e PRT, $\underline{\sigma}(j \omega)$ em baixas frequências e $\bar{\sigma}(j \omega)$ em altas frequências e no cenário de maior perturbação $\left(\sigma_{e}^{2}=0,5\right)$, os desvios em relação à planta são maiores. Assim, os sinais rotacionados, sinais gerados pelos métodos de dois passos e sinais $\mathrm{SOH}$ com espectros intercalados modificados são aplicáveis à identificação de plantas mal condicionadas.

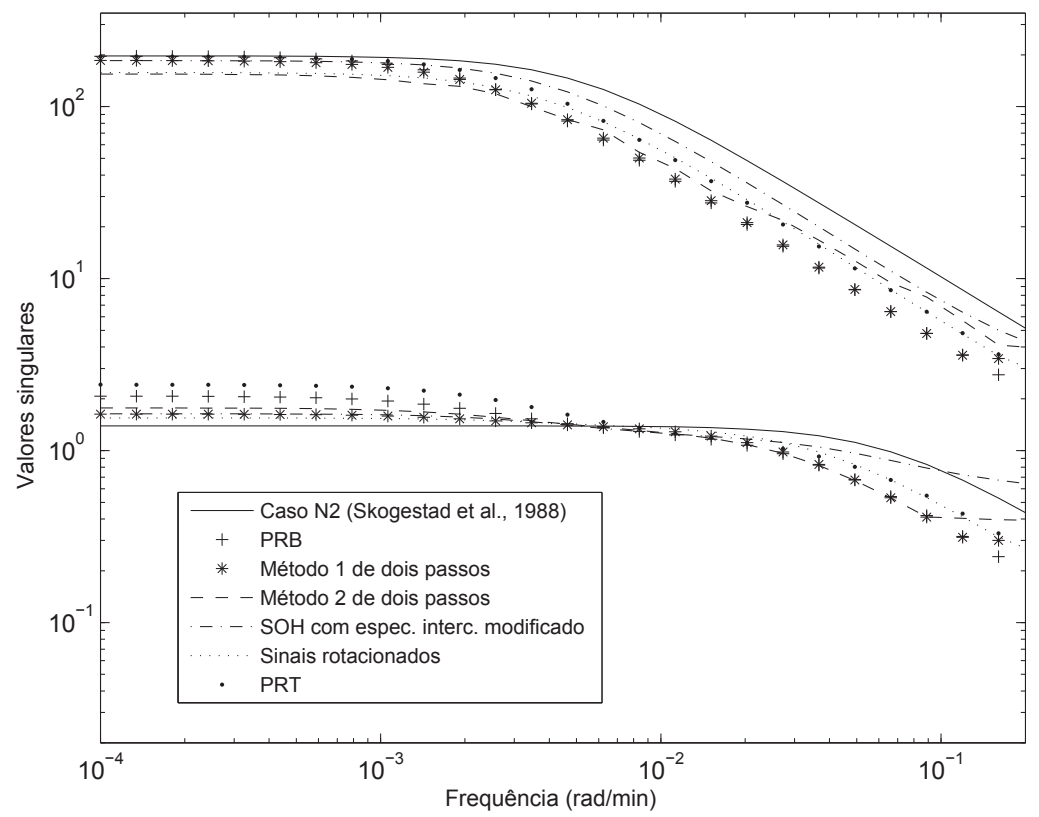

Figura 8.28: Valores singulares do modelo de segunda ordem da coluna de alta pureza e dos modelos ARMAX estimados com $\sigma_{e}^{2}=0,1$. 


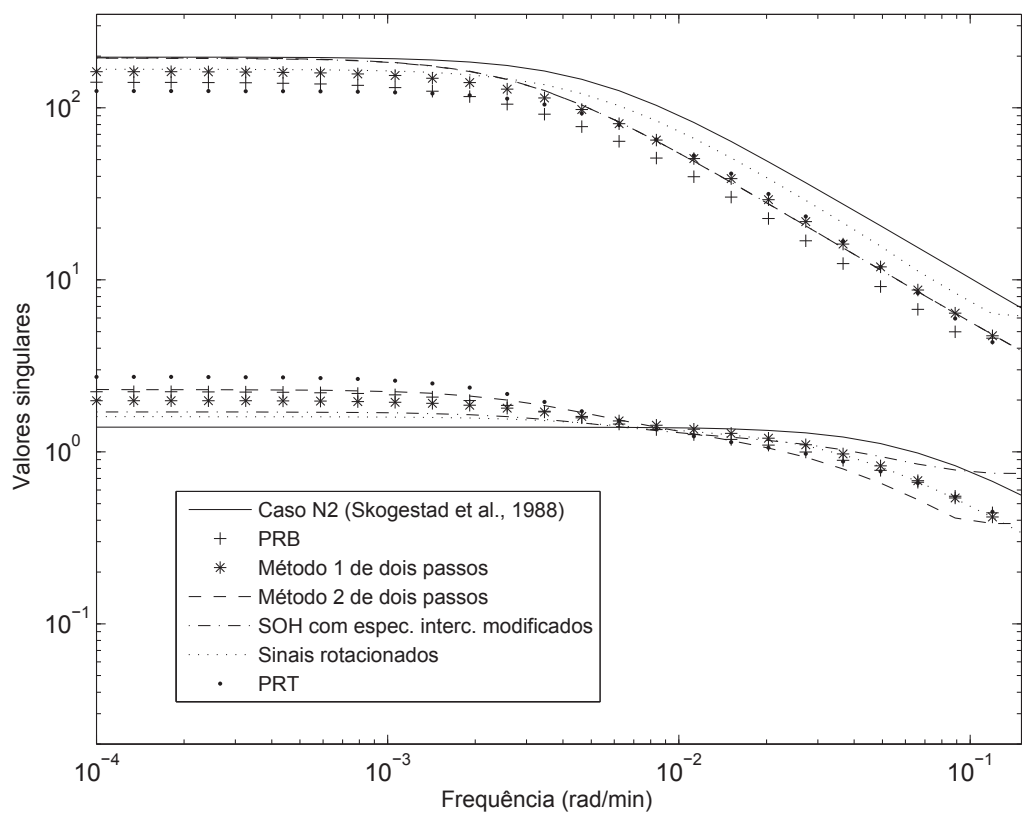

Figura 8.29: Valores singulares do modelo de segunda ordem da coluna de alta pureza e dos modelos ARMAX estimados $\operatorname{com} \sigma_{e}^{2}=0,5$.

\subsubsection{Considerações sobre excitações de plantas mal condiciona- das}

Foi apresentada uma comparação da efetividade de cinco métodos de projeto de sinais de excitação para identificação de sistemas mal condicionados. Por meio de simulações de identificação de plantas com diferentes ordens e diferentes cenários de perturbação com sinais gerados pelos cinco métodos, foram estimados modelos ARX e ARMAX. Observou-se que os métodos resultam em desempenhos diferentes, dependendo de como as direções das saídas são excitadas.

Para medir a proporção da excitação nas direções de alto e baixo ganho, foi proposta uma medida SF para avaliar as saídas do sistema. Os resultados mostraram que um bom desempenho foi obtido com sinais que apresentaram boa SNR e bom SF, o que implica que deve haver um compromisso entre eles. Maximizar apenas a SNR das saídas não é suficiente para bons resultados de estimação de modelos, assim como apenas minimizar os CF dos sinais de entrada também não é condição suficiente.

\subsection{Proposta de rotação de sinais com restrição}

Em um experimento de identificação, é desejável que as saídas sejam excursionadas respeitando limites preestabelecidos. Quanto mais amplas forem as excursões maior será a SNR, o que é desejável para a estimação de parâmetros do modelo. Cabe lembrar 
que é necessário que o fator de dispersão (SF) das saídas também seja elevado para um experimento informativo.

Conforme discutido na seção 3.1, para projetar um sinal de entrada que resulte em um sinal de saída com características de amplitude predefinidas é necessário conhecer o sistema a ser identificado, o que em princípio é contraditório com a identificação de sistemas, onde há pouca ou nenhuma informação sobre o sistema a ser identificado.

Devido à direcionalidade do ganho, na identificação de plantas mal condicionadas determinadas combinações das entradas da planta podem conduzir as saídas a variações de alta magnitude e até exceder os limites predeterminados.

A proposta de rotação de sinais ajusta a amplitude dos sinais de entrada para não exceder os limites de saída por meio do fator $\alpha$ em (8.15), o qual é multiplicativo e comum a todos os sinais do conjunto. O ajuste de amplitude dos sinais $\mathrm{SOH}$ com espectros intercalados modificados também ocorre por meio de um fator $\alpha$ comum a todos os sinais. Com os métodos de dois passos, os ajustes de amplitudes são feitos empiricamente a partir dos dados do teste realizado no primeiro passo. Em (TAN; GODFREY; BARKER, 2009) não foi apresentada uma forma de ajuste das amplitudes dos sinais PRT com harmônicas correlacionadas para identificação multivariável de plantas mal condicionadas.

Os ganhos estáticos da planta são assumidos conhecidos e, inclusive, são utilizados para o projeto dos sinais rotacionados e $\mathrm{SOH}$ com espectros intercalados modificados. É intuitivo que, conhecendo os ganhos estáticos da planta, seja possível ajustar os sinais de excitação dadas restrições de amplitude das saídas na condição estacionária da planta.

Nesta seção é proposto um método sistemático para ajuste dos sinais de excitação, dadas restrições de saídas da planta, considerando apenas o conhecimento dos ganhos estáticos da planta. Com esse método, qualquer combinação de sinais de entrada produz no caso estático saídas da planta em toda a faixa permitida (ou de segurança), atingindo os seus limites, porém, não superando-os. Essa característica de máximo SNR e SF nas saídas é a condição desejável para um experimento informativo.

Encontra-se na literatura a proposta de (LEE; RIVERA; MITTELMANN, 2003) (LEE et al., 2003) (LEE, 2006) (RIVERA et al., 2009), que utiliza um método iterativo de otimização de fases dos sinais $\mathrm{SOH}$ com espectros intercalados modificados para limitar as saídas da planta de primeira ordem $G_{1}(s)$. O método proposto neste trabalho e apresentado a seguir é totalmente algébrico e de menor complexidade de implementação. 
Considere uma planta $G^{o}$ de $n$ entradas e $n$ saídas. Seja a decomposição em valores singulares (SVD) da matriz de ganhos estáticos da planta $\left(K=G^{o}(0)\right)$ :

$$
K=M \Sigma V^{T}
$$

onde $M$ e $V \in \mathbb{R}^{n \times n}$ são matrizes unitárias de rotação das saídas e entradas, respectivamente. A matriz $\Sigma$ contém os valores singulares arranjados de forma descendente em sua diagonal principal:

$$
\Sigma=\left[\begin{array}{cccc}
\sigma_{1} & 0 & \cdots & 0 \\
0 & \sigma_{2} & \cdots & 0 \\
\vdots & \vdots & \ddots & \vdots \\
0 & 0 & \cdots & \sigma_{n}
\end{array}\right]
$$

onde:

$$
\sigma_{1}>\sigma_{2}>\ldots>\sigma_{n}
$$

Sejam $b_{1}, b_{2}, \ldots, b_{n}>0 \in \mathbb{R}$ os limites de amplitude das saídas $\mathbf{y}_{1}, \mathbf{y}_{2}, \ldots, \mathbf{y}_{n}$, tal que:

$$
-b_{p} \leq y_{p}(i) \leq b_{p}, \quad \text { para } \forall 0 \leq i \leq N_{e}-1
$$

Esses limites são organizados na diagonal principal da matriz $B$ :

$$
B=\left[\begin{array}{cccc}
b_{1} & 0 & \cdots & 0 \\
0 & b_{2} & \cdots & 0 \\
\vdots & \vdots & \ddots & \vdots \\
0 & 0 & \cdots & b_{n}
\end{array}\right]
$$

Deseja-se obter uma transformação de um conjunto qualquer de sinais de excitação $U$ tal que: 


$$
Y^{T}=K U^{T}=\left[\begin{array}{c}
\mathbf{y}_{1}^{T} \\
\mathbf{y}_{2}^{T} \\
\vdots \\
\mathbf{y}_{n}^{T}
\end{array}\right]
$$

$\operatorname{com} \mathbf{y}_{p}^{T}=\left[y_{p}(0) y_{p}(1) \ldots y_{p}\left(N_{e}-1\right)\right] \mathrm{e}-b_{p} \leq y_{p}(i) \leq b_{p}$.

Sejam $a_{1}, a_{2}, \ldots, a_{n_{r}}>0 \in \mathbb{R}$ as amplitudes de pico dos sinais $U=\left[\begin{array}{l}\mathbf{u}_{1} \\ \mathbf{u}_{2} \ldots \mathbf{u}_{n}\end{array}\right]$, tal que:

$$
-a_{r} \leq u_{r}(i) \leq a_{r}, \text { para } \forall 0 \leq i \leq N_{e}-1
$$

Esses limites são organizados na diagonal principal da matriz A:

$$
A=\left[\begin{array}{cccc}
a_{1} & 0 & \cdots & 0 \\
0 & a_{2} & \cdots & 0 \\
\vdots & \vdots & \ddots & \vdots \\
0 & 0 & \cdots & a_{n}
\end{array}\right]
$$

Assim, $U$ que representa um conjunto qualquer de sinais de excitação pode ser reescrito:

$$
\begin{aligned}
U & =\left[\begin{array}{llll}
\mathbf{u}_{1} & \mathbf{u}_{2} & \ldots & \mathbf{u}_{\mathbf{n}_{\mathbf{r}}}
\end{array}\right] \\
& =A X \\
& =A\left[\begin{array}{lllll}
\mathbf{x}_{1} & \mathbf{x}_{2} & \ldots & \mathbf{x}_{\mathbf{n}_{\mathbf{r}}}
\end{array}\right]
\end{aligned}
$$

onde $\left|x_{r}\right| \leq 1$.

Seja a transformação linear $W$ :

$$
W=\tilde{V} \tilde{\Sigma}^{-1} \tilde{M}^{T} A^{-1}
$$

com $\tilde{V}, \tilde{\Sigma}$ e $\tilde{M}$ são obtidos por meio da SVD: 


$$
B^{-1} K=\tilde{M} \tilde{\Sigma} \tilde{V}^{T}
$$

onde $\tilde{M}$ e $\tilde{V} \in \mathbb{R}^{n \times n}$ são matrizes unitárias e $\tilde{\Sigma}$ é a matriz diagonal dos valores singulares de $B^{-1} K$.

Aplicando-se a transformação $W$ aos sinais $U$, tem-se:

$$
\begin{aligned}
\tilde{U}^{T} & =W U^{T} \\
& =\tilde{V} \tilde{\Sigma}^{-1} \tilde{M}^{T} A^{-1} U^{T}
\end{aligned}
$$

As saídas da planta excitada pelas entradas transformadas $\tilde{U}$ é:

$$
\begin{aligned}
Y^{T} & =K \tilde{U}^{T} \\
& =B B^{-1} K \tilde{U}^{T} \\
& =B \tilde{M} \tilde{\Sigma} \tilde{V}^{T} \tilde{V} \tilde{\Sigma}^{-1} \tilde{M}^{T} A^{-1} U^{T} \\
& =B A^{-1} U^{T} \\
& =B A^{-1} A X^{T} \\
& =B X^{T}
\end{aligned}
$$

onde $\tilde{V}^{T} \tilde{V}=I$ e $\tilde{M}^{T} \tilde{M}=I$, pois $\tilde{V}$ e $\tilde{M}$ são matrizes unitárias.

Observe que as saídas $Y$ são limitadas por $B$ :

$$
\begin{aligned}
{\left[\begin{array}{c}
y_{1}(i) \\
y_{2}(i) \\
\vdots \\
y_{n}(i)
\end{array}\right] } & =B\left[\begin{array}{c}
x_{1}(i) \\
x_{2}(i) \\
\vdots \\
x_{n}(i)
\end{array}\right] \\
& =\left[\begin{array}{c}
b_{1} x_{1}(i) \\
b_{2} x_{2}(i) \\
\vdots \\
b_{n} x_{n}(i)
\end{array}\right]
\end{aligned}
$$

lembrando que $\left|x_{r}(i)\right| \leq 1$.

Portanto, a transformação $W$ dada por (8.38) e (8.39) aplicada a sinais de excitação 
$\mathbf{u}_{r}$ com limites dados pelos elementos $a_{r}$ da diagonal principal de $A$, resulta em saídas $\mathbf{y}_{p}$ com limites dados pelos elementos $b_{p}$ da diagonal principal de $B$. Essa transformação proposta aqui é chamada de rotação de sinais de excitação com restrições.

A próxima seção exemplifica a utilização da rotação com restrições para limitar as variações das saídas da coluna de alta pureza, conforme discutido na seção 8.1.

\subsubsection{Exemplos de rotação de sinais de excitação com restrições}

Sejam as combinações de sinais de excitação $\mathbf{u}_{1}$ e $\mathbf{u}_{2}$ definidos no intervalo $\left|u_{1}(i)\right|,\left|u_{2}(i)\right| \leq$ 0,003. As figuras 8.30a e 8.30b apresentam o plano dessas combinações de entradas e o plano das saídas $\mathbf{y}_{1}$ e $\mathbf{y}_{2}$, respectivamente, em estado estático para a coluna de destilação de alta pureza (8.11). Observe que as saídas estão altamente correlacionadas assumindo valores nos intervalos $\left|y_{1}(i)\right| \leq 0,52$ e $\left|y_{2}(i)\right| \leq 0,65$.
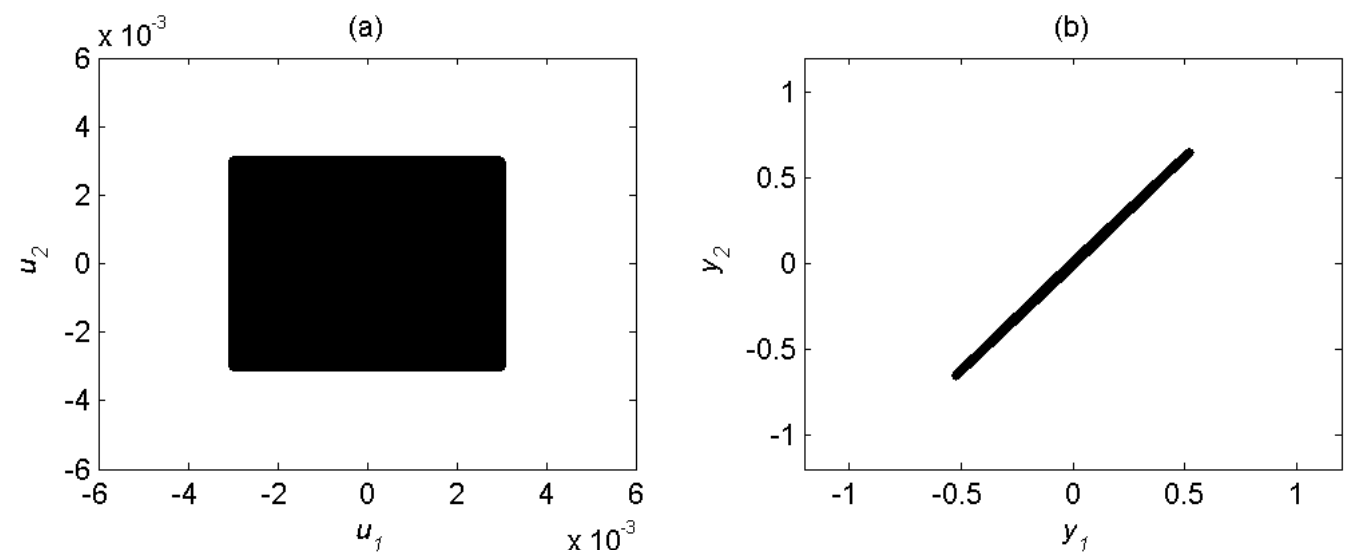

Figura 8.30: Plano das combinações dos sinais de excitação $\mathbf{u}_{1}$ e $\mathbf{u}_{2}$ definidos no intervalo $\left|u_{1}(i)\right|,\left|u_{2}(i)\right| \leq 0,003$ e plano das respectivas saídas $\mathbf{y}_{1}$ e $\mathbf{y}_{2}$ em estado estático da coluna de destilação de alta pureza.

Para descorrelacionar os sinais de saída, sugere-se a rotação dos sinais de excitação conforme (8.15). A rotação das combinações de sinais de excitação $\mathbf{u}_{1}$ e $\mathbf{u}_{2}$ definidos no intervalo $\left|u_{1}(i)\right|,\left|u_{2}(i)\right| \leq 1$, conforme (8.15), com $\alpha=0,003$ resulta nos sinais rotacionados $\mathbf{u}_{1}^{\prime}$ e $\mathbf{u}_{2}^{\prime}$ apresentados na figura 8.31a. Observe que os sinais de excitação rotacionados $\mathbf{u}_{1}^{\prime}$ e $\mathbf{u}_{2}^{\prime}$ são altamente correlacionados e assumem valores nos interva$\operatorname{los}\left|u_{1}(i)\right|,\left|u_{2}(i)\right| \leq 0,3$. Na figura $8.31 \mathrm{~b}$ as saídas $\mathbf{y}_{1}$ e $\mathbf{y}_{2}$ foram descorrelacionadas assumindo valores nos intervalos $\left|y_{1}(i)\right|,\left|y_{2}(i)\right| \leq 0,83$.

Com o objetivo de realizar um experimento com menor influência na especificação dos produtos, deseja-se obter combinações de entradas $\mathbf{u}_{1}$ e $\mathbf{u}_{2}(L / F$ e $V / F)$ que resultem, em estado estático, em saídas com as especificações: variação da composição de destilado $\mathbf{y}_{1}\left(y_{D}\right)$ limitada a $0,05(5 \%)$ e variação da composição de produto de fundo 
(a)

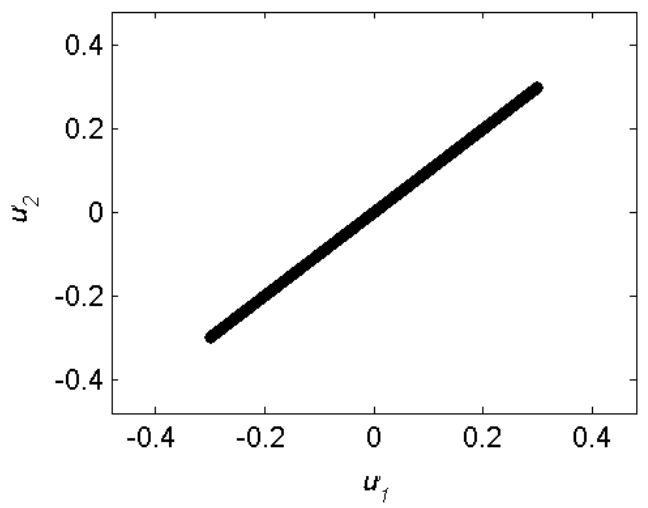

(b)

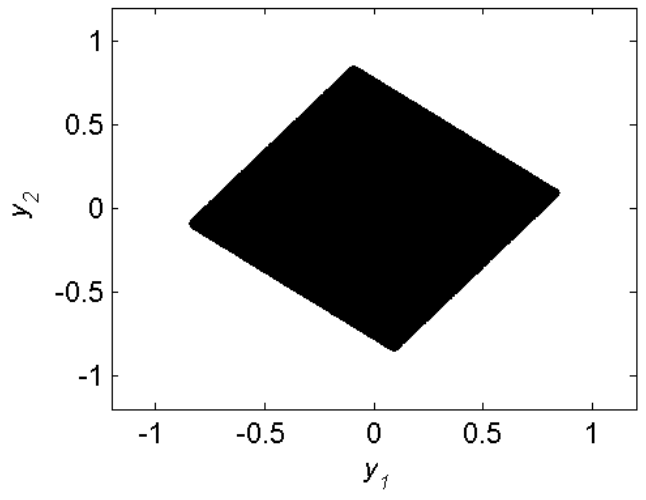

Figura 8.31: Plano das combinações dos sinais de excitação rotacionados $\mathbf{u}_{1}^{\prime}$ e $\mathbf{u}_{2}^{\prime}$ e plano das respectivas saídas $\mathbf{y}_{1}$ e $\mathbf{y}_{2}$ em estado estático para a coluna de destilação de alta pureza.

$\left(x_{B}\right) \mathbf{y}_{2}$ limitada a 0,10 (10\%). Neste caso, tem-se:

$$
B=\left[\begin{array}{cc}
0,05 & 0 \\
0 & 0,10
\end{array}\right]
$$

Utilizando sinais rotacionados, limitando $\mathbf{y}_{1}\left(y_{D}\right)$ a 0,05 , tem-se $\mathbf{y}_{2}$ também limitada a 0,05 (5\%). Essa condição não é desejada, visto que não é necessário que a saída $\mathbf{y}_{2}$ fique restrita a esses limites. Excursões maiores de $\mathbf{y}_{2}$ (limitada a 0,10 (10\%) especificado) possibilitara maior SNR e, portanto, menor influência das perturbações na estimação de parâmetros.

Aplicando-se a transformação $W$ conforme (8.38) e (8.39) às combinações de $\mathbf{u}_{1}$ e $\mathbf{u}_{2}$ definidos no intervalo $\left|u_{1}(i)\right| \leq a_{1}=1$ e $\left|u_{2}(i)\right| \leq a_{2}=1$, obtém-se o plano de entradas $\tilde{\mathbf{u}}_{1}$ e $\tilde{\mathbf{u}}_{2}$ da figura 8.32a. Assim como os sinais rotacionados, observe que esses também estão correlacionados e assumem valores nos intervalos $\left|u_{1}(i)\right|,\left|u_{2}(i)\right| \leq$ 0,05. O plano das saídas da planta em estado estático é apresentado na figura 8.32b. Observe que, conforme especificado, a variação da composição de destilado $\mathbf{y}_{1}\left(y_{D}\right)$ está limitada a $0,05(5 \%)$ e a variação da composição de produto de fundo $\left(x_{B}\right) \mathbf{y}_{2}$ está limitada a $0,10(10 \%)$.

As figuras 8.33a e 8.33b apresentam o plano das entradas e saídas, respectivamente, para o caso da limitação de variação das saídas $\mathbf{y}_{1}$ e $\mathbf{y}_{2}$ ao intervalo $\left|y_{1}(i)\right| \leq 0,15$ e $\left|y_{2}(i)\right| \leq 0,40$. Neste caso, tem-se: 
(a)

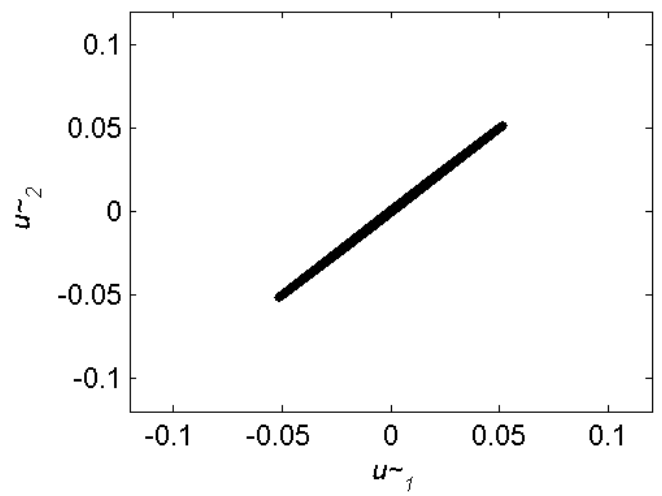

(b)

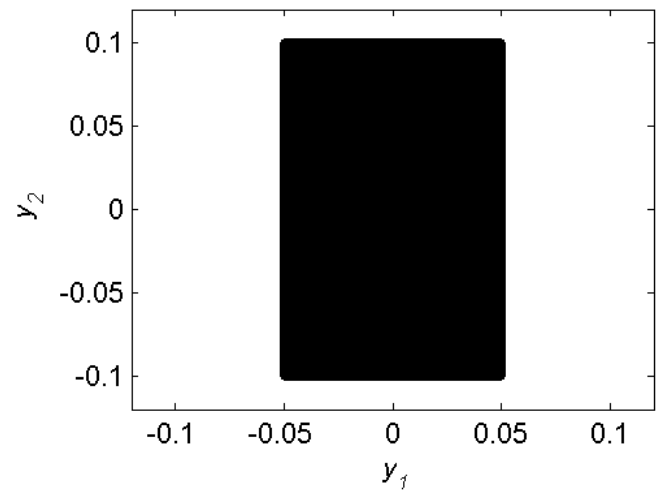

Figura 8.32: Plano das combinações dos sinais de excitação rotacionados com restrições $\tilde{\mathbf{u}}_{1}$ e $\tilde{\mathbf{u}}_{2}$ e plano das respectivas saídas $\mathbf{y}_{1}$ e $\mathbf{y}_{2}$ com restrições $\left(\left|y_{1}(i)\right| \leq 0,05\right.$ e $\left.\left|y_{2}(i)\right| \leq 0,10\right)$ em estado estático para a coluna de destilação de alta pureza.

$$
B=\left[\begin{array}{cc}
0,15 & 0 \\
0 & 0,40
\end{array}\right]
$$

Conforme observado nas figuras 8.33a e 8.33b, a rotação com restrições dos sinais de excitação permite que as saídas da planta em estado estático excursionem por toda a faixa especificada. Nesse cenário, tem-se SNR e SF maximizados, o que é desejável para a identificação de plantas mal condicionadas.

(a)

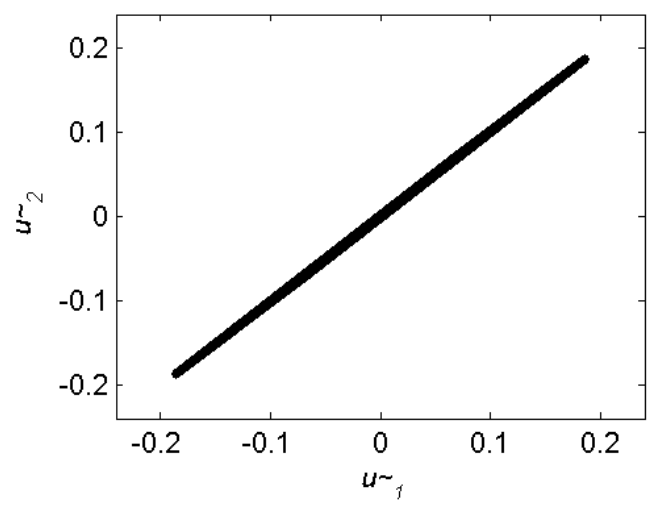

(b)

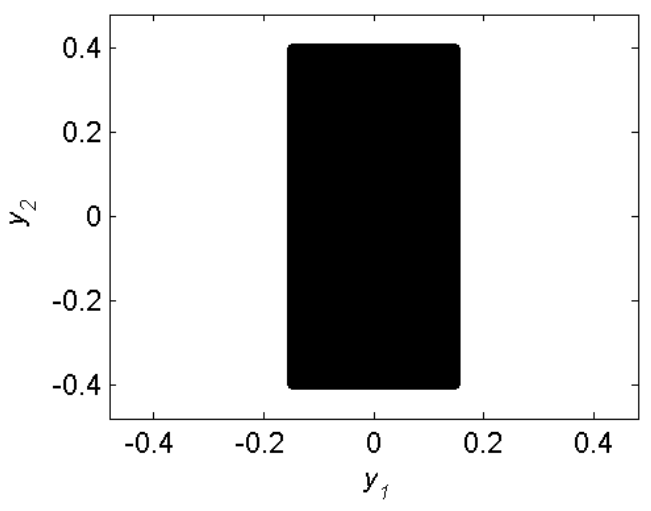

Figura 8.33: Plano das combinações dos sinais de excitação rotacionados com restrições $\mathbf{u}_{1}$ e $\mathbf{u}_{2}$ e plano das respectivas saídas $\mathbf{y}_{1}$ e $\mathbf{y}_{2}$ com restrições $\left(\left|y_{1}(i)\right| \leq 0,15\right.$ e $\left.\left|y_{2}(i)\right| \leq 0,40\right)$ em estado estático para a coluna de destilação de alta pureza. 


\subsubsection{Simulações de identificação com sinais de excitação rotacio- nados com restrições}

Nesta seção são apresentados resultados de simulações de identificação dos modelos de primeira e segunda ordem da coluna de alta pureza discutidos na seção 8.1, utilizando sinais rotacionados com restrições obtidos a partir de sinais PRB.

Nas simulações foram adotados sinais PRB com $N=231$ e $T_{c l k}=40$, resultando em $T_{e}=T_{N_{s}}=231 \times 40=9.240$ minutos, assim como nas simulações de identificação do modelo de segunda ordem com sinais rotacionados (seção 8.2.5.1). Deseja-se que as variações das saídas $\mathbf{y}_{1}$ e $\mathbf{y}_{2}$ estejam limitadas ao intervalo $\left|y_{1}(i)\right| \leq 0,15$ e $\left|y_{2}(i)\right| \leq$ 0,40, assim como no exemplo da seção 8.5.1. A figura 8.34 apresenta segmentos desses sinais. Os sinais de validação para cálculo do FIT são os mesmos utilizados nas simulações da seção 8.4.

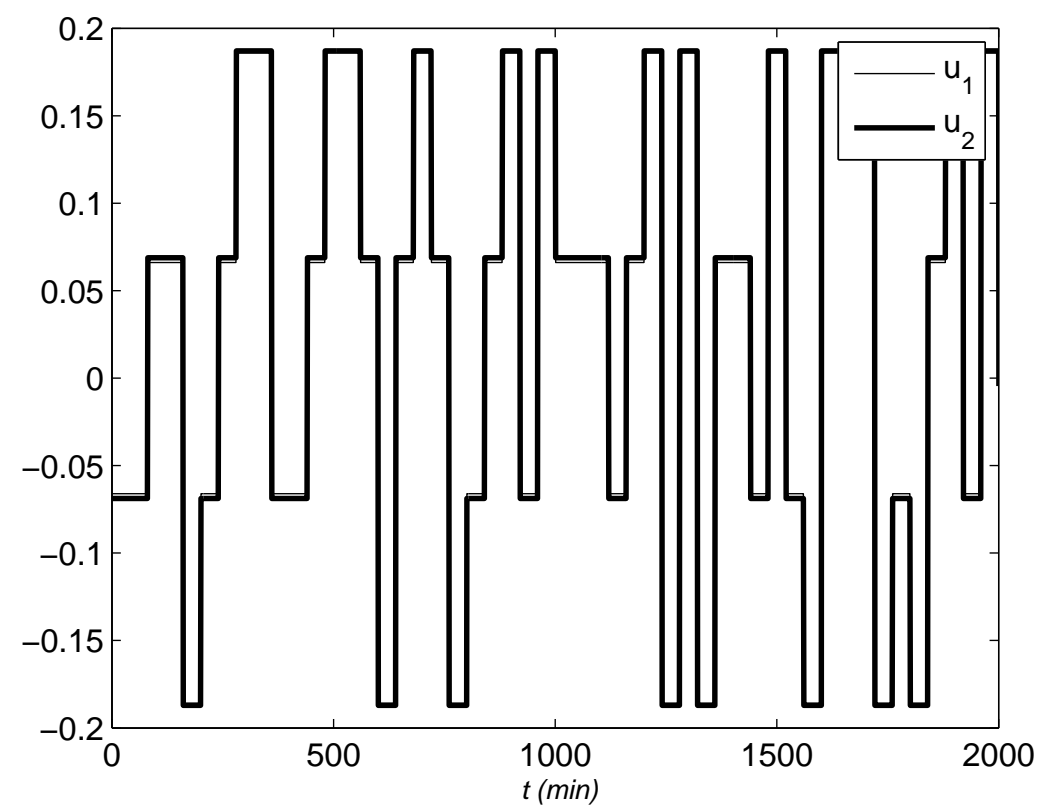

Figura 8.34: Segmentos dos sinais rotacionados com restrições parametrizados para identificação da coluna de alta pureza.

Os resultados da identificação da planta de primeira ordem $G_{1}(s)$ (figura 8.35) mostram que as saídas variaram predominantemente dentro do intervalo $\left|y_{1}(i)\right| \leq 0,15$ e $\left|y_{2}(i)\right| \leq 0,40$, conforme especificado. Alguns pontos $\left\{y_{1} ; y_{2}\right\}$ da figura estão fora do intervalo especificado devido à variável de perturbação do processo $\left(\sigma_{e}^{2}=0,1\right)$. A figura 8.36 apresenta as saídas da planta de primeira ordem na ausência de perturbação. Nesta observa-se que as saídas estão respeitando perfeitamente os limites especificados.

Para a planta de segunda ordem $G_{2}(s)$, observa-se na figura 8.37 que a rotação com 


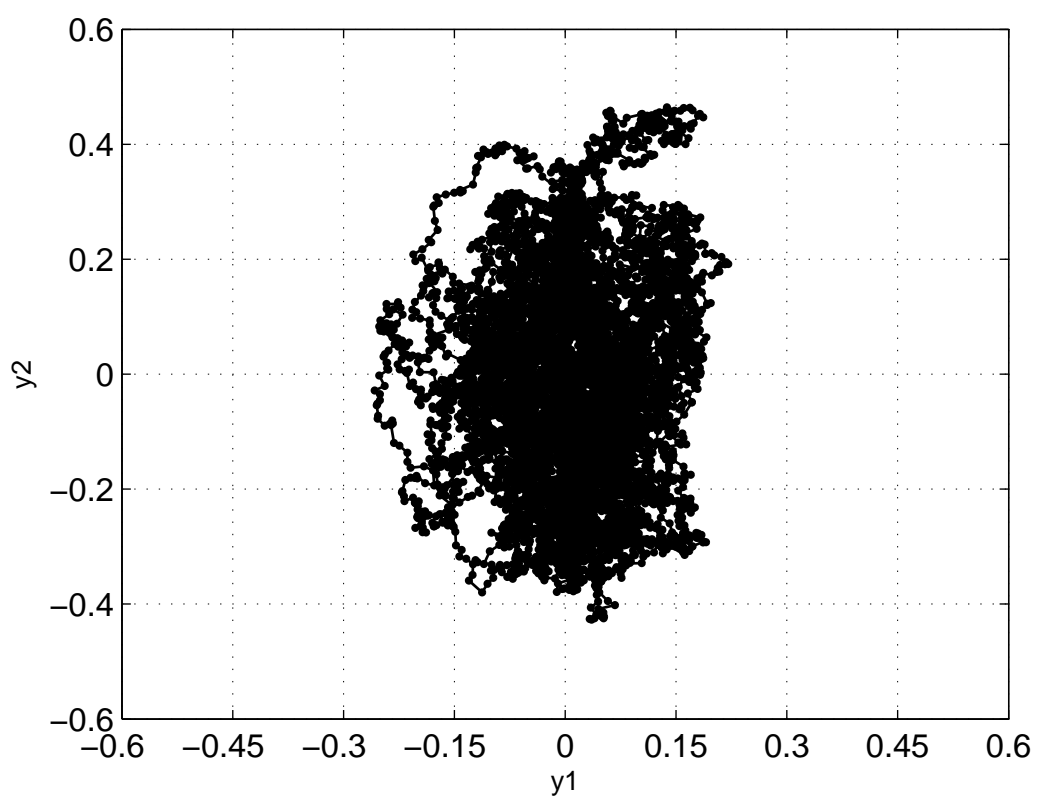

Figura 8.35: Plano de saídas $\left\{y_{1} ; y_{2}\right\}$ do modelo de primeira ordem $G_{1}(s)$ da coluna de alta pureza excitada com sinais rotacionados com restrições e com $\sigma_{e}^{2}=0,1$.

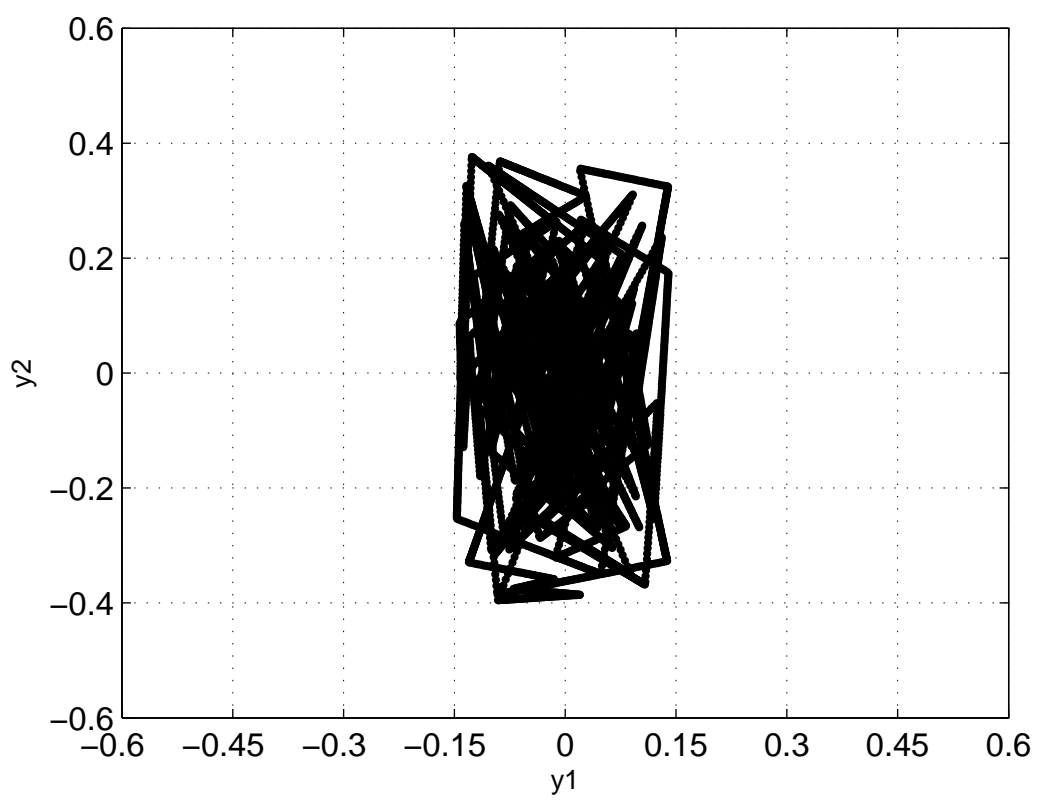

Figura 8.36: Plano de saídas $\left\{y_{1} ; y_{2}\right\}$ do modelo de primeira ordem $G_{1}(s)$ da coluna de alta pureza excitada com sinais rotacionados com restrições e com $\sigma_{e}^{2}=0$.

restrições não é suficiente para limitar as saídas ao intervalo especificado $\left(\left|y_{1}(i)\right| \leq 0,15\right.$ e $\left.\left|y_{2}(i)\right| \leq 0,40\right)$. Esse efeito ocorre devido ao número de condição $\gamma(j \omega)$ não ser constante (figura 8.3). Cabe lembrar que o número de condição varia devido às diferentes constantes de tempo $\tau_{1}=194$ minutos e $\tau_{2}=15$ minutos da planta. Os sinais rotacionados com restrições são projetados de acordo com o caso estático. Assim, quando $\gamma(j \omega) \neq \gamma(0)$ as saídas da planta podem não estar dentro do intervalo especificado. 


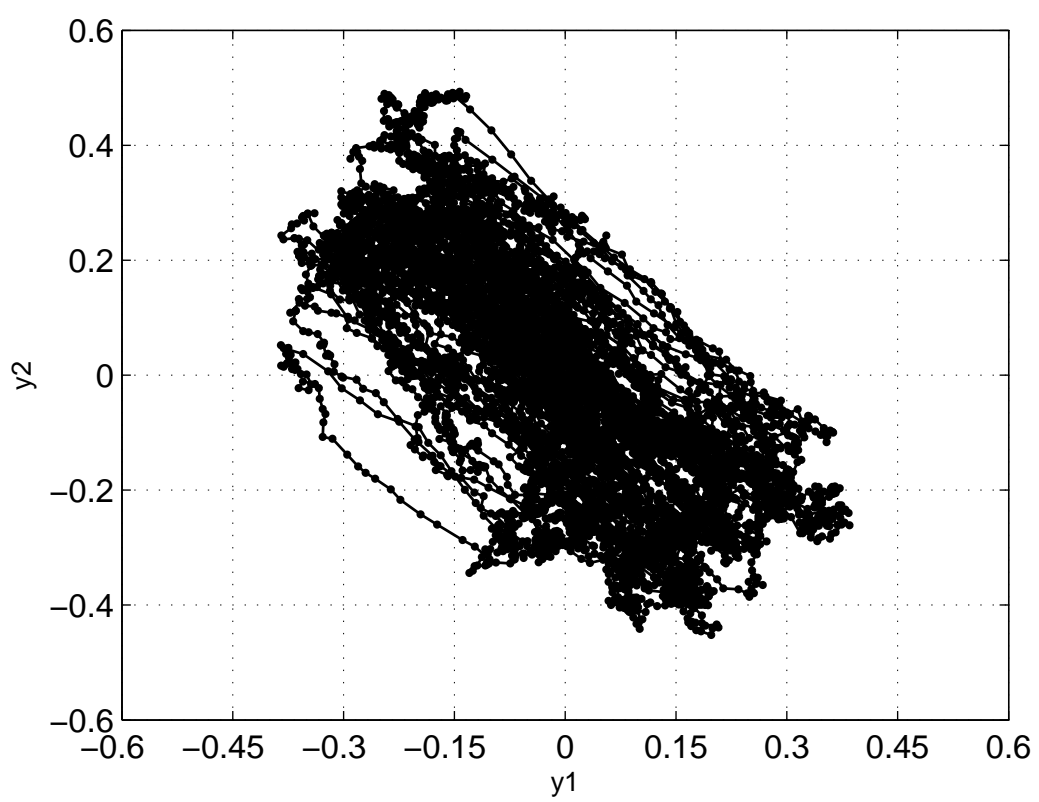

Figura 8.37: Plano de saídas $\left\{y_{1} ; y_{2}\right\}$ do modelo de segunda ordem $G_{2}(s)$ da coluna de alta pureza excitada com sinais rotacionados com restrições e com $\sigma_{e}^{2}=0,1$.

Tabela 8.7: Resumo dos resultados de simulações dos modelos de primeira e segunda ordem da coluna de alta pureza, $G_{1}(s)$ e $G_{2}(s)$, respectivamente, utilizando sinais rotacionados com restrições.

\begin{tabular}{ccccccc}
\hline Planta & $\overline{S F}[\%]$ & Saída & $\overline{F I T}[\%]$ & $\overline{S N R}$ & $C F_{(u)}$ & PIPS [\%] \\
\hline \hline Planta de primeira ordem & \multirow{2}{*}{94,13} & $y_{1}$ & 85,04 & 3,09 & 1,31 & 75,23 \\
$G_{1}(s)$ com $\sigma_{e}^{2}=0,1$ & & $y_{2}$ & 87,12 & 15,61 & 1,32 & 75,53 \\
\hline Planta de primeira ordem & \multirow{2}{*}{89,21} & $y_{1}$ & 100 & $\infty$ & 1,31 & 75,23 \\
$G_{1}(s)$ com $\sigma_{e}^{2}=0$ & \multirow{2}{*}{$y_{2}$} & 100 & $\infty$ & 1,32 & 75,53 \\
\hline Planta de segunda ordem & \multirow{2}{*}{27,73} & $y_{1}$ & 79,62 & 11,44 & 1,31 & 75,23 \\
$G_{2}(s)$ com $\sigma_{e}^{2}=0,1$ & & $y_{2}$ & 77,92 & 20,33 & 1,32 & 75,53 \\
\hline Planta de segunda ordem & \multirow{2}{*}{81,70} & $y_{1}$ & 85,54 & 2,83 & 1,31 & 75,23 \\
$G_{2}(s)$ com $\tau_{1}=90, \tau_{2}=50$ e $\sigma_{e}^{2}=0,1$ & & $y_{2}$ & 82,25 & 21,65 & 1,32 & 75,53 \\
\hline
\end{tabular}

Hipoteticamente, considere a planta $G_{2}(s)$, porém, com menor discrepância entre as constantes de tempo: $\tau_{1}=90$ e $\tau_{2}=50$. Nessa situação, a variação de $\gamma(j \omega)$ em relação a $\gamma(0)$ será menor e, portanto, os sinais rotacionados com restrições se ajustarão melhor à especificação dos limites das saídas. Observe na figura 8.38, resultado da excitação com sinais rotacionados com restrições, que as saídas estão predominantemente limitadas aos intervalos $\left|y_{1}(i)\right| \leq 0,15$ e $\left|y_{2}(i)\right| \leq 0,40$.

A tabela 8.7 resume os resultados das simulações discutidas nesta seção.

De acordo com os resultados de simulações de identificação apresentados nesta seção, a rotação dos sinais de excitação com restrições é efetivo para limitação das variações das saídas de uma planta mal condicionada com $\gamma(j \omega)$ aproximadamente constante, ou seja, $\gamma(j \omega) \approx \gamma(0)$. Quando $\gamma(j \omega)$ apresenta variação significativa, a 


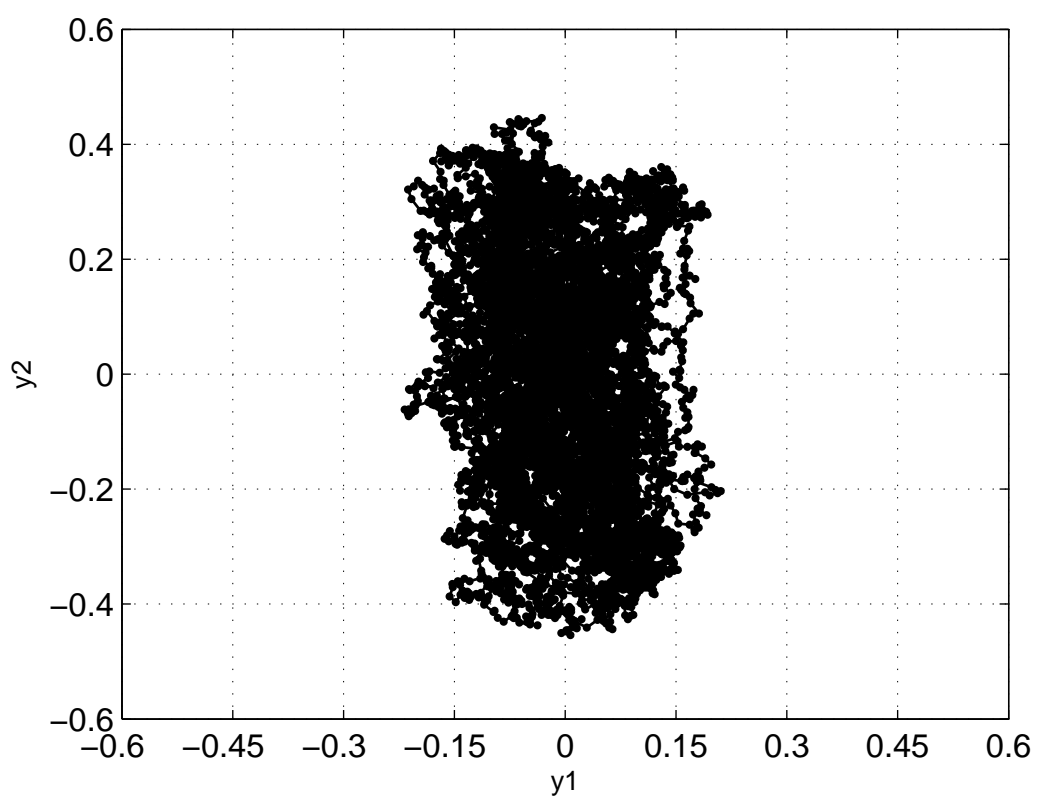

Figura 8.38: Plano de saídas $\left\{y_{1} ; y_{2}\right\}$ do modelo de segunda ordem $G_{2}(s)$, com $\tau_{1}=90$ e $\tau_{2}=50$, da coluna de alta pureza excitada com sinais rotacionados com restrições e $\operatorname{com} \sigma_{e}^{2}=0,1$.

rotação dos sinais de excitação com restrições de acordo com os valores singulares no caso estático, neste caso $\gamma(0)$, não é suficiente para garantir a limitação das variações das saídas.

Em (LEE; RIVERA; MITTELMANN, 2003) (LEE et al., 2003) (LEE, 2006) (RIVERA et al., 2009) foi apresentado um método iterativo de otimização de fases dos sinais SOH com espectros intercalados modificados para limitar as saídas da planta de primeira ordem $G_{1}(s)$, ou seja, $\gamma(j \omega)=\gamma(0)$. O método proposto neste trabalho é simples e atende às especificações de restrições de saída no caso $\gamma(j \omega)=\gamma(0)$. 


\section{Procedimento para seleção de sinais de excitação}

Neste capítulo é resumido um procedimento sistemático para seleção de sinais de excitação dadas informações a priori da planta. Os passos apresentados aqui estão baseados em procedimentos propostos na literatura, porém, também incluem o uso das propostas deste trabalho: índice de avaliação comparativa de conjuntos de sinais de excitação (CISS), fator de dispersão (SF) e as três propostas de construção de sinais de excitação.

O procedimento visa viabilizar a seleção de sinais de excitação para o experimento de identificação com as informações disponíveis ou viáveis de serem obtidas de uma planta em operação (informações a priori, seção 3.2). De forma oposta, como discutido na seção 2.2, o projeto ótimo de sinais de excitação pode necessitar de conhecimentos da planta a ponto de ser contraditório ao objetivo da identificação. Alternativamente, poderia ser utilizada a identificação iterativa, na qual procedimentos de identificação são realizados de forma recorrente utilizando as informações mais aprimoradas dos modelos estimados na iteração anterior. Porém, identificações sucessivas não são desejáveis na prática, pois estendem a duração na qual a planta é excitada.

O procedimento discutido neste capítulo considera que as entradas a serem excitadas e as saídas a serem observadas foram adequada e previamente escolhidas. Por exemplo, foram escolhidas entradas (MV) acessíveis e viáveis de serem excitadas e uma ou mais saídas de interesse (CV) sensíveis a elas.

Em resumo, as etapas para seleção e parametrização dos sinais de excitação para identificação são:

1. Obter as informações a priori da planta;

2. Caso o experimento de identificação seja realizado em malha aberta, verificar se a planta é mal condicionada;

3. Definir as características de amplitude para cada um dos sinais de entrada: sinal contínuo em amplitude, sinal binário, ternário ou multinível e, neste caso, a 
quantidade máxima de níveis possível.

4. Estimar as frequências máximas e mínimas de interesse para cada entrada da planta;

5. Estimar a duração mínima do experimento;

6. Estimar o tempo de amostragem para o experimento de identificação;

7. Definir a envoltória do espectro de potência para cada um dos sinais a serem aplicados nas entradas da planta;

8. De acordo com as restrições de amplitudes de entrada e saída, definir as amplitudes de pico para cada um dos sinais de entrada;

9. Selecionar os conjuntos de sinais que: atendam a quantidade de entradas da planta a serem excitadas simultaneamente, resultem em uma duração de experimento maior ou igual à mínima calculada e não superem a duração $\tilde{T}_{e}$ disponível para o experimento;

10. Calcular os índices de desempenho para os conjuntos de sinais de excitação selecionados e eleger o conjunto mais adequado para a identificação.

A figura 9.1 apresenta um fluxograma das etapas da seleção de sinais de excitação para identificação.

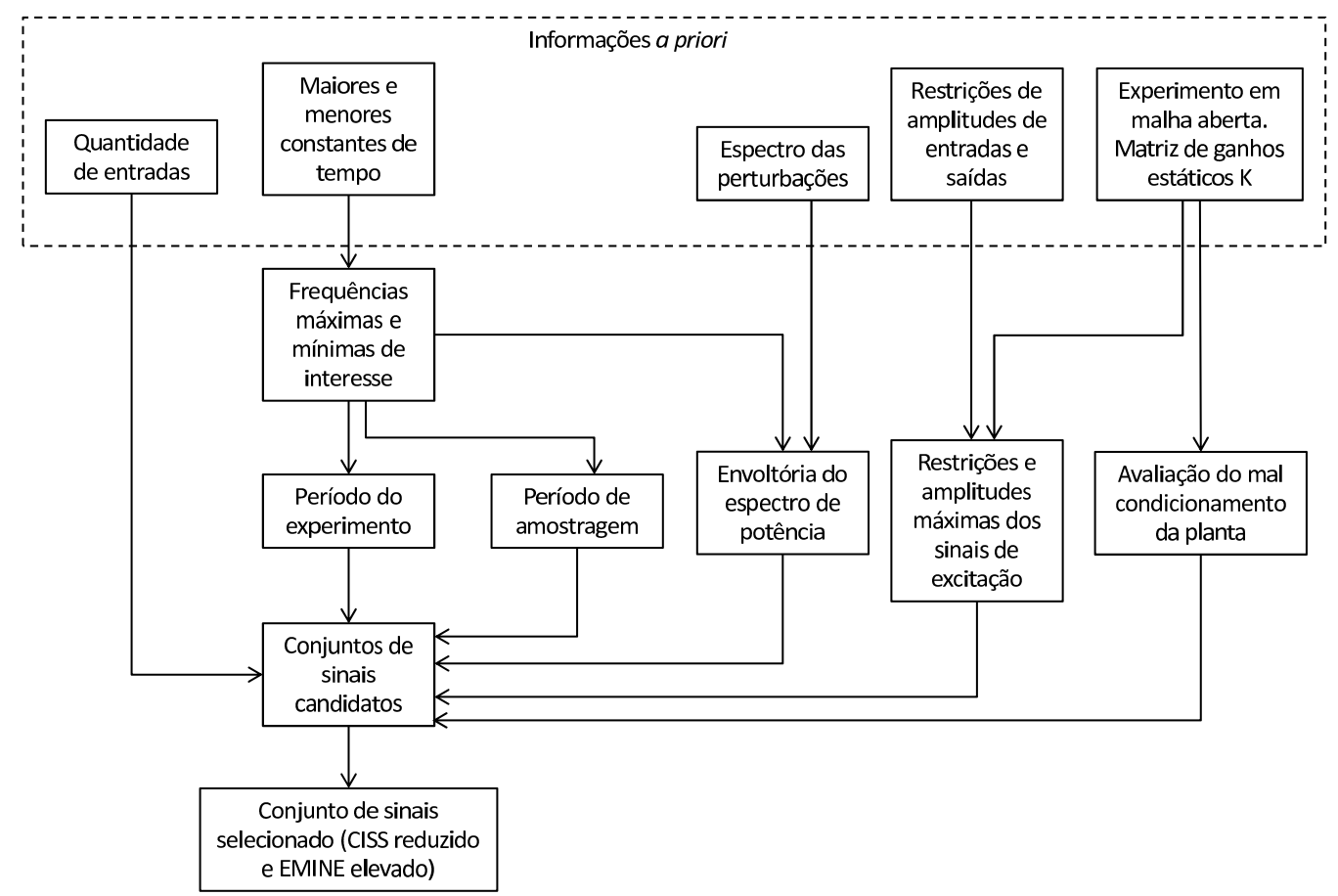

Figura 9.1: Fluxograma para seleção de conjuntos de sinais de excitação. 
Cada uma dessas etapas do processo de seleção e parametrização de sinais de excitação são discutidas com mais detalhes nas próximas seções.

\subsection{Informações a priori da planta}

As informações a priori da planta podem ser obtidas a partir de testes em degrau. Essas informações também podem estar disponíveis em manuais e procedimentos de operação da planta, bem como distribuídas na equipe de operação como conhecimento tácito. Portanto, faz-se necessário a participação de membros da equipe de operação da planta no processo de seleção de sinais de excitação.

As informações a priori do processo de seleção e parametrização de sinais de excitação foram discutidas na seção (seção 3.2):

1. Limites de operação ou de segurança de excursões das entradas $\left(u_{\min , r}\right.$ e $\left.u_{\max , r}\right)$ e das saídas $\left(y_{\min , p}\right.$ e $\left.y_{\max , p}\right)(3.1)$.

2. Ganhos estáticos da planta $\left(K=G^{o}(0)\right)$, quando a identificação for realizada em sistemas sem controle regulatório ou, equivalentemente, com o controle regulatório em malha aberta de uma planta mal condicionada (3.4).

3. Maiores e menores tempos de acomodação dominantes ( $T_{\max , r}^{\text {set }}$ e $T_{\min , r}^{\text {set }}$, respectivamente) observados nas $n_{p}$ saídas para cada uma das entradas $u_{r}$ (3.6).

As funções de autocorrelação das perturbações de cada saída, conforme discutido na seção 2.1.2, são utilizadas para especificar a envoltória do espectro de frequências dos sinais de excitação na faixa de interesse. Porém, nas simulações apresentadas neste trabalho, considera-se que essa informação não está disponível na etapa de projeto dos sinais de excitação e, portanto, não é utilizada.

\subsection{Identificação em malha aberta de planta mal con- dicionada}

A identificação de uma planta mal condicionada em malha aberta requer que sejam utilizadas técnicas adequadas de projetos de sinais de excitação, conforme discutido no capítulo 8.

A informação mínima necessária para verificação do mal condicionamento da planta é a matriz de ganhos estáticos (3.4). O número de condição da matriz pode 
ser calculado (8.2) e, caso esse revele que a planta é mal condicionada, deve-se utilizar métodos adequados de projeto de sinais para a excitação da planta. Esses métodos são aqueles apresentados no capítulo 8:

1. Sinais rotacionados;

2. Métodos de dois passos de Zhu;

3. Sinais com espectros intercalados modificados;

4. Sinais PRT;

5. Sinais rotacionados com restrição (propostos neste trabalho).

Conforme o capítulo 8, encontram-se na literatura outros métodos que consistem em modificações desses. Por exemplo, métodos que utilizam algoritmos de otimização para minimizar o CF dos sinais, ou métodos que utilizam conhecimento quantitativo prévio das dinâmicas da planta para limitar o sinal de saída a amplitudes especificadas.

\subsection{Característica de amplitude dos sinais}

Nos capítulos 5 e 6, foram estudados sinais de excitação com as características de amplitude:

1. Sinal contínuo em amplitude.

2. Sinal quantizado em amplitude: sinal binário, ternário ou multinível.

Conforme discutido no capítulo 3, podem haver limitações físicas e de operação para excitação de uma entrada da planta. Por exemplo, a excitação da velocidade de rotação de uma bomba, compressor ou ventilador depende do tipo de acionador empregado nessas máquinas, o qual pode estar limitado a apenas algumas velocidades determinadas. Nesse caso, os sinais de excitação devem ser quantizados em amplitude com níveis compatíveis com as possibilidades de variações dessas MV.

\subsection{Frequências máximas e mínimas de interesse}

Com apenas as informações a priori: maiores e menores constantes de tempo, $\tau_{\max , r} \mathrm{e}$ $\tau_{\min , r}$, respectivamente, (ou, similarmente, tempos de acomodação) para cada uma das 
$n_{r}$ entradas, definem-se as frequências máximas e mínimas de interesse, $\omega_{L, r}$ e $\omega_{H, r}$, respectivamente. Essas frequências podem ser calculadas conforme (3.8).

$\mathrm{O}$ cálculo das frequências de interesse utilizam os fatores $\beta_{s}$ e $\alpha_{s}$. Esses podem ser ajustados para que a faixa de frequências de interesse da planta seja mais larga ou estreita. Por exemplo, caso um experimento seja realizado em malha aberta e esperase que em malha fechada ele responda 3 vezes mais rápido, ou seja, o desempenho mínimo aceitável para o controlador é uma resposta com tempo de acomodação pelo menos 3 vezes menor, pode-se adotar $\alpha_{s} \geq 3$. Assim, objetiva-se ter um modelo adequadamente ajustado para sua aplicação, ou seja, um modelo que também represente a planta em frequências mais altas.

\subsection{Duração mínima do experimento}

A duração mínima do experimento $T_{e}$ para excitação pode ser calculada por (3.13).

Os sinais $\mathrm{SOH}$ e sinais aleatórios de um mesmo conjunto podem ser construídos de comprimentos diferentes, porém, os sinais de espectro fixo e sinais híbridos não (capítulo 5 e 6). Portanto, é prático adotar a duração mínima do experimento $T_{e}$ igual para todas as entradas e em função da maior constante de tempo da planta $\max _{r, 1 \leq r \leq n_{r}} \tau_{\max , r}$, conforme (3.13). Durante esse intervalo de tempo, todas as entradas são excitadas. Mesmo que esse critério não fosse adotado, durante $T_{e}$, a planta estaria sendo excitada em pelo menos uma de suas entradas. Grosso modo, de qualquer forma, a planta será perturbada durante todo o intervalo de tempo $T_{e}$.

\subsection{Período de amostragem para a identificação}

O período de amostragem $T$ utilizado na identificação é determinado em função da maior frequência de interesse da planta $\omega_{H, r}$. Os critérios para escolha do período de amostragem $T$ são discutidos no apêndice $\mathrm{C}$.

O período de amostragem é tipicamente adotado o mesmo para todas as entradas e saídas da planta, pois estimadores de parâmetros de modelos comumente consideram que as entradas e saídas foram amostradas na mesma taxa (LJUNG, 1999). Assim, caso durante a coleta de dados sejam adotados períodos de amostragem diferentes, será necessário realizar decimações ou interpolações dos dados (pós-tratamentos dos dados) para que possam ser utilizados nesses estimadores.

Quanto à aplicação do modelo, cabe ressaltar que os parâmetros estimados do mo- 
delo são válidos para o período de amostragem $T$ utilizado na identificação. Porém, esses também podem ser ajustados por meio de decimações ou interpolações para serem utilizados em taxas de amostragem distintas. Para evitar as decimações e interpolações, o período de amostragem utilizado na identificação deve ser o mesmo da aplicação do modelo.

\subsection{Envoltória do espectro de potência}

Conforme a equação (2.26), a variância dos parâmetros estimados do modelo é função do quociente entre a potência das perturbações e a potência da excitação para cada frequência $\omega$. Dessa forma, para obter uma variância uniforme e reduzida para os parâmetros do modelo, é necessário que a envoltória dos espectros de potência das excitações tenham as mesmas envoltórias dos espetros de potência das perturbações.

Na seção 3.2 foi feita uma breve discussão de como obter o espectro de potência das perturbações. As simulações apresentadas neste trabalho consideram que não se conhece o espectro de potência das perturbações. Para os métodos de construção de sinais de excitação que têm como entrada a envoltória do espectro, adotou-se espectro plano na faixa de frequências de interesse.

\subsection{Amplitudes das entradas}

As restrições de amplitudes de entradas e saídas da planta, conforme discutido no capítulo 3, advém de limites de segurança operacional da planta, limites de variabilidade máxima nas especificações de produtos, limites de linearidade da planta (devidos a saturações de CV e MV), limites físicos de atuadores e etc.

Na seção 8.5 foi proposto um método de projeto de sinais de excitação que resultam em sinais de saída restritos a intervalos de amplitudes especificados. O método foi proposto com aplicação em uma coluna de destilação na configuração LV. As características dinâmicas dessa planta são amplamente conhecidas e discutidas na literatura. Isso torna viável projetar sinais de excitação cujas saídas da planta sejam limitadas em amplitude, assim como foi proposto na seção 8.5. Porém, quando o número de condição $\gamma(\omega)$ é variável, o método proposto não garantirá as restrições de amplitudes das saídas (seção 8.5).

Quando há pouco (por exemplo, apenas as constantes de tempo dominantes) ou nenhum conhecimento da dinâmica da planta não é possível, antes do experimento de identificação, determinar quais serão as amplitudes máximas provocadas nas saídas da 
planta para um dado conjunto de sinais de excitação. A seção 5.2.1.3 discutiu brevemente um algoritmo iterativo para ajustar sinais de excitação para provocar desvios nas saídas dentro de uma faixa especificada minimizando o CF dos sinais de saída. Porém, esse método necessita do conhecimento das dinâmicas da planta, o que pode ser entendido como uma contradição à identificação.

\subsection{Selecionar os conjuntos de sinais candidatos}

De acordo com características de amplitude discutidas na seção 9.3, eliminam-se os sinais de excitação que não atendem esse requisito (ver tabela 7.1).

Conforme discutido no capítulo 3, grosso modo, quando se aumenta a quantidade de sinais em um conjunto, para manter as características de correlação, o comprimento dos sinais também aumenta. Assim, a quantidade de entradas $n_{r}$ e o tempo disponível para o experimento $\tilde{T}_{e}$ serão limitantes para os conjuntos de sinais de excitação.

A seguir é discutida resumidamente a parametrização de cada um dos tipos de sinais: aleatórios, $\mathrm{SOH}$, de espectro fixo e híbridos.

\subsubsection{Sinais aleatórios}

Os espectros dos sinais CBN são formatados por filtros, por exemplo (5.8), especificados para cada entrada $r$ em função das constantes de tempo mínimas $\tau_{\min , r}$.

A probabilidade $p$ de não chaveamento de sinais GBN é calculada conforme (5.17) para cada entrada $n_{r}$. Nesses cálculos são utilizadas as frequências mínima e máxima $\left(\omega_{L, r}\right.$ e $\omega_{H, r}$, respectivamente) de interesse para cada entrada da planta.

O período para os sinais de excitação pode ser escolhido $T_{N_{s}}=T_{e}$.

Os métodos de construção de conjuntos de sinais aleatórios não limitam a quantidade de sinais no conjunto para excitação das $n_{r}$ entradas, porém, quanto maior a quantidade de sinais de um comprimento $N_{s}$ fixo, mais correlacionados eles estarão. Para possibilitar sinais aleatórios menos correlacionados, aumenta-se o comprimento $N_{s}$ (seção 3.6) com prejuízo à duração do experimento (aumento de $T_{e}$ ).

\subsubsection{Sinais $\mathrm{SOH}$}

O comprimento $N_{s}$ mínimo para os sinais $\mathrm{SOH}$ é calculado por (5.47) utilizando as frequências mínima e máxima $\left(\omega_{L, r}\right.$ e $\omega_{H, r}$, respectivamente) de interesse para cada entrada da planta e a quantidade de harmônicas não nulas especificadas $n_{s}$. 
O período de amostragem $T$ máximo para os sinais $\mathrm{SOH}$ é calculado por (5.50) e também utiliza as frequências mínima e máxima $\left(\omega_{L, r}\right.$ e $\omega_{H, r}$, respectivamente $)$ de interesse para cada entrada da planta e a quantidade de harmônicas não nulas especificadas $n_{s}$.

Pode-se especificar a envoltória do espectro de amplitudes dos sinais SOH. Idealmente, esse deve ser igual ao espectro das perturbações. Neste trabalho, nas simulações foram adotadas harmônicas com amplitudes uniformes, ou seja, sinais SOH com espectro plano no intervalo definido por $\omega_{L, r}$ e $\omega_{H, r}$.

O menor período de sinal para um conjuntos de $n_{r}$ sinais $\mathrm{SOH}$ ocorrerá quando a quantidade de harmônicas especificadas $n_{s}$ for igual à quantidade de sinais $n_{r}$. Neste caso, tem-se $N=2 n_{s}=2 n_{r}$, conforme (5.18). Não é desejável gerar sinais $\mathrm{SOH}$ com esses parâmetros, pois haverá apenas uma harmônica especificada não nula para cada sinal. É evidente que com apenas uma harmônica não será possível excitar a planta no espectro de interesse dado por $B W=\left\{\omega_{L} ; \omega_{H}\right\}$. Assim, sinais SOH devem ser escolhidos com $n_{s}>>n_{r}$. Nesse caso, $n_{s}$ terá forte influência no comprimento $N_{s}$ mínimo dos sinais e no período de amostragem $T$ máximo, conforme (5.47) e (5.50), respectivamente. Cabe lembrar que o comprimento dos sinais está limitado pelo tempo disponível para o experimento $N_{s} \leq \frac{\tilde{T}_{e}}{T}$.

\subsubsection{Sinais de espectro fixo e sinais híbridos}

O período de chaveamento $T_{c l k}$ máximo de sinais de espectro fixo é calculado por (5.96), utilizando $\tau_{\min }=\min _{r, 1 \leq r \leq n_{r}} \tau_{\min , r}$.

O comprimento $N$ das sequências que dão origem aos sinais de excitação de comprimento $N_{s}=\frac{T_{c l k}}{T} N$ devem atender (5.99). A restrição é calculada em função de $\tau_{\max }=\max _{r, 1 \leq r \leq n_{r}} \tau_{\max , r}$.

Como não é possível construir sequências de qualquer comprimento, deve-se escolher $N$ que atende a (5.99) e $N \leq \frac{\tilde{T}_{e}}{T_{c l k}}$.

Quanto maior a quantidade de sinais de espectro fixo ou híbridos em um conjunto, maiores são seus comprimentos $N_{s}$, conforme discutido nas seções 5.3.7, 5.3.8, 6.1 e 6.2.

\subsection{Escolher os conjuntos de sinais mais adequados}

A partir dos conjuntos de sinais selecionados, calculam-se os índices de avaliações de sinais de excitações discutidos no capítulo 4. No caso de plantas mal condicionadas, 
calcula-se o SF utilizando os ganhos estáticos da planta (8.3). Os índices calculados permitirão uma avaliação comparativa dos sinais.

Conforme discutido na seção 4.6, os índices encontrados na literatura não avaliam os sinais de forma conjunta. As correlações entre os sinais de excitação também afetam o desempenho do estimador de parâmetros do modelo quando há perturbações aditivas nos dados de saída da planta, provocando maior variância dos parâmetros estimados. Assim, faz-se necessário avaliar os sinais de forma conjunta, considerando as correlações existentes entre eles. Neste trabalho foi proposto o índice CISS para avaliar os sinais de excitação com relação ao desempenho dos estimadores (variância dos parâmetros estimados do modelo). Para o caso particular de identificação de plantas mal condicionadas, foi proposto o SF.

\subsubsection{Caso particular de plantas mal condicionadas}

Em plantas mal condicionadas, são utilizadas elevadas correlações entre os sinais para gerar saídas com maior SNR, porém, com o cuidado de manter a persistência de excitação para a unicidade da solução de estimação de parâmetros. Observa-se que um bom ajuste do modelo, as correlações entre os sinais de excitação são estabelecidas com compromisso entre as SNR nas saídas e variância dos parâmetros estimados (seção 8.2.1).

Previamente ao experimento de identificação é adequado utilizar a medida SF, proposta no capítulo 8, para avaliar na condição estática os sinais de excitações escolhidos (seção 8.3).

Caso não haja restrições operacionais, a duração do experimento $T_{e}$ pode ser escolhida, por exemplo, duas vezes maior que o período dos sinais de excitação parametrizados (pelo menos duas vezes maior que a duração mínima do experimento), com o objetivo de obter futuramente uma grande quantidade de dados para um bom ajuste do modelo. Neste caso, durante o experimento de identificação, após completar um período dos sinais de excitação, a medida SF pode ser calculada para verificar se o projeto dos sinais está excitando de forma equilibrada as direções de alto e baixo ganho da planta. Caso as direções de alto e baixo ganho sejam perfeitamente equilibradas, ter-se-á $S F=100 \%$. Quando houver um desequilíbro grande da excitação, ter-se-á $S F \approx 0 \%$. Caso essa condição seja observada durante o experimento, é necessário ajustar o fator $\Gamma$, de forma a obter o resultado que proporcionará dados mais informativos para a estimação dos parâmetros do modelo. É desejável que o experimento seja realizado com SF elevado pelo menos durante à duração mínima do experimento, calculada previamente. Vale lembrar que a identificação MISO não é adequada para 
uma planta com característica altamente iterativa (KOUNG; MACGREGOR, 1993) (ZHU; STEC, 2006).

$\mathrm{Na}$ identificação das plantas mal condicionadas discutidas no capítulo 8 , verificouse que o índice SF mostra uma forte relação com o ajuste do modelo. Os sinais de excitação com simultaneamente $\mathrm{SF}$ elevados e $\mathrm{CF}$ reduzidos (próximos à unidade) resultaram em melhores ajustes (FIT) dos modelos. Assim, deve-se dar menor prioridade a realizar experimentos em plantas mal condicionadas com conjuntos de sinais de excitação cujos SF forem reduzidos e CF elevados (ou equivalentemente PIPS reduzidos).

\subsubsection{Menor variância dos parâmetros estimados}

Quando não há o mal condicionamento da planta, a elevada correlação entre os sinais de entrada não é necessária para obter SNR nas saídas suficiente para identificação. Assim, evitam-se as correlações elevadas entre os sinais de entrada com o objetivo de menores variâncias dos parâmetros estimados (seção 2.2.1) e, portanto, melhor desempenho do estimador.

A medida CISS (4.25) proposta neste trabalho (seção 4.7) permite avaliar comparativamente conjuntos de sinais de excitação com respeito ao desempenho proporcionado a um estimador LS de parâmetros de modelos FIR a partir de dados em meio a ruído branco aditivo. Será mostrado no capítulo 10 que o CISS é uma boa medida para avaliação comparativa de sinais de excitação previamente ao experimento de identificação. Os conjuntos de sinais de excitação cujos CISS são comparativamente maiores geram dados que proporcionam desempenhos comparativamente inferiores para os estimadores (maior variância dos parâmetros estimados). Cabe lembrar que a minimização da variância dos parâmetros estimados é um critério para o projeto ótimo de experimentos (seção 2.1).

O objetivo da identificação é obter modelos que representem a planta. Assim, melhor será o modelo quanto maior for seu FIT (8.26). Exemplos do capítulo 10 mostram que conjuntos de sinais de excitação cujos CISS $\rightarrow \infty$ geram dados que modelos por eles ajustados resultam em FIT insatisfatórios.

Conforme discutido na seção 4.7, o índice EMINE complementa a avaliação dos sinais de excitação pelo índice CISS, pois esse não considera em sua avaliação o espectro de interesse da planta. Assim, deve-se dar menor prioridade a realizar experimentos com sinais de excitação que apresentam $C I S S \rightarrow \infty$ e EMINE $\approx 0$. 


\subsection{Ferramenta desenvolvida para selecionar conjun- tos de sinais de excitação}

Os métodos de construção de sinais de excitação discutidos neste trabalho não estão disponíveis em uma única plataforma para simulação numérica. Alguns deles são encontrados implementados em softwares dedicados dificultando seu uso nos softwares de simulação numérica e outros são comercializados em pacotes de ferramentas (toolbox) do software MATLAB. Adicionalmente, algumas implementações apresentam restrições em parâmetros utilizados para construção dos sinais. Abaixo estão listados os endereços da internet onde são possíveis encontrar essas ferramentas de construção de sinais (TAN; GODFREY; BARKER, 2009), bem como as restrições das implementações.

1. DIB, DIT e SOH: conjunto de rotinas MATLAB comerciais. Limitações não conhecidas. Disponível em:

http://elecwww.vub.ac.be/fdident

2. MLMH: conjunto de rotinas MATLAB gratuitas. Não geram conjuntos de sinais para identificação multivariável. Disponível em:

http://www . eng . warwick . ac.uk/eed/dsm/multilev_new

3. QRB, QRT, HAB, TPB e PRB: conjunto de rotinas MATLAB gratuitas. Geram sinais limitados ao comprimento $N=50.000$. Não geram conjuntos de sinais para identificação multivariável. Disponível em:

http://www . eng. warwick . ac .uk/eed/dsm/prs

4. PRT e PRML: software dedicado gratuito intitulado GALOIS (BARKER, 2001). Limitação de sinais sobre $G F(p)$, com $p<31$. Não geram conjuntos de sinais para identificação multivariável. Disponível em:

http://www . eng. warwick. ac.uk/eed/dsm/galois

5. Sinais SOH e PRB: conjunto de rotinas MATLAB gratuitas intitulado CR-IDENT (LEE; RIVERA, 2006). Limitações não conhecidas. Disponível em:

http: //csel .asu.edu/?q=crident 
Para possibilitar as avaliações de sinais de excitações discutidos neste trabalho, foram desenvolvidas rotinas em MATLAB para gerar todos conjuntos de sinais de excitação discutidos aqui. Visando maior praticidade em gerar os sinais, foi também desenvolvida uma interface gráfica que utiliza tais rotinas. Nessa interface, dadas as características de espectro, amplitude e duração do experimento, podem ser gerados conjuntos de sinais de excitação utilizando qualquer um dos métodos discutidos neste trabalho. Os dados de entrada para a interface gráfica são:

1. Maiores e menores constantes de tempo, $\tau_{\max }$ e $\tau_{\min }$;

2. Fatores $\beta_{s}$ que representam os tempos de acomodação a excitações em cada uma das entradas (3.8);

3. Fatores $\alpha_{s}$ que representam as velocidades de resposta da planta em malha fechada (3.8);

4. Amplitudes máximas para cada entrada;

5. Duração do experimento $T_{e}$;

6. Método de geração de sinais de excitação.

Caso não seja possível com o método escolhido gerar um conjunto de sinais de excitação que resulte na duração do experimento exatamente igual a $T_{e}$, será retornado o conjunto com o menor $T_{N_{s}}$ que atenda $T_{N_{s}} \geq T_{e}$.

Foram também desenvolvidas rotinas que calculam todos os índices de desempenho de sinais de excitação discutidos neste trabalho. Essa ferramenta computacional (rotinas e interface gráfica) possibilitou realizar os estudos e gerar os resultados apresentados aqui.

A figura 9.2 apresenta a tela de entradas de informações a priori da interface gráfica desenvolvida. Exemplos de resultados gerados pela ferramenta estão nas figuras 9.3 a 9.6 . 


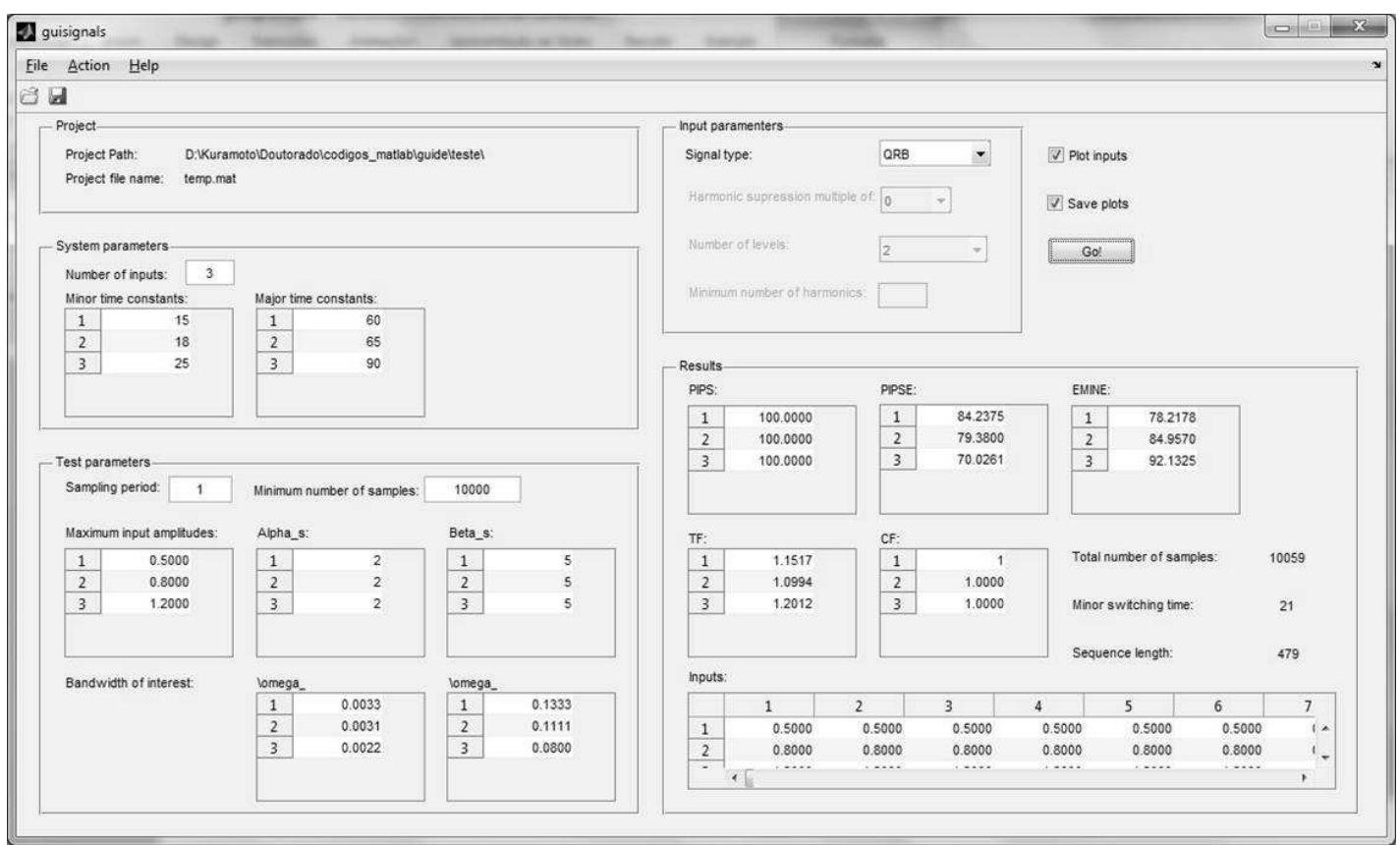

Figura 9.2: Tela de entradas de informações a priori e de resultados da ferramenta desenvolvida para a construção de conjuntos de sinais de excitação.

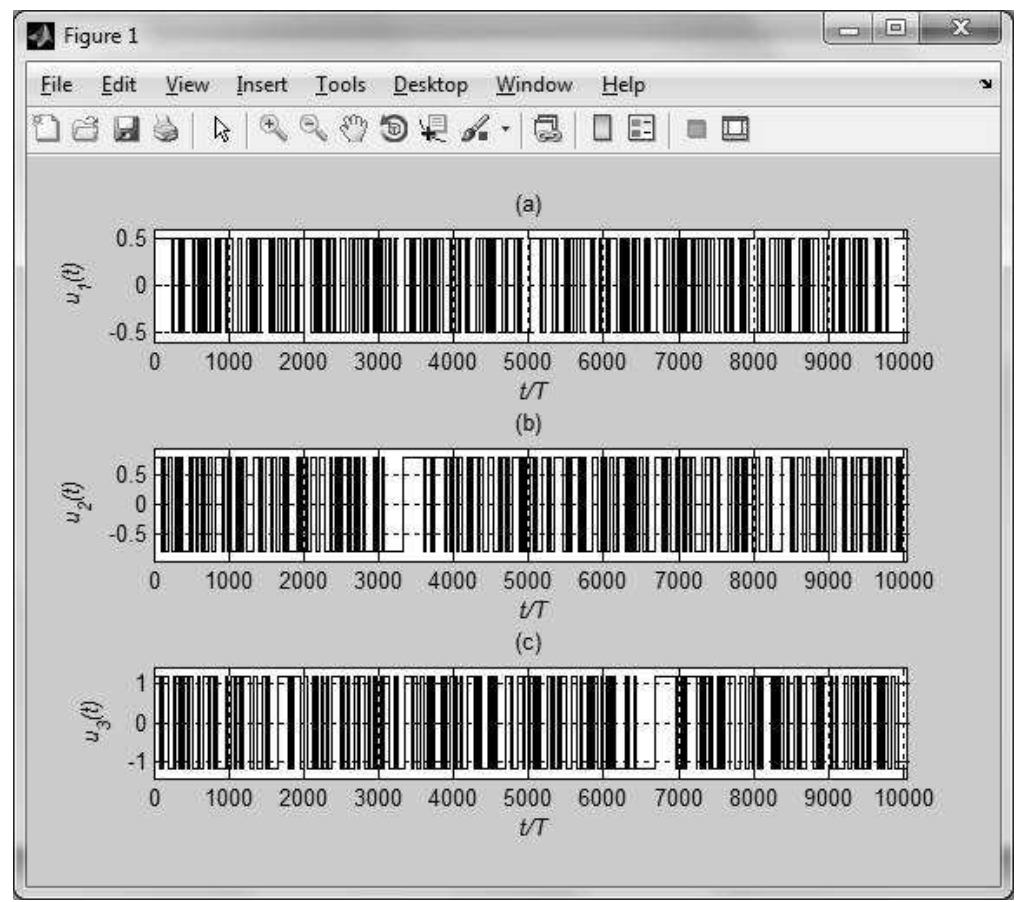

Figura 9.3: Exemplos de sinais gerados pela ferramenta desenvolvida. 


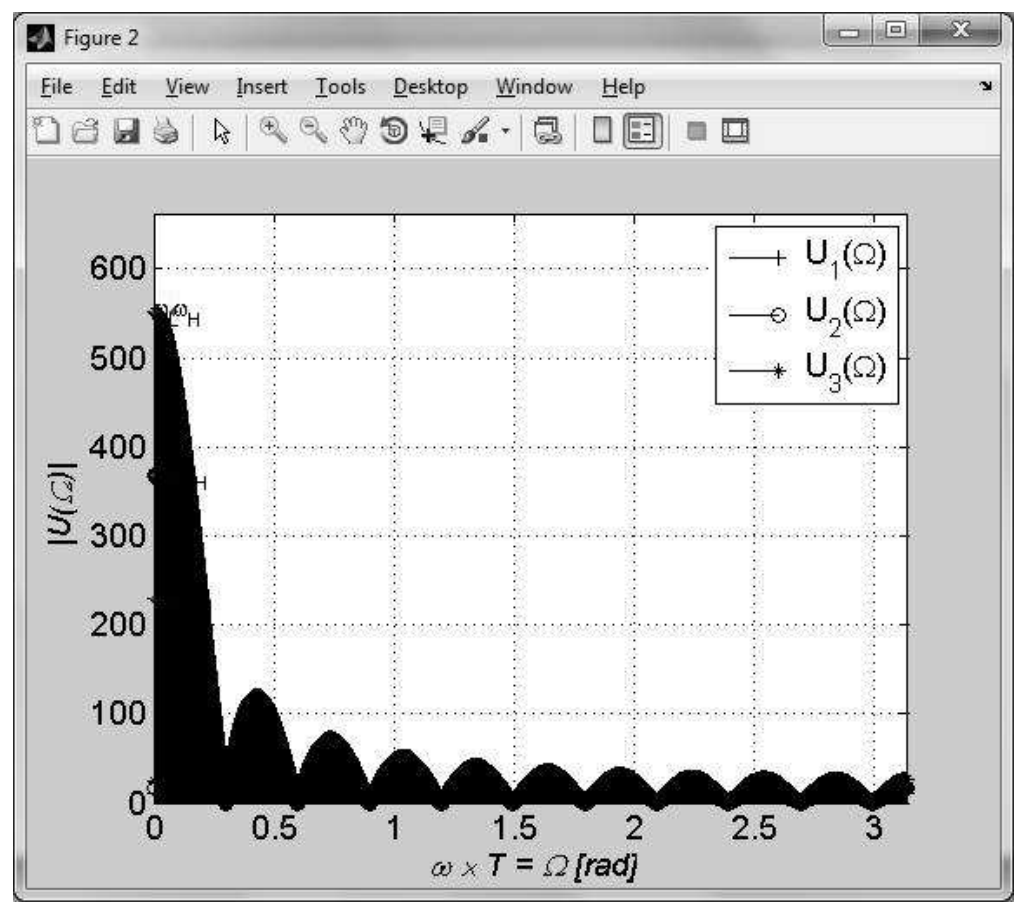

Figura 9.4: Espectro de amplitudes dos exemplos de sinais gerados pela ferramenta desenvolvida.

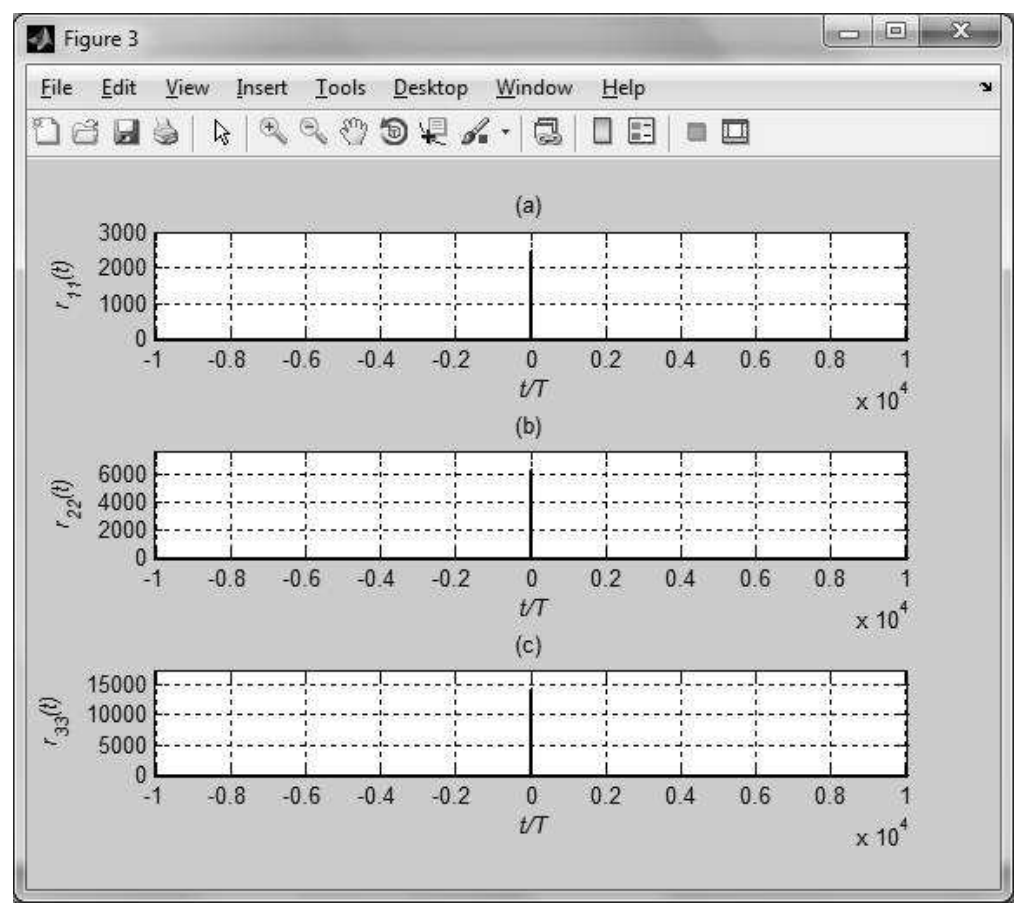

Figura 9.5: Autocorrelações dos exemplos de sinais gerados pela ferramenta desenvolvida. 


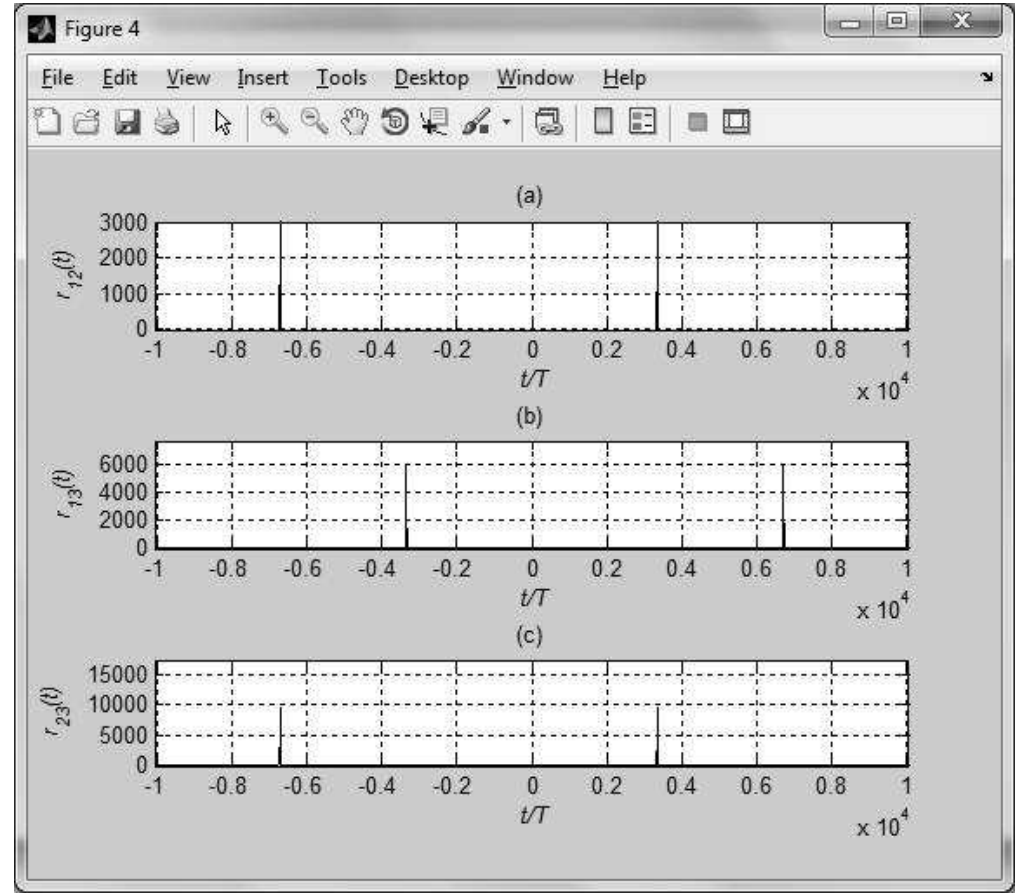

Figura 9.6: Correlação cruzada dos exemplos de sinais gerados pela ferramenta desenvolvida. 


\section{Estudo de caso: identificação de uma planta de processamento}

Neste capítulo são apresentadas e discutidas simulações de experimentos, identificações e validações de parte de uma planta de processamento de frações pesadas do petróleo, conhecida como craqueamento catalítico fluido (fluid catalytic cracking, FCC). Os assuntos discutidos nos capítulos anteriores relativos a sinais de excitação, suas parametrizações e avaliações por meio de índices são aqui aplicados no projeto do experimento. Todos os sinais de excitação discutidos no capítulo 5, bem como as propostas de sinais do capítulo 6, são utilizados nas simulações. As limitações observadas no projeto do experimento e os resultados obtidos com a aplicação de cada um dos sinais são apresentados e discutidos de forma comparativa. A próxima seção apresenta resumidamente as características da planta. Como o objetivo aqui não é analisar ou propor melhorias à planta, não é apresentado detalhadamente nem discutido o processamento realizado por ela.

\subsection{Características da planta}

A planta utilizada nas simulações é um modelo linear de (GROSDIDIER et al., 1993) obtido por meio de identificação do conjunto reator-regenerador de uma unidade de FCC da refinaria Neste Oy em Porvo, Finlândia. Essa unidade de processamento converte gasóleos em outros produtos, sendo a gasolina o de maior valor. Conforme discussões anteriores, neste trabalho, entende-se por planta o modelo utilizado para simulações numéricas em substituição aos experimentos que seriam realizados na planta real.

A figura 10.1 apresenta o diagrama da planta. Sua carga é uma mistura composta de óleo de recliclo, gasóleo frio e quente. Essa mistura é preaquecida pelo gasóleo pesado (heavy cycle gas oil, HCGO) e injetada no fundo do riser. Nesse ponto, a carga se mistura com o catalisador fresco (regenerado) e, enquanto se deslocam, ocorrem as reações de conversão. A reação produz vapores de hidrocarbonetos e coque, o qual se deposita sobre o catalisador, inibindo sua reatividade. Esse catalisador gasto e os 


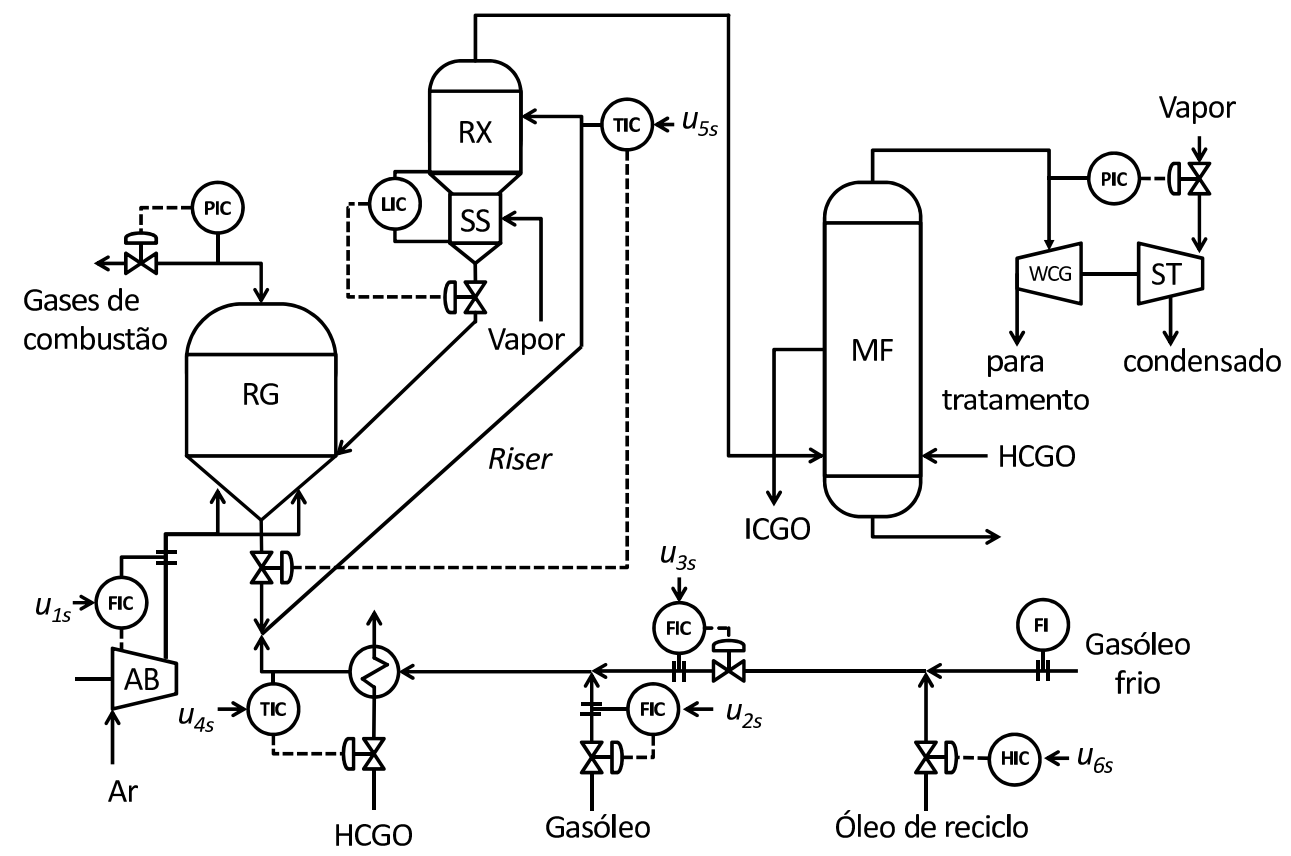

Figura 10.1: Diagrama da planta FCC simulada (GROSDIDIER et al., 1993).

vapores (produtos da conversão) são separado no reator (RX) por meio de ciclones. A temperatura de saída do riser é controlada manipulando a válvula slide para alterar a taxa de circulação de catalisadores. O catalisador gasto é mantido em leito fluidizado na seção stripping (stripping section, $\mathrm{SS}$ ) antes de ser devolvido ao regenerador (RG). O vapor injetado, o qual mantém o leito fluidizado na SS, é responsável por remover os hidrocarbonetos absorvidos pelas partículas de catalisadores. O nível na SS é controlado manipulando a válvula slide de catalisador gasto. O catalisador é regenerado por meio da queima do coque depositado. Um soprador de ar (air blower, AB) alimenta o RG com o oxigênio necessário à queima do coque depositado sobre o catalisador. A vazão de ar de combustão é controlada manipulando o ângulo das aletas do soprador. Os gases da combustão do coque são enviados a uma caldeira. A pressão do RG é controlada manipulando a válvula slide da linha de gases da combustão. Os vapores de hidrocarbonetos oriundos do RX são enviados para o fundo da fracionadora principal (main fractionator, MF). O HCGO, após preaquecer a carga, é injetado no fundo da MF. Uma fração intermediária de gasóleo (intermediate cycle gas oil, ICGO) é retirada da MF e enviada à carga como óleo de reciclo, após passar por uma stripper. Os produtos de topo da MF são comprimidos pelo compressor de gás úmido (wet gas compressor, WGC) antes de serem enviados para tratamento. A pressão de sucção do WCG é controlada manipulando a vazão de vapor para a turbina acionadora do WCG.

Em resumo, a planta representa 7 variáveis controladas $(\mathrm{CV})$ e 6 variáveis manipuladas (MV) da unidade FCC, cujos set points estão indicados no diagrama da figura 10.1. Nas simulações discutidas neste capítulo são consideradas excitações si- 
Tabela 10.1: Variáveis manipuladas (MV), controladas (CV) e seus limites da planta FCC.

\begin{tabular}{|c|c|c|c|c|}
\hline $\mathrm{MV} / \mathrm{CV}$ & Descrição & Unidade & $\begin{array}{l}\text { Valores médios } \\
\text { de operação } \\
\left(\overline{u_{s r}} \text { e } \overline{y_{p}}\right)\end{array}$ & Limites \\
\hline$u_{1}$ & Vazão de ar de combustão & $\mathrm{t} / \mathrm{h}$ & 147,5 & $140-155$ \\
\hline$u_{2}$ & Vazão de gasóleo quente & $\mathrm{m}^{3} / \mathrm{h}$ & 100 & $90-110$ \\
\hline$u_{3}$ & $\begin{array}{l}\text { Vazão de gasóleo frio combinado } \\
\text { com óleo de reciclo }\end{array}$ & $\mathrm{m}^{3} / \mathrm{h}$ & 100 & $90-110$ \\
\hline$u_{4}$ & Temperatura da carga preaquecida & ${ }^{\circ} \mathrm{C}$ & 240 & $230-250$ \\
\hline$u_{5}$ & Temperatura na saída do riser & ${ }^{\circ} \mathrm{C}$ & 525 & $515-535$ \\
\hline$u_{6}$ & $\begin{array}{l}\text { Abertura da válvula } \\
\text { de óleo de reciclo }\end{array}$ & $\%$ & 50 & $20-80$ \\
\hline$y_{1}$ & $\begin{array}{l}\text { Concentração de } \mathrm{O}_{2} \text { nos } \\
\text { gases de combustão }\end{array}$ & $\%$ & 0,9 & $0-2$ \\
\hline$y_{2}$ & Temperatura do leito do regenerador & ${ }^{\circ} \mathrm{C}$ & 712 & $705-735$ \\
\hline$y_{3}$ & Vazão de gás combustível & $\mathrm{t} / \mathrm{h}$ & 15,5 & $14-16$ \\
\hline$y_{4}$ & $\begin{array}{l}\text { Saída do controlador de pressão de } \\
\text { sucção do compressor de gás úmido }\end{array}$ & $\%$ & 60 & $20-70$ \\
\hline$y_{5}$ & $\begin{array}{l}\text { Saída do controlador de temperatura } \\
\text { da saída do riser }\end{array}$ & $\%$ & 70 & $20-80$ \\
\hline$y_{6}$ & $\begin{array}{l}\text { Pressão diferencial na válvula slide } \\
\text { de catalisador regenerado }\end{array}$ & $\mathrm{kPa}$ & 35 & $22-40$ \\
\hline$y_{7}$ & $\begin{array}{l}\text { Pressão diferencial na válvula slide } \\
\text { de catalisador gasto }\end{array}$ & $\mathrm{kPa}$ & 20 & $10-24$ \\
\hline
\end{tabular}

multâneas nos set points das $6 \mathrm{MV}\left(n_{r}=6\right)$ e observadas as $7 \mathrm{CV}\left(n_{p}=7\right)$. As descrições resumidas das MV e CV, seus valores médios $\left(\overline{u_{r}}\right.$ e $\left.\overline{y_{p}}\right)$ de operação e limites estão listadas na tabela 10.1. Os motivos pelos quais se deseja controlar essas 7 variáveis manipulando as outras 6 estão descritos em (GROSDIDIER et al., 1993).

Os set points das MV $\left(u_{s} r\right)$ se relacionam com as CV $\left(y_{p}\right)$ conforme a figura 10.2. As funções de transferência da planta são apresentadas nas tabelas 10.2 e 10.3. Aos vetores $\tilde{\mathbf{y}}_{p}$ são adicionados ruídos de medição $\mathbf{e}_{p}$ e perturbações não medidas $\mathbf{v}_{p}$ para gerar os vetores de saídas da planta $\mathbf{y}_{p}=\tilde{\mathbf{y}}_{p}+\mathbf{e}_{p}+\mathbf{v}_{p}$.

\subsection{Parametrização das simulações}

As simulações dos experimentos foram realizadas aplicando sinais de excitação nos set points das MV. Foram realizados experimentos com os sinais discutidos nos capítulos 5 e 6 . A próxima seção apresenta as características desses sinais.

Para atender às restrições de amplitudes das $\mathrm{MV}$ e CV, foram adotadas as seguintes amplitudes de pico para as excitações: 


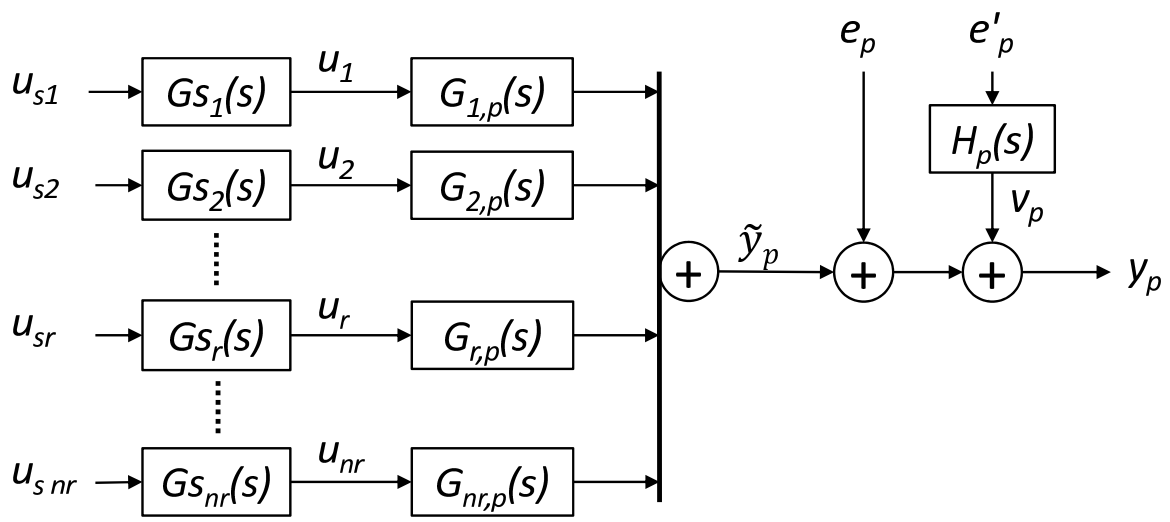

Figura 10.2: Diagrama de blocos relacionando as entradas $\left(u_{s r}\right)$ com saídas $\left(y_{p}\right)$ da planta FCC.

Tabela 10.2: Funções de transferência $G_{r, p}(s)$.

\begin{tabular}{ccccccc}
\hline & $u_{1}$ & $u_{2}$ & $u_{3}$ & $u_{4}$ & $u_{5}$ & $u_{6}$ \\
\hline$\tilde{y}_{1}$ & $\frac{0,097(1,7 s+1) e^{-2 s}}{19 s^{2}+6,5 s+1}$ & $\frac{-0,87 e^{-2 s}}{13 s^{2}+4,9 s+1}$ & $\frac{-0,092(0,25 s+1) e^{-3 s}}{3,7 s^{2}+4,7 s+1}$ & $\frac{0,026 e^{-7 s}}{12 s+1}$ & $\frac{0,074(4,8 s+1)}{9,3 s^{2}+3,4 s+1}$ & $\frac{0,48 s e^{-12 s}}{(6,0 s+1)(8,0 s+1)}$ \\
$\tilde{y}_{2}$ & 0 & $\frac{0,55 e^{-4 s}}{27 s^{2}}$ & $\frac{0,55 e^{-4 s}}{10 s^{2}+4,9 s+1}$ & 0 & $\frac{0,74(1,7 s+1) e^{-2 s}}{11 s^{2}+7,3 s+1}$ & $\frac{0,36 e^{-11 s}}{33 s^{2}+6,5 s+1}$ \\
$\tilde{y}_{3}$ & 0 & $\frac{0,14 e^{-11 s}}{46 s^{2}+8,5 s+1}$ & $\frac{0,14 e^{-6 s}}{46 s^{2}+8,5 s+1}$ & 0 & $\frac{0,27(16 s+1)}{53 s^{2}+23 s+1}$ & $\frac{0,015(12 s+1) e^{-9 s}}{66 s^{2}+27 s+1}$ \\
$\tilde{y}_{4}$ & 0 & $\frac{0,25 e^{-11 s}}{17 s^{2}+7,0 s+1}$ & $\frac{0,25 e^{-7 s}}{3,0 s+1}$ & 0 & $\frac{0,70}{3,0 s+1}$ & $\frac{0,079(6,3 s+1) e^{-10 s}}{24 s^{2}+12 s+1}$ \\
$\tilde{y}_{5}$ & 0 & $\frac{0,66 e^{-s}}{2,5 s+1}$ & $\frac{0,66 e^{-s}}{2,5 s+1}$ & $\frac{0,9 e^{-10 s}}{6 s+1}$ & $\frac{1,0}{2,0 s+1}$ & $\frac{-0,54 e^{-11 s}}{9,0 s+1}$ \\
$\tilde{y}_{6}$ & 0 & $\frac{-0,84 e^{-s}}{6,1 s+1}$ & $\frac{0,90}{1,5 s+1}$ & $\frac{0,35 e^{-10 s}}{5,0 s+1}$ & $\frac{-(0,64 s+1)}{13 s^{2}+7,0 s+1}$ & $\frac{0,23(0,50 s+1) e^{-14 s}}{3,6 s^{2}+11 s+1}$ \\
$\tilde{y}_{7}$ & 0 & $\frac{0,81}{6,0 s+1}$ & $\frac{0,90}{s+1}$ & $\frac{-0,35 e^{-10 s}}{5,0 s+1}$ & 0,80 & $\frac{-0,26 e^{-18 s}}{7,1 s+1}$ \\
\hline
\end{tabular}

$$
\begin{aligned}
& \max \left|u_{s 1}-\overline{u_{s 1}}\right|=3,75 \mathrm{t} / \mathrm{h} \\
& \max \left|u_{s 2}-\overline{u_{s 2}}\right|=0,50 \mathrm{~m}^{3} / \mathrm{h} \\
& \max \left|u_{s 3}-\overline{u_{s 3}}\right|=1,67 \mathrm{~m}^{3} / \mathrm{h} \\
& \max \left|u_{s 4}-\overline{u_{s 4}}\right|=5{ }^{\circ} \mathrm{C} \\
& \max \left|u_{s 5}-\overline{u_{s 5}}\right|=0,83{ }^{\circ} \mathrm{C} \\
& \max \left|u_{s 6}-\overline{u_{s 6}}\right|=7,5 \%
\end{aligned}
$$

Esses valores de amplitudes de entrada foram ajustados observando-se as saídas da planta em algumas simulações realizadas. 
Tabela 10.3: Funções de transferência $G s_{r}(s)$.

\begin{tabular}{cccccc}
\hline$G s_{1}(s)$ & $G s_{2}(s)$ & $G s_{3}(s)$ & $G s_{4}(s)$ & $G s_{5}(s)$ & $G s_{6}(s)$ \\
\hline$\frac{1}{(0,75 s+1)(4,5 s+1)}$ & $\frac{1}{s+1}$ & $\frac{1}{1,7 s^{2}+2,1 s+1}$ & $\frac{(3,3 s+1) e^{-s}}{40 s^{2}+13 s+1}$ & $\frac{0,64 s+1}{13 s^{2}+7,0 s+1}$ & 1 \\
\hline
\end{tabular}

Às saídas $\tilde{y}_{p}, \operatorname{com} p=1,2, \ldots, 7$, são adicionados ruído de medição $e_{p}$ e perturbação não medida $v_{p}$. O ruído de medição é do tipo Gaussiano. A perturbação $v_{p}$ é do tipo ruído Gaussiano filtrado por uma estrutura de primeira ordem $H_{p}(s)=\frac{1}{0,5 s+1}$, com $e_{p}^{\prime}(t)$ variando a cada 10 minutos (figura 10.2). Os experimentos foram realizados em dois cenários diferentes de variância de ruído de medição $\sigma_{e}^{2}$ e variância de perturbação $\sigma_{e^{\prime}}^{2}$. A tabela 10.4 apresenta as características dos ruídos de medição e perturbação não medidas utilizados nos cenários. O cenário 1 é o de ruído de medição e perturbação não medida mais intensos. O cenário 2 possui ruído de medição e perturbações não medidas menos intensos. As variâncias $\left(\sigma_{e}^{2}\right.$ e $\left.\sigma_{e^{\prime}}^{2}\right)$ foram ajustadas por meio de algumas simulações de forma a resultar em condições de SNR nas saídas tanto reduzidas quanto elevadas, podendo avaliar a robustez dos sinais frente a ruídos e perturbações. Neste caso, o termo robustez se refere a quão informativos para a identificação são os experimentos realizados com cada um dos sinais em cenários de elevados e reduzidos ruídos e perturbações.

Tabela 10.4: Características dos ruídos de medição e perturbação não medidas utilizados nos experimentos.

\begin{tabular}{ccccc}
\hline & \multicolumn{2}{c}{ Cenário 1 } & \multicolumn{2}{c}{ Cenário 2 } \\
Saída & $\sigma_{e}^{2}$ & $\sigma_{e^{\prime}}^{2}$ & $\sigma_{e}^{2}$ & $\sigma_{e^{\prime}}^{2}$ \\
\hline$y_{1}$ & $10^{-3}$ & 0,005 & $10^{-4}$ & 0,001 \\
$y_{2}$ & $10^{-3}$ & 0,100 & $10^{-4}$ & 0,020 \\
$y_{3}$ & $10^{-3}$ & 0,001 & $10^{-4}$ & 0,001 \\
$y_{4}$ & $10^{-3}$ & 0,005 & $10^{-4}$ & 0,001 \\
$y_{5}$ & $10^{-3}$ & 0,200 & $10^{-4}$ & 0,020 \\
$y_{6}$ & $10^{-3}$ & 0,050 & $10^{-4}$ & 0,010 \\
$y_{7}$ & $10^{-3}$ & 0,050 & $10^{-4}$ & 0,010 \\
\hline
\end{tabular}

Cada simulação de experimento, identificação e validação foi realizada com 20 iterações. Os ruídos de medição e as perturbações não medidas são tratados como processos estocásticos e são gerados aleatoriamente a cada iteração (característica da simulação de Monte-Carlo).

A planta foi identificada em malha aberta utilizando as estruturas FIR, ARX e ARMAX (LJUNG, 1999). A cada iteração não são realizadas estimativas de ordens dos modelos nem de tempos mortos. Os tempos mortos são assumidos conhecidos. As ordens adotadas para as estruturas ARX e ARMAX são apresentadas na tabela 10.5. As ordens para a estrutura FIR são apresentadas na tabela 10.6. Foi também realizada identificação com estruturas ARX com $n_{a}=9, n_{b}=9$ e $n_{k}$ definido conforme a tabela 
Tabela 10.5: Ordens dos polinômios $A, B, C$ e $k$, para as estruturas ARX e ARMAX.

\begin{tabular}{ccccccccccccccc}
\hline & $n_{a}$ & $u_{1}$ & $u_{2}$ & $u_{3}$ & $u_{4}$ & $u_{5}$ & $u_{6}$ & $n_{c}$ & $u_{1}$ & $u_{2}$ & $u_{3}$ & $u_{4}$ & $u_{5}$ & $u_{6}$ \\
\hline$y_{1}$ & 4 & 4 & 3 & 4 & 3 & 4 & 4 & 1 & 2 & 2 & 3 & 8 & 0 & 12 \\
$y_{2}$ & 4 & NA & 3 & 4 & NA & 4 & 4 & 1 & NA & 4 & 4 & NA & 2 & 11 \\
$y_{3}$ & 4 & NA & 3 & 4 & NA & 4 & 4 & 1 & NA & 11 & 6 & NA & 0 & 9 \\
$y_{4}$ & 4 & NA & 3 & 3 & NA & 3 & 4 & 1 & NA & 11 & 7 & NA & 0 & 10 \\
$y_{5}$ & 3 & NA & 2 & 3 & 3 & 3 & 3 & 1 & NA & 1 & 1 & 11 & 0 & 11 \\
$y_{6}$ & 4 & NA & 2 & 3 & 3 & 4 & 4 & 1 & NA & 1 & 0 & 11 & 0 & 14 \\
$y_{7}$ & 3 & NA & 2 & 3 & 3 & 3 & 3 & 1 & NA & 0 & 0 & 11 & 0 & 18 \\
\hline
\end{tabular}

Tabela 10.6: Ordens da estrutura FIR.

\begin{tabular}{lcccccc}
\hline & $u_{1}$ & $u_{2}$ & $u_{3}$ & $u_{4}$ & $u_{5}$ & $u_{6}$ \\
\hline$y_{1}$ & 21 & 22 & 17 & 61 & 20 & 48 \\
$y_{2}$ & NA & 22 & 19 & NA & 30 & 33 \\
$y_{3}$ & NA & 41 & 42 & NA & 58 & 81 \\
$y_{4}$ & NA & 18 & 13 & NA & 23 & 29 \\
$y_{5}$ & NA & 11 & 11 & 44 & 7 & 35 \\
$y_{6}$ & NA & 24 & 7 & 42 & 19 & 41 \\
$y_{7}$ & NA & 24 & 6 & 42 & 42 & 27 \\
\hline
\end{tabular}

10.5. Essa estrutura é chamada aqui de ARX de alta ordem.

Foram ainda simulados experimentos com excitações em degrau. Um pulso positivo e um negativo de período 75 minutos cada (4.500 segundos) espaçados de 75 minutos são aplicados sequencialmente em cada uma das 6 entradas da planta. A duração desse experimento é de $T_{e}=4 \times 75 \times 6=1.800$ minutos (108.000 segundos). A figura 10.3 apresenta as excitações em degrau aplicadas. Na identificação foi utilizada a estrutura ARX de ordens $n_{a}=4, n_{b}=4$ e $n_{k}$ definido conforme a tabela 10.5 .

\subsection{Parametrização dos sinais}

Para a parametrização dos sinais de excitação, foram estimados os tempos de acomodação máximos e mínimos ( $T_{\max , r}$ e $T_{\min , r}$, respectivamente) para cada entrada $u_{r}$ da planta, a partir das respostas a excitações em degrau. Foram adotados os tempos para as saídas atingirem 99\% de seus valores finais. Os tempos máximos e mínimos de acomodação por entrada (3.6) e as respectivas constantes de tempo máximas e mínimas (3.7) para $\beta_{s}=5$ são apresentados na tabela 10.7 .

A faixa de frequências de interesse $B W_{r}=\left\{\omega_{L, r} ; \omega_{H, r}\right\}$ é dada por (3.8). Adotandose $\alpha_{s}=1$ e $\beta_{s}=5$, tem-se: 

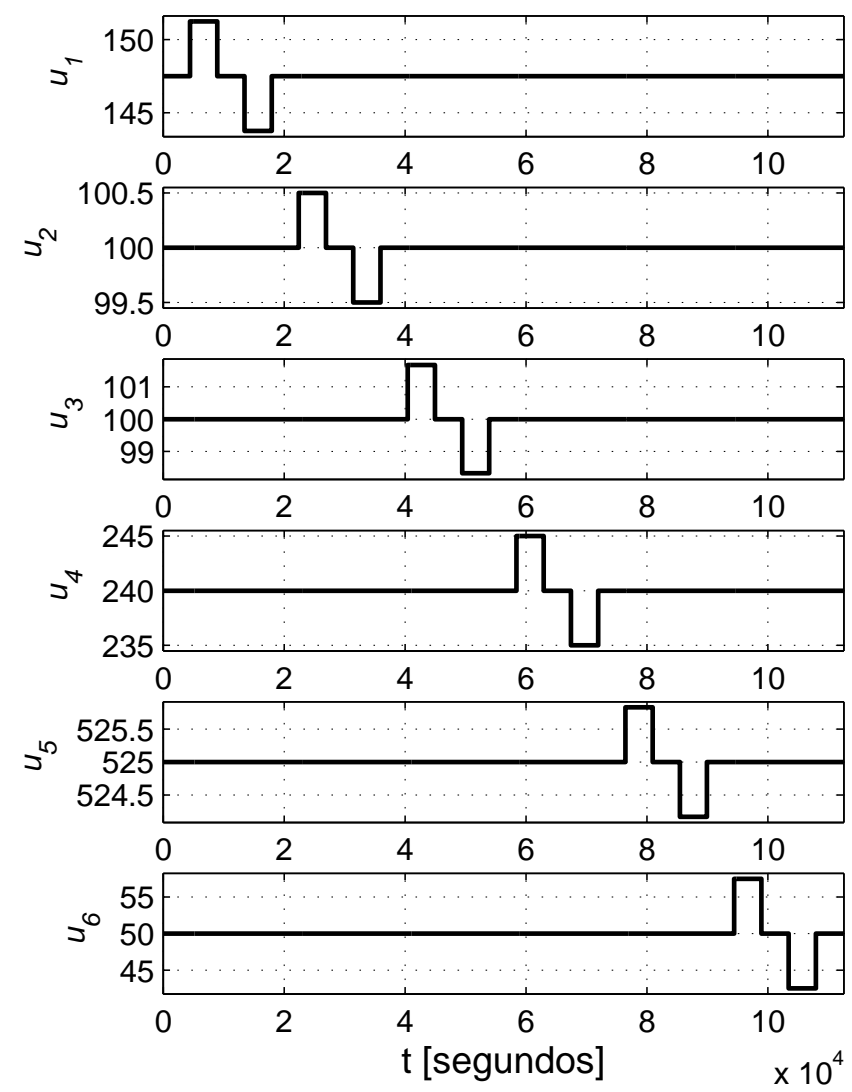

Figura 10.3: Excitações em degrau utilizadas para identificação da planta.

$$
\begin{gathered}
\omega_{L, r}=\frac{1}{\beta_{s} \tau_{\max , r}} \leq \omega \leq \frac{\alpha_{s}}{\tau_{\min , r}}=\omega_{H, r} \\
\omega_{L, r}=\frac{1}{5 \tau_{\max , r}} \leq \omega \leq \frac{1}{\tau_{\min , r}}=\omega_{H, r}
\end{gathered}
$$

Os valores de $\omega_{L, r}$ e $\omega_{H, r}$ para $r=1,2, \ldots, 6$ são apresentados na tabela 10.7.

Foi adotado período de amostragem $T=60$ segundos, ou seja, $f_{s}=16,667 \times 10^{-3}$ $\mathrm{Hz}$, o qual é aproximadamente 12 vezes maior que a maior frequência de interesse:

Tabela 10.7: Tempos máximos e mínimos de acomodação da planta, constantes de tempo e frequências máximas e mínimas de interesse.

\begin{tabular}{ccccccc}
\hline $\begin{array}{c}\text { Entrada } \\
\left(u_{r}\right)\end{array}$ & $\begin{array}{c}T_{\text {min, } r} \\
\text { (minutos) }\end{array}$ & $\begin{array}{c}T_{\max , r} \\
\text { (minutos) }\end{array}$ & $\begin{array}{c}\tau_{\max , r} \\
(\text { minutos })\end{array}$ & $\begin{array}{c}\tau_{\min , r} \\
(\text { minutos })\end{array}$ & $\begin{array}{c}\omega_{L, r} \\
(\mathrm{rad} / \text { min.) }\end{array}$ & $\begin{array}{c}\omega_{H, r} \\
(\mathrm{rad} / \mathrm{min} .)\end{array}$ \\
\hline$u_{1}$ & 33,5 & 33,5 & 6,7 & 6,7 & 0,0299 & 0,1493 \\
$u_{2}$ & 32,5 & 56,0 & 6,5 & 11,2 & 0,0179 & 0,1538 \\
$u_{3}$ & 19,5 & 67,5 & 3,9 & 13,5 & 0,0148 & 0,2564 \\
$u_{4}$ & 39,5 & 68,5 & 7,9 & 13,7 & 0,0146 & 0,1266 \\
$u_{5}$ & 10,0 & 55,5 & 2,0 & 11,1 & 0,0180 & 0,5000 \\
$u_{6}$ & 34,5 & 67,5 & 6,9 & 13,5 & 0,0148 & 0,1449 \\
\hline
\end{tabular}




$$
\max _{1 \leq r \leq 6}\left\{\frac{\omega_{H, r}}{2 \pi}\right\}=1,326 \times 10^{-3} \mathrm{~Hz}
$$

Como para cada entrada $u_{r}$ há uma constante de tempo máxima $\tau_{\max , r}$ diferente (e, consequentemente, uma faixa de frequências $B W_{r}$ diferente), a duração do experimento $T_{e}$ pode ser escolhida diferente para cada entrada, conforme (3.13), desde que o conjunto de sinais possua essa flexibilidade. Os sinais $\mathrm{SOH}$ e sinais aleatórios de um mesmo conjunto podem ser construídos com comprimentos diferentes, porém, os sinais de espectro fixo e sinais híbridos não (capítulo 5 e 6). Contudo, é prático adotar o maior $T_{e}$ e excitar todas as entradas da planta, visto durante esse intervalo a planta estaria sendo excitada em pelo menos uma de suas entradas. Nas simulações apresentadas aqui, optou-se por excitar as 6 entradas da planta durante todo o experimento $\left(T_{e}\right)$. Então, para todos os sinais, seus comprimentos $N_{e}$ são iguais. O comprimento mínimo dos sinais é determinado por:

$$
\max _{1 \leq r \leq 6}\left\{\tau_{\max , r}\right\}=\tau_{\max }
$$

De (10.4) e (3.13), tem-se que a duração mínima do experimento é:

$$
\begin{aligned}
T_{e} & \geq 2 \pi \beta_{s} \tau_{\max }=2 \pi 5 \times 13,7 \\
& \geq 430,4 \text { minutos }
\end{aligned}
$$

Os experimentos foram realizados com duração pelo menos três vezes maior que a duração mínima, ou seja, $T_{e} \geq 1.293$ minutos. Foram realizados três conjuntos de experimentos:

- Todos os sinais com períodos exatos de 5.115 minutos (85, 25 horas) na condição de ruído de medição e de perturbação do cenário 1 (tabela 10.4). Os sinais de espectro fixo são repetidos ciclicamente para todos os experimentos atingirem a duração de 5.115 minutos. Assim, caso não exista sinais de espectro fixo e sinais híbridos de comprimento $N_{s}=5.115$, um sinal de período menor é escolhido e repetido ciclicamente para atingir esse tempo de experimento.

- Caso semelhante ao anterior, com diferença no cenário de ruído de medição e perturbação adotado: cenário 2 (tabela 10.4).

- Todos os sinais com períodos de aproximadamente 1.293 minutos (21, 55 horas) na condição de ruído de medição e de perturbação do cenário 2 (tabela 10.4). As 
Tabela 10.8: Características dos conjuntos de experimentos.

\begin{tabular}{ccc}
\hline $\begin{array}{c}\text { Conjuntos de } \\
\text { experimentos }\end{array}$ & $\begin{array}{c}T_{e} \\
\text { (minutos) }\end{array}$ & $\begin{array}{c}\text { Cenário de ruído de } \\
\text { medição e perturbação }\end{array}$ \\
\hline $\mathrm{A}$ & 5.115 & Cenário 1 \\
$\mathrm{B}$ & 5.115 & Cenário 2 \\
$\mathrm{C}$ & $\approx 1.293$ & Cenário 2 \\
\hline
\end{tabular}

durações dos experimentos com sinais de espectro fixo e sinais híbridos não são iguais devido às restrições de comprimentos discutidas nos capítulos 5, 6 e 7. Fica evidente a limitação desses sinais quando se objetiva definir uma duração exata de experimento.

A tabela 10.8 resume os três conjuntos de experimentos realizados.

\subsubsection{Sinais aleatórios}

Para os sinais CBN, aplicam-se filtros conforme (5.8) especificados para cada entrada $r$, onde as constantes $\tau_{\min , r}$ são aquelas da tabela 10.7 .

A probabilidade $p$ de não chaveamento de cada um dos $n_{r}$ sinais GBN é calculada conforme (5.17). Nesse cálculo são utilizadas as frequências $\omega_{L, r}$ e $\omega_{H, r}$ da tabela 10.7. A tabela 10.9 apresenta as probabilidades $p$ de não chaveamento calculadas para cada um $\operatorname{dos} n_{r}$ sinais GBN.

Tabela 10.9: Probabilidades $p$ de não chaveamento calculadas para cada um dos $n_{r}$ sinais GBN.

\begin{tabular}{cc}
\hline Sinal (entrada) & Probabilidade de não chaveamento $(p)$ \\
\hline$u_{1}$ & 0,7695 \\
$u_{2}$ & 0,7732 \\
$u_{3}$ & 0,7303 \\
$u_{4}$ & 0,7900 \\
$u_{5}$ & 0,6604 \\
$u_{6}$ & 0,7795 \\
\hline
\end{tabular}

As características dos sinais aleatórios para os experimentos A, B e C são apresentadas nas tabelas 10.10 e 10.11 , respectivamente.

\subsubsection{Sinais $\mathrm{SOH}$}

De (5.47), o comprimento mínimo para os sinais $\mathrm{SOH}$ é: 


$$
\begin{aligned}
N_{s} & \geq \max \left(\frac{2 \pi}{T \min \left\{\omega_{L, r}\right\}} ; \frac{2 \pi\left(n_{s}-1\right)}{T\left(\max \left\{\omega_{H, r}\right\}-\min \left\{\omega_{L, r}\right\}\right)}\right) \\
& \geq \max \left(\frac{2 \pi}{0,0148} ; \frac{2 \pi\left(n_{s}-1\right)}{(0,500-0,0148)}\right) \\
& \geq \max \left(\frac{2 \pi}{0,0148} ; \frac{2 \pi\left(n_{s}-1\right)}{0,4852}\right) \\
& \geq \max \left(430,4 ; 12,95\left(n_{s}-1\right)\right)
\end{aligned}
$$

Para os sinais $\mathrm{SOH}$ utilizados nos experimentos A e B, especificou-se $n_{s}=390$ harmônicas intercaladas, ou seja, 65 harmônicas não nulas para cada um dos 6 sinais. As harmônicas não nulas, portanto, são espaçadas de $\frac{2 \pi}{T} \frac{6}{N_{s}} \mathrm{rad} /$ minutos. Substituindose $n_{s}=390$ em (10.6), tem-se:

$$
\begin{aligned}
N_{s} & \geq \max (430,4 ; 12,95(390-1)) \\
& \geq 5.037,5
\end{aligned}
$$

O comprimento $N_{s}=5.115$ adotado para os sinais $\mathrm{SOH}$ dos experimentos A e B atende a essa restrição (tabela 10.10).

No conjunto de experimentos $\mathrm{C}$, os sinais tiveram $n_{s}=150$ harmônicas intercaladas, ou seja, 25 harmônicas não nulas para cada um dos 6 sinais. Neste caso:

$$
\begin{aligned}
N_{s} & \geq \max (430,4 ; 12,95(150-1)) \\
& \geq 1.929,6
\end{aligned}
$$

Conforme tabela 10.11 , o comprimento $N_{s}=2.000$ adotado para o experimento C atende a essa restrição.

De (5.50), o período de amostragem $T$ máximo é:

$$
\begin{aligned}
T & \leq \min \left(\frac{\pi}{\max \left\{\omega_{H, r}\right\}} ; \frac{\pi\left(n_{s}-1\right)}{n_{s}\left(\max \left\{\omega_{H, r}\right\}-\min \left\{\omega_{L, r}\right\}\right)}\right) \\
T & \leq \min \left(\frac{\pi}{0,500} ; \frac{\pi\left(n_{s}-1\right)}{n_{s}(0,500-0,0148)}\right) \\
T & \leq \min \left(\frac{\pi}{0,500} ; \frac{\pi\left(n_{s}-1\right)}{n_{s} 0,4852}\right)
\end{aligned}
$$




$$
T \leq \min \left(6,28 ; \frac{6,47\left(n_{s}-1\right)}{n_{s}}\right)
$$

Assim, tanto para os experimentos A e B $\left(n_{s}=390\right)$ quanto para os experimentos $\mathrm{C}\left(n_{s}=150\right)$, tem-se:

$$
T \leq 6,28 \text { minutos }
$$

O período de amostragem adotado $(T=1$ minuto) atende a essa restrição. As características dos sinais $\mathrm{SOH}$ para os experimentos A, B e C são apresentadas nas tabelas 10.10 e 10.11 , respectivamente.

\subsubsection{Sinais de espectro fixo}

Para os sinais de espectro fixo, o período máximo de chaveamento é (5.96):

$$
\begin{aligned}
T_{c l k} & \leq \frac{2,8 \tau_{\min }}{\alpha_{s}} \\
& \leq \frac{2,82}{1} \\
& \leq 5,6 \text { minutos }
\end{aligned}
$$

Foi adotado período mínimo de chaveamento de $T_{c l k}=5$ minutos.

Os comprimentos $N$ adotados para os sinais atendem (5.99):

$$
\begin{aligned}
N & \geq \frac{2 \pi \beta_{s} \tau_{\max }}{T_{c l k}} \\
& \geq \frac{2 \pi 513,7}{5} \\
& \geq 86,1
\end{aligned}
$$

As características dos sinais de espectro fixo para os experimentos A, B e C são apresentadas nas tabelas 10.10 e 10.11 , respectivamente.

\subsubsection{Sinais híbridos}

Na construção dos sinais Gallev e MLNL foram utilizados sinais Schroeder-SOH como sequências sementes. Nos experimentos A e B, os sinais Gallev são gerados sobre o 
corpo $G F(31)$ e, portanto, as sementes têm comprimento 30 e seus espectros têm no máximo $n_{s}=\frac{30}{2}=15$ harmônicas, conforme (5.18). Então, especifica-se o espectro intercalado de 15 harmônicas para as 6 sementes. No conjunto de experimentos $\mathrm{C}$, escolheu-se sinais Gallev sobre o corpo $G F(23)$, os quais necessitam de sementes de comprimento 22. Seus espectros têm no máximo $n_{s}=\frac{22}{2}=11$ harmônicas. Então, especifica-se o espectro intercalado de 11 harmônicas para as 6 sementes.

As sequências MLNL adotadas para os experimentos A e B possuem comprimento $N=2^{10}-1=1.023 \mathrm{e}$, portanto, suas sementes possuem comprimento $2^{5}-1=31$. $\mathrm{O}$ espectro foi especificado intercalado com 15 harmônicas para cada semente. No caso do experimento $\mathrm{C}$, as sequências MLNL adotadas possuem comprimentos $N=$ $5^{4}-1=624$. O comprimento das sementes é $5^{2}-1=24$. Foram especificadas 12 harmônicas para o espectro intercalado de cada semente.

Outras características da construção dos sinais Gallev e MLNL para os experimentos A, B e C são apresentadas nas tabelas 10.10 e 10.11, respectivamente.

Tabela 10.10: Características dos sinais aplicados nos conjuntos de experimentos A e B de duração $T_{e}=5.115$ minutos.

\begin{tabular}{|c|c|c|}
\hline Sinais & $N_{s}$ & Características \\
\hline Rademacher-QRB & 4.960 & $\begin{array}{l}N=992, k=8, L=4 k-1=31, \\
\text { funções Rademacher de ordem } 2^{(6-1)}=32, \\
T_{c l k}=5 \times 60=300 \text { segundos }\end{array}$ \\
\hline Rademacher-QRT & 4.960 & $\begin{array}{l}N=992, k=8, L=4 k-1=31 \\
\text { funções Rademacher de ordem } 2^{(6-1)}=32, \\
T_{c l k}=5 \times 60=300 \text { segundos }\end{array}$ \\
\hline Rademacher-HAB & 4.960 & $\begin{array}{l}N=992, k=1, L=4 k^{2}+27=31, \\
\text { funções Rademacher de ordem } 2^{(6-1)}=32, \\
T_{c l k}=5 \times 60=300 \text { segundos }\end{array}$ \\
\hline Rademacher-TPB & 2.400 & $\begin{array}{l}N=480, k=3, L=k(k+2)=15 \\
\text { funções Rademacher de ordem } 2^{(6-1)}=32 \\
T_{c l k}=5 \times 60=300 \text { segundos }\end{array}$ \\
\hline Rademacher-PRB & 4.960 & $\begin{array}{l}N=992, x^{4}+x+1, m=5, L=2^{m}-1=31, \\
\text { funções Rademacher de ordem } 2^{(6-1)}=32, \\
T_{c l k}=5 \times 60=300 \text { segundos }\end{array}$ \\
\hline shift-QRB & 4.955 & $\begin{array}{l}k=248, N=4 k-1=991 \\
T_{c l k}=5 \times 60=300 \text { segundos }\end{array}$ \\
\hline shift-QRT & 4.955 & $\begin{array}{l}k=248, N=4 k-1=997 \\
T_{c l k}=5 \times 60=300 \text { segundos }\end{array}$ \\
\hline
\end{tabular}




\begin{tabular}{|c|c|c|}
\hline Sinais & $N_{s}$ & Características \\
\hline shift-HAB & 4.055 & $\begin{array}{l}k=14, N=4 k^{2}+27=811 \\
T_{c l k}=5 \times 60=300 \text { segundos }\end{array}$ \\
\hline shift-TPB & 4.495 & $\begin{array}{l}k=29, N=k(k+2)=899 \\
T_{c l k}=5 \times 60=300 \text { segundos }\end{array}$ \\
\hline shift-PRB & 5.115 & $\begin{array}{l}m=10, x^{10}+x^{3}+1, N=2^{1} 0-1=1023 \\
T_{c l k}=5 \times 60=300 \text { segundos }\end{array}$ \\
\hline shift-PRML & 3.120 & $\begin{array}{l}p=5, m=4, x^{3}+3 x+2, N=5^{4}-1=624 \\
T_{c l k}=5 \times 60=300 \text { segundos }\end{array}$ \\
\hline PRT & 4.800 & $\begin{array}{l}p=31, m=2, x^{2}+x+12, N=31^{2}-1=960 \\
T_{c l k}=5 \times 60=300 \text { segundos }\end{array}$ \\
\hline Gallev & 4.800 & $\begin{array}{l}p=31, m=2, x^{2}+x+12, N=31^{2}-1=960 \\
\text { sementes sinais Schroeder-SOH com } \\
\text { espectros intercalados, } \\
T_{c l k}=5 \times 60=300 \text { segundos }\end{array}$ \\
\hline PRMO & 2.080 & $\begin{array}{l}N=416, p=3, m=3, x^{3}+2 x+1, L=\frac{3^{3}-1}{2}=13, \\
\text { funções Rademacher de ordem } 2^{(6-1)}=32, \\
T_{c l k}=5 \times 60=300 \text { segundos }\end{array}$ \\
\hline MLNL & 5.115 & $\begin{array}{l}p=2, n=10, m=5, x^{10}+x^{3}+1, x^{5}+x^{2}+1 \\
N=p^{n}-1=2^{1} 0-1=1023 \\
\text { sementes sinais Schroeder-SOH com } \\
\text { espectros intercalados, } \\
T_{c l k}=5 \times 60=300 \text { segundos }\end{array}$ \\
\hline Schroeder-SOH & 5.115 & $n_{s}=65$ para cada um dos 6 sinais \\
\hline clipping-SOH & 5.115 & $\begin{array}{l}n_{s}=65 \text { para cada um dos } 6 \text { sinais, } \\
\text { ceifamentos de } 75 \%, 2.000 \text { iterações }\end{array}$ \\
\hline DIB & 5.115 & $\begin{array}{l}n_{s}=65 \text { para cada um dos } 6 \text { sinais } \\
1.000 \text { iterações }\end{array}$ \\
\hline DIT & 5.115 & $n_{s}=65$ para cada um dos 6 sinais, $q=4,1.000$ iterações \\
\hline MLMH & 5.115 & $\begin{array}{l}n_{s}=65 \text { para cada um dos } 6 \text { sinais, } \\
5 \text { níveis, } q=4,1.000 \text { iterações }\end{array}$ \\
\hline CBN & 5.115 & $\begin{array}{l}\text { filtro de primeira ordem com } \\
\tau=\{2010 ; 1950 ; 1170 ; 2370 ; 600 ; 2070\} \text { segundos }\end{array}$ \\
\hline GBN & 5.115 & $\begin{array}{l}p=\{0,7854 ; 0,7901 ; 0,7507 ; 0,8059 ; 0,6849 ; \ldots \\
\ldots 0,7963\}\end{array}$ \\
\hline
\end{tabular}


Tabela 10.11: Características dos sinais aplicados no conjunto de experimentos $\mathrm{C}$ de duração $T_{e}=N_{s} \times T$.

\begin{tabular}{|c|c|c|}
\hline Sinais & $N_{s}$ & Características \\
\hline Rademacher-QRB & 1.760 & $\begin{array}{l}N=352, k=3, L=4 k-1=11 \\
\text { funções Rademacher de ordem } 2^{(6-1)}=32, \\
T_{c l k}=5 \times 60=300 \text { segundos }\end{array}$ \\
\hline Rademacher-QRT & 1.760 & $\begin{array}{l}N=352, k=3, L=4 k-1=11 \\
\text { funções Rademacher de ordem } 2^{(6-1)}=32, \\
T_{c l k}=5 \times 60=300 \text { segundos }\end{array}$ \\
\hline Rademacher-HAB & 4.960 & $\begin{array}{l}N=992, k=1, L=4 k^{2}+27=31 \\
\text { funções Rademacher de ordem } 2^{(6-1)}=32, \\
T_{c l k}=5 \times 60=300 \text { segundos }\end{array}$ \\
\hline Rademacher-TPB & 2.400 & $\begin{array}{l}N=480, k=3, L=k(k+2)=15 \\
\text { funções Rademacher de ordem } 2^{(6-1)}=32 \\
T_{c l k}=5 \times 60=300 \text { segundos }\end{array}$ \\
\hline Rademacher-PRB & 2.400 & $\begin{array}{l}N=480, x^{4}+x+1, m=4, L=2^{m}-1=15 \\
\text { funções Rademacher de ordem } 2^{(6-1)}=32, \\
T_{c l k}=5 \times 60=300 \text { segundos }\end{array}$ \\
\hline shift-QRB & 1.795 & $\begin{array}{l}k=90, N=4 k-1=359 \\
T_{c l k}=5 \times 60=300 \text { segundos }\end{array}$ \\
\hline shift-QRT & 1.795 & $\begin{array}{l}k=90, N=4 k-1=359 \\
T_{c l k}=5 \times 60=300 \text { segundos }\end{array}$ \\
\hline shift-HAB & 1.415 & $\begin{array}{l}k=8, N=4 k^{2}+27=283 \\
T_{c l k}=5 \times 60=300 \text { segundos }\end{array}$ \\
\hline shift-TPB & 1.615 & $\begin{array}{l}k=17, N=k(k+2)=323 \\
T_{c l k}=5 \times 60=300 \text { segundos }\end{array}$ \\
\hline shift-PRB & 2.555 & $\begin{array}{l}m=9, x^{7}+x^{3}+1, N=2^{9}-1=511 \\
T_{c l k}=5 \times 60=300 \text { segundos }\end{array}$ \\
\hline shift-PRML & 1.710 & $\begin{array}{l}p=7, m=3, x^{3}+3 x+2, N=7^{3}-1=342 \\
T_{c l k}=5 \times 60=300 \text { segundos }\end{array}$ \\
\hline PRT & 4.800 & $\begin{array}{l}p=31, m=2, x^{2}+x+12, N=31^{2}-1=960, \\
T_{c l k}=5 \times 60=300 \text { segundos }\end{array}$ \\
\hline Gallev & 2.640 & $\begin{array}{l}p=23, m=2, x^{2}+x+7, N=23^{2}-1=528 \\
\text { sementes sinais Schroeder-SOH com } \\
\text { espectros intercalados, } \\
T_{c l k}=5 \times 60=300 \text { segundos }\end{array}$ \\
\hline
\end{tabular}




\begin{tabular}{|c|c|c|}
\hline Sinais & $N_{s}$ & Características \\
\hline PRMO & 2.080 & $\begin{array}{l}N=416, p=3, m=3, x^{3}+2 x+1, L=\frac{3^{3}-1}{2}=13, \\
\text { funções Rademacher de ordem } 2^{(6-1)}=32, \\
T_{c l k}=5 \times 60=300 \text { segundos }\end{array}$ \\
\hline MLNL & 3.120 & $\begin{array}{l}p=5, n=4, m=2, x^{4}+x^{2}+2 x+2, x^{2}+x+2 \\
N=p^{n}-1=5^{4}-1=624 \\
\text { sementes sinais Schroeder-SOH com } \\
\text { espectros intercalados, } \\
T_{c l k}=5 \times 60=300 \text { segundos }\end{array}$ \\
\hline Schroeder-SOH & 2.000 & $n_{s}=25$ para cada um dos 6 sinais \\
\hline clipping-SOH & 2.000 & $\begin{array}{l}n_{s}=25 \text { para cada um dos } 6 \text { sinais, } \\
\text { ceifamentos de } 90 \%\end{array}$ \\
\hline DIB & 2.000 & $n_{s}=25$ para cada um dos 6 sinais \\
\hline DIT & 2.000 & $n_{s}=25$ para cada um dos 6 sinais, $q=6$ \\
\hline MLMH & 2.000 & $\begin{array}{l}n_{s}=25 \text { para cada um dos } 6 \text { sinais, } \\
5 \text { níveis, } q=8\end{array}$ \\
\hline CBN & 2.000 & $\begin{array}{l}\text { filtro de primeira ordem com } \\
\tau=\{2010 ; 1950 ; 1170 ; 2370 ; 600 ; 2070\} \text { segundos }\end{array}$ \\
\hline GBN & 2.000 & $\begin{array}{l}p=\{0,7854 ; 0,7901 ; 0,7507 ; 0,8059 ; 0,6849 ; \ldots \\
\ldots 0,7963\}\end{array}$ \\
\hline
\end{tabular}

\subsubsection{Medidas de desempenho dos sinais}

As medidas de desempenho dos sinais de excitação da tabela 10.10, os quais são aplicados nos conjuntos de experimentos A e B, são apresentadas na tabela 10.12. Medidas equivalentes para os sinais da tabela 10.11, os quais são aplicados no conjunto de experimentos C, são apresentadas na tabela 10.13 .

Tabela 10.12: Medidas de desempenho dos sinais aplicados nos conjuntos de experimentos $\mathrm{A}$ e $\mathrm{B}$.

\begin{tabular}{llllllll}
\hline Sinais & $r$ & PIPS & PIPSE & EMINE & TF & CF & CISS \\
\hline & 1 & 100,00 & 73,41 & 97,77 & 0,55 & 1,00 & \\
& 2 & 100,00 & 77,20 & 17,88 & 16,29 & 1,00 & \\
Rademacher-QRB & 3 & 100,00 & 73,25 & 17,66 & 16,71 & 1,00 & \\
& 4 & 100,00 & 73,57 & 9,61 & 56,51 & 1,00 & 344,09 \\
& 5 & 100,00 & 71,71 & 6,42 & 126,55 & 1,00 & \\
& 6 & 100,00 & 71,49 & 4,48 & 259,66 & 1,00 & \\
\hline
\end{tabular}




\begin{tabular}{|c|c|c|c|c|c|c|c|}
\hline Sinais & $r$ & PIPS & PIPSE & EMINE & $\mathrm{TF}$ & $\mathrm{CF}$ & CISS \\
\hline \multirow{6}{*}{ Rademacher-QRT } & 1 & 98,37 & 72,26 & 97,87 & 0,56 & 1,02 & \multirow{6}{*}{352,38} \\
\hline & 2 & 98,37 & 75,99 & 98,01 & 0,56 & 1,02 & \\
\hline & 3 & 98,37 & 72,04 & 97,94 & 0,56 & 1,02 & \\
\hline & 4 & 98,37 & 72,36 & 53,00 & 1,92 & 1,02 & \\
\hline & 5 & 98,37 & 70,51 & 35,30 & 4,33 & 1,02 & \\
\hline & 6 & 98,37 & 70,30 & 24,60 & 8,91 & 1,02 & \\
\hline \multirow{6}{*}{ Rademacher-HAB } & 1 & 100,00 & 73,41 & 97,77 & 0,55 & 1,00 & \multirow{6}{*}{344,09} \\
\hline & 2 & 100,00 & 77,20 & 17,88 & 16,29 & 1,00 & \\
\hline & 3 & 100,00 & 73,25 & 17,66 & 16,71 & 1,00 & \\
\hline & 4 & 100,00 & 73,57 & 9,61 & 56,51 & 1,00 & \\
\hline & 5 & 100,00 & 71,71 & 6,42 & 126,55 & 1,00 & \\
\hline & 6 & 100,00 & 71,49 & 4,48 & 259,66 & 1,00 & \\
\hline \multirow{6}{*}{ Rademacher-TPB } & 1 & 100,00 & 71,46 & 97,38 & 0,55 & 1,00 & \multirow{6}{*}{344,97} \\
\hline & 2 & 100,00 & 79,52 & 25,70 & 7,87 & 1,00 & \\
\hline & 3 & 100,00 & 76,01 & 25,39 & 8,09 & 1,00 & \\
\hline & 4 & 100,00 & 68,87 & 13,81 & 27,36 & 1,00 & \\
\hline & 5 & 100,00 & 68,19 & 9,23 & 61,30 & 1,00 & \\
\hline & 6 & 100,00 & 75,22 & 6,45 & 125,81 & 1,00 & \\
\hline \multirow{6}{*}{ Rademacher-PRB } & 1 & 100,00 & 73,41 & 97,77 & 0,55 & 1,00 & \multirow{6}{*}{344,09} \\
\hline & 2 & 100,00 & 77,20 & 17,88 & 16,29 & 1,00 & \\
\hline & 3 & 100,00 & 73,25 & 17,66 & 16,71 & 1,00 & \\
\hline & 4 & 100,00 & 73,57 & 9,61 & 56,51 & 1,00 & \\
\hline & 5 & 100,00 & 71,71 & 6,42 & 126,55 & 1,00 & \\
\hline & 6 & 100,00 & 71,49 & 4,48 & 259,66 & 1,00 & \\
\hline \multirow{6}{*}{ shift-QRB } & 1 & 100,00 & 74,31 & 97,94 & 0,54 & 1,00 & \multirow{6}{*}{344,50} \\
\hline & 2 & 100,00 & 74,31 & 97,94 & 0,54 & 1,00 & \\
\hline & 3 & 100,00 & 74,31 & 97,94 & 0,54 & 1,00 & \\
\hline & 4 & 100,00 & 74,31 & 97,94 & 0,54 & 1,00 & \\
\hline & 5 & 100,00 & 74,31 & 97,94 & 0,54 & 1,00 & \\
\hline & 6 & 100,00 & 74,31 & 97,94 & 0,54 & 1,00 & \\
\hline \multirow{6}{*}{ shift-QRT } & 1 & 99,95 & 74,26 & 97,94 & 0,54 & 1,00 & \multirow{6}{*}{344,76} \\
\hline & 2 & 99,95 & 74,26 & 97,94 & 0,54 & 1,00 & \\
\hline & 3 & 99,95 & 74,26 & 97,94 & 0,54 & 1,00 & \\
\hline & 4 & 99,95 & 74,26 & 97,94 & 0,54 & 1,00 & \\
\hline & 5 & 99,95 & 74,26 & 97,94 & 0,54 & 1,00 & \\
\hline & 6 & 99,95 & 74,26 & 97,94 & 0,54 & 1,00 & \\
\hline
\end{tabular}




\begin{tabular}{|c|c|c|c|c|c|c|c|}
\hline Sinais & $r$ & PIPS & PIPSE & EMINE & $\mathrm{TF}$ & $\mathrm{CF}$ & CISS \\
\hline \multirow{6}{*}{ shift-HAB } & 1 & 100,00 & 74,39 & 97,94 & 0,54 & 1,00 & \multirow{6}{*}{344,46} \\
\hline & 2 & 100,00 & 74,39 & 97,94 & 0,54 & 1,00 & \\
\hline & 3 & 100,00 & 74,39 & 97,94 & 0,54 & 1,00 & \\
\hline & 4 & 100,00 & 74,39 & 97,94 & 0,54 & 1,00 & \\
\hline & 5 & 100,00 & 74,39 & 97,94 & 0,54 & 1,00 & \\
\hline & 6 & 100,00 & 74,39 & 97,94 & 0,54 & 1,00 & \\
\hline \multirow{6}{*}{ shift-TPB } & 1 & 100,00 & 74,35 & 97,94 & 0,54 & 1,00 & \multirow{6}{*}{344,48} \\
\hline & 2 & 100,00 & 74,35 & 97,94 & 0,54 & 1,00 & \\
\hline & 3 & 100,00 & 74,35 & 97,94 & 0,54 & 1,00 & \\
\hline & 4 & 100,00 & 74,35 & 97,94 & 0,54 & 1,00 & \\
\hline & 5 & 100,00 & 74,35 & 97,94 & 0,54 & 1,00 & \\
\hline & 6 & 100,00 & 74,35 & 97,94 & 0,54 & 1,00 & \\
\hline \multirow{6}{*}{ shift-PRB } & 1 & 100,00 & 74,33 & 97,94 & 0,54 & 1,00 & \multirow{6}{*}{344,51} \\
\hline & 2 & 100,00 & 74,33 & 97,94 & 0,54 & 1,00 & \\
\hline & 3 & 100,00 & 74,33 & 97,94 & 0,54 & 1,00 & \\
\hline & 4 & 100,00 & 74,33 & 97,94 & 0,54 & 1,00 & \\
\hline & 5 & 100,00 & 74,33 & 97,94 & 0,54 & 1,00 & \\
\hline & 6 & 100,00 & 74,33 & 97,94 & 0,54 & 1,00 & \\
\hline \multirow{6}{*}{ shift-PRML } & 1 & 70,77 & 52,73 & 97,94 & 1,09 & 1,41 & \multirow{6}{*}{519,66} \\
\hline & 2 & 70,77 & 52,73 & 97,94 & 1,09 & 1,41 & \\
\hline & 3 & 70,77 & 52,73 & 97,94 & 1,09 & 1,41 & \\
\hline & 4 & 70,77 & 52,73 & 97,94 & 1,09 & 1,41 & \\
\hline & 5 & 70,77 & 52,73 & 97,94 & 1,09 & 1,41 & \\
\hline & 6 & 70,77 & 52,73 & 97,94 & 1,09 & 1,41 & \\
\hline \multirow{6}{*}{ PRT } & 1 & 71,88 & 53,46 & 97,94 & 1,05 & 1,39 & \multirow{6}{*}{432,31} \\
\hline & 2 & 71,88 & 53,34 & 97,94 & 1,05 & 1,39 & \\
\hline & 3 & 88,03 & 64,86 & 97,94 & 0,70 & 1,14 & \\
\hline & 4 & 88,03 & 65,79 & 97,94 & 0,70 & 1,14 & \\
\hline & 5 & 80,36 & 58,61 & 97,94 & 0,84 & 1,24 & \\
\hline & 6 & 98,43 & 73,86 & 97,94 & 0,56 & 1,02 & \\
\hline \multirow{6}{*}{ Gallev } & 1 & 49,21 & 36,26 & 97,94 & 2,24 & 2,03 & \multirow{6}{*}{703,47} \\
\hline & 2 & 54,41 & 40,09 & 97,94 & 1,84 & 2,03 & \\
\hline & 3 & 49,21 & 36,26 & 97,94 & 2,24 & 2,03 & \\
\hline & 4 & 56,60 & 41,70 & 97,94 & 1,70 & 2,03 & \\
\hline & 5 & 49,21 & 36,78 & 97,94 & 2,24 & 2,03 & \\
\hline & 6 & 78,74 & 58,84 & 97,94 & 0,88 & 2,03 & \\
\hline
\end{tabular}




\begin{tabular}{|c|c|c|c|c|c|c|c|}
\hline Sinais & $r$ & PIPS & PIPSE & EMINE & $\mathrm{TF}$ & $\mathrm{CF}$ & CISS \\
\hline \multirow{6}{*}{ PRMO } & 1 & 83,21 & 60,76 & 90,55 & 0,92 & 1,20 & \multirow{6}{*}{437,74} \\
\hline & 2 & 83,21 & 62,09 & 98,03 & 0,78 & 1,20 & \\
\hline & 3 & 83,21 & 62,06 & 97,94 & 0,78 & 1,20 & \\
\hline & 4 & 83,21 & 62,51 & 53,00 & 2,68 & 1,20 & \\
\hline & 5 & 83,21 & 61,99 & 35,31 & 6,04 & 1,20 & \\
\hline & 6 & 83,21 & 62,08 & 24,60 & 12,44 & 1,20 & \\
\hline \multirow{6}{*}{ MLNL } & 1 & 52,47 & 38,59 & 97,94 & 1,97 & 2,03 & \multirow{6}{*}{703,22} \\
\hline & 2 & 53,04 & 39,01 & 97,94 & 1,93 & 2,03 & \\
\hline & 3 & 49,87 & 36,68 & 97,94 & 2,19 & 2,03 & \\
\hline & 4 & 51,44 & 37,83 & 97,94 & 2,05 & 2,03 & \\
\hline & 5 & 53,04 & 39,55 & 97,94 & 1,93 & 2,03 & \\
\hline & 6 & 63,02 & 46,99 & 97,94 & 1,37 & 2,03 & \\
\hline \multirow{6}{*}{ Schroeder-SOH } & 1 & 45,01 & 44,90 & 100,00 & 2,48 & 2,23 & \multirow{6}{*}{$\infty$} \\
\hline & 2 & 49,18 & 49,07 & 100,00 & 2,08 & 2,18 & \\
\hline & 3 & 44,47 & 44,37 & 100,00 & 2,54 & 2,25 & \\
\hline & 4 & 45,15 & 45,04 & 100,00 & 2,46 & 2,25 & \\
\hline & 5 & 47,87 & 47,31 & 100,00 & 2,19 & 2,09 & \\
\hline & 6 & 45,35 & 44,81 & 100,00 & 2,44 & 2,23 & \\
\hline \multirow{6}{*}{ clipping-SOH } & 1 & 31,83 & 31,76 & 100,00 & 4,96 & 3,15 & \multirow{6}{*}{$\infty$} \\
\hline & 2 & 44,16 & 44,06 & 100,00 & 2,58 & 2,37 & \\
\hline & 3 & 36,51 & 36,42 & 100,00 & 3,77 & 2,75 & \\
\hline & 4 & 36,12 & 36,04 & 100,00 & 3,85 & 2,87 & \\
\hline & 5 & 43,71 & 43,19 & 100,00 & 2,63 & 2,29 & \\
\hline & 6 & 38,62 & 38,17 & 100,00 & 3,37 & 2,69 & \\
\hline \multirow{6}{*}{ DIB } & 1 & 100,00 & 87,85 & 65,90 & 1,48 & 1,00 & \multirow{6}{*}{331,60} \\
\hline & 2 & 100,00 & 88,97 & 60,13 & 1,74 & 1,00 & \\
\hline & 3 & 100,00 & 87,17 & 64,52 & 1,57 & 1,00 & \\
\hline & 4 & 100,00 & 88,61 & 68,69 & 1,35 & 1,00 & \\
\hline & 5 & 100,00 & 87,61 & 59,32 & 1,81 & 1,00 & \\
\hline & 6 & 100,00 & 88,47 & 65,40 & 1,48 & 1,00 & \\
\hline \multirow{6}{*}{ DIT } & 1 & 72,06 & 67,07 & 83,03 & 1,61 & 1,39 & \multirow{6}{*}{556,30} \\
\hline & 2 & 83,72 & 78,95 & 71,93 & 1,55 & 1,19 & \\
\hline & 3 & 74,79 & 70,22 & 80,66 & 1,56 & 1,34 & \\
\hline & 4 & 74,88 & 70,31 & 81,92 & 1,51 & 1,34 & \\
\hline & 5 & 77,88 & 72,28 & 76,92 & 1,58 & 1,28 & \\
\hline & 6 & 75,59 & 69,86 & 80,87 & 1,52 & 1,32 & \\
\hline
\end{tabular}




\begin{tabular}{|c|c|c|c|c|c|c|c|}
\hline Sinais & $r$ & PIPS & PIPSE & EMINE & $\mathrm{TF}$ & $\mathrm{CF}$ & CISS \\
\hline \multirow{6}{*}{ MLMH } & 1 & 58,74 & 56,22 & 85,40 & 2,17 & 1,70 & \multirow{6}{*}{756,21} \\
\hline & 2 & 74,27 & 71,75 & 78,62 & 1,57 & 1,35 & \\
\hline & 3 & 56,71 & 53,78 & 85,14 & 2,38 & 1,76 & \\
\hline & 4 & 59,27 & 56,58 & 86,66 & 2,08 & 1,69 & \\
\hline & 5 & 58,10 & 55,08 & 81,02 & 2,47 & 1,72 & \\
\hline & 6 & 59,88 & 56,89 & 86,77 & 2,01 & 1,67 & \\
\hline \multirow{6}{*}{$\mathrm{BN}$} & 1 & 100,00 & 74,58 & 15,85 & 21,06 & 1,00 & \multirow{6}{*}{277,27} \\
\hline & 2 & 100,00 & 81,49 & 8,89 & 66,04 & 1,00 & \\
\hline & 3 & 100,00 & 78,35 & 0,00 & $\infty$ & 1,00 & \\
\hline & 4 & 100,00 & 79,06 & 7,22 & 101,08 & 1,00 & \\
\hline & 5 & 100,00 & 78,03 & 5,47 & 181,77 & 1,00 & \\
\hline & 6 & 100,00 & 80,24 & 10,39 & 48,74 & 1,00 & \\
\hline \multirow{6}{*}{ GBN } & 1 & 100,00 & 62,18 & 2,27 & 1070,33 & 1,00 & \multirow{6}{*}{93,15} \\
\hline & 2 & 100,00 & 61,31 & 2,30 & 1038,99 & 1,00 & \\
\hline & 3 & 100,00 & 57,59 & 0,85 & 7754,88 & 1,00 & \\
\hline & 4 & 100,00 & 64,55 & 1,58 & 2182,59 & 1,00 & \\
\hline & 5 & 100,00 & 51,42 & 1,87 & 1654,05 & 1,00 & \\
\hline & 6 & 100,00 & 64,90 & 0,81 & 8276,73 & 1,00 & \\
\hline
\end{tabular}

Tabela 10.13: Medidas de desempenho dos sinais aplicados no conjunto de experimentos $\mathrm{C}$.

\begin{tabular}{llllllll}
\hline Sinais & $r$ & PIPS & PIPSE & EMINE & TF & CF & CISS \\
\hline & 1 & 100,00 & 72,46 & 96,98 & 0,56 & 1,00 & \\
& 2 & 100,00 & 83,12 & 30,00 & 5,77 & 1,00 & \\
Rademacher-QRB & 3 & 100,00 & 74,14 & 29,65 & 5,93 & 1,00 & \multirow{2}{*}{ (10,24 } \\
& 4 & 100,00 & 74,08 & 16,13 & 20,08 & 1,00 & \\
& 5 & 100,00 & 72,67 & 10,78 & 44,99 & 1,00 & \\
& 6 & 100,00 & 72,50 & 7,53 & 92,34 & 1,00 & \\
Rademacher-QRT & 1 & 95,35 & 69,37 & 97,78 & 0,60 & 1,05 & \\
& 2 & 95,35 & 79,58 & 98,16 & 0,59 & 1,05 & \\
& 4 & 95,35 & 70,55 & 97,94 & 0,60 & 1,05 & \multirow{2}{*}{372,88} \\
& 5 & 95,35 & 69,06 & 35,30 & 4,62 & 1,05 & \\
& 6 & 95,35 & 68,88 & 24,60 & 9,51 & 1,05 & \\
\hline
\end{tabular}




\begin{tabular}{|c|c|c|c|c|c|c|c|}
\hline Sinais & $r$ & PIPS & PIPSE & EMINE & $\mathrm{TF}$ & $\mathrm{CF}$ & CISS \\
\hline \multirow{6}{*}{ Rademacher-HAB } & 1 & 100,00 & 49,48 & 41,19 & 3,13 & 1,00 & \multirow{6}{*}{386,23} \\
\hline & 2 & 100,00 & 90,30 & 45,11 & 2,52 & 1,00 & \\
\hline & 3 & 100,00 & 81,75 & 44,79 & 2,60 & 1,00 & \\
\hline & 4 & 100,00 & 60,58 & 24,29 & 8,92 & 1,00 & \\
\hline & 5 & 100,00 & 59,16 & 16,21 & 20,13 & 1,00 & \\
\hline & 6 & 100,00 & 58,20 & 11,31 & 41,47 & 1,00 & \\
\hline \multirow{6}{*}{ Rademacher-TPB } & 1 & 100,00 & 71,46 & 97,38 & 0,55 & 1,00 & \multirow{6}{*}{344,97} \\
\hline & 2 & 100,00 & 79,52 & 25,70 & 7,87 & 1,00 & \\
\hline & 3 & 100,00 & 76,01 & 25,39 & 8,09 & 1,00 & \\
\hline & 4 & 100,00 & 68,87 & 13,81 & 27,36 & 1,00 & \\
\hline & 5 & 100,00 & 68,19 & 9,23 & 61,30 & 1,00 & \\
\hline & 6 & 100,00 & 75,22 & 6,45 & 125,81 & 1,00 & \\
\hline \multirow{6}{*}{ Rademacher-PRB } & 1 & 100,00 & 71,46 & 97,38 & 0,55 & 1,00 & \multirow{6}{*}{344,97} \\
\hline & 2 & 100,00 & 79,52 & 25,70 & 7,87 & 1,00 & \\
\hline & 3 & 100,00 & 76,01 & 25,39 & 8,09 & 1,00 & \\
\hline & 4 & 100,00 & 68,87 & 13,81 & 27,36 & 1,00 & \\
\hline & 5 & 100,00 & 68,19 & 9,23 & 61,30 & 1,00 & \\
\hline & 6 & 100,00 & 75,22 & 6,45 & 125,81 & 1,00 & \\
\hline \multirow{6}{*}{ shift-QRB } & 1 & 100,00 & 74,71 & 97,94 & 0,54 & 1,00 & \multirow{6}{*}{344,16} \\
\hline & 2 & 100,00 & 74,71 & 97,94 & 0,54 & 1,00 & \\
\hline & 3 & 100,00 & 74,71 & 97,94 & 0,54 & 1,00 & \\
\hline & 4 & 100,00 & 74,71 & 97,94 & 0,54 & 1,00 & \\
\hline & 5 & 100,00 & 74,71 & 97,94 & 0,54 & 1,00 & \\
\hline & 6 & 100,00 & 74,71 & 97,94 & 0,54 & 1,00 & \\
\hline \multirow{6}{*}{ shift-QRT } & 1 & 99,86 & 74,60 & 97,94 & 0,55 & 1,00 & \multirow{6}{*}{344,87} \\
\hline & 2 & 99,86 & 74,60 & 97,94 & 0,55 & 1,00 & \\
\hline & 3 & 99,86 & 74,60 & 97,94 & 0,55 & 1,00 & \\
\hline & 4 & 99,86 & 74,60 & 97,94 & 0,55 & 1,00 & \\
\hline & 5 & 99,86 & 74,60 & 97,94 & 0,55 & 1,00 & \\
\hline & 6 & 99,86 & 74,60 & 97,94 & 0,55 & 1,00 & \\
\hline \multirow{6}{*}{ shift-HAB } & 1 & 100,00 & 75,01 & 97,94 & 0,54 & 1,00 & \multirow{6}{*}{344,03} \\
\hline & 2 & 100,00 & 75,01 & 97,94 & 0,54 & 1,00 & \\
\hline & 3 & 100,00 & 75,01 & 97,94 & 0,54 & 1,00 & \\
\hline & 4 & 100,00 & 75,01 & 97,94 & 0,54 & 1,00 & \\
\hline & 5 & 100,00 & 75,01 & 97,94 & 0,54 & 1,00 & \\
\hline & 6 & 100,00 & 75,01 & 97,94 & 0,54 & 1,00 & \\
\hline
\end{tabular}




\begin{tabular}{|c|c|c|c|c|c|c|c|}
\hline Sinais & $r$ & PIPS & PIPSE & EMINE & $\mathrm{TF}$ & $\mathrm{CF}$ & CISS \\
\hline \multirow{6}{*}{ shift-TPB } & 1 & 100,00 & 74,87 & 97,94 & 0,54 & 1,00 & \multirow{6}{*}{344,11} \\
\hline & 2 & 100,00 & 74,87 & 97,94 & 0,54 & 1,00 & \\
\hline & 3 & 100,00 & 74,87 & 97,94 & 0,54 & 1,00 & \\
\hline & 4 & 100,00 & 74,87 & 97,94 & 0,54 & 1,00 & \\
\hline & 5 & 100,00 & 74,87 & 97,94 & 0,54 & 1,00 & \\
\hline & 6 & 100,00 & 74,87 & 97,94 & 0,54 & 1,00 & \\
\hline \multirow{6}{*}{ shift-PRB } & 1 & 100,00 & 74,64 & 97,94 & 0,54 & 1,00 & \multirow{6}{*}{344,32} \\
\hline & 2 & 100,00 & 74,64 & 97,94 & 0,54 & 1,00 & \\
\hline & 3 & 100,00 & 74,64 & 97,94 & 0,54 & 1,00 & \\
\hline & 4 & 100,00 & 74,64 & 97,94 & 0,54 & 1,00 & \\
\hline & 5 & 100,00 & 74,64 & 97,94 & 0,54 & 1,00 & \\
\hline & 6 & 100,00 & 74,64 & 97,94 & 0,54 & 1,00 & \\
\hline \multirow{6}{*}{ shift-PRML } & 1 & 80,30 & 60,32 & 97,94 & 0,84 & 1,25 & \multirow{6}{*}{455,75} \\
\hline & 2 & 80,30 & 60,32 & 97,94 & 0,84 & 1,25 & \\
\hline & 3 & 80,30 & 60,32 & 97,94 & 0,84 & 1,25 & \\
\hline & 4 & 80,30 & 60,32 & 97,94 & 0,84 & 1,25 & \\
\hline & 5 & 80,30 & 60,32 & 97,94 & 0,84 & 1,25 & \\
\hline & 6 & 80,30 & 60,32 & 97,94 & 0,84 & 1,25 & \\
\hline \multirow{6}{*}{ PRT } & 1 & 71,88 & 53,46 & 97,94 & 1,05 & 1,39 & \multirow{6}{*}{432,31} \\
\hline & 2 & 71,88 & 53,34 & 97,94 & 1,05 & 1,39 & \\
\hline & 3 & 88,03 & 64,86 & 97,94 & 0,70 & 1,14 & \\
\hline & 4 & 88,03 & 65,79 & 97,94 & 0,70 & 1,14 & \\
\hline & 5 & 80,36 & 58,61 & 97,94 & 0,84 & 1,24 & \\
\hline & 6 & 98,43 & 73,86 & 97,94 & 0,56 & 1,02 & \\
\hline \multirow{6}{*}{ Gallev } & 1 & 69,22 & 49,99 & 97,94 & 1,13 & 1,44 & \multirow{6}{*}{530,84} \\
\hline & 2 & 70,65 & 51,02 & 97,94 & 1,09 & 1,44 & \\
\hline & 3 & 69,22 & 49,99 & 97,94 & 1,13 & 1,44 & \\
\hline & 4 & 70,65 & 51,02 & 97,94 & 1,09 & 1,44 & \\
\hline & 5 & 69,22 & 49,98 & 97,94 & 1,13 & 1,44 & \\
\hline & 6 & 70,65 & 53,01 & 97,94 & 1,09 & 1,44 & \\
\hline \multirow{6}{*}{ PRMO } & 1 & 83,21 & 60,76 & 90,55 & 0,92 & 1,20 & \multirow{6}{*}{437,74} \\
\hline & 2 & 83,21 & 62,09 & 98,03 & 0,78 & 1,20 & \\
\hline & 3 & 83,21 & 62,06 & 97,94 & 0,78 & 1,20 & \\
\hline & 4 & 83,21 & 62,51 & 53,00 & 2,68 & 1,20 & \\
\hline & 5 & 83,21 & 61,99 & 35,31 & 6,04 & 1,20 & \\
\hline & 6 & 83,21 & 62,08 & 24,60 & 12,44 & 1,20 & \\
\hline
\end{tabular}




\begin{tabular}{|c|c|c|c|c|c|c|c|}
\hline Sinais & $r$ & PIPS & PIPSE & EMINE & $\mathrm{TF}$ & $\mathrm{CF}$ & CISS \\
\hline \multirow{6}{*}{ MLNL } & 1 & 49,03 & 36,83 & 97,94 & 2,26 & 2,04 & \multirow{6}{*}{685,49} \\
\hline & 2 & 58,26 & 43,23 & 97,94 & 1,60 & 2,04 & \\
\hline & 3 & 49,03 & 36,38 & 97,94 & 2,26 & 2,04 & \\
\hline & 4 & 65,37 & 48,51 & 97,94 & 1,27 & 2,04 & \\
\hline & 5 & 49,03 & 36,38 & 97,94 & 2,26 & 2,04 & \\
\hline & 6 & 80,06 & 59,51 & 69,25 & 1,70 & 1,67 & \\
\hline \multirow{6}{*}{ Schroeder-SOH } & 1 & 43,06 & 27,84 & 100,00 & 2,76 & 2,32 & \multirow{6}{*}{$\infty$} \\
\hline & 2 & 42,69 & 27,60 & 100,00 & 2,81 & 2,35 & \\
\hline & 3 & 42,64 & 26,91 & 100,00 & 2,82 & 2,35 & \\
\hline & 4 & 44,21 & 28,59 & 100,00 & 2,62 & 2,29 & \\
\hline & 5 & 42,66 & 27,59 & 100,00 & 2,82 & 2,34 & \\
\hline & 6 & 45,05 & 29,13 & 100,00 & 2,53 & 2,32 & \\
\hline \multirow{6}{*}{ clipping-SOH } & 1 & 39,46 & 25,51 & 100,00 & 3,29 & 2,53 & \multirow{6}{*}{$\infty$} \\
\hline & 2 & 40,50 & 26,18 & 100,00 & 3,12 & 2,49 & \\
\hline & 3 & 43,41 & 27,39 & 100,00 & 2,72 & 2,30 & \\
\hline & 4 & 39,65 & 25,64 & 100,00 & 3,26 & 2,53 & \\
\hline & 5 & 37,82 & 24,45 & 100,00 & 3,58 & 2,64 & \\
\hline & 6 & 45,08 & 29,15 & 100,00 & 2,52 & 2,28 & \\
\hline \multirow{6}{*}{ DIB } & 1 & 100,00 & 68,20 & 17,96 & 26,18 & 1,00 & \multirow{6}{*}{339,40} \\
\hline & 2 & 100,00 & 66,87 & 20,82 & 19,84 & 1,00 & \\
\hline & 3 & 100,00 & 67,03 & 21,34 & 18,69 & 1,00 & \\
\hline & 4 & 100,00 & 67,11 & 23,09 & 16,47 & 1,00 & \\
\hline & 5 & 100,00 & 66,99 & 23,45 & 16,07 & 1,00 & \\
\hline & 6 & 100,00 & 50,36 & 17,33 & 43,54 & 1,00 & \\
\hline \multirow{6}{*}{ DIT } & 1 & 73,35 & 55,24 & 28,52 & 16,38 & 1,36 & \multirow{6}{*}{575,84} \\
\hline & 2 & 70,64 & 53,88 & 30,02 & 16,04 & 1,42 & \\
\hline & 3 & 81,98 & 52,57 & 20,74 & 31,87 & 1,22 & \\
\hline & 4 & 71,76 & 53,69 & 25,31 & 22,25 & 1,39 & \\
\hline & 5 & 72,39 & 54,13 & 25,31 & 21,89 & 1,38 & \\
\hline & 6 & 71,90 & 40,24 & 30,86 & 23,18 & 1,39 & \\
\hline \multirow{6}{*}{ MLMH } & 1 & 76,84 & 58,16 & 29,04 & 13,98 & 1,30 & \multirow{6}{*}{624,85} \\
\hline & 2 & 76,06 & 58,04 & 28,27 & 15,22 & 1,31 & \\
\hline & 3 & 84,73 & 54,27 & 25,70 & 20,19 & 1,18 & \\
\hline & 4 & 75,60 & 57,31 & 30,37 & 13,49 & 1,32 & \\
\hline & 5 & 77,33 & 57,82 & 26,59 & 17,00 & 1,29 & \\
\hline & 6 & 75,80 & 41,52 & 28,94 & 23,18 & 1,32 & \\
\hline
\end{tabular}




\begin{tabular}{llllllll}
\hline Sinais & $r$ & PIPS & PIPSE & EMINE & TF & CF & CISS \\
\hline \multirow{4}{*}{ BN } & 1 & 100,00 & 84,47 & 19,38 & 13,94 & 1,00 & \\
& 2 & 100,00 & 81,41 & 10,87 & 44,51 & 1,00 & \\
& 3 & 100,00 & 81,74 & 1,11 & 4314,83 & 1,00 & \\
& 4 & 100,00 & 75,74 & 4,96 & 213,75 & 1,00 & 301,17 \\
& 5 & 100,00 & 77,63 & 5,56 & 176,36 & 1,00 & \\
& 6 & 100,00 & 81,70 & 14,40 & 25,14 & 1,00 & \\
& 1 & 100,00 & 63,37 & 1,92 & 1492,67 & 1,00 & \\
& 2 & 100,00 & 59,97 & 1,39 & 2821,27 & 1,00 & \\
& 3 & 100,00 & 57,66 & 7,15 & 109,01 & 1,00 & \multirow{2}{*}{108,25} \\
& 4 & 100,00 & 63,22 & 2,35 & 979,03 & 1,00 & \\
& 5 & 100,00 & 50,82 & 2,61 & 848,29 & 1,00 & \\
& 6 & 100,00 & 64,00 & 1,21 & 3740,96 & 1,00 & \\
\hline
\end{tabular}

Para cálculo do PIPSE dos sinais aplicados à entrada $u_{r}$, foram consideradas as faixas de frequências de interesse $B W_{r}$ definidas por $\omega_{L, r}$ e $\omega_{H, r}$. No cálculo dos índices EMINE e TF, considerou-se:

- Para sinais CBN, os espectros especificados são as respostas em frequência dos filtros de primeira ordem utilizados na construção dos sinais CBN, ou seja, com constantes de tempo dadas por $\tau_{\min , r}$ (tabela 10.7).

- Para sinais GBN, os espectros especificados são calculados a partir de (5.15) e as probabilidades de não chaveamento são aquelas utilizadas nas suas construções (tabela 10.9).

- Para sinais de espectro fixo, os espectros especificados são intercalados (zippered spectrum) com harmônicas não nulas de magnitudes obtidas do espectro do segurador de ordem zero (ZOH) (D.4) com $T_{c l k}=5$ minutos.

- Para sinais $\mathrm{SOH}$, os espectros especificados consideram as harmônicas utilizadas na construção dos sinais, porém, com magnitudes constantes.

Os CISS mostrados nas tabelas 10.12 e 10.13 foram calculados conforme (4.25) com $d_{r}=\left\lceil\frac{\tau_{\max , r}}{T} 70 \%\right\rceil$.

Observa-se que os sinais shift-QRB, shift-HAB, shift-TPB e shift-PRB apresentam EMINE menores que $100 \%$. As sequências QRB, HAB, TPB e PRB possuem comprimentos ímpares e são binárias. Portanto, são sequências não balanceadas (seção 
5.3), o que resulta em magnitude não nula para a frequência $\omega=0$. Como no espectro especificado a frequência nula possui magnitude nula, essa discrepância resulta em $E M I N E<100 \%$. Essa característica não é observada nos sinais shift-QRT, os quais também possuem comprimentos ímpares, porém, são balanceados. Em sequências QRT, as ocorrências de elementos positivos e negativos são iguais e há um elemento nulo (seção 5.3.2).

A modulação por funções de Rademacher mantém a característica de magnitude não nula para a frequência $\omega=0$ para os sinais derivados de sequências $\mathrm{QRB}, \mathrm{HAB}$, TPB e PRB. Assim, os sinais Rademacher-QRB, Rademacher-HAB, Rademacher-TPB e Rademacher-PRB também apresentam EMINE menores que 100\%. Adicionalmente, a modulação de sequências por funções de Rademacher não garante que a característica de magnitude das harmônicas não nulas seja mantida (seção 5.3.7). Por esse motivo, sinais PRMO, os quais também utilizam modulação por funções de Rademacher, também podem apresentar EMINE reduzidos.

Sinais Schroeder-SOH e clipping-SOH apresentam EMINE $=100 \%$, pois o método de geração dos sinais (seção 5.2) garante que suas harmônicas são examente iguais às harmônicas especificadas. Por outro lado, o PIPS e PIPSE são reduzidos (e CF elevados). O espectro dos sinais são intercalados e esparsos. Para se obter 6 sinais com espectros intercalados, há uma harmônica não nula para cinco harmônicas nulas no espectro de cada sinal. Essa característica de espectro esparso, conforme discutido na seção 5.2.1.1, não permite uma boa otimização das fases das harmônicas pelo método de Schroeder. Assim, os valores de PIPS e PIPSE obtidos com os sinais SchroederSOH são reduzidos (e CF elevados). A otimização das fases com o algoritmo clipping também não foi efetiva nos sinais dos experimentos (A, B e C), resultando em sinais clipping-SOH com valores reduzidos de PIPS e PIPSE.

Os demais sinais SOH (DIB, DIT e MLMH) apresentam EMINE reduzidos e PIPS (e PIPSE) mais elevados que os sinais Schroeder-SOH e clipping-SOH. As fases das harmônicas desses sinais são ajustadas por algoritmo de otimização com o objetivo de maximizar o PIPS (ou PIPSE), permitindo EMINE menores que 100\%.

Os sinais binários apresentam PIPS $=100 \%$ e PIPSE elevado. Os sinais ternários e multinível (espectro fixo e SOH) apresentam PIPS menores que 100\%, porém, elevados. Os sinais híbridos Gallev e MLNL, os quais foram gerados a partir de sinais Schroeder-SOH, resultaram em PIPS reduzidos, porém, mais elevados que os PIPS obtidos com os sinais Schroeder-SOH e clipping-SOH. Os valores de EMINE obtidos com os sinais Gallev e MLNL também foram elevados.

Como os sinais CBN e GBN são aleatórios, seus espectros também são aleatórios, 
o que resulta em EMINE reduzidos e TF elevados. Os PIPSE também ficaram reduzidos, mostrando que a filtragem utilizada na geração dos sinais $\mathrm{CBN}$ e as probabilidades de não chaveamento calculadas para os sinais GBN não foram suficientes para concentrar um parte significativa da potência dos sinais na faixa de interesse.

Os CISS calculados para o sinais utilizados nos experimentos são da mesma ordem de grandeza, exceto para os sinais Schroeder-SOH e clipping-SOH onde CIS S $\rightarrow \infty$, o que sugere que as matrizes de correlações (4.25) para esses sinais são mal condicionadas (ou singulares) nesta condição de $d_{r}$. O CISS para os sinais Gallev, MLNL e DIT assumem valores relativamente superiores ao CISS para os demais sinais. Conforme discutido na seção 4.7, CISS mais elevado sugere pior desempenho do estimador de parâmetros do modelo, ou seja, maior variância dos parâmetros estimados. Os menores valores de CISS são obtidos com os sinais GBN. As figuras 10.4 e 10.5 apresentam valores de CISS calculados com $d_{r}=\left\lceil\frac{\tau_{\max , r}}{T} \frac{k}{100}\right\rceil$, com $k=0$ a 100, para sinais aplicados nos experimentos A, B e C. Observa-se que para os sinais Schroeder-SOH e clipping-SOH, tem-se $C I S S \rightarrow \infty$ para $d_{r}=\left\lceil\frac{\tau_{\max , r}}{T} 0,1\right]$. Essa característica sugere que o desempenho do estimador de uma estrutura FIR é comprometido na identificação de sistemas em meio a ruído branco, mesmo com constantes de tempo (ou tempos de acomodação) reduzidas (2.34). Assim, os sinais Schroeder-SOH e clipping-SOH que foram parametrizados não são bons candidatos a serem utilizados para obter dados informativos para a identificação.

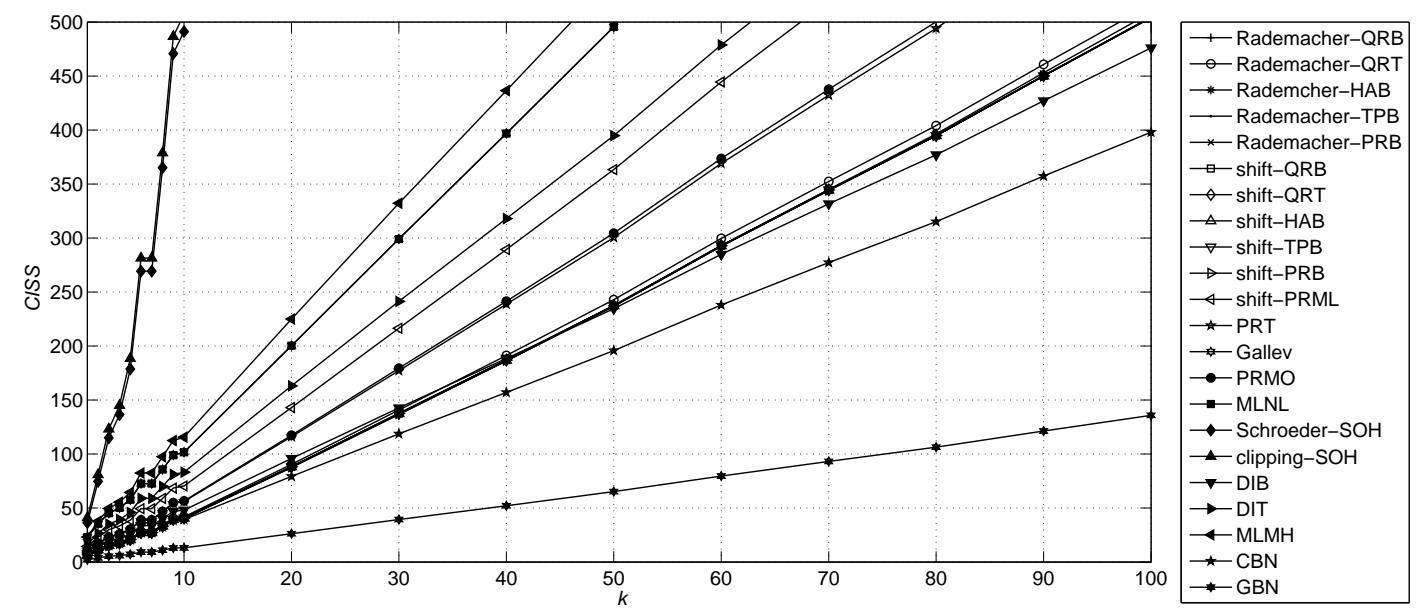

Figura 10.4: Índice CISS calculado com $d_{r}=\left[\frac{\tau_{\max , r}}{T} \frac{k}{100}\right\rceil$ para os sinais de excitação dos conjuntos de experimentos A e B. 


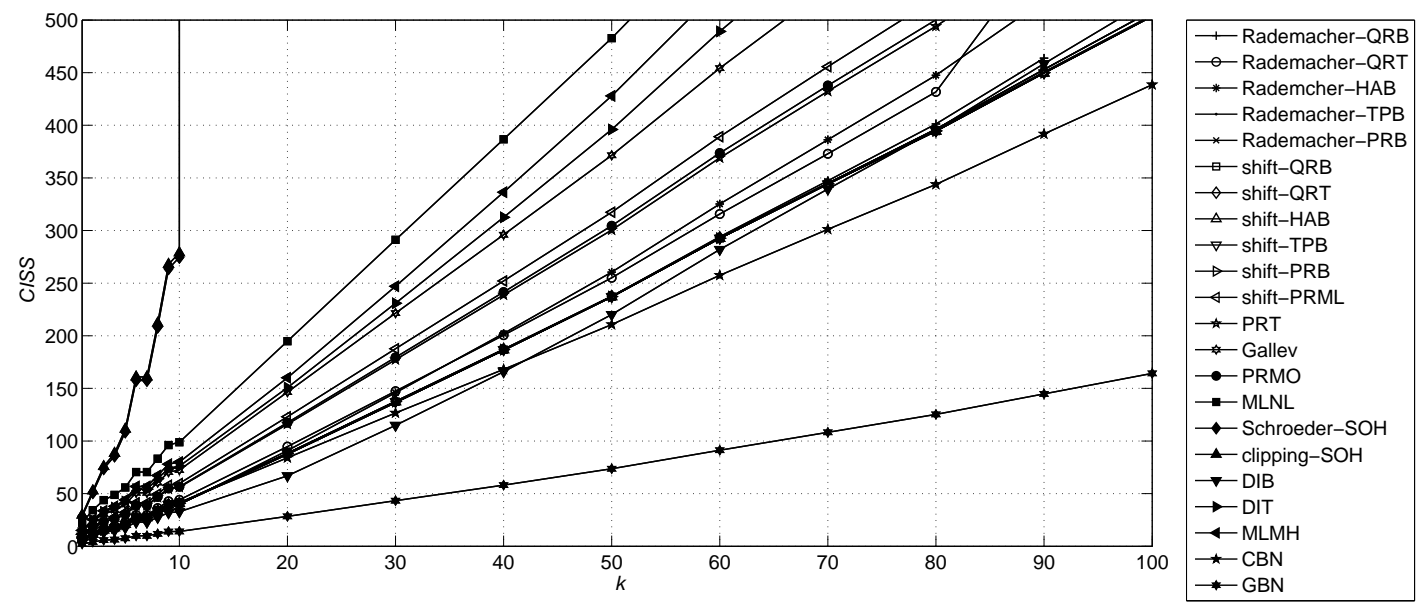

Figura 10.5: Índice CISS calculado com $d_{r}=\left\lceil\frac{\tau_{\max , r}}{T} \frac{k}{100}\right\rceil$ para os sinais de excitação do conjunto de experimentos $\mathrm{C}$.

\subsection{Método de validação}

Para a validação dos modelos são aplicados os sinais GBN e onda quadrada na planta e nos modelos. As respostas dos modelos e da planta são comparadas por meio da medida de ajuste $(F I T)$ conforme (8.26). Os resultados são apresentados em termos da média $\left(\overline{F I T}_{p}\right)$ e desvio-padrão $\left(\sigma_{F I T, p}\right)$ de $F I T_{p}$ das iterações das simulações de Monte-Carlo, conforme (8.27) e (8.28), respectivamente.

As características dos sinais de validação utilizados são:

1. Sinais GBN de comprimento $N_{s}=430$ aplicados nas 6 entradas da planta, o que equivale a um período de 430 minutos. As amplitudes e probabilidades de não chaveamento dos sinais GBN escolhidas são as mesmas adotadas para os experimentos de identificação, as quais foram discutidas em seção anterior (tabela 10.9). A figura 10.6 apresenta os sinais GBN utilizados para validação dos modelos. Com esses sinais de validação, objetiva-se testar os modelos ajustados em toda faixa de frequências de interesse da planta.

2. Ondas quadradas aplicadas nas 6 entradas da planta da mesma forma que as excitações em degrau da figura 10.3. A validação com sinais do tipo onda quadrada tem como objetivo testar os modelos ajustados preferencialmente nas frequências baixas.

Assim, com esses sinais de validação, tanto as características de resposta em frequências baixas como em frequências altas dos modelos ajustados são reveladas. 

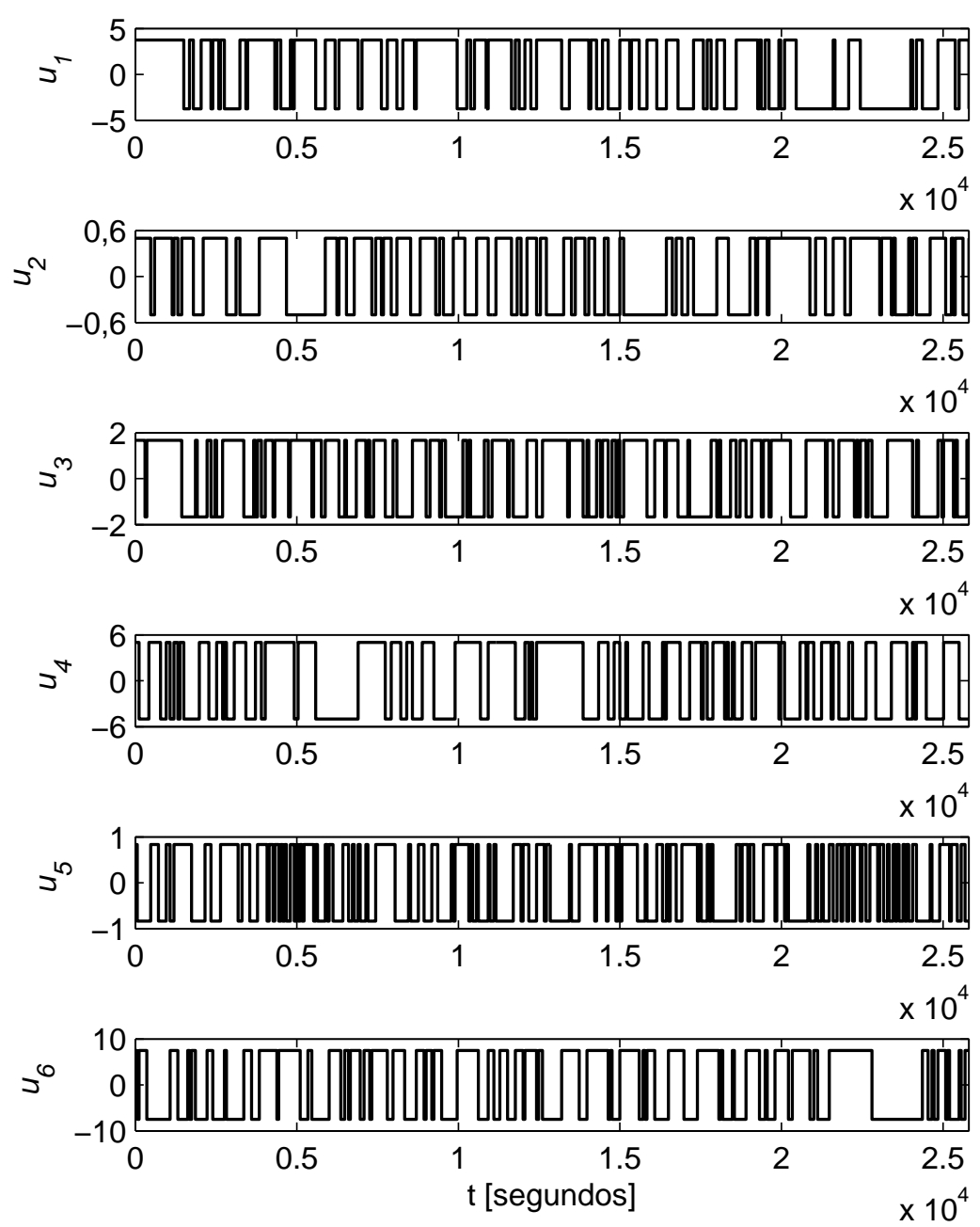

Figura 10.6: Sinais GBN utilizados na validação dos modelos.

\subsection{Resultados}

A figura 10.7 apresenta a resposta da planta às excitações em degrau (figura 10.3). Observa-se que as entradas $u_{2}, u_{3}, u_{5}$ e $u_{6}$ são representativas em todas as 7 saídas da planta, ou seja, há significativa interação dessas entradas nas saídas da planta. As perturbações adicionadas às saídas da planta são apresentadas na figura 10.8.

Com referência aos desempenhos dos sinais de excitação, estruturas ARX, com $n_{a}=4, n_{b}=4$ e $n_{k}$ da tabela 10.5 , foram ajustadas a partir de dados de experimentos com excitação em degrau nos cenários 1 e 2 de variâncias de ruídos de medição e de perturbações não medidas. Assim como os demais experimentos, foram realizadas 20 iterações (Monte-Carlo) desse experimento. Os resultados em termos de $\overline{F I T}$ e $\sigma_{F I T}$ são apresentados na tabela 10.14 para validação com sinais GBN e sinais do tipo onda quadrada.

Para exemplificar a resposta da planta a sinais de excitação, a figura 10.9 apresenta a resposta da planta a excitações shift-QRB do conjunto de testes C. Para todas as 

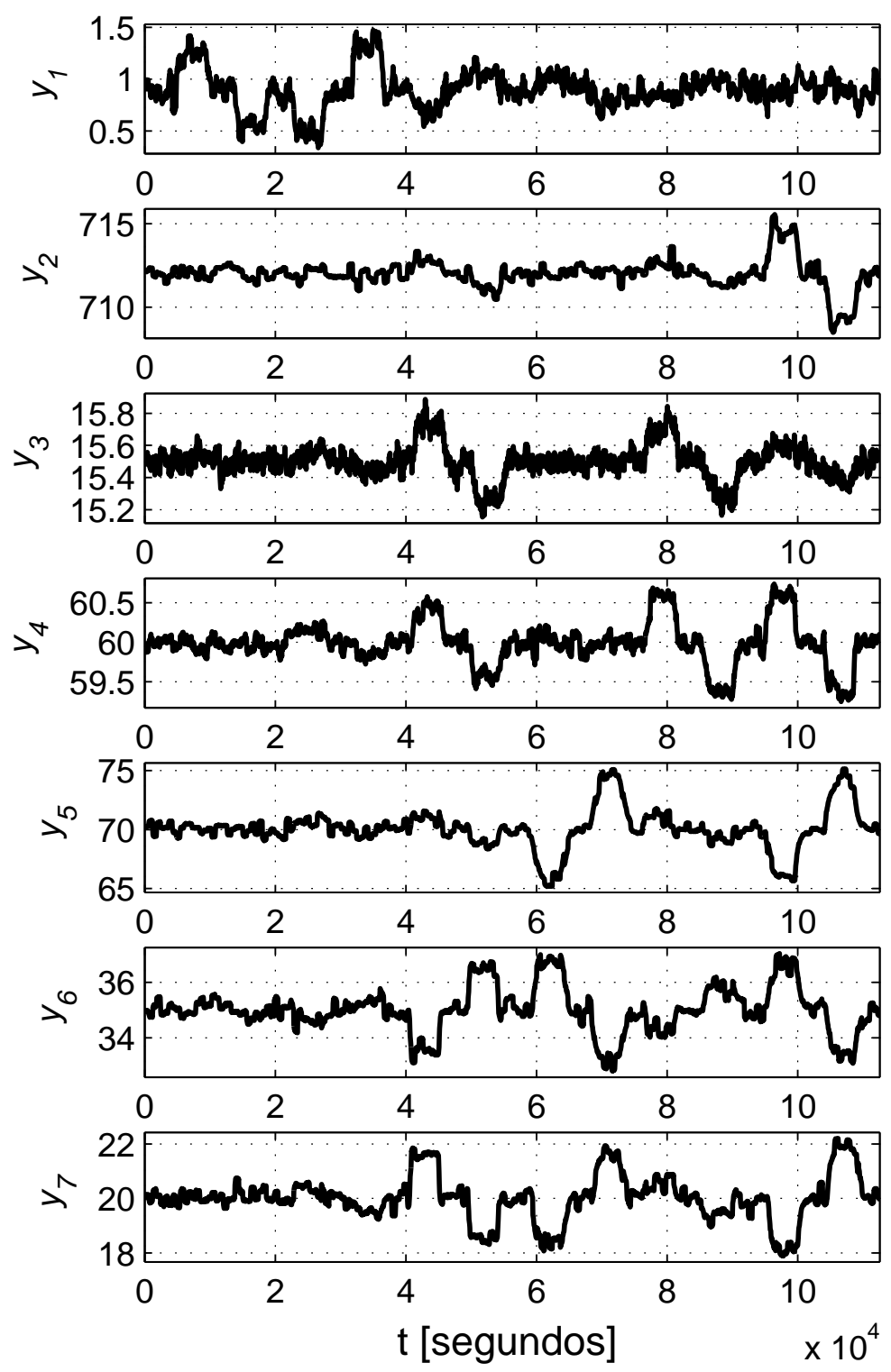

Figura 10.7: Respostas da planta FCC a excitações em degrau.

Tabela 10.14: $\overline{F I T}$ e $\sigma_{F I T}$ dos modelos ARX ajustados a partir de dados de experimentos com excitações em degrau e validação com sinais GBN e sinais do tipo onda quadrada.

\begin{tabular}{ccccccccc}
\hline & \multicolumn{3}{c}{ Validação com sinais GBN } & \multicolumn{3}{c}{ Validação com ondas quadradas } \\
Senánio 1 & \multicolumn{2}{c}{ Cenário 2 } & \multicolumn{2}{c}{ Cenário 1 } & \multicolumn{2}{c}{ Cenário 2 } \\
\cline { 2 - 8 } & $\overline{F I T}$ & $\sigma_{F I T}$ & $\overline{F I T}$ & $\sigma_{F I T}$ & $\overline{F I T}$ & $\sigma_{F I T}$ & $\overline{F I T}$ & $\sigma_{F I T}$ \\
\hline$y_{1}$ & 47,50 & 3,82 & 60,33 & 2,63 & 41,19 & 3,08 & 46,31 & 2,10 \\
$y_{2}$ & 59,29 & 4,58 & 70,37 & 2,37 & 57,20 & 2,17 & 66,31 & 1,78 \\
$y_{3}$ & 28,46 & 6,58 & 46,56 & 3,73 & 44,95 & 2,81 & 48,65 & 3,57 \\
$y_{4}$ & 58,62 & 2,85 & 64,32 & 1,60 & 40,64 & 2,71 & 39,53 & 1,45 \\
$y_{5}$ & 56,68 & 4,03 & 62,00 & 1,93 & 55,03 & 3,10 & 55,89 & 1,24 \\
$y_{6}$ & 50,39 & 2,94 & 55,23 & 2,15 & 42,28 & 2,47 & 40,95 & 1,36 \\
$y_{7}$ & 54,65 & 3,13 & 59,38 & 2,22 & 43,16 & 2,52 & 43,30 & 1,39 \\
\hline
\end{tabular}



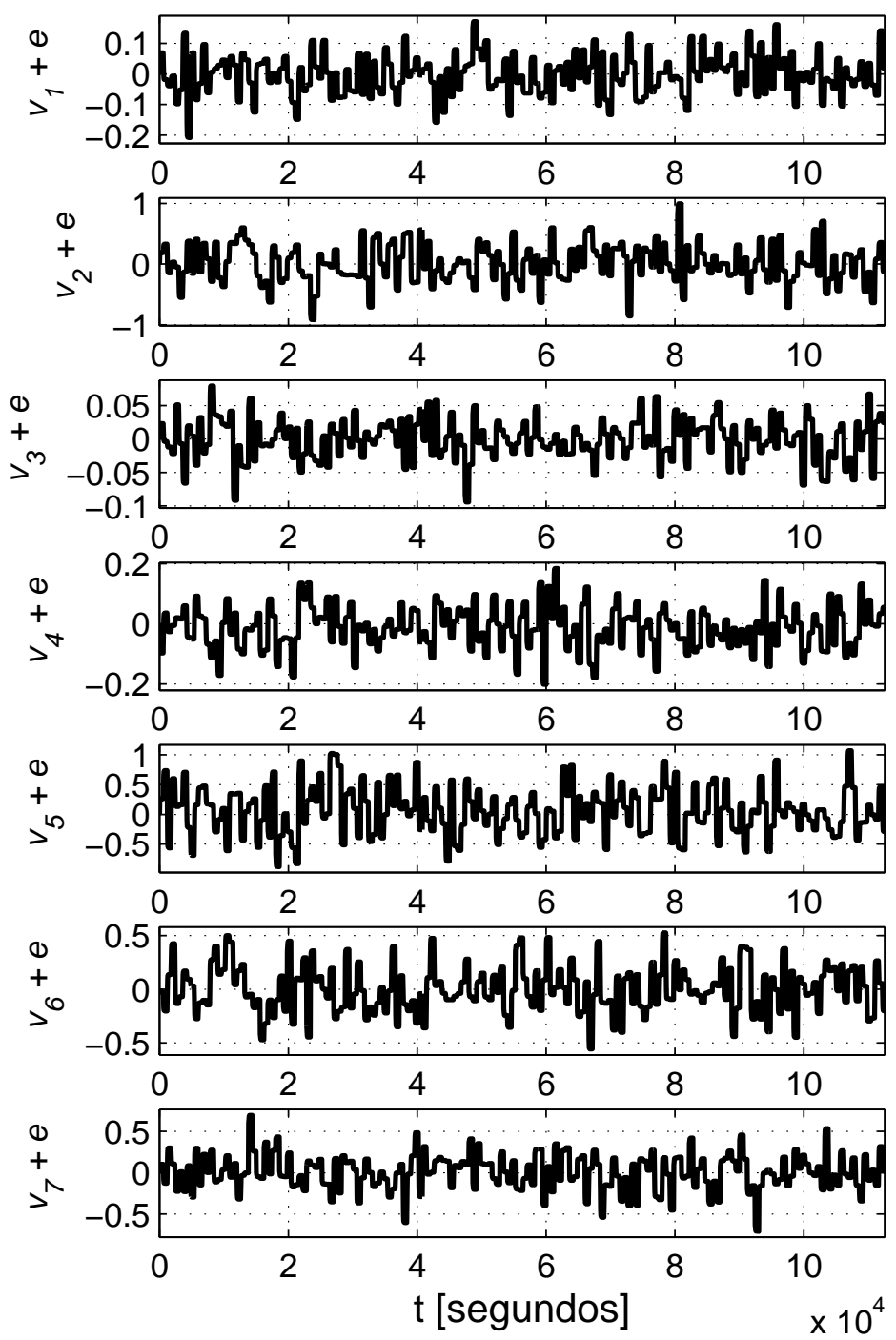

Figura 10.8: Perturbações adicionadas às saídas da planta.

excitações aplicadas, os limites das MV e CV (tabela 10.1) são respeitados, assim como se observa nas figuras 10.3, 10.6, 10.7 e 10.9 .

Conforme a seção 4.7, o conjunto de sinais com menor CISS tendem a resultar em menores variâncias dos parâmetros do modelo FIR identificado a partir de dados imersos em ruído branco. Nas simulações aqui discutidas, há ruído de medição que é do tipo branco Gaussiano, porém, há também perturbações não medidas, as quais não são do tipo ruído branco. Nas simulações de Monte-Carlo foram calculadas as medidas A-optimality (seção 2.1) para avaliação das variâncias dos parâmetros estimados dos modelos FIR. As figuras 10.10 a 10.12 apresentam as medidas A-optimality para os modelos FIR e os correspondentes valores de CISS. Observa-se que os conjuntos de sinais com maior CISS tendem a resultar em valores mais elevados da medida A-optimality, ou seja, maior variância dos parâmetros estimados do modelo FIR. As figura 10.13 a 10.15 apresentam a dispersão dos valores da medida A-optimality ver- 

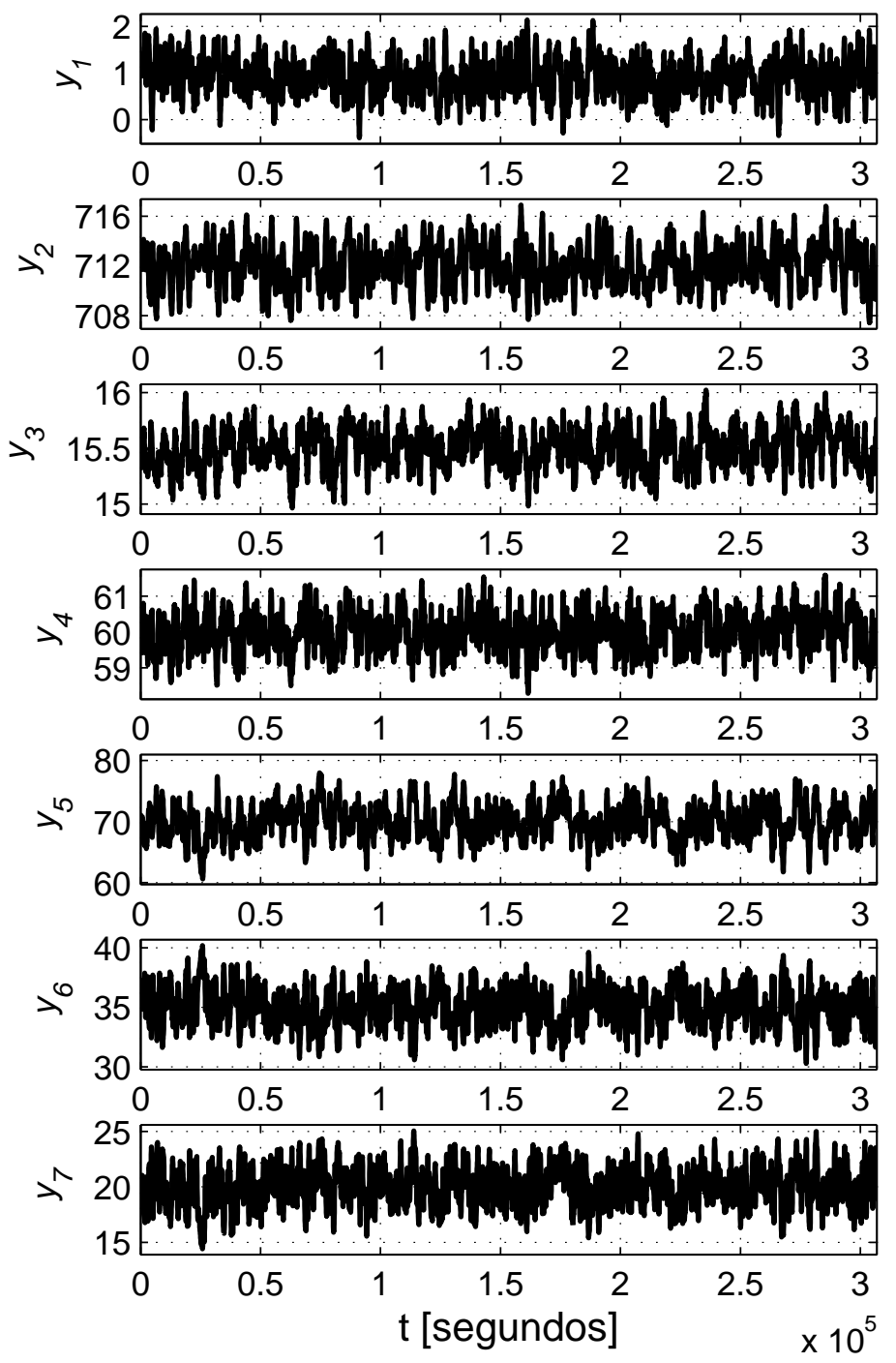

Figura 10.9: Respostas da planta FCC a excitações shift-QRB.

sus CISS. Com essas figuras, confirma-se a correlação entre os valores de CISS e a variância dos parâmetros estimados do modelo FIR. Os sinais com maiores valores de CISS tendem a resultar em maiores variâncias dos parâmetros estimados do modelo FIR (maior medida A-optimality). Dessa forma, nas simulações, o CISS mostrou-se uma boa medida de avaliação dos conjuntos de sinais de excitação previamente ao experimento de identificação. Os valores da medida A-optimality e CISS para os sinais Schroeder-SOH e clipping-SOH não aparecem nas figuras 10.10 a 10.15, pois tendem ao infinito, conforme discutido anteriormente. 

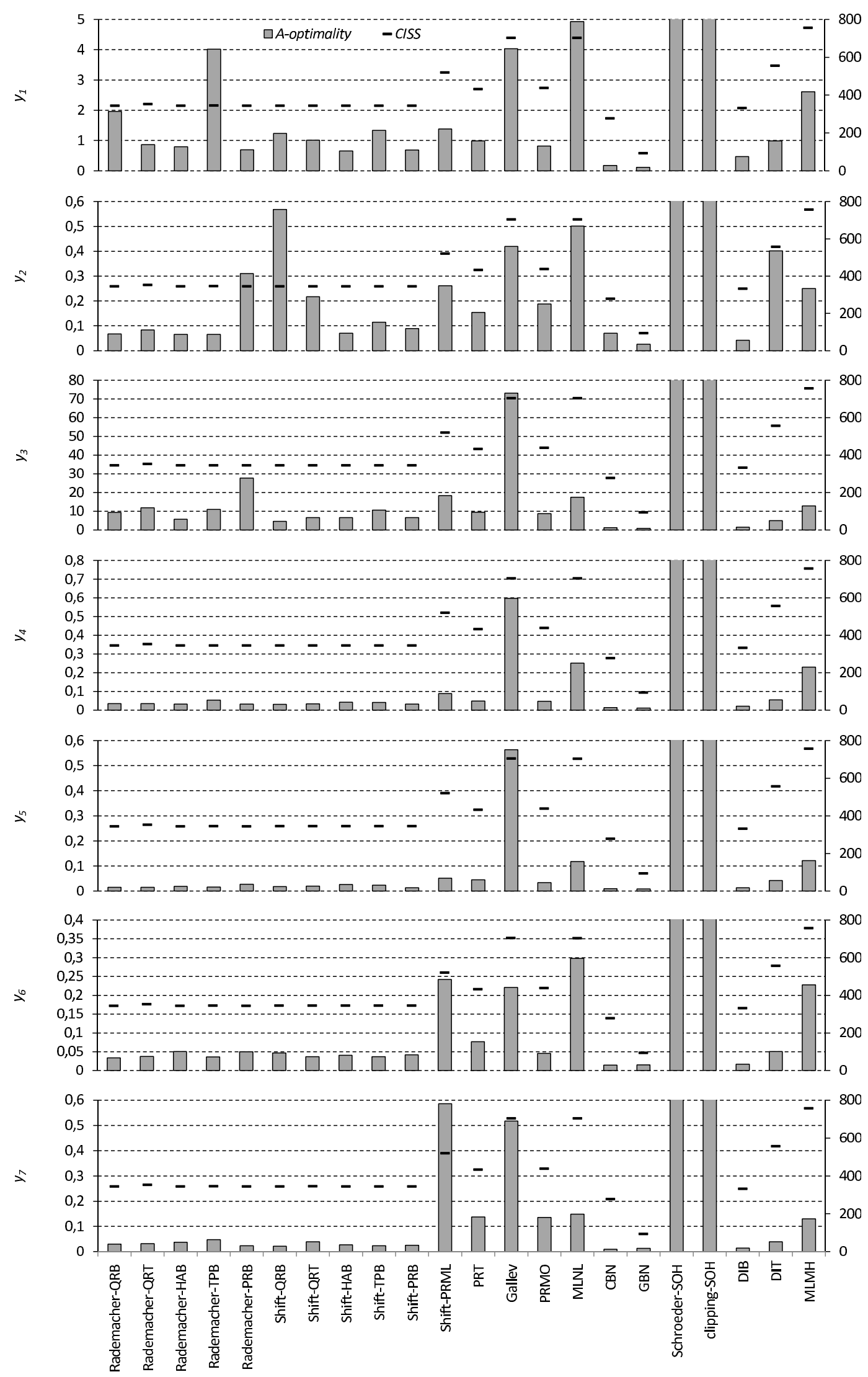

Figura 10.10: Medidas A-optimality para os modelos FIR ajustados a partir dos dados do experimento A e os correspondentes valores de CISS. 

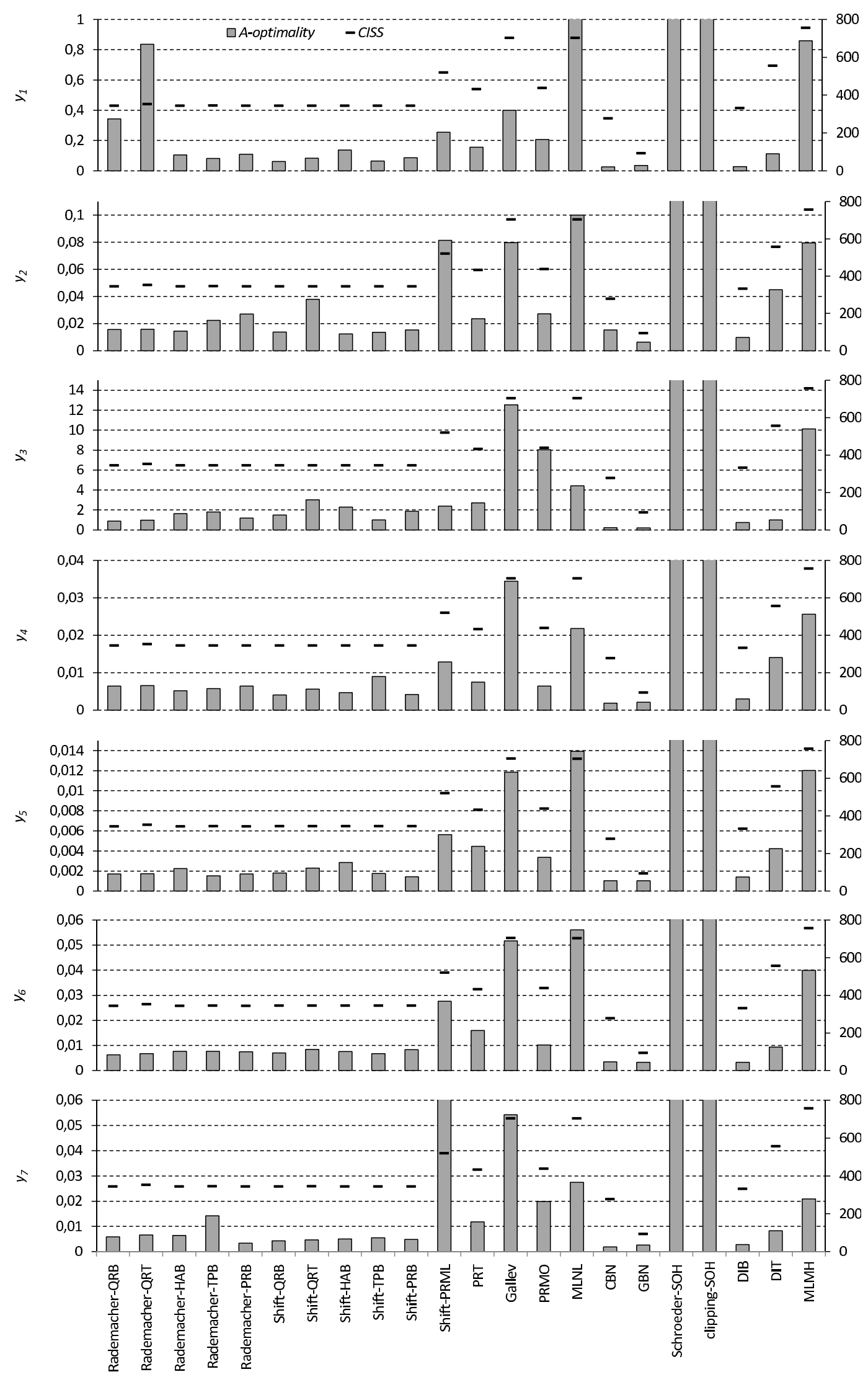

Figura 10.11: Medidas A-optimality para os modelos FIR ajustados a partir dos dados do experimento $\mathrm{B}$ e os correspondentes valores de CISS. 

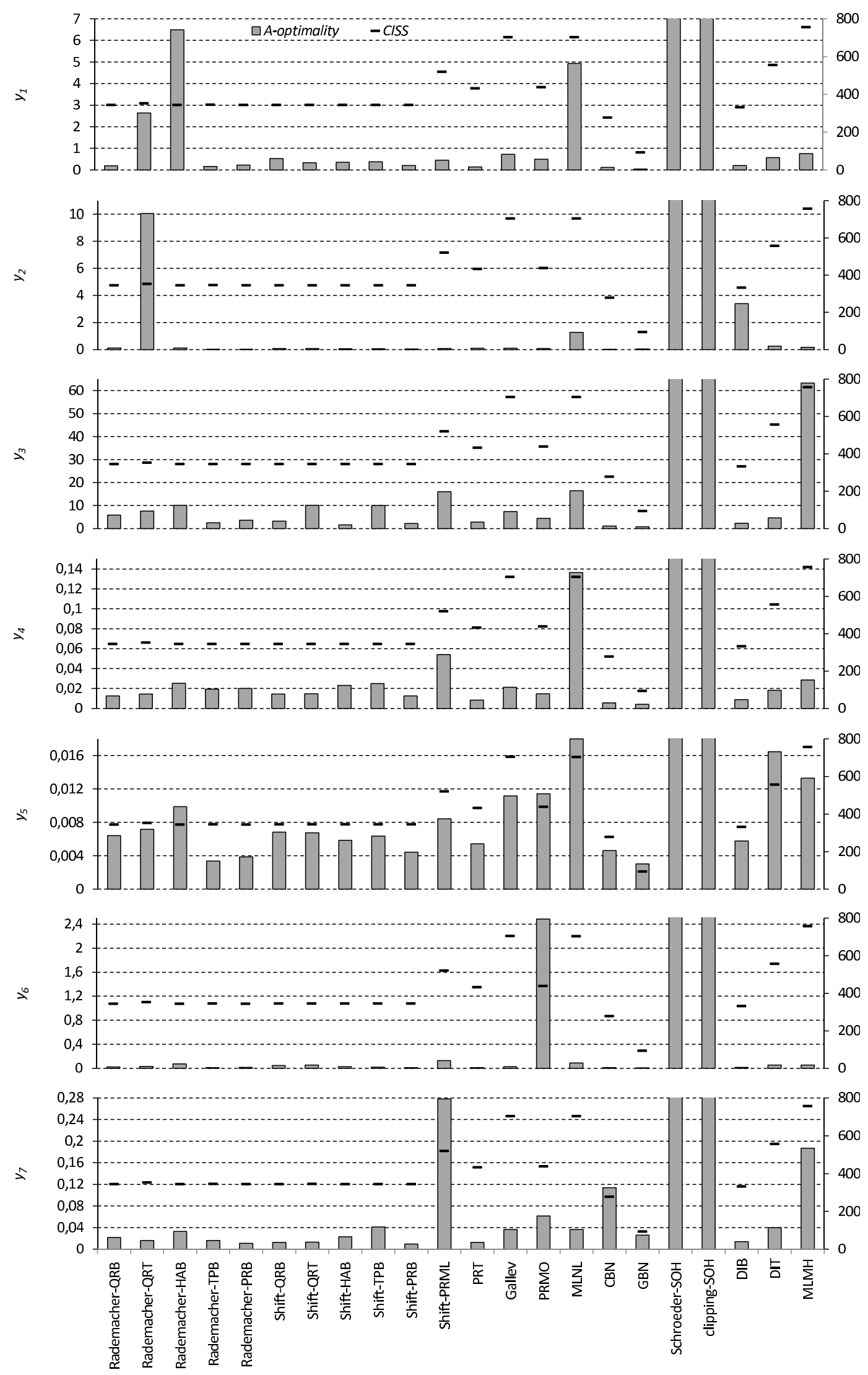

Figura 10.12: Medidas A-optimality para os modelos FIR ajustados a partir dos dados do experimento $\mathrm{C}$ e os correspondentes valores de CISS. 

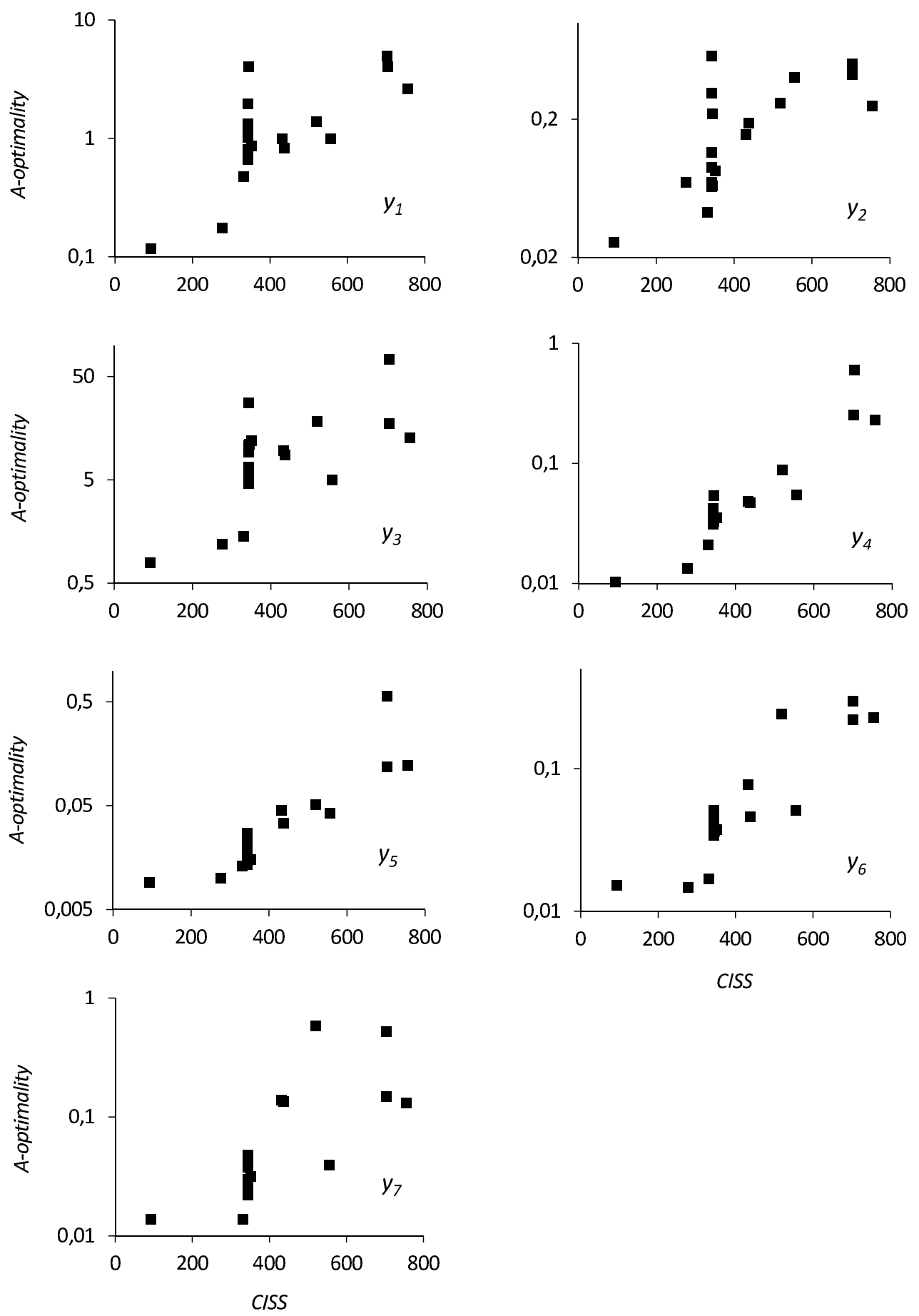

Figura 10.13: Dispersão dos valores da medida A-optimality versus CISS para os modelos FIR ajustados a partir dos dados do experimento A. 

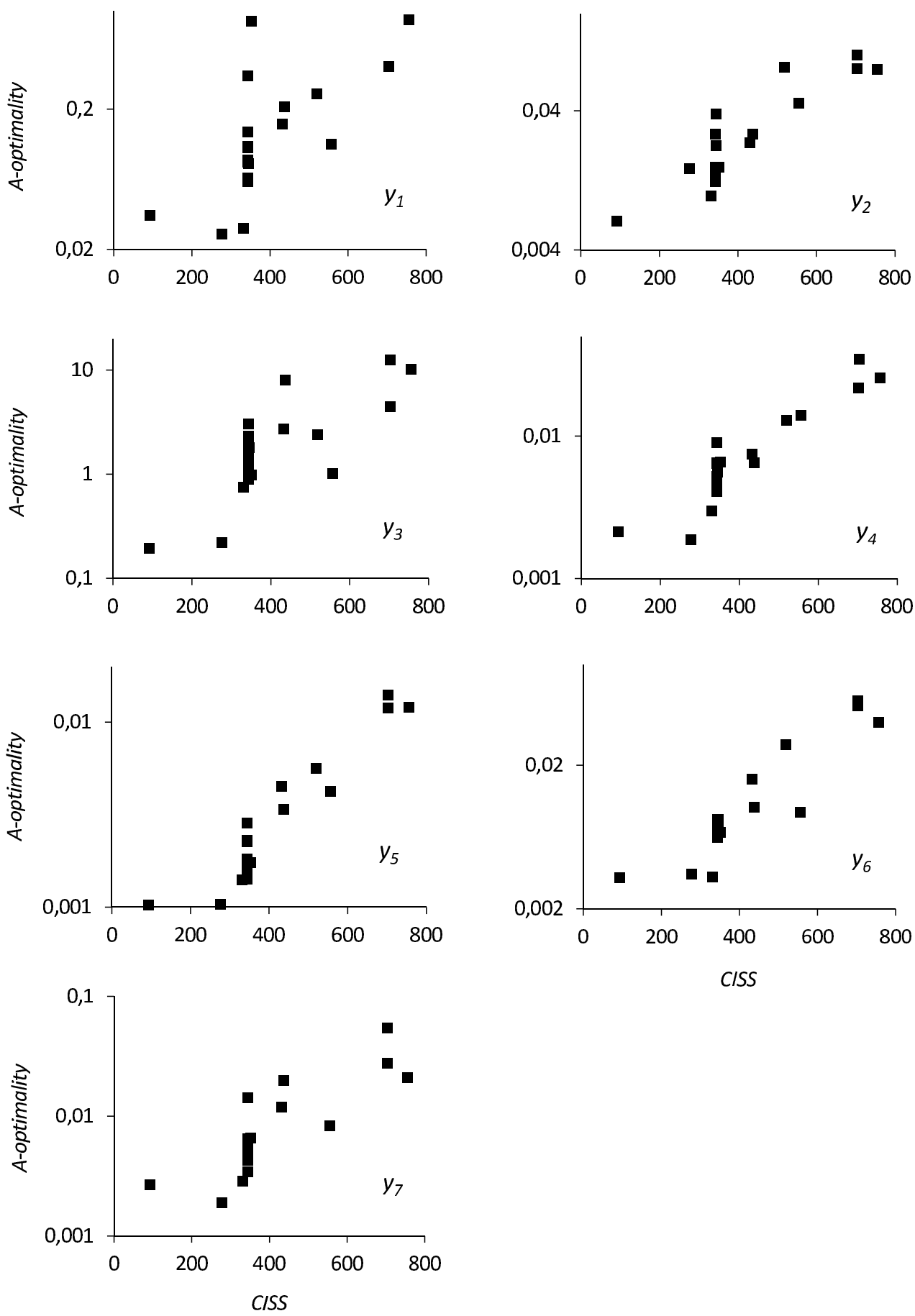

Figura 10.14: Dispersão dos valores da medida A-optimality versus CISS para os modelos FIR ajustados a partir dos dados do experimento B. 

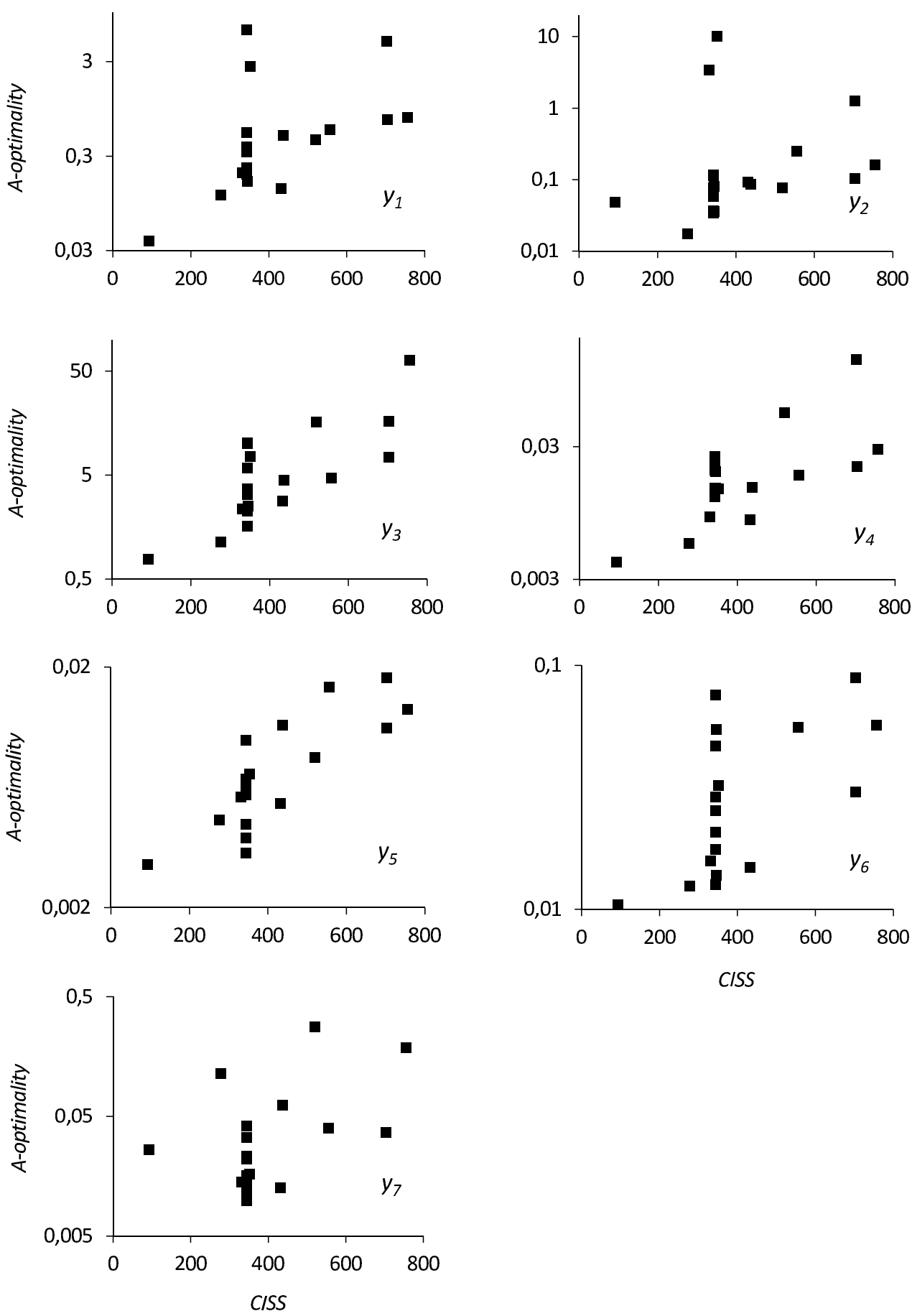

Figura 10.15: Dispersão dos valores da medida A-optimality versus CISS para os modelos FIR ajustados a partir dos dados do experimento $\mathrm{C}$. 
A figura 10.16 apresenta a comparação dos $\overline{F I T}$ obtidos com modelos ARX de alta ordem, ARX, FIR e ARMAX ajustados a partir de dados do conjunto de testes A, quando excitados com o sinal de validação GBN. A figura 10.17 apresenta a comparação dos $\overline{F I T}$ quando esses modelos são submetidos ao sinal de validação do tipo onda quadrada. Nos casos em que se obteve $\overline{F I T}<0$, considerou-se que os modelos não representaram a planta e, portanto, esses não são apresentados.

Para a validação com sinais GBN, os melhores $\overline{F I T}$ obtidos entre os modelos (ARX de alta ordem, ARX, FIR e ARMAX) ajustados a partir dos testes A são apresentados na figura 10.18. Nessa figura também são apresentados os desvios padrão do FIT. Os resultados da validação com sinais do tipo onda quadrada são apresentados na figura 10.19 .

Os resultados da validação dos modelos referentes aos testes B e C são apresentados nas figuras 10.20 a 10.27 .

As SNR obtidas nas saídas da planta são apresentadas nas figuras 10.28, 10.29 e 10.30. Como os experimentos do conjunto A foram realizados com maiores variâncias de ruídos de medição e de perturbações não medidas, observa-se que as SNR obtidas nas saídas da planta são menores que as obtidas nos experimentos B e C. Conforme a tabela 10.8, foram utilizados nos experimentos A e B sinais com características diferentes (tabelas 10.10 e 10.11). Assim, apesar das variâncias de ruídos de medição e de perturbações não medidas serem iguais para os experimentos B e C (tabela 10.4), as SNR obtidas nas saídas da planta nos experimentos B são diferentes das obtidas nos experimentos C (figuras 10.29 e 10.30, respectivamente).

Comparando-se as tabelas 10.12 e 10.13 com as figuras 10.28, 10.29 e 10.30, observa-se que elevados PIPS em geral resultam em valores mais elevados de SNR nas saídas. Porém, elevadas SNR não implicam em bons ajustes ( $\overline{F I T}$ elevados $)$ dos modelos para todos os sinais de excitação (figuras 10.18, 10.19, 10.22, 10.23, 10.26 e $10.27)$.

Conforme esperado, verifica-se que é possível obter melhores ajustes dos modelos (maiores $\overline{F I T}$ ) quando são utilizados sinais de excitação ao invés de testes em degrau. Essa conclusão pode ser obtida comparando-se os valores de $\overline{F I T}$ das figuras 10.18 , $10.19,10.22,10.23,10.26$ e 10.27 com os da tabela 10.14. Cabe lembrar que a duração $T_{e}$ dos testes em degrau é semelhante às dos experimentos do conjunto $\mathrm{C}$.

Os modelos ARX ajustados a partir dos conjuntos de dados dos experimentos A, B e C, em geral, resultaram em menores $\overline{F I T}$ em relação aos modelos ARX de alta ordem, FIR e ARMAX. 

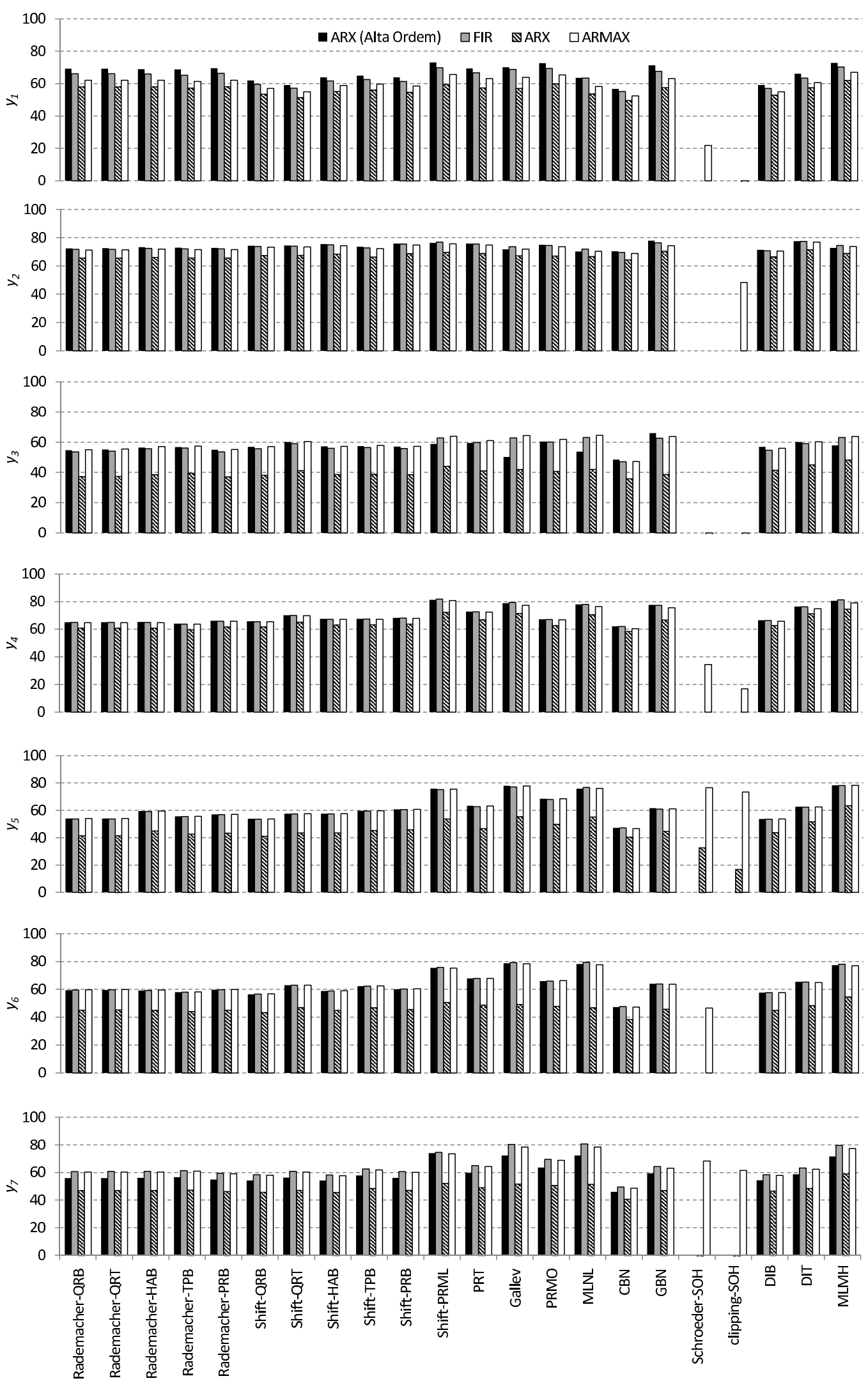

Figura 10.16: Validação $\overline{F I T}$ dos modelos ARX de alta ordem, ARX, FIR e ARMAX ajustados a partir dos dados do experimento A quando excitados com o sinal de validação GBN. 

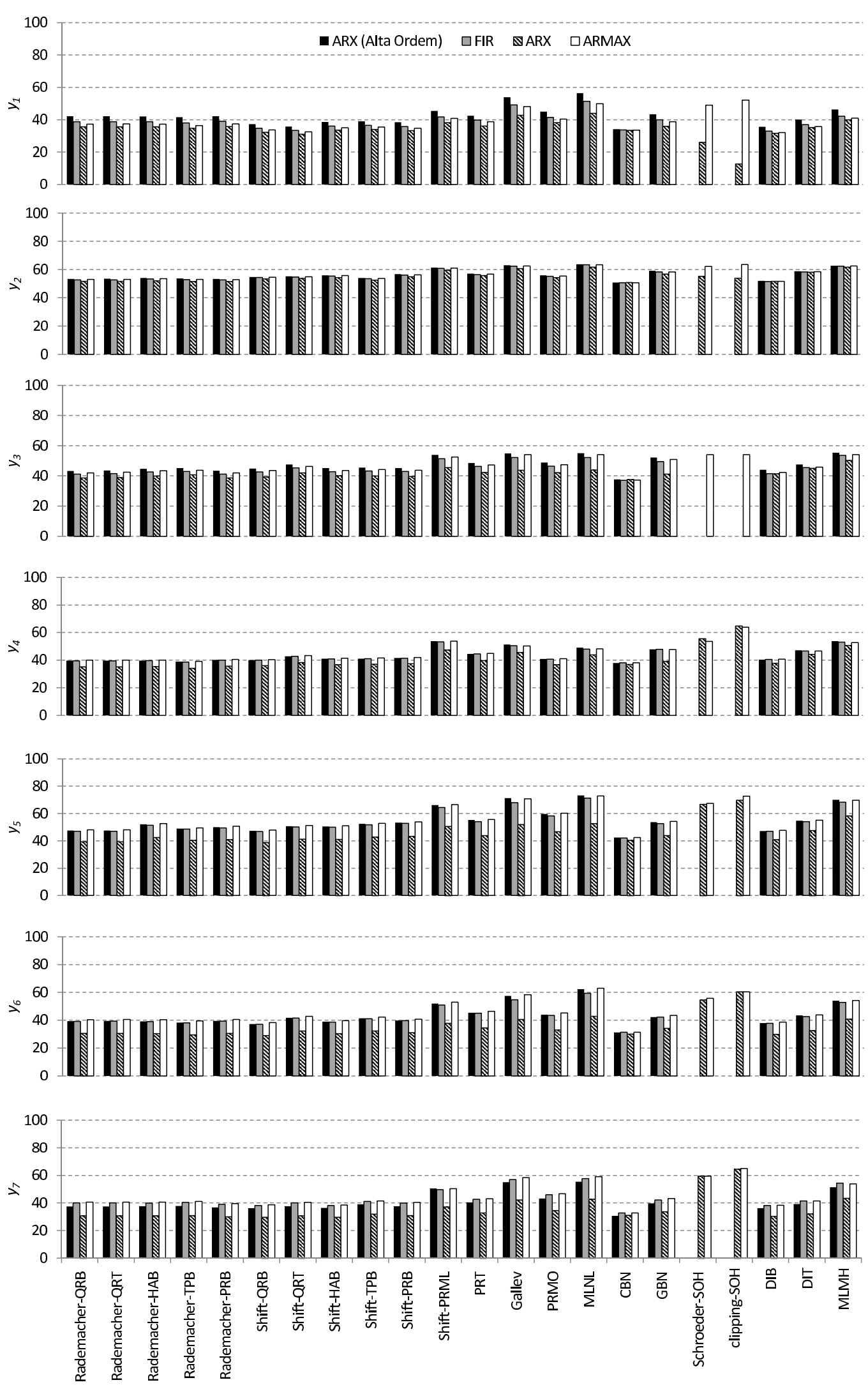

Figura 10.17: Validação $\overline{F I T}$ dos modelos ARX de alta ordem, ARX, FIR e ARMAX ajustados a partir de dados do experimento A quando excitados com o sinal de validação do tipo onda quadrada. 

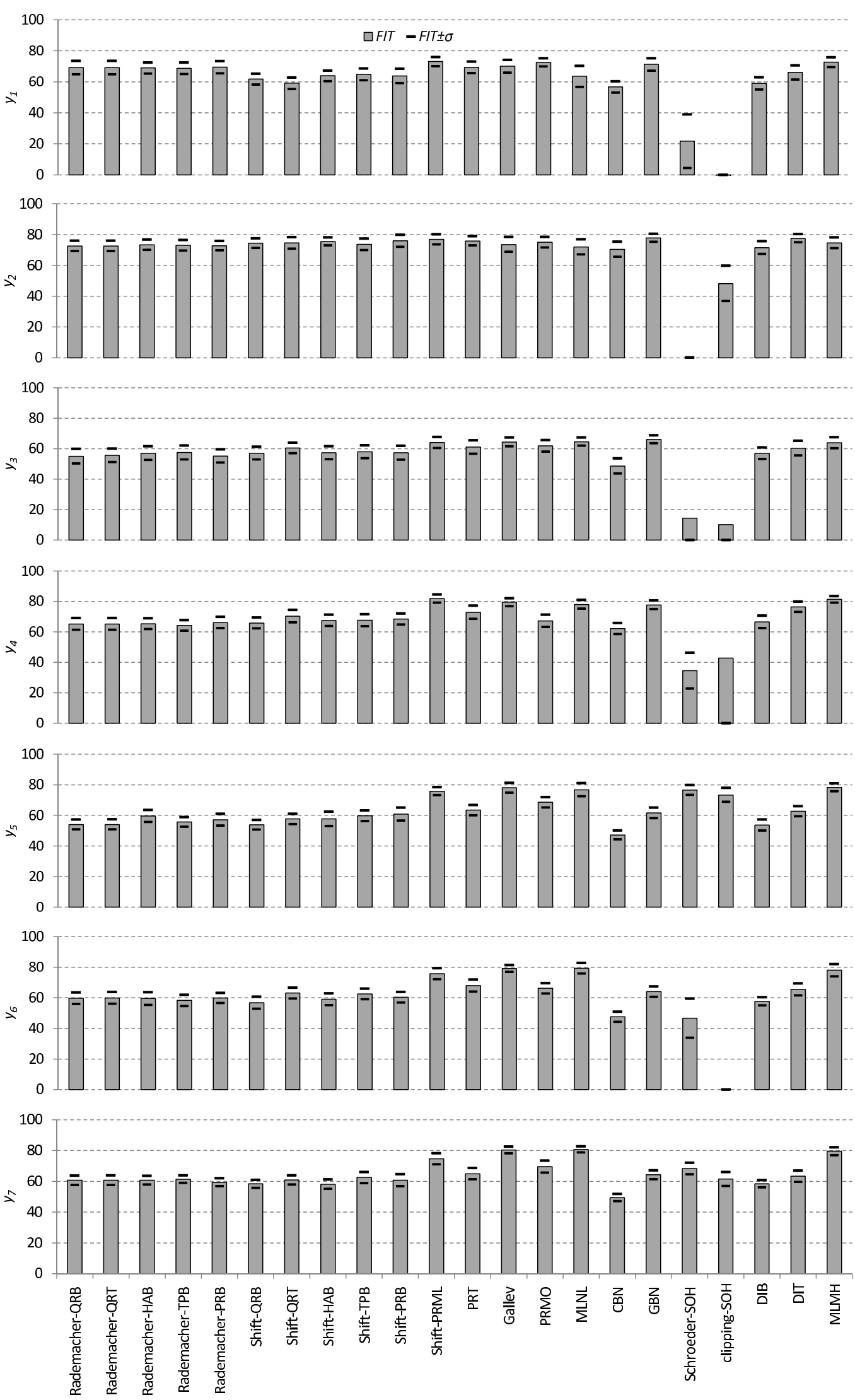

Figura 10.18: Melhor $\overline{F I T}$ obtido com os modelos ARX de alta ordem, ARX, FIR e ARMAX ajustados a partir de dados do experimento A quando excitados com o sinal de validação GBN. 

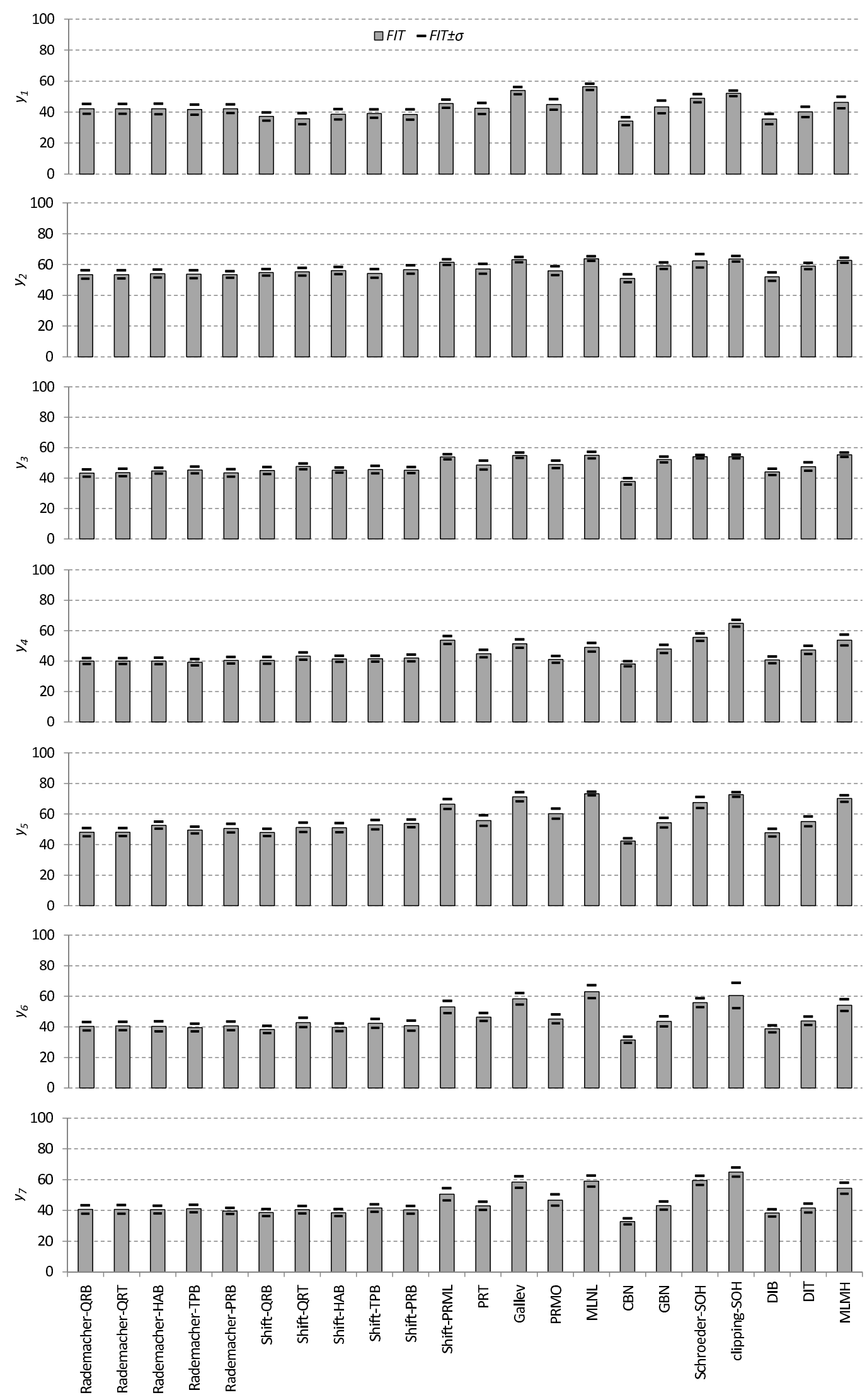

Figura 10.19: Melhor $\overline{F I T}$ obtido com os modelos ARX de alta ordem, ARX, FIR e ARMAX ajustados a partir de dados do experimento A quando excitados com o sinal de validação do tipo onda quadrada. 

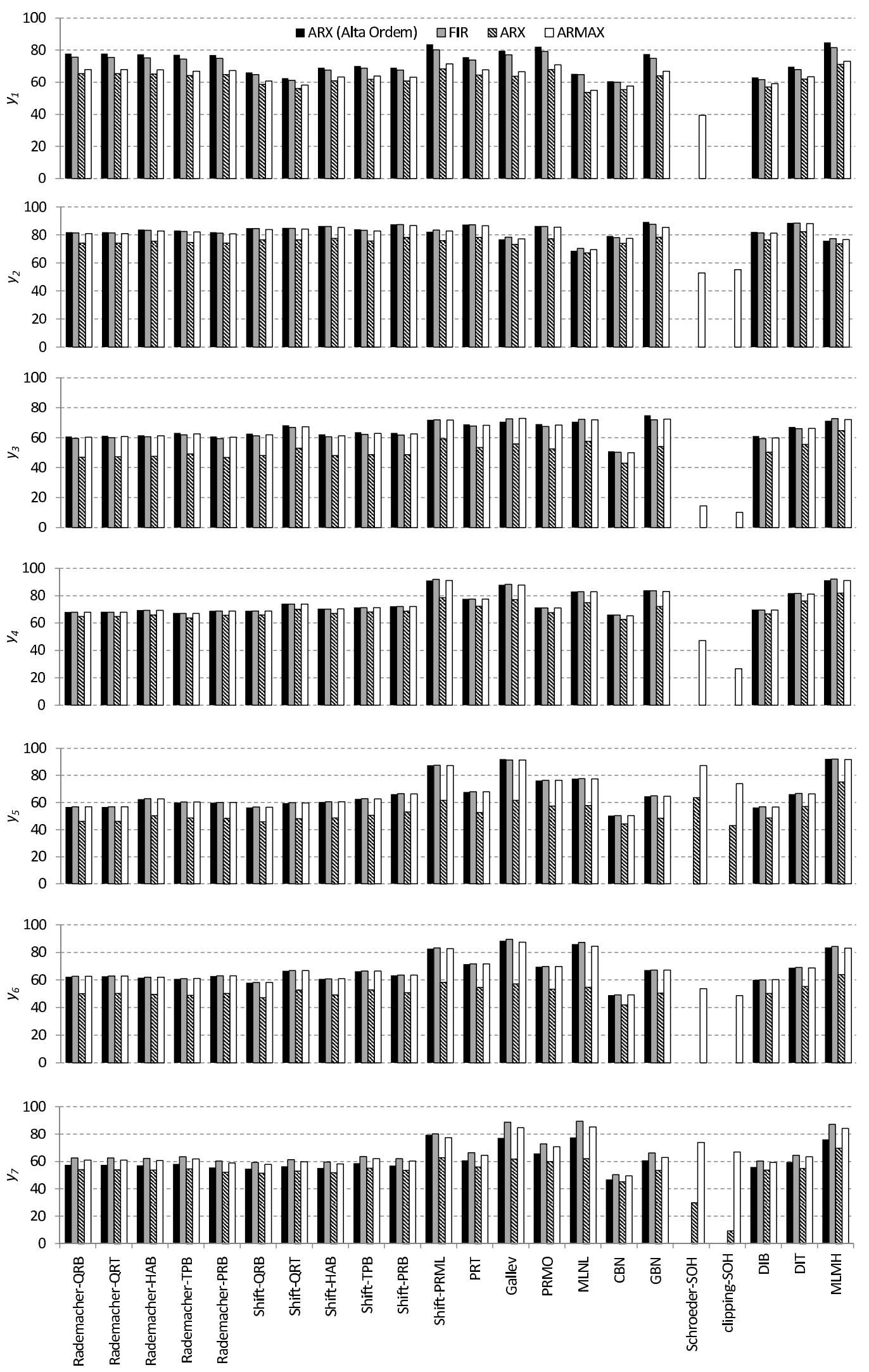

Figura 10.20: Validação $\overline{F I T}$ dos modelos ARX de alta ordem, ARX, FIR e ARMAX ajustados a partir de dados do experimento B quando excitados com o sinal de validação GBN. 

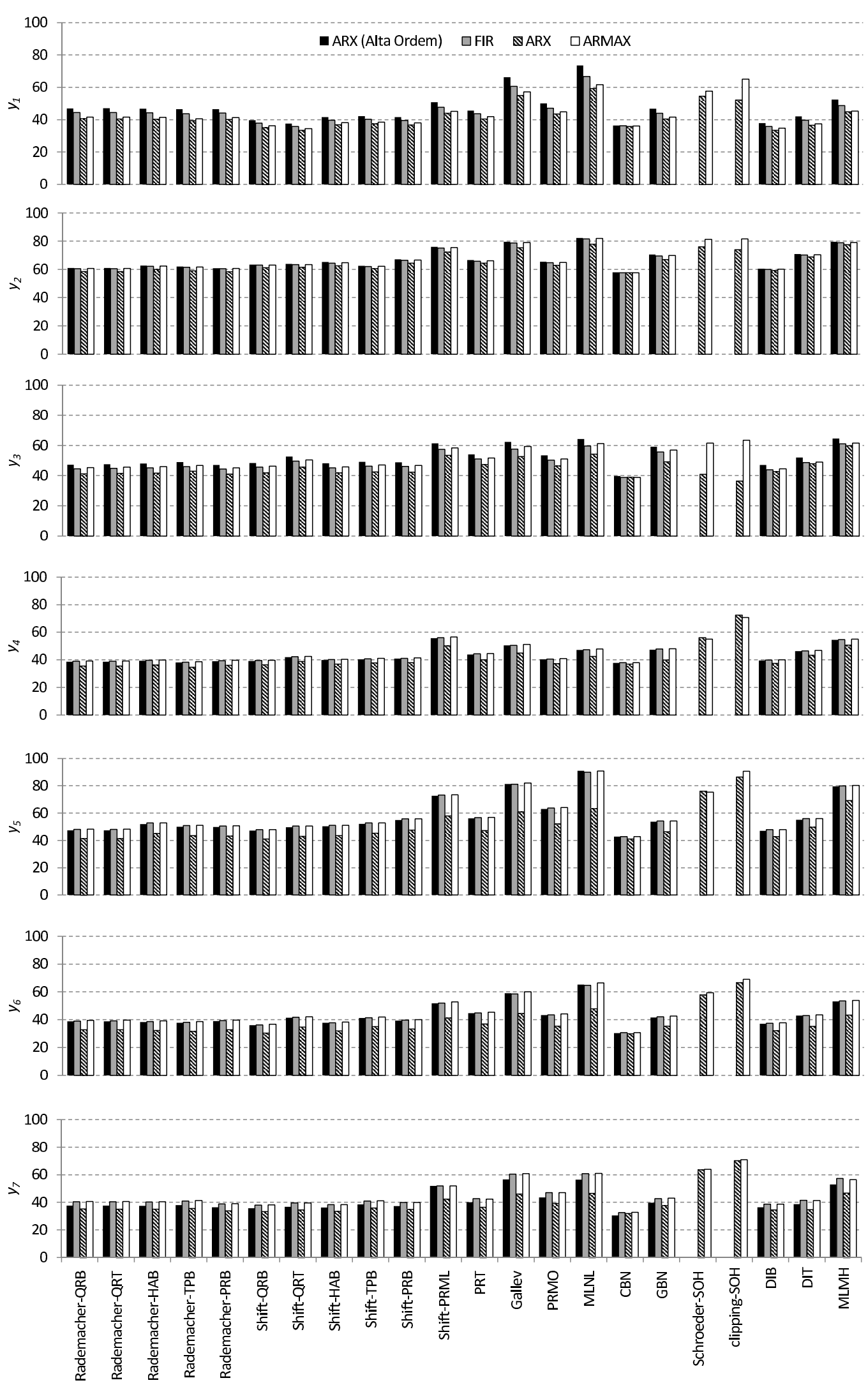

Figura 10.21: Validação $\overline{F I T}$ dos modelos ARX de alta ordem, ARX, FIR e ARMAX ajustados a partir de dados do experimento B quando excitados com o sinal de validação do tipo onda quadrada. 

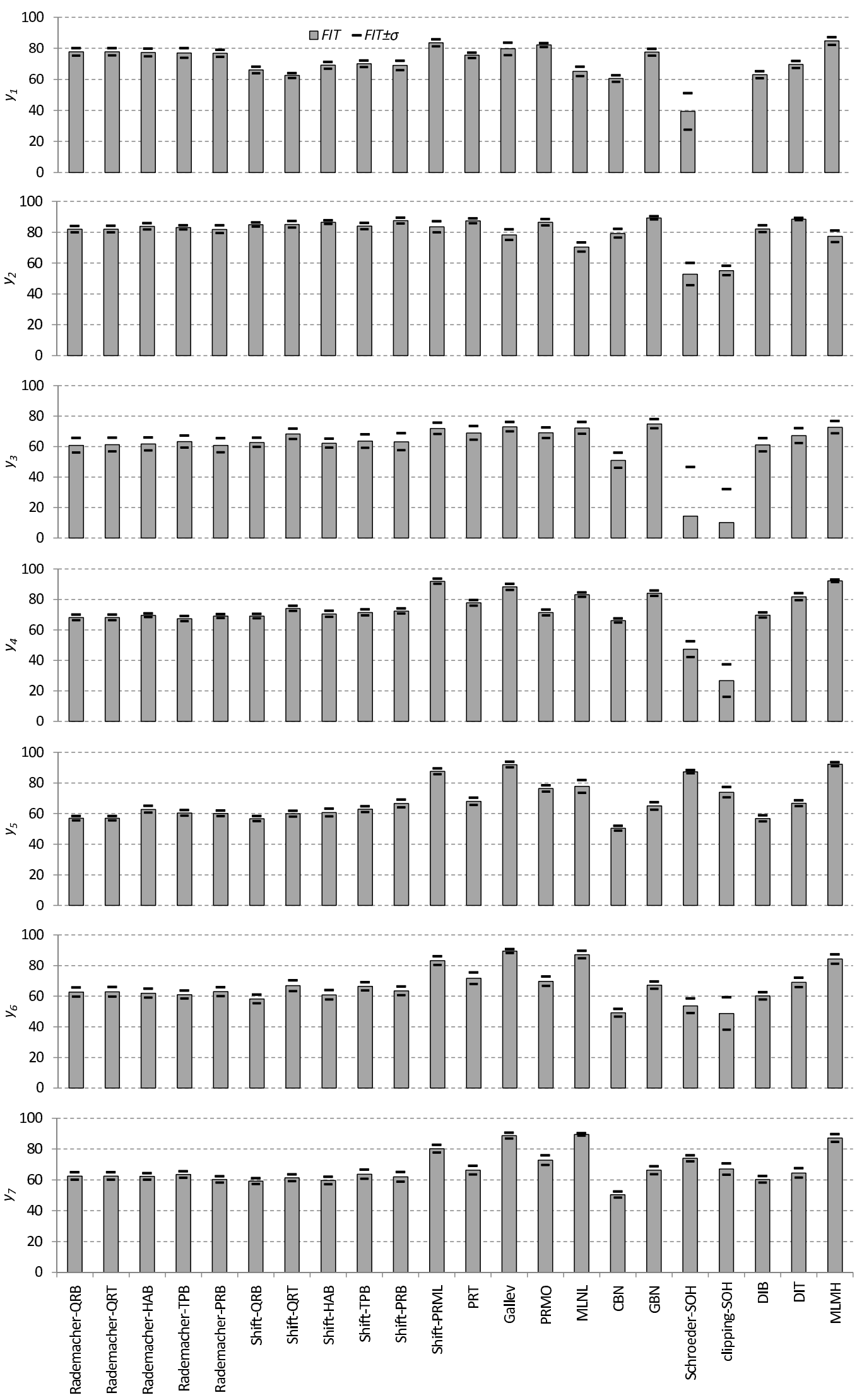

Figura 10.22: Melhor $\overline{F I T}$ obtido com os modelos ARX de alta ordem, ARX, FIR e ARMAX ajustados a partir de dados do experimento B quando excitados com o sinal de validação GBN. 

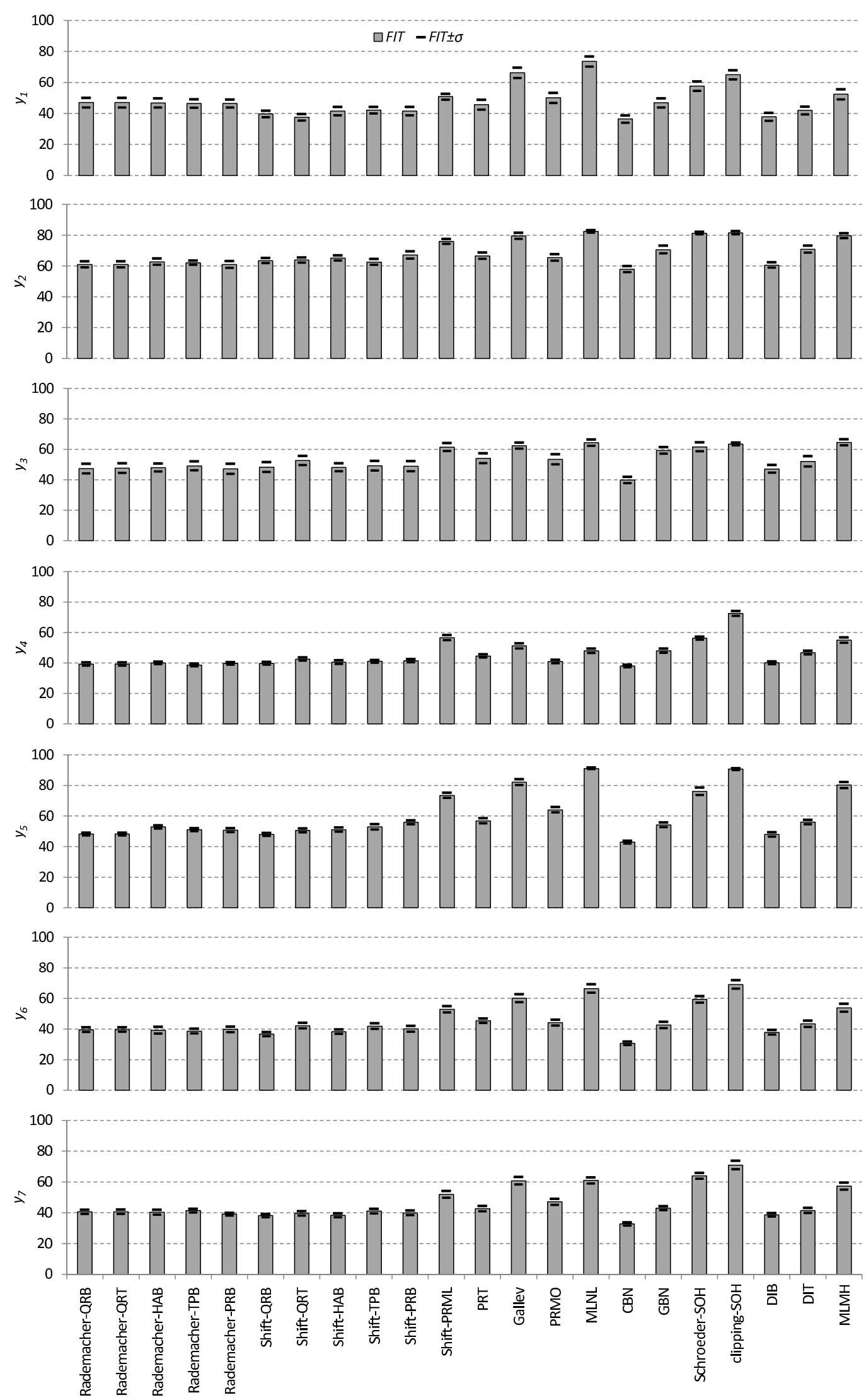

Figura 10.23: Melhor $\overline{F I T}$ obtido com os modelos ARX de alta ordem, ARX, FIR e ARMAX ajustados a partir de dados dos experimentos B quando excitados com o sinal de validação do tipo onda quadrada. 

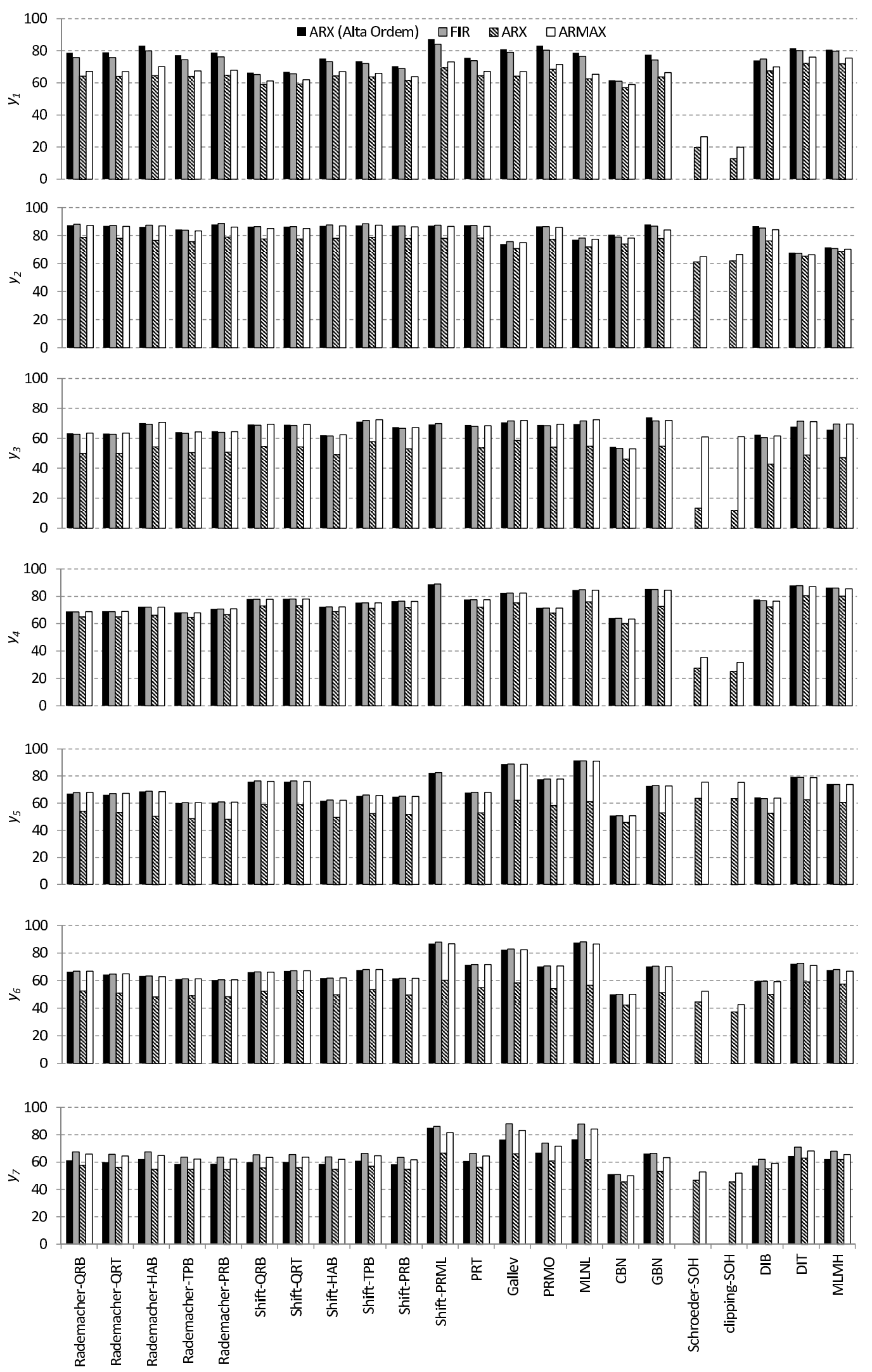

Figura 10.24: Validação $\overline{F I T}$ dos modelos ARX de alta ordem, ARX, FIR e ARMAX ajustados a partir de dados do experimento $\mathrm{C}$ quando excitados com o sinal de validação GBN. 

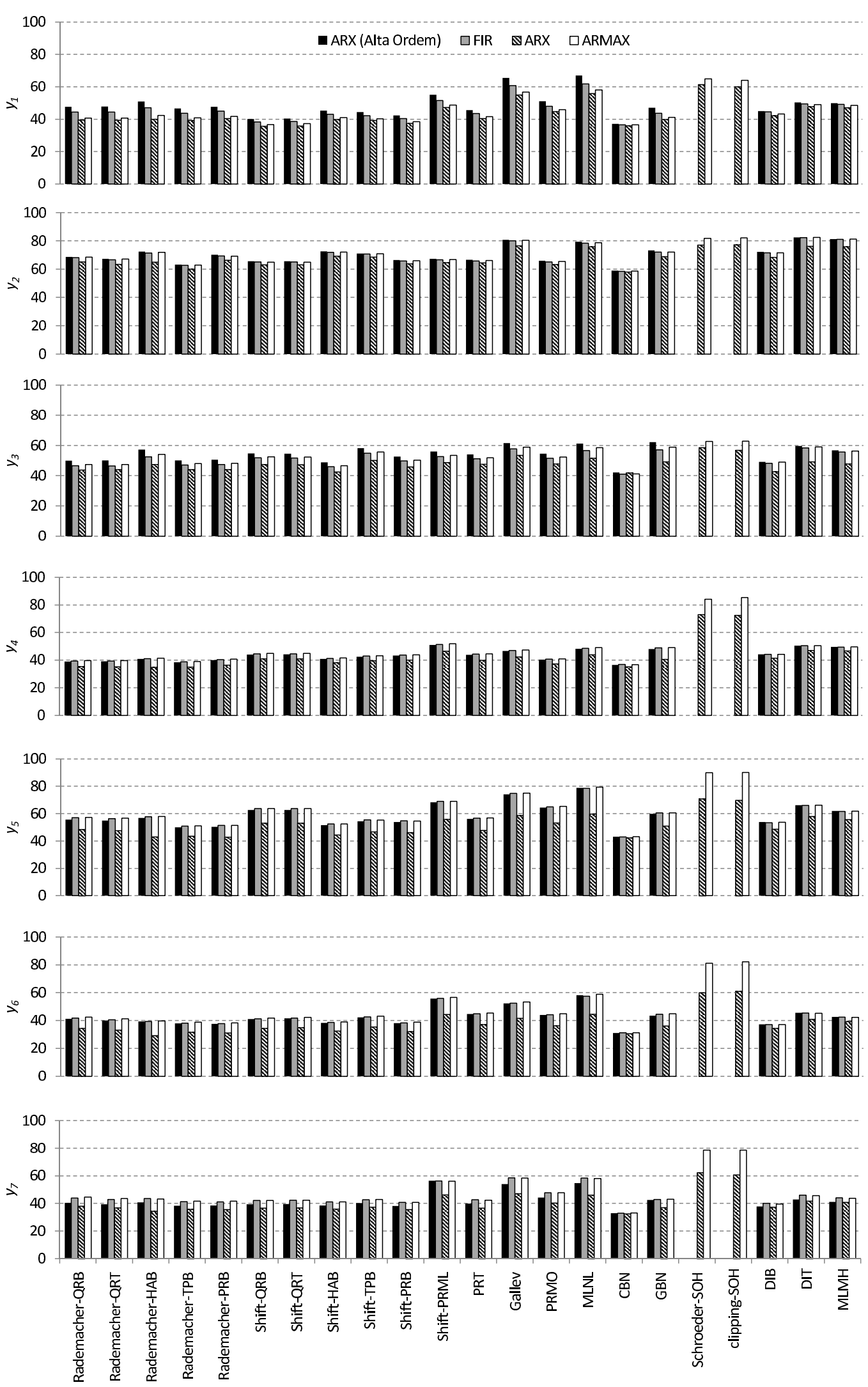

Figura 10.25: Validação $\overline{F I T}$ dos modelos ARX de alta ordem, ARX, FIR e ARMAX ajustados a partir de dados do experimento $\mathrm{C}$ quando excitados com o sinal de validação do tipo onda quadrada. 

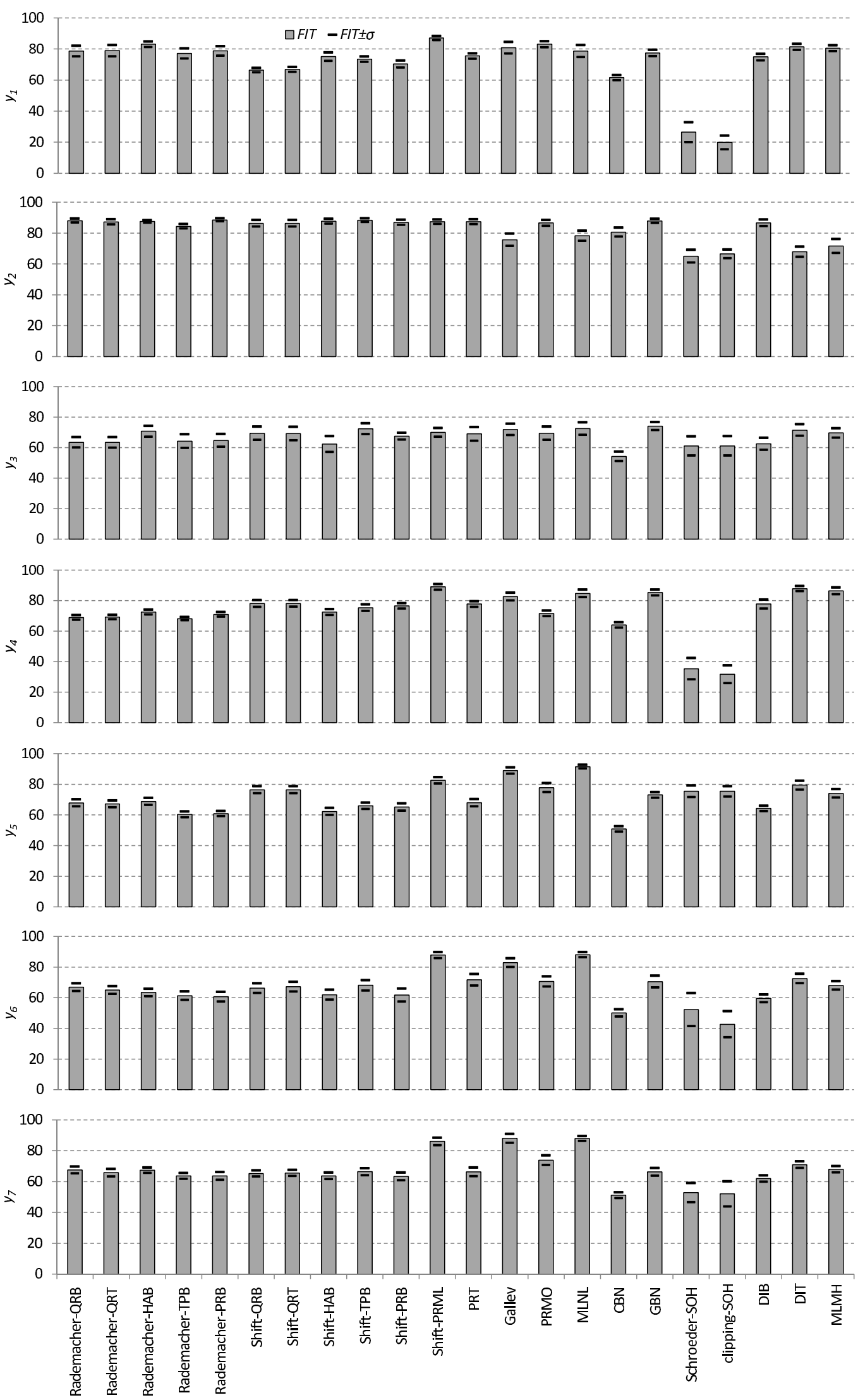

Figura 10.26: Melhor $\overline{F I T}$ obtido com os modelos ARX de alta ordem, ARX, FIR e ARMAX ajustados a partir de dados do experimento $\mathrm{C}$ quando excitados com o sinal de validação GBN. 

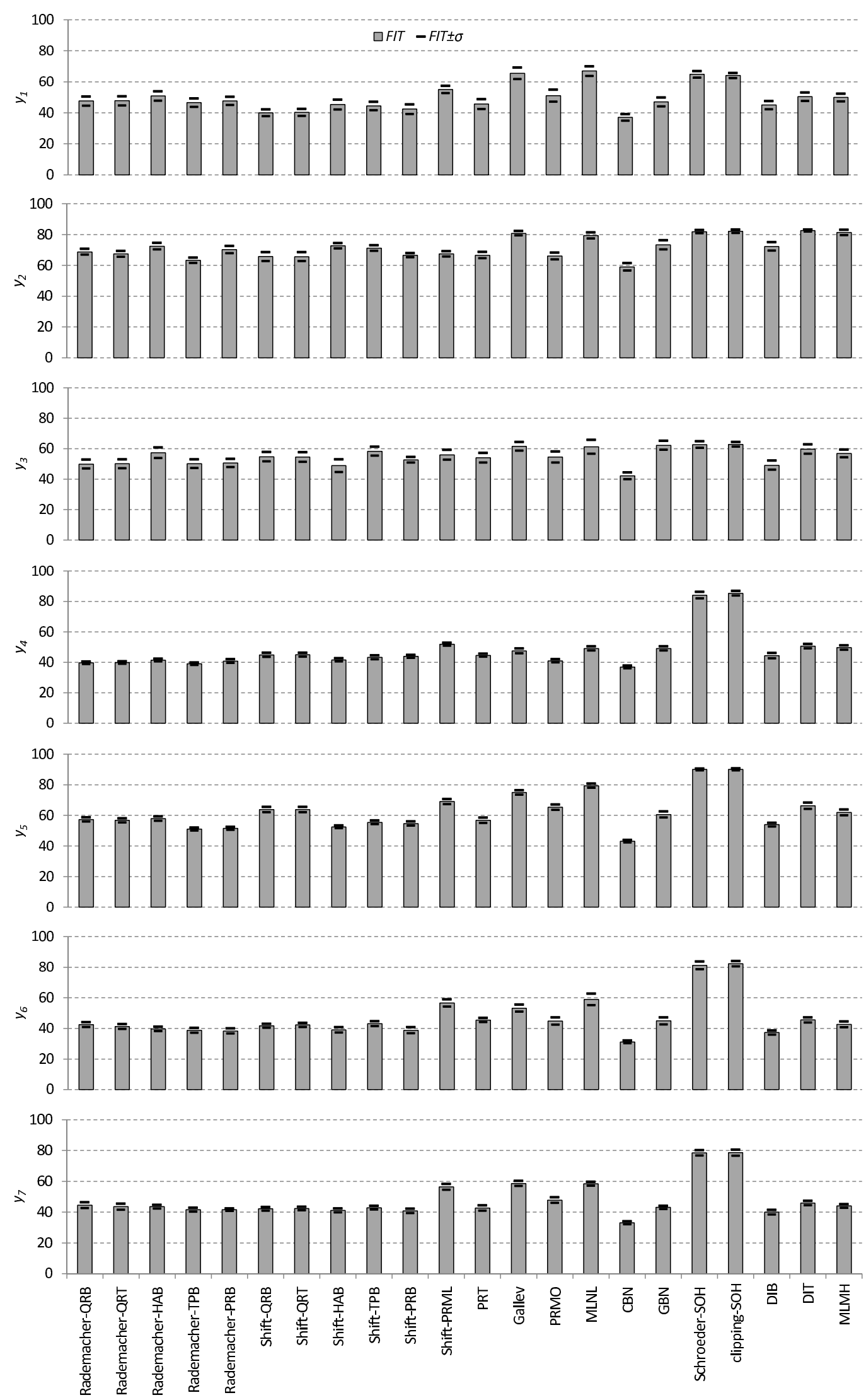

Figura 10.27: Melhor $\overline{F I T}$ obtido com os modelos ARX de alta ordem, ARX, FIR e ARMAX ajustados a partir de dados do experimento $\mathrm{C}$ quando excitados com o sinal de validação do tipo onda quadrada. 

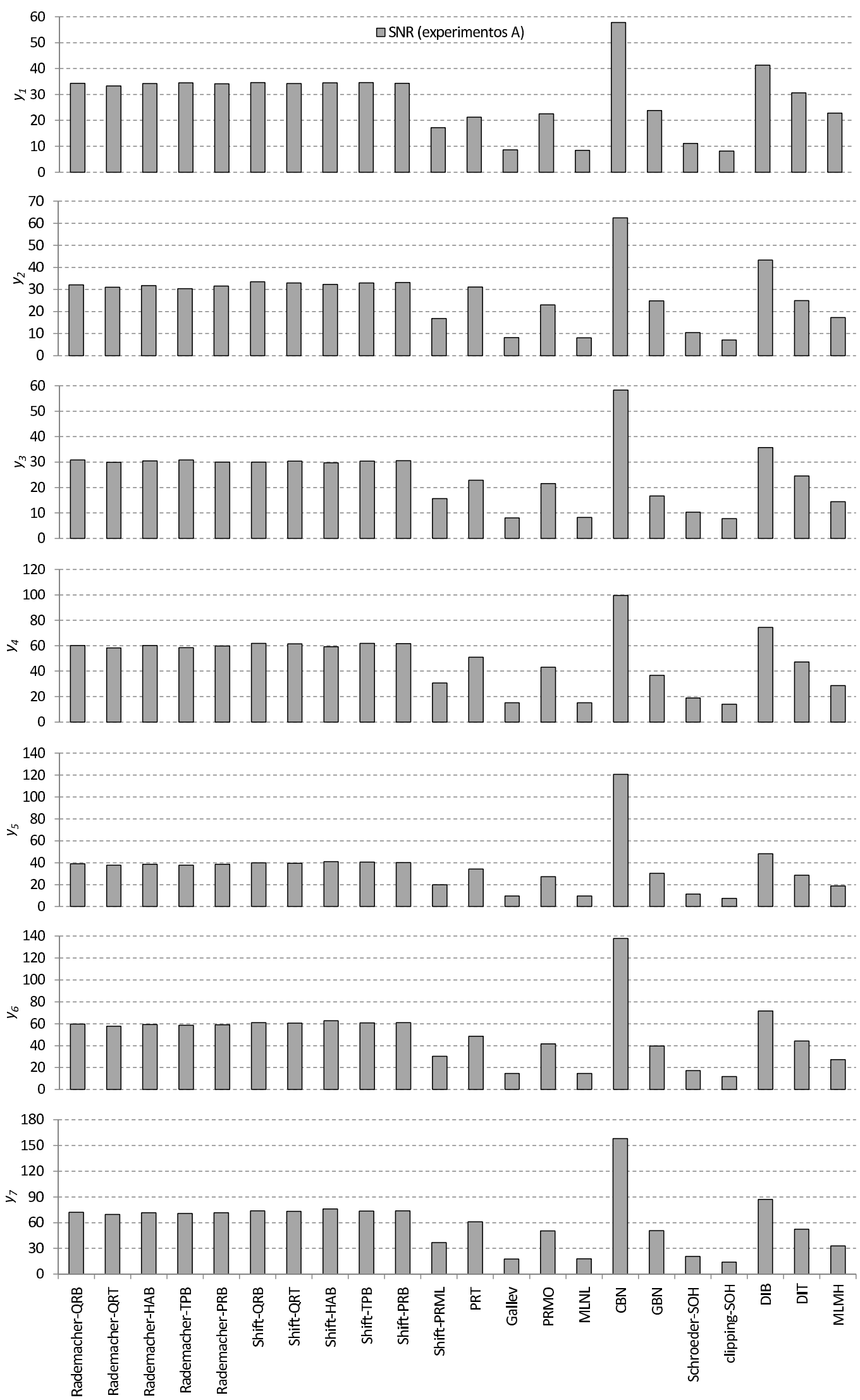

Figura 10.28: SNR nas saídas da planta obtidas no conjunto de experimentos A. 

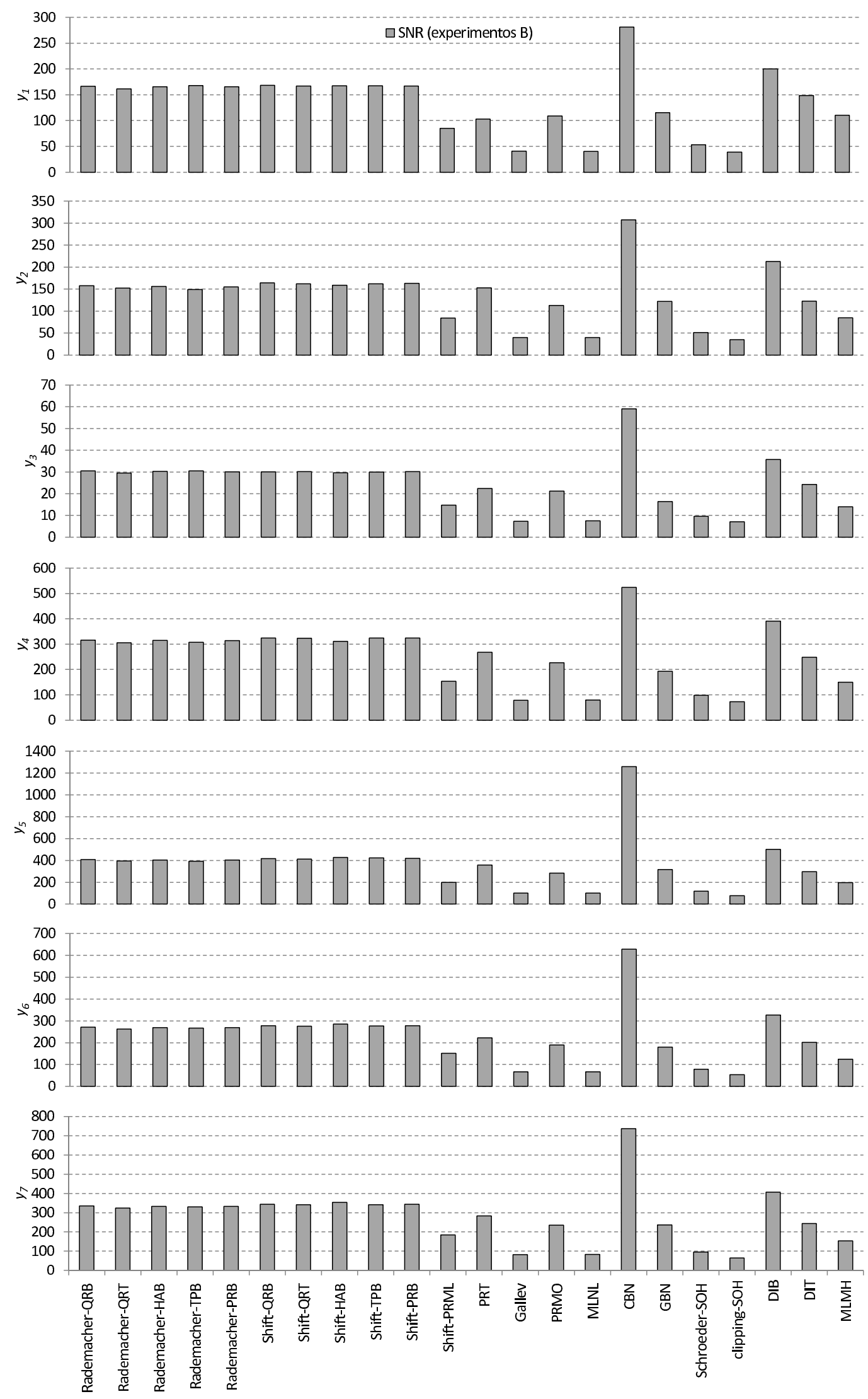

Figura 10.29: SNR nas saídas da planta obtidas no conjunto de experimentos B. 

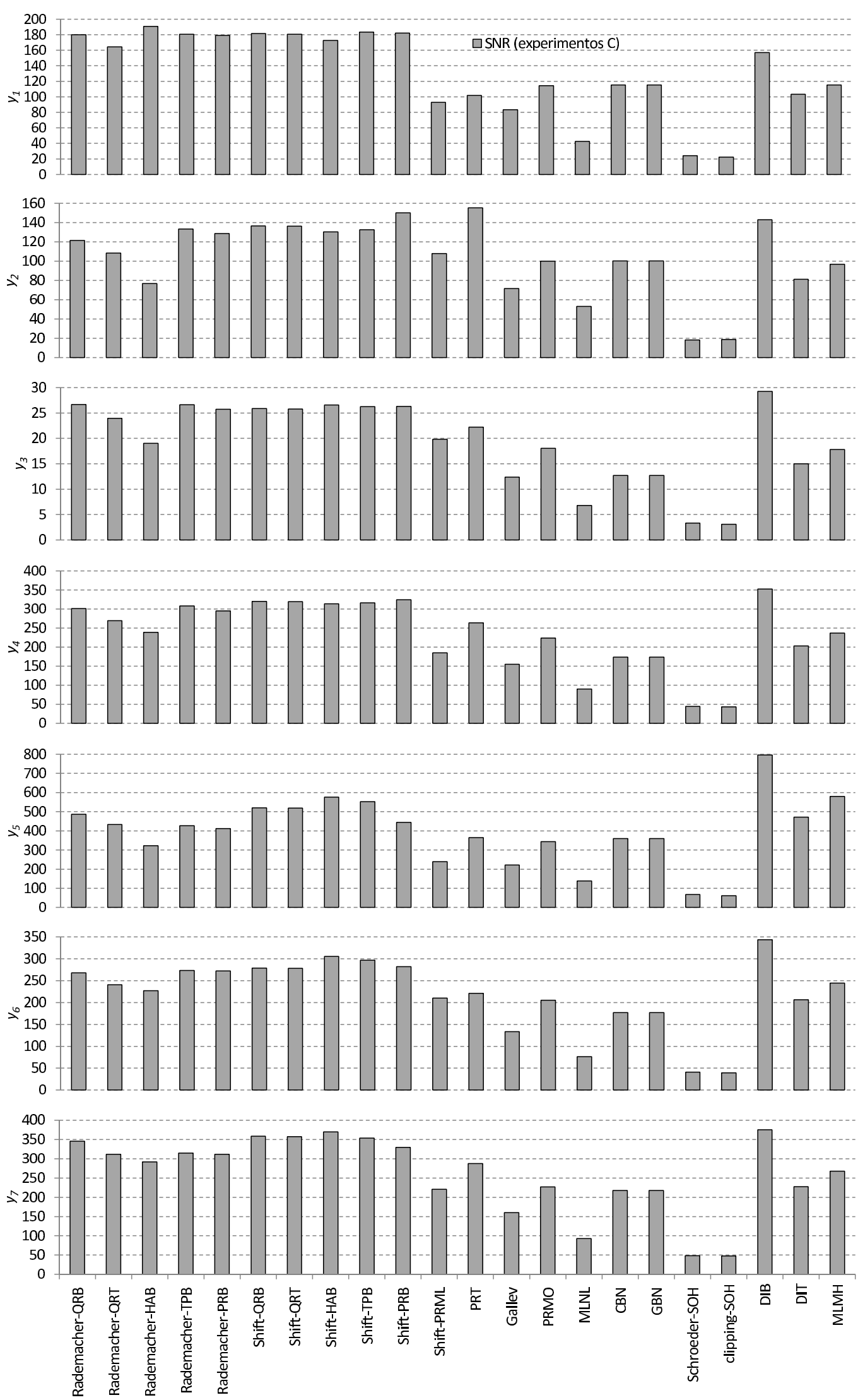

Figura 10.30: SNR nas saídas da planta obtidas no conjunto de experimentos $C$. 
A tabela 10.15 apresenta as médias, valores mínimos e máximos dos valores de $\overline{F I T}$ obtidos dos modelos de melhores ajustes (ARX de alta ordem, ARX, FIR ou ARMAX) a partir de dados de experimentos com cada um dos sinais, considerando todas as saídas $y$, todos conjuntos de experimentos (A, B e C) e todas as validações (sinais GBN e sinais do tipo onda quadrada). As tabelas 10.16 e 10.17 apresentam resultados análogos, porém, considerando isoladamente validações com sinais GBN e validações com sinais do tipo onda quadrada, respectivamente.

Tabela 10.15: Médias, valores mínimos e máximos dos $\overline{F I T}$ obtidos em todas as saídas $y_{p}$, todos experimentos (A, B e C) e validação com sinais GBN e com sinais do tipo onda quadrada.

\begin{tabular}{lccc}
\hline Sinais & $\overline{F I T}$ & $\min \{\overline{F I T}\}$ & $\max \{\overline{F I T}\}$ \\
\hline MLNL & 71,45 & 47,87 & 91,5 \\
Gallev & 71,44 & 47,41 & 91,96 \\
shift-PRML & 69,38 & 45,45 & 91,9 \\
MLMH & 68,16 & 42,68 & 92,18 \\
GBN & 62,61 & 42,62 & 89,2 \\
PRMO & 62,39 & 40,89 & 86,53 \\
DIT & 61,87 & 40,16 & 88,51 \\
PRT & 60,86 & 42,42 & 87,32 \\
Schroeder-SOH & 59,70 & 14,4 & 89,98 \\
clipping-SOH & 59,53 & 0 & 90,61 \\
shift-TPB & 58,26 & 39,1 & 88,35 \\
Rademacher-HAB & 58,21 & 39,23 & 87,44 \\
shift-QRT & 57,92 & 35,78 & 86,35 \\
shift-PRB & 57,50 & 38,53 & 87,47 \\
Rademacher-QRB & 56,89 & 39,19 & 88,05 \\
Rademacher-QRT & 56,76 & 39,2 & 87,25 \\
Rademacher-PRB & 56,54 & 38,34 & 88,52 \\
shift-HAB & 56,39 & 38,27 & 87,6 \\
shift-QRB & 56,24 & 36,71 & 86,35 \\
Rademacher-TPB & 56,22 & 38,61 & 84,34 \\
DIB & 55,09 & 35,6 & 86,64 \\
Degrau ${ }^{1}$ & 49,97 & 28,46 & 66,31 \\
CBN & 48,33 & 30,69 & 80,58 \\
\hline
\end{tabular}

${ }^{1}$ Os experimentos com excitações em degrau foram realizados em dois cenário de distúrbio (tabela 10.14).

Modelos ajustados a partir de dados dos experimentos A, B e C com sinais Schroeder-SOH e clipping-SOH, para os quais o índice CISS calculado tende a infinito (tabelas 10.12 e 10.13), em geral resultaram em $\overline{F I T}$ reduzidos nas validações com sinais GBN (figuras 10.16, 10.20, 10.24 e tabela 10.16). Nas validações com sinais do tipo onda quadrada, os $\overline{F I T}$ obtidos com esses modelos são comparativamente maiores (tabela 10.17). Essa característica sugere que a elevada correlação cruzada (CISS elevado) entre os sinais de cada conjunto (Schroeder-SOH e clipping-SOH) prejudicou 
Tabela 10.16: Médias, valores mínimos e máximos dos $\overline{F I T}$ obtidos em todas as saídas $y_{p}$, todos experimentos (A, B e C) e validação com sinais GBN.

\begin{tabular}{lccc}
\hline Sinais & $\overline{F I T}$ & $\min \{\overline{F I T}\}$ & $\max \{\overline{F I T}\}$ \\
\hline shift-PRML & 80,66 & 64 & 91,9 \\
Gallev & 80,24 & 64,44 & 91,96 \\
MLNL & 78,16 & 63,61 & 91,5 \\
MLMH & 77,94 & 63,87 & 92,18 \\
PRMO & 73,42 & 61,83 & 86,53 \\
GBN & 73,40 & 61,58 & 89,2 \\
DIT & 71,94 & 60,36 & 88,51 \\
PRT & 71,74 & 61,11 & 87,32 \\
shift-TPB & 68,61 & 57,93 & 88,35 \\
Rademacher-HAB & 68,44 & 57,07 & 87,44 \\
shift-QRT & 68,27 & 57,65 & 86,35 \\
shift-PRB & 67,76 & 57,3 & 87,47 \\
Rademacher-QRB & 67,06 & 54,05 & 88,05 \\
Rademacher-QRT & 66,92 & 54,07 & 87,25 \\
Rademacher-PRB & 66,66 & 55,14 & 88,52 \\
shift-HAB & 66,37 & 57,27 & 87,6 \\
Rademacher-TPB & 66,37 & 55,7 & 84,34 \\
shift-QRB & 66,33 & 53,82 & 86,35 \\
DIB & 64,99 & 53,67 & 86,64 \\
CBN & 57,22 & 47,22 & 80,58 \\
Degrau & 52,09 & 28,46 & 59,29 \\
Schroeder-SOH & 51,83 & 14,4 & 87,28 \\
clipping-SOH & 46,15 & 0 & 75,38 \\
\hline
\end{tabular}

${ }^{1}$ Os experimentos com excitações em degrau foram realizados em dois cenário de distúrbio (tabela 10.14).

em maior intensidade o ajuste dos modelos nas frequências mais altas.

Conforme as tabelas 10.12 e 10.13, o CISS para os sinais Rademacher-QRB, Rademacher-QRT, Rademacher-HAB, Rademacher-TPB, Rademacher-PRB, shift-QRB, shift-QRT, shift-HAB, shift-TPB e shift-PRB são semelhantes. Os valores de $\overline{F I T}$ obtidos com modelos ajustados a partir de dados de experimentos com esses sinais também são semelhantes (figuras 10.18, 10.19, 10.22, 10.23, 10.26, 10.27 e tabelas 10.15 a 10.17). Observa-se que nas validações com sinais do tipo onda quadrada, os $\overline{F I T}$ obtidos com esses modelos são significativamente inferiores aos obtidos nas validações com sinais GBN. Sugere-se que os sinais Rademacher-QRB, RademacherQRT, Rademacher-HAB, Rademacher-TPB, Rademacher-PRB, shift-QRB, shift-QRT, shift-HAB, shift-TPB e shift-PRB não ofereceram dados informativos para bons ajustes dos modelos em baixas frequências.

Os CISS dos sinais shift-PRML, PRT (ternários) e PRMO (multinível, porém, ternários nos experimentos $\mathrm{A}, \mathrm{B}$ e C) apresentam valores maiores que os CISS dos 
Tabela 10.17: Médias, valores mínimos e máximos dos $\overline{F I T}$ obtidos em todas as saídas $y_{p}$, todos experimentos (A, B e C) e validação com sinais do tipo onda quadrada.

\begin{tabular}{lccc}
\hline Sinais & $\overline{F I T}$ & $\min \{\overline{F I T}\}$ & $\max \{\overline{F I T}\}$ \\
\hline clipping-SOH & 71,00 & 52,15 & 90,61 \\
Schroeder-SOH & 66,82 & 48,94 & 89,98 \\
MLNL & 64,74 & 47,87 & 91,04 \\
Gallev & 62,65 & 47,41 & 82,05 \\
MLMH & 58,39 & 42,68 & 81,33 \\
shift-PRML & 58,09 & 45,45 & 75,91 \\
GBN & 51,82 & 42,62 & 73,23 \\
DIT & 51,80 & 40,16 & 82,52 \\
PRMO & 51,36 & 40,89 & 65,98 \\
PRT & 49,98 & 42,42 & 66,57 \\
Degrau ${ }^{1}$ & 48,80 & 39,53 & 66,31 \\
Rademacher-HAB & 47,98 & 39,23 & 72,41 \\
shift-TPB & 47,92 & 39,1 & 71,12 \\
shift-QRT & 47,57 & 35,78 & 65,65 \\
shift-PRB & 47,24 & 38,53 & 67,08 \\
Rademacher-QRB & 46,71 & 39,19 & 68,73 \\
Rademacher-QRT & 46,59 & 39,2 & 67,36 \\
shift-HAB & 46,42 & 38,27 & 72,62 \\
Rademacher-PRB & 46,41 & 38,34 & 70,18 \\
shift-QRB & 46,14 & 36,71 & 65,66 \\
Rademacher-TPB & 46,07 & 38,61 & 63,26 \\
DIB & 45,20 & 35,6 & 72,18 \\
CBN & 39,45 & 30,69 & 58,95 \\
\hline
\end{tabular}

${ }^{1}$ Os experimentos com excitações em degrau foram realizados em dois cenário de distúrbio (tabela 10.14).

sinais binários de espectro fixo (Rademacher-QRB, Rademacher-HAB, RademacherTPB, Rademacher-PRB, shift-QRB, shift-HAB, shift-TPB e shift-PRB) e quase binários (Rademacher-QRT e shift-QRT) (tabelas 10.12 e 10.13). Os sinais PRT e PRMO apresentaram CISS $\frac{435-345}{345}=26 \%$ maior que os sinais binários de espectro fixo, conforme tabelas 10.12 e 10.13. Apesar do CISS mais elevado, os $\overline{F I T}$ obtidos com os modelos ajustados a partir de dados de experimentos com os sinais shift-PRML, PRT e PRMO foram superiores aos obtidos com modelos ajustados a partir de dados de experimentos com os sinais binários e quase binários, tanto para a validação com sinais GBN quanto para a validação com sinais do tipo onda quadrada (figuras 10.18, 10.19, $10.22,10.23,10.26$ e 10.27). Observando-se as médias desses $\overline{F I T}$ nas tabelas 10.15 a 10.17 , verifica-se quantitativamente o quanto em média o $\overline{F I T}$ foi superior.

Os sinais DIB, os quais são do tipo SOH, resultaram em CISS semelhante aos dos sinais de espectro fixo binários e quase binários (tabelas 10.12 e 10.13). Os $\overline{F I T}$ ob- 
tidos com os modelos ajustados a partir de dados de experimentos com os sinais DIB também são semelhantes aos $\overline{F I T}$ de modelos ajustados a partir de dados de experimentos com sinais binários ou quase binários (figuras 10.18, 10.19, 10.22, 10.23, 10.26 e 10.27). Nas tabelas tabelas 10.15 a 10.17 observa-se que em média os $\overline{F I T}$ obtidos com os sinais DIB são pouco inferiores. Os sinais DIT, os quais são ternários e do tipo $\mathrm{SOH}$, apresentam CISS maiores que os sinais DIB $\left(\frac{556-331}{331}=68 \%\right.$ e $\frac{576-340}{340}=69 \%$, conforme tabelas 10.12 e 10.13 , respectivamente). Porém, os $\overline{F I T}$ obtidos com os modelos ajustados a partir de dados de experimentos com sinais DIT são superiores (figuras $10.18,10.19,10.22,10.23,10.26$ e 10.27). Essa característica é melhor evidenciada observando-se a média dos $\overline{F I T}$ nas tabelas 10.15 a 10.17 .

Os modelos ajustados a partir de dados de experimentos com sinais CBN apresentaram $\overline{F I T}$ em geral menores que os modelos ajustados a partir de dados de experimentos com os demais sinais, exceto em relação aos modelos ajustados a partir de dados de experimentos com sinais Schroeder-SOH e clipping-SOH. Conforme discutido anteriormente, a validação desses modelos com sinais GBN mostraram ajuste comparativamente ruim dos modelos. As tabelas 10.15 e 10.17 mostram que as menores médias dos $\overline{F I T}$ foram obtidas com os sinais CBN. Apesar de elevadas SNR nas saídas obtidas nos experimentos A e B (figuras 10.28 e 10.29), os resultados com esses sinais em termos de $\overline{F I T}$ foram ruins. Nas tabelas 10.12 e 10.13 , observa-se que os CISS para os sinais CBN são $\frac{345-277}{345} \approx 20 \%$ e $\frac{345-301}{345} \approx 13 \%$ menores que os CISS dos sinais binários de espectro fixo, respectivamente. Porém, os EMINE para esses sinas são extremamente reduzidos. Isso evidencia a característica aleatória do espectro dos sinais CBN, a qual não permite gerar sinais com espectro semelhante ao especificado. Assim, harmônicas de interesse podem ser pouco excitadas pelos sinais CBN, resultando em ajuste ruins dos modelos.

Assim como os sinais CBN, os sinais GBN apresentaram EMINE reduzidos (tabelas 10.12 e 10.13). Porém, o CISS dos sinais GBN são, conforme tabelas 10.12 ou $10.13, \frac{301-108}{301} \approx 64 \%$ ou $\frac{277-93}{277} \approx 66 \%$, respectivamente, menores que os CISS dos sinais CBN. Os $\overline{F I T}$ obtidos com os sinais GBN foram superiores aos obtidos com os sinais CBN e semelhantes aos obtidos com os sinais de espectro fixo binários e quase binários.

Os sinais MLMH, os quais são do tipo SOH, apresentaram, em geral, resultados em termos de $\overline{F I T}$ superiores aos obtidos com os sinais de espectro fixo binários e quase binários e sinais DIB e DIT (tabelas 10.15 a 10.17), apesar do CISS para os sinais MLMH ser maior. Das tabelas 10.12 e 10.13, verifica-se que o CISS para os sinais MLMH é $\frac{624-345}{345}=81 \%$ maior que os obtidos com os sinais de espetro fixo binários. Nos casos de SNR mais elevadas nas saídas, como é o caso das saídas $y_{5}, y_{6}$ 
e $y_{7}$ (figuras $10.28,10.29$ e 10.30), os sinais MLMH proporcionaram maiores $\overline{F I T}$ que os sinais de espectro fixo binários e quase binários e sinais DIB e DIT (figuras 10.18, $10.19,10.22,10.23,10.26$ e 10.27$)$.

Nos experimentos A e B, os sinais Gallev e MLNL apresentaram CISS semelhantes $(\approx 703)$ e mais elevados que os demais sinais, exceto os sinais Schroeder-SOH e clipping-SOH com $C I S S=\infty$. Essa situação também ocorre nos experimentos $\mathrm{C}$, onde o CISS para os sinais MLNL é de $\approx 685$. Nesse experimento, o CISS para o sinal Gallev é $\frac{685-530}{685} \approx 23 \%$ menor. Porém, os modelos ajustados a partir de dados de experimentos com esses sinais, apresentaram $\overline{F I T}$ elevados para todas as saídas $y_{p}$ e validação tanto com sinais GBN quanto com sinais do tipo onda quadrada. Os $\overline{F I T}$ são superiores aos obtidos com os demais modelos nas condições de maior SNR. Em média, os $\overline{F I T}$ obtidos com os sinais MLNL e Gallev são superiores aos demais (tabela 10.15). Considerando-se apenas a validação com sinais do tipo onda quadrada, em média os $\overline{F I T}$ obtidos com os sinais MLNL e Gallev, apesar de elevados, são inferiores aos obtidos com os sinais Schroeder-SOH e clipping-SOH (tabela 10.17). Cabe ressaltar que os $\overline{F I T}$ obtidos com os modelos ajustados a partir de dados de experimentos com esses sinais e validados com sinais GBN foram reduzidos (tabela 10.16).

A partir das observações anteriores, tem-se que os $\overline{F I T}$ dos modelos são pouco sensíveis aos índices CISS dos sinais que geraram os dados. Nos casos em que o CISS tende ao infinito (sinais Schroeder-SOH e clipping-SOH) os dados dos experimentos resultaram em vários modelos que não representaram a planta $(\overline{F I T}<0)$. Esses resultados motivam o uso do índice CISS para indicar a tendência do conjunto de sinais não gerar dados suficientemente informativos para bons ajustes de modelos.

Os sinais MLNL e Gallev permitiram gerar dados para bons ajustes dos modelos nos cenários de mais elevadas ou mais reduzidas variâncias de ruído de medição ou de perturbações não medidas. Essa característica de robustez dos sinais é desejável, visto que em experimentos práticos pode-se ter pouco (ou nenhum) conhecimento sobre as perturbações que poderão ocorrer durante o experimento. Os sinais MLMH também possibilitaram bons ajustes dos modelos, porém, conforme discutido em capítulos anteriores, a construção desses sinais depende de algoritmos iterativos de otimização de suas fases, os quais podem requerer maior recurso de engenharia nas etapas anteriores do experimento. Os sinais Gallev e MLNL também podem utilizar sementes do tipo sinais otimizados por computador. Nos experimentos A, B e C (tabelas 10.10 e 10.11), os sinais MLNL e Gallev utilizaram sementes Schroeder-SOH e, portanto, suas construções foram totalmente algébricas, não dependendo de algoritmos de otimização. Os bons resultados obtidos com esses sinais gerados algebricamente motivam seus usos para aplicações práticas de identificação de plantas, onde se objetiva 
automatizar os procedimentos de planejamento dos experimentos, visando agilidade na obtenção de bons modelos.

As figuras 10.31, 10.32 e 10.33 apresentam a validação com sinais GBN em termos de $\overline{F I T}$ em função dos passos de predição dos modelos ARX de alta ordem obtidos de experimentos com sinais MLNL, Gallev e MLMH. Observa-se que o $\overline{F I T}$ acima de 10 passos de predição é aproximadamente constante para todos esses modelos.

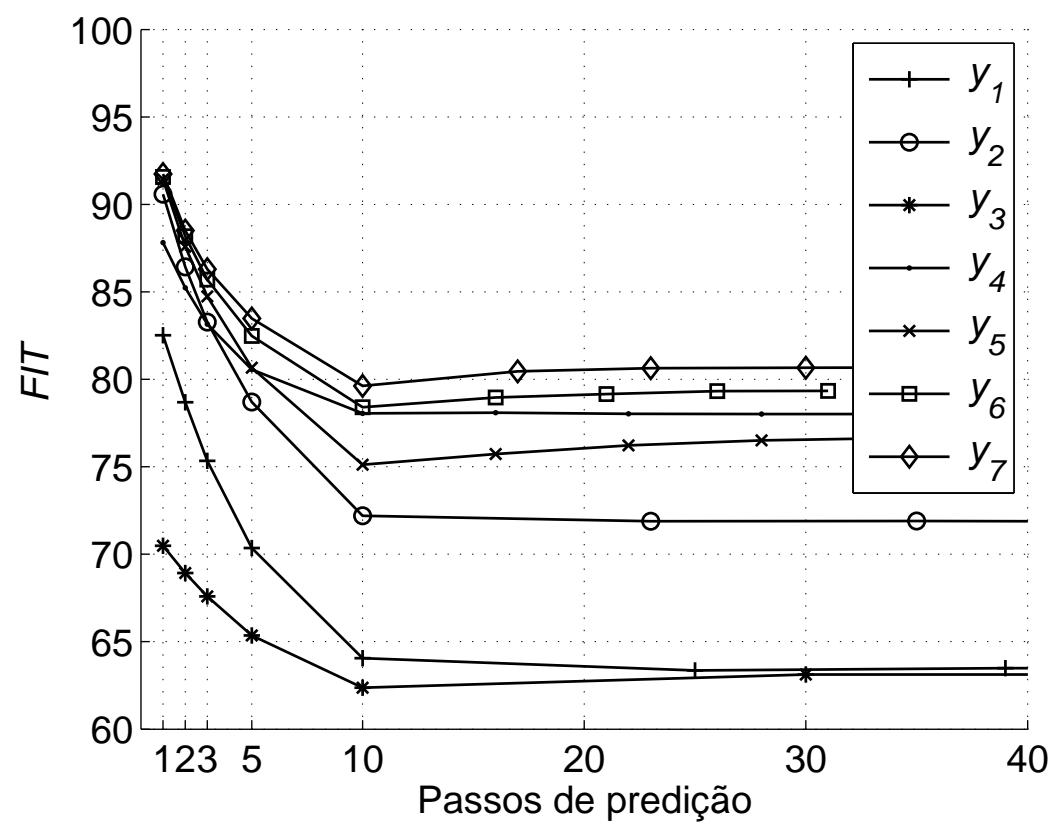

Figura 10.31: Validação com sinais GBN em termos de $\overline{F I T}$ em função dos passos de predição dos modelos ARX de alta ordem obtidos de experimentos com sinais MLNL.

\subsection{Resumo do capítulo}

Os sinais de excitação discutidos em capítulos anteriores foram comparados em termos de seus desempenhos obtidos em simulações de Monte-Carlo de identificação de uma planta de processamento. A planta simulada consiste em um modelo linear obtido por meio de identificação do conjunto reator-regenerador de uma unidade FCC da refinaria Neste Oy (GROSDIDIER et al., 1993). A medida de desempenho utilizada na comparação dos modelos identificados foi o $\overline{F I T}(8.27)$.

As simulações das identificações foram realizadas em dois cenários diferentes de ruídos de medição e de perturbação. Foram realizadas simulações de experimentos com os períodos dos sinais mais próximos da duração mínima do experimento $T_{e}$ calculado (10.5), como também com os períodos mais longos. Os dois cenários de intensidade de ruídos e perturbações, bem como durações de experimento, geraram 


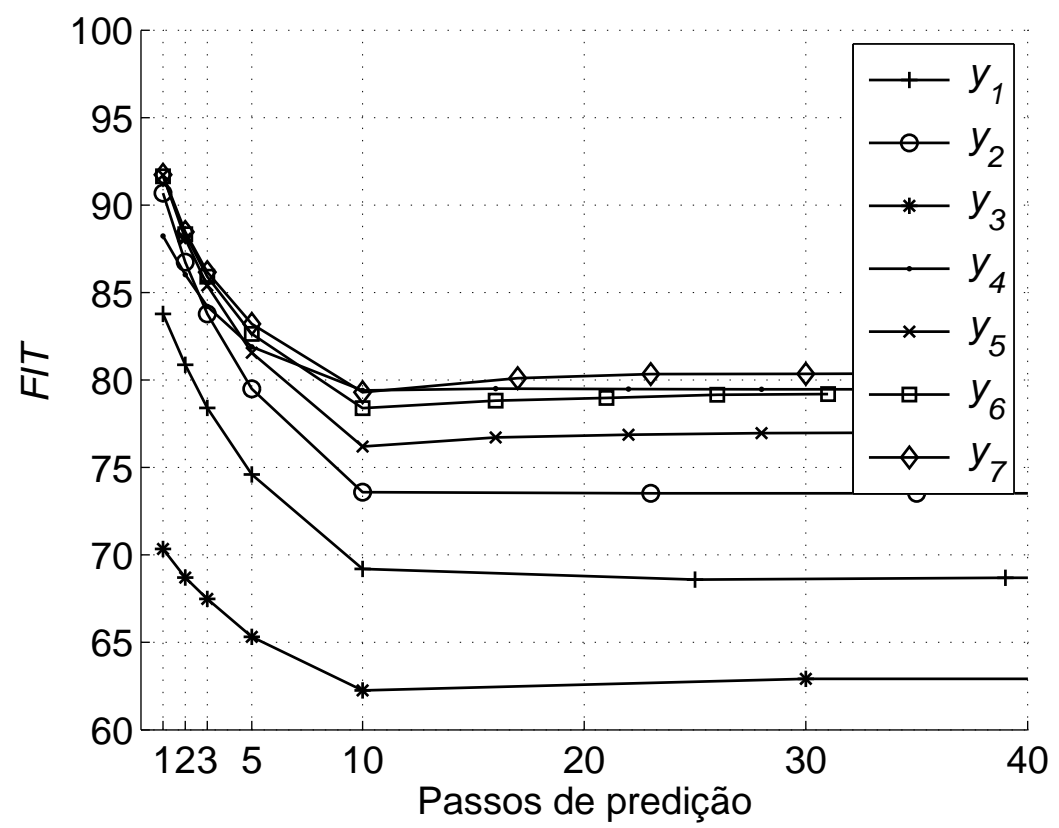

Figura 10.32: Validação com sinais GBN em termos de $\overline{F I T}$ em função dos passos de predição dos modelos ARX de alta ordem obtidos de experimentos com sinais Gallev.

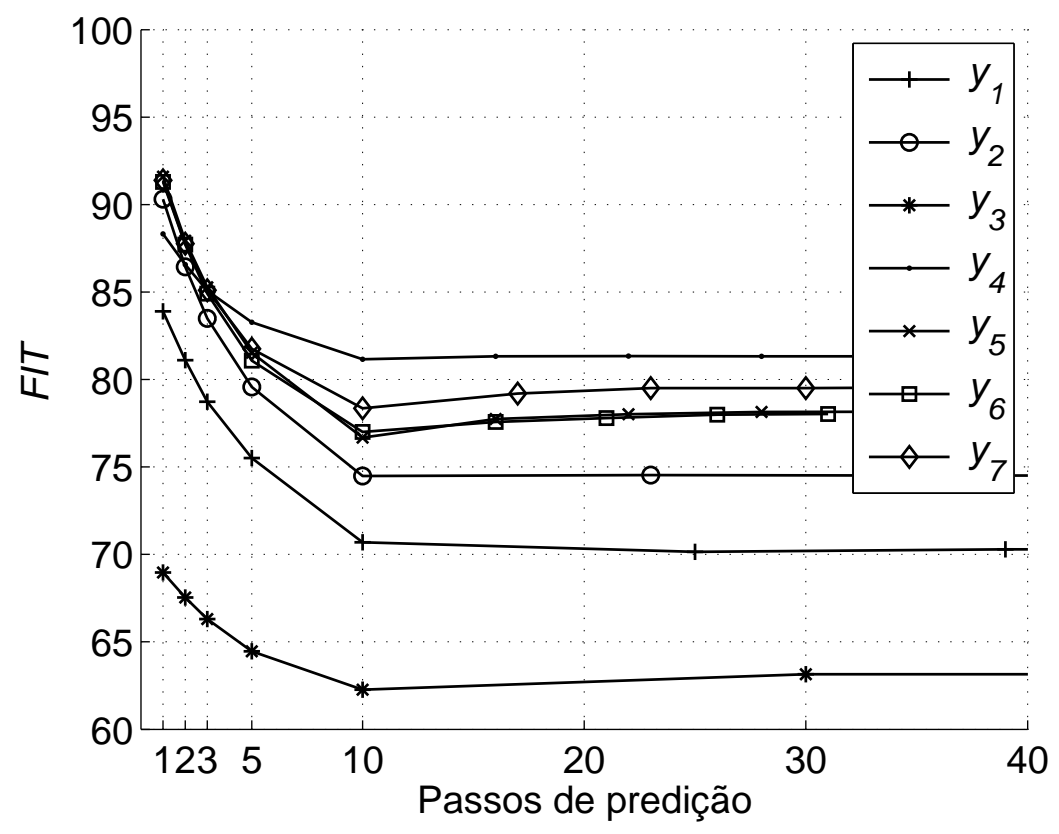

Figura 10.33: Validação com sinais GBN em termos de $\overline{F I T}$ em função dos passos de predição dos modelos ARX de alta ordem obtidos de experimentos com sinais MLMH.

três grupos de experimentos (tabela 10.8). Assim, é possível avaliar a flexibilidade de geração dos sinais e suas robustez em fornecer dados informativos para identificação frente a ruídos e perturbações. 
Os índices de desempenho dos sinais de excitação foram calculados e comparados com os desempenhos dos respectivos modelos identificados. As estruturas de modelos utilizadas na identificação foram: ARX de alta ordem, ARX, FIR e ARMAX.

Comparando-se o índice CISS, proposto neste trabalho, com a medida A-optimality, confirma-se a correlação dele com a variância dos parâmetros estimados do modelo FIR. Assim, conclui-se que o índice CISS é uma boa medida comparativa de sinais de excitação relativa ao desempenho do estimador previamente ao experimento de identificação.

Foram realizadas também identificações com excitações em degrau positivo e negativo aplicados sequencialmente nas entradas da planta. Conforme esperado, verificou-se que há ganho de desempenho quando sinais de excitação são utilizados em detrimento às excitações em degrau.

Verificou-se que os sinais com elevados PIPS e PIPSE (reduzidos CF) em geral resultam em valores mais elevados de SNR nas saídas da planta. Porém, elevadas SNR não implicaram em bons ajustes dos modelos. Esse resultado sugere que não só as potências dos sinais, mas suas respostas em frequência e correlações são também importantes para a obtenção de dados informativos para a identificação. Os conjuntos de sinais com elevados CISS (tendendo ao infinito) não permitiram bom desempenho dos modelos quando validados com sinais GBN. Nos demais conjuntos de sinais, os quais tiveram CISS distintos, porém, de mesma ordem, não foi observada uma relação direta entre CISS e $\overline{F I T}$. Porém, a medida CISS utilizada de forma comparativa é útil para, de uma seleção de conjuntos de sinais para identificação, segregar aqueles conjuntos de sinais que devem ser utilizados com menor prioridade (aqueles com valores de CISS tendendo ao infinito).

Os sinais híbridos Gallev e MLNL, este último proposto neste trabalho, os sinais MLMH, os quais são do tipo SOH otimizados por computador, e os sinais shiftPRML proporcionaram à identificação, em média, desempenhos distintos e melhores que aqueles obtidos por meio dos demais sinais. Os sinais shift-PRML e MLMH resultaram em $\overline{F I T}$ inferiores aos obtidos com os sinais Gallev e MLNL nas validações com sinais do tipo onda quadrada. Outra vantagem dos sinais Gallev e MLNL frente aos sinais MLMH refere-se à não necessidade de utilizar algoritmos iterativos de otimização em suas construções. Assim como nas simulações realizadas neste capítulo, os sinais Gallev e MLNL podem ter suas sementes geradas por sinais Schroeder-SOH, os quais são de construção puramente algébrica, não dependentes de algoritmos iterativos de otimização. Assim, os sinais MLNL propostos neste trabalho também podem ser considerados como opção à identificação de plantas de processamento. 


\section{Conclusões}

\subsection{Principais conclusões}

O capítulo 1 discutiu as motivações para o estudo de sinais de excitação para identificação de plantas industriais. O capítulo 2 mostrou, sob o ponto de vista do projeto ótimo do experimento de identificação, que o conjunto de sinais ótimos é aquele que minimiza a variância dos parâmetros estimados do modelo. Para obter os sinais ótimos para a identificação de uma planta segundo esse critério é necessário conhecer a planta, o que é contraditório ao objetivo da identificação. A partir da discussão do projeto ótimo de sinais de excitação, foram estabelecidos requisitos quanto à potência, espectro e características das funções de correlação dos sinais de excitação.

No capítulo 3, os requisitos para os conjuntos de sinais de excitação discutidos no capítulo 2 são transformados em critérios de projeto viáveis de serem atendidos com poucas informações sobre a planta. Essas informações são assumidas conhecidas previamente ao experimento de identificação e possibilitam projetar sinais segundo os critérios discutidos.

As excitações das plantas alteram sua operação normal. Portanto, é desejável que os experimentos de identificação não sejam extensos e tenham sucesso, evitando sua repetição. Assim, surge a necessidade de garantir a efetividade dos sinais de excitação na obtenção de dados informativos previamente ao experimento de identificação. $\mathrm{Na}$ literatura encontram-se várias medidas de desempenho de sinais de excitação que objetivam avaliá-los frente aos critérios de potência da excitação e espectro. Foi proposta no capítulo 4 uma medida, intitulada CISS, que avalia comparativamente conjuntos de sinais de excitação quanto às variâncias dos parâmetros estimados de um modelo FIR.

O capítulo 5 foi dedicado à uma revisão bibliográfica sobre os sinais de excitação encontrados na literatura. Foram discutidos métodos de construção de sinais aleatórios, sinais otimizados por computador, sinais de espectro fixo e sinais híbridos. A discussão envolve, além dos passos para construção dos sinais, as vantagens e desvantagens de cada método e apresenta exemplos de parametrizações desses sinais. 
Na revisão bibliográfica foram identificadas duas lacunas nos métodos de geração de sinais de excitação.

1. Na literatura não se encontra um método sistemático para construção de conjuntos de sinais multinível ortogonais sem a utilização de algoritmos de otimização. No capítulo 6 foi proposto um método de construção de conjuntos de sinais multinível ortogonais, intitulados PRMO, que utiliza apenas operações algébricas e, portanto, não depende de algoritmos iterativos de otimização.

2. A proposta encontrada na literatura para construção de sinais híbridos (sinais Gallev) fornece uma gama limitada de comprimentos de sinais. No capítulo 6 foi proposto um método que permite construir sinais híbridos, intitulados MLNL, com comprimentos complementares aos sinais Gallev.

Os métodos de construção de sinais da literatura e os propostos neste trabalho foram comparados em relação às suas características (capítulo 7): amplitude quantizada ou contínua; comprimentos disponíveis; flexibilidade de modelar a envoltória do espectro e possibilidade de construir sinais ortogonais desejáveis para identificação multivariável.

O capítulo 8 discutiu a identificação de plantas mal condicionadas. Foram avaliados cinco métodos de construção de sinais de excitação encontrados na literatura desenvolvidos para identificação de plantas mal condicionadas: sinais rotacionados, sinais $\mathrm{SOH}$ com espectros intercalados modificados, sinais PRT e sinais construídos pelos métodos 1 e 2 de dois passos. A avaliação foi realizada por meio de comparação de índices de desempenho de sinais de excitação e por meio de comparação de resultados de simulações de identificação de colunas de destilação de alta pureza (modelos de primeira e segunda ordem) em diferentes cenários de perturbação. Os cinco conjuntos de sinais de excitação foram utilizados nos experimentos que geraram dados para ajustar parâmetros de modelos ARX e ARMAX. Sinais PRB, não desenvolvidos com características específicas para identificação de plantas com direcionalidade de ganho, também foram utilizados na identificação com o objetivo de comparação com a efetividade dos demais sinais. A medida FIT foi utilizada para avaliar a adequação dos conjuntos de sinais para identificação das plantas. Por meio dessa medida constatouse que os quatro conjuntos de sinais: rotacionados, $\mathrm{SOH}$ com espectros intercalados modificados e construídos pelos métodos 1 e 2 de dois passos proporcionaram FIT sensivelmente mais elevados que os obtidos com os sinais PRT e PRB. No caso das simulações com a planta de primeira ordem, verificou-se que os sinais $\mathrm{SOH}$ com espectros intercalados modificados proporcionaram FIT mais elevados que os demais. 
Nas simulações com a planta de segunda ordem, os FIT obtidos com os quatro conjuntos de sinais foram semelhantes.

Os sinais propostos na literatura para identificação de plantas mal condicionadas utilizam entradas correlacionadas para produzir saídas não correlacionadas, superando a característica de direcionalidade de ganho dessas plantas. Os índices discutidos no capítulo 4 não avaliam os conjuntos de sinais de excitação quanto a essa característica particular. Assim, visando garantir a efetividade dos sinais de excitação aplicáveis a identificação de plantas mal condicionadas quanto à geração de dados informativos para identificação, no capítulo 8 foi proposto o índice SF (fator de dispersão). Esse índice pode ser usado para avaliar a dispersão das saídas da planta na condição estática, sendo necessário conhecimento a priori dos ganhos estáticos da planta. Alternativamente, o índice pode ser calculado com o decorrer do experimento, antes de seu término, utilizando os dados das saídas da planta. Assim, é possível avaliar a adequação dos sinais de excitação e, caso identificar que os dados não são informativos (SF reduzido), interromper o experimento evitando excitar a planta sem efetividade para identificação. Nas simulações realizadas, o SF também foi calculado e se mostrou aderente ao FIT, ou seja, experimentos com SF elevados resultam em modelos com FIT também elevados. Essa contatação confirma a utilidade do índice proposto.

Ainda no capítulo 8 foi proposta uma modificação em um dos métodos que utiliza a rotação de sinais binários. Nessa proposta os sinais são rotacionados de forma a obter saídas com amplitudes com limites especificados, o que é desejável em um experimento de identificação. Por meio de simulações utilizando as plantas de primeira e segunda ordem foi avaliada a efetividade da proposta. Verificou-se que os sinais propostos geram saídas atendendo perfeitamente às restrições impostas quando o número de condição da matriz de transferência da planta em função da frequência é constante. Quando a planta não possui essa característica, as saídas superam os limites definidos. Em (LEE; RIVERA; MITTELMANN, 2003) (LEE et al., 2003) (LEE, 2006) (RIVERA et al., 2009) foi apresentado um método com o mesmo objetivo, porém, utiliza um método iterativo de otimização de fases de sinais $\mathrm{SOH}$. Nesses trabalhos, foi demonstrada a efetividade do método apenas na mesma planta de primeira ordem, onde número de condição da matriz de transferência em função da frequência é constante. O método proposto neste trabalho é totalmente algébrico e, portanto, de maior simplicidade de implementação.

Não havia disponível um software capaz de gerar em um único ambiente de simulação todos os sinais de excitação discutidos neste trabalho e avaliá-los com referência aos índices de desempenho de sinais. Assim, para viabilizar as avaliações de sinais de excitação e seus índices de desempenho, neste trabalho foi desenvolvida 
uma ferramenta que gera conjuntos de sinais ajustados aos conhecimentos a priori da planta em estudo, utilizando todos os métodos discutidos aqui. Essa ferramenta, apresentada no capítulo 9, também calcula os índices de desempenho desses sinais. Nesse capítulo também foi apresentada uma metodologia sistemática para parametrização e seleção de sinais de excitação para identificação de plantas de processos industriais. A metodologia abrange os sinais de excitação encontrados na literatura e também os propostos aqui. Para parametrização e seleção dos sinais são utilizados os conceitos encontrados na literatura e também o índice de avaliação de conjuntos de sinais de excitação proposto neste trabalho (CISS).

O capítulo 10 apresentou simulações de identificação de um conjunto reator-regenerador de craqueamento catalítico fluido (FCC) utilizando os 22 conjuntos de sinais de excitação discutidos neste trabalho. As simulações foram realizadas em dois cenários de ruído de medição e perturbação. Para cada conjunto de sinais foram calculados os seis índices de desempenho (capítulo 4). Os resultados de identificação confirmaram que há correlação entre o índice CISS proposto neste trabalho e a variância dos parâmetros estimados do modelo FIR. Conjuntos de sinais com CISS mais elevados tendem a gerar dados de experimentos que proporcionam menor desempenho do estimador de parâmetros do modelo FIR, ou seja, maior variância dos parâmetros estimados. Os conjuntos de sinais com CISS tendendo ao infinito geraram alguns conjuntos de dados que não permitiram ajuste adequado (FIT próximo a zero) de modelos ARX, FIR ou ARMAX. Esses resultados confirmam a efetividade do CISS para avaliação e seleção de conjuntos de sinais de excitação para identificação de plantas. Porém, exceto os casos de CISS tendendo ao infinito que resultaram em FIT próximos a zero, não se observa forte correlação entre a variância dos parâmetros estimados e o FIT do modelo.

Os resultados apresentados no capítulo 10 também mostram que os sinais híbridos MLNL propostos neste trabalho são efetivos na identificação multivariável. Os resultados em termos de FIT de modelos ajustados com dados de experimentos com sinais MLNL em geral foram superiores aos demais 21 conjuntos de sinais de excitação avaliados, mas muito próximos dos FIT obtidos com sinais Gallev, os quais também são sinais híbridos. Assim, os sinais MLNL são boas opções para identificação multivariável.

\subsection{Trabalhos futuros}

Durante o programa deste doutorado foram elaborados dois artigos técnicos, (KURAMOTO; VAILLANT; GARCIA, 2012) e (VAILLANT; KURAMOTO; GARCIA, 2012), que 
contêm estudos, propostas e resultados apresentados e discutidos aqui:

- KURAMOTO, A. S. R.; VAILLANT, O. R.; GARCIA, C. Effectiveness of signal excitation design methods for ill-conditioned processes identification. International Symposium on Advanced Control of Chemical Process (ADCHEM 2012), july 2012.

- VAILLANT, O. R.; KURAMOTO, A. S. R.; GARCIA, C. Effectiveness of signal excitation design methods for identification of ill-conditioned and highly interactive processes. In revision process: Industrial $\mathcal{E}$ Engineering Chemistry Research.

Outros tópicos não contemplados nesses artigos serão assunto de, pelo menos, outros três artigos técnicos que estão em elaboração:

1. Propostas de construção e seleção de sinais multinível para identificação multivariável (conteúdo do capítulo 6 e das seções 4.7 e 9.10)

2. Excitação multivariável de plantas mal condicionadas com restrições de variabilidade das saídas (conteúdo da seção 8.5).

3. Avaliação comparativa de sinais de excitação para identificação multivariável de plantas industriais (conteúdo do capítulo 10).

Como continuidade do estudo desenvolvido neste trabalho, sugere-se avaliar:

1. Os sinais PRMO e MLNL propostos neste trabalho, os quais possuem espectros intercalados, associados à identificação no domínio da frequência. A filtragem nas saídas das harmônicas especificadas nulas nas entradas provê ganhos de desempenho na estimação de parâmetros do modelo (PINTELON; SCHOUKENS, 2001).

2. O desempenho dos sinais de excitação multinível propostos neste trabalho na identificação multivariável de sistemas não lineares.

3. A efetividade de métodos otimização combinatória (PAPADIMITRIOU; STEIGLITZ, 1998) (KURAMOTO et al., 2012) para gerar sementes de sinais MLNL. Otimizar as sementes de comprimento $L=q^{m}-1$ é um problema de otimização de ordem exponencialmente menor comparado ao comprimento das sequências MLNL $N=q^{n}-1$, pois $m$ é fator de $n$. 


\section{Apêndice A - Identificação em malha fechada e em malha aberta}

Em identificação de planta de processos industriais é frequentemente desejável, do ponto de vista operacional, que o experimento seja executado em malha fechada, ou seja, identificação em malha fechada. Com a planta em malha fechada, os controles regulatórios e avançados, caso houver, estão atuando e minimizam os efeitos na variabilidade dos produtos e, consequentemente, minimizam eventuais perdas de produção. Adicionalmente, os riscos relativos à segurança da planta também diminuem, pois os controladores estarão atuando de forma a conduzir as variáveis controladas a seu ponto de operação. Assim, as intervenções da equipe de operação são menos prováveis quando comparado à identificação em malha aberta, onde não há atuação de controladores (ZHU, 2001).

Além das questões operacionais citadas, a identificação em malha fechada possui vantagens de provocar maior variância nas CV. Em malha fechada, o controle regulatório atuará para que o efeito na $\mathrm{CV}$ de uma perturbação seja extinto em um tempo reduzido. A variância na $\mathrm{CV}$ tende ser maior quando comparado ao efeito lento de uma perturbação em malha aberta. Operacionalmente é possível ter maior variância nas $\mathrm{CV}$, pois os limites de excursão das CV na prática são definidos em termos de amplitude e não em termos de variância (ZHU, 2001).

Em malha fechada as formas comuns de excitar a planta são a aplicação de sinais de excitação no set point das CV ou nas saídas do controladores. Há trabalhos recentes que apresentam outras forma mais elaboradas de excitar o sistema, por exemplo, variando o sinal de atuação nas MV de um MPC (SOTOMAYOR; ODLOAK; MORO, 2009).

A principal desvantagem da identificação em malha fechada é decorrente da realimentação, a qual faz com que a entrada da planta seja correlacionada com a perturbação $v(t)$. Essa correlação pode provocar o efeito de polarização dos parâmetros estimados, tornando o estimador não consistente (LJUNG, 1999) (ZHU, 2001).

A identificação em malha aberta pode ser necessária em casos que o controle regulatório não está projetado e sintonizado adequadamente ou simplesmente caso ele não 
exista. Porém, mesmo que a planta seja estável para as excitações sem atuação de controladores, essas podem conduzir as saídas a regiões não desejáveis de operação, por exemplo, regiões não lineares, regiões limites para especificações de produtos, regiões não seguras de operação, etc. 


\section{Apêndice B - Identificação de plantas com distorções não lineares}

Os sinais binários são comumente utilizados na identificação de sistemas lineares. Em (AGUIRRE, 2007) mostra-se que é possível também identificar bons modelos não lineares a partir de testes que usam sinais PRB. Entretanto, em (LEONTARITIS; BILLINGS, 1987) e (BARKER; GODFREY; TUCKER, 2000) argumenta-se do ponto de vista teórico que sinais binários não são adequados para identificação de sistemas não lineares. Os casos discutidos em (BARKER; GODFREY; TUCKER, 2000) serão apresentados a seguir.

Considere um sistema com uma não linearidade quadrática conforme o modelo de Hammerstein da figura B.1 (BARKER; GODFREY; TUCKER, 2000). Os subsistemas indicados como $w_{1}$ e $w_{2}$ são lineares e o bloco $(.)^{2}$ implementa a não linearidade quadrática do modelo. Aplicando um sinal $u(t)$ binário na entrada do sistema, o sinal $v_{2}(t)$ será um sinal constante e, portanto, somente será possível identificar o ganho estático do sistema $w_{2}$. Assim, observa-se que um sinal binário pode não ser adequado para identificação de sistemas em que há não linearidades quadráticas. Sendo possível descorrelacionar os sinais $y_{1}(t)$ e $y_{2}(t)$ do sinal $y(t)$, os subsistemas $w_{1}(t)$ e $w_{2}(t)$ poderão ser identificados separadamente. Considere $u(t)$ um sinal com mais de 2 níveis cujo espectro não contém componentes harmônicos pares, ou seja, todas as harmônicas múltiplas de 2 estão suprimidas, existindo apenas harmônicas ímpares. O sinal $v_{2}(t)$ consequentemente terá apenas harmônicas pares. Os subsistemas lineares $w_{1}(t)$ e $w_{2}(t)$ não provocam distorção harmônica e, portanto, o sinal $y_{1}(t)$ irá conter apenas harmônicas ímpares e o sinal $y_{2}(t)$ irá conter apenas harmônicas pares. Assim, é possível descorrelacionar os sinais $y_{1}(t)$ e $y_{2}(t)$ do sinal $y(t)$ e identificar os subsistemas $w_{1}(t)$ e $w_{2}(t)$. É desejável que as harmônicas ímpares do sinal $u(t)$ possuam potências iguais, promovendo a característica de sinal persistente na identificação dos subsistemas. A identificação do sistema $w_{1}(t)$ é imediata relacionando o sinal $u(t)$ com apenas as harmônicas ímpares do sinal $y(t)$, ou seja, $y_{1}(t)$. A identificação do sistema $w_{2}(t)$ pode ser feita relacionando o sinal $u(i)^{2}$ com apenas as harmônicas pares do sinal $y(t)$, ou seja, $y_{2}(t)$. Portanto, na identificação de sistemas não lineares a supressão de harmônicas pares do sinal de excitação pode ser útil caso exista alguma não linearidade 
quadrática no sistema a ser identificado. Adicionalmente, um sinal binário pode não excitar um sistema não linear, caso exista não linearidade quadrática. Em (BARKER; TAN; GODFREY, 2004b), é apresentada uma metodologia para determinar a quantidade adequada de níveis para identificação de não linearidades de ordem $r \geq 2, r \in \mathbb{N}$. Esse assunto não é discutido nesse trabalho.

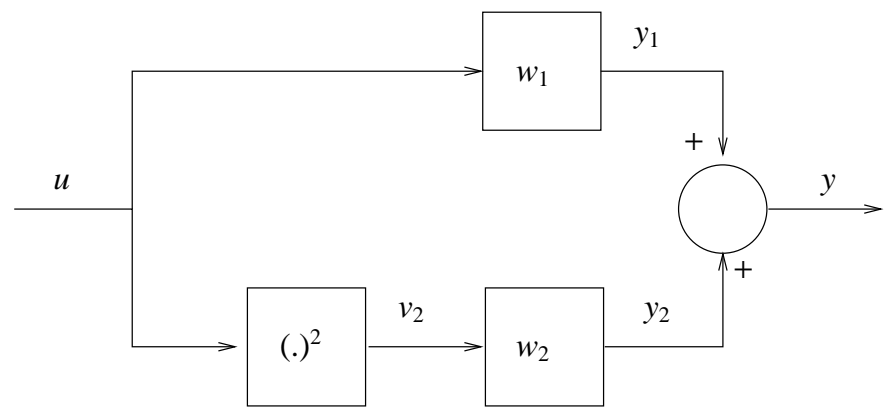

Figura B.1: Modelo com estrutura não linear quadrática de Hammerstein (BARKER; GODFREY; TUCKER, 2000).

No caso de um sistema com uma não linearidade quadrática conforme o modelo de Wiener da figura B.2 (BARKER; GODFREY; TUCKER, 2000), é possível identificá-lo com um sinal binário. Caso o subsistema linear $w_{2}$ resultar um sinal $v_{2}(t)$ não binário, ou seja, o sistema $w_{2}$ não é apenas um ganho escalar, o sinal $y_{2}(t)$ não será constante. Assim como no modelo da figura B.1, a identificação do subsistema $w_{1}$ é imediata. Porém, a identificação do subsistema $w_{2}$ necessita previamente aplicar a transformada de Fourier inversa nas harmônicas pares do sinal $y(t)$ e posteriormente extrair a raiz quadrada, obtendo o sinal $v_{2}(t)$. Relacionando esse sinal com o sinal $u(t)$, identifica-se o subsistema $w_{2}(t)$.

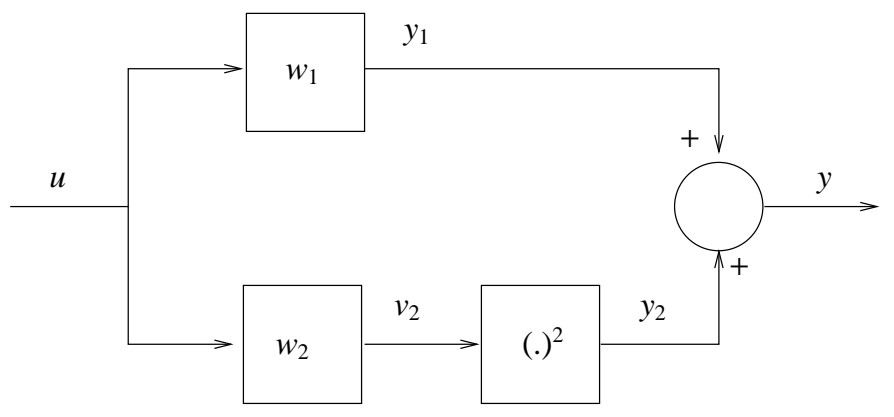

Figura B.2: Modelo com estrutura não linearidade quadrática de Wiener (BARKER; GODFREY; TUCKER, 2000).

No modelo com estrutura não linear quadrática de Wiener (figura B.2), os subsitemas $w_{1}$ e $w_{2}$ serão excitados apenas por harmônicas ímpares. No modelo com estrutura não linear quadrática de Hammerstein (figura B.1) o subsistema $w_{1}$ será excitado apenas por harmônicas ímpares e o subsistema $w_{2}$ apenas por harmônicas pares. As 
harmônicas não excitadas não serão identificadas e, portanto, essas características podem não estar representadas fielmente no modelo estimado. Uma resolução melhor do modelo do sistema poderia ser obtida caso fossem excitadas todas as harmônicas (pares e ímpares). Essa é a desvantagem da supressão de harmônicos do sinal de excitação para identificação de sistemas não lineares. A não linearidade é identificada com o custo da redução de qualidade da identificação dos subsistemas lineares (PINTELON; SCHOUKENS, 2001). Na seção 5.2.4 foi discutido como a supressão de harmônicos também pode ser usada para obter conjuntos de sinais não correlacionados, o que é desejável na identificação multivariável.

Similarmente ao apresentado para distorções não lineares quadráticas (ou não linearidades pares), caso a distorção não linear seja cúbica (.) (ou ímpar) haverá também no sinal de saída do sistema alteração do conteúdo harmônico. Por exemplo, caso o sinal de entrada $u(t)$ possua apenas uma harmônica $f_{0}$, ou seja, uma senoide de frequência $f_{0}$, o sinal de saída de um sistema que seja simplesmente uma não linearidade cúbica será $y(t)=u(t)^{3}$. O sinal de saída possuirá as harmônicas $f_{0}$ e $3 f_{0}$. Como a distorção resulta também em energia na harmônica $f_{0}$, não seria possível separá-la da saída de um subsistema linear associado. Em (PINTELON; SCHOUKENS, 2001) é apresentada uma forma de identificar, além das não linearidades pares, as não linearidades ímpares por meio de supressão de harmônicos do sinal de excitação. Não é objetivo desse trabalho apresentar técnicas de detecção de não linearidades, porém, as boas características de sinais para detecção de não linearidades como a supressão de harmônicos foram explicitadas, pois são flexibilidades dos sinais de excitação que permitem que eles sejam aplicados em identificação de sistemas não lineares além de sistemas lineares.

Em resumo, para identificar as dinâmicas do sistema, sejam elas com características lineares ou não lineares, é necessário que o sinal de excitação possua potência significativa na faixa de frequências que represente as dinâmicas de interesse (os modos) do sistema. Para identificar características não lineares, adicionalmente, é necessário um sinal de excitação com amplitude suficiente para revelar as características não lineares e, preferencialmente, um sinal não binário permitindo a identificação adequada de sistemas Hammerstein como da figura B.1. Por outro lado, para obter modelos lineares deve-se ter o cuidado em não excitar as características não lineares do sistema, limitando a excursão do sinal de excitação. Assim, tanto o conteúdo espectral quanto a forma de onda do sinal de excitação são importantes na identificação de sistemas (AGUIRRE, 2007). 


\section{Apêndice C - Período de amostragem}

Os processos industriais reais são contínuos no tempo. Para ser possível manipular dados de processos contínuos em sistemas digitais, é necessário amostrar as variáveis contínuas.

Segundo o teorema de Nyquist, resumidamente, um sinal que não tem componentes de frequência acima de $1 / 2 T$ pode ser determinado unicamente a partir de amostras de tal sinal separadas no tempo por $T$, onde $T$ é conhecido como tempo (ou período ou intervalo) de amostragem. De outra forma, a frequência (ou taxa) de amostragem $f_{s}$ deve ser 2 vezes maior que a maior frequência de interesse. Esse valor de frequência de amostragem é conhecido como frequência de Nyquist. Na prática utiliza-se uma frequência de amostragem entre 5 a 10 vezes maior do que a maior frequência de interesse (AGUIRRE, 2007). Assim, torna-se necessário utilizar filtros para evitar o rebatimento (ou falseamento ou, ainda, aliasing) do sinal (OPPENHEIM; SCHAFER, 1999).

O período de amostragem não pode ser pequeno de forma a tornar a estimação dos parâmetros do modelo um problema mal condicionado. Amostras tomadas em instantes próximos podem estar bem correlacionadas. Foi mostrado na seção 3.5 que a matriz de regressores é composta de elementos que incluem valores amostrados de entrada e saída em determinados instantes, $y((k-1) T), y((k-2) T), \ldots$ e $u((k-1) T), u((k-$ $2) T), \ldots$ No caso da redução do tempo de amostragem $T \rightarrow 0$, tem-se $y((k-1) T) \approx$ $y((k-2) T)$. Assim, a matriz de regressores tende a ter colunas linearmente dependentes (AGUIRRE, 2007), o que não é desejável, pois pode-se inviabilizar ou provocar erros na estimação dos parâmetros do modelo.

Para se aplicar o critério de frequência de amostragem entre 5 a 10 vezes maior do que a maior frequência de interesse é necessário conhecer ou, pelo menos, estimar a frequência de interesse (conhecimento a a priori), a qual representa a maior frequência significativa para modelar as características desejadas do sistema real. A seção 5.3.9 apresentou uma forma de estimar a faixa de frequências de interesse do sistema a partir das constantes de tempo dominantes do sistema. A próxima seção descreve a técnica de determinação da frequência de amostragem apresentada em (AGUIRRE, 2007). 


\section{C.1 Determinação da frequência de amostragem empi- ricamente}

A técnica de (AGUIRRE, 2007) descrita aqui pode ser facilmente aplicada para a identificação de processos reais por não necessitar executar diversos testes com a planta, o que poderia implicar em custos elevados.

Inicialmente, obtém-se um sinal $y^{*}(k)$ garantidamente superamostrado, ou seja, com $\frac{1}{T}>2 \pi \omega_{H}$. Objetiva-se, então, obter um sinal $y(k)$, devidamente amostrado para a modelagem do sistema, a partir da decimação de $y^{*}(k)$. Em outras palavras, deseja-se determinar $\Delta \in \mathbb{N}$ de forma que $y(k)=y^{*}(\Delta k)$. Quanto mais superamostrado o sinal, maior a correlação entre observações consecutivas. O sinal $y^{*}(k)$ pode ser, por exemplo, um registro das dinâmicas do sistema feito pelo DCS com a planta em operação normal.

Definem-se as funções de autocovariância linear e não linear do sinal superamostrado $y^{*}(k)$ :

$$
\begin{gathered}
r_{y^{*}}(d)=\mathbb{E}\left[\left(y^{*}(k)-\overline{y^{*}(k)}\right)\left(y^{*}(k-d)-\overline{y^{*}(k)}\right]\right. \\
r_{y^{* 2}}(d)=\mathbb{E}\left[\left(y^{* 2}(k)-\overline{y^{* 2}(k)}\right)\left(y^{* 2}(k-d)-\overline{y^{* 2}(k)}\right]\right.
\end{gathered}
$$

onde $\mathbb{E}\{$.$\} representa a esperança matemática. Se y^{*}(k)$ for ergódico, substitui-se a esperança matemática pela média temporal.

Os primeiros mínimos das funções de autocovariância (C.1) e (C.2) são representados por $d_{y^{*}}$ e $d_{y^{* 2}}$, respectivamente. O menor desses mínimos é representado por $d_{m}^{*}=\min \left\{d_{y^{*}} ; d_{y^{* 2}}\right\}$.

Dado o sinal superamostrado $y^{*}(k)$, deseja-se determinar a taxa de decimação $\Delta$, tal que as funções de autocovariância (C.1) e (C.2) de $y^{*}(k)$ satisfaçam $10 \Delta \leq d_{m}^{*} \leq 20 \Delta$. Por exemplo, para o caso de $d_{m}^{*} \approx 150$, taxas de decimação na faixa de $7 \leq \Delta \leq$ 15 podem ser escolhidas para gerar o sinal $y(k)$ adequado para o procedimento de identificação.

Nos DCSs aplicados na indústria de processos, o tempo de amostragem já está previamente definido em função da necessidade do controle regulatório. Frequentemente esse tempo é inferior ao que seria determinado pelo procedimento apresentado. Assim, o procedimento acima torna-se útil para determinar a decimação a ser utilizada pelo procedimento de identificação. Cabe ressaltar que o modelo assim obtido possuirá 
parâmetros ajustados em função da decimação adotada, não sendo válido para outros valores de decimação ou períodos de amostragem. 


\section{Apêndice D - Reforço de frequências baixas ou médias}

Neste apêndice é apresentada uma forma simples de alterar o espectro do sinal de excitação privilegiando as frequências baixas ou médias em detrimento das frequências altas, o que pode ser desejável para o sinal de excitação.

Em modelos para controle de processos pode ser desejável que o sinal de excitação possua maior potência em frequências médias e baixas. Uma forma de alterar o espectro do sinal de excitação privilegiando as frequências médias e baixas em detrimento das frequências altas é utilizando um segurador de ordem zero (zero-order holder, $\mathrm{ZOH}$ ), cuja função de transferência é dada por:

$$
h_{0}(t)= \begin{cases}1 & , 0<t<T_{M} \\ 0 & , \text { caso contrário. }\end{cases}
$$

onde $T_{M}=M \times T$ é o período no qual o $\mathrm{ZOH}$ mantém fixa sua saída, aqui neste trabalho considerado múltiplos do período de amostragem.

O ZOH associado a uma sequência discreta $x(n)$ irá gerar o sinal de excitação $x_{0}(t)$ com espectro ajustado representado por:

$$
x_{0}(t)=\sum_{n=-\infty}^{\infty} x(n) h_{0}\left(t-n T_{M}\right)
$$

A resposta em frequência do sinal $x_{0}(t)$ será dada pela transformada de Fourier de (D.2):

$$
X_{0}(j \Omega)=X\left(e^{j \Omega T_{M}}\right) H_{0}(j \Omega)
$$

onde a transformada de Fourier do ZOH (D.1) será:

$$
H_{0}(j \Omega)=\frac{2 \sin \left(\Omega T_{M} / 2\right)}{\Omega} e^{-j \Omega T_{M} / 2}
$$


Portanto, o sinal no qual for aplicado um ZOH com o objetivo de reforçar frequências médias e baixas possuirá resposta em frequência com envoltória dada por (D.4), cujo módulo está representado na figura D.1.

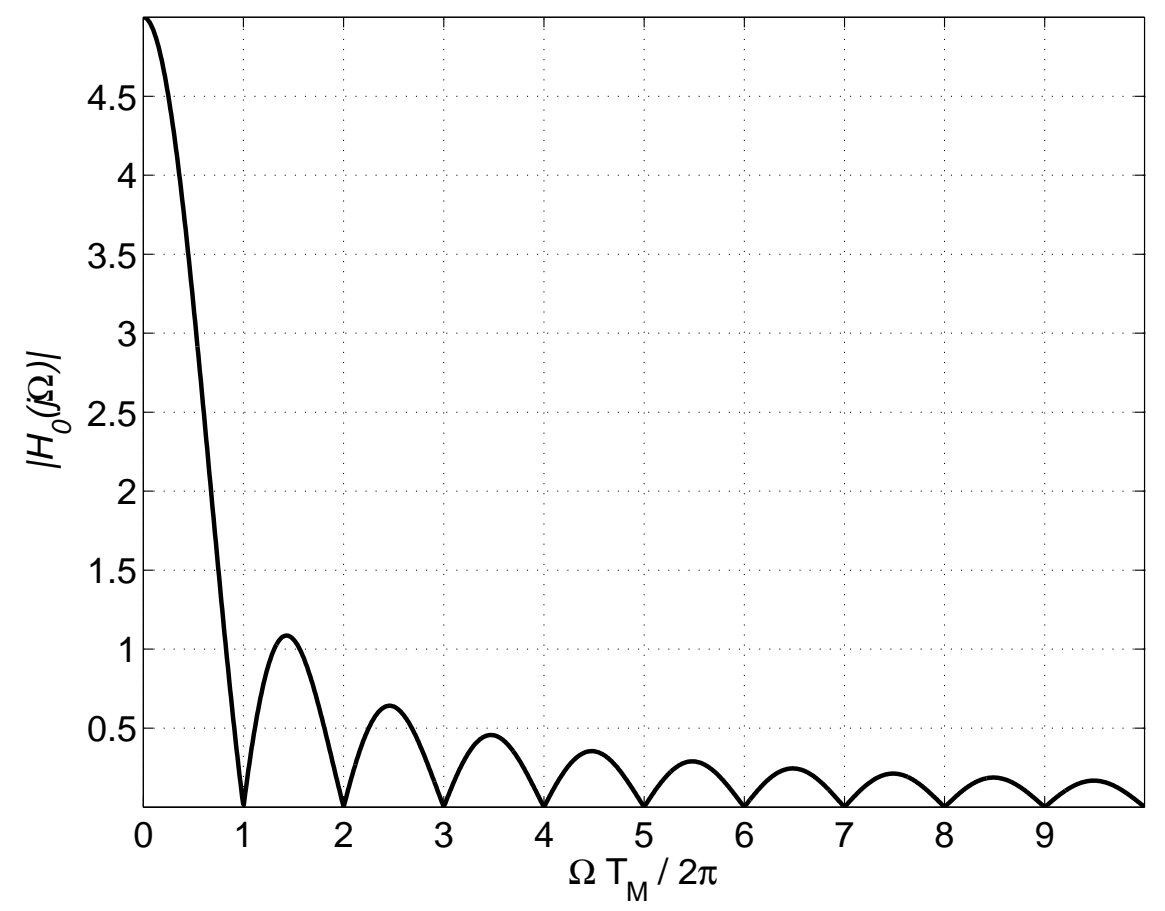

Figura D.1: Resposta em frequência do $\mathrm{ZOH}$.

Considere o exemplo de um sinal binário associado a um ZOH conforme os parâmetros da tabela D.1. O sinal binário amostrado $u(i)$ é apresentado na figura D.2 e o sinal $u_{0}(t)$ após o $\mathrm{ZOH}$ é apresentado na figura D.3.

Tabela D.1: Exemplo de sinal associado a ZOH.

\begin{tabular}{ll}
\hline Parâmetro & Valor \\
\hline Tipo de sinal & binário pseudo-aleatório (PRB) \\
Comprimento do sinal & $N=31$ \\
Período de amostragem (em segundos) & $T=0,1$ \\
Frequência de amostragem (em Hertz) & $1 / T=10$ \\
Período de chaveamento (em segundos) & $T_{c l k}=T_{M}=M \times T=50 \times 0,1=5$ \\
Período do sinal (em segundos) & $T_{N}=T_{c l k} \times N=155$ \\
\hline
\end{tabular}

A resposta em frequência do sinal amostrado $\left|U\left(e^{j \Omega T_{M}}\right)\right|$ é apresentada na figura D.4 e a resposta em frequência do sinal amostrado associado ao $\mathrm{ZOH}\left|H_{0}(j \Omega)\right|$ é apresentada na figura D.5. A resposta em frequência (espectro de amplitudes) do sinal em tempo discreto é calculada por meio da transformada discreta de Fourier (discrete Fourier transform, DFT) dada por (OPPENHEIM; SCHAFER, 1999):

$$
U(k)=\sum_{n=0}^{N-1} u(n) e^{-\frac{2 \pi j}{N} k n}
$$




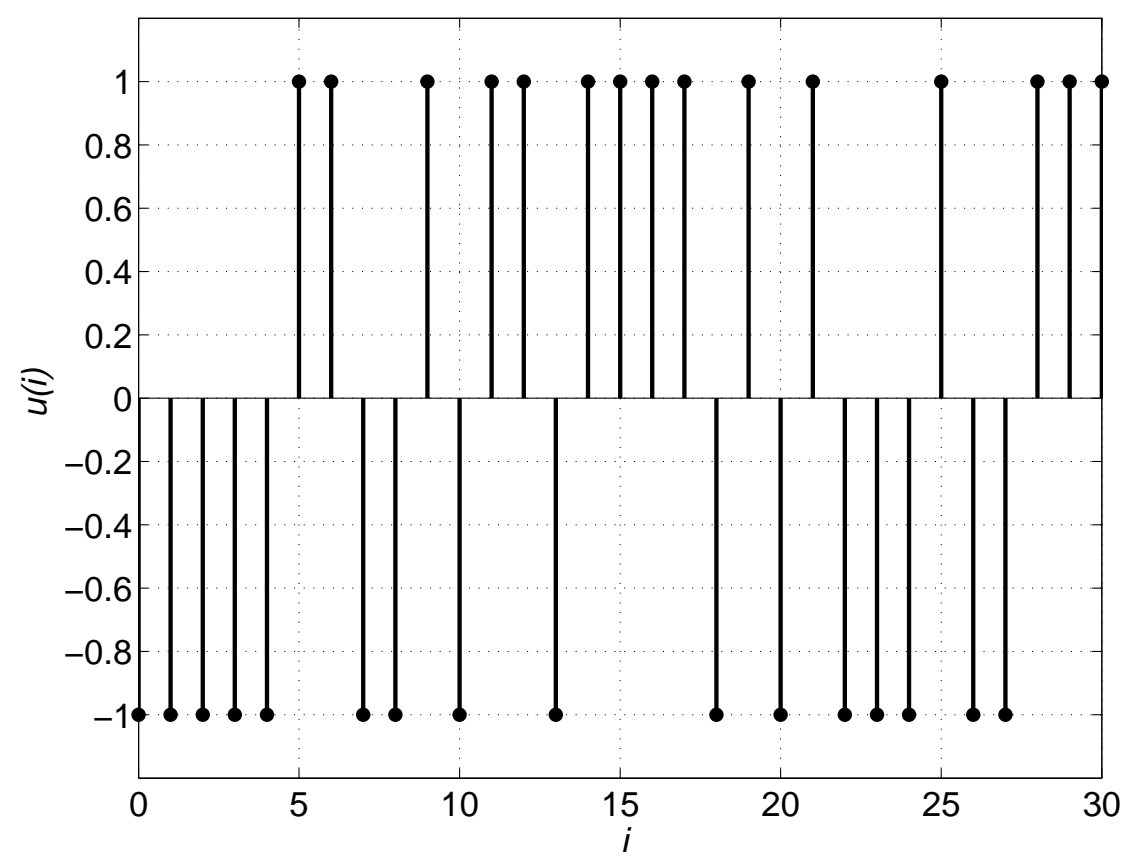

Figura D.2: Sinal binário amostrado de comprimento $N=7$.

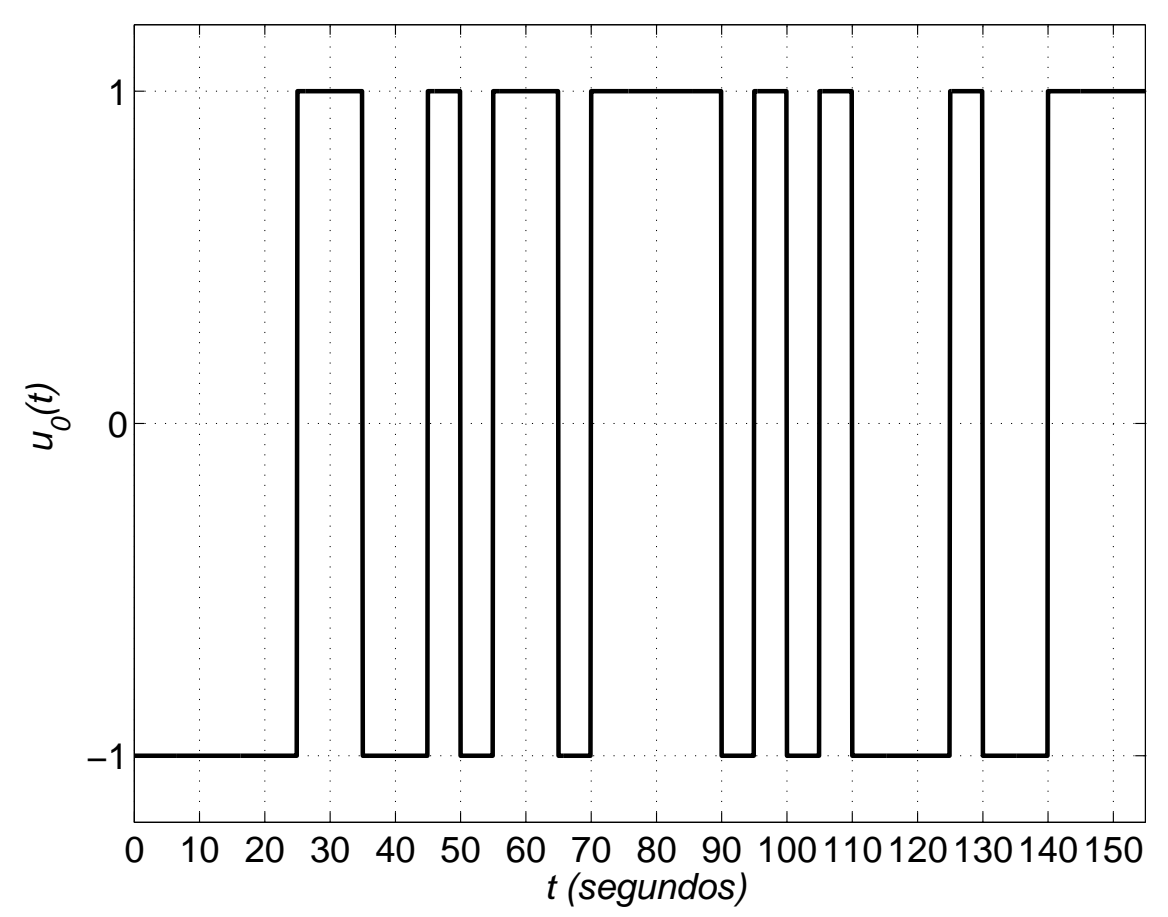

Figura D.3: Sinal binário amostrado associado ao ZOH.

onde $j=\sqrt{-1}$.

Observa-se na equação (D.4) e nas figuras D.1 e D.5 que a resposta do sinal $x_{0}(t)$ terá envoltória determinada também pela envoltória do ZOH (D.4), além da envoltória do próprio sinal $U\left(e^{j \Omega T}\right)$. Dessa forma, o sinal $u_{0}(t)$ terá nulos nas frequências $1 / T_{c l k}, 2 / T_{c l k}, 3 / T_{c l k}, \ldots$, onde $T_{c l k}$ é o período de chaveamento do sinal $u_{0}(t)$, o qual é igual ao tempo de ação do ZOH (equação (D.1) com $T_{M}=T_{c l k}$ ). Essa característica não 


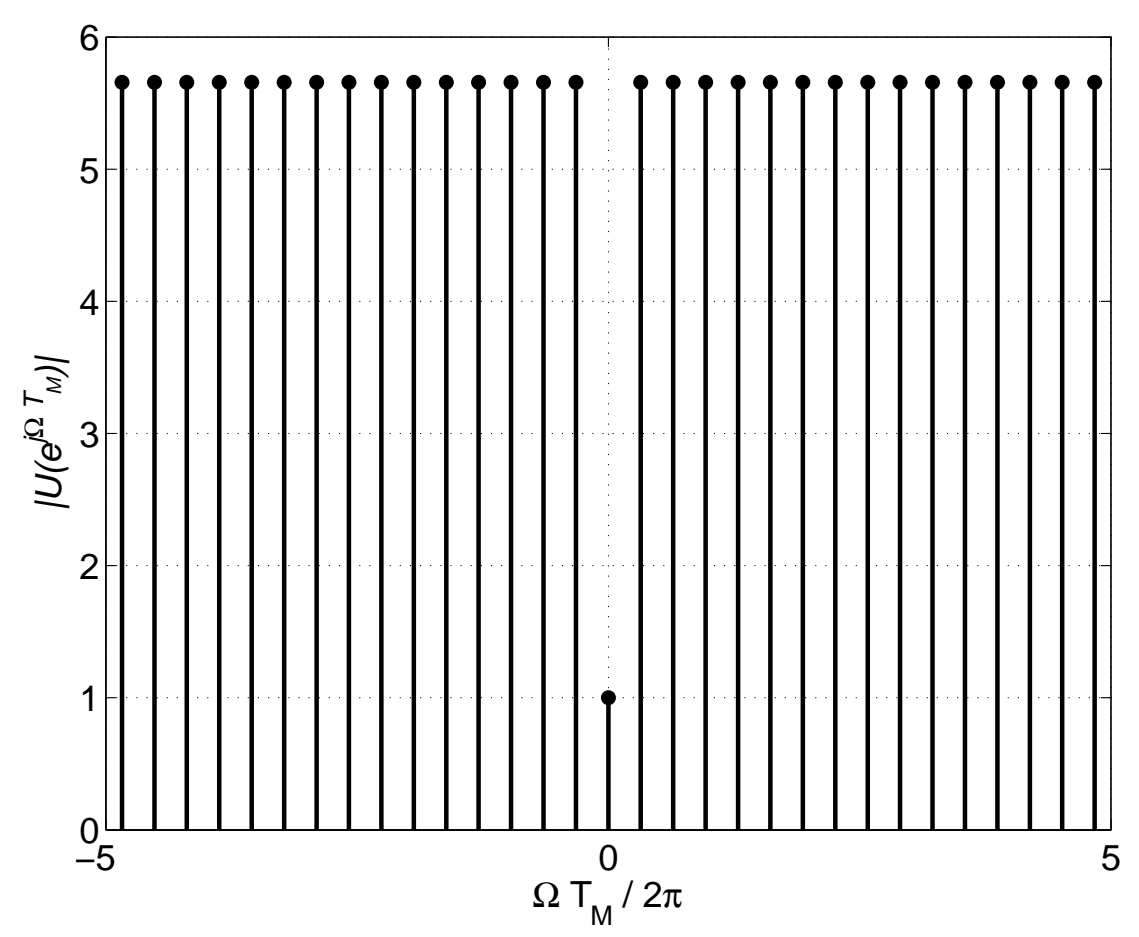

Figura D.4: Resposta em frequência do sinal amostrado.

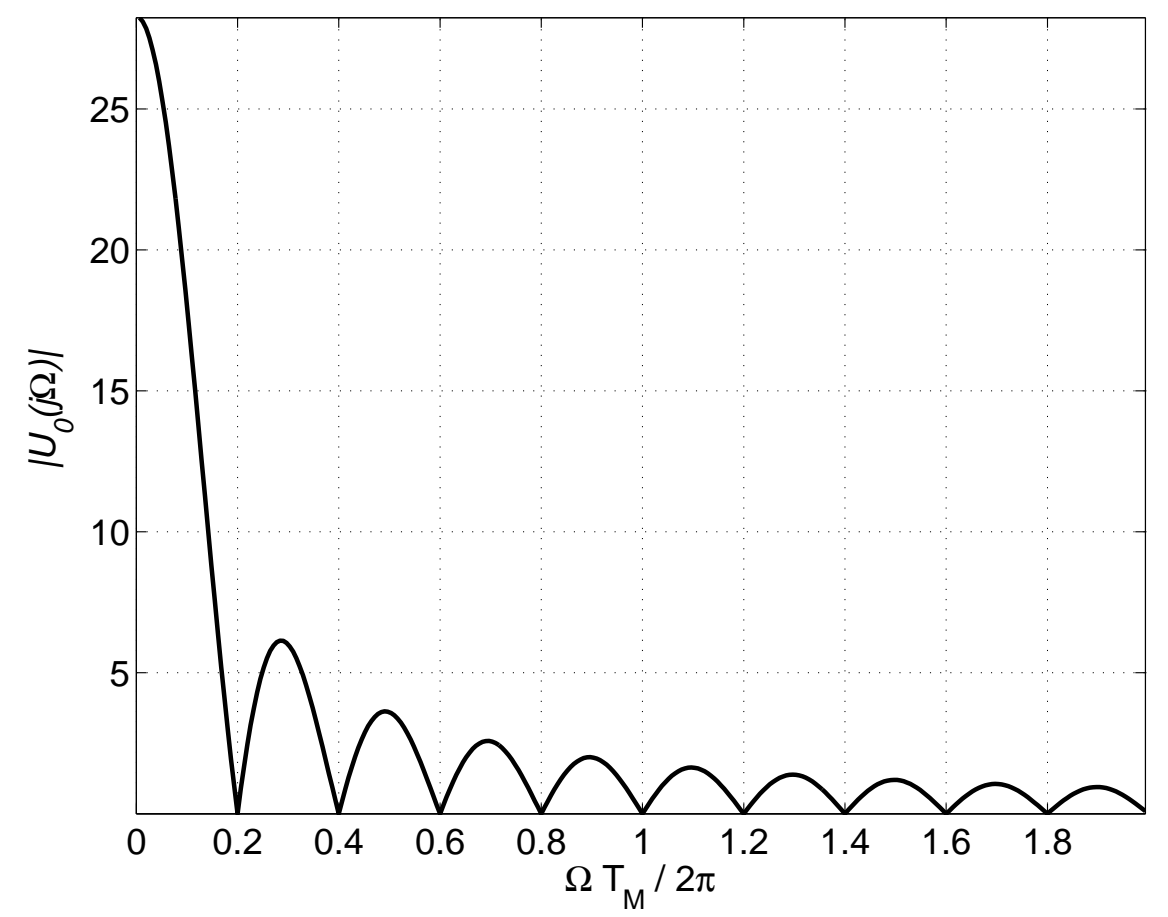

Figura D.5: Resposta em frequência do sinal amostrado associado ao ZOH.

é desejável, pois o sistema não será excitado nas frequências $1 / T_{c l k}, 2 / T_{c l k}, 3 / T_{c l k}, \ldots$ e será pouco excitado nas frequências próximas a essas. Devido a essa característica, conforme a seção 5.3.9, escolhe-se $T_{c l k}$ de forma que a faixa de frequências de interesse da planta esteja contida no primeiro lóbulo da envoltória da resposta da figura D.1, evitando os nulos. 


\section{Apêndice E - Teorema de Woodward}

O Teorema de Woodward (BLACHMAN; MCALPINE, 1969) afirma que o espectro de um sinal modulado em frequência (FM) de ordem elevada é aproximadamente dado pela distribuição de probabilidades das frequências instantâneas. De outra forma, o espectro do sinal FM é aproximadamente dado pela distribuição univariável do sinal modulante deslocado pela frequência da portadora.

A demonstração do Teorema de Woodward apresentada em (BLACHMAN; MCALPINE, 1969) e reescrita aqui é uma prova direta baseada na análise espectral de um sinal senoidal modulado em frequência sendo filtrado por um banco de filtros de banda fixa e infinitesimal $d f$ dispostos de forma contígua e centrados em frequências adjacentes $f$.

Considere o espectro do sinal senoidal modulado em frequência (FM) (BLACHMAN; MCALPINE, 1969):

$$
v(t)=A \cos \left[2 \pi f_{c} t+\phi(t)\right]
$$

com $A$ sendo a amplitude do sinal, $f_{c}$ a frequência da portadora e $\phi(t)$ é o sinal modulante.

O sinal modulante $\phi(t)$ causa um desvio de frequência dado por $D(t)=\frac{d \phi(t)}{d t} \frac{1}{2 \pi}$. Suponha que a potência média de saída do banco de filtros será medida dentro de um intervalo de tempo $T$. Seja $p(D)$ a função densidade de probabilidade (probability density function, PDF) do desvio de frequência $D(t)$. Em outras palavras, $p(D)$ relaciona a fração do período $T$ em que $D(t)$ assume determinado valor.

Considere a alteração na escala de tempo $t_{1}=\frac{t}{\beta}$ :

$$
\phi\left(t_{1}\right)=\phi(t / \beta)
$$

O formato da PDF de $\phi\left(t_{1}\right)$ não se alterará em relação ao formato da PDF de $\phi(t)$. Isso significa que, para a análise da PDF de $\phi(t)$, o sinal $v(t)$ pode ser tão lento quanto 
se deseja e, consequentemente, o intervalo de análise $T$ pode ser tão longo quanto se deseja.

Para a frequência instantânea $f_{c}+D(t)$ passar pela banda infinitesimal $d f$ do filtro centrado em $f$ será utilizada a fração de tempo dada por $p(D) d f=p\left(f-f_{c}\right) d f$. A potência média medida na saída deste filtro em questão será dada pela potência média de entrada $\frac{1}{2} A^{2}$ multiplicada pela fração de tempo $p\left(f-f_{c}\right) d f$. Lembrando que no espectro metade da potência está nas frequências positivas e a outra metade nas frequências negativas, tem-se o espectro de potência na saída do banco de filtros, ou seja, o espectro de potência do sinal FM $v(t)$ :

$$
\Phi(f)=\frac{1}{4} A^{2} p\left(f-f_{c}\right)+\frac{1}{4} A^{2} p\left(-f-f_{c}\right)
$$

Portanto, tem-se que o espetro do sinal $v(t)$ é aproximadamente dado pela distribuição univariável do sinal modulante deslocado pela frequência da portadora. Diz-se aproximadamente porque existem dois casos em que o teorema de Woodward não se aplicará exatamente como exposto na equação E.3. Um deles é o caso de o sinal modulante ser senoidal e, portanto, o espectro seria composto de funções impulso. O outro é o caso do espectro ser composto de funções delta o qual ocorre quando a modulação é o tipo chaveamento de frequências (frequency-shift keying, FSK). Para ambos os casos, a banda $d f$ dos filtros tenderiam a zero. Assim, a fração de tempo de $T$ que a frequência instantânea $f_{c}+D(t)$ utilizaria para percorrer a banda $d f$ do filtro seria zero, tornando incoerente a análise acima. Esses dois casos são tratados em (BLACHMAN; MCALPINE, 1969). 


\section{Apêndice F - Convergência do algoritmo clipping de reconstrução de sinais}

Esse Apêndice apresenta uma demonstração baseada em (TOM; QUATIERI, 1981). O objetivo é provar que o algoritmo clipping apresentado em (OUDERAA; SCHOUKENS; RENNEBOOG, 1988b) não diverge para uma certa medida Euclideana. A demonstração apresentada em (TOM; QUATIERI, 1981) é mais completa do que a reescrita aqui. Naquele trabalho, a demonstração é generalizada para outros algoritmos baseados na reconstrução iterativa de sinais. Aqui a demonstração se restringe ao caso de algoritmos de mapeamento tempo-frequência.

A medida de convergência (ou divergência ou até mesmo erro) será a métrica Euclideana definida no espaço $\mathbb{R}^{N}$ :

$$
d(x, y)=\left\{\sum_{n=0}^{N-1}[x(n)-y(n)]^{2}\right\}^{1 / 2}
$$

onde $x(n)$ e $y(n)$ são os $n$-ésimos elementos de sinais de comprimentos $N$. Os elementos desses sinais serão mapeados conforme o algoritmo clipping.

O sinal desejado, o qual atende às restrições no domínio do tempo e no domínio da frequência, será dado por $h(n)$ cuja forma no domínio da frequêcia será dada por $H(k)$.

O mapeamento no domínio do tempo é definido como:

$$
T[x(n)]= \begin{cases}x(n) & n \notin I_{T} \\ h(n) & n \in I_{T}\end{cases}
$$

onde $I_{T}$ é um subconjunto do intervalo [0;N-1] sobre o qual os valores $x(n)$ são alterados por novos valores $h(n)$.

O mapeamento no domínio da frequência pode ser representado como $F=W^{-1} B W$, onde $W$ e $W^{-1}$ são as matrizes transformada discreta de Fourier (discrete Fourier transform, DFT) e transformada inversa discreta de Fourier (inverse discrete Fourier trans- 
form, IDFT) e:

$$
B[X(k)]= \begin{cases}X(k) & k \notin I_{B} \\ H(k) & k \in I_{B}\end{cases}
$$

onde $I_{B}$ é um subconjunto do intervalo [0;N-1] sobre o qual os valores $X(k)$ são alterados por novos valores $H(k)$.

Para demonstrar que o mapeamento no domínio do tempo (F.2) é não expansível, de F.1, tem-se:

$$
d^{2}(x, y)=\sum_{n \in I_{T}}[x(n)-y(n)]^{2}+\sum_{n \notin I_{T}}[x(n)-y(n)]^{2}
$$

Como o primeiro termo da soma de (F.4) é um número não negativo, tem-se:

$$
d^{2}(x, y) \geq \sum_{n \notin I_{T}}[x(n)-y(n)]^{2}
$$

De (F.4) e (F.2), tem-se:

$$
d^{2}(T x, T y)=\sum_{n \notin I_{T}}[x(n)-y(n)]^{2}
$$

onde $T x$ e $T y$ são os mapeamentos $T[x(n)]$ e $T[y(n)]$, respectivamente, dados por (F.2).

Assim, de (F.5) e (F.6), tem-se:

$$
d(x, y) \geq d(T x, T y)
$$

Fazendo $y(n)=h(n)$ em (F.7), tem-se:

$$
d(x, h) \geq d(T x, h)
$$

De (F.8), portanto, observa-se que o mapeamento no domínio do tempo (F.2) é não expansível.

Para demonstrar que o mapeamento no domínio da frequência (F.3) também é não expansível, de F.1, tem-se: 


$$
\begin{aligned}
d^{2}(x, y) & =\sum_{n=0}^{N-1}[x(n)-y(n)]^{2} \\
& =\sum_{n=0}^{N-1}|x(n)-y(n)|^{2}
\end{aligned}
$$

Da forma discreta do Teorema de Parseval (OPPENHEIM; SCHAFER, 1999) e (F.9), tem-se:

$$
\begin{aligned}
d^{2}(x, y) & =\sum_{n=0}^{N-1}|X(k)-Y(k)|^{2} \\
& =\sum_{k \in I_{B}}|X(k)-Y(k)|^{2}+\sum_{k \notin I_{B}}|X(k)-Y(k)|^{2}
\end{aligned}
$$

Como o primeiro termo da soma de (F.11) é um número não negativo, tem-se:

$$
d^{2}(x, y) \geq \sum_{k \notin I_{B}}|X(k)-Y(k)|^{2}
$$

De (F.13), $F=W^{-1} B W$ e (F.3), tem-se:

$$
d^{2}(F x, F y)=\sum_{k \notin I_{B}}|X(k)-Y(k)|^{2}
$$

Assim, de (F.14) e (F.13), tem-se:

$$
d(x, y) \geq d(F x, F y)
$$

Fazendo $y(n)=h(n)$ em (F.15), tem-se:

$$
d(x, h) \geq d(F x, h)
$$

De (F.16), portanto, observa-se que o mapeamento no domínio da frequência definido por $F=W^{-1} B W$ e (F.3) é não expansível.

Considere o mapeamento tempo-frequência definido por $G=T F$. De (F.7) e (F.15), tem-se:

$$
d(G x, G y)=d(T F x, T F y) \leq d(F x, F y) \leq d(x, y)
$$


Fazendo $y(n)=h(n)$ em (F.17), tem-se:

$$
d(G x, h)=d(T F x, h) \leq d(F x, h) \leq d(x, h)
$$

pois, de (F.2) e (F.3), tem-se $F h=h$ e $T h=h$, respectivamente.

De (F.18), portanto, observa-se que o mapeamento tempo-frequência definido por $G=T F$ é não expansível. Assim, após os mapeamentos (ou transformações) executadas pelo algoritmo em uma dada iteração sobre o sinal $x(n)$, com $n=0,1, \ldots, N-1$, ter-se-á um sinal $G x(n)$ cuja a distância Euclideana do sinal desejado $h(n)$, com $n=$ $0,1, \ldots, N-1$, definida por (F.1), será menor ou igual à distância antes dos mapeamentos no domínio da frequência e do tempo daquela iteração. 


\section{Apêndice G - Sequência de máximo comprimento sobre $G F(q), \operatorname{com} q>2$}

Esta seção tem como objetivo analisar as características das SMC sobre $G F(q)$, com $q>2$.

Define-se $\mathcal{T}$ como:

$$
\mathcal{T}=\frac{q^{m}-1}{q-1}
$$

Então, escreve-se a SMC definida no anexo B (B.1) em forma matricial, sendo que a SMC $\left\{u_{t}\right\}$ é dada pela concatenação das linhas da matriz:

$$
\mathbf{U}=\left[\begin{array}{cccc}
\operatorname{Tr}_{1}^{m}\left(\alpha^{0}\right) & \operatorname{Tr}_{1}^{m}\left(\alpha^{1}\right) & \ldots & \operatorname{Tr}_{1}^{m}\left(\alpha^{\mathcal{T}-1}\right) \\
\operatorname{Tr}_{1}^{m}\left(\alpha^{\mathcal{T}}\right) & \operatorname{Tr}_{1}^{m}\left(\alpha^{\mathcal{T}+1}\right) & \ldots & \operatorname{Tr}_{1}^{m}\left(\alpha^{2 \mathcal{T}-1}\right) \\
\operatorname{Tr}_{1}^{m}\left(\alpha^{2 \mathcal{T}}\right) & \operatorname{Tr}_{1}^{m}\left(\alpha^{2 \mathcal{T}+1}\right) & \ldots & \operatorname{Tr}_{1}^{m}\left(\alpha^{3 \mathcal{T}-1}\right) \\
\vdots & \vdots & \ddots & \vdots \\
\operatorname{Tr}_{1}^{m}\left(\alpha^{(q-2) \mathcal{T}}\right) & \operatorname{Tr}_{1}^{m}\left(\alpha^{(q-2) \mathcal{T}+1}\right) & \ldots & \operatorname{Tr}_{1}^{m}\left(\alpha^{(q-1) \mathcal{T}-1}\right)
\end{array}\right]
$$

Observe que a ordem de $\alpha^{\mathcal{T}}$ é $q$, pois:

$$
\begin{aligned}
\left(\alpha^{\mathcal{T}}\right)^{q} & =\left(\alpha^{\mathcal{T}}\right)^{q-1+1}=\left(\alpha^{\mathcal{T}}\right)^{q-1}\left(\alpha^{\mathcal{T}}\right)^{1}=\left(\alpha^{q^{q^{m}-1}}\right)^{q-1}\left(\alpha^{\mathcal{T}}\right)^{1}=\left(\alpha^{q^{m}-1}\right)\left(\alpha^{\mathcal{T}}\right) \\
& =\alpha^{\mathcal{T}}
\end{aligned}
$$

Assim, verifica-se que $\alpha^{\mathcal{T}} \in G F(q)$ e pode-se aplicar a propriedade 3 da função traço (anexo seção A.8) em $\operatorname{Tr}_{1}^{m}\left(\alpha^{k \mathcal{T}+i}\right)$ :

$$
\operatorname{Tr}_{1}^{m}\left(\alpha^{k \mathcal{T}+i}\right)=\alpha^{k \mathcal{T}} \operatorname{Tr}_{1}^{m}\left(\alpha^{i}\right)
$$

Aplicando tal propriedade a todos os elementos de (G.2), tem-se: 


$$
\mathbf{U}=\left[\begin{array}{cccc}
\alpha^{0 \mathcal{T}} \operatorname{Tr}_{1}^{m}\left(\alpha^{0}\right) & \alpha^{0 \mathcal{T}} \operatorname{Tr}_{1}^{m}\left(\alpha^{1}\right) & \ldots & \alpha^{0 \mathcal{T}} \operatorname{Tr}_{1}^{m}\left(\alpha^{\mathcal{T}-1}\right) \\
\alpha^{1 \mathcal{T}} \operatorname{Tr}_{1}^{m}\left(\alpha^{0}\right) & \alpha^{1 \mathcal{T}} \operatorname{Tr}_{1}^{m}\left(\alpha^{1}\right) & \ldots & \alpha^{1 \mathcal{T}} \operatorname{Tr}_{1}^{m}\left(\alpha^{\mathcal{T}-1}\right) \\
\alpha^{2 \mathcal{T}} \operatorname{Tr}_{1}^{m}\left(\alpha^{0}\right) & \alpha^{2 \mathcal{T}} \operatorname{Tr}_{1}^{m}\left(\alpha^{1}\right) & \ldots & \alpha^{2 \mathcal{T}} \operatorname{Tr}_{1}^{m}\left(\alpha^{\mathcal{T}-1}\right) \\
\vdots & \vdots & \ddots & \vdots \\
\alpha^{(q-2) \mathcal{T}} \operatorname{Tr}_{1}^{m}\left(\alpha^{0}\right) & \alpha^{(q-2) \mathcal{T}} \operatorname{Tr}_{1}^{m}\left(\alpha^{1}\right) & \ldots & \alpha^{(q-2) \mathcal{T}} \operatorname{Tr}_{1}^{m}\left(\alpha^{\mathcal{T}-1}\right)
\end{array}\right]
$$

Observando os elementos de uma coluna da matriz (G.5), pode-se escrever os elementos em sequência de cada coluna como:

$$
\alpha^{k \mathcal{T}} \theta
$$

com $k=0,1,2, \ldots, q-2$ e $\theta \in G F(q)$ constante, onde $\theta=\operatorname{Tr}_{1}^{m}\left(\alpha^{j}\right)=\alpha^{d \mathcal{T}}, j=$ $0,1,2, \ldots, \mathcal{T}-1$ e $d=0,1,2, \ldots, q-2,-\infty$.

Note que (G.6) compõem todos os elementos de $G F(q)$ não nulos em sequência $\left\{1, \beta^{1}, \beta^{2} \ldots, \beta^{q-2}\right\}$, onde $\beta$ é elemento primitivo de $G F(q)$, ajustados com uma fase $d$ definida por $\theta$. Essa sequência de elementos de $G F(q)$ que compõe a SMC é chamada de sequência primitiva ou semente:

$$
\mathbf{m}=\left\{m_{t}\right\}=\left\{\beta^{t}\right\}=\left\{1, \beta^{1}, \beta^{2} \ldots, \beta^{q-2}\right\}
$$

onde $\beta$ é elemento primitivo de $G F(q)$.

Então, para obter uma SMC basta calcular fases $\theta$ apropriadas. O conjunto de fases $\theta=\operatorname{Tr}_{1}^{m}\left(\alpha^{j}\right)=\alpha^{d \mathcal{T}}$ será dado pela sequência $s$ composta pelos expoentes $d$ de $\alpha^{\mathcal{T}}$ :

$$
\mathbf{s}=\left\{s_{0}, s_{1}, s_{2}, \ldots, s_{\mathcal{T}-1}\right\}, s_{j}=d, \operatorname{com} \operatorname{Tr}_{1}^{m}\left(\alpha^{j}\right)=\alpha^{d \mathcal{T}}
$$

onde $d$ poderá assumir os valores $d=0,1,2, \ldots, q^{m}-2$ e $-\infty$; este último ocorre quando $\operatorname{Tr}_{1}^{m}\left(\alpha^{j}\right)=0$. Quando $s_{j}=-\infty, \operatorname{Tr}_{1}^{m}\left(\alpha^{j}\right)=0$ e, portanto, todos os elementos da $j$-ésima coluna de (G.5) serão nulos.

Assim, pode-se reescrever (G.5) como:

$$
\mathbf{U}=\left[\begin{array}{ccccc}
m_{0+s_{0}} & m_{0+s_{1}} & m_{0+s_{2}} & \ldots & m_{0+s_{\mathcal{T}-1}} \\
m_{1+s_{0}} & m_{1+s_{1}} & m_{1+s_{2}} & \ldots & m_{1+s_{\mathcal{T}-1}} \\
m_{2+s_{0}} & m_{2+s_{1}} & m_{2+s_{2}} & \ldots & m_{2+s_{\mathcal{T}-1}} \\
\vdots & \vdots & \vdots & \ddots & \vdots \\
m_{q-2+s_{0}} & m_{q-2+s_{1}} & m_{q-2+s_{2}} & \ldots & m_{q-2+s_{\mathcal{T}-1}}
\end{array}\right]
$$


Quando $s_{j}=-\infty$, ou seja, $\operatorname{Tr}_{m}^{n}\left(\alpha^{j}\right)=0$, todos os elementos da coluna referente à $s_{j}$ em (G.9) serão nulos. Isso significa que $u_{i}=m_{k+s_{j}}=0$, quando $s_{j}=-\infty$.

A quantidade de elementos nulos na SMC é $q^{m-1}-1$ (HELLESETH, 1976). Quando um elemento em uma coluna de (G.9) for nulo todos os demais elementos da mesma coluna também serão. Sabe-se que (G.9) possui $q-1$ linhas e $\mathcal{T}$ colunas. Portanto, o número de colunas nulas em (G.9) é dado por $\frac{q^{m-1}-1}{q-1}$. Este resultado é importante, pois é utilizado para projetar sinais pseudo-aleatórios multinível (pseudo-random multilevel signals, PRML signals), apresentados na seção 5.3.6.

A quantidade de colunas não nulas em (G.9) é $\frac{q^{m}-1}{q-1}-\frac{q^{m-1}-1}{q-1}=\frac{q^{m}-q^{m-1}}{q-1}=\frac{q^{m-1}(q-1)}{q-1}=$ $q^{m-1}$. Em cada coluna não nula, cada elemento não nulo de $G F(p)$ aparece uma única vez. Portanto, cada um dos $q-1$ elementos não nulos da SMC aparecerão $q^{m-1}$ vezes na sequência. 


\section{Anexo A - Teoria básica de corpos finitos}

Os anexos desse trabalho são transcrições de (KURAMOTO, 2005). Neste é apresentada a teoria básica para o estudo e análise de sequências construídas algebricamente, ou sequências sobre $G F(p)$, como são conhecidas. As definições e notações utilizadas estão apresentadas conforme (MCELIECE, 1987). As referências bibliográficas para esta seção são (GOLOMB, 1982), (MCELIECE, 1987) e (LIDL; NIEDERREITER, 1997).

\section{A.1 Corpos finitos}

Em (MCELIECE, 1987) define-se, informalmente, corpo como um "lugar" onde se pode somar, subtrair, multiplicar e dividir. Formalmente, é um conjunto $F$ no qual realizamse duas operações binárias “+” e “.”, soma e multiplicação, respectivamente. Operação binária em um conjunto $A$ não vazio é um mapeamento $f: A \times A \rightarrow A$ tal que $f$ é definido para todo elemento de $A$ e a imagem de $A$ sobre $f$ é única. A imagem de $A$ sobre $f$ é o conjunto de todos os valores que $f$ pode assumir à medida que seu argumento $A$ varia.

Para o corpo, como foi definido, valem os axiomas:

- F é um grupo ${ }^{1}$ Abeliano ${ }^{2}$ sobre “+”, com elemento identidade 0 , ou seja, $0+a=$ $a+0, a \in F$

- Os elementos não nulos de $F$ formam um grupo Abeliano sobre “.”;

- A lei distributiva $a \cdot(b+c)=a \cdot b+a \cdot c$ é aplicável.

Um corpo pode ser finito ou infinito, de acordo com o conjunto (finito ou infinito) em que é definido. Alguns exemplos de corpo infinito incluem números reais, números racionais e números complexos. Um corpo finito é um corpo com número de elementos (também chamado de ordem do corpo, anexo seção A.4) finito.

\footnotetext{
${ }^{1}$ grupo é um conjunto finito ou infinito de elementos e uma operação binária os quais conjuntamente satisfazem as quatro propriedades fundamentais: fechamento, associativa, identidade e inversibilidade.

${ }^{2}$ grupo Abeliano é um grupo no qual seus elementos comutam.
} 
Pode-se definir o corpo finito da seguinte forma:

$$
F_{p}=\{0,1, \ldots, p-1\}, \text { aritmética } \bmod p .
$$

Por exemplo, o conjunto $Z_{2}=\{0,1\}$ é um corpo finito. Em contrapartida, o conjunto $Z_{4}=\{0,1,2,3\}$ não é um corpo, pois não há nenhum elemento $x$ tal que $2 x \equiv 1$, onde $\equiv$ denota equivalência (a relação de equivalência será tratada a seguir), ou seja, a propriedade de inversibilidade não é verificada. Ainda nesta seção, será mostrado que $p$ deve ser primo para $Z_{p}$ ser um corpo finito.

\section{A.2 Domínio Euclidiano}

Um domínio integral é um conjunto $D$, acrescido de duas operações binárias, + e $\cdot$, tais que:

1. Os elementos de $D$ formam um grupo Abeliano sobre + , no qual a identidade de adição é denotado pelo elemento 0 ;

2. A multiplicação é associativa e comutativa. Adicionalmente, tem como elemento identidade o elemento denotado por 1;

3. A lei de cancelamento é aplicável. Isto é, se $a b=a c$ e $a \neq 0$, então $b=c$;

4. A lei distributiva é aplicável. Isto é, se $a, b$ e $c$ pertencem a $D$, então $a(b+c)=$ $a b+a c$.

O domínio Euclidiano é um domínio integral com uma característica adicional: a noção de "tamanho" entre os elementos. O "tamanho" do elemento $a$, com $a \neq 0$, denotado por $g(a)$, é um inteiro não negativo tal que:

$$
g(a) \leq g(a b) \text { se } b \neq 0
$$

e ainda, para todo $a, b \neq 0$, existem $q$ e $r$ ("quociente" $\mathrm{e}$ "resto") tais que $a=q b+r$, com $r=0$ ou $g(r)<g(b)$.

Alguns exemplos de domínios Euclidianos são: o conjunto dos números inteiros com $g(n)=|n|$ e polinômios sobre um corpo, $\operatorname{com} g(f(x))=\operatorname{grau}(f)$. 


\section{A.3 Construção de um corpo finito}

Nesta seção será mostrado um teorema muito importante da álgebra de corpos e fundamental para o estudo de sequências.

Teorema A.3.1 Se p for primo, $D \bmod p$ é um corpo.

Considere um elemento $m \in D$ não necessariamente primo. Define-se uma relação de equivalência " $\equiv "$ como $a \equiv b(\bmod m)$ se e somente se $m \mid(a-b)$, ou seja, se $a$ for congruente com $b$ módulo $m$. Verifica-se que a relação definida é realmente uma relação de equivalência, pois são verificadas as três propriedades de equivalência completamente independentes:

1. Reflexividade: $a \equiv a$;

2. Simetria: $a \equiv b$ implica em $b \equiv a$;

3. Transitividade: $a \equiv b$ e $b \equiv c$ implica em $a \equiv c$.

sendo essas três propriedades completamente independentes.

Essa relação de equivalência, como qualquer outra relação de equivalência, divide o conjunto fundamental, nesse caso $D$, em subconjuntos disjuntos chamados classes ${ }^{3}$ equivalentes. Se $a \in D$, denota-se $\bar{a}$ a única classe equivalente que contém $a$.

Exemplo A.3.1 Seja $D$ o conjunto dos inteiros e $m=6$. Conforme a relação de equivalência descrita anteriormente, existem seis classes equivalentes:

$$
\begin{aligned}
& \overline{0}=\{0, \pm 6, \pm 12, \pm 18, \ldots\} \\
& \overline{1}=\{\ldots,-17,-11,-5,1,7,13,19, \ldots\} \\
& \overline{2}=\{\ldots,-16,-10,-4,2,8,14,20, \ldots\} \\
& \overline{3}=\{\ldots,-15,-9,-3,3,9,15,21, \ldots\} \\
& \overline{4}=\{\ldots,-14,-8,-2,4,10,16,22, \ldots\} \\
& \overline{5}=\{\ldots,-13,-7,-1,5,11,17,23, \ldots\}
\end{aligned}
$$

Note que a classe equivalente $\overline{1}$ poderia ser chamada de $\overline{7}, \overline{13},-\overline{-5}$, etc. Entretanto, costuma-se representar uma classe equivalente particular pelo seu menor elemento não negativo. De fato, a notação $a$ mod $m$ é comumente utilizada para representar o menor elemento não negativo de $\bar{a}$.

\footnotetext{
${ }^{3}$ dá-se o nome classe a um grupo de objetos com alguma propriedade comum.
} 
Define-se adição de classe equivalente. como:

$$
\bar{a}+\bar{b}=\overline{a+b}
$$

e multiplicação, como:

$$
\bar{a} \cdot \bar{b}=\overline{(a \cdot b)}
$$

Para ilustrar, observe no exemplo que $\overline{1}+\overline{2}=\overline{3}$ e também $\overline{1}+\overline{2}=\overline{-5}+\overline{20}=\overline{15}$, pois $\overline{3}=\overline{15}$. Observa-se que o conjunto de classes equivalentes formam um anel. $\mathrm{O}$ anel, no contexto matemático, é definido como um conjunto $S$ com duas operações binárias (comumente a adição e multiplicação) que satisfazem as condições:

1. Associativa para a adição: para todo $a, b$ e $c \in S,(a+b)+c=a+(b+c)$;

2. Comutativa para a adição: para todo $a$ e $b \in S, a+b=b+a$;

3. Identidade para a adição: existe um elemento $0 \in S$ tal que para todo $a \in S$, $a+0=0+a=a ;$

4. Inversibilidade para a adição: para todo $a \in S$, existe um elemento $-a \in S$ tal que, $a+(-a)=(-a)+a=0$;

5. Associativa para a multiplicação: para todo $a, b$ e $c \in S,(a \cdot b) \cdot c=a \cdot(b \cdot c)$;

6. Distributiva: para todo $a, b$ e $c \in S, a \cdot(b+c)=(a \cdot b)+(a \cdot c)$ e $(b+c) \cdot a=$ $(b \cdot a)+(c \cdot a)$.

A identidade para a adição é dada por:

$$
\overline{0}=\{x \in D: x \equiv 0(\bmod m)\}
$$

e a identidade para a multiplicação por:

$$
\overline{1}=\{x \in D: x \equiv 1(\bmod m)\}
$$

onde 0 e 1 são as identidades da adição e multiplicação no domínio Euclidiano, respectivamente. Nesse caso, o anel é representado por $D \bmod m$. O exemplo A.3.1 mostrou que $Z \bmod 6$, sendo $Z$ o conjunto dos números inteiros, é um anel com 6 elementos. Para $D \bmod m$ ser um corpo, deve existir, para qualquer $\bar{a} \neq \overline{0}$, um $\bar{b}$ tal que: 


$$
\bar{a} \cdot \bar{b}=\overline{1}
$$

No exemplo A.3.1 não se verifica essa condição, portanto, não se pode ter um corpo. Porém, se $m$ for um número primo $p, \bar{a} \neq 0$ significa que $p \nmid a$ ( $p$ não é fator de $a$ ). Se $p \in D$ é primo e $p \nmid a$, então $p$ e $a$ são primos relativos ${ }^{4}$. Isso é facilmente verificado. Seja $d$ um divisor comum de $p$ e $a$. Como $p$ é primo, $d$ deve ser a unidade ou um $\operatorname{associado}^{5}$ de $p$. Como $p \nmid a$, nenhum associado de $p$ pode dividir $a$, então $d$ é a unidade. Conclui-se, portanto, que $\operatorname{mdc}(p, a)=1$ e então existem elementos $b$ e $t$ em $D$ tais que $a b+p t=1$. Portanto, com $a b \equiv 1$ (mod) $p$ satisfazendo (A.8) e conforme o Teorema A.3.1, tem-se que $D \bmod p$ é um corpo.

A seguir, é apresentado um exemplo de corpo finito com $D=Z$, ou seja, o domínio Euclidiano será o conjunto dos números inteiros.

Exemplo A.3.2 Seja $D=Z$ e $p=5$. Tem-se $D \bmod p$ com 5 elementos ( a partir de agora, chamar-se-á de elementos as classes equivalentes por questão de simplicidade de redação), os quais serão denotados por $\overline{0}, \overline{1}, \overline{2}, \overline{3}$ e $\overline{4}$.

$$
\begin{aligned}
& \overline{0}=\{0, \pm 5, \pm 10, \pm 15, \ldots\} \\
& \overline{1}=\{\ldots,-14,-9,-4,1,6,11,16, \ldots\} \\
& \overline{2}=\{\ldots,-13,-8,-3,2,7,12,17, \ldots\} \\
& \overline{3}=\{\ldots,-12,-7,-2,3,8,13,18, \ldots\} \\
& \overline{4}=\{\ldots,-13,-6,-1,4,9,14,19, \ldots\}
\end{aligned}
$$

A aritmética sobre o corpo é da forma:

$$
\overline{4}+\overline{3}=\overline{2}, \overline{2} \cdot \overline{3}=\overline{1}, \text { etc } .
$$

Para encontrar o inverso de um elemento basta aplicar o algoritmo de Euclides (MCELIECE, 1987). O algoritmo de Euclides é utilizado para obter o mdc $(a, b)$ e combinações lineares de $a$ e $b$ que resultam em um outro elemento específico.

Em sua versão estendida, o algoritmo compreende as equações de recorrência:

$$
\begin{aligned}
& r_{i-2}=q_{i} r_{i-1}+r_{i} \\
& s_{i}=s_{i-2}-q_{i} s_{i-1} \\
& t_{i}=t_{i-2}-q_{i} t_{i-1}
\end{aligned}
$$

\footnotetext{
${ }^{4}$ dois inteiros são primos relativos se não existe nenhum fator positivo comum exceto o 1 .

${ }^{5}$ nas circunstâncias de $p$ primo e $p \nmid a$, o associado de um elemento $x \in\{1,2,3, \ldots, p-1\}$, denotado por $x^{\prime}$, é tal que $x x^{\prime} \equiv a(\bmod p)$.
} 
onde $q_{i}$ é o quociente da divisão de $r_{i-2}$ por $r_{i-1}$ e $r_{i}$ o resto. $\mathrm{O}$ algoritmo é realizado até $r_{n+1}=0$ e, nesse ponto, tem-se $r_{n}=\operatorname{mdc}(a, b)$. As outras variáveis $s_{i}$ e $t_{i}$ relacionam-se $\operatorname{com} a$ e $b$ através da equação:

$$
s_{i} a+t_{i} b=r_{i}
$$

As condições iniciais para o algoritmo são:

$$
\begin{aligned}
& s_{i-1}=1, s_{0}=0 \\
& t_{i-1}=0, t_{0}=1
\end{aligned}
$$

Para aplicar o algoritmo na determinação do inverso de $\overline{3}$ do Exemplo A.3.2, faz-se $a=p=5$ e $b=3$. Assim:

\begin{tabular}{ccccc}
\hline$i$ & $s_{i}$ & $t_{i}$ & $r_{i}$ & $q_{i}$ \\
\hline-1 & 1 & 0 & 5 & - \\
0 & 0 & 1 & 3 & - \\
1 & 1 & -1 & 2 & 1 \\
2 & -1 & 2 & 1 & 1 \\
3 & 2 & -3 & 1 & 1 \\
4 & -3 & 5 & 0 & 1 \\
\hline
\end{tabular}

Tem-se o ponto de parada do algoritmo em $i=4$, pois $r_{4}=0$, assim, $r_{3}=1=$ $\operatorname{mdc}(5,3)$. Da linha $i=2$ obtém-se a expressão $2 \cdot 3-1 \cdot 5=1$. Então, $\overline{2} \cdot \overline{3}=\overline{1}$, ou seja, $(\overline{3})^{-1}=\overline{2}$. Observe que $\overline{3} \cdot \overline{2}=\overline{6}=\overline{1}$, conforme (A.9), e, portanto, o inverso de $\overline{3}$ é realmente $\overline{2}$.

O algoritmo de Euclides é um método sistemático para a obtenção do máximo divisor comum entre dois elementos e também para a obtenção de combinações lineares para determinar, por exemplo, o inverso de um elemento. No exemplo A.3.2 o corpo é reduzido, então, não se faz necessário utilizar o algoritmo de Euclides para determinar o inverso de elementos. Como um corpo do tipo $Z \bmod p$ possui $p$ elementos, onde $p$ é primo e existem infinitos números primos, a determinação do inverso de um elemento pode ser uma tarefa exaustiva, caso não seja utilizado um método sistemático.

O corpo finito $D \bmod p \operatorname{com} p$ elementos anteriormente denotado por $F_{p}$ é também comumente denotado por $G F(p)$.

O exemplo a seguir irá introduzir a construção de corpos finitos $D \bmod p$ quando $D$ é o conjunto de polinômios no indeterminado $x$ com coeficientes no corpo finito 
$F_{p}=Z \bmod p$. Esse tipo de construção é fundamental para o entendimento de corpos finitos, pois todo corpo finito pode ser construído dessa forma.

Exemplo A.3.3 Seja $D=F_{2}[x]$ e $p(x)=x^{3}+x+1$. Construir-se-á um corpo $F$ composto por polinômios sobre $F_{p}$. Observe que $p(x)$ é irredutivel. Inicialmente, calcula-se potências de $x$ módulo $p(x)=x^{3}+x+1$ :

$$
\begin{array}{ll}
x^{0} \equiv 1 & \bmod x^{3}+x+1 \\
x^{1} \equiv x & \bmod x^{3}+x+1 \\
x^{2} \equiv x^{2} & \bmod x^{3}+x+1 \\
x^{3} \equiv x+1 & \bmod x^{3}+x+1 \\
x^{4} \equiv x^{2}+x & \bmod x^{3}+x+1 \\
x^{5} \equiv x^{3}+x^{2} \equiv x^{2}+x+1 & \bmod x^{3}+x+1 \\
x^{6} \equiv x^{3}+x^{2}+x \equiv x^{2}+1 & \bmod x^{3}+x+1 \\
x^{7} \equiv x^{3}+x \equiv 1 & \bmod x^{3}+x+1
\end{array}
$$

Por questões de simplicidade de notação, representa-se as classes equivalentes (elementos) do corpo $\bar{x}$ por $\alpha$. Assim, tem-se os elementos do corpo:

$$
\begin{aligned}
& \alpha^{0}=1 \\
& \alpha^{1}=x \\
& \alpha^{2}=x^{2} \\
& \alpha^{3}=x+1 \\
& \alpha^{4}=x^{2}+x \\
& \alpha^{5}=x^{2}+x+1 \\
& \alpha^{6}=x^{2}+1 \\
& \alpha^{7}=1
\end{aligned}
$$

Observe que as 7 primeiras potências de $\alpha$ são distintas em GF(8). Como existem 7 elementos não nulos em GF(8), conforme (A.1), tem-se que todos os elementos não nulos de GF(8) são potências de $\alpha$. Verifica-se que o Teorema A.3.1 "transforma” o espaço vetorial tridimensional sobre $F_{2}$ em um corpo finito, podendo-se representar $\alpha=[010]$, onde $\alpha^{k}=a \alpha^{2}+b \alpha+1=[a b c]$.

As operações $+e \cdot$ são realizadas da forma convencional:

$$
\begin{aligned}
& \alpha^{3} \cdot \alpha^{6}=\alpha^{3+6}=\alpha^{9}=\alpha^{2}=[100] \\
& \alpha^{3}+\alpha^{6}=\alpha+1+\alpha^{2}+1=\alpha^{2}+\alpha=\alpha^{4}=[110]
\end{aligned}
$$


A seguir, serão definidos alguns conceitos básicos relacionados à corpos importantes para o estudo de sequências. Tais conceitos são: raiz primitiva, polinômio mínimo, polinômio primitivo, recorrência linear e polinômio característico.

\section{A.4 Raiz primitiva}

Um gerador de um grupo cíclico ${ }^{6} F^{*}=F-\{0\}$, é chamado de raiz primitiva do corpo $F$.

Exemplo A.4.1 Considere o corpo do Exemplo A.3.2, $F_{5}=Z \bmod 5$, cujos elementos são $\{0,1,2,3,4\}$. Verifica-se que o elemento 2 é uma raiz primitiva de $F_{5}$, pois $2^{0}=1$, $2^{1}=2,2^{2}=4$ e $2^{3}=3$, ou seja, as potências $0,1,2$ e 3 do elemento gerador 2 formam um grupo cíclico. O elemento 3 também é raiz primitiva de $F_{5}$, pois $3^{0}=1,3^{1}=3$, $3^{2}=4$ e $3^{3}=2$. Por outro lado, o elemento 4 não é raiz primitiva de $F_{5}$, pois $4^{0}=1$, $4^{1}=4,4^{2}=1$ e $4^{3}=4$, ou seja, as $n$ potências de 4 não formam um grupo cíclico.

A ordem de um grupo representa o número de elementos que esse compreende. A ordem de um elemento $\alpha$, ord $(\alpha)$, é dado por $t$ tal que $\left(\alpha^{0}, \alpha^{1}, \alpha^{2}, \ldots, \alpha^{t-1}\right)$ são todos distintos.

Do Exemplo A.4.1 tem-se que a ordem dos elementos geradores do grupo cíclico $\alpha$ é $\operatorname{ord}(2)=\operatorname{ord}(3)=5$.

Um Lema bastante útil no estudo de sequências é enunciado a seguir:

Lema A.4.1 Se a ordem do elemento $\alpha$ é $\operatorname{ord}(\alpha)=t$, então $\operatorname{ord}\left(\alpha^{i}\right)=t / \operatorname{mdc}(i, t)$.

Segue a prova. Um resultado direto do Exemplo A.3.3 é que para qualquer $\beta \neq 0$ vale:

$$
\beta^{s}=1 \quad \text { se e somente } \operatorname{se} \operatorname{ord}(\beta) \mid s
$$

O desenvolvimento da prova será separado em itens para facilitar o entendimento:

1. No Lema A.4.1, seja $\operatorname{mdc}(i, t)=d$;

2. Observe que $\left(\alpha^{i}\right)^{(t / d)}=\left(\alpha^{t}\right)^{(i / d)}$ e, de (A.18), $\left(\alpha^{t}\right)^{(i / d)}=1$. Diretamente de (A.18), tem-se que ord $\left(\alpha^{i}\right) \mid(t / d)$;

\footnotetext{
${ }^{6}$ dá-se o nome de grupo cíclico de ordem $n$ ao grupo formado por seu gerador e suas $n$ potências, tal que o gerador elevado à potência $n$ é o objeto identidade.
} 
3. Seja agora, do item anterior, $\operatorname{ord}\left(\alpha^{i}\right)=s$, então, $\alpha^{i s}=1 \mathrm{e}$, de (A.18), $\operatorname{ord}(\alpha) \mid i s$. Assim, do Lema A.4.1, tem-se $t \mid i s$.

4. No item 1 foi assumido $d=\operatorname{mdc}(i, t)$. Isso significa que $i a+t b=d$ para algum inteiro $a$ e $b$. Multiplicando essa equação por $s$ tem-se $i s a+t s b=d s$. Como, do item anterior, $t \mid i s$, segue-se que $t \mid d s$ também.

5. De outra forma do item anterior, $(t / d) \mid s$ e, do item 3, $(t / d) \mid \operatorname{ord}\left(\alpha^{i}\right)$;

Assim, foi provado que tanto ord $\left(\alpha^{i}\right) \mid(t / d)$ como $(t / d) \mid \operatorname{ord}\left(\alpha^{i}\right)$. Então, $\operatorname{ord}\left(\alpha^{i}\right)=$ $t / d$, como afirmado pelo Lema.

\section{A.5 Polinômio mínimo e polinômio primitivo}

Seja $F$ um corpo finito com $p^{m}$ elementos, onde $p$ é um número primo. O corpo $F$ pode ser visto como um espaço vetorial $m$-dimensional sobre o subcorpo $F_{p}$. Seja $\alpha$ um elemento arbitrário de $F$. Como $F$ tem dimensão $m$ sobre $F_{p}$, segue-se que os $m+1$ elementos, $\alpha^{0}, \alpha^{1}, \alpha^{2}, \ldots, \alpha^{m}$, devem ser linearmente dependentes sobre $F_{p}$. Então, devem existir $m+1$ elementos $A_{0}, A_{1}, \ldots, A_{m}$ de $F_{p}$, tais que:

$$
A_{0}+A_{1} \alpha+\ldots+A_{m} \alpha^{m}=0
$$

Ou seja, se o polinômio $A(x)=A_{0}+A_{1} x+\ldots+A_{m} x^{m}, \alpha$ é raiz da equação polinomial $A(x)=0$. É claro que $\alpha$ pode satisfazer outras equações polinomiais de outros polinômios. Define-se $S(\alpha)$ como o conjunto de tais polinômios:

$$
S(\alpha)=\left\{f(x) \in F_{p}(x): f(\alpha)=0\right\}
$$

Seja $p(x)$ um polinômio não nulo de menor grau (denota-se grau $(p))$ de $S(\alpha)$ e $f(x)$ qualquer polinômio de $S(\alpha)$. Através da divisão polinomial, tem-se:

$$
f(x)=q(x) p(x)+r(x), \quad \operatorname{grau}(r)<\operatorname{grau}(p)
$$

Como $f(\alpha)=0$, tem-se que $p(\alpha)=0$ e $r(\alpha)=0$. Então, se $r(x) \equiv 0$, conclui-se que grau $(p)$ é mínimo, ou seja, o menor grau dos polinômios não nulos de $S(\alpha)$. Adicionalmente, verifica-se que $p(x) \mid f(x)$ para todo $f(x) \in S(\alpha)$. Chama-se, assim, $p(x)$ polinômio mínimo de $\alpha$ em relação ao corpo $F$. Se for definido que o coeficiente do monômio de maior grau de $p(x)$ deva ser 1 (ou seja, se $p(x)$ for um monic polynomial), 
tem-se que $p(x)$ de $\alpha$ é irredutível. Essa afirmação é clara, pois se for possível fatorar $p(x)=a(x) b(x)$, necessariamente $a(\alpha)=0$ ou $b(\alpha)=0$ e isso contradiz o grau mínimo de $p(x)$.

Dá-se o nome de polinômio primitivo ao polinômio mínimo $p(x)$ de $\alpha$, sendo $\alpha$ uma raiz primitiva de $F$.

Para obter sistematicamente o polinômio mínimo de um elemento qualquer $\alpha$, introduzir-se-á o conceito de conjugados de $\alpha$ em relação a um corpo $F$.

Seja $F$ um corpo sobre o subcorpo com $q$ elementos, $F_{p}$, onde $p$ é primo. Os elementos de $F$ são dados em potências de $\alpha$. Nesse corpo estão contidos subcorpos $K$, assim como o $F_{p}$. Note-se que esses subcorpos podem ser muito maiores que $F_{p} \mathrm{e}$ menores que $F$.

Dá-se o nome de conjugados de $\alpha$ em relação ao subcorpo $K$ aos elementos:

$$
\alpha, \alpha^{q}, \alpha^{q^{2}}, \alpha^{q^{3}}, \ldots, \alpha^{q^{d}}
$$

onde $d$, chamado de grau de $\alpha$ e denotado por grau $(\alpha)$, é tal que $\alpha^{q^{d}}=\alpha$. Assim, tem-se que:

$$
q^{d} \equiv 1 \bmod t
$$

onde $t=\operatorname{ord}(\alpha)$.

Se $\alpha$ é raiz de uma equação polinomial $p(x)=0, \operatorname{com} p(x)=p_{0}+p_{1} x+p_{2} x^{2}+$ $\ldots+p_{d} x^{d}$, tem-se que:

$$
\sum_{k=0}^{d} p_{k} \alpha^{k}=0
$$

Fazendo $p\left(\alpha^{q}\right)$, tem-se:

$$
\begin{aligned}
0 & =\left(\sum_{k=0}^{d} p_{k} \alpha^{k}\right)^{q} \\
& =\sum_{k=0}^{d} p_{k}^{q} \alpha^{q k} \\
& =\sum_{k=0}^{d} p_{k}\left(\alpha^{q}\right)^{k} \\
& =p\left(\alpha^{q}\right)
\end{aligned}
$$


ou seja, todos os conjugados de $\alpha$ são também raizes de $p(x)$, pois:

$$
\begin{aligned}
0 & =\left(\sum_{k=0}^{d} p_{k} \alpha^{k}\right)^{q^{j}} \\
& =p\left(\alpha^{q^{j}}\right)
\end{aligned}
$$

Na equação (A.25) foi utilizada a propriedade:

$$
\left(\alpha_{1}+\alpha_{2}\right)^{p^{k}}=\alpha_{1}^{p^{k}}+\alpha_{2}^{p^{k}}
$$

onde $k=1,2,3, \ldots$

Essa é facilmente verificada para $k=1$ :

$$
\left(\alpha_{1}+\alpha_{2}\right)^{p}=\alpha_{1}^{p}+\left(\begin{array}{c}
p \\
1
\end{array}\right) \alpha_{1}^{p-1} \alpha_{2}+\ldots+\left(\begin{array}{c}
p \\
p-1
\end{array}\right) \alpha_{1} \alpha_{2}^{p-1}+\alpha_{2}^{p}
$$

onde, por definição:

$$
\left(\begin{array}{l}
p \\
k
\end{array}\right)=\frac{p(p-1) \ldots(p-k+1)}{k(k-1) \ldots 1}
$$

Em (A.29), pode-se observar que o numerador é divisível por $p$, assim, em um corpo com característica $p$, todos os coeficientes de (A.27) serão equivalentes a zero. Assim, verifica-se a propriedade de (A.27) para $k=1$. Para verificar a propriedade com $k>1$, basta escrever $\left(\alpha_{1}+\alpha_{2}\right)^{p^{k}}$ em produtos de $\left(\alpha_{1}+\alpha_{2}\right)^{p}$ e utilizar o mesmo argumento de coeficientes equivalentes a zero.

Sabendo que todos os conjugados de $\alpha$ em relação ao subcorpo $K$ são também raízes da mesma equação polinomial da qual $\alpha$ é raiz, tem-se que o polinômio mínimo de $\alpha$ em relação ao subcorpo $K$ é dado por:

$$
f_{\alpha}(x)=(x-\alpha)\left(x-\alpha^{q}\right) \ldots\left(x-\alpha^{q^{d-1}}\right)
$$

onde $d$ é o grau de $\alpha$, grau $(\alpha)$, em relação ao subcorpo $K$.

O exemplo a seguir mostra a construção de um corpo finito $G F\left(2^{4}\right)$. A construção será $D \bmod p$, onde $D=F_{2}[x]$ e $p(x)=x^{4}+x+1$. Isso significa que o domínio Euclidiano em questão é o conjunto de polinômios no indeterminado $x$, com coeficientes no corpo finito $F_{2}=Z \bmod 2$, onde $Z$ é o conjunto dos números inteiros.

Exemplo A.5.1 Sejam $D=F_{2}[x]$ e $p(x)=x^{4}+x+1$. Para obter o corpo $D \bmod p$, de- 
notado por $G F\left(2^{4}\right)$, primeiramente calcula-se as 15 primeiras potências de x módulo $p(x)=x^{4}+x+1$ :

$$
\begin{array}{rlr}
x^{0} & \equiv 1 & \bmod x^{4}+x+1 \\
x^{1} & \equiv x & \bmod x^{4}+x+1 \\
x^{2} \equiv x^{2} & \bmod x^{4}+x+1 \\
x^{3} \equiv x^{3} & \bmod x^{4}+x+1 \\
x^{4} \equiv x+1 & \bmod x^{4}+x+1 \\
x^{5} \equiv x^{2}+x & \bmod x^{4}+x+1 \\
x^{6} \equiv x^{3}+x^{2} & \bmod x^{4}+x+1 \\
x^{7} \equiv x^{4}+x^{3} \equiv x^{3}+x+1 & \bmod x^{4}+x+1 \\
x^{8} \equiv x^{4}+x^{2}+x \equiv x^{2}+1 & \bmod x^{4}+x+1 \\
x^{9} \equiv x^{3}+x & \bmod x^{4}+x+1 \\
x^{10} \equiv x^{4}+x^{2} \equiv x^{2}+x+1 & \bmod x^{4}+x+1 \\
x^{11} \equiv x^{3}+x^{2}+x & \bmod x^{4}+x+1 \\
x^{12} \equiv x^{4}+x^{3}+x^{2} \equiv x^{3}+x^{2}+x+1 & \bmod x^{4}+x+1 \\
x^{13} \equiv x^{4}+x^{3}+x^{2}+x \equiv x^{3}+x^{2}+1 & \bmod x^{4}+x+1 \\
x^{14} \equiv x^{4}+x^{3}+x \equiv x^{3}+1 & \bmod x^{4}+x+1 \\
x^{15} \equiv x^{4}+x \equiv 1 & \bmod x^{4}+x+1
\end{array}
$$

Voltando ao corpo $G F\left(2^{4}\right)$, representam-se as classes equivalente $\bar{x}$ por $\alpha$. Então, da tabela de potências de $x$, obtém-se a tabela de potências de $\alpha$ e vetores de dimensão 4 sobre $G F(2)$ : 


$$
\begin{array}{ll}
\alpha^{0}=1 & 0001 \\
\alpha^{1}=\alpha & 0010 \\
\alpha^{2}=\alpha^{2} & 0100 \\
\alpha^{3}=\alpha^{3} & 0011 \\
\alpha^{4}=\alpha+1 & 0110 \\
\alpha^{5}=\alpha^{2}+\alpha & 1100 \\
\alpha^{6}=\alpha^{3}+\alpha^{2} & 1011 \\
\alpha^{7}=\alpha^{4}+\alpha^{3}=\alpha^{3}+\alpha+1 & 0101 \\
\alpha^{8}=\alpha^{4}+\alpha^{2}+\alpha=\alpha^{2}+1 & 1010 \\
\alpha^{9}=\alpha^{3}+\alpha & 0111 \\
\alpha^{10}=\alpha^{4}+\alpha^{2}=\alpha^{2}+\alpha+1 & 1110 \\
\alpha^{11}=\alpha^{3}+\alpha^{2}+\alpha & 1111 \\
\alpha^{12}=\alpha^{4}+\alpha^{3}+\alpha^{2}=\alpha^{3}+\alpha^{2}+\alpha+1 & 1101 \\
\alpha^{13}=\alpha^{4}+\alpha^{3}+\alpha^{2}+\alpha=\alpha^{3}+\alpha^{2}+1 & 1101 \\
\alpha^{14}=\alpha^{4}+\alpha^{3}+\alpha=\alpha^{3}+1 & 1001 \\
\alpha^{15}=\alpha^{4}+\alpha=1 & 0001
\end{array}
$$

Observe que $\alpha^{15}=\alpha^{0}$ (o grupo é cíclico $)$, então $\left\{\alpha^{0}, \alpha^{1}, \ldots, \alpha^{14}\right\}$ são os 15 elementos não nulos de $G F\left(2^{4}\right)$.

Agora, verificar-se-á se $\alpha^{5}$ é raiz primitiva de $G F\left(2^{4}\right)$, ou seja, se $\alpha^{5}$ é um gerador do grupo cíclico $G F\left(2^{4}\right)^{*}=G F\left(2^{4}\right)-\{0\}$. Tomam-se as potências de $\alpha^{5}$ :

$$
\begin{array}{ll}
\hline i & \left(\alpha^{5}\right)^{i} \\
\hline 0 & \alpha^{0}=1 \\
1 & \alpha^{5} \\
2 & \alpha^{10} \\
3 & \alpha^{15}=\alpha^{0} \\
4 & \alpha^{20}=\alpha^{5} \\
5 & \alpha^{25}=\alpha^{10} \\
\hline
\end{array}
$$

Verifica-se que potências de $\alpha^{5}$ não geram o grupo cíclico $G F\left(2^{4}\right)^{*}$.

De (A.33) tem-se que $\left(\alpha^{5}\right)^{0},\left(\alpha^{5}\right)^{1} e\left(\alpha^{5}\right)^{2}$ são distintos e portanto a ordem de $\alpha^{5} e ́$ $\operatorname{ord}\left(\alpha^{5}\right)=3$. Então, $\alpha^{5}$ pertence ao subcorpo $G F\left(2^{2}\right)$, o qual contém 3 elementos não nulos. Além disso, $\alpha^{5}$ é uma raiz primitiva do subcorpo $G F\left(2^{2}\right)$.

Calcula-se, agora, o polinômio mínimo de $\alpha^{5}$ em $G F\left(2^{2}\right)$. Para tanto, deve-se obter o número de conjugados de $\alpha^{5}$. O número de conjugados de $\alpha$, ou o grau de $\alpha$, $\operatorname{grau}(\alpha)$, é facilmente obtido de (A.23): 


$$
\begin{aligned}
2^{d} & \equiv 1 \bmod \operatorname{ord}\left(\alpha^{5}\right) \\
2^{d} & \equiv 1 \bmod 3 \\
d & =2
\end{aligned}
$$

Assim, tem-se que o grau de $\alpha^{5}$ é grau $\left(\alpha^{5}\right)=d=2$. Os conjugados de $\alpha^{5}$ são: $\alpha^{5}$ $e\left(\alpha^{5}\right)^{2}$. O elemento $\left(\alpha^{5}\right)^{2^{2}}=\left(\alpha^{5}\right)^{4}=\alpha^{20}=\alpha^{5}$ não é contabilizado como conjugado de $\alpha^{5}$ pois é um elemento equivalente à $\alpha^{5}$. Esse resultado pode ser verificado em (A.33).

O polinômio mínimo de $\alpha^{5}$ no subcorpo $G F\left(2^{2}\right)$ é dado por:

$$
\begin{aligned}
& f_{\alpha^{5}}(x)=\left(x-\alpha^{5}\right)\left(x-\left(\alpha^{5}\right)^{2}\right) \\
& f_{\alpha^{5}}(x)=x^{2}+x+1
\end{aligned}
$$

Esse polinômio é um polinômio mínimo de uma raiz primitiva do subcorpo $G F\left(2^{2}\right)$, portanto, é um polinômo primitivo em $G F\left(2^{2}\right)$.

Agora, será obtido o polinômio mínimo de $\alpha^{4}$. A ordem de $\alpha^{4}$ é 15, pois $\left(\alpha^{4}\right)^{0}$, $\left(\alpha^{4}\right)^{1}, \ldots,\left(\alpha^{4}\right)^{14}$, são distintos:

$$
\begin{array}{ll}
\hline i & \left(\alpha^{4}\right)^{i} \\
\hline 0 & \left(\alpha^{4}\right)^{0}=1 \\
1 & \left(\alpha^{4}\right)^{1}=\alpha^{4} \\
2 & \left(\alpha^{4}\right)^{2}=\alpha^{8} \\
3 & \left(\alpha^{4}\right)^{3}=\alpha^{12} \\
4 & \left(\alpha^{4}\right)^{4}=\alpha^{1} \\
5 & \left(\alpha^{4}\right)^{5}=\alpha^{5} \\
6 & \left(\alpha^{4}\right)^{6}=\alpha^{9} \\
7 & \left(\alpha^{4}\right)^{7}=\alpha^{13} \\
8 & \left(\alpha^{4}\right)^{8}=\alpha^{2} \\
9 & \left(\alpha^{4}\right)^{9}=\alpha^{6} \\
10 & \left(\alpha^{4}\right)^{10}=\alpha^{10} \\
11 & \left(\alpha^{4}\right)^{11}=\alpha^{14} \\
12 & \left(\alpha^{4}\right)^{12}=\alpha^{3} \\
13 & \left(\alpha^{4}\right)^{13}=\alpha^{7} \\
14 & \left(\alpha^{4}\right)^{14}=\alpha^{11}
\end{array}
$$


Como a ordem de $\alpha^{4}$ é $\operatorname{ord}(\alpha)=15$, tem-se que $\alpha^{4}$ é gerador do grupo cíclico de 15 elementos, $G F\left(2^{4}\right)^{*}$.

O grau de $\alpha^{4}$, grau $(\alpha)$, é dado por (A.23):

$$
\begin{aligned}
2^{d} & \equiv 1 \bmod \operatorname{ord}\left(\alpha^{4}\right) \\
2^{d} & \equiv 1 \bmod 15 \\
d & =4
\end{aligned}
$$

Assim, tem-se que o grau de $\alpha^{4}$ é grau $\left(\alpha^{4}\right)=d=4$ e seus 4 conjugados são: $\left(\alpha^{4}\right)^{2^{0}}=\alpha^{4},\left(\alpha^{4}\right)^{2^{1}}=\left(\alpha^{4}\right)^{2},\left(\alpha^{4}\right)^{2^{2}}=\left(\alpha^{4}\right)^{4} e\left(\alpha^{4}\right)^{2^{3}}=\left(\alpha^{4}\right)^{8}$.

O polinômio mínimo de $\alpha^{4}$ no subcorpo $G F\left(2^{4}\right)$ é dado por:

$$
\begin{aligned}
& f_{\alpha^{4}}(x)=\left(x-\alpha^{4}\right)\left(x-\left(\alpha^{4}\right)^{2}\right)\left(x-\left(\alpha^{4}\right)^{4}\right)\left(x-\left(\alpha^{4}\right)^{8}\right) \\
& f_{\alpha^{4}}(x)=x^{4}+x+1
\end{aligned}
$$

O polinômio obtido é um polinômio mínimo da raiz primitiva do corpo $G F\left(2^{4}\right)$, $D \bmod p, \operatorname{com} D=F_{2}[x]$ e $p(x)=x^{4}+x+1$, portanto, é um polinômo primitivo em $G F\left(2^{4}\right)$.

Com a mesma metodologia, obtém-se o polinômio mínimo de $\alpha^{8}$. A ordem de $\alpha^{8}$ é $\operatorname{ord}\left(\alpha^{8}\right)=15$ e o grau $\operatorname{grau}\left(\alpha^{8}\right)=4$. Assim, o polinômio mínimo é:

$$
f_{\alpha^{4}}(x)=x^{4}+x^{3}+1
$$

Novamente, o polinômio obtido é um polinômio mínimo da raiz primitiva do corpo $G F\left(2^{4}\right)$. Porém, agora, o corpo $G F\left(2^{4}\right)$ é construído de $D \bmod p$, com $D=F_{2}[x]$ e $p(x)=x^{4}+x^{3}+1$. Portanto, $f_{\alpha^{4}}(x)$ é um polinômo primitivo desse corpo $G F\left(2^{4}\right)$.

\section{A.6 Coconjuntos ciclotômicos}

O conjunto dos números inteiros de 1 a $p,\{1,2,3,4, \ldots, p\}$, primos relativos a $p$ formam um grupo sob a multiplicação módulo $p$. A função de Euler $\phi(p)$ denota o número de primos relativos a $p$ pertencentes ao conjunto $\{1,2, \ldots, p\}$. Se $p$ é impar, é claro que $\{1,2,4,8, \ldots\}$ forma um subgrupo daquele grupo. No caso de $p=2^{m}-1$, o subgrupo é composto de $m$ elementos: 


$$
\left\{1,2,4,8, \ldots, 2^{m-1}\right\}
$$

Um coconjunto é obtido multiplicando (módulo $p$ ) todos os elementos do subgrupo por qualquer elemento do conjunto dos números inteiros de 1 a $p$. Por exemplo, para $p=15$, o subgrupo (A.40) é $\{1,2,4,8\}$. Os coconjuntos desse subgrupo são:

$$
\begin{array}{lllll}
C_{0}: & 0 & & & \\
C_{1}: & 1 & 2 & 4 & 8 \\
C_{2}: & 3 & 6 & 12 & 9 \\
C_{3}: & 5 & 10 & & \\
C_{4}: & 7 & 14 & 13 & 11
\end{array}
$$

Dos coconjuntos de um subgrupo, pelo menos um é impróprio e $\frac{\phi(p)}{m}$ são próprios. Coconjuntos impróprios são obtidos da multiplicação de cada um dos elementos do subgrupo por um número que não é primo relativo a $p$. No exemplo, os coconjuntos $C_{0}$, $C_{2}$ e $C_{3}$ são impróprios e os demais são próprios. O conjunto de todos os coconjuntos (próprios e impróprios) de um subgrupo compõem os coconjuntos ciclotômicos.

Para o polinômio mínimo de um elemento $\alpha \in G F\left(2^{m}\right)$ ser de grau $m$ e primitivo, deve-se ter $\operatorname{ord}(\alpha)=2^{m}-1$, pois, nesse caso, de (A.23):

$$
\begin{aligned}
2^{d} & \equiv 1 \bmod \operatorname{ord}(\alpha) \equiv 1 \bmod \left(2^{m}-1\right) \\
d & =m
\end{aligned}
$$

$\mathrm{e}, \operatorname{portanto}, \operatorname{grau}(\alpha)=m$

Do lema A.4.1, a ordem de $\beta=\alpha^{r}$ será $\operatorname{ord}(\beta)=\operatorname{ord}\left(\alpha^{r}\right)=\frac{\operatorname{ord}(\alpha)}{\operatorname{mdc}(r, \operatorname{ord}(\alpha))}$. Assim, para o polinômio mínimo de $\alpha^{r}$ ser primitivo e de grau $m$, deve-se ter $r$ e $2^{m}-1$ primos relativos.

Então, o polinômio mínimo de $\alpha^{r} \operatorname{com} r \in C$, onde $C$ é um coconjunto próprio, é primitivo e de grau $m$.

Observe que:

$$
\begin{aligned}
f_{\alpha}(x) & =(x-\alpha)\left(x-\alpha^{2}\right) \ldots\left(x-\alpha^{2^{m-1}}\right) \\
& =\left(x-\alpha^{2}\right)\left(x-\alpha^{2 \times 2}\right) \ldots\left(x-\alpha^{2^{m-2} 2}\right)\left(x-\alpha^{2^{m-1} 2}\right) \\
& =\left(x-\alpha^{2}\right)\left(x-\alpha^{4}\right) \ldots\left(x-\alpha^{2^{m-1}}\right)(x-\alpha)
\end{aligned}
$$




$$
=f_{\alpha}(x)
$$

Como os elementos $c_{i}$ de um coconjunto são do tipo $c_{i}=2^{i} c_{0}$, tem-se que para $r, s \in C$, o polinômio mínimo de $\alpha^{r}$ é igual ao polinômio mínimo de $\alpha^{s}$.

Com as observações anteriores, tem-se que o número de polinômios primitivos de grau $m$ é dado pelo número de coconjuntos próprios do subgrupo $\left\{1,2,4,8, \ldots, 2^{m-1}\right\}$. Logo, o número de polinômios primitivos de grau $m$ é dado por $\frac{\phi(p)}{m}=\frac{\phi\left(2^{m}-1\right)}{m}$.

\section{A.7 Elemento primitivo}

O elemento primitivo de um corpo distingue-se da raiz primitiva por não estar situado em um subcorpo. Ou seja, o elemento primitivo do corpo $F$ forma uma base para o corpo $F$. No Exemplo A.5.1 foi visto que $\alpha^{4}$ pertence ao corpo $G F\left(2^{4}\right)$ e é raiz primitiva do corpo $G F\left(2^{2}\right)$. Assim, $\alpha^{4}$ não é elemento primitivo de $G F\left(2^{4}\right)$. Em outras palavras, não forma uma base para $G F\left(2^{4}\right)$.

\section{A.8 Função traço}

A função traço, ou simplesmente traço, é uma ferramenta muito útil na álgebra de corpos finitos. Seja $F=G F\left(q^{m}\right)$ e $K=G F\left(q^{n}\right), F$ é um subcorpo de $K$. Se $\alpha$ é um elemento de $K$, seu traço em relação ao subcorpo $F$ é definido como:

$$
\operatorname{Tr}_{m}^{n}(\alpha)=\sum_{i=0}^{\frac{n}{m}-1} \alpha^{q^{m i}}
$$

É também utilizada algumas vezes, por conveniência, a notação $\operatorname{Tr}_{F}^{K}(\alpha)$.

As principais propriedades do traço são:

1. $\operatorname{Tr}_{m}^{n}(\alpha) \in G F\left(2^{m}\right)$. Para verificar a propriedade, mostrar-se-á que $\operatorname{Tr}_{m}^{n}(\alpha)$ pertence à um grupo cíclico de ordem $q^{m}$, ou seja, $\operatorname{Tr}_{m}^{n}(\alpha)^{q^{m}}=\operatorname{Tr}_{m}^{n}(\alpha)$. Então, $\operatorname{Tr}_{m}^{n}(\alpha)^{q^{m}}=\left(\alpha+\alpha^{q^{m}}+\alpha^{q^{2 m}}+\ldots+\alpha^{q^{n-m}}\right)^{q^{m}}=\alpha^{q^{m}}+\alpha^{q^{2 m}}+\ldots+\alpha^{q^{n-m}}+\alpha^{q^{n}}$. Porém, $\alpha^{q^{n}}=\alpha$, pois $\alpha$ é elemento de $G F\left(2^{n}\right)$. Assim, $\operatorname{Tr}_{m}^{n}(\alpha)^{q^{m}}=\operatorname{Tr}_{m}^{n}(\alpha)$.

2. $\operatorname{Tr}(\alpha+\beta)=\operatorname{Tr}(\alpha)+\operatorname{Tr}(\beta)$. Essa propriedade é diretamente verificada por (A.27).

3. $\operatorname{Tr}_{m}^{n}(\lambda \alpha)=\lambda T r_{m}^{n}(\alpha) \operatorname{com} \lambda \in G F\left(2^{m}\right)$. Verificação:

$$
\operatorname{Tr}_{m}^{n}(\lambda \alpha)=\sum_{i=0}^{\frac{n}{m}-1}(\lambda \alpha)^{q^{m i}}
$$




$$
\begin{aligned}
& =\lambda \alpha+\lambda^{q^{m}} \alpha^{q^{m}}+\lambda^{q^{2 m}} \alpha^{q^{2 m}}+\ldots+\lambda^{q^{\left(\frac{n}{m}-1\right) m}} \alpha^{q^{\left(\frac{n}{m}-1\right) m}} \\
& =\lambda \alpha+\lambda \alpha^{q^{m}}+\lambda \alpha^{q^{2 m}}+\ldots+\lambda \alpha^{q^{\left(\frac{n}{m}-1\right) m}} \\
& =\lambda\left(\alpha+\alpha^{q^{m}}+\alpha^{q^{2 m}}+\ldots+\alpha^{q^{\left(\frac{n}{m}-1\right) m}}\right) \\
& =\lambda \operatorname{Tr}_{m}^{n}(\alpha)
\end{aligned}
$$

4. $\operatorname{Tr}_{m}^{n}\left(\alpha^{q}\right)=\operatorname{Tr}_{m}^{n}(\alpha)$. Observe que $\alpha^{q^{n}}=\alpha$. Como $\alpha$ é raiz primitiva de $G F\left(2^{n}\right)$, o grau de $\alpha$ é $n$. Então:

$$
\begin{aligned}
\operatorname{Tr}_{m}^{n}\left(\alpha^{q}\right) & =\alpha^{q}+\alpha^{q^{2}}+\ldots+\alpha^{q^{n-1}}+\alpha^{q^{n}} \\
& =\alpha^{q}+\alpha^{q^{2}}+\ldots+\alpha^{q^{n-1}}+\alpha \\
& =\operatorname{Tr}_{m}^{n}(\alpha)
\end{aligned}
$$

Para simplificar a notação, será utilizado $\operatorname{Tr}(\alpha)$, com $\alpha \in G F\left(2^{n}\right)$, para representar $\operatorname{Tr}_{1}^{n}(\alpha)$.

\section{A.9 Recorrência linear e polinômio característico}

Chama-se de recorrência linear de ordem $m$ a equação de recorrência da forma:

$$
s_{t}=a_{1} s_{t-1}+a_{2} s_{t-2}+\ldots+a_{m} s_{t-m}
$$

onde, por exemplo, $\left(s_{0}, s_{1}, s_{2}, \ldots\right)$ pode ser a sequência dos números reais e $a_{1}, a_{2}, \ldots, a_{m}$ constantes reais quaisquer. Porém, será dada atenção ao caso em que $\left(s_{t}\right)$ é uma sequência de elementos de um corpo finito $F$ e $a_{1}, a_{2}, \ldots, a_{m}$ elementos fixos também de $F$.

O polinômio característico da recorrência de (A.47) é definido como:

$$
f(x)=x^{m}-a_{1} x^{m-1}-a_{2} x^{m-2}-\ldots-a_{m}
$$

Um importante teorema para a obtenção de sequências é enunciado a seguir:

Teorema A.9.1 Se o polinômio característico (A.48) é irredutível e seus coeficientes estão em $G F(q)$, então para qualquer $\theta \in G F\left(q^{m}\right)$, a sequência definida por:

$$
s_{t}=\operatorname{Tr}_{1}^{m}\left(\theta \alpha^{t}\right)
$$

satisfaz (A.47). 
A prova do Teorema é imediata. Se $\alpha$ é uma raiz da equação polinomial $f(x)=0$, onde $f(x)$ é o polinômio característico (A.48) com coeficientes em $G F(q)$, tem-se:

$$
\alpha^{m}=\sum_{i=i}^{m} a_{i} \alpha^{m-i}
$$

Utilizando essa expressão em (A.49), tem-se:

$$
\begin{aligned}
s_{t} & =\operatorname{Tr}_{m}^{n}\left(\theta \alpha^{t-m} \alpha^{m}\right) \\
& =\operatorname{Tr}_{m}^{n}\left(\theta \alpha^{t-m} \cdot \sum_{i=1}^{m} a_{i} \alpha^{m-i}\right) \\
& =\sum_{i=1}^{m} \operatorname{Tr}_{m}^{n}\left(a_{i} \theta \alpha^{t-i}\right) \\
& =\sum_{i=1}^{m} a_{i} \operatorname{Tr}_{m}^{n}\left(\theta \alpha^{t-i}\right) \\
& =\sum_{i=1}^{m} a_{i} s_{t-i}
\end{aligned}
$$

Então (A.47) é satisfeita. Isso mostra que sequências podem ser geradas com o auxílio do traço de um elemento.

A recorrência linear (A.47) com $\left(s_{t}\right)$ uma sequência de elementos de $G F\left(2^{m}\right)$ com coeficientes $a_{1}, a_{2}, \ldots, a_{m}$ sobre $G F(2)$ pode ser implementada em circuito pelo registrador de deslocamento apresentado na figura A.1.

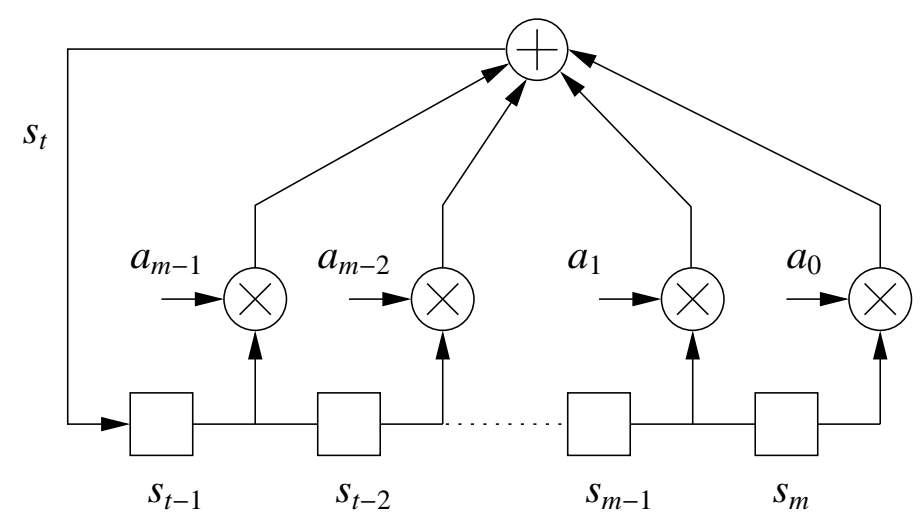

Figura A.1: Circuito que implementa a recorrência linear

Uma sequência $\left(s_{t}\right)$ tem período $N$, se:

$$
s_{t+N}=s_{t}, \text { para todo } t \geq 0
$$

onde $N$ é o menor inteiro que satisfaz (A.52). 
Se $\left(s_{t}\right)$ é uma solução de (A.47) e o polinômio característico é irredutível, do Teorema A.9.1, $s_{t}=\operatorname{Tr}_{1}^{m}\left(\theta \alpha^{t}\right)$ para algum $\theta \in G F\left(q^{m}\right)$. Se o período da sequência for $N$ :

$$
\begin{gathered}
\operatorname{Tr}_{1}^{m}\left(\theta \alpha^{t+N}\right)=\operatorname{Tr}_{1}^{m}\left(\theta \alpha^{t}\right), \quad t \geq 0 \\
\operatorname{Tr}_{1}^{m}\left(\theta \alpha^{t}\left(\alpha^{N}-1\right)\right)=0, \quad t \geq 0
\end{gathered}
$$

Isso ocorre somente se $\theta=0$ ou $\alpha^{N}=\alpha^{0}$. No primeiro caso, tem-se $s_{t}=0$ para todo $t$. No segundo caso, tem-se $\left(s_{t}\right)$ periódica com período $N$ se, e somente se, a ordem de $\alpha$ dividir $N$. O menor $N$ para o qual $s_{t+N}=s_{t}$ é $N=\operatorname{ord}(\alpha)$. Então, no caso em que $f(x)$ é irredutível, o período da sequência definida por $\left(s_{t}\right), s_{t}=\operatorname{Tr}_{1}^{m}\left(\theta \alpha^{t}\right)$, é dado por $N=\operatorname{ord}(\alpha)$. Esse é um importante Teorema:

Teorema A.9.2 Se $f(x)$ é irredutível, então toda solução não nula de (A.47) tem período $N$, onde $N=\operatorname{ord}(\alpha)$. De forma equivalente, $N$ é o menor inteiro tal que $x^{N} \equiv 1(\bmod f(x))$. 


\section{Anexo B - Sequência de máximo comprimento}

Uma sequência de máximo comprimento (SMC) de grau $m$ é uma sequência que satisfaz uma recorrência linear cujo polinômio característico de grau $m$ é primitivo (MCELIECE, 1987). O polinômio primitivo de grau $m$ é um polinômio mínimo do elemento $\alpha$, o qual é raiz primitiva de um corpo $G F\left(p^{m}\right)$, vide anexo A. Todo polinômio primitivo é irredutível (anexo A) e do Teorema A.9.2 a sequência definida por ${ }^{1}$ :

$$
s_{t}=\operatorname{Tr}_{1}^{m}\left(\theta \alpha^{t}\right)
$$

tem período ${ }^{2} N=\operatorname{ord}(\alpha)$. A ordem do elemento $\alpha$ é $p^{m}-1$, pois $\alpha$ é raiz primitiva de $G F\left(p^{m}\right)$. Assim, tem-se que o período da SMC é $p^{m}-1$.

Neste anexo são apresentadas as principais propriedades das SMC binárias, ou seja, compostas de elementos de $G F(p) \operatorname{com} p=2$.

\section{B.1 Principais propriedades da SMC}

Uma propriedade muito importante das SMC é a da distribuição dos blocos de comprimento $r$. Por exemplo, a sequência 1110000110000 possui um bloco-1 de comprimento 3, dois blocos-0 de comprimento 4 e um bloco-1 de comprimento 2. Determinar a distribuição dos blocos em uma sequência de período pequeno é fácil, basta contar. Verificar-se-á a seguir que as SMC possuem a distribuição dos blocos bem determinada.

Da recorrência linear (anexo equação A.47) tem-se que a SMC é gerada da combinação de $m$ termos anteriores, chamados de grânulo- $m$. Por exemplo: considere a SMC $\left(s_{0}, s_{1}, \ldots, s_{N-1}\right)$; um grânulo- $m$ é definido como:

$$
\left(s_{t}, s_{t+1}, \ldots, s_{t+m-1}\right), \quad \text { para } t=0,1, \ldots, N-1
$$

${ }^{1} \operatorname{Tr}_{m}^{n}(\alpha)$ representa a função traço de $\alpha$, a qual mapeia elementos de $G F\left(p^{n}\right)$ em elementos de $G F\left(p^{m}\right)$ (anexo seção A.8).

${ }^{2} \operatorname{ord}(\alpha)$ representa a ordem do elemento $\alpha$ (anexo seção A.3). 
onde os índices de (B.2) são tomados $\bmod N$, se necessário.

Pode-se identificar o período da sequência quando houver uma repetição de um dos grânulos-m. Como a SMC tem período $N=2^{m}-1$, verifica-se que uma SMC contém $2^{m}-1$ grânulos- $m$ distintos. Tais grânulos- $m$ são dados por todas as combinações de (B.2), exceto o $(0,0, \ldots, 0)$, pois uma soma de zeros resultará sempre em zero e, assim, a sequência definida pela recorrência linear (A.47) deixaria de ser periódica.

Com isso prova-se um importante Teorema para as SMC:

Teorema B.1.1 Cada um dos $2^{m}-1$ grânulos-m, exceto o $(0,0, \ldots, 0)$, em uma SMC de período $N=2^{m}-1$ ocorre apenas uma vez.

Observa-se na figura A.1 que o número de coeficientes $a_{i}$ iguais a 1 da recorrência linear (ou do polinômio característico) para uma SMC deve ser par, pois, se for ímpar, o grânulo- $m$ dado por 11...1 aplicado na recorrência linear (A.47) resultará sempre em 1 e a sequência deixa de ser periódica.

Então, tem-se que uma SMC não tem nenhum bloco-0 de comprimento $m$ e apenas um bloco-1 de comprimento $m$. O único bloco-1 de comprimento $m$ está cercado (delimitado) por 0 . Assim, a subsequência $011 \ldots 10$ de comprimento $m+2$ aparecerá apenas uma vez na SMC. Em consequência, aparecerão os grânulos 011...1 e 11...10. Se, na SMC, existir um bloco-1 de comprimento $m-1$, este estará cercado por $0 \mathrm{e}$, em consequência, os grânulos $011 \ldots 1$ e $11 \ldots 10$ apareceriam novamente. Isso é contraditório ao Teorema B.1.1, o que significa que em uma SMC não há blocos-1 de comprimento $m-1$. Porém, ocorre um bloco-0 de comprimento $m-1$ devido aos grânulos- $m 100 \ldots 0$ e 00...01, os quais ocorrem em sequência e apenas uma vez cada, conforme o Teorema B.1.1.

Observe que os blocos de comprimento $r \leq m-2$ aparecerão nos grânulos- $m$ na forma:

$$
\overbrace{0 \underbrace{11 \ldots 1}_{r} 0 \underbrace{x x \ldots x}_{m-r-2}}^{m}
$$

onde $x \in\{0,1\}$.

De (B.3) tem-se que o número de grânulos- $m$ contendo um bloco-1 de comprimento $r \leq m-2$ é $2^{m-r-2}$. Assim, o número de blocos- 1 de comprimento $r \leq m-2 \mathrm{em}$ uma SMC é $2^{m-r-2}$. Analogamente, o número de blocos-0 de comprimento $r \leq m-2$ em uma SMC é $2^{m-r-2}$.

Com os comentários anteriores prova-se o Teorema da distribuição dos blocos em 
uma SMC:

Teorema B.1.2 A distribuição dos blocos em uma SMC de período $N$ é dada pela Tabela B.1.

\begin{tabular}{ccc}
\hline comprimento & blocos-0 & blocos-1 \\
\hline 1 & $2^{m-3}$ & $2^{m-3}$ \\
2 & $2^{m-4}$ & $2^{m-4}$ \\
$\vdots$ & $\vdots$ & $\vdots$ \\
$r$ & $2^{m-r-2}$ & $2^{m-r-2}$ \\
$\vdots$ & $\vdots$ & $\vdots$ \\
$m-2$ & 1 & 1 \\
$m-1$ & 1 & 0 \\
$m$ & 0 & 1 \\
\hline Total: & $2^{m-2}$ & $2^{m-2}$ \\
\hline
\end{tabular}

Tabela B.1: Distribuição dos blocos em uma SMC.

Observe na Tabela B.1 que o número de elementos 1 em uma SMC supera em uma unidade o número de elementos 0 . Então, uma SMC de período $N=2^{m}-1$ possui $2^{m-1}$ elementos 1 e $2^{m-1}-1$ elementos 0 .

No caso de sinais binários, as funções de correlação definidas na seção 3.5 consideram sequências compostas de elementos não nulos. Para se obter tal característica a partir de sequências $\left\{s_{t}\right\}$ sobre $G F(2)$, faz-se:

$$
c_{t}=(-1)^{s_{t}}
$$

Assim, $\mathbf{c}=\left\{c_{t}\right\}$ é uma sequência composta de elementos tais que $\left|c_{t}\right|=1$.

Outra propriedade importante da SMC é sobre a sua função de autocorrelação periódica dada por:

$$
\begin{aligned}
r(\mathbf{c}, \mathbf{c}, \tau) & =\sum_{t=0}^{N-1}(-1)^{\operatorname{Tr}\left(\theta \alpha^{t}\right)+\operatorname{Tr}\left(\theta \alpha^{t+\tau}\right)} \\
& =\sum_{t=0}^{N-1}(-1)^{\operatorname{Tr}\left(\theta \alpha^{t}\left(1+\alpha^{\tau}\right)\right)}
\end{aligned}
$$

onde foi utilizado a propriedade 2 do traço (anexo seção A.8).

Se $\tau \equiv 0(\bmod N), \operatorname{Tr}\left(\theta \alpha^{t}(1+1)\right)=\operatorname{Tr}(0)=0$. Então, $r(\mathbf{c}, \mathbf{c}, \tau)=N$, para $\tau=0(\bmod N)$. 
Se $\tau \not \equiv 0(\bmod N)$, tem-se que $1+\alpha^{\tau} \neq 0$. Observe que $1+\alpha^{\tau}$ é um elemento $\alpha^{\sigma}$ de $G F\left(2^{m}\right), \operatorname{com} \sigma \in\{1,2, \ldots, N-1\}$ e $\alpha$ o elemento primitivo do $G F\left(2^{m}\right)$. Adicionalmente, existe apenas um $\sigma$ que satisfaz $1+\alpha^{\tau}=\alpha^{\sigma}$. Assim, $\operatorname{Tr}\left(\theta \alpha^{t}\left(1+\alpha^{\tau}\right)\right)=\operatorname{Tr}\left(\theta \alpha^{t+\sigma}\right)$, ou seja, é uma SMC com fase $\theta \alpha^{\sigma}$. Como o número de elementos 1 em uma SMC supera em uma unidade o número de elementos 0 , tem-se que $r(\mathbf{c}, \mathbf{c}, \tau)=-1$, para $\tau \neq 0(\bmod N)$.

Assim prova-se duas importantes propriedades da SMC. Uma para a função de autocorrelação da SMC, descrita pelo Teorema B.1.3, e outra descrita pelo Teorema B.1.4.

Teorema B.1.3 A função de autocorrelação periódica de uma SMC é dada por:

$$
r(\boldsymbol{c}, \boldsymbol{c}, \tau)= \begin{cases}-1 & \text { se } \tau \not \equiv 0(\bmod N) \\ N & \text { se } \tau \equiv 0(\bmod N)\end{cases}
$$

Nota-se que esse comportamento é válido também para uma sequência de $n$ elementos, os quais são variáveis aleatórias independentes e identicamente distribuídas.

Teorema B.1.4 Seja $\left(s_{t}\right)$ uma SMC de período $N=2^{m}-1$. Então, para qualquer $\tau \not \equiv 0(\bmod N)$ existe um único inteiro $\sigma$, com $1 \leq \sigma \leq N-1$, tal que:

$$
s_{t}+s_{t+\tau}=s_{t+\sigma}
$$

Por fim, será mostrado que existem exatamente ${ }^{3} \phi\left(2^{m}-1\right) / m$ SMC distintas de período $2^{m}-1$, bem como algumas formas de obtê-las.

Se duas SMC de mesmo período distinguem-se por apenas uma fase, ou translação, elas são equivalentes. De outra forma, foram geradas de uma mesma recorrência linear. Assim, para duas SMC serem distintas, ou uma não ser o resultado da translação da outra, elas devem ser geradas de recorrências lineares diferentes. Então, SMC distintas possuem seus respectivos polinômios característicos distintos.

Conclui-se, portanto, que o número de SMC distintas de mesmo período $N=$ $2^{m}-1$ é dado pelo número de polinômios primitivos de grau $m$, pois os polinômios característicos das SMC devem ser primitivos. Esse número é dado pela função de Euler com argumento $2^{m}-1$ dividido por $m, \phi\left(2^{m}-1\right) / m$ (anexo seção A.6).

A SMC dada por $s_{t}=\operatorname{Tr}\left(\theta \alpha^{t}\right)$, onde $\alpha$ é o elemento primitivo do corpo $G F\left(2^{m}\right)$ ou $D \bmod p, \operatorname{com}^{4} D=F_{2}[x]$ e $p(x)$ um polinômio primitivo de grau $m$, será distinta

\footnotetext{
${ }^{3} \phi($.$) representa a função de Euler (anexo seção A.6).$

${ }^{4} F_{p}[x]$ é o conjunto de polinômios no indeterminado $x$ com coeficientes no corpo finito $F_{p}=$ $\mathbb{Z} \bmod p($ anexo seção A.3).
} 
da SMC dada por $r_{t}=\operatorname{Tr}\left(\theta \beta^{t}\right)$, onde $\beta$ é o elemento primitivo do corpo $G F\left(2^{m}\right)$ ou $D \bmod h, \operatorname{com} D=F_{2}[x]$ e $h(x)$ um polinômio primitivo de grau $m$ se, e somente se, $h(x)$ for distinto de $p(x)$.

Há outra forma de obter SMC distintas. Inicialmente, obtém-se os polinômios mínimos dos elementos do corpo $G F\left(2^{m}\right)$ que gerou a SMC. Para algum elemento $\alpha^{d}$, entre outro(s) para $m>2$, seu polinômio mínimo será de grau $m$ e primitivo. Construindo um novo corpo $G F^{\prime}\left(2^{m}\right)$ com esse polinômio primitivo, obtém-se uma SMC, distinta da original, pelo traço (foi assumido a fase $\theta=1$ para simplificar a notação):

$$
r_{t}=\operatorname{Tr}\left(\beta^{t}\right)
$$

onde $\beta$ é o elemento primitivo do novo corpo $G F^{\prime}\left(2^{m}\right)$, ou $\beta=\alpha^{d}$, com $\alpha$ o elemento primitivo do corpo original $G F\left(2^{m}\right)$. Assim:

$$
r_{t}=\operatorname{Tr}\left(\alpha^{d t}\right)
$$

Conclui-se que basta decimar a SMC original de $d$ para obter a nova SMC:

$$
r_{t}=s_{t d}, \quad \text { para todo } t \geq 0
$$

Essa decimação, que resulta em outra SMC, é chamada de decimação própria.

Observe-se que, se $d$ for tal que o polinômio mínimo de $\alpha^{d}$ for um polinômio primitivo de $G F\left(2^{k}\right)$ com $k<m$, a decimação conforme (B.10) resulta em uma SMC de período $N^{\prime}=2^{k}-1$ menor que $N=2^{m}-1$. Agora, considere $d$ tal que o polinômio mínimo de $\alpha^{d}$ não é um polinômio primitivo. Ou seja, $\alpha^{d}$ não gera um grupo cíclico $G F\left(2^{m}\right)^{*}=G F\left(2^{m}\right)-\{0\}$ e portanto não é raiz primitiva. Como $\alpha^{d}$ não gera um grupo cíclico $G F\left(2^{m}\right)^{*}$, a ordem de $\alpha^{d}$ é menor que $N=2^{m}-1$. Do Teorema A.9.2 tem-se que o período da sequência gerada não será máximo $\left(2^{m}-1\right)$ e, portanto, não será uma SMC. O período $N^{\prime}$ dessa sequência cujo polinômio característico não é primitivo é diretamente obtido do $\operatorname{Lema}^{5}$ A.4.1, $N^{\prime}=\operatorname{ord}\left(\alpha^{d}\right)=\operatorname{ord}(\alpha) / \operatorname{mdc}(d, \operatorname{ord}(\alpha))=$ $N / \operatorname{mdc}(d, N)$. Essa decimação, que resulta em outra sequência que não é SMC, é chamada de decimação imprópria. O período da sequência decimada é obtido do período da sequência original e da decimação utilizada. Como resultado, tem-se que em uma decimação própria, o máximo divisor comum entre a decimação e o comprimento da SMC é $1, \operatorname{mdc}(d, N)=1$. Assim, tem-se que as decimações próprias são elementos

\footnotetext{
${ }^{5} \operatorname{mdc}(x, y)$ representa o máximo divisor comum entre $x$ e $y$.
} 
dos coconjuntos próprios do subgrupo $\left\{1,2,4,8, \ldots, 2^{m}-1\right\}$ e as decimações impróprias são elementos dos coconjuntos impróprios desse mesmo subgrupo. 


\section{Referências}

AGUIRRE, L. A. Introdução à identificação de sistemas: técnicas lineares e não-lineares aplicadas a sistemas reais. 3ra. ed. Belo Horizonte: Editora da Universidade Federal de Minas Gerais, 2007.

ANDERSEN, H. W.; KüMMEL, M. Identifying gain directionality of multivariable process. Proceedings of the european control conference, Hérmes, Paris, 1991.

ANDERSEN, H. W.; KüMMEL, M. Evaluating estimation of gain directionality, part 1: Methodology. Journal of process control, v. 2, p. 59-66, 1992.

ARMSTRONG, J. S.; COLLOPY, F. Error measures for generalizing about forecasting methods: Empirical comparisons. International Journal of Forecasting, n. 8, p. 69-80, 1992.

ASPEN. aspenONE Advanced Process Control Datasheet. 2011. Aspen Technology Datasheets (11-391-0411). Http://www.aspentech.com.

BACCALá, L. A.; SAMESHIMA, K.; VALlE, C. T.-I. G. Ballester A. C. do. Studying the iteraction between brain structures via directed coherence and granger causality. Applied Signal Processing, v. 5, p. 40-48, 1998.

BARENTHIN, M. On input design in system identification for control. Tese (Doutorado) - School of Electrical Engineering, KTH Royal Institute of Technology, June 2006.

BARKER, H. A. Galois a program for generating pseudo-random perturbation signals. Proceedings of the 12th IFAC Symposium on System Identification (SYSID), p. 505-508, 2001.

BARKER, H. A.; GODFREY, K. R. System identification with multi-level periodic perturbation signals. Control Engineering Pratice, v. 7, p. 717-726, March 1999.

BARKER, H. A.; GODFREY, K. R.; TUCKER, A. J. Nonlinear system identification with multilevel perturbation signals. Proceedings 12th IFAC Symposium on System Identification (SYSID), p. 1175-1178, June 2000.

BARKER, H. A.; RIVERA, D. E.; TAN, A. H.; GODFREY, K. R. Perturbation signal design. Preprint for the 14th IFAC Symposium on System Identification, March 2006.

BARKER, H. A.; TAN, A. H.; GODFREY, K. R. Criteria for determining the optimal levels of multilevel perturbation signals for nonlinear system identification. IEEE Proceedings of the American Control Conference, p. 4409-4414, June 2003.

BARKER, H. A.; TAN, A. H.; GODFREY, K. R. The performance of multilevel perturbation signals for nonlinear system identification. Proceedings 13th IFAC Symposium on System Identification (SYSID), p. 683-688, August 2003. 
BARKER, H. A.; TAN, A. H.; GODFREY, K. R. Design of multilevel perturbation signals with harmonic properties suitable for nonlinear system identification. IEE Proceedings Control Theory and Applications, v. 151, n. 2, p. 145-151, March 2004.

BARKER, H. A.; TAN, A. H.; GODFREY, K. R. Optimal levels of perturbation signals for nonlinear system identification. IEEE Transactions on Automatic Control, v. 49, n. 8, p. 1404-1407, August 2004.

BARKER, H. A.; TAN, A. H.; GODFREY, K. R. Ternary input signal design for system identification. IET Control Theory and Applications, v. 1, n. 5, p. 1224-1233, September 2007.

BARKER, H. A.; ZHUANG, M. Galois a program for generating pseudo-random perturbation signals. Proceedings of the 11th IFAC Symposium on System Identification (SYSID), p. 1641, 1997.

BEGA, E. A. Instrumentação Industrial. 2da. ed. [S.1.]: Editora Interciência, 2006.

BEQUETTE, B. W. Process control: modeling, design, and simulation. [S.1.]: Prentice-Hall, 2003.

BLACHMAN, N. M.; MCALPINE, G. A. The spectrum of a high-index fm waveform: Woodward's theorem revisited. IEEE Transactions on communication technology, COM-17, n. 2, April 1969.

BOS, A. V. den; KROL, R. G. Synthesis of discrete interval binary signals with specified fourier amplitude spectra. International Journal of Control, v. 30, p. 871-884, 1979.

BOX, G. E. P.; JENKINS, G. M. Time series analysis, forecasting and control. 3rd. ed. San Francisco: Holden-Day, 1994.

BRIGGS, P. A. N.; GODFREY, K. R. Pseudorandom signals for the dynamic analysis of multivariable systems. Proceedings IEE, n. 7, p. 1259-1267, july 1966.

BRISTOL, E. On a new measure of interaction for multivariable process control. IEEE Transactions on Automatic Control, v. 11, n. 1, p. 133-134, jan. 1966.

CHEN, J.-K.; YU, C.-C. Optimal input design using generalized binary sequence. Automatica, v. 33, n. 11, p. 2081-2084, 1997.

CONNER, J. S.; SEBORG, D. E. An evaluation of mimo input design for process identification. Industrial and engineering chemistry research, v. 43, n. 14, p. 3847-3854, April 2004.

COOLEY, B. L.; LEE, J. H. Control-relevant experiment design for multivariable systems described by expansions in orthonormal bases. Automatica, p. 273-281, 2001.

CUTLER, C.; MORSHEDI, A.; HAYDEL, J. An industrial perspective on advanced control. In AICHE annual meeting, Washington,DC, October 1983.

CUTLER, C. R.; RAMAKER, B. L. Dynamic matrix control: a computer control algorithm. AICHE national meeting, April 1979. 
CUTLER, C. R.; RAMAKER, B. L. Dynamic matrix control: a computer control algorithm. In Proceedings of the joint automatic control conference, 1980.

DARBY, M. L.; NIKOLAOU, M. Multivariable system identification for integral controllability. Automatica, v. 45, n. 10, p. 2194-2204, 2009.

DARNELL, M.; FAN, P. Z.; JIN, F. Perfect sequences derived from m-sequences. IEEE International symposium on information theory, p. 461, september 1995.

EPE, E. de P. E. Plano Nacional de Energia 2030 (PNE 2030). [S.1.], 2007.

EVERETT, D. Periodic digital sequences with pseudonoise properties. G. E. C. J. Science Technology, v. 33, p. 115-126, 1996.

FEATHERSTONE, A. P.; BRAATZ, R. D. Integrated robust identification and control of large-scale processes. Industrial $\mathcal{E}$ Eng. Chem. Research, v. 37, n. 1, p. 97-106, 1998.

GAIKWAD, S. V.; RIVERA, D. R. Control-relevant input design for multivariable system identification: application to high-purity distillation. Proceedings of the 13th IFAC World Congress (IFAC'96), 1996.

GAMES, R. A. Crosscorrelation of m-sequences and gmw-sequences with the same primitive polynomial. Discrete Applied Mathematics, n. 12, p. 139-146, 1984.

GARCíA, C. E.; PRETT, D. M.; MORARI, M. Model predictive control: Theory and practice - a survey. Automatica, v. 25, n. 3, p. 335-348, 1989.

GARCIA, C. Modelagem e simulação de processos industriais e de sistemas eletromecânicos. 2da. ed. São Paulo: Editora da Universidade de São Paulo, 2005.

GENTILIN, C. W. J. Controle preditivo por modelo interno aplicado a unidades de craqueamento catalítico. Dissertação (Mestrado) - Programa de pós graduação em engenharia elétrica e informática industrial, Centro Federal de Educação Tecnológica do Paraná, Curitiba, Brasil, 2004.

GERTCHBERG, R. W.; SAXTON, W. O. A pratical algorithm for the determination of phase from image and diffraction plane pictures. Optik, v. 35, n. 2, p. 237-247, 1972.

GEVERS, M. A decade of progress in iterative process control design: from theory to practice. Journal of Process Control, p. 519-531, 2002.

GODFREY, K. Perturbation signals for system identification. Hemel Hempstead: Prentice Hall, 1993.

GODFREY, K. R.; BARKER, H. A.; TUCKER, A. J. Comparison of perturbation signals for linear system identification in the frequency domain. IEE Proceedings of Control Theory and Applications, v. 146, n. 6, p. 535-548, November 1999.

GODFREY, K. R.; TAN, A. H.; BARKER, H. A.; CHONG, B. A survey of readily accessible perturbation signals for system identification in the frequency domain. Control engineering pratice, v. 13, p. 1391-1402, March 2005.

GOLD, R. Optimal binary sequences for spread spectrum multiplexing. IEEE Transactions on Information Theory, p. 619-621, October 1967. 
GOLOMB, S. W. Shift Register Sequences. Revised. Laguna Hills, California: Aegean Park Press, 1982.

GOLOMB, S. W.; GONG, G. Signal design for good correlation for wireless communication, cryptography, and radar. [S.1.]: Cambridge University Press, 2005.

GORDON, B.; MILLS, W. H.; WELCH, L. R. Some new differences sets. Canadian Journal of Mathematics, v. 14, p. 614-625, 1962.

GROSDIDIER, P.; FROISY, B.; HAMMANN, M. The idcom-m controller. Proceedings of the 1988 IFAC workshop on model based process control, Pergamon Press, Oxford, p. 31-36, 1988.

GROSDIDIER, P.; MASON, A.; AITOLAHTI, A.; HEINONEN, P.; VANHAMäKI, V. Fcc unit reactor-regenerator control. Computers Chem. Engng., v. 17, n. 2, p. 165-179, 1993.

GUILLAUME, P.; SCHOUKENS, J.; PINTELON, R.; KOLLáR, I. Crest-factor minimization using nonlinear chebyshev approximation methods. IEEE Transactions on instrumentation and measurement, v. 40, n. 6, p. 982-989, december 1991.

HELLESETH, T. Some results about the cross-correlation function between two maximal linear sequences. Discrete Mathematics, v. 16, n. 3, p. 209-232, 1976.

HILDEBRAND, R.; SOLARI, G. Identification for control: Optimal input intended to identify a minimum variance controller. Automatica, p. 758-767, March 2007.

HONEYWELL. Profit Suite Solutions General Brochure. 2010. Honeywell Brochures (Br-05-005-ENG). Https://www.honeywellprocess.com.

INVENSYS. Connoisseur Datasheet. 2010. Invensys Datasheets (PN SE-0118). Http://iom.invensys.com.

JACOBSEN, E. W. Identification for control of strongly interactive plants. AIChE Annual Meeting, 1994.

JACOBSEN, E. W.; SKOGESTAD, S. Inconsistencies in dynamic models for ill-conditioned plants: Application to low-order models of distillation columns. Industrial E Engineering Chemistry Research, v. 33, n. 3, p. 631-640, mar. 1994.

JR., H. Q. P.; MOTTA, P. S. A evolução dos preços do petróleo: as dificuldades de previsão para 2005. International Journal of Systems Science, v. 6, n. 1, p. 3-5, Fevereiro 2005.

KAISARE, N. S.; LEE, J. H. Optimal design of periodic test input signals for multivariable impulse response models. Optimal Control and Applications Methods, n. 5, p. 451-469, June 2010.

KALMAN, R. E. Contributions to the theory of optimal control. Bulletin de la Societe Mathematique de Mexicana, v. 5, p. 102-119, 1960.

KALMAN, R. E. A new approach to linear filtering and prediction problems. Transactions of ASME Journal of Basic Engineering, v. 87, p. 35-45, 1960.

KASAMI, T. Some lower bounds on the minimum weight of cyclic codes of composite length. IEEE Transactions on Information Theory, v. 14, n. 6, p. 814-818, November 1968. 
KOLLáR, I. Frequency domain system identification toolbox for use with MATLAB. Natick, MA: The MathWorks, 1994.

KOUNG, C. W.; MACGREGOR, J. F. Design of identification experiments for robust control. a geometric approach for bivariate processes. Industrial $\mathcal{E}$ Eng. Chemistry Res., v. 32, n. 8, p. 1658-1666, ago. 1993.

KURAMOTO, A. S. R. Metodologias de seleção de seqüências de espalhamento para sistemas DS/CDMA quase síncronos. Dissertação (Mestrado) - Escola Politécnica da Universidade de São Paulo, Departamento de Telecomunicações e Controle, Área de Sistemas Eletrônicos, May 2005.

KURAMOTO, A. S. R.; CIRIACO, F.; ABRãO, T.; JESZENSKY, P. J. E. Sequence design for mpg qs-cdma systems based on heuristic combinatorial optimization. Wireless Communications and Mobile Computing, v. 12, n. 3, p. 236-247, february 2012.

KURAMOTO, A. S. R.; VAILLANT, O. R.; GARCIA, C. Effectiveness of signal excitation design methods for ill-conditioned processes identification. International Symposium on Advanced Control of Chemical Process (ADCHEM 2012), july 2012.

LARA, J. M. V. Identificação de Modelos para Controle Preditivo: Aplicação a uma Planta de Lodos Ativados. Tese (Doutorado) - Faculdade de Engenharia Elétrica e de Computação, Universidade Estadual de Campinas, Fevereiro 2005.

LEE, H. A plant-friendly multivariable system identification framework based on identification test monitoring. Tese (Doutorado) - Arizona state university, December 2006.

LEE, H.; RIVERA, D. E. Cr-ident: a matlab toolbox for multivariable control-relevant system identification. 14th IFAC Symposium on System Identification (SYSID 2006), p. 708-713, March 2006.

LEE, H.; RIVERA, D. E.; MITTELMANN, H. D. Constrained minimum crest factor multisine signals for "plant-friendly" identification of highly interactive systems. Proceedings of 13th IFAC Sysmposium on System Identification, p. 947-952, 2003.

LEE, H.; RIVERA, D. E.; MITTELMANN, H. D.; SYSTEMS, C. A novel approach to plant-friendly multivariable identification of highly interactive systems. Systems Engineering, 2003.

LEONTARITIS, I. J.; BILLINGS, S. A. Experimental design and identifiability for nonlinear systems. International Journal of Systems Science, v. 18, n. 1, p. 189-202, 1987.

LIDL, R.; NIEDERREITER, H. Encyclopedia of Mathematics and its Applications: Finite fields. 2nd. ed. The Edinburgh Building, Cambridge: Cambridge University Press, 1997.

LIN, X. D.; CHANG, K. H. Optimal PN sequence design for quasisynchronous CDMA communication systems. IEEE Transactions on Communications, v. 45, n. 2, p. 221-226, February 1997.

LJUNG, L. Asymptotic variance expressions for identfied black-box expression for identified black-box transfer functions models. IEEE Transactions on Automatic Control, n. 30, p. 834-844, 1985. 
LJUNG, L. System Identification: theory for the user. 2nd. ed. Upper Saddle River, New Jersey: Prentice Hall PTR, 1999.

MARKS, R. J.; REIGHTLEY, T. On iterative evaluation of extrema of integral of trigonametric polynomials. IEEE Transaction on acoustic speech signal processing, v. 35, n. 2, p. 237-247, August 1985.

MCCOMARCK, A. S.; GODFREY, K. R.; FLOWER, J. O. The design of multilevel multiharmonic signals. International Conference on Control, v. 1, p. 520-525, March 1994.

MCCOMARCK, A. S.; GODFREY, K. R.; FLOWER, J. O. Design of multilevel multiharmonic signals for system identification. IEE Proceedings of Control Theory and Applications, v. 142, p. 257-252, 1995.

MCELIECE, R. J. Finite Field for Computer Scientists and Engineers. [S.1.]: Kluwer Academic Publishers, 1987.

MEHRA, R. Optimal input signals for parameter estimation in dynamic systems survey and new results. IEEE Transactions on Automatic Control, n. 6, p. 753-768, December 1974.

MISRA, P.; NIKOLAOU, M. Input design for model order determination in subspace identification. AIChE Journal, v. 49, n. 8, p. 2124-2132, ago. 2003.

MORO, L. F. L. Desenvolvimento de um controlador preditivo multivariável para um conversor industrial de craqueamento catalítico. Dissertação (Mestrado) Dissertação de mestrado em engenharia química. Escola Politécnica da Universidade de São Paulo, São Paulo, Brasil, 1992.

MORO, L. F. L. Sicon - uma solução cliente servidor para controle avançado. IV Congresso Petrobras de Informática e Telecomunicações, INFTEL, 1997.

OGATA, K. Engenharia de controle moderno. 4th. ed. [S.1.]: Prentice-Hall, 2003.

OGUNNAIKE, B. A.; LEMAIRE, J. P.; MORARI, M. Advanced multivariable control of a pilot-plant distillation column. AIChE Journal, v. 29, n. 4, p. 632-640, 1983.

OPPENHEIM, A. V.; SCHAFER, R. W. Discrete-Time Signal Processing. 2nd. ed. Upper Saddle River, NJ: Prentice Hall, 1999.

OUDERAA, E. V. der; SCHOUKENS, J.; RENNEBOOG, J. Peak factor minimization of input and output sinals of linear systems. IEEE Transactions on instrumentation and measurement, v. 37, p. 207-212, 1988.

OUDERAA, E. V. der; SCHOUKENS, J.; RENNEBOOG, J. Peak factor minimization using a time-frequency domain swapping algorithm. IEEE Transactions on instrumentation and measurement, v. 37, n. 1, p. 145-147, March 1988.

PAPADIMITRIOU, C. H.; STEIGLITZ, K. Combinatorial Optimization: Algorithms and Complexity. [S.1.]: Dover Publications, 1998.

PAPOULIS, A. Probability, Random Variables, and Stocastic Processes. 3rd. ed. [S.1.]: Mc Graw-Hill, 1991. (Electrical engineering. Communications ans signal processing). 
PEARSON, R. K.; OGUNNAIKE, B. A.; DOYLE, F. J. Identification of nonlinear input/output models using non-gaussian input sequences. American Control Conference, p. 1465-1469, June 1993.

PENG, D.; FAN, P. Generalised sarwate bounds on periodic autocorrelations and cross-correlations of binary sequences. Electronics Letters, v. 38, n. 4, p. 1521-1523, November 2002.

PENG, D.; FAN, P. Bounds on aperiodic auto- and cross-correlations of binary sequences with low or zero correlation zone. Proceedings of the Fourth International Conference on Parallel and Distributed Computing, Applications and Technologies, 2003, v. 38, p. 882-886, November 2003.

PENG, D.; FAN, P. Generalized sarwate bounds on the periodic correlation of complex roots of unity sequences. IEEE Proceedings on 14th Personal, Indoor and Mobile Radio Communications, 2003, v. 1, p. 449-452, September 2003.

PINTELON, R.; SCHOUKENS, J. System identification: a frequency domain approach. New York: IEEE Press, 2001.

PRETT, D. M.; GILLETTE, R. D. Optimization and constrained multivariable control of a catalytic cracking unit. In Proceedings of the joint automatic control conference, 1980 .

PROAKIS, J. G. Digital Communications. 3th. ed. [S.1.]: McGraw-Hill, 1995. (Electrical and Computer Engineering. Communications and Signal Processing).

PROPOI, A. I. Use of linear programming methods for synthesizing sampled-data automatic systems. Automatic Remote Control, v. 24, n. 7, p. 837-844, 1963.

PROSDOSSIMO, C. Uma contribuição ao controle preditivo multivariável de unidades de craqueamento catalítico. Dissertação (Mestrado) - Programa de pós graduação em engenharia elétrica e informática industrial, Centro Federal de Educação Tecnológica do Paraná, Curitiba, Brasil, 2003.

QIN, S. J.; BADGWELL, T. A. A survey of industrial model predictive control technology. Control engineering pratice, v. 11, n. 7, p. 1-32, 2002.

RAWLINGS, J. B. Tutorial overview of model predictive control. IEEE Control Systems Magazine, v. 20, p. 38-52, 2000.

RICHALET, J.; RAULT, A.; TESTUD, J. L.; PAPON, J. Algorithmic control of industrial processes. In Proceedings of the 4th IFAC symposium on identification and system parameter estimation, p. 1119-1167, 1976.

RICHALET, J.; RAULT, A.; TESTUD, J. L.; PAPON, J. Model predictive heuristic control: Applications to industrial processes. Automatica, v. 14, p. 413-428, 1978.

RIVERA, D. E.; CHEN, X.; BAYARD, D. S. Experimental design for robust process control using schroeder-phased input signals. p. 895 -899, june 1993.

RIVERA, D. E.; GAIKWAD, S. V.; CHEN, X. Control-id: a demonstration prototype for control-relevant identification. American Control Conference, v. 2, p. 2055-2059, June 1994. 
RIVERA, D. E.; LEE, H.; BRAUN, M. W.; MITTELMANN, H. D. Plant-friendly system identification: a challenge for the process industries. Proceedings of 13th IFAC Sysmposium on System Identification, p. 917-922, 2003.

RIVERA, D. E.; LEE, H.; MITTELMANN, H. D.; BRAUN, M. W. High-purity distillation: using plant-friendly multisine signals to identify a strongly interactive process. IEEE Control systems magazine, v. 28, p. 72-89, 2007.

RIVERA, D. E.; LEE, H.; MITTELMANN, H. D.; BRAUN, M. W. Constrained multisine input signals for plant-friendly identification of chemical process systems. Journal of Process Control, v. 19, n. 4, p. 623-635, April 2009.

SARWATE, D. V. Bounds on crosscorrelation and autocorrelation of sequences. IEEE Transactions on Information Theory, IT-25, n. 6, p. 720-724, November 1979.

SCHOLTZ, R. A.; WELCH, L. R. GMW sequences. IEEE Transaction on Information Theory, IT-30, n. 3, p. 548-553, 1984.

SCHOUKENS, J.; PINTELON, R.; DOBROWIECKI, T. Frequency response function measurements in the presence of linear distortion. Automatica, v. 37, p. 939-946, 2001.

SCHOUKENS, J.; PINTELON, R.; OUDERAA, E. V. der; RENNEBOOG, J. Survey of excitation signals for fft-based signal analyzers. IEEE Transactions on instrumentation and measurement, v. 37, p. 342-352, 1988.

SCHROEDER, M. R. Synthesis of low-peak-factor signals and binary sequences with low autocorrelation. IEEE Transactions on information theory, v. 16, p. 85-89, 1970.

SöDERSTRöM, T.; STOICA, P. System Identification. Hemel Hempstead, United Kingdom: Prentice-Hall International, 1989.

SINGER, J. A theorem in finite projective geometry and some applications to number theory. Transaction of American Mathematics Society, v. 43, p. 377-385, 1938.

SKOGESTAD, S. Dynamics and control of distillation columns: A tutorial introduction. Science And Technology, v. 75, p. 8-10, 1997.

SKOGESTAD, S.; MORARI, M. Implications of large rga-elements on control performance. Industrial $\mathcal{F}$ engineering chemistry research, v. 26, n. 11, p. 2323-2330, nov. 1987.

SKOGESTAD, S.; MORARI, M.; DOYLE, J. C. Robust control of ill-conditioned plants: High-purity distillation. IEEE Trans. on Automatic Control, v. 33, n. 12, p. 1092-1105, 1988.

SOTOMAYOR, O. A. Z.; ODLOAK, D.; MORO, L. F. L. Closed-loop model re-identification of processes under mpc with zone control. Control Engineering Practice, v. 17, p. 551-563, 2009.

SOUZA, R. R. de. Panorama, oportunidades e desafios para o mercado mundial de álcool automotivo. Dissertação (Mestrado) - Dissertação de mestrado em ciências. Universidade Federal do Rio de Janeiro, Rio de Janeiro, Brasil, Fevereiro 2007.

STEC, P.; ZHU, Y. Some study on identification of ill-conditioned process for control. Proceedings of the american control conference, v. 2, p. 1202-1207, 2001. 
STEC, P.; ZHU, Y. Some study on identification of ill-conditioned processes for control. IEEE American control conference, v. 2, p. 1202-1207, 2001.

STRAND, S.; SAGLI, J. R. Mpc in statoil - advantages with in-house technology. International Symposium on Advanced Control of Chemical Processes (ADCHEM 2003), p. 97-103, January 2003.

TAI-JI. Tai-Ji ID: A New Generation MPC Identification Technology. 2011. Tai-Ji ID Brochure. Http://www.taijicontrol.com.

TAN, A. H. Design of truncated maximum lengh ternary signals where their squared versions have uniform even harmonics. IEEE Transactions on automatic control, v. 52, n. 5, p. 957-961, 2007.

TAN, A. H.; FOO, M. F. L. Ternary pseudorandom signal design for uniform excitation and reduced effect of nonlinear distortion. Electronics Letters, v. 42, n. 12, June 2006.

TAN, A. H.; GODFREY, K. R. The generation of binary and near-binary pseudorandom signals: an overview. IEEE Transaction on instrumentation and measurement, v. 51, n. 4, p. 583-588, August 2002.

TAN, A. H.; GODFREY, K. R. A improved routine for designin multi-level multi-harmonic signals. Proceedings of the UKACC international conference “Control 2004”, ID-027, September 2004.

TAN, A. H.; GODFREY, K. R. Modeling of direction-dependent processes using wiener models and neural networks with nonlinear output error structure. Instrumentation, v. 53, n. 3, p. 744-753, 2004.

TAN, A. H.; GODFREY, K. R. A guide to the design and selection of perturbation signals. IEEE Conference on Decision and Control, p. 464-469, december 2009.

TAN, A. H.; GODFREY, K. R.; BARKER, H. A. Design of computer-optimized pseudorandon maximum length signals for linear identification in the presence os nonlinear distortion. IEEE Transactions on instrumentation and measurement, v. 54, n. 6, p. 2513-2519, 2005.

TAN, A. H.; GODFREY, K. R.; BARKER, H. A. Design of ternary signals for mimo identification in presence of noise and nonlinear distortion. IEEE Transactions on control system technology, v. 17, n. 4, p. 926-933, july 2009.

TANG, X. H.; FAN, P. Z. Bounds on aperiodic and odd correlations of spreading sequences with low and zero correlation zone. Electronics Letters, v. 37, n. 19, p. 1201-1203, September 2001.

TANG, X. H.; FAN, P. Z. A class of pseudonoise sequences over GF(P) with low correlation zone. IEEE Transactions on Information Theory, v. 47, n. 4, p. 1644-1649, May 2001.

TANG, X. H.; FAN, P. Z.; MATSUFUJI, S. Lower bounds on correlation of spreading sequences set with low or zero correlation zone. Electronics Letters, v. 36, n. 6, p. 551-552, March 2000. 
TOM, V. T.; QUATIERI, T. F. Convergence of iterative nonexpansive signal reconstruction algorithms. IEEE Transaction on acoustic speech signal processing, v. 29, n. 5, p. 1052-1058, October 1981.

TULLEKEN, H. J. A. F. Generalized binary noise test-signal concept for improved identification-experiment design. Automatica, v. 27, n. 1, p. 37-49, 1990.

VAILLANT, O. R.; KURAMOTO, A. S. R.; GARCIA, C. Effectiveness of signal excitation design methods for identification of ill-conditioned and highly interactive processes. In revision process: Industrial E Engineering Chemistry Research, 2012.

WALLER, J. B. Directionality and Nonlinearity - Challenges in Process Control. Tese (Doutorado) - Abo Akademi University, 2003.

WALLER, J. B.; WALLER, K. V. Defining directionality: Use of directionality measures with respect to scaling. Industrial $\mathcal{E}$ Engineering Chemistry Research, v. 34, n. 4, p. 1244-1252, 1996.

WELCH, L. R. Lower bounds on the maximum cross correlation of signals. IEEE Transactions on Information Theory, IT-20, n. 3, p. 397-399, May 1974.

WILSON, R. G. Orthogonal multilevel pseudorandom sequences and impulse sequences derived from them. IEEE Transactions on information theory, IT-27, n. 3, p. 339-342, May 1982.

WOOD, R.; BERRY, M. W. Terminal composition control of a binary distillation column. Chemical Engineering Science, v. 28, n. 9, p. 1707-1717, set. 1973.

YOKOGAWA. Benefits-oriented APC Suite for Your Processes. 2007. Yokogawa Datasheets (Ed:03/b). Http://www.yokogawa.com.

YOKOGAWA; SHELL. Advanced Identification and Data Analysis (AIDA) Datasheet. 1999. Yokogawa Datasheets (36J06D20-01E). Http://www.yokogawa.com.

YUAN, Z. D.; LJUNG, L. Unprejudiced optimal open loop input design for identification of transfer functions. Automática, p. 697-708, 1985.

ZANIN, A. C.; GOUVêA, T. M.; ODLOAK, D. Integrating real-time optimization into the model predictive controller of the fcc system. Control Engineering Practice, Pergamon Press, v. 10, p. 819-831, 2002.

ZANIN, A. C.; NETO, E. A.; MORO, L. F. L. Controle avançado e otimização de processos em tempo real. 2002. Material de treinamento, Petrobras S. A.

ZHU, Y. Multivariable process identification for mpc: the asymptotic method and its applications. Journal of process control, v. 8, n. 2, p. 101-115, 1998.

ZHU, Y. Multivariable system identification for process control. 1st. ed. [S.1.]: Pergamon, 2001.

ZHU, Y. Progress in mpc identification: A case study on totally closed-loop plant test. ERTC Computing, June 2003.

ZHU, Y.; STEC, P. Simple control-relevant identification test methods for a class of ill-conditioned processes. J. of Process Control, v. 16, n. 10, p. 1113-1120, dez. 2006. 